INSTITUTO DE PESQUISAS ENERGÉTICAS E NUCLEARES Autarquia Associada à Universidade de São Paulo

\title{
AVALIAÇÃO DA QUALIDADE DA ÁGUA NA BACIA HIDROGRÁFICA DO RIBEIRA DE IGUAPE COM VISTAS AO ABASTECIMENTO PÚBLICO
}

\section{MARYCEL ELENA BARBOZA COTRIM}

Tese apresentada como parte dos requisitos para a obtenção do Grau de Doutor em Ciências na Área de Tecnologia Nuclear - Materiais

ORIENTADORA:

Dra. Maria Ap. Faustino Pires

SÃO PAULO

2006 


\section{AGRADECIMENTOS}

À Dra. Maria Aparecida Faustino Pires pela orientação, apoio, incentivo, confiança e amizade.

Ao Instituto de Pesquisas Energéticas e Nucleares - IPEN-CNEN/SP e ao Centro de Química e Meio Ambiente - CQMA pela oportunidade de desenvolver este trabalho.

À SABESP - Companhia de Saneamento Básico do Estado de São Paulo - Unidade de Negócios Ribeira de Iguape - $R R$, pela parceria $e$ colaboração no projeto de pesquisa, em especial ao Osvaldo Beltrame Filho, pelo apoio irrestrito à execução de todo o projeto e discussões técnicas. A todos os funcionários da ETA de Registro, em especial ao Célio de Sousa, Guilherme Francisco Gomes da Silva, Eduardo Okawa, Ivon Villanova, Itamar Teixeira de Oliveira, Júlio César de Morais, Sebastião Kierme dos Santos, pelo trabalho com as coletas e todo o apoio logístico.

Aos pesquisadores Augusta Viana, Cleide Moreira da Silva, Cristina Sisti, Elias Santana da Silveira, Elizabeth Dantas, Hélio Akira Furusawa e Tânia Grigoletto pelo apoio nas realizações das análises.

Aos colegas Hélio Akira Furusawa, Elizabeth Dantas, Elaine Arantes Jardins Martins, Maria Nogueira Marques, Edson Tocaia e Ajibola Issau Abadiru, pelas discussões técnicas e valiosas sugestões.

As amigas Elita Urano de Carvalho e Elizabeth Dantas, pelo incentivo, amizade, apoio e ajuda na realização do trabalho.

À FAPESP - Fundação de Amparo a Pesquisa do Estado de São Paulo, pelo apoio financeiro.

A todos os colegas do CQMA, pela colaboração na realização do trabalho.

A minha família, que sempre me apoiou. 


\title{
AVALIAÇÃO DA QUALIDADE DA ÁGUA NA BACIA HIDROGRAFIA DO RIBEIRA DE IGUAPE COM VISTAS AO ABASTECIMENTO PÚBLICO
}

\author{
Marycel Elena Barboza Cotrim
}

\begin{abstract}
RESUMO
A bacia hidrográfica do Ribeira de Iguape, localizada na região sudeste do estado de São Paulo, é um importante ecossistema com a maior concentração de Mata Atlântica, onde a disponibilidade de água versus demanda é extremamente positiva.
\end{abstract}

Para o abastecimento público da região, a SABESP (Companhia de Saneamento Básico do Estado de São Paulo) - Unidade de Negócios do Vale do Ribeira - RR, utiliza diferentes tipos de ecossistemas para captação de água; com mecanismos de funcionamento distintos, destacando-se mananciais superficiais; de serra e subterrâneos (poços).

No presente trabalho, foram avaliados 43 sistemas de produtores, sendo: 10 mananciais de serra (localizados em áreas protegidas), 15 poços (águas subterrâneas) e 18 captações em mananciais superficiais com estações de tratamento de água (ETA's). Para avaliar a atual situação dos sistemas foram analisados 30 parâmetros, principalmente os parâmetros representativos de potabilidade da água, em amostras de água, água tratada e sedimento de fundo de março de 2002 a fevereiro de 2003, verificando o atendimento a Resolução CONAMA 357/05, classificação de corpos de água e a Portaria 518/04 que estabelece as características da água para abastecimento público,

A análise descritiva mostrou que a região apresenta em geral, altas concentrações de $\mathrm{Al}, \mathrm{Fe}$ e $\mathrm{Mn}$ nas amostras de água dos mananciais, excedendo os valores da resolução CONAMA 357, porém nas amostras de água para abastecimento público (manancial de serra, água de poço e água tratada) 
analisadas, a concentração média de todos os elementos encontram-se, em geral, abaixo dos limites estabelecidos pela Portaria 518/MS.

Os mananciais de serra, superficial e subterrâneo apresentam características diferentes em relação à concentração de elementos, como Ca, Fe, $\mathrm{Mn} \mathrm{Na}$ entre outros.

$\mathrm{Na}$ avaliação dos sedimentos de fundo (fração $<63 \mu \mathrm{m}$ ), na fração total as maiores concentrações foram encontradas para os elementos $\mathrm{Al}$, Fe e Mg. Para os elementos $\mathrm{Pb}$ e $\mathrm{Zn}$ também presentes na fração total as concentrações de até $142,0 \mu \mathrm{g} \cdot \mathrm{g}^{-1}$ e 1 a $172 \mu \mathrm{g} \cdot \mathrm{g}^{-1}$, respectivamente. Analisando-se o teor dos metais biodisponíveis encontrados nas amostras de sedimentos do Vale do Ribeira, verifica-se que, com exceção do $\mathrm{Pb}$, nas regiões de Sete Barras e Eldorado, os demais elementos analisados encontram-se com concentrações bem abaixo do valor estipulado para o PEL (Probable Effect Level - nível provável de efeito adverso à comunidade biológica). 


\title{
RIBEIRA DO IGUAPE BASIN WATER QUALITY ASSESSMENT FOR DRINKING WATER SUPPLY
}

\author{
Marycel Elena Barboza Cotrim
}

\begin{abstract}
Ribeira do Iguape Basin, located in the Southeast region of São Paulo state, is the largest remaining area of Mata Atlântica which biodiversity as rich as Amazon forest, where the readiness of water versus demand is extremely positive. With sparse population density and economy almost dependent on banana agriculture, the region is still well preserved.

To water supply SABESP (São Paulo State Basic Sanitation Company) -Ribeira do Iguape Businesses Unit - RR, uses different types of water supplies.

In the present work, in order to ascertain water quality for human consumption, major and minor elements were evaluated in various types of water supply (surface and groundwater's as well as the drinking water supplied)

Forty three producing systems were monitored: 18 points of surface waters and treated distributed water, 10 points of groundwater and 15 points of surface water in preserved areas, analyzing 30 elements. Bottom sediments (fraction $<63 \mu \mathrm{m}$ ) were also evaluated.
\end{abstract}

The sampling period covered dry and wet seasons from March 2002 to February 2003.

The descriptive analysis showed that $\mathrm{Al}$, Fe and $\mathrm{Mn}$, exceeding CONAMA 357 quality guideline. A comparison of the elemental concentrations with the Brazilian Drinking Water Legislation (Portaria 518/04) showed that with the exception of some violations, the levels of all the elements investigated were below the Brazilian Legislation maximum allowed concentrations. 
This study examined the relationship between the type of water supply and the quality of water used, showed different characteristics on $\mathrm{Ca}, \mathrm{Fe}, \mathrm{Mn}$ concentration.

In bottom sediments (fraction <63 $\mu \mathrm{m}$ ), $\mathrm{Al}, \mathrm{Fe}$ and $\mathrm{Mg}$ largest concentrations were found. $\mathrm{Pb}$ and $\mathrm{Zn}$ presents concentrations up to $142,0 \mu \mathrm{g} . \mathrm{g}-1$ and $172 \mu \mathrm{g} . \mathrm{g}-1$, respectively. Data revealed that trace elements concentration in the sediment were below PEL (Probable Effect Level - probable level of adverse effect to the biological community), exception for $\mathrm{Pb}$ in Sete Barras and Eldorado. 
ÍNDICE

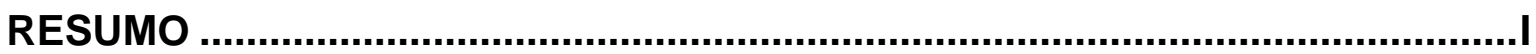

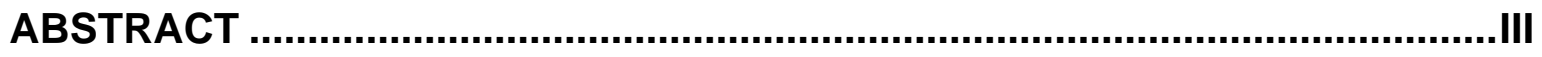

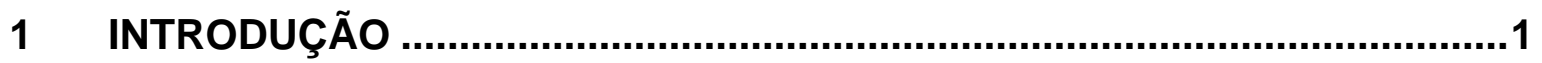

2 OBJETIVO

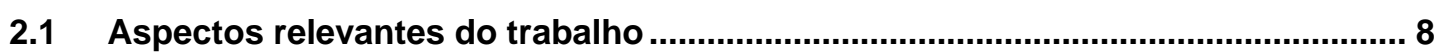

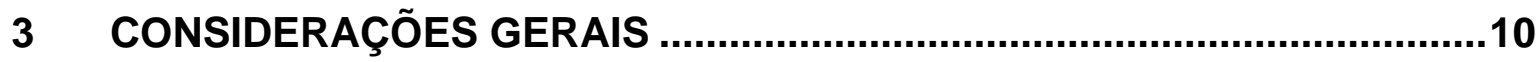

3.1 Avaliação e monitoramento da qualidade da água.............................................. 10

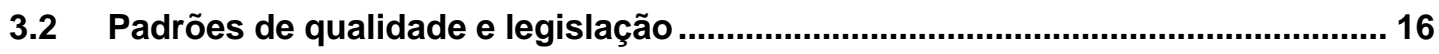

4 ÁREA DE ESTUDO

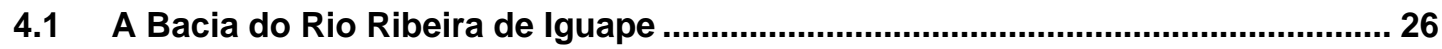

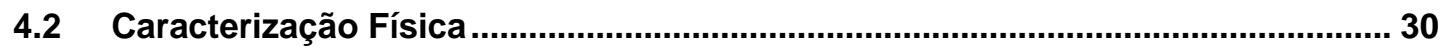

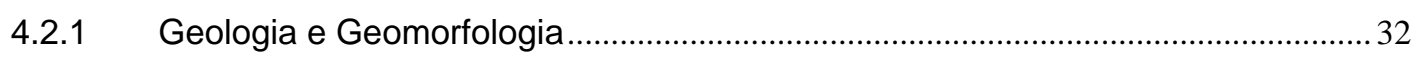

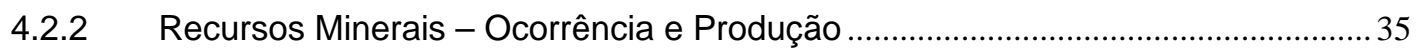

4.2.3 Pedologia (IPT, 1981; ROSS, 1997; CETEC, 2000) …............................................... 38

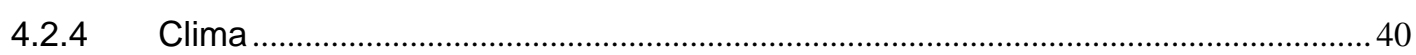

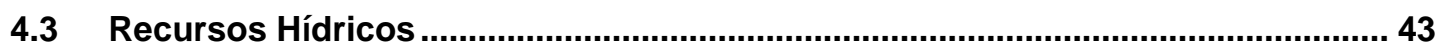

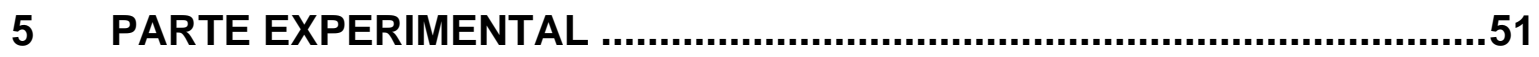

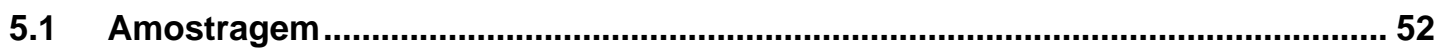

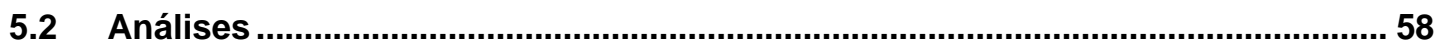

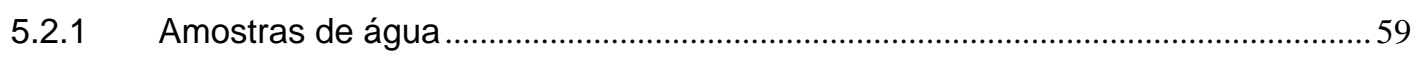

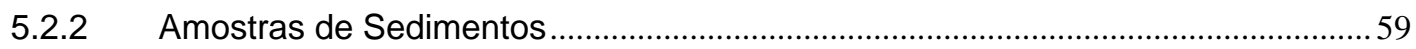

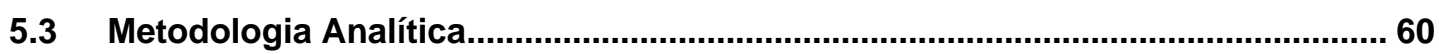

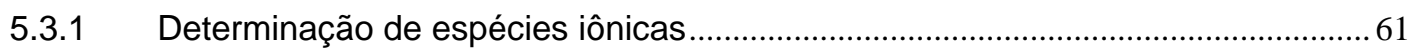

5.3.2 Determinação de metais e elementos traços por espectrometria de emissão com plasma de argônio (ICP-OES)

5.3.3 Determinação $\mathrm{Hg}$, Se, As, Sb, Pb e Cd por Espectrometria de Absorção Atômica

5.3.4 Determinação metais e elementos traços por Fluorescência de Raios X.............66

5.3.5 Tratamento matemático e estatístico dos dados....................................................67 
$6 \quad$ RESULTADOS E DISCUSSÃO .............................................................

6.1 Avaliação de Metais e elementos-traço.................................................................. 72

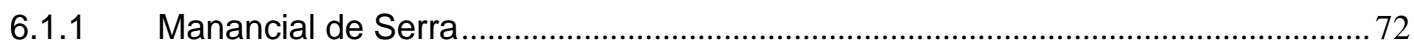

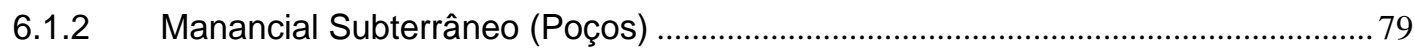

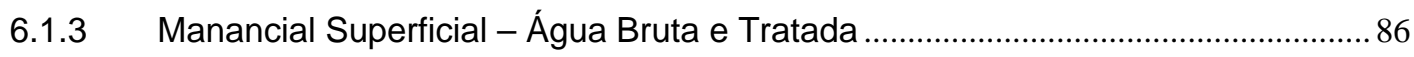

6.1.4 Comparação manacial superficial, manancial de serra e poços. ............................. 99

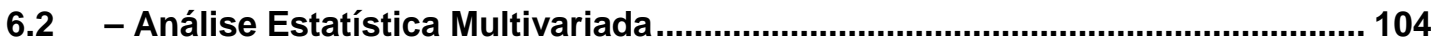

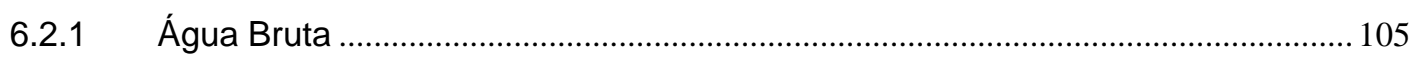

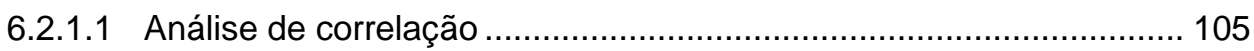

6.2.1.2 Análise de Componentes Principais .............................................. 107

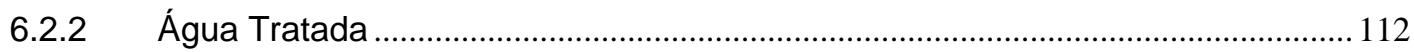

6.2.2.1 Análise de correlação ...................................................................... 112

6.2.2.2 Análise de Componentes Principais .............................................. 114

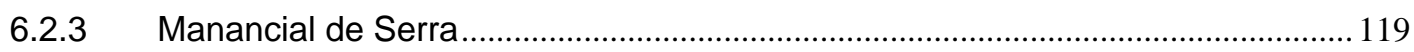

6.2.3.1 Análise de correlação .............................................................. 119

6.2.3.2 Análise de Componentes Principais ............................................... 121

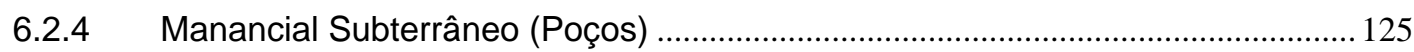

6.2.4.1 Análise de correlação ................................................................ 125

6.2.4.2 Análise de Componentes Principais ................................................. 128

6.3 Análise Discriminante e Melhores Predictores …............................................... 132

6.3.1 Análise de Melhores Preditores: ........................................................................... 134

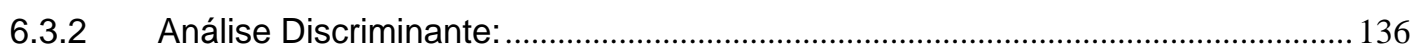

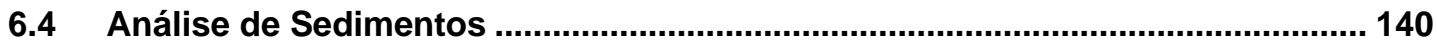

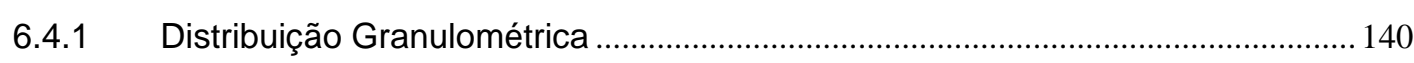

6.4.2 Determinação de metais e elementos-traço em sedimentos ..................................141

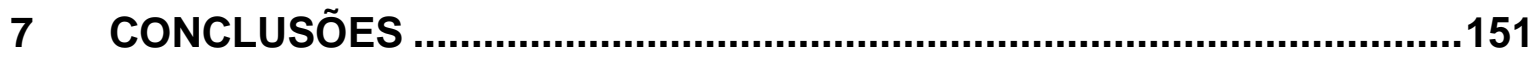

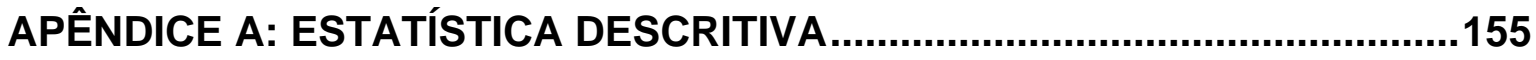

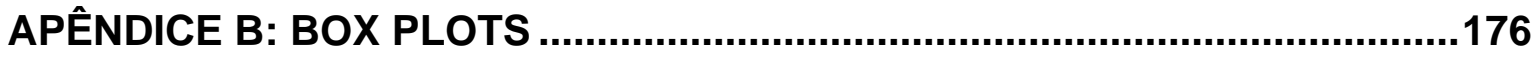

APÊNDICE C: FREQÜÊNCIA DE DISTRIBUIÇÃO ..........................................189

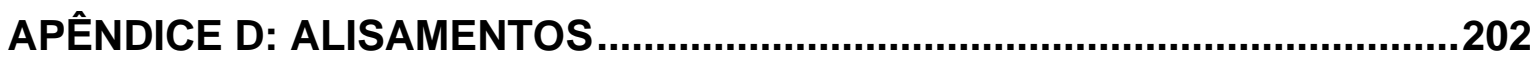

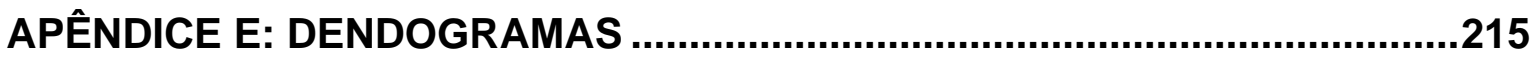

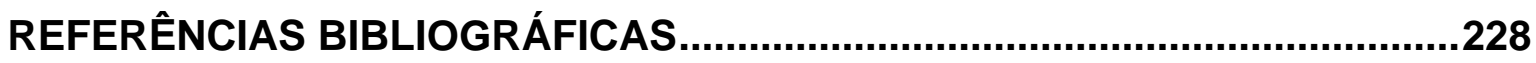




\section{ÍNDICE DE FIGURAS}

Figura 4.1 - Localização da área de estudo no estado de São Paulo (CETESB,2003 modificado). .28

Figura 4.2 - Distribuição da área ocupada por floresta tropical natural no estado de São Paulo (CATI - LUPA, 2004) e distribuição por Unidade de Conservação, na Bacia Hidrográfica do Ribeira de Iguape, SP ...................32

Figura 4.3 - Mapa pedológico do Vale do Ribeira. 41

Figura 4.4 - Comparação disponibilidade $\left(Q_{7,10}\right) \times$ demanda (D) para a Bacia Hidrográfica do Rio Ribeira de Iguape (CETEC, 2000). 44

Figura 5.1 - Localização dos Pontos de coleta - captações superficiais e estações de tratamento de água (ETA's). .55

Figura 5.2 - Área de captação de Manancial de Serra, Município de Musácea. ...56 Figura 5.3 - Captação em poço profundo, Bairro Conchal; Município de Miracatu. .56

Figura 5.4 - ETA do Município de Juquiá. 57

Figura 5.5 - ETA do Município de Cajati. .57

Figura 6.1 - Distribuição dos elementos chumbo, alumínio e manganês nas amostras de água captada em manancial de serra. .73

Figura 6.2 - Distribuição dos elementos zinco, sódio e magnésio nas amostras de água captada em manancial de serra. 74

Figura 6.3 - Distribuição dos elementos fósforo, potássio e cálcio nas amostras de água captada em manancial de serra. 75

Figura 6.4 - Distribuição dos elementos bário, ferro e fluoreto nas amostras de água captada em manancial de serra. .76

Figura 6.5 - Distribuição dos elementos sulfato, cloreto e nitrato nas amostras de água captada em manancial de serra.

Figura 6.6 - Distribuição dos elementos alumínio, manganês e zinco em amostras de água subterrânea. 80

Figura 6.7 - Distribuição dos elementos sódio, magnésio e fósforo em amostras de água subterrânea.

Figura 6.8 - Distribuição dos elementos potássio, cálcio e ferro em amostras de água subterrânea. 82 
Figura 6.9 - Distribuição dos elementos bário, chumbo e cloreto em amostras de água subterrânea. .83

Figura 6.10 - Distribuição dos elementos nitrato, fluoreto e sulfato em amostras de águas subterrâneas.

Figura 6.11 - Distribuição dos elementos Al, Mn e Fe em amostras de água bruta.

Figura 6.12 - Distribuição dos elementos chumbo, zinco e magnésio em amostras de água bruta. .88

Figura 6.13 - Distribuição dos elementos sódio, fósforo e potássio em amostras de água bruta......

Figura 6.14 - Distribuição dos elementos cálcio, bário e fluoreto em amostras de água bruta. .90

Figura 6.15 - Distribuição dos elementos cloreto, sulfato e nitrato em amostras de água bruta.

Figura 6.16 - Distribuição dos elementos alumínio, manganês e ferro em amostras de água tratada.

Figura 6.17 - Distribuição dos elementos chumbo, zinco e magnésio em amostras de água tratada. .95

Figura 6.18 - Distribuição dos elementos sódio, fósforo e potássio em amostras de água tratada. 96

Figura 6.19 - Distribuição dos elementos cálcio, bário e fluoreto em amostras de água tratada.

Figura 6.20 - Distribuição dos elementos cloreto, sulfato e nitrato em amostras de água tratada. .98

Figura 6.21 - Distribuição de alumínio em amostras de água de manancial superficial, de serra e poço. 100

Figura 6.22 - Distribuição de manganês em amostras de água de manancial superficial, de serra e poço. 100

Figura 6.23 - Distribuição de sódio em amostras de água de manancial superficial, de serra e poço. 100

Figura 6.24 - Distribuição de fósforo em amostras de água de manancial superficial, de serra e poço. 101

Figura 6.25 - Distribuição de cálcio em amostras de água de manancial superficial, de serra e poço. 101 
Figura 6.26 - Distribuição de ferro em amostras de água de manancial superficial, de serra e poço.

Figura 6.27 - Distribuição de magnésio em amostras de água de manancial superficial, de serra e poço.

Figura 6.28 - Distribuição de sulfato em amostras de água de manancial superficial, de serra e poço. 102

Figura 6.29 - Projeção das variáveis retidas nos fatores 1, 2 e 3. 110

Figura 6.30 - Dendograma da concentração dos elementos avaliados para água bruta

Figura 6.31 - Projeção dos pontos de captação - água bruta. 111

Figura 6.32 - Projeção das variáveis retidas nos fatores 1, 2 e 3.

Figura 6.33 - Dendograma da concentração dos elementos avaliados para água tratada. 118

Figura 6.34 - Projeção dos pontos de coleta. 118

Figura 6.35 - Projeção das variáveis retidas nos fatores 1 e 2 em manancial de serra.

Figura 6.36 - Dendograma da concentração dos elementos avaliados para água de manancial de serra. 125

Figura 6.37 - Projeção das variáveis retidas nos fatores 1 e 2 . 131

Figura 6.38 - Dendograma da concentração dos elementos avaliados para água de poço.

Figura 6.39 - Tela do ambiente "Minning", onde as análises são representadas. 133

Figura 6.40 - Representação esquemática da análise de melhores preditores Água bruta.

Figura 6.41 - Representação esquemática da análise de melhores preditores Manancial de Serra. 135

Figura 6.42 - Representação esquemática da análise de melhores preditores Manancial Subterrâneo - Água de poços. 136

Figura 6.43 - Representação da função discriminante para captações superficiais. 


\section{ÍNDICE DE TABELAS}

Tabela 3.1 - Parâmetros de qualidade de água de legislações Federais, do Estado de São Paulo e Internacionais.

Tabela 4.1 - Resumo das principais características da Bacia Hidrográfica do Ribeira de Iguape (CETESB, 1999, adaptado*).

Tabela 4.2 - Principais pólos de indústria extrativa mineral no Vale do Ribeira ...36 Tabela 4.3 - Ocorrência de bens minerais no Vale do Ribeira (CETEC, 2002,

SEDAE, 2002)

Tabela 4.4 - Estimativa da demanda para irrigação nas sub-bacias (CETEC, 2002). 45

Tabela 4.5 - Características da potencialidade de água subterrânea da Bacia do Ribeira de Iguape e Litoral Sul (CETEC, 2002). .45

Tabela 4.6 - Sistemas produtores operados pela SABESP, apresentando tipo de manancial, situação atual do manancial com perspectivas de racionamento, bem como percentagens de ligações (Dados fornecidos pela SABESP Unidade Operacional Vale do Ribeira - RR - Registro.

Tabela 5.1 - Caracterização e localização dos sistemas produtores do Vale do Ribeira (Dados fornecidos pela SABESP - Unidade de Negócios Vale do Ribeira/Litoral Sul -RR). .53

Tabela 5.2 - Coeficiente de correlação, faixa de concentração, limite de detecção

(L.D.) e limite de quantificação (L.Q.) dos analitos iônicos.

Tabela 5.3 - Reprodutibilidade, precisão e desvio padrão relativo. .62

Tabela 5.4 - Condições operacionais do sistema (ICP-OES). 62

Tabela 5.5 - Comprimento de onda, faixa de concentração, limite de detecção e quantificação para as metodologias utilizadas na análise de águas e sedimentos na fração disponível.

Tabela 5.6 - Reprodutibilidade, precisão e desvio padrão relativo para a análise do material de referência NIST - SRM-1643c (Trace Elements in Water), por ICP-OES. 65

Tabela 5.7 - Reprodutibilidade, precisão e desvio padrão relativo para o procedimento de lixiviação com $\mathrm{HCl} 0,1 \mathrm{M}$ do material de referência NIST SRM-2704.

Tabela 5.8 - Limites de quantificação, e a faixa de trabalho estabelecida (AAS)..66 
Tabela 6.1 - Razão entre o número de valores que não estão de acordo com a legislação (Portaria 158/04 e CONAMA 357) e o número de coletas realizadas nos mananciais de serra.

Tabela 6.2 - Razão entre o número de valores que não estão de acordo com a Legislação e o número total de análises realizadas para esses parâmetros. 86 Tabela 6.3 - Razão entre o número de valores que não estão de acordo com a Legislação e o número total de análises realizadas para esses parâmetros em mananciais superficiais. .93

Tabela 6.4 - Média e faixa de concentração $\left(\mathrm{mg} \cdot \mathrm{L}^{-1}\right)$ de metais e elementos iônicos em águas superficiais, mananciais de serra e poços dos sistemas produtores do Vale do Ribeira, bem como os limites estabelecidos para água potável pela Portaria 518/MS de 2004 - Água Distribuída. 103

Tabela 6.5 - Média e faixa de concentração $\left(\mathrm{mg} \cdot \mathrm{L}^{-1}\right)$ de metais e elementos iônicos em água bruta e tratada nos sistemas produtores do Vale do Ribeira que utilizam captação superficial, bem como os limites estabelecidos pelo CONAMA 357 para corpos de água Classe II 104

Tabela 6.6 - Matriz de correlação entre pH, turbidez, elementos metálicos e iônicos em água bruta................................................................ 106

Tabela 6.7 - Análise de componentes principais - água bruta........................107

Tabela 6.8 - Resultados da análise de componentes principais para a água bruta. 108

Tabela 6.9 - Esquematização das informações da ACP para os elementos na água bruta...... 109

Tabela 6.10 - Matriz de correlação entre pH, turbidez, elementos metálicos e iônicos em água tratada.

Tabela 6.11 - Análise de componentes principais - água tratada. 114

Tabela 6.12 - Resultados da análise de componentes principais para a água tratada.

Tabela 6.13 - Esquematização das informações da ACP para os elementos em água tratada.

Tabela 6.14 - Matriz de correlação entre pH, turbidez, elementos metálicos e iônicos em manancial de serra.

Tabela 6.15 - Análise de componentes principais - manancial de serra. 121 
Tabela 6.16 - Resultados da análise de componentes principais para manancial de serra.

Tabela 6.17 - Esquematização das informações da ACP para os elementos em manancial de serra.

Tabela 6.18 - Matriz de correlação entre pH, turbidez, elementos metálicos e iônicos em água de poços.

Tabela 6.19 - Análise de componentes principais - água poços. 128

Tabela 6.20 - Resultados da análise de componentes principais para água de poço.

Tabela 6.21 - Esquematização das informações da ACP para os elementos em água de poço.

Tabela 6.22 - Matriz de correlação para água bruta

Tabela 6.23 - Funções discriminantes. 138

Tabela 6.24 - Resumo do método "stepwise". 139

Tabela 6.25 - Média e faixa de concentração $\left(\mu \mathrm{g} \mathrm{g}^{-1}\right)$ de elementos disponíveis em sedimentos pertencentes as áreas de captação da Bacia do Vale do Ribeira.

Tabela 6.26 - Distribuição de elementos (macro constituintes) na fração total e lixiviada das amostras de sedimentos (fração < 0,63 $\mu \mathrm{m}$ ). 143

Tabela 6.27 - Concentração total e lixiviada de metais tóxicos nas amostras de sedimentos de fundo (fração $<0,63 \mu \mathrm{m}$ ) dos mananciais superficiais e de serra do Vale do Ribeira. 145

Tabela 6.28 - Porcentagem das concentrações dos elementos disponível em relação à concentração total.

Tabela 6.29 - Comparação entre as concentrações de metais na fase lixiviada em $\mu \mathrm{g} \mathrm{g}^{-1}$, de sedimento seco (fração $<0,63 \mu \mathrm{m}$ ), em vários trabalhos da literatura, com os resultados encontrados neste trabalho 149 


\section{INTRODUÇÃO}

A água representa insumo fundamental à vida, configurando elemento insubstituível em diversas atividades humanas, além de manter o equilíbrio do meio ambiente.

O acelerado crescimento populacional no mundo tem conduzido ao aumento da demanda de água, o que vem ocasionando, em várias regiões, problemas de escassez desse recurso.

O crescimento da demanda mundial de água de boa qualidade, a uma taxa superior à da renovabilidade do ciclo hidrológico é consensual, previsto nos meios técnicos e científicos internacionais. Este crescimento tende a se tornar uma das maiores pressões antrópica sobre os recursos naturais do planeta neste novo século. $\mathrm{Na}$ sociedade moderna, a busca do conforto implica necessariamente num aumento considerável das necessidades diárias de água e energia. A melhoria da qualidade de vida reflete entre outras coisas, nas condições de habitação e infra-estrutura.

A preocupação com os recursos hídricos e sua importância para a qualidade de vida tem crescido em todo o mundo. Apesar de possuírem na natureza um ciclo equilibrado de renovação e sustentação, sem qualquer intervenção humana, as perspectivas atuais de uso e qualidade desse recurso para um futuro próximo são preocupantes, principalmente em razão da falta de equilíbrio entre a necessidade de consumo e a compreensão dos fenômenos naturais. Há cerca de 2.000 anos, a população mundial correspondia a 3\% da população atual, enquanto o volume de água permanece o mesmo. A partir de 1950, o consumo de água triplicou em todo o mundo e o consumo de água por habitante aumentou em 50\% (CETESB, 2005). Muitos países têm enfrentado desafios em relação aos recursos d'água disponíveis, cujo problema também se relaciona com a perda da biodiversidade e desmatamentos das florestas. 
As estatísticas da Organização Meteorológica Mundial das Nações Unidas demonstram que nos próximos 30 anos a situação global das reservas hídricas tende consideravelmente a piorar, caso não haja ações emergentes para a melhoria da gestão da oferta da demanda d'água. Eutrofização, metais tóxicos, acidificação, poluentes orgânicos e efluentes tóxicos tem degradado os corpos d'água principalmente em áreas densamente povoadas. Os recursos hídricos superficiais são os primeiros a serem afetados e os responsáveis pela alteração da qualidade de vida da população dele servida.

As reservas hídricas do planeta Terra são estimadas em 1.400 milhões de $\mathrm{km}^{3}$. Embora expressivas, apenas $2 \%$ são de água doce, constituindo os rios, lagos e águas subterrâneas, praticamente 1\% de neve e geleiras permanentes e apenas 0,0005\% de vapor d'água na atmosfera. Excluindo-se a água contida nas calotas polares e nos aqüíferos, a humanidade conta com pouco mais de 2.000 $\mathrm{km}^{3}$ das águas dos rios para suprir quase a totalidade de suas demandas. Destes recursos, quase metade $\left(946 \mathrm{~km}^{3}\right.$ ) encontra-se na América do Sul (REBOUÇAS et al., 1999).

O Brasil é um país de dimensões continentais, ocupando quase 50\% do território da América do Sul. Desta, 92\% está localizado na faixa tropical com predominância de climas quentes com temperaturas médias anuais acima de $20^{\circ} \mathrm{C}$. Em função da variação geomorfológica e climática este apresenta grande diversidade de biomas. Podemos verificar a existência de climas muito distintos, como por exemplo, regiões onde o calor e a chuva são constantes - Floresta Amazônica (temperatura média anual é de $26^{\circ} \mathrm{C}$ e $27^{\circ} \mathrm{C}$ ), assim como regiões onde o clima é quente e sem chuvas durante a maior parte do ano - Caatinga (ANA, 2002; ANA , 2003).

Apesar da situação aparentemente favorável observa-se, no Brasil, uma enorme desigualdade regional na distribuição dos recursos hídricos. Quando se comparam essas situações com a abundância de água da Bacia Amazônica, que corresponde às regiões Norte e Centro-Oeste, contrapondo-se a problemas de escassez no Nordeste e conflitos de uso nas regiões Sul e Sudeste, a situação se agrava. Ao se considerar, em lugar de disponibilidade absoluta de recursos hídricos renováveis, àquela relativa à população dele dependente, o Brasil deixa de ser o primeiro e passa ao vigésimo terceiro no mundo (Projeto Água, 2003). 
O Brasil possui situação privilegiada em relação à sua disponibilidade hídrica, porém cerca de $70 \%$ da água doce do país encontra-se na região amazônica, que é habitada por menos de $5 \%$ da população. A idéia de abundância serviu durante muito tempo como suporte à cultura do desperdício da água disponível, à sua pouca valorização como recurso e ao adiamento dos investimentos necessários à otimização de seu uso (REBOUÇAS et al., 1999).

A maior demanda de água no país é exercida pela agricultura, especialmente pela irrigação, com quase $56 \%$ de toda demanda; seguida pelo uso urbano $21 \%$, indústria $12 \%$, rural $6 \%$ e animal $5 \%$. Observa-se que existem grandes diferenças entre as regiões hidrográficas com relação à disponibilidade hídrica e demanda.

Os problemas de escassez hídrica no Brasil decorrem, fundamentalmente entre o crescimento exagerado das demandas localizadas e da degradação da qualidade das águas. Esse quadro é conseqüência dos desordenados processos de urbanização, industrialização e expansão agrícola.

O Estado de São Paulo caracteriza-se por possuir a mais diversificada e intensa produção agrícola do país. Estima-se que 43,5\% da demanda de água do Estado é usada para atender à agricultura, contra $31,8 \%$ para a indústria e 24,7\% para o abastecimento público (IBGE, 1997).

Apesar da existência de normas legais como o Código Florestal (Lei 4.771, de 15-09-1965), a Lei de Parcelamento do Solo Urbano (Lei 6.766, de 1912-1979) e dos artigos da Lei 6.766, que restringem a ocupação de encostas e de margens de rios, as regiões Sul e Sudeste, onde vivem $60 \%$ da população do país, passaram a enfrentar uma crescente ameaça de escassez de água. O processo de crescimento econômico do Brasil iniciado a partir da década de 50 propiciou um desenvolvimento mais rápido das cidades do que o campo, incentivando um fluxo migratório, especialmente para a região sudeste (REIS, 2005).

Os recursos hídricos por outro lado, constituem-se em um importante aliado para a implementação de ações de saúde e ambiente, haja vista a importância da água para a vida humana, agricultura e a geração de energia. Há que se levar em conta o papel dos cursos de água na veiculação de inúmeras enfermidades. Além disso, intervenções no campo dos aproveitamentos 
hidráulicos, como barragens, hidrovias, aduções e projetos de irrigação acarretam riscos de incremento na incidência de algumas doenças (Uniagua, 2004).

A aplicação dos princípios orientadores de gestão das águas deverá ordenar seu uso múltiplo e possibilitar sua preservação para as futuras gerações, minimizando ou mesmo evitando problemas decorrentes da escassez e da poluição dos cursos de água, os quais afetam e comprometem diversos usos dos recursos hídricos.

Um dos grandes desafios na área de políticas públicas é harmonizar o desenvolvimento econômico/industrial com a preservação do meio ambiente, de forma que a exploração destes recursos não acarrete maiores danos aos ambientes e ao homem. Dessa forma, os recursos hídricos, principalmente os recursos hídricos destinados ao abastecimento público, deve ser integrado a um planejamento regional unindo o conhecimento científico e a ação do poder público para sua utilização e manutenção (NAKAMURA et al. , 1998; BRAGA et al., 1998).

O presente trabalho, em apoio ao desenvolvimento de políticas públicas relacionadas ao controle da qualidade de água, tem como proposta avaliar de forma integrada o comportamento de sistemas hídricos utilizados para o abastecimento público, contribuindo para o desenvolvimento de estudos de diagnóstico ambiental, com ênfase em programas de monitoramento em ambientes aquáticos naturais e nos sistemas de tratamento de água.

A área de estudo engloba a Unidade de Gerenciamento de Recursos Hídricos - UGRHI 11 - Vale do Ribeira e Litoral Sul, considerada um importante reservatório de água doce, à meia distância das metrópoles Curitiba e São Paulo. É um importante ecossistema para o desenvolvimento regional e estadual, no tocante a disponibilidade de recursos hídricos, contemplando o principal bioma do estado, as áreas urbanas e agrícolas, ainda com escassez industrial. Atualmente este sistema tem sido estudado sob vários aspectos, principalmente social, e ambiental (Programa SOS - Mata Atlântica).

A área possui um histórico alarmante quanto a contaminação de chumbo, além de ser detentora do mais importante e principal potencial mineral do Estado de São Paulo, com grande variedade de substâncias minerais desde 
ferrosos, metálicos, além de minerais raros como prata, antimônio e terras raras. Todo esse contexto se reflete nas características geoquímicas da água, do sedimento de drenagem e do material em suspensão (PIRES et al., 2002; NOGUEIRA et al., 2003).

O estudo está voltado para a avaliação da contribuição de metais tóxicos e elementos essenciais à saúde, bem como ânios e cátions abordando o núcleo temático de recursos hídricos, captação, tratamento e distribuição de água. Na UGHRI 11, nos municípios do estado de São Paulo, a captação, tratamento e distribuição de água é de responsabilidade da SABESP que opera 43 sistemas na região, sendo 18 sistemas com captações superficiais e respectivas estações de tratamento de água, 15 captações subterrâneas (poços) e 10 captações em mananciais de serra. O programa de monitoramento realizado caracterizou a água, nos mananciais da região, e o sedimento de fundo dos mananciais superficiais, além de avaliar a água distribuída (água tratada).

A abordagem integrada das ações dentro do tema pretende disseminar a informação, promover a capacitação permanente das instituições, padronizar metodologias de análise, com foco na geração de informação regionalizada.

A avaliação ambiental da bacia torna-se um importante instrumento que poderá contribuir não só para a avaliação da qualidade da água, como também, para o entendimento da dinâmica do sistema e para a escolha de medidas de manejo e recuperação deste ecossistema.

Este trabalho esta inserido no Projeto Políticas Públicas FAPESP 00/02024-4 - "Análise crítica da legislação sobre potabilidade das águas destinadas ao abastecimento público no estado de São Paulo", coordenado pela Dra. Maria Aparecida Faustino Pires no Centro de Química e Meio Ambiente CQMA, e realizado em parceria com a SABESP e CETESB.

Além disso, este trabalho fornece também subsídios a um outro Projeto - Políticas Públicas coordenado pela Dra. Maria Aparecida Faustino Pires no Centro de Química e Meio Ambiente - CQMA - FAPESP 03/01694-1 "Gerenciamento de lodos de ETAs. Influência do lançamento do lodo de ETA no processo de tratamento de esgotos por lagoas de estabilização em cidades de pequeno/médio porte" , realizado em parceria com a Companhia de Saneamento 
Básico do Estado de São Paulo - SABESP, Escola Politécnica e Faculdade de Saúde Pública da Universidade de São Paulo - USP.

Nesse sentido, o Centro de Química e Meio Ambiente - CQMA do IPEN - CNEN/SP, tendo como foco principal o tema água, vem desenvolvendo a 10 anos projetos com financiamento de agências de fomento como CNPq, FINEP e FAPESP, realizados em parceria com a Companhia de Saneamento Básico do Estado de São Paulo - SABESP, a Universidade de São Paulo - USP, a CETESB. Esses projetos sempre buscaram e, continuam priorizando a formação de equipes multidisciplinares envolvendo profissionais, pesquisadores, alunos de iniciação científica e pós-graduação, atuantes nas áreas de química, geociências, saneamento básico e toxicologia ambiental, reforçando a importância da realização de estudos integrados na interface ambiente - políticas públicas, em cujo seio possa estabelecer-se a comunicação indispensável entre pesquisa sociedade. 


\section{OBJETIVO}

O principal objetivo deste trabalho é aprofundar o conhecimento científico e a integração no contexto regional quanto à qualidade ambiental da água na Bacia Hidrográfica do Ribeira de Iguape com vistas ao abastecimento público. Dentro da proposta principal do trabalho, podem ser destacadas como principais metas:

1. Caracterizar os mananciais (superficial, subterrâneo e de serra) em pontos de captação de água utilizados para consumo humano, operados pela SABESP, quanto à contribuição de elementos inorgânicos (metais, elementos-traço, ânions e cátions) naturais e antropogênicos, avaliando amostras de água bruta e sedimento de fundo, utilizando como critérios de avaliação a legislação referente CONAMA 357/05;

2. Verificar a influência da sazonalidade no aporte das contaminações;

3. Avaliar a eficiência dos processos de tratamento completo aplicados nas Estações de Tratamento de Água (ETA's) para todos os sistemas produtores operadas pela SABESP, por meio da análise da água tratada, utilizando como critérios a Portaria 518/04/MS;

4. Realizar um banco de dados qualidade da água da região e entender os fatores que afetam essas condições de qualidade regionalmente e nacionalmente;

5. Estabelecer técnicas estatísticas adequadas para amostras ambientais, por meio da correlação dos dados obtidos a partir da análise multi-elementar dos elementos químicos propostos. 


\subsection{Aspectos relevantes do trabalho}

A introdução de substâncias tóxicas na água é uma das causas mais complexas de deterioração da qualidade da água. A constante utilização dos recursos hídricos tem requerido um maior número de estudos para avaliar e manter a sua qualidade.

"Integridade" tem sido definida como a habilidade de um ecossitema em se sustentar e manter uma comunidade de organismos balanceada, integrada e adaptada, tendo uma composição de espécies comparável ao da região natural (Fergusun, 1994; Polls, 1994, Karr,1991). "Equilíbrio", é um conceito controverso na ecologia de comunidades/ecossistemas. Muitos autores concordam na separação prática dos conceitos "saúde" e "integridade". Saúde refere-se ao desejado estado de sistemas modificado pelo homem; integridade refere-se ao grau em que um ecossitema varia do original, em condições não impactadas (Karr, 1991; Steedman, 1994; Scrimgeour \& Wicklum, 1996). Implícita nesta separação está a noção de que sistemas podem ser "saudáveis" (=desejável) e não necessáriamente "íntegros" (= similar à sua condição original).

Nesse sentido, programas de avaliação e monitoramento ambiental podem fornecer importantes informações sobre a extensão do grau de poluição no ambiente e os seus prováveis impactos, gerando também dados sobre a deterioração ou melhoria ambiental numa escala temporal. Além de importantes para a avaliação do grau de degradação ambiental, estes processos são o primeiro passo para se conhecer o funcionamento destes ecossistemas.

Neste estudo foi realizada uma avaliação da qualidade da água na Bacia do Ribeira do Iguape, abrangendo 3 tipos diferentes tipos de ecossitemas com mecanismos de funcionamento distintos. Cabe salientar que essa região não é contemplada pelo Monitoramento de Águas Subterrâneas realizado pela CETESB, não existindo um histórico da qualidade dessas águas

Assim, o programa de monitoramento realizado neste estudo, fornece um banco de dados sobre a qualidade da água, mostrando a situação atual, que 
permite entender os fatores que afetam essas condições de qualidade regionalmente, constituindo um panorama geral da área, destacando desta forma, a importância do tema. 


\subsection{Avaliação e monitoramento da qualidade da água}

Os processos de industrialização e de urbanização, nas últimas décadas, têm tornado cada vez mais crítica a questão da contaminação do meio ambiente. Entre os diversos contaminantes, os metais têm contribuído de forma significativa para a poluição do ar, da água e do solo, transformando-se em uma nova e perigosa classe de contaminantes, uma vez que a intervenção humana na geração e utilização, como subproduto de atividades industriais, tem criado graves problemas, em escala local e global, levando a um estresse da natureza, associado aos seus efeitos crônicos à saúde humana (BRAYNER, 1998).

A poluição ambiental por metais iniciou-se com a domesticação do fogo. Com a descoberta das minas e técnicas de extração de metal em tempos antigos, a relação entre metais, poluição por metal e história humana foi formada. As minas e o comércio de fontes mineiras tornaram-se características marcantes da economia inicial e, as técnicas de descoberta de metal alcançaram status como um barômetro do avanço tecnológico de culturas antigas (NRIAGU, 1996).

A Revolução industrial trouxe a demanda por metais a um exponencial na intensidade de emissões desses elementos, tanto em massa absoluta, como número de espécies tóxicas (NRIAGU, 1996).

De fato, a problemática relativa às intoxicações por metais data de épocas remotas, no entanto pouca atenção foi dada pelas autoridades a esse problema até a década de 50, quando ocorreu o acidente na baía de Minamata no Japão, onde centenas de pessoas morreram ou sofreram distúrbios neurológicos devido ao consumo de peixes contaminados com mercúrio (GOLDWATER, 1971; SORENSEN, 1991). 
Os metais podem ser introduzidos nos sistemas aquáticos como resultado de processos naturais, como intemperismo, erosão e erupções vulcânicas, bem como por uma série de atividades praticadas pelo homem (FOSTER \& CHARLESWORTH, 1996). Na água os metais podem estar presentes nas formas particulada (em suspensão ou sedimento de fundo), coloidal e dissolvida, sendo constantemente redistribuídos entre estas fases durante o transporte (SHI et al., 1998).

A ação antrópica sobre o meio aquático é a responsável pela maioria das alterações nos recursos hídricos. Os rios vêm sendo depositários de rejeitos por muitos anos, alterando profundamente o estado normal do meio aquático. As alterações da qualidade da água representam uma das maiores evidências do impacto da atividade humanas sobre a biosfera (PORTO et al., 1991).

Os metais traço ocorrem como constituintes naturais da crosta terrestre e estão sempre presentes como constituintes de solos, águas naturais e organismos vivos. Alguns desses elementos têm demonstrado serem essenciais para as funções de organismos vivos, enquanto outros elementos interagem somente de maneira tóxica com a matéria viva (LEPP, 1981).

Um número de doze metais e metalóides têm sido reconhecidos como potencialmente perigosos à saúde humana e a biota aquática, sendo incluídos na "Priority Pollutants List (Black List)" por agências de controle ambiental em todo o mundo, incluindo antimônio, arsênio, berílio, cádmio, cobre, chumbo, mercúrio, níquel, selênio, prata, tálio e zinco.

A toxicidade dos metais é uma questão de dose ou tempo de exposição, da forma física e química do elemento e da via de administração/adsorção. Os níveis máximos permitidos pelos órgãos de controle ambiental, CONAMA (Conselho Nacional do Meio Ambiente), EPA (Environmental Protection Agency, EUA) e WHO (World Health Organization, ONU), quanto a qualidade da água variam entre si, sendo as diferenças reflexos do potencal toxicológico do metal e da qualidade ambiental de cada país (PIRES et al., 2000). 
No monitoramento dos níveis de metais no ambiente aquático, diferentes amostras são utilizadas, seja para o controle ou prevenção de possíveis contaminações. Dentre as mais comuns estão as amostras de água, material particulado em suspensão, sedimento de fundo e biota, destacando-se os peixes, moluscos, macroinvertebrados e alguns tipos de macrófitas.

Os níveis de metais dissolvidos na água são extremamente variáveis, sendo que a avaliação deste parâmetro isolado fornece pouca informação sobre a contaminação do ambiente. O material particulado, tanto em suspensão (MPS) como na forma de sedimento de fundo, representa importante parâmetro na análise da dinâmica de distribuição de metais, visto que grande parte dos elementos transportados na água está associada a essas partículas.

$\mathrm{Na}$ coluna d'água os teores de metais dissolvidos tendem a variar por várias ordens de magnitude ao longo do tempo, o que se deve ao grande número de variáveis envolvidas na sua dinâmica, tais como variações diárias e sazonais no fluxo da água, descargas locais de efluentes urbanos e industriais, variações de $\mathrm{pH}$ e condições redox (FORSTNER \& WITTMAN, 1983). Apesar de tais variações, a determinação das concentrações dos metais dissolvidos na água constitui uma ferramenta útil na avaliação do grau de contaminação de um determinado ecossistema e tem sido utilizada por diferentes pesquisadores em todo o mundo (GARBADINO et al., 1995; HURLEY et al., 1995, 1998; ASUBIOJO et al., 1997; MASTRINE et al., 1999). Entretanto, a análise dos teores de metais dissolvidos na água deve ser sempre acompanhada pela análise de outros materiais (sedimentos, biota). Atualmente, é reconhecido que as concentrações totais de metais dissolvidos na água é, frequentemente insuficiente como indicador de toxicidade aos organismos aquáticos. Em muitos casos, a toxicidade biológica está relacionada às concentrações de uma espécie química particular (TOKALIGLU et al., 2000).

Em rios, as concentrações de metais nos sedimentos são, em geral, maiores que as concentrações dissolvidas na coluna d'água, embora as transferências de metais entre tais compartimentos estejam relacionadas às características do íon metálico, ao tamanho das partículas, ao conteúdo orgânico 
e à concentração do sedimento. Entretanto, em ambientes altamente contaminados por metais, os níveis detectados na forma dissolvida podem ser relativamente elevados. Por outro lado, em ambientes não contaminados, as concentrações de metais na forma dissolvida são baixas, sendo que estes elementos encontram-se preferencialmente associados ao MPS e ao sedimento de fundo (FORSTNER \& CHARLESWORTH, 1996).

Os metais associados às partículas do MPS podem ser depositados no sedimento de fundo. Dependendo da vazão e da velocidade da água, as partículas em suspensão podem precipitar e serem incorporadas ao sedimento de fundo; portanto, a composição química do sedimento reflete a composição da coluna d'água. Assim, a capacidade dos sedimentos de concentrar a maioria dos contaminantes fez deles um indicador particularmente útil em monitoramentos (MOLISANI et al., 1999; HUGGETT et al., 2001; LEMES, 2001; ARRIBÉRE et al., 2003).

O estudo de metais nos rios brasileiros ainda é escasso, em vista da grande rede hidrográfica do território nacional. Um programa sistemático e amplo de monitoramento da água no Brasil não foi ainda realizado, talvez por falta de uma proposta mais objetiva e econômica para que seja viabilizado pelo governo (PIRES et al., 2000).

Muitas pesquisas sobre a contaminação do ambiente aquático por $\mathrm{Hg}$ foram desenvolvidas na região Amazônica, principalmente nas regiões com atividades mineradoras, onde esse elemento é utilizado na amalgamação do ouro (BRABO et al., 2000; GUIMARÃES et al., 2000; LIMA et al., 200; URYU et al., 2001).

No Rio Grande do Sul, PESTANA et al. (1997, 2000) estudaram os níveis de metais na bacia do rio Camaquã, em uma região onde existia, no passado, mineração de ouro e cobre.

Em Minas Gerais, VEADO et al. (1997) e RIETZLER et al. (2001) estudaram os níveis de metais nas águas do rio Velhas e de tributários da represa 
de Pampulha, respectivamente, detectando concentrações de alguns metais maiores que as permitidas pela Legislação Brasileira.

Vários estudos têm sido desenvolvidos no Estado do Rio de Janeiro, os quais enfatizam a influência das atividades antrópicas nos níveis de metais pesados no ambiente aquático. O Rio Paraíba do Sul, um dos mais importantes para o estado, foi estudado em relação aos metais associados ao material particulado em suspensão (CARVALHO et al., 1999; SALOMÃO et al., 2001) e ao sedimento de fundo (MOLISANI et al., 1999).

DePAULA \& MOZETO (2001) analisaram teores de metais de uma pequena bacia hidrográfica (bacia do rio Capivari), localizada na reserva biológica da Praia do Sul (Ilha Grande, RJ), em uma tentativa de estabelecer níveis de referência para metais em sedimentos da costa sudeste do Brasil. O mesmo tipo de estudo foi realizado por SALOMÃO et al., (2003) em micro bacias localizadas nos parques Estaduais de Intervales, Morro do Diabo e Vassununga, localizados no estado de São Paulo, para estabelecer níveis de referência para este Estado. Os parques protegidos por lei apresentam, em geral, pouca ou nenhuma influência antrópica; portanto, as concentrações de metais detectadas nas amostras de tais ambientes podem ser utilizadas em comparações com níveis detectados em ambientes afetados por atividades urbanas, mineradoras e industriais, servindo como níveis basais ou de referência.

GATTI et al. (1999) avaliaram os níveis de 20 elementos em amostras de perfis de sedimentos da Lagoa do Infernão, localizada na bacia do rio MogiGuaçu, concluindo que a região não foi afetada por altos níveis de metais oriundos de atividades antrópicas.

Ainda no rio Mogi-Guaçu, destaca-se o trabalho de TOMAZELLI et al. (2003), que realizaram um monitoramento de $\mathrm{Pb}$ e $\mathrm{Cd}$ utilizando o bivalve Anodontiles trapesialis como monitor biológico e, compararam os níveis dos metais com os detectados no rio Piracicaba. Os resultados mostraram maiores concentrações de $\mathrm{Pb}$ nos bivalve do rio Mogi-Guaçu em relação aos do Piracicaba. 
Observa-se, portanto, que os estudos no Brasil e principalmente em São Paulo estão restritos a regiões com maiores influências antrópicas, não sendo programas de monitoramento amplo e sistemático, mas sim estudos isolados.

Nos Estados Unidos, por exemplo, um programa de avaliação da qualidade de rios e aquíferos denominado NAWQA - National Water Quality Assessment, foi iniciado em 1991. Realizado pela U.S.Geological Survey e U.S. Departament of the Interior, abrange aproximadamente metade dos Estados Unidos e inclui $70 \%$ das fontes destinadas ao abastecimento público, abrangendo mais de cinquenta dos maiores rios e aquiferos. A principal meta do programa é realizar um banco de dados sobre a qualidade da água e entender os fatores que afetam essas condições de qualidade regionalmente e nacionalmente (BERNDT et al., 1998).

Em 1994 foi iniciado na Gra-Bretanha o Programa LOIS (Land Ocean Interaction Study) (NEAL et al., 1998) com o objetivo de estudar as influências dos centros populacionais, agricultura e indústria nos rios que deságuam no Mar do Norte. Esse programa conta com a colaboração de universidades da Inglaterra e agências ambientais da Inglaterra, País de Gales e Escócia.

Os estudos são direcionados de modo sazonal, sendo os principais indicadores da qualidade da bacia: pH, alcalinidade, oxigênio dissolvido, condutividade, clorofila, fluxo e metais e compostos inorgânicos (maiores, menores e nível traço: boro, bário, ferro, manganes, níquel, molibdênio, chumbo, estroncio, alumínio, escandio, zinco, sódio, potássio, cálcio, lítio, cobre, fósforo, nitrito, nitrato, sulfato, cobalto, cromo), herbicidas (clortoluton, diuron, isoproturon, mecoprop, MCPA, MCPB, 2,4-D, atrazina, simazina e propazina) organoclorados, analisados na água e no sedimento (NEAL et al., 2000 a ; 2000b).

A Agencia Ambiental Americana, na publicação Water Quality Guidance for the Great Lakes System, estabeleceu critérios para a qualidade da água para 29 poluentes. Esses critérios foram designados em termos de proteção a vida aquática, a vida selvagem (terrestre) e saúde humana. PCBs (bifenilas 
policloradas), trans-nonachlor (componente do chlrodano), atrazina e mercúrio foram incluídos na lista dos 29 poluentes, por serem correntemente utilizados na agricultura e potencialmente causadores de risco a organismos aquáticos e terrestres, são bioacumulativos, persistentes e cancerigenos.

A Cetesb (Companhia de Tecnologia de Saneamento Ambiental do Estado de São Paulo) avalia a qualidade das águas interiores desde 1974. Iniciou o estudo com 47 pontos de coleta e atualmente conta com 154 pontos de monitoramento, sendo 38 coincidentes com mananciais de abastecimetno público. A partir de 1990, iniciou um programa de monitoramento de águas subterrâneas, avaliando 76 poços profundos e em 2003, iniciou o monitoramento de sedimentos em 18 pontos, correspondendo a 7 UGRHI's.

Nesse aspecto, LEMES (2001) realizou um monitoramento na Bacia Hidrográficas dos Rios Mogi-Guaçu e Pardo, avaliando metais em amostras de águas e sedimento de fundo, avaliando as captações utilizadas para abastecimento público, criando um enorme banco de dados que forneceram subsídios ao setor de saneamento e saúde pública.

Portanto, avaliar a qualidade dos mananciais em áreas menos industrializadas ou com populações menores, é extremamente importante, tanto para determinar áreas potencialmente afetadas por poluição difusa, quanto para determinar níveis de referência para essas áreas, criando um banco de dados para futuros estudos.

\subsection{Padrões de qualidade e legislação}

Os padrões de qualidade de água são utilizados para regulamentar os níveis de qualidade a serem mantidos em um corpo de água, dependendo do uso a que ele está destinado. A utilização de padrões de qualidade atende a dois propósitos: 1. manter a qualidade do curso da água ou definir a meta a ser atingida e, 2. ser a base para definir os níveis de tratamento a serem adotados na bacia, de modo que os efluentes lançados não alterem as características do curso de água estabelecidos pelo padrão (PORTO et al., 1991). 
Devemos lembrar que as normas e os padrões de qualidade asseguram e protegem a saúde pública e o meio ambiente, disciplinando o uso. Devem atender a prioridades nacionais, fatores econômicos, segurança e saúde com base em conhecimento tecnológico (PIRES, 2004).

Na Esfera Federal, a Resolução 357/05 do Conselho Nacional do Meio Ambiente (CONAMA) estabelece a classificação para as águas doces, bem como para as águas salobras e salinas do Território Nacional. São definidas 9 classes, segundo os usos preponderantes a que as águas se destinam.

No Estado de São Paulo a Lei no 997/79, regulamentada pelo Decreto ñ 8.468/76, dispõe sobre a preservação e o controle da poluição do meio ambiente. Esse decreto define a classificação das águas interiores situadas no território do Estado de São Paulo, segundo seus usos preponderantes. Também são estabelecidos, entre outros, padrões de qualidade das águas para as quatro classes e padrões de emissão para efluentes líquidos de qualquer natureza tratam os recursos hídricos por classes, diferenciando-as pelos padrões numéricos de emissão dos poluentes que podem ser lançados nos corpos d’água.

No Brasil, o controle de qualidade da água de abastecimento público é efetuado através de dois instrumentos. O primeiro deles é executado pelo próprio produtor, o qual é denominado "controle operacional", e visa à adaptação dos processos produtivos para o atendimento de qualidade pré-estabelecido. $\mathrm{O}$ segundo instrumento designado "controle legal" ou vigilância sanitária, deveria ser realizado por entidades distintas, autônomas e independentes, sendo atribuição dos Ministérios de Saúde ou, por delegação das Secretarias Estaduais de Saúde (Pires, 2004).

A Portaria n-518/MS/2004 estabelece os padrões atuais de potabilidade de água para o abastecimento público no território nacional. Esta Portaria promoveu uma prorrogação de 12 meses para sua implantação a partir de sua publicação (30 de Março de 2004), sendo uma cópia praticamente fiel do texto da Portaria no 1469/MS/00. As alterações se encontram no capítulo III, seção I Art. 5ำ que delega a competência para editar normas regulamentadoras 
desta Portaria ao presidente da FUNASA e passa a delegar ao Secretário de

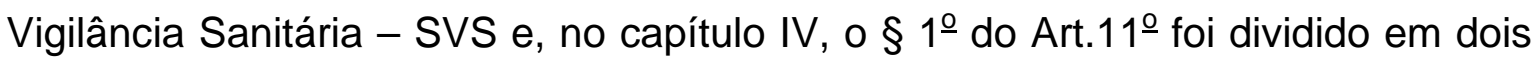
parágrafos.

A Portaria $\mathrm{n}^{0}$ 1469/MS/2000, foi mais abrangente que a anterior, a Portaria no 36/MS/90, abordando temas como controle e gerenciamento de mananciais, controle de cianobactérias e a inserção de novas substâncias nos padrões de potabilidade como antimônio, acrilamida e alguns agrotóxicos.

No estado de São Paulo, a Resolução SS no 178/96 da Vigilância Sanitária do Estado orienta as empresas responsáveis pelo abastecimento público de água potável no sentido de efetuarem os seus respectivos cadastramentos junto à Vigilância Sanitária do Estado. Apresentar seus próprios planos mensais e semestrais de amostragem e efetuar, elas próprias, o controle da qualidade da água que produzem. Institucionalizando uma prática já bem difundida no país, de se outorgar ao produtor de água potável, a competência legal, para que ele próprio exerça a vigilância sanitária da água que produz.

A Portaria n 518/MS/04 concorda com esta prática, delegando aos responsáveis pela Operação de Sistema o controle da qualidade da água produzida e distribuída (seção IV, art. $8^{\circ}$ e $9^{\circ}$ ) e a elaboração dos planos de amostragem (capítulo $\mathrm{V}$, art. $18^{\circ}$ e $19^{\circ}$ ).

A Tabela 3.1 relaciona os padrões de qualidade da água estabelecidos por diferentes instituições governamentais. 
Tabela 3.1 - Parâmetros de qualidade de água de legislações Federais, do Estado de São Paulo e Internacionais.

\begin{tabular}{|c|c|c|c|c|c|c|c|c|c|c|c|c|}
\hline \multirow{3}{*}{ PARÂMETROS } & \multicolumn{9}{|c|}{$\begin{array}{c}\text { Parâmetros de Qualidade de Água - Valores Máximos Permissíveis } \\
\text { PADRÃO DE POTABILIDADE }\end{array}$} & \multirow{2}{*}{\multicolumn{3}{|c|}{$\begin{array}{l}\text { PADRÃO DE QUALIDADE AMBIENTAL } \\
\text { CONAMA N } 357 / 05\end{array}$}} \\
\hline & \multirow{2}{*}{ UNIDADES } & \multirow{2}{*}{$\begin{array}{l}\text { PORTARIA N } \\
36 / 90\end{array}$} & \multirow{2}{*}{\begin{tabular}{|l|} 
PORTARIAS \\
N¹469/00/ \\
$N^{\circ} 518 / 04$
\end{tabular}} & \multirow{2}{*}{$\begin{array}{l}\text { D. ESTADUAL/SP } \\
\mathrm{N}^{\circ} 12.486 / 78\end{array}$} & \multirow{2}{*}{$\begin{array}{l}\text { OMS } \\
1995\end{array}$} & \multirow{2}{*}{$\begin{array}{l}\text { EPA } \\
2003\end{array}$} & \multicolumn{3}{|c|}{$\star \star S S-293$} & & & \\
\hline & & & & & & & I & ॥ & III & CLASSE 1 & CLASSE 2 & CLASSE 3 \\
\hline \multicolumn{13}{|l|}{ I - Físicos Organolépticos } \\
\hline Cor & $\mathrm{UH}^{(1)}$ & 5 & 15 & $10-20$ & 15 & 15 & $\leq 5$ & $5<x \leq 15$ & $>15$ & Natural & $\leq 75$ & $\leq 75$ \\
\hline Odor & - & n. 0. & n.o. & Isento / livr. cloro & - & $3^{(11)}$ & n. 0. & n.o. & n. 0. & - & - & - \\
\hline Sabor & - & n. 0. & n.o. & - & - & - & n. 0. & n.o. & n. 0. & - & - & - \\
\hline Turbidez & $\mathrm{UT}^{(2)}$ & 1 & 1 & $2-5$ & 5 & 5 & $\leq 1$ & $1<x \leq 5$ & $>5$ & $\leq 40$ & $\leq 100$ & $\leq 100$ \\
\hline Temperatura & ${ }^{\circ} \mathrm{C}$ & - & - & - & - & - & - & - & - & - & - & - \\
\hline$\overline{\mathrm{PH}}$ & - & $6,5-8,5$ & $6,0-9,5$ & $5,0-9,0$ & $<8,5$ & $6,5-8,5$ & $6,5 / 8,5$ & $6,0 / 10$ & $6,0 / 10$ & $6,0-9,0$ & $6,0-9,0$ & $6,0-9,0$ \\
\hline Condutividade $\left(20^{\circ} \mathrm{C}\right)$ & $\mu \mathrm{Scm}^{-1}$ & - & - & - & - & - & - & - & - & - & - & - \\
\hline Aspecto & - & - & - & Límpido & - & - & - & - & - & - & - & - \\
\hline Mat. flutuantes, inc. esp. não naturais & - & - & - & - & - & - & - & - & - & v. a. & v. a. & v. a. \\
\hline Óleo e graxas & - & - & - & - & - & - & - & - & - & v. a. & v. a. & v. a. \\
\hline Sub. que comuniquem gosto ou odor & - & - & - & - & - & - & - & - & - & v. a. & v. a. & v. a. \\
\hline Corantes artificiais & - & - & - & - & - & - & - & - & - & v. a. & $-(8)$ & $-(8)$ \\
\hline Sub. que formem depósitos objetáveis & - & - & - & - & - & - & - & - & - & v. a. & v. a. & v. a. \\
\hline \multicolumn{13}{|l|}{ II - Químicos } \\
\hline OD & $\mathrm{mg} / \mathrm{L} \mathrm{O}_{2}$ & - & - & - & - & - & - & - & - & $\geq 6,0$ & $\geq 5,0$ & $\geq 4,0$ \\
\hline$\overline{\mathrm{DBO} 5}$ à $20^{\circ} \mathrm{C}$ & $\mathrm{mg} / \mathrm{L} \mathrm{O} \mathrm{O}_{2}$ & - & - & - & - & - & - & - & - & $\leq 3,0$ & $\leq 5,0$ & $\leq 10,0$ \\
\hline$\overline{\mathrm{DQO}}$ & $\mathrm{mg} / \mathrm{L} \mathrm{O} \mathrm{O}_{2}$ & - & - & - & - & - & - & - & - & - & - & - \\
\hline \multicolumn{13}{|l|}{ Compostos Inorgânicos } \\
\hline Antimônio & $\mathrm{mg} / \mathrm{L}$ & - & 0,005 & - & 0,005 & 0,006 & - & - & - & - & - & - \\
\hline Arsênio & $\mathrm{mg} / \mathrm{L}$ & 0,05 & 0,01 & 0,05 & 0,01 & 0,01 & - & - & - & 0,05 & 0,05 & 0,05 \\
\hline Bário & $\mathrm{mg} / \mathrm{L}$ & 1,0 & 0,7 & 1,0 & 0,7 & 2,0 & - & - & - & 1,0 & 1,0 & 1,0 \\
\hline
\end{tabular}


Cont.

\begin{tabular}{|c|c|c|c|c|c|c|c|c|c|c|c|c|}
\hline \multirow{3}{*}{ PARÂMETROS } & \multirow{3}{*}{ UNIDADES } & \multicolumn{8}{|c|}{ PADRÃO DE POTABILIDADE } & \multirow{2}{*}{\multicolumn{3}{|c|}{$\begin{array}{l}\text { PADRÃO DE QUALIDADE AMBIENTAL } \\
\text { CONAMA N }^{\circ} 357 / 05\end{array}$}} \\
\hline & & \multirow{2}{*}{$\begin{array}{l}\text { PORTARIA No } \\
36 / 90\end{array}$} & \multirow{2}{*}{$\begin{array}{l}\text { PORTARIAS } \\
\text { N¹469/00/ } \\
\text { N518/04 }\end{array}$} & \multirow{2}{*}{$\begin{array}{l}\text { D. ESTADUAL/SP } \\
N^{0} 12.486 / 78\end{array}$} & \multirow{2}{*}{$\begin{array}{l}\text { OMS } \\
1995\end{array}$} & \multirow{2}{*}{$\begin{array}{l}\text { EPA } \\
2003\end{array}$} & \multicolumn{3}{|c|}{ **SS-293 } & & & \\
\hline & & & & & & & 1 & II & III & CLASSE 1 & CLASSE 2 & CLASSE 3 \\
\hline Berílio & $\mathrm{mg} / \mathrm{L}$ & - & - & - & - & 0,004 & - & - & - & 0,1 & 0,1 & 0,1 \\
\hline Boro & $\mathrm{mg} / \mathrm{L}$ & - & - & - & 0,3 & & - & - & - & 0,75 & 0,75 & 0,75 \\
\hline Bromato & $\mathrm{mg} / \mathrm{L}$ & - & 0,025 & - & 0,025 & 0.01 & - & - & - & & & \\
\hline Cádmio & $\mathrm{mg} / \mathrm{L}$ & 0,005 & 0,005 & 0,01 & 0,003 & 0,005 & - & - & - & 0,001 & 0,001 & 0,01 \\
\hline Chumbo & $\mathrm{mg} / \mathrm{L}$ & 0,05 & 0,01 & 0,05 & 0,01 & 0,015 & - & - & - & 0,03 & 0,03 & 0,03 \\
\hline Cianetos & $\mathrm{mg} / \mathrm{L}$ & 0,1 & 0,07 & 0,2 & 0,07 & 0,2 & - & - & - & 0,01 & 0,01 & 0,2 \\
\hline Cromo hexavalente & $\mathrm{mg} / \mathrm{L}$ & - & - & 0,05 & - & - & - & - & - & 0,05 & 0,05 & 0,05 \\
\hline Cromo total & $\mathrm{mg} / \mathrm{L}$ & 0,05 & 0,05 & - & 0,05 & 0,1 & - & - & - & - & - & - \\
\hline Cromo trivalente & $\mathrm{mg} / \mathrm{L}$ & - & - & - & - & - & - & - & - & 0,5 & 0,5 & 0,5 \\
\hline Clorito & $\mathrm{mg} / \mathrm{L}$ & - & 0,2 & - & 0,2 & 1,0 & - & - & - & - & - & - \\
\hline Cloro residual & $\mathrm{mg} / \mathrm{L}$ & - & $3\left(\mathrm{NH}_{2} \mathrm{Cl}\right)$ & 0,3 & $0,6-1,0$ & 4,0 & $>0.2$ & $>0.2$ & $<0,2$ & 0,01 & 0,01 & - \\
\hline Cloro residual livre & $\mathrm{mg} / \mathrm{L}$ & $>0,2$ & 5,0 & - & - & 4,0 & $\geq 2,0$ & $\geq 2,0$ & - & - & - & - \\
\hline Cobalto & $\mathrm{mg} / \mathrm{L}$ & - & - & - & - & - & - & - & - & 0,2 & 0,2 & 0,2 \\
\hline Estanho & $\mathrm{mg} / \mathrm{L}$ & - & - & - & - & - & - & - & - & 2,0 & 2,0 & 2,0 \\
\hline Fluoretos & $\mathrm{mg} / \mathrm{L}$ & $0,6-0,7$ & 1,5 & 1,0 & 1,5 & 4,0 & $0,6 / 0,8$ & $0,6 / 0,8$ & $0,6 / 1,0$ & 1,4 & 1,4 & 1,4 \\
\hline Fosfato total & $\mathrm{mg} / \mathrm{L}$ & - & - & - & - & - & - & - & - & 0,025 & 0,025 & 0,025 \\
\hline Lítio & $\mathrm{mg} / \mathrm{L}$ & - & - & - & - & - & - & - & - & 2,5 & 2,5 & 2,5 \\
\hline Mercúrio & $\mathrm{mg} / \mathrm{L}$ & 0,001 & 0,001 & - & 0,001 & 0,002 & - & - & - & 0,0002 & 0,0002 & 0,002 \\
\hline Níquel & $\mathrm{mg} / \mathrm{L}$ & - & - & - & - & - & - & - & - & 0,025 & 0,025 & 0,025 \\
\hline Nitratos (como N) & $\mathrm{mg} / \mathrm{L}$ & 10,0 & 10,0 & 10,0 & 50,0 & 10,0 & - & - & - & 10,0 & 10,0 & 10,0 \\
\hline Nitritos (como N) & $\mathrm{mg} / \mathrm{L}$ & - & 1,0 & - & 3,0 & 1,0 & - & - & - & 1,0 & 1,0 & 1,0 \\
\hline Níquel & $\mathrm{mg} / \mathrm{L}$ & - & - & - & - & - & - & - & - & - & - & - \\
\hline Oxigênio consumido & $\mathrm{mg} / \mathrm{L}$ & - & - & 2,5 & - & - & - & - & - & - & - & - \\
\hline Potássio & $\mathrm{mg} / \mathrm{L}$ & - & - & - & - & - & - & - & - & - & - & - \\
\hline Prata & $\mathrm{mg} / \mathrm{L}$ & 0,05 & - & - & - & 0,10 & - & - & - & 0,01 & 0,01 & 0,05 \\
\hline
\end{tabular}


Cont.

\begin{tabular}{|c|c|c|c|c|c|c|c|c|c|c|c|c|}
\hline \multicolumn{13}{|c|}{ Parâmetros de Qualidade de Água - Valores Máximos Permissíveis } \\
\hline \multirow{3}{*}{ PARÂMETROS } & \multirow{3}{*}{ UNIDADES } & \multicolumn{8}{|c|}{ PADRÃO DE POTABILIDADE } & \multirow{2}{*}{\multicolumn{3}{|c|}{$\begin{array}{l}\text { PADRÃO DE QUALIDADE AMBIENTAL } \\
\text { CONAMA N }{ }^{\circ} 357 / 05\end{array}$}} \\
\hline & & \multirow{2}{*}{$\begin{array}{l}\text { PORTARIA N } \\
36 / 90\end{array}$} & \multirow{2}{*}{\begin{tabular}{|l} 
PORTARIAS \\
N¹469/00/ \\
No518/04
\end{tabular}} & \multirow{2}{*}{$\begin{array}{l}\text { D. ESTADUAL/SP } \\
\text { No}^{0} 12.486 / 78\end{array}$} & \multirow{2}{*}{$\begin{array}{l}\text { OMS } \\
1995\end{array}$} & \multirow{2}{*}{$\begin{array}{l}\text { EPA } \\
2003\end{array}$} & \multicolumn{3}{|c|}{ **SS-293 } & & & \\
\hline & & & & & & & 1 & II & III & Classe 1 & CLASSE 2 & CLASSE 3 \\
\hline Selênio & $\mathrm{mg} / \mathrm{L}$ & 0,01 & 0,01 & 0,01 & 0,01 & 0,05 & - & - & - & 0,01 & 0,01 & 0,01 \\
\hline Tálio & $\mathrm{mg} / \mathrm{L}$ & - & - & - & - & 0,002 & - & - & - & - & - & - \\
\hline Urânio total & $\mathrm{mg} / \mathrm{L}$ & - & - & - & - & 0,03 & - & - & - & 0,02 & 0,02 & 0,02 \\
\hline Vanádio & $\mathrm{mg} / \mathrm{L}$ & - & - & - & - & - & - & - & - & 0,1 & 0,1 & 0,1 \\
\hline Compostos Orgânicos & & & & & & & & & & & & \\
\hline Acrilamida & $\mu \mathrm{g} / \mathrm{L}$ & - & 0,5 & - & 0,5 & 0,5 & - & - & - & - & - & - \\
\hline Alaclor* & $\mu \mathrm{g} / \mathrm{L}$ & - & 20,0 & - & 20,0 & 2,0 & - & - & - & - & - & - \\
\hline Aldrin e Diedrin* & $\mu \mathrm{g} / \mathrm{L}$ & 0,03 & 0,03 & - & 0,03 & - & - & - & - & $0,01 / 0,005^{(9)}$ & $0,01 / 0,005^{(9)}$ & $0,01 / 0,005^{(9)}$ \\
\hline Atrazina* & $\mu \mathrm{g} / \mathrm{L}$ & - & 2,0 & - & 2,0 & 3,0 & - & - & - & - & - & - \\
\hline Bentazona* & $\mu \mathrm{g} / \mathrm{L}$ & - & 300 & - & 30,0 & - & - & - & - & - & - & - \\
\hline Benzeno & $\mu \mathrm{gg} / \mathrm{L}$ & 10,0 & 5,0 & - & 10,0 & 5,0 & - & - & - & 10,0 & 10,0 & 10,0 \\
\hline Benzo-a-pireno & $\mu \mathrm{g} / \mathrm{L}$ & 0,01 & 0,7 & - & 0,7 & 0,2 & - & - & - & 0,01 & 0,01 & 0,01 \\
\hline Bifenilas policloradas (BCP's) & $\mu \mathrm{g} / \mathrm{L}$ & - & - & - & - & 0,5 & - & - & - & 0,001 & 0,001 & 0,001 \\
\hline Carbaril * & $\mu \mathrm{g} / \mathrm{L}$ & - & - & - & - & - & - & - & - & 0,02 & 0,02 & 70,0 \\
\hline Clordano (isômeros)* & $\mu \mathrm{g} / \mathrm{L}$ & 0,3 & 0,2 & - & 0,2 & 2,0 & - & - & - & 0,04 & 0,04 & 0,3 \\
\hline Cloreto de vinila & $\mu \mathrm{g} / \mathrm{L}$ & - & 5 & - & 5,0 & 2,0 & - & - & - & - & - & - \\
\hline Clorobenzenos & $\mu \mathrm{g} / \mathrm{L}$ & $0,1-0,3$ & $120^{(4)}$ & - & $20-1000$ & 100 & - & - & - & - & - & - \\
\hline Clorofenóis & $\mu \mathrm{g} / \mathrm{L}$ & 0,1 & - & - & $0,1-1,0$ & - & - & - & - & - & - & - \\
\hline 1,2 Dicloroetano & $\mu \mathrm{g} / \mathrm{L}$ & 10,0 & 10,0 & - & 30,0 & 5,0 & - & - & - & 10,0 & 10,0 & 10,0 \\
\hline 1,1 Dicloroeteno & $\mu \mathrm{g} / \mathrm{L}$ & 0,3 & 30,0 & - & 30,0 & - & - & - & - & 0,3 & 0,3 & 0,3 \\
\hline $2,4 D^{*}$ & $\mu \mathrm{g} / \mathrm{L}$ & 100 & 30,0 & - & 30,0 & 70,0 & - & - & - & 4,0 & 4,0 & 20 \\
\hline Diclorometano & $\mu \mathrm{g} / \mathrm{L}$ & - & 20,0 & - & 20,0 & 5,0 & - & - & - & - & - & - \\
\hline DDT (isômeros)* & $\mu \mathrm{g} / \mathrm{L}$ & 1,0 & 2,0 & - & 2,0 & - & - & - & - & 0,002 & 0,002 & 1,0 \\
\hline
\end{tabular}


Cont.

\begin{tabular}{|c|c|c|c|c|c|c|c|c|c|c|c|c|}
\hline \multicolumn{13}{|c|}{ Parâmetros de Qualidade de Água - Valores Máximos Permissíveis } \\
\hline \multirow{3}{*}{ PARÂMETROS } & \multirow{3}{*}{ UNIDADES } & \multicolumn{8}{|c|}{ PADRÃO dE POTABILIDADE } & \multirow{2}{*}{\multicolumn{3}{|c|}{$\begin{array}{l}\text { PADRÃO DE QUALIDADE AMBIENTAL } \\
\text { CONAMA N }{ }^{\circ} 357 / 05\end{array}$}} \\
\hline & & \multirow{2}{*}{$\begin{array}{l}\text { PORTARIA No } \\
36 / 90\end{array}$} & \multirow{2}{*}{$\begin{array}{l}\text { PORTARIAS } \\
\text { N¹469/00/ } \\
\text { N518/04 }\end{array}$} & \multirow{2}{*}{$\begin{array}{l}\text { D. ESTADUAL/SP } \\
N^{0} 12.486 / 78\end{array}$} & \multirow{2}{*}{$\begin{array}{l}\text { OMS } \\
1995\end{array}$} & \multirow{2}{*}{$\begin{array}{l}\text { EPA } \\
2003\end{array}$} & \multicolumn{3}{|c|}{ **SS-293 } & & & \\
\hline & & & & & & & I & II & III & CLASSE 1 & CLASSE 2 & CLASSE 3 \\
\hline Demeton * & $\mu \mathrm{g} / \mathrm{L}$ & - & - & - & - & - & - & - & - & 0,1 & 0,1 & 14,0 \\
\hline Dodecacloro + Nonacloro & $\mu \mathrm{g} / \mathrm{L}$ & - & - & - & - & - & - & - & - & 0,001 & 0,001 & 0,001 \\
\hline Endossulfan * & $\mu \mathrm{g} / \mathrm{L}$ & - & 20,0 & - & - & - & - & - & - & 0,056 & 0,056 & 150 \\
\hline Endrin * & $\mu \mathrm{g} / \mathrm{L}$ & 0,2 & 0,6 & - & - & 2,0 & - & - & - & 0,004 & 0,004 & 0,2 \\
\hline Estireno & $\mu g / L$ & - & 20,0 & \begin{tabular}{|l}
- \\
\end{tabular} & 20,0 & 100 & - & - & - & - & - & - \\
\hline Fenol & $\mu \mathrm{g} / \mathrm{L}$ & 0,1 & - & - & - & - & - & - & - & 1,0 & 1,0 & 300 \\
\hline Glifosato* & $\mu \mathrm{g} / \mathrm{L}$ & - & 500 & - & - & 700 & - & - & - & - & \begin{tabular}{|l}
- \\
\end{tabular} & - \\
\hline Gution* & $\mu \mathrm{g} / \mathrm{L}$ & - & - & - & - & - & - & - & - & 0,005 & 0,005 & 0,005 \\
\hline Heptacloro + hept. Epóxido* & $\mu \mathrm{g} / \mathrm{L}$ & 0.1 & 0,03 & - & 0,03 & $0,4 / 0,2^{(10)}$ & - & - & - & $0,01 / 0,01^{(10)}$ & $0,01 / 0,01^{(10)}$ & $0,1 / 0,1^{(10)}$ \\
\hline Hexaclorobenzeno * & $\mu g / L$ & 0,01 & 1,0 & - & 0,1 & 1,0 & - & - & - & - & - & - \\
\hline Lindano $(\gamma-\mathrm{HCH})^{\star}$ & $\mu \mathrm{g} / \mathrm{L}$ & 3,0 & 2,0 & - & 2,0 & 0,2 & - & - & - & 0,02 & 0,02 & 3,0 \\
\hline Malation* & $\mu \mathrm{g} / \mathrm{L}$ & - & - & - & - & - & - & - & - & 0,1 & 0,01 & 100 \\
\hline Metolacloro* & $\mu \mathrm{g} / \mathrm{L}$ & - & 10,0 & - & 10,0 & - & - & - & - & - & - & - \\
\hline Metoxicloro * & $\mu \mathrm{g} / \mathrm{L}$ & 30,0 & 20,0 & - & 20,0 & 4,0 & - & - & - & 0,03 & 0,03 & 30 \\
\hline Molinato * & $\mu \mathrm{g} / \mathrm{L}$ & - & 6,0 & - & 6,0 & - & - & - & - & - & - & - \\
\hline Organofosf. e Carbamatos* & $\mu \mathrm{g} / \mathrm{Lp}$ parat. & - & - & - & - & - & - & - & - & 10,0 & 10,0 & 10,0 \\
\hline Paration * & $\mu \mathrm{g} / \mathrm{L}$ & - & - & - & - & - & - & - & - & 0,04 & 0,04 & 35,0 \\
\hline Pendimetalina* & $\mu \mathrm{g} / \mathrm{L}$ & - & 20,0 & - & 20,0 & - & - & - & - & - & - & - \\
\hline Pentaclorofenol* $^{*}$ & $\mu \mathrm{g} / \mathrm{L}$ & 10,0 & 9,0 & - & 9,0 & 1,0 & - & - & - & 10,0 & 10,0 & 10,0 \\
\hline Permetrina * & $\mu \mathrm{g} / \mathrm{L}$ & - & 20,0 & - & 20,0 & - & - & - & - & - & - & - \\
\hline Propanil * & $\mu g / L$ & - & 20 & - & 20,0 & - & - & - & - & - & - & - \\
\hline Simazina * & $\mu \mathrm{g} / \mathrm{L}$ & - & 2,0 & - & 2,0 & 4,0 & - & - & - & - & \begin{tabular}{|l}
- \\
\end{tabular} & - \\
\hline Tetracloreto de carbono & $\mu \mathrm{g} / \mathrm{L}$ & 3,0 & 2,0 & - & 2,0 & - & - & - & - & 3,0 & 3,0 & 3,0 \\
\hline Tetracloroeteno & $\mu \mathrm{g} / \mathrm{L}$ & 10,0 & 40,0 & - & 40,0 & 5,0 & - & - & - & 10,0 & 10,0 & $\begin{array}{l}10,0 \\
\end{array}$ \\
\hline
\end{tabular}


Cont.

\begin{tabular}{|c|c|c|c|c|c|c|c|c|c|c|c|c|}
\hline \multicolumn{13}{|c|}{ Parâmetros de Qualidade de Água - Valores Máximos Permissíveis } \\
\hline \multirow{3}{*}{ PARÂMETROS } & \multirow{3}{*}{ UNIDADES } & \multicolumn{8}{|c|}{ PADRÃO DE POTABILIDADE } & \multirow{2}{*}{\multicolumn{3}{|c|}{\begin{tabular}{|l|} 
PADRÃO DE QUALIDADE AMBIENTAL \\
CONAMA N ${ }^{\circ} 357 / 05$
\end{tabular}}} \\
\hline & & \multirow{2}{*}{$\begin{array}{l}\text { PORTARIA N }{ }^{\circ} \\
36 / 90\end{array}$} & \multirow{2}{*}{\begin{tabular}{|l|} 
PORTARIAS \\
N¹469/00/ \\
N518/04
\end{tabular}} & \multirow{2}{*}{$\begin{array}{l}\text { D. ESTADUAL/SP } \\
N^{\circ} 12.486 / 78\end{array}$} & \multirow{2}{*}{$\begin{array}{l}\text { OMS } \\
1995\end{array}$} & \multirow{2}{*}{$\begin{array}{l}\text { EPA } \\
2003\end{array}$} & \multicolumn{3}{|c|}{ **SS-293 } & & & \\
\hline & & & & & & & 1 & II & III & CLASSE 1 & CLASSE 2 & CLASSE 3 \\
\hline Toxafeno*? & $\mu \mathrm{g} / \mathrm{L}$ & 5,0 & - & - & - & 3,0 & - & - & - & 0,01 & 0,01 & 5,0 \\
\hline Triclorobenzeno & $\mu \mathrm{gg} / \mathrm{L}$ & - & 20,0 & - & 20,0 & 70,0 & - & - & - & - & - & - \\
\hline Tricloetenos & $\mu \mathrm{g} / \mathrm{L}$ & 30,0 & 70,0 & - & 70,0 & 5,0 & - & - & - & 30,0 & 30,0 & 30,0 \\
\hline $\mathrm{I}, \mathrm{I}, \mathrm{I}$, Tricloroetano & $\mu \mathrm{g} / \mathrm{L}$ & - & - & - & 2000 & 200 & - & - & - & - & - & - \\
\hline 2,4,6 Triclorofenol & $\mu g / L$ & 10,0 & 200 & - & $2,0-300$ & - & - & - & - & 10,0 & 10,0 & 10,0 \\
\hline Trihalometanos & $\mu \mathrm{g} / \mathrm{L}$ & $100^{(3)}$ & 100 & - & 200 & 80,0 & - & - & - & - & - & - \\
\hline Trifluralina * & $\mu \mathrm{g} / \mathrm{L}$ & - & 20 & - & 20,0 & - & - & - & - & - & - & - \\
\hline Pesticidas - individual & $\mu \mathrm{g} / \mathrm{L}$ & - & - & - & - & - & - & - & - & - & - & - \\
\hline Pesticidas - total & $\mu \mathrm{g} / \mathrm{L}$ & - & - & - & - & - & - & - & - & - & - & - \\
\hline $2,4,5, \mathrm{TP}$ & $\mu \mathrm{g} / \mathrm{L}$ & - & - & - & - & 50,0 & - & - & - & 10,0 & 10,0 & 10,0 \\
\hline $2,4,5 \mathrm{~T}$ & $\mu \mathrm{g} / \mathrm{L}$ & - & - & - & 9,0 & - & - & - & - & 2,0 & 2,0 & 2,0 \\
\hline \multicolumn{13}{|c|}{ Afetam a Qualidade Organoléptica } \\
\hline Alumímio & $\mathrm{mg} / \mathrm{L}$ & $0,2^{(3)}$ & 0,2 & - & 0,2 & $0,05-0,2$ & - & - & - & 0,1 & 0,1 & 0,1 \\
\hline Amônia (como $\mathrm{NH}_{3}$ ) & $\mathrm{mg} / \mathrm{L}$ & - & 1,5 & - & 1,5 & - & - & - & - & 0,02 & 0,02 & - \\
\hline Surfactantes (LAS) & $\mathrm{mg} / \mathrm{L}$ & 0,2 & 0,5 & - & - & 0,5 & - & - & - & 0,5 & 0,5 & 0,5 \\
\hline Cloretos & $\mathrm{mg} / \mathrm{L}$ & 250 & 250 & 250 & 250 & 250 & - & - & - & 250 & 250 & 250 \\
\hline Cobre & $\mathrm{mg} / \mathrm{L}$ & 1,0 & 2,0 & 1,0 & 1,0 & 1,0 & - & - & - & 0,02 & 0,02 & 0,5 \\
\hline Dureza total $\left(\mathrm{como} \mathrm{CaCO}_{3}\right)$ & $\mathrm{mg} / \mathrm{L}$ & 500 & 500 & - & 500 & - & - & - & - & - & - & - \\
\hline Etilbenzeno & $\mathrm{mg} / \mathrm{L}$ & - & 0,2 & - & $0,002-0,2$ & - & - & - & - & - & - & - \\
\hline Ferro solúvel & $\mathrm{mg} / \mathrm{L}$ & - & - & - & - & - & - & - & - & 0,3 & 0,3 & 5,0 \\
\hline Ferro total & $\mathrm{mg} / \mathrm{L}$ & 0,3 & 0,3 & 0,3 & 0,3 & 0,3 & - & - & - & - & - & - \\
\hline Manganês & $\mathrm{mg} / \mathrm{L}$ & 0,1 & 0,1 & 0,05 & 0,1 & 0,05 & - & - & - & 0,1 & 0,1 & 0,5 \\
\hline Magnésio & $\mathrm{mg} / \mathrm{L}$ & - & - & - & - & - & - & - & - & - & - & - \\
\hline
\end{tabular}


Cont.

\begin{tabular}{|c|c|c|c|c|c|c|c|c|c|c|c|c|}
\hline \multicolumn{13}{|c|}{ Parâmetros de Qualidade de Água - Valores Máximos Permissíveis } \\
\hline \multirow{3}{*}{ PARÂMETROS } & \multirow{3}{*}{ UNIDADES } & \multicolumn{8}{|c|}{ PADRÃO DE POTABILIDADE } & \multirow{2}{*}{\multicolumn{3}{|c|}{$\begin{array}{l}\text { PADRÃO DE QUALIDADE AMBIENTAL } \\
\text { CONAMA N }{ }^{\circ} 357 / 05\end{array}$}} \\
\hline & & \multirow{2}{*}{$\begin{array}{l}\text { PORTARIA N } \\
36 / 90\end{array}$} & \multirow{2}{*}{\begin{tabular}{|l|} 
PORTARIAS \\
N¹469/00/ \\
N518/04
\end{tabular}} & \multirow{2}{*}{$\begin{array}{l}\text { D. ESTADUAL/SP } \\
N^{\circ} 12.486 / 78\end{array}$} & \multirow{2}{*}{$\begin{array}{l}\text { OMS } \\
1995\end{array}$} & \multirow{2}{*}{$\begin{array}{l}\text { EPA } \\
2003\end{array}$} & \multicolumn{3}{|l|}{$\star \star S S-293$} & & & \\
\hline & & & & & & & I & ॥ & III & CLASSE 1 & CLASSE 2 & CLASSE 3 \\
\hline Sódio & $\mathrm{mg} / \mathrm{L}$ & - & 200 & - & 200 & - & - & - & - & - & - & - \\
\hline Sólidos suspensos & ppm & - & - & - & - & - & - & - & - & - & - & - \\
\hline Sólidos dissolvidos totais & $\mathrm{mg} / \mathrm{L}$ & 1000 & 1000 & - & 1000 & 500 & - & - & - & 500 & 500 & 500 \\
\hline Sólidos totais & $\mathrm{mg} / \mathrm{L}$ & - & - & 500 & - & - & - & - & - & - & - & - \\
\hline Sulfatos & $\mathrm{mg} / \mathrm{L}$ & 400 & 250 & 250 & 250 & 250 & - & - & - & 250 & 250 & 250 \\
\hline Sulfeto de hidrogênio & $\mu \mathrm{g} / \mathrm{LS}$ & $0,025-0,25$ & 500 & - & 50,0 & - & - & - & - & 2,0 & 2,0 & 300 \\
\hline Tolueno & $\mathrm{mg} / \mathrm{L}$ & - & 0,17 & - & 0,17 & 1,0 & - & - & - & - & - & - \\
\hline Zinco & $\mathrm{mg} / \mathrm{L}$ & 5 & 5,0 & 5,0 & 3,0 & 5,0 & - & - & - & 0,18 & 0,18 & 5,0 \\
\hline Xileno & $\mathrm{mg} / \mathrm{L}$ & - & 0,3 & - & $0,02-1,8$ & 10,0 & - & - & - & - & - & - \\
\hline \multicolumn{13}{|l|}{ III - Cianotoxinas } \\
\hline Microcistinas & $\mu \mathrm{g} / \mathrm{L}$ & - & 1,0 & - & - & - & - & - & - & - & - & - \\
\hline \multicolumn{13}{|l|}{ IV - Radioativos } \\
\hline Radioatividade $\alpha$ total & $\mathrm{Bq} / \mathrm{L}$ & 0,1 & 0,1 & - & 0,1 & $15 \mathrm{pCi} / \mathrm{L}$ & - & - & - & - & - & - \\
\hline Radioatividade $\beta$ total & $\mathrm{Bq} / \mathrm{L}$ & 1,0 & 1,0 & - & 1,0 & $4 \mathrm{mrem}$ & - & - & - & - & - & - \\
\hline \multicolumn{13}{|l|}{ V-Microbiológicos } \\
\hline Coliformes termotoleráveis & $\mathrm{n} \% 100 \mathrm{~mL}$ & 0 & 0 & - & 0 & - & Ausente & Ausente & Presente & 200 & 1000 & 4000 \\
\hline Coliformes totais & $\mathrm{n}^{\circ} / 100 \mathrm{~mL}$ & 0 & 0 & - & 0 & - & $3^{(12)}$ & $3^{(12)}$ & 3 & - & - & - \\
\hline \multicolumn{4}{|c|}{1 - UH unidade de escala Hazen ( de platina-cobalto } & onc. Aldrin/ conc. D & Dieldrin & & & & ก. o. - não o & bjjetável & & \\
\hline 2 - UT unidade de turbidez & & & & conc. Heptacloro/ & conc. Hept & . Epóxido & & & n. d. - nãod & detectável & & \\
\hline 3 - valor experimental & & & & odor limite & & & & & v. a. - visua & Imente ause & & \\
\hline 4 - Valor para monoclorobe & & & & até 3 em $100 \mathrm{~mL}$ er & $\mathrm{m} 5 \%$ das & nostras & & & & & & \\
\hline * - Agrotóxicos & & & & & & & & & & & & \\
\hline
\end{tabular}

Cont. 
5 - Taxa de diluição

OMS - Guia para qualidade de água potável - $2^{\circ}$ edição vol. 1, 1995

6 - Prevalece a Qualidade natural do corpo receptor

EPA - Padrões para água potável - verão de 2000-EPA 822-B-00-001

7 - Quando para uso de abastecimento público

**Resolução SS-293: I - Água Boa, II - Água Adequada e III - Água Inadequada

8 - Presença não permitida de corantes artificiais, não removíveis por processos de coagulação, sedimentação e filtração convencional. 


\section{4 ÁREA DE ESTUDO}

\subsection{A Bacia do Rio Ribeira de Iguape}

A bacia hidrográfica do Ribeira de Iguape, objeto deste estudo, está localizada na região sul do estado de São Paulo e leste do Estado do Paraná, entre as latitudes $23^{\circ} 30^{\prime}$ e $25^{\circ} 30^{\prime}$ sul e longitudes $46^{\circ} 50^{\prime \prime}$ e $50^{\circ} 00^{\prime}$ norte abrangendo uma área total de $24.980 \mathrm{~km}^{2}$, dos quais $61 \%$ estão no território paulista.

Apresenta uma conformação alongada no sentido SO - NE, quase paralela à orla marítima, confrontando-se com as bacias dos rios Tietê ao norte, Paranapanema a oeste, Iguaçu ao sul e, tendo a leste pequenos cursos d'água da vertente atlântica (SETTI et al. 2001).

A legislação sobre recursos hídricos do estado de São Paulo, Legislação Estadual no 7.663 de dezembro de 1991, dividiu o estado de São Paulo em 22 Unidades de Gerenciamento dos Recursos Hídricos - UGRHI's. A UGRHI - 11 - Ribeira do Iguape/Litoral Sul compreende as Bacias dos rios Juquiá, Ribeira e Ribeira de Iguape, além dos rios que deságuam no mar, desde o município de Iguape até a divisa com o estado do Paraná. Abrange 21 municípios, sendo 3 no estado do Paraná e 18 no Estado de São Paulo (CETESB, 2003).

Situada entre as regiões metropolitanas de São Paulo e Curitiba, das quais incorpora parcelas, a bacia abriga apenas cidades de porte pequeno com destaque para Registro, Iguape, Apiaí, Juquitiba e Juquiá, na parte paulista e Rio Branco do Sul na parte paranaense. Juntamente com o Complexo Estuário Lagunar de Iguape, Cananéia e Paranaguá, compõem o denominado Vale do Ribeira, com uma extensão de 260 km, 140 km de costa para o Oceano Atlântico e, uma população estimada em 400 mil habitantes (HOGAN, 2002). 
Sua área de drenagem é de 17.180,09 $\mathrm{km}^{2}$. Possui nascentes na vertente marítima da serra do Mar e, após vencerem desníveis acentuados, conformam planícies flúvio - marinhas, drenam manguezais e deságuam no oceano ou canais estuarinos.

Os principais cursos d'água são: Rios Juquiá, Ribeira, Ribeira de Iguape, São Lourenço (rio que passa pelo município de Miracatu), Jacupiranga, Pardo, Uma da Aldeia e Itariri. Na Bacia do Ribeira de Iguape encontram-se os reservatórios de Alecrim, Barra, França, Porto Raso, Salto de Iporanga e Serraria.

O rio Ribeira de Iguape nasce no Estado do Paraná, formado pelos rios Açungui e Ribeirão Grande, a uma altitude de $1000 \mathrm{~m}$, permanecendo com o nome de rio Ribeira até a cidade de Eldorado, no Estado de São Paulo. Apresenta uma extensão de aproximadamente $470 \mathrm{~km}$, sendo $120 \mathrm{~km}$ em terras paranaenses, com sua foz localizada no município de Iguape (HOGAN, 2002).

A partir da jusante da confluência dos rios Ribeira de Iguape e Juquiá, aproximadamente na região central do Vale do Ribeira, observa-se que a topografia da região vai suavizando, transformando-se em uma ampla planície que se estende até a orla litorânea.

A Tabela 4.1 apresenta um resumo das principais características da bacia Hidrográfica do Ribeira de Iguape e a Figura 4.1 apresenta a localização área de estudo no estado de São Paulo (CETESB, 2003). 


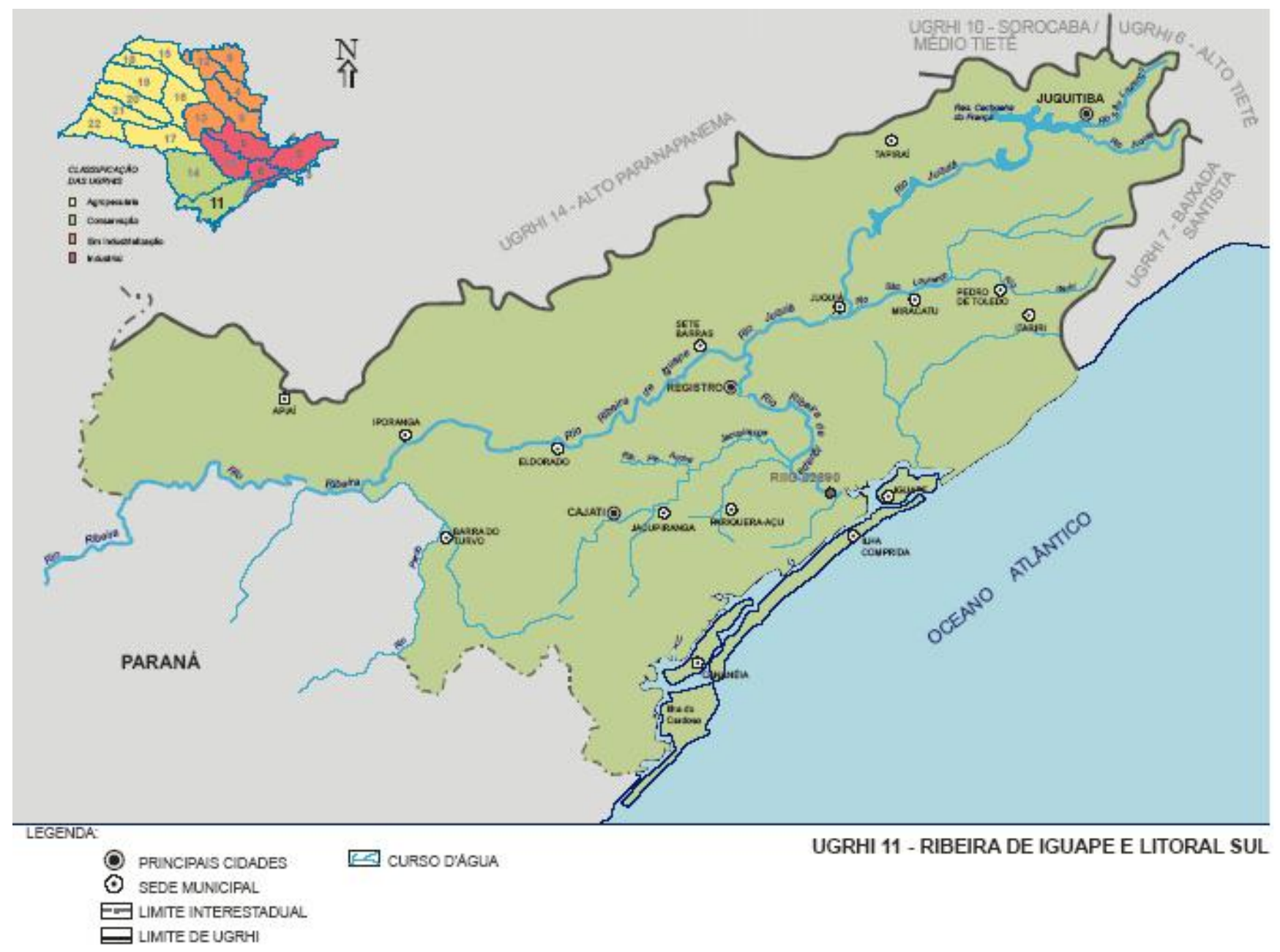

Figura 4.1 - Localização da área de estudo no estado de São Paulo (CETESB,2003 modificado). 
Tabela 4.1 - Resumo das principais características da Bacia Hidrográfica do Ribeira de Iguape (CETESB, 1999, adaptado*)

\begin{tabular}{|c|c|c|c|c|c|}
\hline UGRHI & $\begin{array}{l}\text { Área / } \\
\text { municípios }\end{array}$ & $\begin{array}{l}\text { Constituinte } \\
\text { Principais }\end{array}$ & Uso do solo & Uso da água & $\begin{array}{l}\text { Principais } \\
\text { atividades } \\
\text { industriais }\end{array}$ \\
\hline $\begin{array}{l}11 \\
\text { Ribeira de } \\
\text { Iguape e } \\
\text { Litoral Sul }\end{array}$ & $\begin{array}{l}16.771 \text { km2 } \\
\\
21 \text { Municípios } \\
\text { (sendo } 18 \\
\text { pertencentes a } \\
\text { Unidade de } \\
\text { Negocio do } \\
\text { Vale do } \\
\text { Ribeira - RR } \\
\text { operados pela } \\
\text { SABESP, } \\
\text { objeto do } \\
\text { nosso estudo) } \\
\\
286.639 \text { hab. }\end{array}$ & Rio Ribeira & $\begin{array}{l}\text { Atividades } \\
\text { agrícolas, } \\
\text { urbana e } \\
\text { industrial. } \\
\text { Predomínio de } \\
\text { Cultura de } \\
\text { banana e } \\
\text { pastagem* } \\
\text { APA's:Serra do } \\
\text { mar, Parques } \\
\text { Estaduais do } \\
\text { Alto do Ribeira e } \\
\text { Jacupiranga; } \\
\text { APA's: } \\
\text { Cananéia- } \\
\text { Iguape - } \\
\text { Peroíbe e da Iha } \\
\text { Comprida; } \\
\text { Estação } \\
\text { Ecológica da } \\
\text { Juréia }\end{array}$ & $\begin{array}{l}\text { Afastamento de } \\
\text { efluentes } \\
\text { domésticos }\end{array}$ & $\begin{array}{l}\text { Mineração } \\
\text { exploração } \\
\text { de areia }\end{array}$ \\
\hline
\end{tabular}

A UGRHI 11 - Ribeira de Iguape/Litoral Sul apresenta características bastante singulares, como os mais baixos índices de desenvolvimento do estado, uma economia baseada principalmente na agricultura (banana, chá e arroz), mineração e extrativismo vegetal (palmito). Os parâmetros sócio-econômicos e demográficos apresentam uma imagem contrastante com o resto do estado. Além disso, é uma região peculiar por ser uma das áreas menos urbanizadas do estado. Nesta encontram-se a Área de Proteção Ambiental da Serra do Mar, os Parques Estaduais do Alto Ribeira e Jacupiranga, as Áreas de Proteção Ambiental de Cananéia-Iguape-Peruíbe e da Ilha Comprida e a Estação Ecológica da Juréia. 


\subsection{Caracterização Física}

A região possui uma diversidade de ambientes terrestres e aquáticos, com extensas áreas de relevo serrano, com fortes declividades e várzeas encaixadas e um setor composto por planícies costeiras, manguezais, terraços marinhos e fluviais, com destaque para o complexo estuarino - lagunar de Iguape-Cananéia.

Apesar da capital regional do Vale do Ribeira, o município de Registro, estar localizada a menos de $200 \mathrm{~km}$ da Região Metropolitana de São Paulo, a industrialização nunca foi importante no Vale, sua contribuição não passou de 0,3\%, no período de 1985 a 1996. Razões históricas, dificuldades de acesso e condições naturais adversas às atividades econômicas garantiram até hoje um relativo isolamento e a preservação dos seus recursos naturais.

Esta Bacia compõem a região dos Estados de São Paulo e Paraná mais privilegiados pelas belezas que a natureza pode oferecer. O relevo extremamente movimentado na maior parte da área enseja o encachoeiramento de seus rios que descem velozmente as encostas das serras. Isso ocorre principalmente com os afluentes da margem esquerda do Rio Ribeira, até a proximidade de Sete Barras, e do Rio Juquiá, seu maior contribuinte, que tem suas nascentes em altitudes de cerca de 700m. Recebendo também contribuição de cursos d’água com nascentes a mais de $1.000 \mathrm{~m}$, desaguando em altitudes menores que 200m num desnível, em poucos quilômetros, de mais de $700 \mathrm{~m}$ (URENIUK, 1989).

A alta pluviosidade da região propicia o desenvolvimento de vegetação, de grande exuberância, cobrindo a paisagem de verde mesmo nas áreas recentemente devastadas pela ação antrópica. Nesta encontram-se a Área de Proteção Ambiental da Serra do Mar, os Parques Estaduais do Alto Ribeira e Jacupiranga, as Áreas de Proteção Ambiental de Cananéia-Iguape-Peruíbe e da Ilha Comprida e a Estação Ecológica da Juréia. 
A região possui um patrimônio ambiental que se traduz em mais de 2,1 milhões de hectares de florestas (aproximadamente 21\% da área remanescente de Mata Atlântica do Brasil), contendo o maior número de unidades de conservação da mata atlântica e a maior extensão contínua de áreas remanescentes de mata atlântica do Estado de São Paulo (mais de meio milhão de hectares). É um dos mais importantes patrimônios espeleológicos do país, protegidos pela criação de sete parques estaduais, duas estações ecológicas e três áreas de preservação. Este bioma, possui uma biodiversidade tão rica quanto à da Floresta Amazônica e é atualmente objeto de campanhas de preservação, entre elas o Programa "Homem e a Biosfera - MAB" da UNESCO (HOGAN, 2001).

A Figura 4.2 apresenta a distribuição da área ocupada por floresta tropical no Estado de São Paulo e a distribuição das unidades de conservação na Bacia do Ribeira do Iguape, 


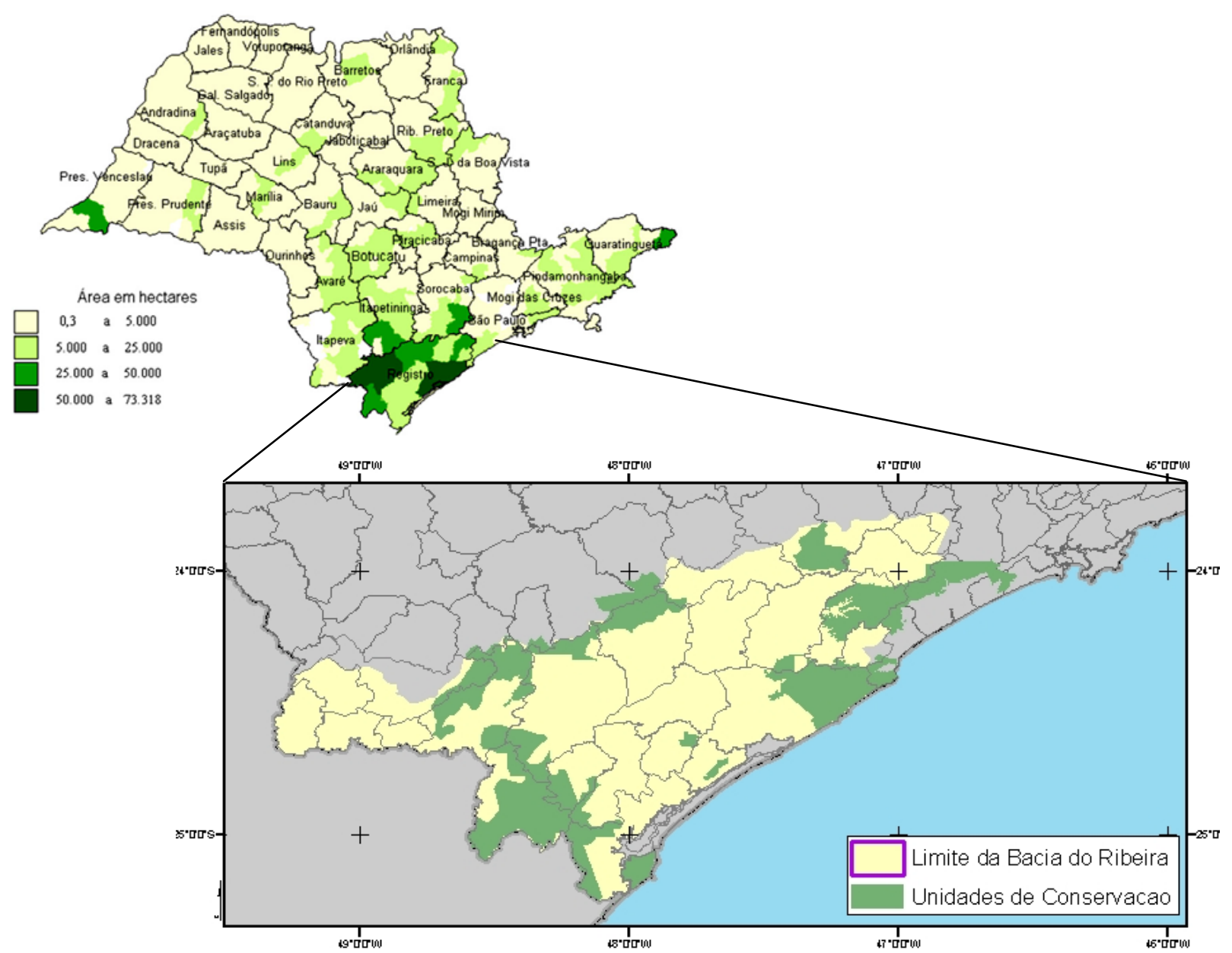

Figura 4.2 - Distribuição da área ocupada por floresta tropical natural no estado de São Paulo (CATI - LUPA, 2004) e distribuição por Unidade de Conservação, na Bacia Hidrográfica do Ribeira de Iguape, SP.

\subsubsection{Geologia e Geomorfologia}

Do ponto de vista da geologia a região contém uma grande variedade de rochas com características distintas, agrupadas e, três grandes domínios geológicos: rochas metamórficas pré-cambrianas, rochas magnáticas e rochas brandas e sedimentos inconsolidados. Conseqüentemente isso reflete na composição química da água.

As rochas metamórficas pré-cambrianas caracterizadas, em geral, pelo comportamento mais resistente (duras e coerentes) e principalmente pela presença de estruturas orientadas, tanto xistosas como migmatíticas e gnáissicas. As rochas cataclásticas antigas e mais jovens (Paleozóicas) também pertencem a 
este grupo, e todas são dominantes na bacia, sendo encontradas principalmente nas áreas mais acidentadas.

As rochas magnáticas representadas por corpos intrusivos graníticos, básicos e alcalinos, correspondem ao segundo domínio.

O terceiro domínio corresponde às rochas brandas e aos sedimentos inconsolidados nas porções de relevo suavizados e planos, principalmente na Baixada litorânea. (IPT, 1981 e CETEC, 2002).

A bacia do rio Ribeira de Iguape desenvolve-se sobre rochas arqueanas e proterozóicas, formando uma seqüência complexa em função de inúmeros eventos termodinâmicos que ocorreram na região. Sua origem deve-se a uma particularidade da geologia do Estado de São Paulo que corresponde a toda a faixa costeira situada entre o Vale do Ribeira e os confins do Estado do Rio de Janeiro. Toda esta região é constituída de gnaisses e granitos, rochas muito resistentes à erosão, e capazes de manter em destaque a Serra do Mar, que é um extenso conjunto de escarpas e montanhas que muito se aproximam da orla marinha.

Contudo, na área do Vale do Ribeira, chegam ao mar os xistos e filitos, rochas que por serem menos resistentes à erosão, permitiram que a drenagem tributária direta do Atlântico recuasse profundamente para o interior do continente, expandindo-se amplamente através da abertura dos vales dos rios Juquiá, São Lourenço, Jacupiranga, além do próprio rio Ribeira, que recuou suas nascentes para o interior do Estado do Paraná. Desta forma, o frontão escarpado da Serra do Mar regrediu da borda até $60 \mathrm{~km}$ para se apoiar nos batólitos granolíticos da serra de Paranapiacaba.

Todo esse processo erosivo vem se realizando durante os 70 milhões de anos do período Cenozóico. No Quaternário, derradeiro milhão de anos deste período, o nível do mar sofreu em todo o mundo grandes oscilações devido às sucessivas fases de congelamento e degelo do período glacial. O crescimento das massas de gelo nas regiões frias provocou o abaixamento do nível do mar a 
100m em relação ao nível do mar atual, ativando a erosão fluvial. Posteriormente, o mar novamente em ascensão, inundou as depressões formando as planícies costeiras e as baías, ainda não de todos assoreadas. Estas áreas de relevo suave correspondem hoje às planícies aluviais desenvolvidas ao longo dos rios Ribeira, Juquiá e Jacupiranga (HOGAN,2002).

O alto e o médio Vale do Ribeira localizam-se na zona serrana, apresentando um relevo muito complexo, com até $1.300 \mathrm{~m}$ sobre o mar, e com amplitudes locais de até $300 \mathrm{~m}$. Tais áreas correspondem às porções de cabeceira e médio curso dos rios Ribeira de Iguape e Juquiá, situadas nos planaltos paranaense e paulistano, devido ao recuo da Serra do Mar. Os mais elevados divisores de águas são suportados principalmente por gnaisses, granitos e, em menor parte, por rochas quartzíticas. Zonas mais baixas, onde se localizam os municípios de Apiaí, Iporanga e Ribeira, são baseadas em filitos e xistos com calcários intercalados.

Na porção sul da bacia, composta principalmente pelos rios Ribeira de Iguape, Juquiá e Jacupiranga, destaca-se o relevo cáustico associado à presença de rochas calcárias. Com formações de idade arqueana, constituída de migmatitos e gnaisses, e também xistos, quartzitos, rochas calcossilicatadas, metabasitos e granulitos. Na porção central da bacia, do proterozóico inferior, encontram-se micaxistos, ardósias, filitos, mármores, metabasitos, quartzitos, rochas calcossilicatadas, gnaisses, anfibolitos e migmatitos.

Na porção oeste podem ser encontrados orto e paragnaisses, além de micaxistos, anfibolitos, talcoxistos e metaultrabasitos. A porção norte é do período pré-cambriano, constituído especialmente por migmatitos, gnaisses, xistos, filitos, quartzitos, anfibolitos, mármore e dolomitos. No terço médio e inferior do rio Ribeira de Iguape observam-se extensos depósitos sedimentares pertencentes a aluviões fluviais e marinhos.

A erosão hídrica é comum em toda a bacia, em função da natureza e espessura dos solos, às amplitudes do relevo e à alta pluviosidade. 


\subsubsection{Recursos Minerais - Ocorrência e Produção}

A região do Vale do Ribeira é detentora de importante potencial mineral, na realidade, o principal do estado de São Paulo. Na região ocorre grande variedade de substâncias minerais, desde ferrosos, metálicos não ferrosos e preciosos, além de minerais industriais diversos e materiais naturais destinados a indústria da construção civil (CETEC, 2002).

Devido às condições geológicas da região, houve a ocorrência de ouro em certas áreas, em grande quantidade. Muitos mineradores e aventureiros foram atraídos em busca do ouro e da riqueza. Nos séculos XVIII e XIX o metal foi explorado em algumas cidades do Alto Vale como Jacupiranga e principalmente Eldorado.

Já no século XX o alvo de exploração no Alto Vale passou a ser 0 chumbo, além de outros metais como o cobre, o zinco e a prata. Em 1919, a mina de Furnas teve sua lavra iniciada, e nas décadas seguintes outros depósitos foram revelados, como a mina do Rocha, Panelas, Perau, entre outras. Em 1943, foi instalada no Vale do Ribeira a empresa Plumbum, que passaria a refinar todo o chumbo produzido no Vale. Quando a Plumbum foi fechada em 1995, os donos das minas de extração e beneficiamento se viram obrigados a fechar seus negócios, e apesar disso, os reflexos da exploração mineira no ambiente ocorrem até os dias de hoje (YAMASHITA, 1997).

O desenvolvimento da atividade de extração e diversidade de minérios possibilitou a fixação da população na região desde o inicio da colonização. Iniciado com a mineração do ouro e seguido da descoberta de outras ocorrências de minerais metálicos, hoje o setor enfrenta total paralisação das lavras de chumbo, uma continua extração de calcários e dolomitos, novas descobertas de minerais raros em diversos pontos da região e um avanço da exploração de areias. Existe uma grande precariedade de infra-estrutura e uma falta de política de desenvolvimento dos recursos minerais a região. Existes diversos mapeamentos geológicos, porém, pouca pesquisa mineral detalhada. 
Quanto à atividade de extração mineral, há grande ocorrência de jazidas na região, que representam um grande potencial econômico. Destaca-se a produção de calcário, fosfato, argila e dolomita. Em termos de participação estadual destacam as produções de fosfato, chumbo, calcita e prata.

Os principais pólos da indústria extrativista mineral no vale estão relacionados na Tabela 4.2. A Tabela 4.3 - Ocorrência de bens minerais no Vale do Ribeira (CETEC, 2002, SEDAE, 2002). Apresenta o registro de ocorrência de bens minerais no vale do Ribeira (CETEC, 2002).

Tabela 4.2 - Principais pólos de indústria extrativa mineral no Vale do Ribeira

\begin{tabular}{|l|l|l|l|}
\hline Município & Tipo & Produto & Uso \\
\hline Cajati & $\begin{array}{l}\text { Jazida de apatita e } \\
\text { carbonatito do } \\
\text { Complexo Alcalino de } \\
\text { Jacupiranga. }\end{array}$ & Concentrado fosfáltico & $\begin{array}{l}\text { Fertilizantes } \\
\text { Alimentação humana; } \\
\text { rações para animais e } \\
\text { na industria cimenteira } \\
\text { Para produção de brita } \\
\text { na indústria construção } \\
\text { civil }\end{array}$ \\
\hline Apiaí & $\begin{array}{l}\text { Extensos depósitos de } \\
\text { calcário (mármore) }\end{array}$ & $\begin{array}{l}\text { Calcário } \\
\text { (com infra-estrutura } \\
\text { para escoamento de } \\
\text { produção tambenteira via } \\
\text { ferroviária) }\end{array}$ & \\
\hline $\begin{array}{l}\text { Juquiá } \\
\text { Miracatu } \\
\text { Registro } \\
\text { Sete Barras }\end{array}$ & Depósitos de areia \\
\hline $\begin{array}{l}\text { Cananéia } \\
\text { (Serra do Arrepio) }\end{array}$ & $\begin{array}{l}\text { Areia para mercado } \\
\text { local }\end{array}$ & \\
\hline $\begin{array}{l}\text { Iguape } \\
\text { Barra de Icapara } \\
\text { Serra do Tapuá } \\
\text { SP222, entre fazenda / } \\
\text { Córrego Aguapé }\end{array}$ & $\begin{array}{l}\text { Areia industrial } \\
\text { Cascalheira }\end{array}$ & $\begin{array}{l}\text { Argila lavras registadas } \\
\text { sendo } \\
18 \text { paralisadas }\end{array}$ & \\
\hline
\end{tabular}


Tabela 4.3 - Ocorrência de bens minerais no Vale do Ribeira (CETEC, 2002, SEDAE, 2002).

\begin{tabular}{|c|c|c|c|c|c|c|c|}
\hline \multicolumn{2}{|c|}{ Minerais ferrosos } & \multicolumn{2}{|c|}{$\begin{array}{l}\text { Minerais metálicos não } \\
\text { ferrosos e preciosos }\end{array}$} & \multicolumn{2}{|c|}{$\begin{array}{l}\text { Materiais Naturais para } \\
\text { construção e matérias } \\
\text { primas para construção }\end{array}$} & \multicolumn{2}{|c|}{$\begin{array}{l}\text { Minerais industriais } \\
\text { diversos }\end{array}$} \\
\hline Mineral & $\begin{array}{l}\text { Número } \\
\text { de } \\
\text { ocorrência }\end{array}$ & Mineral & $\begin{array}{l}\text { Número } \\
\text { de } \\
\text { ocorrência }\end{array}$ & Mineral & $\begin{array}{l}\text { Número } \\
\text { de } \\
\text { ocorrência }\end{array}$ & Mineral & $\begin{array}{l}\text { Número } \\
\text { de } \\
\text { ocorrência }\end{array}$ \\
\hline Ferro & 15 & Azurita & 1 & Areia & 37 & Agalmatolito & 1 \\
\hline Especularita & 2 & Calcopirita & 2 & Argila & 33 & $\begin{array}{l}\text { Água } \\
\text { mineral }\end{array}$ & 1 \\
\hline Hematita & 2 & Chumbo & 155 & Brita & 3 & Amianto & 4 \\
\hline Limonita & 2 & Cobre & 4 & Calcário & 46 & Apatita & 9 \\
\hline Magnetita & 4 & Malaquita & 3 & Cascalho & 34 & Barita & 15 \\
\hline Manganês & 12 & Ouro & 89 & Dolomito & 34 & Calamina & 1 \\
\hline Molibbdenita & 12 & Prata & 6 & $\begin{array}{l}\text { Gabro } \\
\text { ornamental }\end{array}$ & 1 & Calcita & 6 \\
\hline Níquel & 6 & $\begin{array}{l}\text { Sulfetos } \\
\text { polimetálicos } \\
\text { de } \mathrm{Pb}, \mathrm{Zn} \text { e } \\
\mathrm{Cu}\end{array}$ & 3 & Granito & 9 & Caulim & 15 \\
\hline Pirita & 6 & $Z n$ & 1 & $\begin{array}{l}\text { Granito } \\
\text { ornamental }\end{array}$ & 23 & Crisotila & 1 \\
\hline Pirolusita & 3 & & & Mármore & 32 & Feldspato & 3 \\
\hline Pirrotita & 2 & & & Quartzito & 4 & Fluorita & 7 \\
\hline Scheelita & 3 & & & Saibro & 2 & Grafita & 14 \\
\hline Vanádio & 2 & & & Traventino & 3 & Muscovita & 2 \\
\hline Terras raras & 2 & & & & & Quartzo & 8 \\
\hline $\begin{array}{l}\text { Óxido de } \\
\text { ferro }\end{array}$ & 1 & & & & & Sambaquis & 1 \\
\hline Tungatênio & 1 & & & & & Talco & 33 \\
\hline $\begin{array}{l}\text { Óxido de } \\
\text { ferro }\end{array}$ & 1 & & & & & Terras raras & 2 \\
\hline \multirow[t]{2}{*}{ Óxido de $M n$} & 5 & & & & & Titânio & 15 \\
\hline & & & & & & Turfa & 23 \\
\hline Total & 79 & & 264 & & 261 & & 161 \\
\hline
\end{tabular}




\subsubsection{Pedologia (IPT, 1981; ROSS, 1997; CETEC, 2000)}

Os solos identificados refletem de um modo geral, as particularidades climáticas, o relevo plano da várzea ou acidentado em rochas cristalinas. Destacando-se:

Latossolo Amarela Ático (Laa): Compreendem solos minerais geralmente ácidos, pobres em nutrientes, bem atentadamente drenados e com intemperismo. Duas variações foram identificadas:

Latossolo Amarelo Álico, horizonte A moderado, textura argilosa, são solos mais profundos, sendo encontrados nas áreas de relevo suave ondulado, onde ocorrem os sedimentos da formação Pariquera-Açú. São encontrados principalmente, nos municípios de Registro e Pariquera-Açú.

Latossolo Amarelo Álico, horizonte A, moderado, textura argilosa, destacando-se pela pouca profundidade. A espessura do solum ( $A+B)$, varia de 100 a $150 \mathrm{~cm}$. Ocorrem em áreas de revelo ondulado, a forte ondulado. São encontrados principalmente nos planaltos do município de Barra do Turvo.

Latossolo Vermelho-Amarelo Ático ( Lva): São solos de coloração vermelho-amarelada, com baixos teores de óxidos de ferro $(<8 \%)$. A maior parte desses latossolos é intermediária para cambisolos, sendo por isso classificado como latossolo vermelho amarelo Câmbico, pouco profundo. Ocorrem, principalmente, em antigas superfícies dissecadas de altos planaltos em relevo ondulado ou forte ondulado.

Nas bacias também são encontradas pequenas áreas de Latossolo com horizonte A húmico (Latossolo vermelho-Amarelo Húmico) caracterizado pela baixa fertilidade natural.

Latossolo Variação Uma Distrófico ou Ático (Lud): É a classe de solos com horizonte $B$ latossódico de coloração vermelho amarelada e alto a moderado teor de óxidos de ferro. Na região são encontrados em áreas identificadas geologicamente como pertencentes aos domos alcalinos de Cajati 
(Jacupiranga), Morro do Serrote (Registro e Complexo Gábrico de Apiaí). São solos de fertilidade média, sendo na sua maioria, classificados como distróficos (ou com saturação por base inferior a 50\%. Na área de estudo constitui o tipo Lud).

Terra Bruna estruturada Distrófica (TBd): São solos minerais, não hidromórficos, argilosos, com horizonte $B$ textural e argila de atividade baixa, além de bem drenados e profundos. A fertilidade natural baixa é o fator limitante à utilização agrícola.

Podzóico vermelho-Amarelo (PVd): Solos com profundidade variável, encontrados normalmente em áreas de relevo ondulado e forte ondulado ou montanhoso. Ao contrario dos latossolos, apresenta na maior parte dos casos, acentuada diferenciação de horizontes, destacando-se horizonte B textural enriquecido de argila iluviada do horizonte $A$.

Cambissolo (Ca): Solos minerais com horizonte B câmbico ou incipiente, não hidromórficos, com pouca diferenciação de textura entre o horizonte A para o B. Muitas vezes apresentam características similares aos solos com horizonte B latossódico, diferenciando-se por serem menos evoluídos, menos profundos e por apresentarem minerais primários de fácil intemperização, ou pela atividade da argila, que apesar de variar de alta a baixa é normalmente superior à dos Latossolos, ou ainda pelos teores de silte mais elevados.

Latossolo vermelho-amarelo: São solos minerais, não hidromórficos com horizonte $B$ do tipo latossódico porém com cores mais amareladas e presença de teores de $\mathrm{Fe}_{2} \mathrm{O}_{3}$ mais baixos que os latossolos vermelho-escuro. São normalmente muito profundos, com seqüência de horizontes A,B.e C e, com transições entre os sub-horizontes difusos e graduais, acentuadamente a bem drenados. Possui baixa reserva nutritiva para as plantas. A relação solti argila é menor que 0,70. É um solo muito poroso, propiciando maior resistência à erosão. São solos muito utilizados com pastagens, culturas de café e milho. 
Podzólico Bruno-Acizentado Eutrófico. Ocorrem em porções relativamente pequenas em áreas de relevo ondulado do município de Apiaí.

Na Figura 4.3 apresenta-se o mapa pedológico do Vale do Ribeira, com a distribuição dos tipos de solo da região.

\subsubsection{Clima}

Com clima tropical úmido com ligeira variação entre as zonas costeiras e a Serra de Paranapiacada, a classificação dos tipos climáticos do Vale do Ribeira, tendo com base no sistema Kopper são:

Tipo Af - tropical úmido sem estação seca que core 5\% da bacia;

Cfs, subtropical úmido com verão quente, que cobre $50 \%$ da bacia;

Cfb, subtropical úmido com verão fresco, cobrindo os $45 \%$ restantes, abrangendo as encostas das serras a norte e oeste da UGRHI. 
Figura 4.3 - Mapa pedológico do Vale do Ribeira. 
O trecho baixo da UGRHI (estação de Iguape) apresenta características climáticas com temperatura média anual de $21,5^{\circ} \mathrm{C}$, precipitação normal anual de cerca de $1.900 \mathrm{~mm}$ e unidade relativa do ar de aproximadamente $70 \%$.

Chove em média cerca de 1.400 mm/ano, sendo que na sub bacia de Juquiá, com 1.500 mm/ano, chove mais que na sub bacia do Ribeira de Iguape, abrangendo as áreas de drenagens a jusante de Registro. O período mais chuvoso vai de setembro a março, sendo janeiro o mês de maior pluviosidade. Entre os meses de abril e agosto, período de seca, a precipitação média fica ao redor de $50 \mathrm{~mm}$, sendo que o mês de agosto é o mês que chove menos.

O período de chuvas na região é caracterizado por provocar o transbordamento de rios e córregos, com conseqüentes transtornos à população ribeirinha seja na área urbana, seja na área rural. A Bacia do Ribeira possui características peculiares em relação à possibilidade de ocorrência de cheias. As condições climáticas da região são altamente favoráveis à ocorrência de chuvas do tipo frontal, de grande intensidade e duração, que tendem a produzir grandes volumes de deflúvio superficial.

Por outro lado, as características geomorfológicas da bacia também favorecem a ocorrência de grandes cheias. No trecho superior e médio, o rio Ribeira e seus afluentes correm por vales encaixados, com uma declividade média muito elevada. No curso inferior, a jusante de Eldorado e após receber a contribuição do rio Juquiá, o Ribeira do Iguape apresenta-se como um rio típico de planície, recortando terrenos alagadiços de baixada, com declividade praticamente nula. A superposição desses dois fatores constitui a causa básica das cheias de grande magnitude, tanto em termos de vazão de pico como de volume, sendo o trecho inferior da bacia o que sofre as maiores conseqüências, em virtude das características geomorfológicas citadas. Por outro lado, embora o índice pluviométrico seja menor nas outras estações do ano, mesmo no período de estiagem podem ser observados transbordamentos no rio Ribeira de Iguape. As cheias do Ribeira de Iguape geram grandes impactos, com prejuízos com a inundação de habitações, estabelecimentos comerciais, e perda da produção 
agrícola, com graves conseqüências econômicas e sociais (DAEE, 1998). Córregos e pequenos rios que percorrem tanto a área rural quanto à área urbana são também passíveis de inundações.

\subsection{Recursos Hídricos}

O rio Ribeira nasce no Paraná sendo classificado como rio Classe 2 de acordo com o CONAMA 357/05. Somente passa a ser denominado Ribeira de Iguape após a confluência com seu principal afluente o Juquiá. Ambos, nos últimos anos, obtiveram a classificação Boa para suas médias anuais do Índice de Qualidade de Água (IQA) (CETESB, 2000).

As condições da saúde pública no Vale do Ribeira são reflexos da baixa qualidade de vida de sua população, das relações de produção desfavoráveis, da fragilidade da base econômica e da precariedade das infraestruturas, apresentando deficiências nos sistemas públicos de esgoto, bem como carência de assistência médica e sanitária, principalmente nas áreas rurais. (SETTI et al 2001).

A Bacia do Ribeira/Litoral Sul é a única no estado de São Paulo onde a relação disponibilidade versus demanda é extremamente positiva. Com uma situação privilegiada em relação às demais no tocante a qualidade e quantidade de água, tanto por apresentar a mais elevada disponibilidade como pela demanda ainda pequena de 1,0\% e 0,6\% dos recursos hídricos superficiais e subterrâneos, respectivamente (DAEE, 2000). Portanto, é importante que se faça um planejamento avaliando-se a demanda atual e o potencial da bacia e ainda analisem-se as perspectivas de evolução. Procurando compatibilizar o desenvolvimento regional com a proteção dos recursos hídricos, escolhendo diretrizes de desenvolvimento adequadas à implantação na região de atividades que sejam compatíveis com a estrutura do solo e a preservação da sua cobertura vegetal na medida em que isto apresente maior ou menor importância.

Segundo o DAEE e a SRHSO, a demanda solicitada por uso, urbano, industrial e irrigação, disponibilidade hídrica na forma de $Q_{7,10}$ para a Bacia do 
Ribeira de Iguape é respectivamente: 1,$11 ; 2,67$ e $22,3 \mathrm{~m}^{3} / \mathrm{s}$. Sendo o total 6,08 $\mathrm{m}^{3} / \mathrm{s}$ da relação demanda/disponibilidade de $3,39 \%$ para toda a bacia.

$\mathrm{Na}$ Figura 4.4 é apresentado o gráfico comparativo entre a disponibilidade da bacia hidrográfica e as demandas superficiais para o uso e abastecimento urbano e industrial.

De acordo com o cadastro do DAEE, o total de água captada para a indústria é de 2,672 $\mathrm{m}^{3} \mathrm{~s}^{-1}$, em que a Serrana Mineração e a Fazenda Vale do Eta captam 1,29 e 0,98 $\mathrm{m}^{3} \mathrm{~s}^{-1}$ dos rios Jacupiranguinha e Eta, respectivamente, sendo os maiores consumidores.

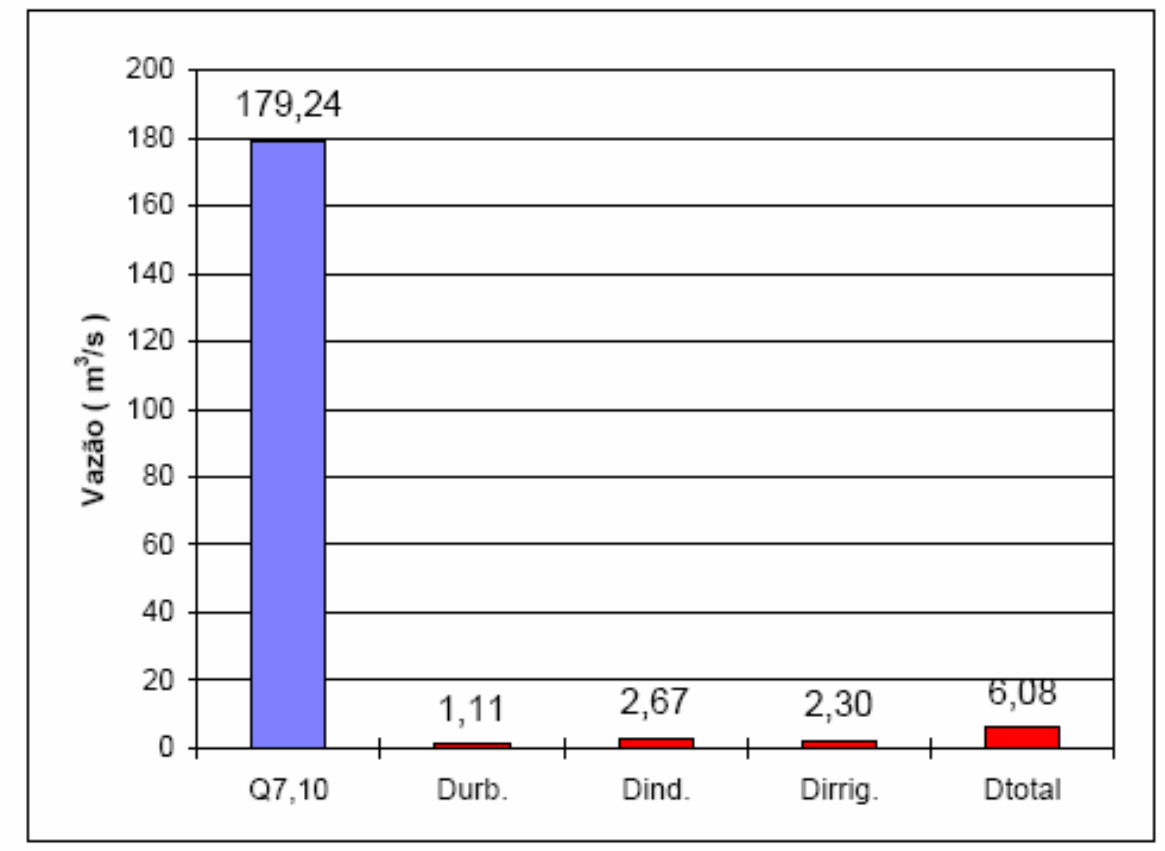

Figura 4.4 - Comparação disponibilidade $\left(Q_{7,10}\right) \times$ demanda (D) para a Bacia Hidrográfica do Rio Ribeira de Iguape (CETEC, 2000).

Na Tabela 4.4 são apresentadas as demandas de água para irrigação distribuída entre as treze sub-bacias da UGRHI 11. As sub-bacias de Jacupiranga e Ribeira de Iguape respondem por $57 \%$ da irrigação dos histogramas de vazões, seguida das sub-bacias de São Lourenço e Baixa Ribeira com 24\%. 
As potencialidades de água subterrânea na região da UGRHI 11 apresentam características mostradas na.Tabela 4.5.

Tabela 4.4 - Estimativa da demanda para irrigação nas sub-bacias (CETEC, 2002).

\begin{tabular}{|l|c|c|c|}
\hline \multicolumn{1}{|c|}{ SUB-BACIA } & $\begin{array}{c}\text { CULTURA } \\
\left(\mathrm{KM}^{2}\right)\end{array}$ & $\begin{array}{c}\text { ÁREA IRRIGADA } \\
(\%)\end{array}$ & $\begin{array}{c}\text { Q IRRIGAÇÃO } \\
\left(\mathrm{M}^{3} \mathrm{~s}^{-1}\right)\end{array}$ \\
\hline 1. Córrego Alto Ribeira & 0 & 0 & 0 \\
\hline 2 Baixo Ribeira & 57,2 & 11 & 0,248 \\
\hline 3. Rio Ribeira de Iguape & 138 & 26 & 0,599 \\
\hline 4. Alto Juquiá & 0 & 0 & 0 \\
\hline 5. Médio Juquiá & 8,12 & 2 & 0,035 \\
\hline 6 Baixo Juquiá & 24,3 & 5 & 0,298 \\
\hline 7. São Lourenço da Serra & 68,7 & 13 & 0,045 \\
\hline 8. Itariri & 10,3 & 2 & 0,218 \\
\hline 9. Uma da Aldeia & 50,3 & 9 & 0 \\
\hline 10. Pardo & 0 & 0 & 0,714 \\
\hline 11. Jacupiranga & 165 & 31 & 0,037 \\
\hline 12. Vert. Marítima Sul & 8,53 & 2 & 0 \\
\hline 13 Vert. Maritina Norte & 0 & 0 & \\
\hline
\end{tabular}

Tabela 4.5 - Características da potencialidade de água subterrânea da Bacia do Ribeira de Iguape e Litoral Sul (CETEC, 2002).

\begin{tabular}{|l|c|c|c|c|c|}
\hline $\begin{array}{l}\text { Domínios } \\
\text { Hidrogeológicos }\end{array}$ & $\begin{array}{l}\text { Extensão } \\
(\mathrm{Km})\end{array}$ & $\begin{array}{l}\text { Reservas } \\
\text { Permanentes } \\
\left(10^{8} \mathrm{~m}^{3}\right)\end{array}$ & $\begin{array}{l}\text { Reservas } \\
\text { Reguladoras } \\
\left(10^{6} \mathrm{~m}^{3}\right)\end{array}$ & $\begin{array}{l}\text { Reservas } \\
\text { Explotáveis } \\
\left(10^{6} \mathrm{~m}^{3}\right)\end{array}$ & $\begin{array}{l}\text { Tempo de } \\
\text { Residência } \\
(\text { anos })\end{array}$ \\
\hline Aqüífero Cristalino & 13.670 & 20.505 & 6.200 & 1.550 & 3 \\
\hline $\begin{array}{l}\text { Aqüífero } \\
\text { Sedimentar }\end{array}$ & 3.103 & 23.273 & 1.100 & 275 & 21 \\
\hline Totais & 16.773 & 43.778 & 7.300 & 1.825 & \\
\hline
\end{tabular}

A elaboração de diagnóstico ou prognósticos sobre o aproveitamento de água subterrânea na região do Vale do Ribeira encontra sérias dificuldades no seu desenvolvimento devido à falta de dados hidrogeológicos. Dos cerca de 150 
poços estimados que se encontram atualmente em operação na bacia, mais de 40\% são utilizados para o abastecimento público.

A relação entre a disponibilidade potencial de água subterrânea, de cerca de $60 \mathrm{~m}^{3} / \mathrm{s}$, e seu consumo atual, da ordem de $0,28 \mathrm{~m}^{3} / \mathrm{s}$, mostra uma taxa de utilização abaixo de 0,5\%, que demonstra um aproveitamento atual insignificante do recurso hídrico subterrâneo. (CETEC, 2002).

O Sistema de Saneamento do Vale do Ribeira, Litoral Sul, denominado pela SABESP de Unidade de Negócio Vale do Ribeira/Litoral Sul, abastece 18 municípios e 48 comunidades isoladas. O sistema operacional das estações de tratamento de água (ETA's) da SABESP de Registro é pioneiro em automação, onde $100 \%$ das ETA's são automatizadas, integradas por um Centro de Controle Operacional, em Registro.

A SABESP opera 43 sistemas produtores de água, na região paulista da Bacia Hidrográfica do Ribeira de Iguape para atender a demanda da região. Os sistemas utilizam mananciais superficiais, mananciais de serra e águas subterrâneas (poços) para capatação de água. A Tabela 4.6 apresenta a relação dos mananciais dos sistemas produtores do Vale do Ribeira operados pela SABESP, apresentando tipo de manancial, situação atual do manancial com perspectivas de racionamento, bem como percentagens de ligações.

A captação da água superficial para o município de Registro é realizada no rio Ribeira de Iguape, a jusante da cidade, por meio de bombas submersíveis. À jusante da captação existem portos de areia e muita área agrícola. À montante da captação existe o lançamento dos efluentes das lagoas de tratamento de esgotos de Sete Barras, Eldorado e Jaguarí-Mirim.

A Lei Estadual n. 7.663/91 decretou a instalação do Comitê da Bacia Hidrográfica do Ribeira de Iguape e Litoral Sul - CBD RB, com o objetivo de gerenciar os recursos hídricos e sua preservação, na Unidade de Gerenciamento de Recursos Hídricos (UGRHI -11). 
No entanto, avaliações realizadas nos últimos anos nos aqüíferos da região têm identificado diversas áreas críticas em termos de risco de potencial de contaminação. A CETESB constatou no ano de 1999 uma não conformidade de metais tóxicos (cobre e níquel), apesar de não relacionada às atividades mineradoras de Registro (CETESB, 1999; CETEC, 2001; HOGAN et al, 2002). Por outro lado, a análise de coliformes fecais entre 1989 a 2000 indicou a ocorrência de lançamentos de esgotos domésticos clandestinos como o maior comprometimento das águas nessa cidade (CETESB, 2000).

Tabela 4.6 - Sistemas produtores operados pela SABESP, apresentando tipo de manancial, situação atual do manancial com perspectivas de racionamento, bem como percentagens de ligações (Dados fornecidos pela SABESP - Unidade Operacional Vale do Ribeira - RR - Registro.

\begin{tabular}{|c|c|c|c|c|c|}
\hline TEMA & TIPO DE MANANCIAL & $\begin{array}{l}\text { VAZÃO } \\
\text { CAPTADA } \\
(\mathrm{L} / \mathrm{S})\end{array}$ & $\begin{array}{l}\text { SITUAÇÃO ATUAL } \\
\text { DO MANANCIAL } \\
\text { ( DISPON. } \\
\text { HÍDRICA) }\end{array}$ & $\begin{array}{l}\text { PERSPECTIVA DE } \\
\text { RACIONAMENTO } \\
\text { POR QUEDA DE } \\
\text { DISPON. HÍDRICA }\end{array}$ & $\begin{array}{c}\% . \\
\text { LIGAÇÕES } \\
\text { LR }\end{array}$ \\
\hline REGISTRO & RIO RIBEIRA DE IGUAPE & 158,14 & NORMAL & IMPROVÁVEL & 18,20 \\
\hline SERROTE & POÇO PROFUNDO & 2,84 & NORMAL & IMPROVÁVEL & 0,40 \\
\hline CARAPIRANGA & POÇO PROFUNDO & 2,89 & NORMAL & IMPROVÁVEL & 0,30 \\
\hline SETE BARRAS & RIO RIBEIRA DE IGUAPE & 34,1 & NORMAL & IMPROVÁVEL & 3,10 \\
\hline RIBEIRÃO DA SERRA & POÇO PROFUNDO & 4,48 & NORMAL & IMPROVÁVEL & 0,30 \\
\hline JUQUITIBA & RIBEIRÃO DO GODINHO & 29,01 & NORMAL & IMPROVÁVEL & 3,20 \\
\hline SENHORINHA & POÇO PROFUNDO & 3,25 & NORMAL & IMPROVÁVEL & 0,30 \\
\hline BARNABÉS & POÇO PROFUNDO & 6,99 & \begin{tabular}{|l} 
ESTADO DE \\
ALERTA
\end{tabular} & PODE OCORRER ( 1 ) & 0,90 \\
\hline S. LOURENÇO DA SERRA & RIO SÃO LOURENÇO & 16,72 & NORMAL & IMPROVÁVEL & 1,90 \\
\hline DESPÉZIO & POÇO PROFUNDO & 1,57 & NORMAL & IMPROVÁVEL & 0,20 \\
\hline PAIOL DO MEIO & RIO SÃO LOURENÇO & 14,88 & NORMAL & IMPROVÁVEL & 1,40 \\
\hline JACUPIRANGA & RIO CANHA & 32,77 & NORMAL & IMPROVÁVEL & 4,90 \\
\hline BARRA DO TURVO & RIO PARDO & 9,84 & NORMAL & IMPROVÁVEL & 1,30 \\
\hline CAJATI & RIO JACUPIRANGUINHA & 57,25 & NORMAL & IMPROVÁVEL & 7,90 \\
\hline CAPITÃO BRAZ & POÇO PROFUNDO & 3,75 & NORMAL & IMPROVÁVEL & 0,40 \\
\hline BARRA DO AZEITE & $\begin{array}{l}\text { CÓRR. BRAÇO DO } \\
\text { AZEITE }\end{array}$ & 9,69 & NORMAL & IMPROVÁVEL & 0,60 \\
\hline VILA DECO & POÇO PROFUNDO & 2,4 & NORMAL & IMPROVÁVEL & 0,20 \\
\hline ELDORADO & RIO RIBEIRA DE IGUAPE & 26,58 & NORMAL & IMPROVÁVEL & 2,80 \\
\hline BARRA DO BRAÇO & POÇO PROFUNDO & 1,64 & NORMAL & IMPROVÁVEL & 0,20 \\
\hline
\end{tabular}


Cont.

\begin{tabular}{|c|c|c|c|c|c|}
\hline TEMA & TIPO DE MANANCIAL & $\begin{array}{l}\text { VAZÃO } \\
\text { CAPTADA } \\
(\mathrm{L} / \mathrm{S}) \\
\end{array}$ & $\begin{array}{l}\text { SITUAÇÃO ATUAL } \\
\text { DO MANANCIAL } \\
\text { ( DISPON. } \\
\text { HÍDRICA) }\end{array}$ & $\begin{array}{l}\text { PERSPECTIVA DE } \\
\text { RACIONAMENTO } \\
\text { POR QUEDA DE } \\
\text { DISPON. HIIDRICA }\end{array}$ & $\begin{array}{l}\text { PORCENT. } \\
\text { LIGAÇÕES } \\
\text { LR* }^{*}\end{array}$ \\
\hline ITAPEUNA & POÇO PROFUNDO & 2,9 & NORMAL & IMPROVÁVEL & 0,30 \\
\hline BATATAL & POÇO PROFUNDO & 2,34 & NORMAL & IMPROVÁVEL & 0,20 \\
\hline IPORANGA & RIO IPORANGA & 9,73 & NORMAL & IMPROVÁVEL & 1,00 \\
\hline BAIRRO DA SERRA & CÓRR. MACAQUINHO & 3,36 & NORMAL & IMPROVÁVEL & 0,20 \\
\hline IGUAPE & RIO RIBEIRA DE IGUAPE & 159,4 & NORMAL & IMPROVÁVEL & 19,10 \\
\hline CANANÉIA & RIO ITAPITANGUI & 65,24 & NORMAL & IMPROVÁVEL & 4,90 \\
\hline ARIRI & CÓRR. S/ NOME & 1,20 & EM OBSERVAÇÃO & PODE OCORRER ( 2 ) & 0,20 \\
\hline PARIQUERA-AÇU & CÓRR. BRAÇO GRANDE & 25,58 & EM OBSERVAÇÃO & PODE OCORRER ( 3 ) & 5,20 \\
\hline ANGATUBA & POÇO PROFUNDO & 2,92 & NORMAL & IMPROVÁVEL & 0,10 \\
\hline CONCHAL & POÇO PROFUNDO & 1,90 & NORMAL & IMPROVÁVEL & 0,10 \\
\hline \multicolumn{6}{|l|}{ ILHA COMPRIDA } \\
\hline PEDRINHAS & CÓRR. PARATIÚ & 1,83 & NORMAL & IMPROVÁVEL & 0,20 \\
\hline PEDRO DE TOLEDO & RIO DO PEIXE & 23,22 & NORMAL & IMPROVÁVEL & 3,20 \\
\hline M.AFONSO/M.NÓBREGA & POÇO PROFUNDO & 0,69 & NORMAL & IMPROVÁVEL & 0,10 \\
\hline JUQUIÁ & RIO JUQUIÁ & 39,75 & NORMAL & IMPROVÁVEL & 5,30 \\
\hline COLONIZAÇÃO & CÓRR. S/ NOME & 0,94 & NORMAL & IMPROVÁVEL & 0,10 \\
\hline BAIRRO IPORANGA & CÓRR. S/ NOME & 1,24 & NORMAL & IMPROVÁVEL & 0,01 \\
\hline MIRACATU & RIO SÃO LOURENÇO & 33,03 & NORMAL & IMPROVÁVEL & 3,30 \\
\hline MUSÁCEA & RIBEIRÃO DO PEIXE & 4,36 & NORMAL & IMPROVÁVEL & 0,40 \\
\hline OLIVEIRA BARROS & RIBEIRÃO DA SERRINHA & 18,28 & NORMAL & IMPROVÁVEL & 1,50 \\
\hline SANTA RITA & POÇO PROFUNDO & 3,38 & NORMAL & IMPROVÁVEL & 0,40 \\
\hline BAIRRO DO ENGANO & POÇO PROFUNDO & 1,45 & NORMAL & IMPROVÁVEL & 0,10 \\
\hline ITARIRI & RIBEIRÃO DO AREADO & 11,78 & NORMAL & IMPROVÁVEL & 2,50 \\
\hline ANA DIAS & RIO CABUÇU & 3,72 & NORMAL & IMPROVÁVEL & 0,60 \\
\hline AREIA BRANCA & POÇO PROFUNDO & 1,34 & NORMAL & IMPROVÁVEL & 0,10 \\
\hline TAPIRAÍ & RIO TURVO & 20,24 & NORMAL & IMPROVÁVEL & 2,30 \\
\hline
\end{tabular}

* $\mathrm{LR}=$ rede

(1) Por se tratar de local situado em divisor de águas, a disponibilidade de água no subsolo em épocas de estiagem se reduz drasticamente, podendo haver necessidade de racionamento no local. Está previsto a integração desse sistema com a sede, o que resolverá definitivamente o problema. Foi incluído no Pedido de Financiamento ao BNDES para viabilização. (2) O manancial é de serra e tem uma bacia de contribuição bastante reduzida. No caso de estiagem, a vazão disponível pode ser insuficiente para atender a demanda. O problema será resolvido com a obra de reforço em outro manancial cujas obras já se encontram em licitação.

(3) A bacia de contribuição do manancial no ponto de captação é pouco extensa, e essa bacia é muito susceptível a períodos de estiagem, com redução significativa da vazão. Se houver um período prolongado de estiagem, a vazão disponível pode ser menor que a vazão necessária para o atendimento ao sistema, implicando em racionamento. Existe projeto de nova captação em ponto à jusante aumentando a área da bacia de contribuição, porém, ainda não foi priorizado no PPI. 
Resultados do IAP (Índice de qualidade das águas para fins de abastecimento público) apontaram os rios Ribeira, Ribeira de Iguape e Juquiá como rios de qualidade boa (CETESB, 2004). No entanto, o rio Jacupiranga apresentou classificação regular, com teores elevados de alumínio, manganês, ferro e fósforo total, detectando-se toxidade para a Ceriodaphnia dúbia, e indicando a necessidade de uma investigação mais profunda na região. Pontos de coleta no rio Ribeira de Iguape também apresentaram altas concentrações de fósforo, sendo que um ponto classificou-se como hipereutrófico. Também foi constatada a presença de chumbo em sedimentos do rio Ribeira de Iguape, no trecho de Iporanga, com provável origem nas antigas minerações de chumbo no Estado do Paraná. Foi encontrada uma concentração elevada do elemento (133mgkg ${ }^{-1}$ ), superior a PEL (probabilidade de efeito severo à biota), e mais elevada do que os resultados de contaminantes em sedimento obtidos em 2003.

Estudos recentes (COTRIM et al, 2004; PIRES, 2004) sobre o monitoramento de metais, em especial do chumbo, na bacia do Ribeira de Iguape mostraram que as concentrações de chumbo monitoradas nos mananciais superficiais, variaram de 0,003 a 0,009 $\mathrm{mgL}^{-1}$, e apresentaram valores aproximadamente duas vezes maiores que as concentrações observadas nas águas subterrâneas e nos mananciais de serra. Das 24 amostras de sedimentos analisadas, os sedimentos do Ribeira de Iguape coletados nas áreas de captação de água dos municípios de Eldorado e Sete Barras apresentaram altas concentrações de chumbo (121,5 e 102,3 $\left.\mu \mathrm{gg}^{-1}\right)$.

Vários estudos, realizados a partir da década de 1980, comprovaram inequivocamente que a bacia do Ribeira foi muito afetada pelas atividades econômicas levadas a efeito na região, em especial, pela atividade de mineração e metalúrgica do Alto Vale. Esses efeitos tornam-se visíveis na contaminação dos sedimentos fluviais por chumbo, zinco, cobre e arsênio, e, mais episodicamente, pelo registro de elevadas concentrações de metais nas águas. Entre esses diagnósticos de qualidade ambiental citam-se TESSLER et al. (1987), EYSINK et al. (1988), MORAES (1997), SILVA (1997) e CETESB (1991, 2000). 
No período de 1999-2004 foram realizados estudos do meio físico e saúde humana avaliando a exposição humana à contaminação por chumbo e arsênio no Vale do Ribeira. Os estudos revelaram que, embora as atividades de mineração tenham cessado em 1996, as populações do Alto Ribeira ainda convivem com várias fontes de contaminação ambiental, em especial chumbo e arsênio, tipicamente originadas da atividade de beneficiamento e refino e mineral. Os maiores níveis de exposição humana ao chumbo ocorrem nas comunidades de Vila Mota e Capelinha, município de Adrianópolis (PR). Os maiores níveis de arsênio ocorrem no Bairro da Serra, município de Iporanga (SP) (FIGUEIREDO, 2000; PAOLIELO et al., 2001, 2002 e 2003; TAKAMORI \& FIGUEIREDO, 2002; CUNHA et al., 2003; FIGUEIREDO et al., 2003).

Desta forma, fica clara a necessidade de manter ações de monitoramento e controle, uma vez que a poluição das águas da região pode comprometer o abastecimento público de algumas cidades. 


\section{PARTE EXPERIMENTAL}

O principal interesse deste estudo está relacionado à avaliação de metais e elementos traço dos mananciais utilizados para abastecimento público, pela SABESP, na Região do Vale do Ribeira, bem como o de avaliar a qualidade das águas distribuídas.

Avaliar a qualidade de um ambiente aquático como um todo, sob a perspectiva evolutiva desse ambiente como recurso natural renovável, exige também o monitoramento da qualidade e dinâmica do sedimento (MOZETO e PATELLA, 1999).

Dessa forma, foi definido um programa de monitoramento, levando-se em conta três diferentes tipos de ecossistemas, com mecanismos de funcionamento distintos existentes na região, utilizados para abastecimento público: mananciais superficiais, mananciais de serra e mananciais subterrâneos.

Assim, foram caracterizadas amostras de água das captações superficiais, mananciais de serra, bem como o sedimento de fundo desses mananciais, avaliando a fração disponível e total. Foram também caracterizadas amostras de águas subterrâneas (poços), bem como amostras de água tratada provenientes das 18 estações de tratamento de água da SABESP.

Foram amostradas água bruta, tratada e sedimento de fundo em áreas de captação de água, durante um período sazonal, com coletas trimestrais, abordando principalmente dois períodos distintos, um no período seco (junho) e outro no período chuvoso, em 43 estações sistemas produtores, localizados nas áreas de captação de água superficial, manancial de serra e poços nos municípios do Vale do Ribeira, que utilizam os principais cursos d'água da bacia. 


\subsection{Amostragem}

Foram coletadas amostras de água em 18 pontos de captação superficial e suas respectivas ETA's operadas pela Sabesp, amostras de água em mananciais de serra em 10 pontos, e 15 pontos em poços profundos. Para identificação dos pontos de coleta foram utilizados os mesmos códigos utilizados pela SABESP - Unidade de Negócios Vale do Ribeira - RR.

$\mathrm{Na}$ Tabela 5.1 são apresentados os pontos de coleta identificados e georreferenciados, referentes aos pontos de captação superficial com as respectivas Estação de Tratamento de Água - ETA e as captações subterrâneas e de serra.

$\mathrm{Na}$ Figura 5.1 apresentam-se os principais corpos d'água, os municípios bem como a localização dos pontos de amostragem (para captações superficiais), georeferenciados. A Cetesb atualmente realiza o monitoramento em 7 pontos ao longo da Bacia.

Nas Figura 5.2 a Figura 5.5 são apresentadas evidências fotográficas de alguns dos mananciais utilizados para abastecimento público bem como de uma estação de tratamento de água.

Nas captações superficiais (corpos de água e mananciais superficiais) foram coletadas amostras de sedimentos de fundo.

A caracterização das variáveis físicas e químicas foram realizadas nos 43 sistemas produtores do Vale do Ribeira, com uma periodicidade de amostragem trimestral, no período de março de 2002 a fevereiro de 2003, totalizando 5 campanhas de campo, representando 124 amostras por campanha e um total de 711 amostras.

Para as amostras de sedimento de fundo foram realizadas 3 coletas, sendo uma exploratória, em março de 2002 e, as outras contemplando um período de seca (junho de 2002) e chuva (fevereiro de 2003). 
Tabela 5.1 - Caracterização e localização dos sistemas produtores do Vale do Ribeira (Dados fornecidos pela SABESP - Unidade de Negócios Vale do Ribeira/Litoral Sul-RR).

\begin{tabular}{|c|c|c|c|c|c|}
\hline Município & $\begin{array}{l}\text { Sistema } \\
\text { Produtor }\end{array}$ & $\begin{array}{l}\text { Código } \\
\text { SABESP }\end{array}$ & $\begin{array}{l}\text { Tipo de } \\
\text { Sistema }\end{array}$ & Captação & Localização (GPS) \\
\hline \multirow[t]{3}{*}{ Registro } & Registro & LR001 & ETA & Rio Ribeira do Iguape & $\begin{array}{l}\text { S } 24^{\circ} 28^{\prime} 25^{\prime \prime} \\
\text { O } 47^{\circ} 50^{\prime} 37^{\prime \prime}\end{array}$ \\
\hline & Serrote & LR003 & Poço & Poço profundo & $\begin{array}{l}\text { S } 24^{\circ} 24^{\prime} 25^{\prime \prime} \\
\text { O } 47^{\circ} 44^{\prime} 52^{\prime \prime}\end{array}$ \\
\hline & Carapiranga & LR 004 & Poço & Poço Profundo & $\begin{array}{l}\text { S } 24^{\circ} 31^{\prime} 42^{\prime \prime} \\
\text { O } 47^{\circ} 53^{\prime} 11^{\prime \prime}\end{array}$ \\
\hline \multirow[t]{2}{*}{$\begin{array}{l}\text { Sete } \\
\text { Barras }\end{array}$} & Sete Barras & LR005 & ETA & Rio Ribeira do Iguape & $\begin{array}{l}\mathrm{S} 24^{\circ} 23^{\prime} 33 \\
\mathrm{O} 47^{\circ} 55^{\prime} 43^{\prime \prime}\end{array}$ \\
\hline & $\begin{array}{l}\text { Ribeirão da } \\
\text { Serra }\end{array}$ & LR006 & Poço & Poço profundo & $\begin{array}{l}\text { S } 24^{\circ} 16^{\prime} 33^{\prime \prime} \\
\text { O } 47^{\circ} 56^{\prime} 52^{\prime \prime}\end{array}$ \\
\hline Jacupiranga & Jacupiranga & LR007 & ETA & Rio Canha & $\begin{array}{c}\text { S } 4^{\circ} 43^{\prime} 03^{\prime \prime} \\
\text { O } 47^{\circ} 59^{\prime} 58^{\prime \prime}\end{array}$ \\
\hline \multirow[t]{3}{*}{ Cajati } & $\begin{array}{l}\text { Barra do } \\
\text { Azeite }\end{array}$ & LR 008 & Serra & $\begin{array}{l}\text { Ribeirão Braço do } \\
\text { Azeite }\end{array}$ & $\begin{array}{l}\text { S } 24^{\circ} 47^{\prime} 36^{\prime \prime} \\
\text { O } 48^{\circ} 09^{\prime} 50^{\prime \prime}\end{array}$ \\
\hline & Cajati & LR 011 & ETA & Rio Jacupiranguinha & $\begin{array}{l}\text { S } 24^{\circ} 43^{\prime} 50^{\prime \prime} \\
\text { O } 48^{\circ} 07^{\prime} 56^{\prime \prime}\end{array}$ \\
\hline & Vila Deco & LR 060 & Poço & Poço Profundo & $\begin{array}{l}\mathrm{S} 24^{\circ} 40^{\prime} 27^{\prime \prime} \\
\mathrm{O} 48^{\circ} 08^{\prime} 16^{\prime \prime}\end{array}$ \\
\hline $\begin{array}{l}\text { Barra do } \\
\text { Turvo }\end{array}$ & $\begin{array}{l}\text { Barra do } \\
\text { Turvo }\end{array}$ & LR 012 & ETA & $\begin{array}{l}\text { Rio Pardo e Córrego } \\
\text { Chopim }\end{array}$ & $\begin{array}{l}\text { S } 24^{\circ} 45^{\prime} 50^{\prime \prime} \\
\text { O } 48^{\circ} 30^{\prime} 28^{\prime \prime}\end{array}$ \\
\hline \multirow[t]{2}{*}{ Cananéia } & Cananéia & LR 013 & ETA & Rio Itapitangui & $\begin{array}{l}\text { S } 24^{\circ} 55^{\prime} 58^{\prime \prime} \\
\text { O } 47^{\circ} 57^{\prime} 41^{\prime \prime}\end{array}$ \\
\hline & Ariri & LR 014 & Serra & Córrego Ariri & \\
\hline \multirow[t]{4}{*}{ Eldorado } & Eldorado & LR 017 & ETA & Rio Ribeira do Iguape & $\begin{array}{l}\text { S } 24^{\circ} 31^{\prime} 09^{\prime \prime} \\
\text { O } 48^{\circ} 06^{\prime} 54^{\prime \prime}\end{array}$ \\
\hline & $\begin{array}{l}\text { Barra do } \\
\text { Braço }\end{array}$ & LR 018 & Poço & Poço Profundo & $\begin{array}{l}\text { S } 24^{\circ} 38^{\prime} 15^{\prime \prime} \\
\text { O } 48^{\circ} 17^{\prime} 39^{\prime \prime}\end{array}$ \\
\hline & Itapeuna & LR019 & Poço & Poço Profundo & $\begin{array}{l}\mathrm{S} 24^{\circ} 35^{\prime} 34 \\
\mathrm{O} 48^{\circ} 12^{\prime} 57^{\prime \prime}\end{array}$ \\
\hline & $\begin{array}{l}\text { Barra do } \\
\text { Batatal }\end{array}$ & LR 020 & Poço & Poço Profundo & $\begin{array}{l}\text { S } 4^{\circ} 35^{\prime} 06^{\prime \prime} \\
\text { O } 48^{\circ} 16^{\prime} 18^{\prime \prime}\end{array}$ \\
\hline \multirow[t]{3}{*}{$\begin{array}{l}\text { Pariquera- } \\
\text { Açu }\end{array}$} & Pariquera-Açu & LR 021 & ETA & Córrego Braço Grande & $\begin{array}{l}\text { S } 24^{\circ} 43^{\prime} 21^{\prime \prime} \\
\text { O } 47^{\circ} 53^{\prime} 29^{\prime \prime}\end{array}$ \\
\hline & Angatuba & LR 042 & Poço & Poço Profundo & $\begin{array}{l}\text { S } 24^{\circ} 36^{\prime} 47^{\prime \prime} \\
\text { O } 47^{\circ} 51^{\prime} 46^{\prime \prime}\end{array}$ \\
\hline & Conchal & LR 070 & Poço & Poço profundo & $\begin{array}{l}\text { S } 24^{\circ} 37^{\prime} 44^{\prime \prime} \\
\text { O } 47^{\circ} 53^{\prime} 21^{\prime \prime}\end{array}$ \\
\hline \multirow[t]{3}{*}{ Juquía } & Juquía & LR 022 & ETA & Rio Juquiá & $\begin{array}{l}\text { S } 24^{\circ} 19^{\prime} 12^{\prime \prime} \\
\text { O } 47^{\circ} 37^{\prime} 30^{\prime \prime}\end{array}$ \\
\hline & Colonização & LR 023 & Serra & Córrego sem Nome & $\begin{array}{l}\text { S } 24^{\circ} 09^{\prime} 27^{\prime \prime} \\
\text { O } 47^{\circ} 08^{\prime} 09^{\prime \prime}\end{array}$ \\
\hline & $\begin{array}{l}\text { Bairro } \\
\text { Iporanga }\end{array}$ & LR 024 & Serra & Córrego sem Nome & $\begin{array}{l}\text { S } 24^{\circ} 06^{\prime} 12^{\prime \prime} \\
\text { O } 47^{\circ} 38^{\prime} 41^{\prime \prime}\end{array}$ \\
\hline Miracatu & Miracatu & LR 026 & ETA & Rio São Lourenço & $\begin{array}{l}\text { S } 24^{\circ} 16^{\prime} 24^{\prime \prime} \\
\text { O } 47^{\circ} 27^{\prime} 09^{\prime \prime}\end{array}$ \\
\hline
\end{tabular}


Cont.

\begin{tabular}{|c|c|c|c|c|c|}
\hline Município & $\begin{array}{l}\text { Sistema } \\
\text { Produtor }\end{array}$ & $\begin{array}{l}\text { Código } \\
\text { SABESP }\end{array}$ & $\begin{array}{l}\text { Tipo de } \\
\text { Sistema }\end{array}$ & Captação & Localização (GPS) \\
\hline & Musácea & LR 029 & Serra & & $\begin{array}{l}\text { S } 24^{\circ} 15^{\prime} 45^{\prime \prime} \\
\text { O } 47^{\circ} 19^{\prime} 21^{\prime \prime}\end{array}$ \\
\hline & $\begin{array}{l}\text { Oliveira } \\
\text { Barros }\end{array}$ & LR 030 & Serra/ETA & Sem nome & $\begin{array}{l}\text { S } 24^{\circ} 19^{\prime} 45^{\prime \prime} \\
\text { O } 47^{\circ} 32^{\prime} 34^{\prime \prime}\end{array}$ \\
\hline & Santa Rita & LR 032 & Poço & Poço profundo & $\begin{array}{l}\text { S } 24^{\circ} 08^{\prime} 56^{\prime \prime} \\
\text { O } 47^{\circ} 18^{\prime} 59^{\prime \prime}\end{array}$ \\
\hline Iguape & Iguape & LR 033 & ETA & Rio Ribeira do Iguape & $\begin{array}{l}\text { S } 24^{\circ} 40^{\prime} 54^{\prime \prime} \\
\text { O } 47^{\circ} 35^{\prime} 50^{\prime \prime}\end{array}$ \\
\hline Itariri & Itariri & LR 043 & ETA & Manancial de Serra & $\begin{array}{l}\text { S } 24^{\circ} 18^{\prime} 17^{\prime \prime} \\
\text { O } 47^{\circ} 10^{\prime} 47^{\prime \prime}\end{array}$ \\
\hline $\begin{array}{l}\text { Pedro de } \\
\text { Toledo }\end{array}$ & $\begin{array}{l}\text { Pedro de } \\
\text { Toledo }\end{array}$ & LR 044 & ETA & Rio do Peixe & $\begin{array}{l}\text { S } 24^{\circ} 17^{\prime} 02^{\prime \prime} \\
\text { O } 47^{\circ} 13^{\prime} 40^{\prime \prime}\end{array}$ \\
\hline \multirow[t]{3}{*}{ Juquitiba } & Juquitiba & LR 045 & ETA & Córrego Godinhos & $\begin{array}{l}\text { S } 23^{\circ} 56^{\prime} 00^{\prime \prime} \\
\text { O } 47^{\circ} 03^{\prime} 38^{\prime \prime}\end{array}$ \\
\hline & Barnabés & LR 046 & Poço & Poço profundo & $\begin{array}{l}\text { S } 23^{\circ} 59^{\prime} 10^{\prime \prime} \\
\text { O } 47^{\circ} 08^{\prime} 46^{\prime \prime}\end{array}$ \\
\hline & Senhorinha & LR 047 & Poço & Poço Profundo & $\begin{array}{l}\text { S } 23^{\circ} 56^{\prime} 29^{\prime \prime} \\
\text { O } 47^{\circ} 03^{\prime} 00^{\prime \prime}\end{array}$ \\
\hline \multirow{3}{*}{$\begin{array}{c}\text { São } \\
\text { Lourenço } \\
\text { da Serra }\end{array}$} & $\begin{array}{l}\text { S.Lourenço } \\
\text { da Serra }\end{array}$ & LR 049 & ETA & Rio São Lourenço & $\begin{array}{l}\text { S } 23^{\circ} 51^{\prime} 04^{\prime \prime} \\
\text { O } 46^{\circ} 56^{\prime} 34^{\prime \prime}\end{array}$ \\
\hline & Paiol do Meio & LR 050 & ETA & Rio São Lourenço & $\begin{array}{l}\text { S } 23^{\circ} 52^{\prime} 56^{\prime \prime} \\
\text { O } 46^{\circ} 58^{\prime} 28^{\prime \prime}\end{array}$ \\
\hline & Despézio & LR 057 & Poço & Poço profundo & $\begin{array}{l}\text { S } 23^{\circ} 49^{\prime} 01^{\prime \prime} \\
\text { O } 46^{\circ} 55^{\prime} 46^{\prime \prime}\end{array}$ \\
\hline \multirow[t]{3}{*}{ Itariri } & Ana Dias & LR 052 & Serra & Rio Cabuçu & $\begin{array}{l}\text { S } 24^{\circ} 19^{\prime} 27^{\prime \prime} \\
\text { O } 47^{\circ} 04^{\prime} 51^{\prime \prime}\end{array}$ \\
\hline & $\begin{array}{l}\text { Raposo } \\
\text { Tavares }\end{array}$ & LR 053 & Serra & Sem nome & $\begin{array}{l}\text { S } 24^{\circ} 18^{\prime} 47^{\prime \prime} \\
\text { O } 47^{\circ} 08^{\prime} 19^{\prime \prime}\end{array}$ \\
\hline & Areia Branca & LR 054 & Poço & Poço Profundo & \\
\hline $\begin{array}{c}\text { Ilha } \\
\text { Comprida }\end{array}$ & Pedrinhas & LR 061 & Serra & Ribeirão Paratiu & $\begin{array}{l}\text { S } 24^{\circ} 51^{\prime} 30^{\prime \prime} \\
\text { O } 47^{\circ} 47^{\prime} 55^{\prime \prime}\end{array}$ \\
\hline \multirow[t]{2}{*}{ Iporanga } & Iporanga & LR 068 & ETA & Rio Iporanga & $\begin{array}{l}\text { S } 24^{\circ} 34^{\prime} 49^{\prime \prime} \\
\text { O } 48^{\circ} 35^{\prime} 25^{\prime \prime}\end{array}$ \\
\hline & $\begin{array}{l}\text { Bairro da } \\
\text { Serra }\end{array}$ & LR 069 & Serra & Córrego da Serra & $\begin{array}{l}\mathrm{S} 23^{\circ} 33^{\prime} 04^{\prime \prime} \\
\mathrm{O} 48^{\circ} 41^{\prime} 29^{\prime \prime}\end{array}$ \\
\hline Tapiraí & $\begin{array}{l}\text { Bairro do } \\
\text { Turvo }\end{array}$ & LR 142 & ETA & Rio Turvo & $\begin{array}{l}\mathrm{S} 23^{\circ} 53^{\prime} 48^{\prime \prime} \\
\mathrm{O} 47^{\circ} 30^{\prime} 44^{\prime \prime}\end{array}$ \\
\hline
\end{tabular}

GPS - Global Position System (Latitude Sul - S e Longitude Oeste - O)

As coletas foram realizadas segundo recomendações do guia de coletas da CETESB (1991), e do Standard Methods (1997), considerando o tipo de frasco para cada parâmetro, volume necessário para a análise, preservação da amostra e prazo para a realização da análise. 
As amostras de água dos mananciais superficiais foram coletadas a aproximadamente $10 \mathrm{~cm}$ da superfície em frascos de polietileno, previamente descontaminados, sendo lavados 3 vezes no momento da coleta com a própria amostra.

As amostras de água subterrânea foram coletadas diretamente através de bombas existentes nos poços. O volume inicial retirado pela bomba foi desprezado, sendo adotado a seguir o mesmo procedimento de lavagem do frasco com a amostra.

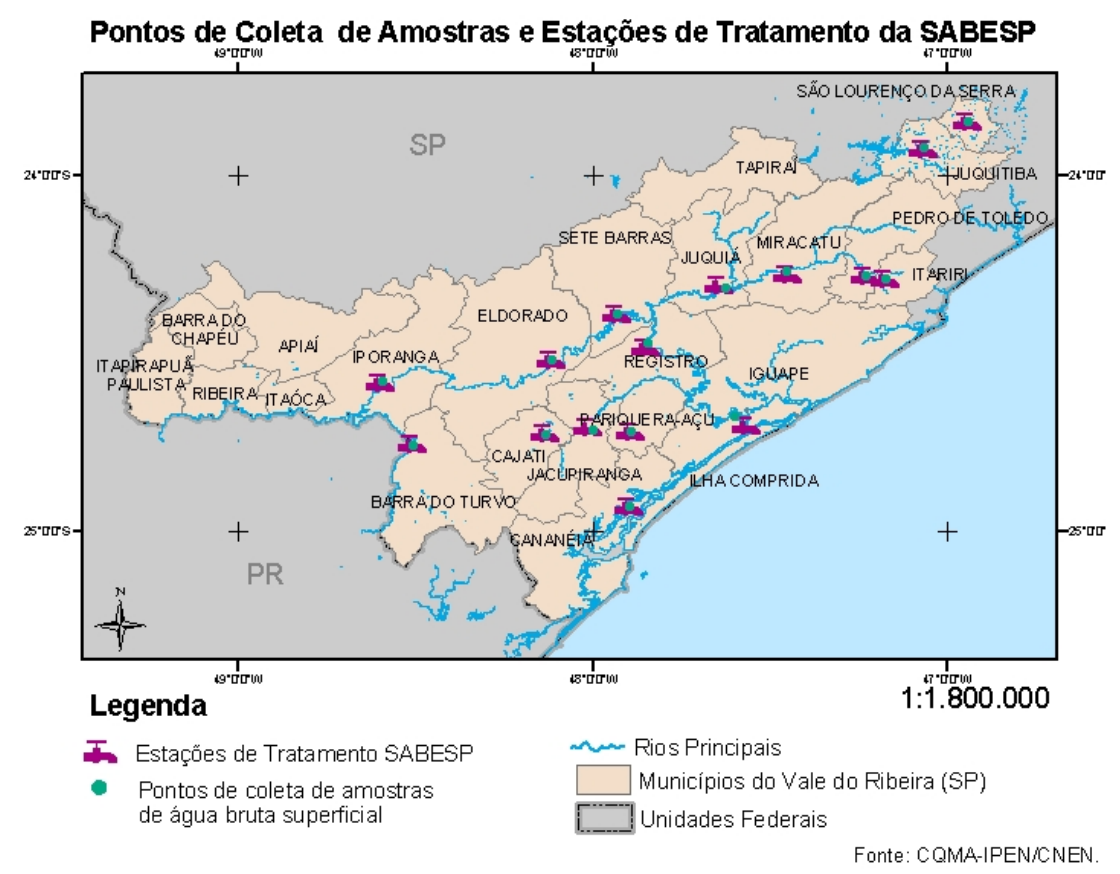

Figura 5.1 - Localização dos Pontos de coleta - captações superficiais e estações de tratamento de água (ETA's). 


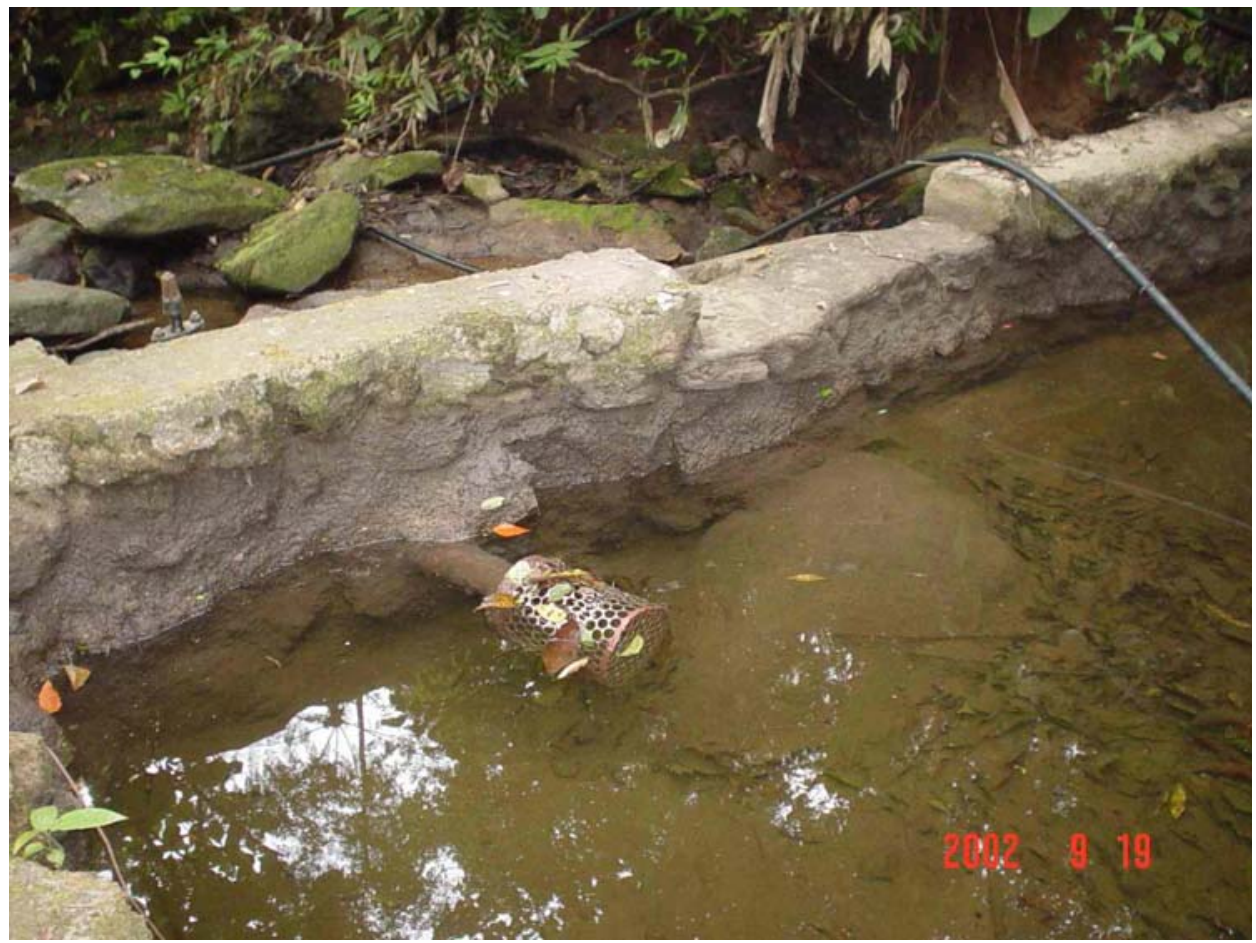

Figura 5.2 - Área de captação de Manancial de Serra, Município de Musácea.

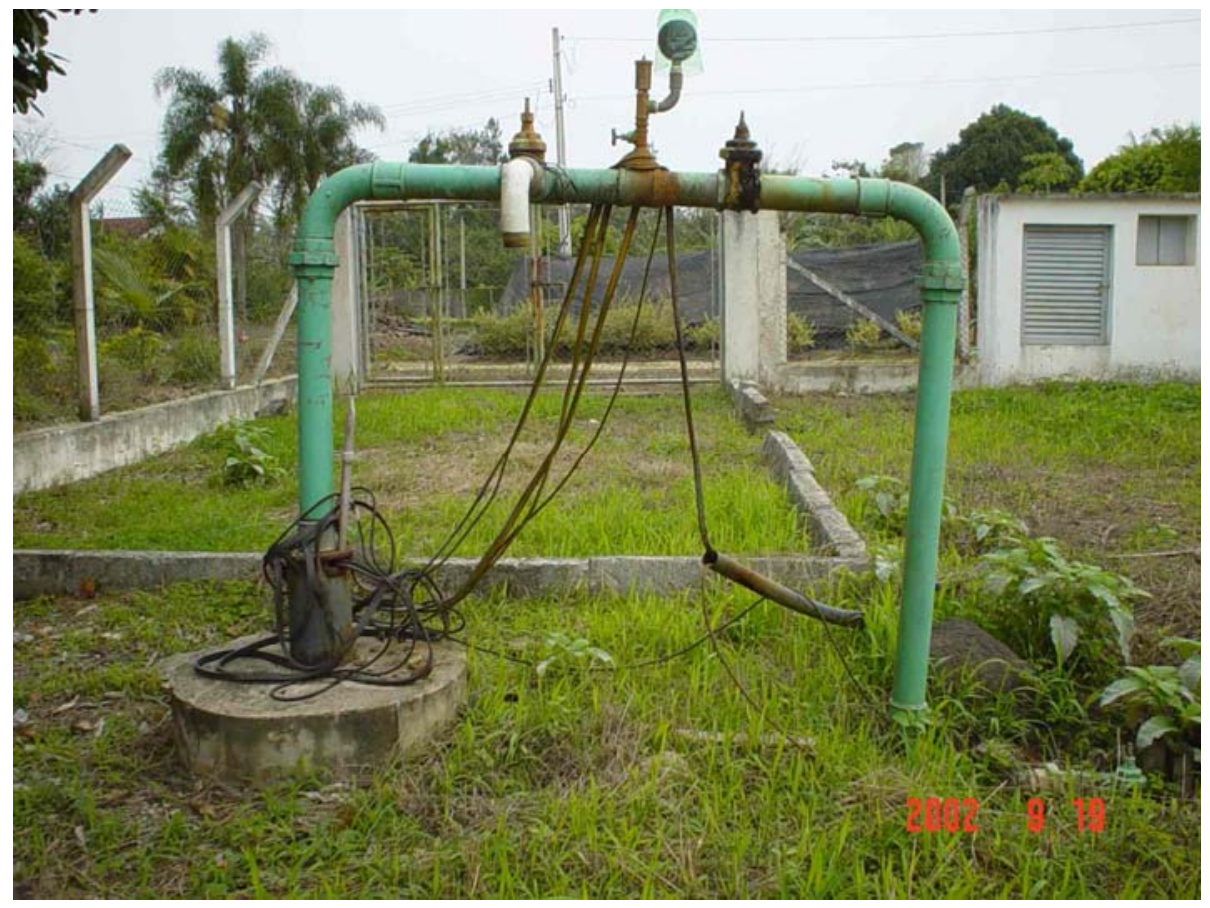

Figura 5.3 - Captação em poço profundo, Bairro Conchal; Município de Miracatu. 


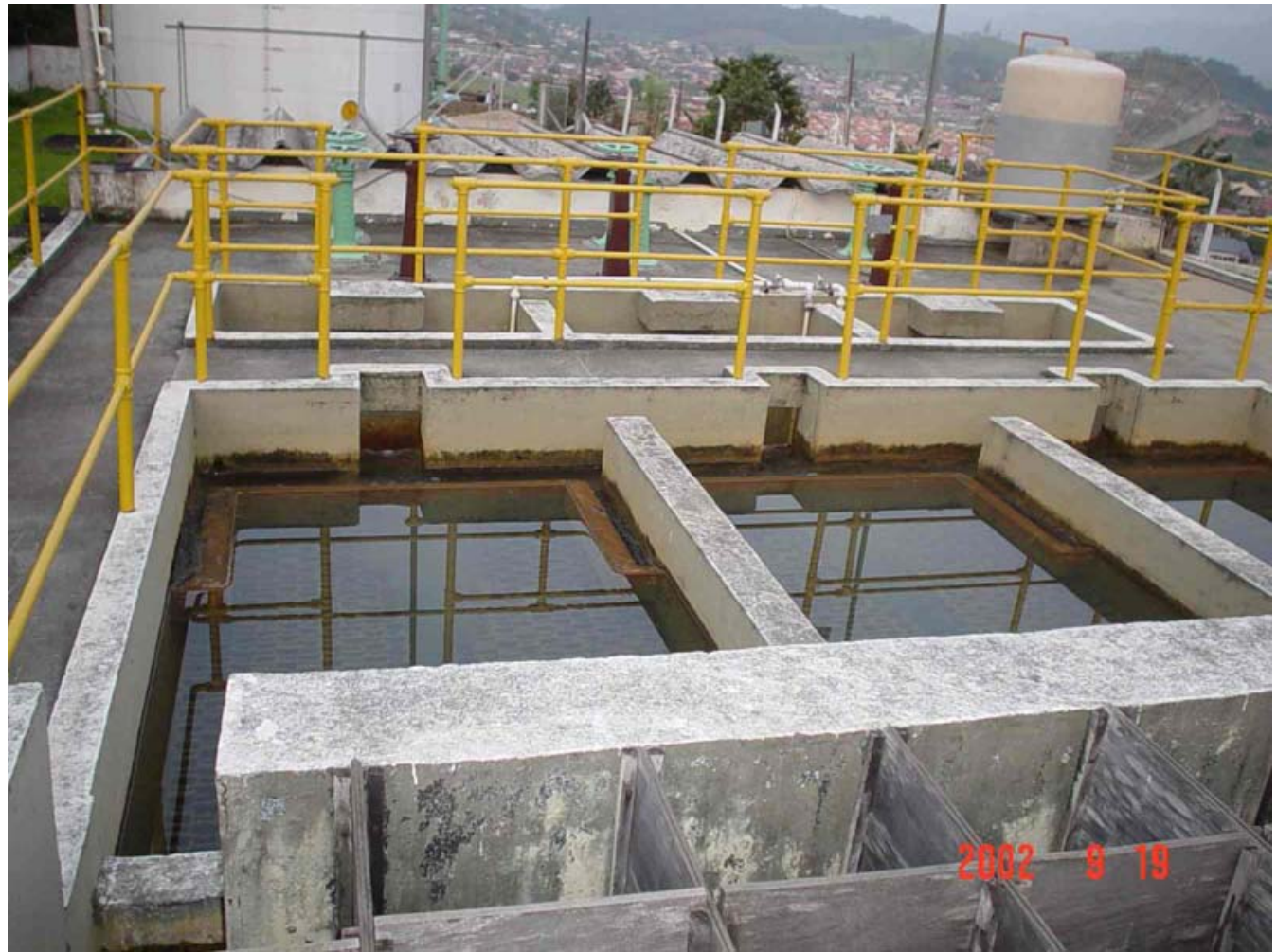

Figura 5.4 - ETA do Município de Juquiá.

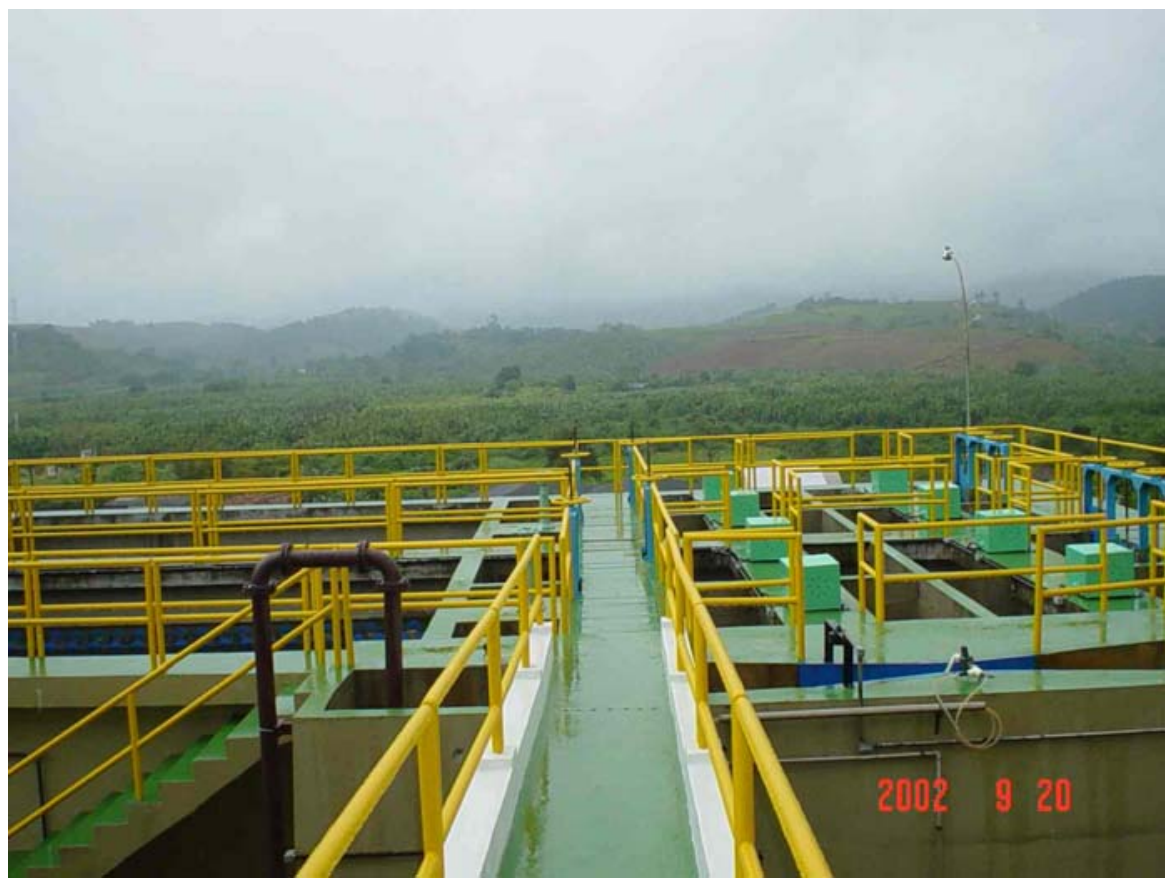

Figura 5.5 - ETA do Município de Cajati. 
Para as amostras de água tratada, a coleta foi realizada na própria estação de tratamento de água, na saída da distribuição da ETA. O procedimento adotado foi o mesmo utilizado para as águas subterrâneas.

Para a determinação de metais, imediatamente após a coleta as amostras foram preservadas com $\mathrm{HNO}_{3} 1: 1$, supra-pur até $\mathrm{pH}<2$. As amostras de água foram coletadas em frascos de polietileno com capacidade de $250 \mathrm{~mL}$, previamente descontaminados (LAXEN e HARRISON, 1981), e preservadas sob refrigeração a $4^{\circ} \mathrm{C}$.

Para a determinação de ânions, as amostras foram coletadas em frascos de polietileno de $250 \mathrm{~mL}$, previamente descontaminados, e preservadas sob refrigeração a $4^{\circ} \mathrm{C}$.

Em campo, no momento da coleta foram medidos os parâmetros $\mathrm{pH}$, temperatura e turbidez.

As amostras de sedimento foram coletadas utilizando-se uma draga do tipo Ekman-Birge, com área igual a $2,5 \mathrm{~cm}^{3}$, em alguns casos devido a dificuldade das coletas, a mesma foi realizada com o auxílio de coletores improvisados. As amostras foram condicionadas em sacos plásticos e mantidas sob refrigeração a $4^{\circ} \mathrm{C}$.

\section{$5.2 \quad$ Análises}

Os elementos avaliados neste estudo foram selecionados atendendose as exigências da Legislação Federal CONAMA 357/05, que estabelece os níveis máximos permissíveis de determinados elementos nos corpos de água, e a Portaria 518/04, que trata da potabilidade.

Após as coletas, as amostras de água e sedimento foram encaminhadas aos laboratórios do CQMA-IPEN, para avaliação de vários parâmetros, a saber: 


\subsubsection{Amostras de água}

Foram avaliados 30 parâmetros, principalmente os parâmetros representativos de potabilidade da água como: $\mathrm{Ag}, \mathrm{Al}, \mathrm{As}, \mathrm{B}, \mathrm{Ba}, \mathrm{Cd}, \mathrm{Co}, \mathrm{Cr}, \mathrm{Ca}$, $\mathrm{Cu}, \mathrm{Fe}, \mathrm{Hg}, \mathrm{K}, \mathrm{Mg}, \mathrm{Mn}, \mathrm{Mo}, \mathrm{Na}, \mathrm{Ni}, \mathrm{P}, \mathrm{Pb}, \mathrm{Se}, \mathrm{Sn}, \mathrm{V}, \mathrm{Zn}, \mathrm{F}^{-} ; \mathrm{Cl}^{-} \mathrm{NO}_{3}{ }^{2-}, \mathrm{PO}_{4}{ }^{3-}$, $\mathrm{SO}_{4}{ }^{2-}$, além do novo parâmetro de potabilidade o $\mathrm{Sb}$.

Em campo foram determinadas as variáveis: $\mathrm{pH}$, temperatura, turbidez.

As amostras foram filtradas em membranas de 0,45 $\mu \mathrm{m}$, e armazenadas a $4^{\circ} \mathrm{C}$ até análise.

As espécies iônicas $\mathrm{F}^{-}, \mathrm{Cl}^{-}, \mathrm{NO}_{3}{ }^{-}, \mathrm{PO}_{4}{ }^{-3} \mathrm{e} \mathrm{SO}_{4}{ }^{-2}$ foram determinados por cromatografia de íons (Cl).

Os elementos $\mathrm{Hg}$, $\mathrm{Se}$, $\mathrm{As}, \mathrm{Sb}, \mathrm{Pb}$ e $\mathrm{Cd}$ foram analisados por espectometria de absorção atômica (AA). Os elementos $\mathrm{Pb}, \mathrm{Cd}$, Sb e Se foram determinados por forno de grafita, o $\mathrm{Hg}$ com atomização por geração de vapor frio e o As por geração de hidreto (FURUSAWA et al, 2002).

Os 18 elementos (Ag, Al, B, Ba, Co, Cr, Ca, Cu, Fe, K, Mg, Mn, Mo, Na, $\mathrm{Ni}, \mathrm{P}, \mathrm{Sn}, \mathrm{V}$ e Zn), foram analisados por especrometria de emissão com fonte de plasma induzido (ICP-OES).

\subsubsection{Amostras de Sedimentos}

As amostras de sedimentos foram distribuídas em bandejas de vidro pyrex para a remoção de materiais indesejáveis, e previamente secas a $60^{\circ} \mathrm{C}$, em estufa com circulação forçada de ar. A essa temperatura, os metais não são arrastados pelo vapor de água.

Após secagem foram realizadas:

- Determinação da Distribuição Granulométrica (CETESB, 1995; NBR 5734). Este ensaio permite a determinação da distribuição 
granulométrica de sedimentos com mineralogia predominantemente quartzo-feldspato, ricos em matéria orgânica ou cimentada por carbonato de cálcio ou ambos. Foram utilizadas 07 peneiras com abertura de $2000 \mathrm{~mm}$ a $0,063 \mathrm{~mm}$, e um tempo de peneiramento de 30 minutos.

- Determinação de metais totais nas amostras de sedimento, utilizando a técnica de Fluorescência de Raios-X.

- Avaliação de elementos na fração disponível - Esta fração foi obtida lixiviando-se a fração fina $(<0,063 \mathrm{~mm})$ do sedimento em solução de $\mathrm{HCl}$ 0,1M, sob agitação por 2 horas. (GATTI, 1997; LEMES, 2001). Este processo permite liberar elementos associados com as frações trocáveis, carbonatos, óxidos de ferro e manganês, além de matéria orgânica (RAURET, 1998).

Após a lixiviação, a amostra foi filtrada e analisada por espectrometria de emissão com plasma induzido (ICP-OES). Como nas amostras de água, foram elaborados programas analíticos para a determinação de todos os elementos de interesse na fração disponível das amostras de sedimentos.

\subsection{Metodologia Analítica}

Todas as análises foram realizadas nos Laboratórios do Centro de Química e Meio Ambiente - CQMA do IPEN-CNEN/SP.

O CQMA possui uma política de qualidade, sendo que alguns laboratórios possuem o Sistema da Qualidade Implantado - ISO-IEC-17025, recebendo auditorias regularmente pelo Sistema Integrado de Qualidade do IPEN.

Os laboratórios tem participado em Programas Interlaboratoriais e Testes de Proficiência, obtendo resultados consistentes.

Além disso, fazem parte do Programa Brasileiro de Metrologia Química, financiado pelos Projetos de Pesquisa do CNPq/FIB - Fase II e III. 


\subsubsection{Determinação de espécies iônicas}

As espécies iônicas $\mathrm{F}^{-}, \mathrm{Cl}^{-}, \mathrm{NO}_{3}{ }^{-}, \mathrm{PO}_{4}^{-3} \mathrm{e} \mathrm{SO}_{4}^{-2}$ foram determinados por cromatografia de íons $(\mathrm{Cl})$. O equipamento utilizado, foi um cromatografo de íons Dionex, DX-120, equipado com sistema supressor auto-regenerante e detetor de condutividade.

Foram obtidas curvas analíticas, para cada elemento, traçando-se a área do pico em função da concentração do analito. As curvas analíticas foram realizadas utilizando metodologia (EPA, 1986; LEMES, 2001), implantada e estabelecida nos laboratórios do CQMA -IPEN.

Na Tabela 5.2, apresentam-se os coeficiente de correlação, limites de detecção (LD) e limite de quantificação (LQ) obtidos.

Tabela 5.2 - Coeficiente de correlação, faixa de concentração, limite de detecção (L.D.) e limite de quantificação (L.Q.) dos analitos iônicos.

\begin{tabular}{|l|c|c|c|c|}
\hline Analito & $\begin{array}{c}\text { Faixa de } \\
\text { concentração } \\
\left(\mathrm{ng} \mathrm{mL} \mathrm{mL}^{-1}\right)\end{array}$ & $\begin{array}{c}\text { Coeficiente } \\
\text { de } \\
\text { correlação }\end{array}$ & $\begin{array}{c}\text { Limite de } \\
\text { Detecção } \\
\left(\mathrm{ng} \mathrm{mL}^{-1}\right)\end{array}$ & $\begin{array}{c}\text { Limite de } \\
\text { Quantificação } \\
\left(\mathrm{ng} \mathrm{mL}^{-1}\right)\end{array}$ \\
\hline $\mathrm{F}^{-}$ & $25-150$ & 0,9988 & 3 & 25 \\
\hline $\mathrm{Cl}^{-}$ & $25-150$ & 0,9996 & 5 & 25 \\
\hline $\mathrm{NO}^{3-}$ & $50-200$ & 0,9958 & 7 & 50 \\
\hline $\mathrm{PO}_{4}{ }^{3-}$ & $25-200$ & 0,9993 & 4 & 25 \\
\hline $\mathrm{SO}_{4}{ }^{2-}$ & $200-1400$ & 0,9995 & 70 & 200 \\
\hline
\end{tabular}

A precisão e a exatidão que afetam os principais parâmetros e a eficiência dos métodos analíticos em termos de variação percentual foram verificadas pela determinação da concentração das espécies de interesse utilizando soluções padrão de referência (DIONEX five anions standard ref. 37157). Os resultados obtidos são apresentados na Tabela 5.3. 
Tabela 5.3 - Reprodutibilidade, precisão e desvio padrão relativo.

\begin{tabular}{|l|c|c|c|c|}
\hline Analito & $\begin{array}{c}\text { Padrão } \\
\left(\mathrm{ng} \mathrm{mL}^{-1}\right)\end{array}$ & $\begin{array}{c}\text { Encontrado } \\
\text { Média } \pm \mathrm{DP} \\
\left(\mathrm{ng} \mathrm{m}{ }^{-1}\right)\end{array}$ & $\begin{array}{c}\text { D.P.R. } \\
(\%)\end{array}$ & $\begin{array}{c}\text { Recuperação } \\
(\%)\end{array}$ \\
\hline $\mathrm{F}^{-}$ & 25 & $24,8 \pm 0,1$ & 0,4 & 99,3 \\
\hline $\mathrm{Cl}^{-}$ & 25 & $24,7 \pm 0,6$ & 2,4 & 98,8 \\
\hline $\mathrm{NO}^{3-}$ & 50 & $49,3 \pm 0,5$ & 1 & 98,7 \\
\hline $\mathrm{PO}_{4}{ }^{3-}$ & 25 & $25,4 \pm 0,2$ & 0,8 & 100,8 \\
\hline $\mathrm{SO}_{4}{ }^{2-}$ & 200 & $205,1 \pm 0,2$ & 0,1 & 100,2 \\
\hline
\end{tabular}

$\mathrm{n}=5$

\subsubsection{Determinação de metais e elementos traços por espectrometria de emissão com plasma de argônio (ICP-OES)}

Os 18 elementos (Ag, Al, B, Ba, Co, Cr, Ca, Cu, Fe, K, Mg, Mn, Mo, Na, $\mathrm{Ni}, \mathrm{P}, \mathrm{Sn}, \mathrm{V}$ e Zn), foram analisados por especrometria de emissão com fonte de palsma induzido (ICP-OES), em amostras de água e sedimento na fração disponível.

O equipamento utilizado foi Spectro Flame M 120 E - Spectro, com tocha axial, que dispõe de recursos em seu programa que possibilitam uma escolha criteriosa das linhas de emissão a serem utilizadas para cada elemento.

Inicialmente, foram elaborados programas analíticos para a determinação de todos os elementos de interesse. Utilizou-se o método da curva analítica na determinação dos elementos, por meio do uso de soluções-padrão multielementares (LEMES, 2001; COTRIM, 2004 e 2005). As condições operacionais do sistema são apresentadas na Tabela 5.4.

Tabela 5.4 - Condições operacionais do sistema (ICP-OES).

\begin{tabular}{|c|c|}
\hline Parâmetros Operacionais & Condições \\
\hline Potência do Plasma & $1200 \mathrm{~W}$ \\
\hline Gás refrigerante (Ar) & $28 \mathrm{~L} \mathrm{~min}^{-1}$ \\
\hline Gás Auxiliar & $1,5 \mathrm{~L} \mathrm{~min}^{-1}$ \\
\hline Pressão do Nebulizador & 2,8 bar \\
\hline Fluxo de amostra & $1,5 \mathrm{~mL} \mathrm{~min}^{-1}$ \\
\hline
\end{tabular}


Foram estabelecidos para cada elemento os coeficientes de correlação, faixa de concentração, limite de detecção e quantificação. Na Tabela 5.5 são apresentados os comprimentos de onda, coeficientes de correlação, limite de detecção e quantificação para as metodologias para análise de águas e sedimentos na fração disponível.

O controle de qualidade analítico baseou-se em análises diárias de soluções padrão e análise em triplicata das amostras.

A validação da metodologia analítica foi efetuada pela análise de material de referência certificado NIST (National Institute of Standards and Technology, Gaithersburg, MA, USA): SRM 1643c (Trace Elements in Water), para a análise de água e SRM 2704 (Buffalo River Sediment), para avaliação do procedimento de lixiviação (disponível) em sedimentos. 
Tabela 5.5 - Comprimento de onda, faixa de concentração, limite de detecção e quantificação para as metodologias utilizadas na análise de águas e sedimentos na fração disponível.

\begin{tabular}{|c|c|c|c|c|c|c|}
\hline & \multicolumn{3}{|c|}{ Águas } & \multicolumn{3}{|c|}{ Sedimentos } \\
\hline Analito & $\lambda(\mathrm{nm})$ & $\begin{array}{l}\text { Faixa de } \\
\text { Concentração } \\
\left(\mathrm{mg} \cdot \mathrm{L}^{-1}\right)\end{array}$ & $\begin{array}{l}\text { Limite de } \\
\text { Quantificação } \\
\left(\mathrm{mg} \cdot \mathrm{L}^{-1}\right)\end{array}$ & $\lambda(\mathrm{nm})$ & $\begin{array}{l}\text { Faixa de } \\
\text { Concentração } \\
\left(\mathrm{mg} \cdot \mathrm{L}^{-1}\right)\end{array}$ & $\begin{array}{l}\text { Limite de } \\
\text { Quantificação } \\
\text { (mg. } \mathrm{L}^{-1} \text { ) }\end{array}$ \\
\hline $\mathrm{Ag}$ & 328,068 & $0,005-6,0$ & 0,005 & 328,068 & $0,3-1,2$ & 0,3 \\
\hline $\mathrm{Al}$ & 167,083 & $0,002-1,2$ & 0,002 & 256,798 & $0,02-1,2$ & 0,02 \\
\hline B & 249,773 & $0,003-1,2$ & 0,003 & - & - & - \\
\hline $\mathrm{Ba}$ & 455,403 & $0,0003-1,2$ & 0,0003 & 455,403 & $0,0005-1,2$ & 0,0005 \\
\hline $\mathrm{Ca}$ & 315,887 & $0,006-12$ & 0,006 & 370,603 & $0,2-120$ & 0,2 \\
\hline Co & 231,498 & $0,05-1,2$ & 0,05 & 238,636 & $0,03-12$ & 0,03 \\
\hline $\mathrm{Cr}$ & 267,716 & $0,03-1,2$ & 0,03 & 267,716 & $0,03-1,2$ & 0,03 \\
\hline $\mathrm{Cu}$ & 324,754 & $0,01-1,2$ & 0,01 & 327,396 & $0,02-1,2$ & - \\
\hline $\mathrm{Fe}$ & 261,187 & $0,02-1,2$ & 0,02 & 273,074 & $0,2-120$ & 0,2 \\
\hline K & 766,491 & $0,001-12$ & 0,001 & 766,491 & $0,001-12$ & 0,001 \\
\hline $\mathrm{Mg}$ & 383,826 & $0,006-12$ & 0,006 & 279,079 & $0,01-60,0$ & 0,01 \\
\hline $\mathrm{Mn}$ & 257,610 & $0,007-1,2$ & 0,007 & 280,106 & $0,02-60,0$ & 0,02 \\
\hline Mo & 202,030 & $0,02-1,2$ & 0,02 & 386,411 & $0,01-1,2$ & 0,01 \\
\hline $\mathrm{Na}$ & 589,592 & $0,002-24$ & 0,002 & 589,592 & $0,002-24$ & 0,02 \\
\hline $\mathrm{Ni}$ & 231,604 & $0,02-1,2$ & 0,02 & 341,476 & $0,05-1,2$ & 0,05 \\
\hline $\mathrm{P}$ & 177,500 & $0,02-12$ & 0,02 & 177,500 & $0,02-1,2$ & 0,02 \\
\hline Sn & 283,999 & $0,02-1,2$ & 0,02 & 283,999 & - & - \\
\hline V & 290,882 & $0,01-1,2$ & 0,01 & 290,882 & $0,01-1,2$ & 0,01 \\
\hline $\mathrm{Zn}$ & 213,856 & $0,003-1,2$ & 0,003 & 334,502 & $0,5-12,0$ & 0,5 \\
\hline
\end{tabular}

Uma comparação entre os valores certificados e os determinados para os materiais de referência analisados, são apresentados nas Tabela 5.6 e Tabela 5.7, demonstrando que as metodologias aplicadas são reprodutíveis. 
Tabela 5.6 - Reprodutibilidade, precisão e desvio padrão relativo para a análise do material de referência NIST - SRM-1643c (Trace Elements in Water), por ICP-OES.

\begin{tabular}{|c|c|c|c|c|}
\hline Elemento & $\begin{array}{c}\text { Valor } \\
\text { Certificado } \\
\left(\mu \mathrm{g} \cdot \mathrm{L}^{-1}\right)\end{array}$ & $\begin{array}{c}\text { Valor } \\
\text { Obtido } \\
\left(\mu g . L^{-1}\right)\end{array}$ & Dpr (\%) & $\begin{array}{c}\text { Recuperação } \\
(\%)\end{array}$ \\
\hline $\mathrm{Al}$ & 114,6 & 114 & 0,9 & 99,9 \\
\hline $\mathrm{Ba}$ & 49,6 & 37,9 & 0,5 & 76,4 \\
\hline $\mathrm{Ca}$ & 36800 & 37500 & 0,5 & 102 \\
\hline $\mathrm{Cd}$ & 12,2 & 13,3 & 1,5 & 109 \\
\hline $\mathrm{Cu}$ & 22,3 & 20 & 5 & 88,8 \\
\hline $\mathrm{Fe}$ & 106,9 & 100 & 2 & 93,8 \\
\hline $\mathrm{Mg}$ & 9400 & 8700 & 0,5 & 92,7 \\
\hline $\mathrm{Mn}$ & 35,1 & 36 & 2,8 & 103 \\
\hline $\mathrm{Ni}$ & 60,6 & 53 & 4 & 88,2 \\
\hline $\mathrm{Zn}$ & 73,9 & 72 & 1,4 & 97,9 \\
\hline
\end{tabular}

Tabela 5.7 - Reprodutibilidade, precisão e desvio padrão relativo para o procedimento de lixiviação com $\mathrm{HCl} 0,1 \mathrm{M}$ do material de referência NIST - SRM-2704.

\begin{tabular}{|l|c|c|c|c|}
\hline \multicolumn{1}{|c|}{ Elemento } & $\begin{array}{c}\text { Valor } \\
\text { Certificado } \\
\left(\mu \mathrm{g} \cdot \mathrm{g}^{-1}\right)\end{array}$ & $\begin{array}{c}\text { Valor Obtido } \\
\left(\mu \mathrm{g} \cdot \mathrm{g}^{-1}\right)\end{array}$ & Dpr (\%) & Lixiviação(\%) \\
\hline $\mathrm{Al}$ & 61100 & 988 & 2,0 & 1,5 \\
\hline $\mathrm{Ca}$ & 26000 & 291000 & 2,8 & 112 \\
\hline $\mathrm{Cu}$ & 98,6 & 56,2 & 1,5 & 56,8 \\
\hline $\mathrm{Fe}$ & 41100 & 5057 & 1,0 & 12,3 \\
\hline $\mathrm{K}$ & 20000 & 140 & 2,1 & 0,7 \\
\hline $\mathrm{Mg}$ & 12000 & 51,2 & 1,5 & 42,5 \\
\hline $\mathrm{Mn}$ & 555 & 348 & 1,5 & 62,7 \\
\hline $\mathrm{Na}$ & 5470 & 112 & 4,5 & 2,0 \\
\hline $\mathrm{Ni}$ & 44,1 & 5,5 & 5,5 & 12,5 \\
\hline $\mathrm{Pb}$ & 161 & 177 & 3,9 & 110 \\
\hline $\mathrm{Zn}$ & 438 & 246 & 0,8 & 56,2 \\
\hline
\end{tabular}

$\mathrm{n}=5$ 


\subsubsection{Determinação $\mathrm{Hg}$, Se, $\mathrm{As}, \mathrm{Sb}, \mathrm{Pb}$ e $\mathrm{Cd}$ por Espectrometria de Absorção Atômica}

Para os elementos $\mathrm{Hg}$, Se, As, Sb, Pb e Cd, cujos limites estabelecidos pela Portaria 158/MS são extremamentes baixos, foi utilizada a técnica de espectrometria de absorção atômica (AAS).

Os elementos $\mathrm{Pb}, \mathrm{Cd}$, Sb e Se foram determinados por forno de grafita (DANTAS et al., 2002), o Hg com atomização por geração de vapor frio (FURUSAWA et al, 2002) e o As por geração de hidreto (FURUSAWA et al, 2002). O equipamento utilizado foi um Espectrômetro de Absorção Atômica AAnalyst 800 - Perkin Elmer.

Foram elaborados programas analíticos para cada elemento individualmente. Utilizou-se o método da curva analítica na determinação dos elementos, utilizando soluções-padrão mono elementares.

Na Tabela 5.8 são apresentados os limites de quantificação e a faixa de trabalho estabelecida.

Tabela 5.8 - Limites de quantificação, e a faixa de trabalho estabelecida (AAS).

\begin{tabular}{|l|c|c|}
\hline Analito & $\begin{array}{c}\text { Faixa de concentração } \\
\left(\mathrm{mg} \mathrm{L}^{-1}\right)\end{array}$ & $\begin{array}{c}\text { Limite de Quantificação } \\
\left(\mathrm{mg} \mathrm{L}^{-1}\right)\end{array}$ \\
\hline $\mathrm{Pb}$ & $0,001-0,1$ & 0,001 \\
\hline $\mathrm{Cd}$ & $0,0001-0,5$ & 0,0001 \\
\hline $\mathrm{Se}$ & $0,001-0,1$ & 0,001 \\
\hline $\mathrm{Sb}$ & $0,001-0,1$ & 0,001 \\
\hline $\mathrm{As}$ & $0,001-0,012$ & 0,001 \\
\hline $\mathrm{Hg}$ & $0,0008-0,006$ & 0,0008 \\
\hline
\end{tabular}

O controle de qualidade analítico baseou-se em análises diárias de soluções padrão e análise em triplicata das amostras. A validação da metodologia foi realizada utilizando o material de referência NIST-SRM 1643c (Trace Elements in Water). 


\subsubsection{Determinação metais e elementos traços por Fluorescência de Raios-X}

Os sedimentos foram analisados com a técnica de fluorescência de raios X com dispersão de comprimento de onda - WDXRF (JENKINS, R, 1998; LACHANCE, G. R., 1995 ; TERTIAN, R., 1991).

O equipamento utilizado foi um Espectrômetro de fluorescência de raios X, sistema WD, Rigaku Co, Modelo RIX 3000, 1996.

As amostras foram preparadas em forma de pastilha prensada de dupla camada, utilizando uma prensa hidráulica e adicionando $10 \%$ de $\mathrm{H}_{3} \mathrm{BO}_{3}$ como material aglutinante. Foi utilizada uma prensa hidráulica, B. Hergoz, modelo HTP40, 1980.

Para excitação e medida da radiação característica dos elementos, melhores condições de parâmetros instrumentais (tensão, corrente, cristal analisador, detector, tempo fixo de contagem e outros) foram estabelecidas no espectrômetro.

Os elementos foram determinados por meio de curvas de calibração individuais. A validação do método foi realizada utilizando materiais de referência da NIST - Soil 2709, aonde foram aplicados testes estatísticos de para avaliação de precisão (testes de Chauvenet e Cocharane) e exatidão ( Z-score).

\subsubsection{Tratamento matemático e estatístico dos dados}

O perfil espacial do corpo de água permite identificar os trechos mais críticos, isto é, onde a qualidade se encontra significativamente comprometida, possibilitando estimar quais são as principais fontes de emissão de poluentes

presentes na bacia em avaliação. Tais fontes podem estar associadas a esgotos domésticos, efluentes industriais ou carga difusas.

Para representar o perfil espacial de cada parâmetro selecionado, ao longo do corpo de água, foram utilizadas representações gráficas do tipo Box-plot. 
Esta metodologia possibilita a visualização da assimetria da distribuição, a faixa de variação dos dados, além de permitir a detecção de possíveis pontos extremos, que podem ou não ser excluídos da análise.

As representações de Box-plot possibilitam ainda a visualização das seguintes grandezas estatísticas: a média, a mediana (divide o conjunto de dados ao meio, deixando metade dos dados abaixo e metade acima dela), o máximo, o mínimo, o $1^{\circ}$ quartil (é o valor que deixa $1 / 4$ das observações abaixo dele), o 30 quartil (é o valorque deixa $3 / 4$ das observações abaixo dele) e os valores extremos da distribuição dosdados. Os pontos extremos podem indicar erros de amostragem, de medida e, mesmo, de transcrição dos dados, ou ainda, simplesmente, um comportamento fora do habitual.

Para melhor avaliar e interpretar a grande base de dados gerada no desenvolvimento de trabalhos de monitoramento e avaliação ambiental, onde tanto o número de casos quanto o número de variáveis são grandes, a análise estatística multivariada (análise descritiva univariada e análise de conglomerados) tem se destacado. Quando duas ou mais variáveis de uma base de dados não são completamente independentes, elas podem ser agrupadas através da criação de uma única nova variável a partir das antigas (GERAB, 1996).

A análise estatística multivariada é uma ferramenta essencial que ajuda a avaliar os resultados, organizar, interpretar e analisar um grande número de dados, como informações sobre as principais tendências da variabilidade das observações: concentração dos diversos metais, localidade da amostragem e sazonalidade. Esse método reduz a complexidade do problema em questão, sem acarretar numa perda relevante de informação, ao mesmo tempo em que evidencia as relações entre as variáveis constituintes da base de dados. Um dos métodos estatísticos muito utilizado é a análise multivariada por componentes principais (ACP), que tem como finalidade identificar novas variáveis, denominadas componentes variáveis, que são combinações lineares das variáveis originais. As novas variáveis são utilizadas para analisar os dados através de algum tipo de geometria ou representação. 
Para interpretar a grande base de dados gerada neste trabalho (Apêndice) e melhor avaliar os resultados obtidos os dados foram divididos em dois grupos de variáveis:

a) variáveis independentes (fatores): comunidades, época de coleta, tipo de amostra analisada; e,

b) variáveis dependentes: variáveis pluviométricas e $\mathrm{pH}$ da água; concentração dos metais: metais (Fe, Mg, Mn, Ca, Al, Co, Ag, Ba, Cr, $\mathrm{Ni}, \mathrm{Cu}, \mathrm{Zn}$, $\mathrm{Cd}$ e $\mathrm{Pb}$ ) e o elemento $\mathrm{P}$ e concentração de elementos iônicos: $\mathrm{F}^{-}, \mathrm{Cl}^{-}, \mathrm{NO}^{3-}, \mathrm{SO}_{4}{ }^{2-}$,

Visando resumir os resultados obtidos, foram construídos três tipos de gráficos - para comparar as concentrações dos elementos analisados nas diversas comunidades nas águas brutas e tratadas, foram construídos box-plot (BUSSAB \& MORETTIN, 1987).

Para avaliar o comportamento das concentrações dos metais ao longo do tempo e verificar esses comportamentos nas diferentes comunidades, foram construídos gráficos onde são representados alisamentos do diagramas de dispersão em função da data de coleta. Esta técnica permite visualizar possíveis tendências das concentrações dos elementos no estudo.

Com o objetivo de agrupar as comunidades com 0 mesmo comportamento das concentrações de cada metal nas coletas, foi utilizada a técnica de análise de agrupamento (BUSSAB et al., 1990). Considerou-se que os dados correspondentes a cada metal, em uma dada comunidade, correspondem à uma realização da variável multidimensional.

A análise foi feita separadamente para as amostras de água bruta, tratada, manancial de serra e poço, utilizando o método da Centróide (que calcula a distância entre dois clusters com a distância entre sua médias para todos os itens, a distância a qual o cluster está combinado pode diminuir de um estágio para outro) e a distância Euclidiana (a diferença entre dois itens é o quadrado da raiz da soma do quadrado das diferenças no valor para cada variável). As frações sobrenadante e intersticial possuem um número menor de valores coletados, portanto, não foi possível realizar a análise de agrupamentos. Os resultados 
obtidos por essa técnica foram analisados através de sua representação gráfica denominada dendrogramas e/ou projeção dos pontos de coleta.

Estudos para o desenvolvimento de métodos que permitam a eficaz gestão do conhecimento constituem uma tendência nos estudos ambientais.

A informação tratada resultante da aplicação de tecnologias da informações como redes neurais, Data warehousing e Data Mining possibilitam cnstruir um modelo lógico das informações disponíveis nas aplicações futuras.

Dessa forma, foi utilizada a análise discriminante e a análise dos melhores predictores aplicando-se os recursos do Statistica Data Mining. 
A Unidade de Gerenciamento de Recursos Hídricos - UGRHI -11 Vale do Ribeira e Litoral Sul possue 43 sistemas produtores de água para abastecimento público operados pela SABESP - Unidade de Negócios Vale do Ribeira - RR, que utilizam mananciais superficiais, mananciais de serra e poços para a captação de água.

Destes sistemas, 18 são captações superficiais seguido de tratamento completo (pré-desinfecção, coagulação, floculação, decantação, filtração, correção de $\mathrm{pH}$, desinfecção e fluoretação), em suas respectivas estações de tratamento de água (ETA's).

Outros 10 sistemas utilizam mananciais de serra para captação de água, localizados em áreas preservadas; além de 15 captações subterrâneas realizadas em poços profudos. Para estes dois tipos de mananciais o tratamento consiste básicamente em cloração e fluoretação.

Nos manancias superficiais foram monitoradas a qualidade da água do corpo de água (água bruta) e a qualidade da água produzida pela ETA's. Nos mananciais de serra e de poço foram monitoradas a qualidade da água captada. Além disso, foram avaliados o sedimento de fundo dos mananciais superficiais e de serra.

Os dados apresentados representam informações sobre os mananciais monitorados por um período de um ano.

Os dados obtidos foram avaliados visando:

- Comparar as concentrações dos metais e elementos traço, na água bruta e tratada avaliando a eficiência dos processos de 
tratamento, de modo a fornecer subsídios a um programa de proteção a saúde pública e conservação e proteção ao meio ambiente.

- Obter informações sobre a distribuição espacial e temporal da ocorrência e abundancia dos elementos avaliados nas áreas de captação para abastecimento público no Vale do Ribeira - São Paulo.

- Avaliar a qualidade dos mananciais do Vale do Ribeira, compreendendo as etapas de monitoramento, uso e tratamento dos resultados, criando um banco de dados para suporte a programas futuros.

\subsection{Avaliação de Metais e elementos-traço.}

\subsubsection{Manancial de Serra}

As Figura 6.1 a Figura 6.5 apresentam os resultados das distribuição dos metais, elementos-traço e íons avaliados nas amostras de água dos mananciais de serra. Como comparativo destaca-se no gráfico os limites estabelecidos pela Resolução CONAMA 357/05, e a Portaria 518/04.

A Tabela A1 (Apendice A) apresenta os resultados da variação das concentrações dos metais, elementos traço e íons avaliados nas amostras de água dos mananciais de serra aplicando análise estatística multivariada. 

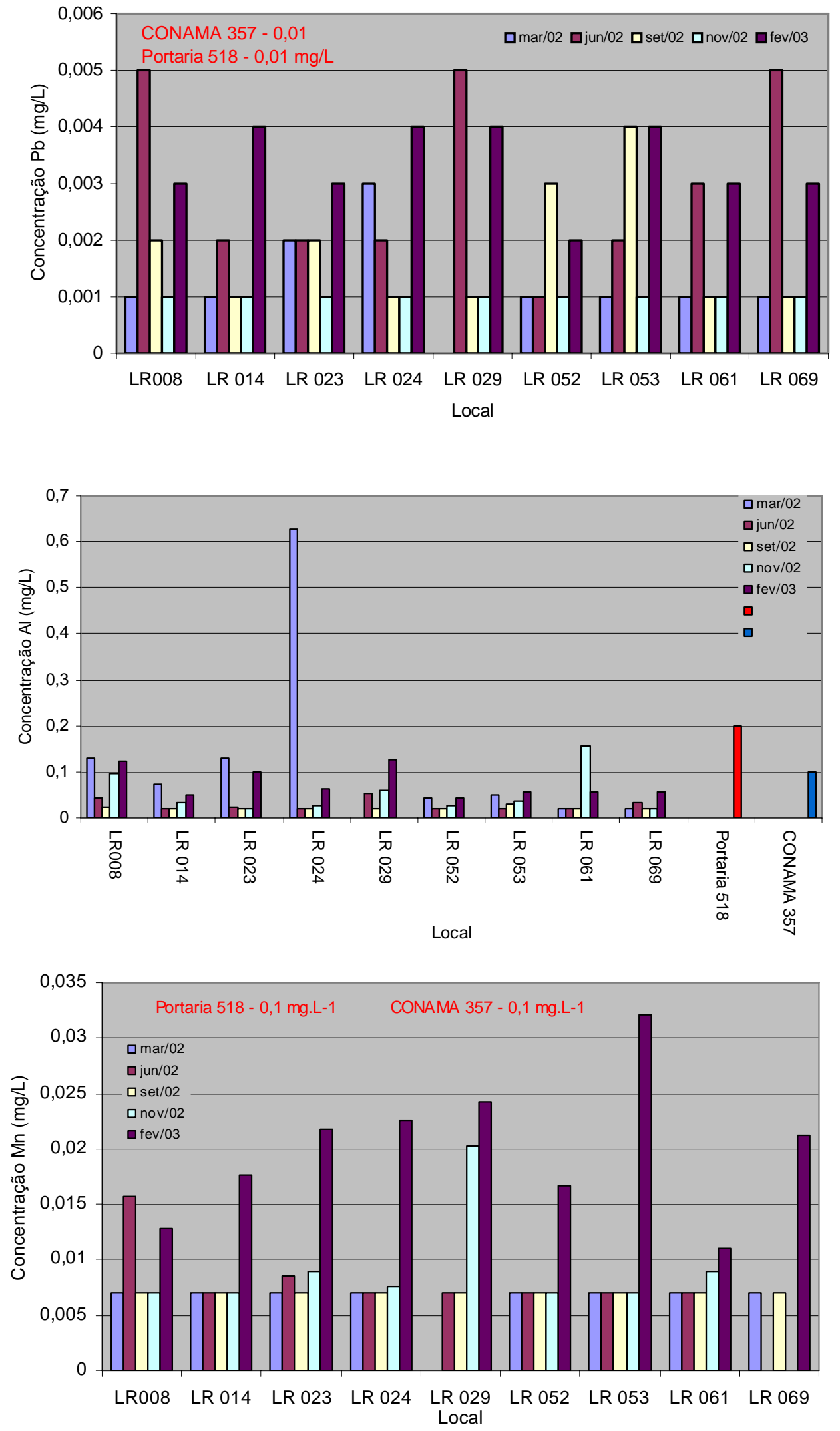

Figura 6.1 - Distribuição dos elementos chumbo, alumínio e manganês nas amostras de água captada em manancial de serra. 

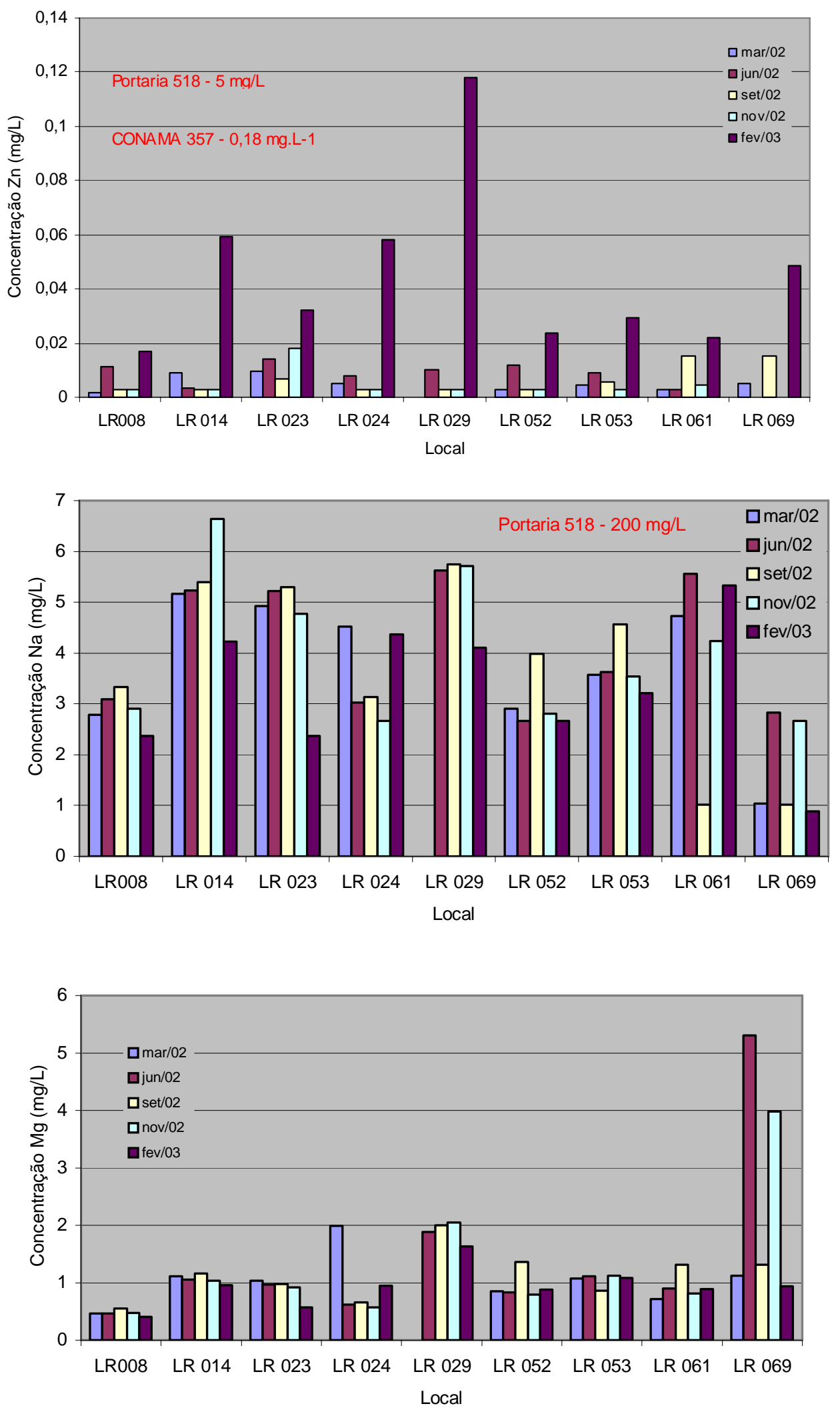

Figura 6.2 - Distribuição dos elementos zinco, sódio e magnésio nas amostras de água captada em manancial de serra. 


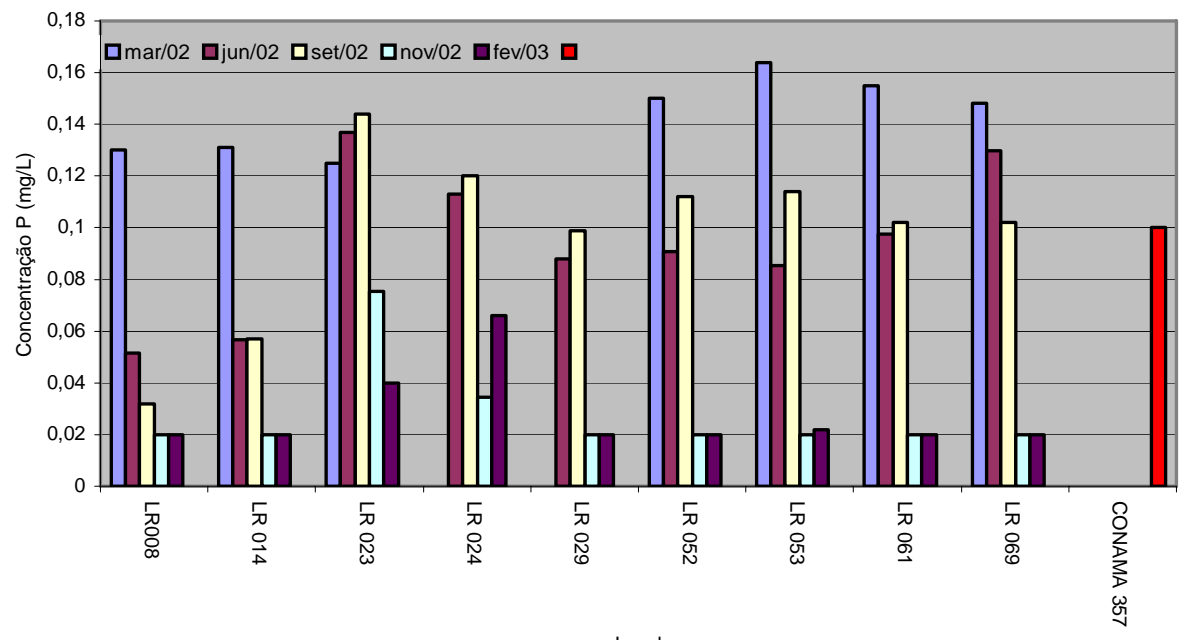

Local
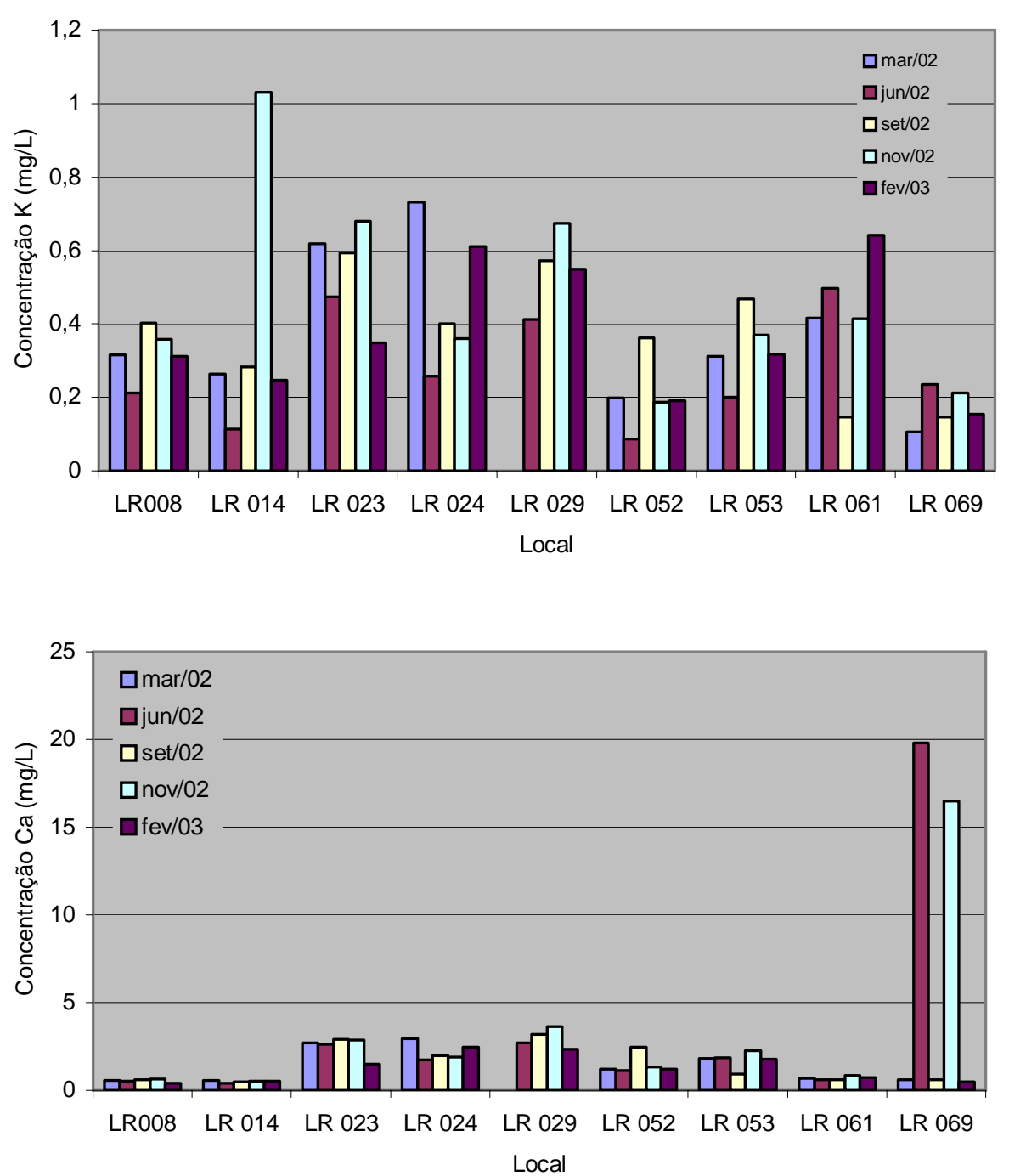

Figura 6.3 - Distribuição dos elementos fósforo, potássio e cálcio nas amostras de água captada em manancial de serra. 

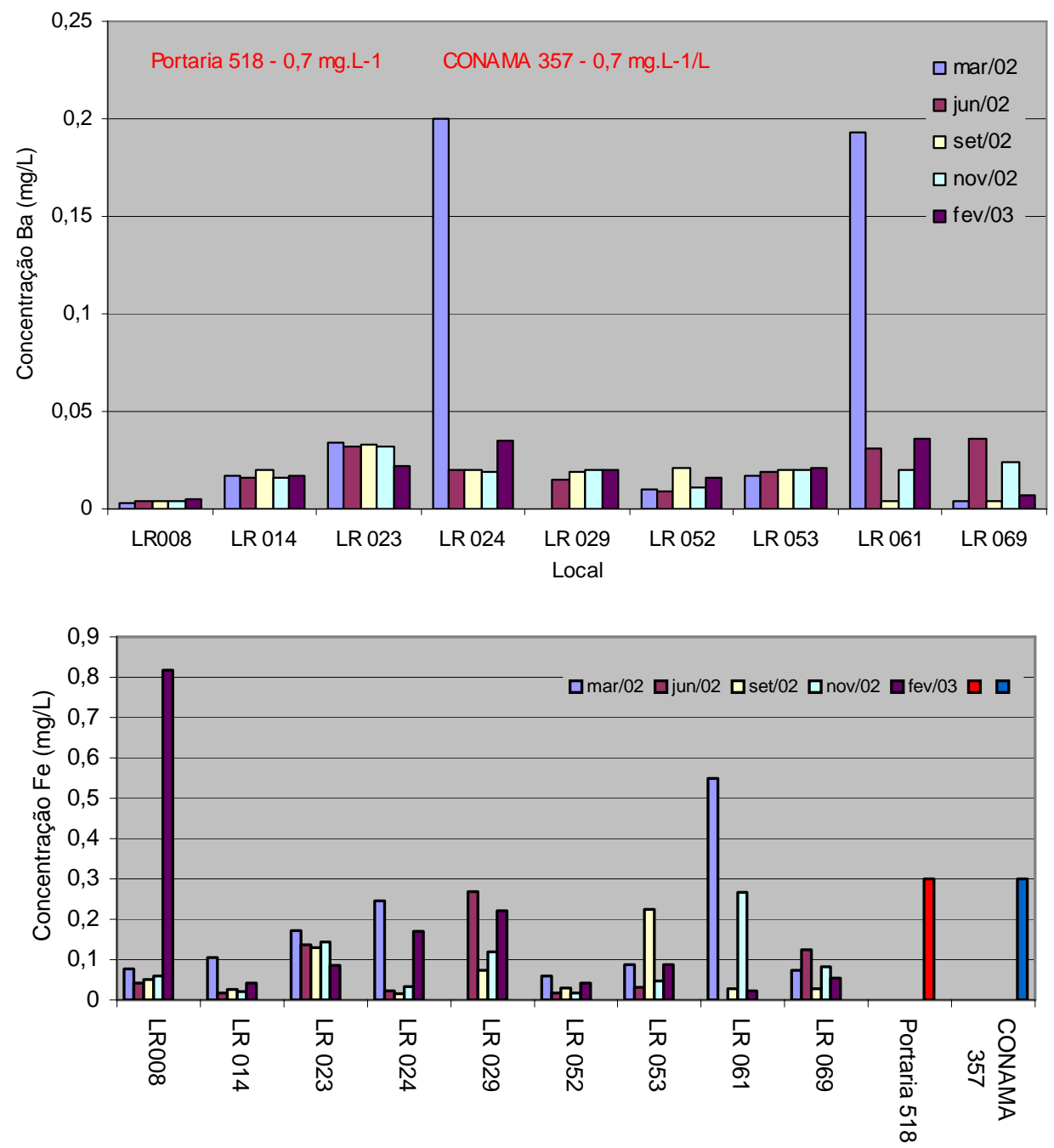

Local

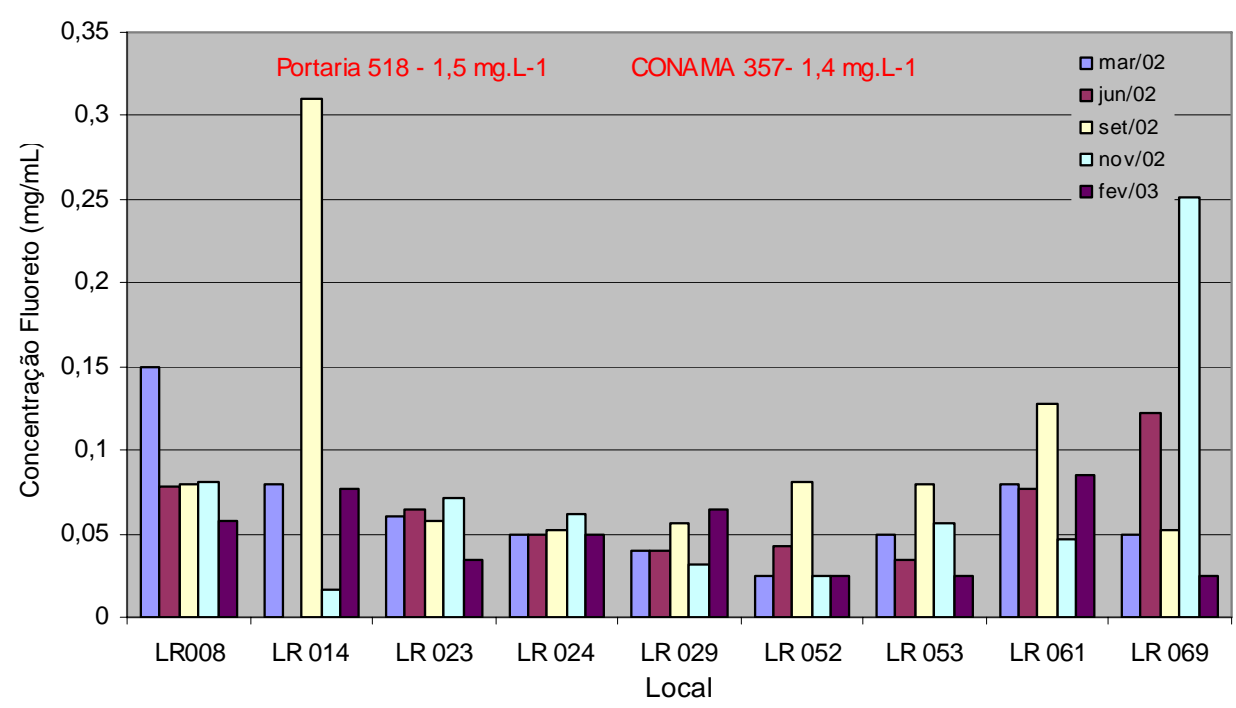

Figura 6.4 - Distribuição dos elementos bário, ferro e fluoreto nas amostras de água captada em manancial de serra. 

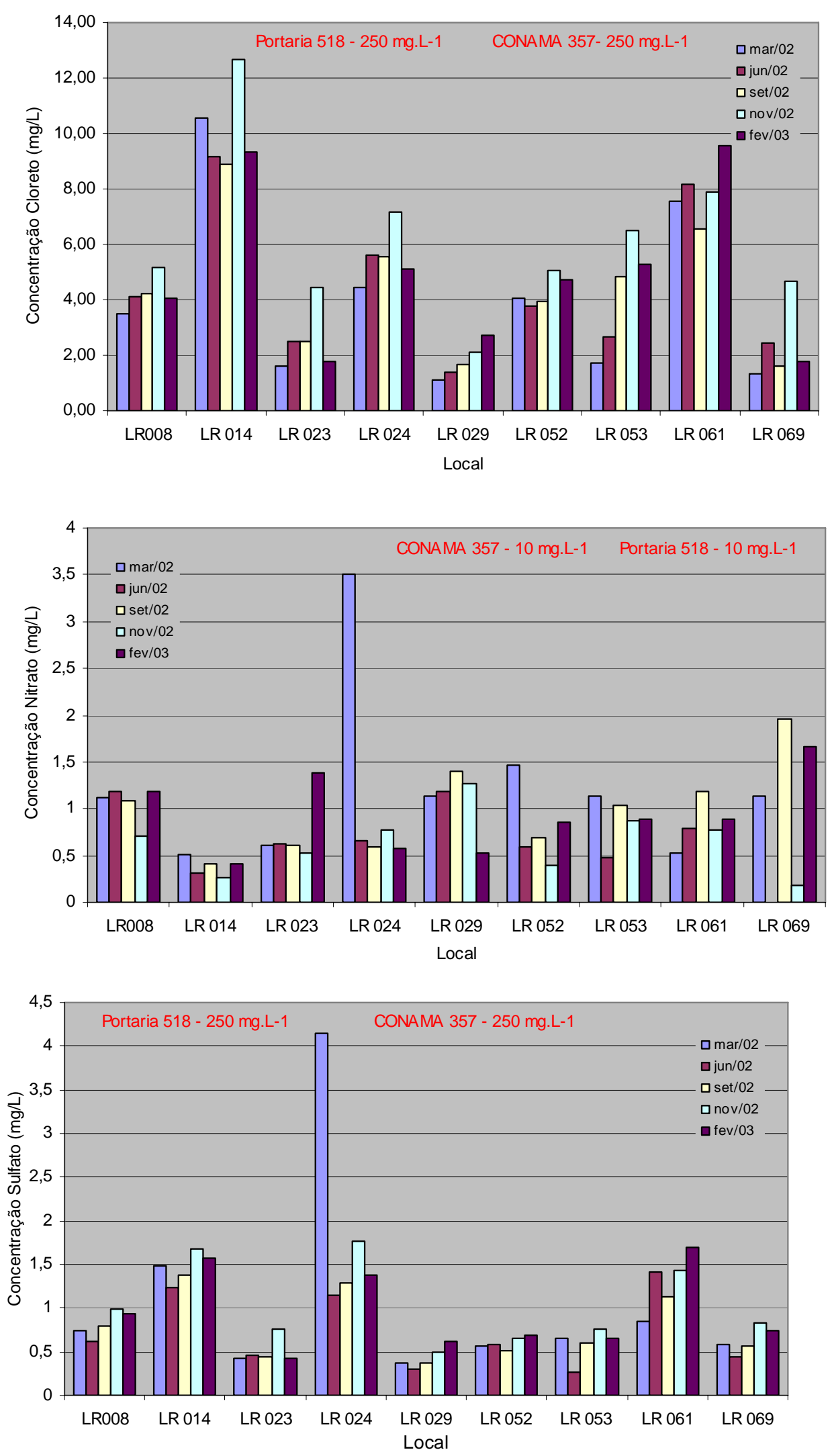

Figura 6.5 - Distribuição dos elementos sulfato, cloreto e nitrato nas amostras de água captada em manancial de serra. 
Avaliando-se as medidas das concentrações dos elementos apresentadas, observa-se que, com exceção do Al, P e Fe, a distribuição dos elementos atende os limites da Resolução CONAMA 357/05, no que se refere ao enquadramento do corpo de água, e a Portaria 518/04 quanto à potabilidade.

Para os elementos Al, P e Fe, foram verificados valores em desacordo com as duas Legislações. A Tabela 6.1, apresenta um resumo dos resultados quanto à razão entre o número de valores que não estão de acordo com a Legislação e o número de coleta realizada para esses parâmetros.

Nas amostras de água de manancial de serra analisadas, não foi observada distribuição para os elementos $\mathrm{Cr}, \mathrm{Ni}, \mathrm{Cu}, \mathrm{Mo}, \mathrm{Ag}, \mathrm{Sn}, \mathrm{V}, \mathrm{Co}, \mathrm{As}$, Se, $\mathrm{Sb}, \mathrm{Hg}, \mathrm{Cd}$ e fosfato, sendo o limite de quantificação da técnica analítica utilizada, o valor determinado.

As concentrações de Al variaram de 0,02 a 0,63 mg. $\mathrm{L}^{-1}$, sendo as maiores concentrações encontradas em Iporanga $\left(0,63 \mathrm{mg} \cdot \mathrm{L}^{-1}\right)$ e Colonização $\left(0,129 \mathrm{mg} \cdot \mathrm{L}^{-1}\right)$, ambos no município de Juquiá, em Barra do Azeite $\left(0,131 \mathrm{mg} \cdot \mathrm{L}^{-1}\right)$ e no município de Cajati.

Para o Al, o único ponto que não atendeu aos padrões de potabilidade $\left(0,2 \mathrm{mg} \cdot \mathrm{L}^{-1}\right)$ foi o manancial Iporanga. Todos os outros mananciais apresentam concentrações de Al dentro dos padrões de Potabilidade, porém, não atendem a Resolução CONAMA 357 no enquadramento do corpo de água $\left(0,1 \mathrm{mg} \cdot \mathrm{L}^{-1}\right)$.

Em praticamente todos os mananciais de serra foram determinados valores de fósforo em desacordo com as Legislações. O teor de fósforo no manancial de serra variou de 0,02 a $0,164 \mathrm{mg} \cdot \mathrm{L}^{-1}$. A maior concentração foi encontrada em Raposo Tavares, município de Itariri.

Para o ferro, foram encontrados valores em desacordo na Barra do Azeite, município de Cajati, e Pedrinhas em Ilha Comprida, com valores de 0,818 $\mathrm{mg} \cdot \mathrm{L}^{-1}$ e $0,550 \mathrm{mg} \cdot \mathrm{L}^{-1}$ respectivamente. 
Tabela 6.1 - Razão entre o número de valores que não estão de acordo com a legislação (Portaria 158/04 e CONAMA 357) e o número de coletas realizadas nos mananciais de serra.

\begin{tabular}{|l|c|c|c|}
\hline Comunidade & Al & $\mathrm{P}$ & $\mathrm{Fe}$ \\
\hline RR 008 & $02 / 05$ & $01 / 05$ & $01 / 05$ \\
\hline RR014 & - & $01 / 05$ & $00 / 05$ \\
\hline RR023 & $01 / 05$ & $03 / 05$ & $00 / 05$ \\
\hline RR 024 & $01 / 05$ & $02 / 05$ & $00 / 05$ \\
\hline RR 029 & $01 / 05$ & - & $00 / 05$ \\
\hline RR 030 & - & - & $00 / 05$ \\
\hline RR 052 & - & $02 / 05$ & $00 / 05$ \\
\hline RR 053 & - & $02 / 05$ & $00 / 05$ \\
\hline RR 061 & $01 / 05$ & $01 / 05$ & $01 / 05$ \\
\hline RR 069 & - & $02 / 05$ & - \\
\hline
\end{tabular}

Nos mananciais de serra foi observada distribuição para $0 \mathrm{~Pb}$, em concentrações baixas, variando de 0,001 a 0,005 mg. $\mathrm{L}^{-1}$. As maiores concentrações nas amostras de água foram verificadas no período de seca.

\subsubsection{Manancial Subterrâneo (Poços)}

Foram avaliadas amostras de água de 15 poços profundos localizados no Vale do Ribeira. Dos 18 municípios atendidos, 10 utilizam captações em poços além das capatações superficiais.

As figuras: Figura 6.6 a Figura 6.10, apresentam os resultados da distribuição dos metais, elementos traço e íons avaliados nas amostras. Como comparativo destaca-se no gráfico os limites estabelecidos pela Portaria 518/04, para avaliar a qualidade das águas subterrâneas da região, assim como sua qualidade para abastecimento público. 

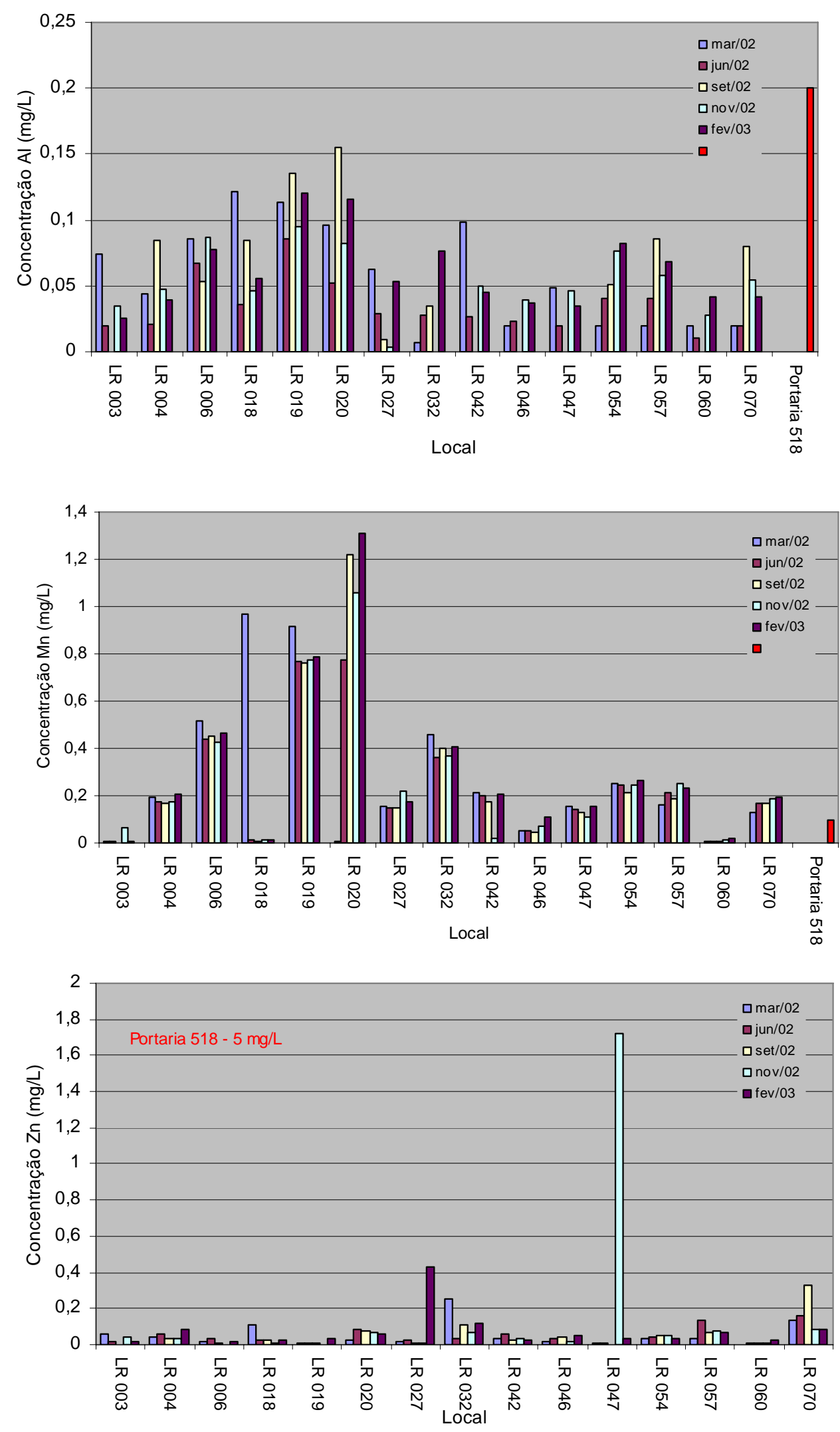

Figura 6.6 - Distribuição dos elementos alumínio, manganês e zinco em amostras de água subterrânea. 

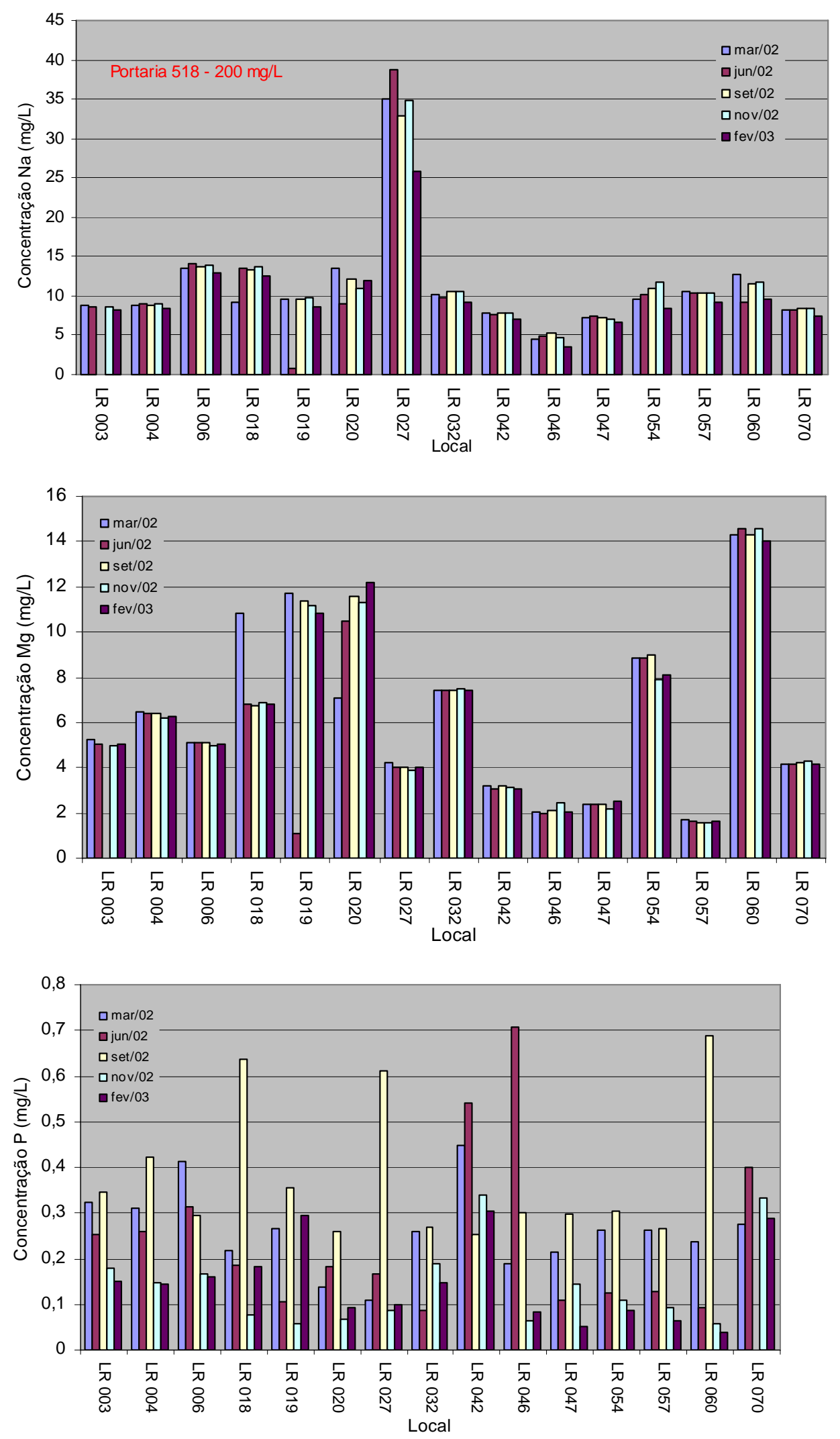

Figura 6.7 - Distribuição dos elementos sódio, magnésio e fósforo em amostras de água subterrânea. 

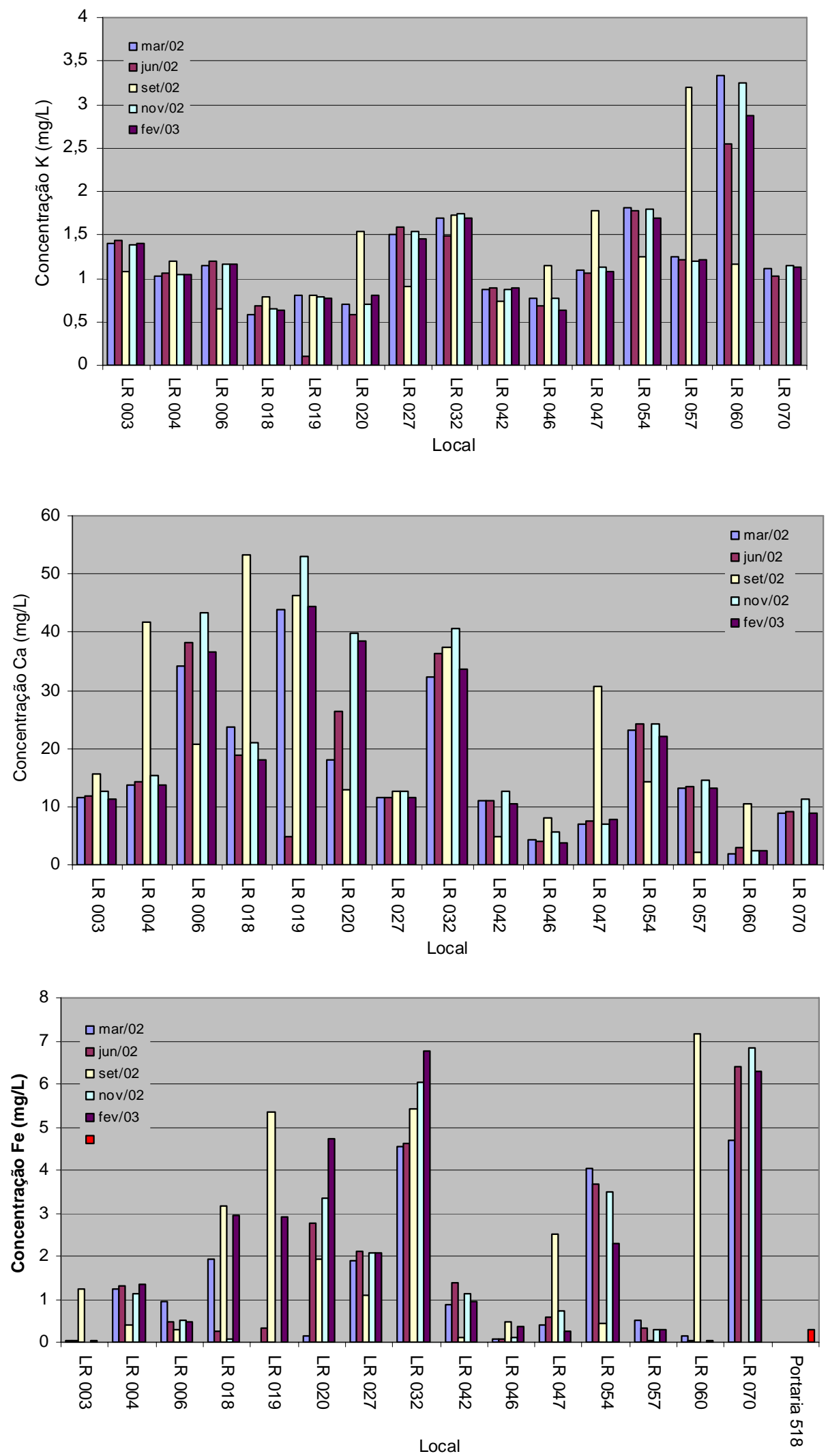

Figura 6.8 - Distribuição dos elementos potássio, cálcio e ferro em amostras de água subterrânea. 

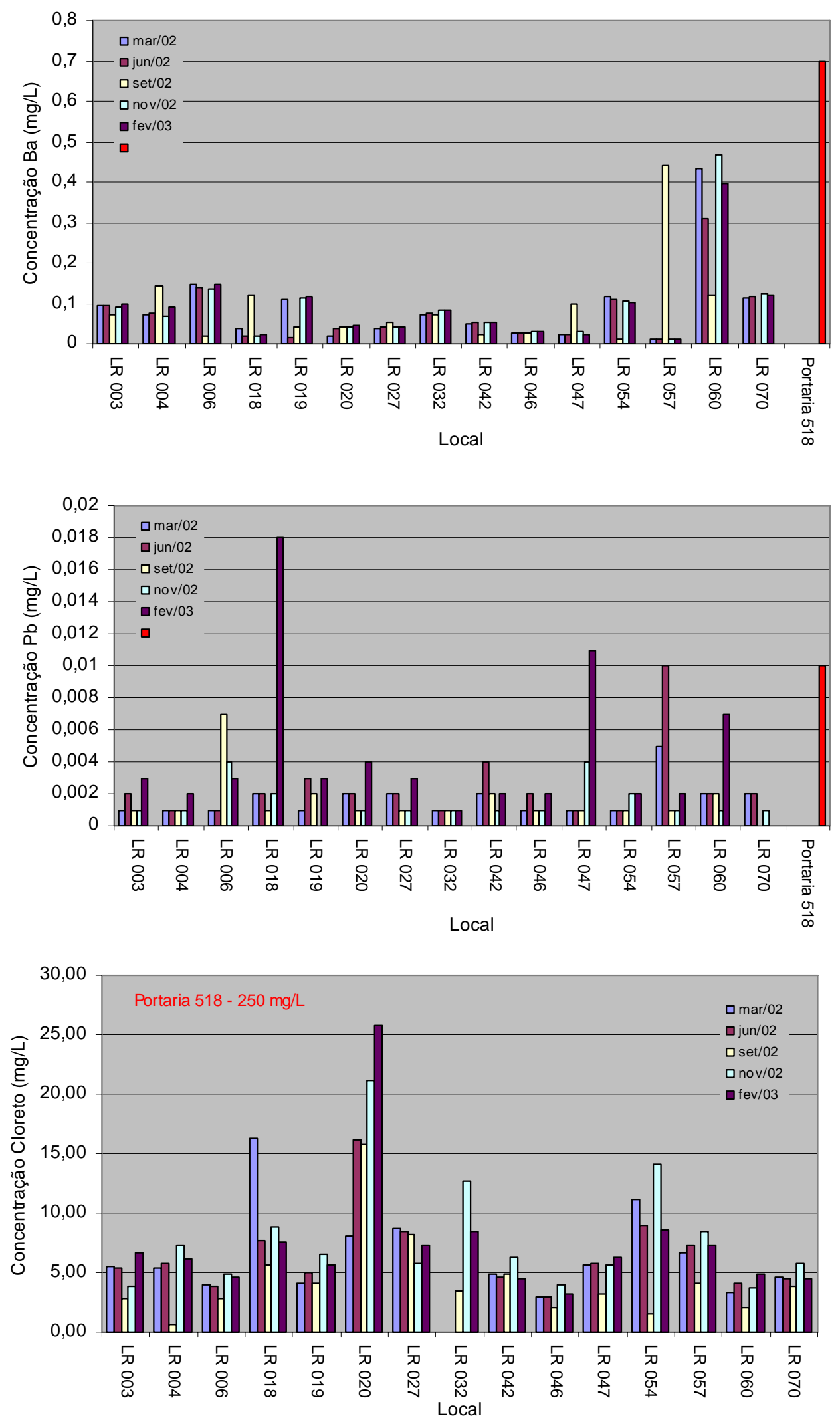

Figura 6.9 - Distribuição dos elementos bário, chumbo e cloreto em amostras de água subterrânea. 

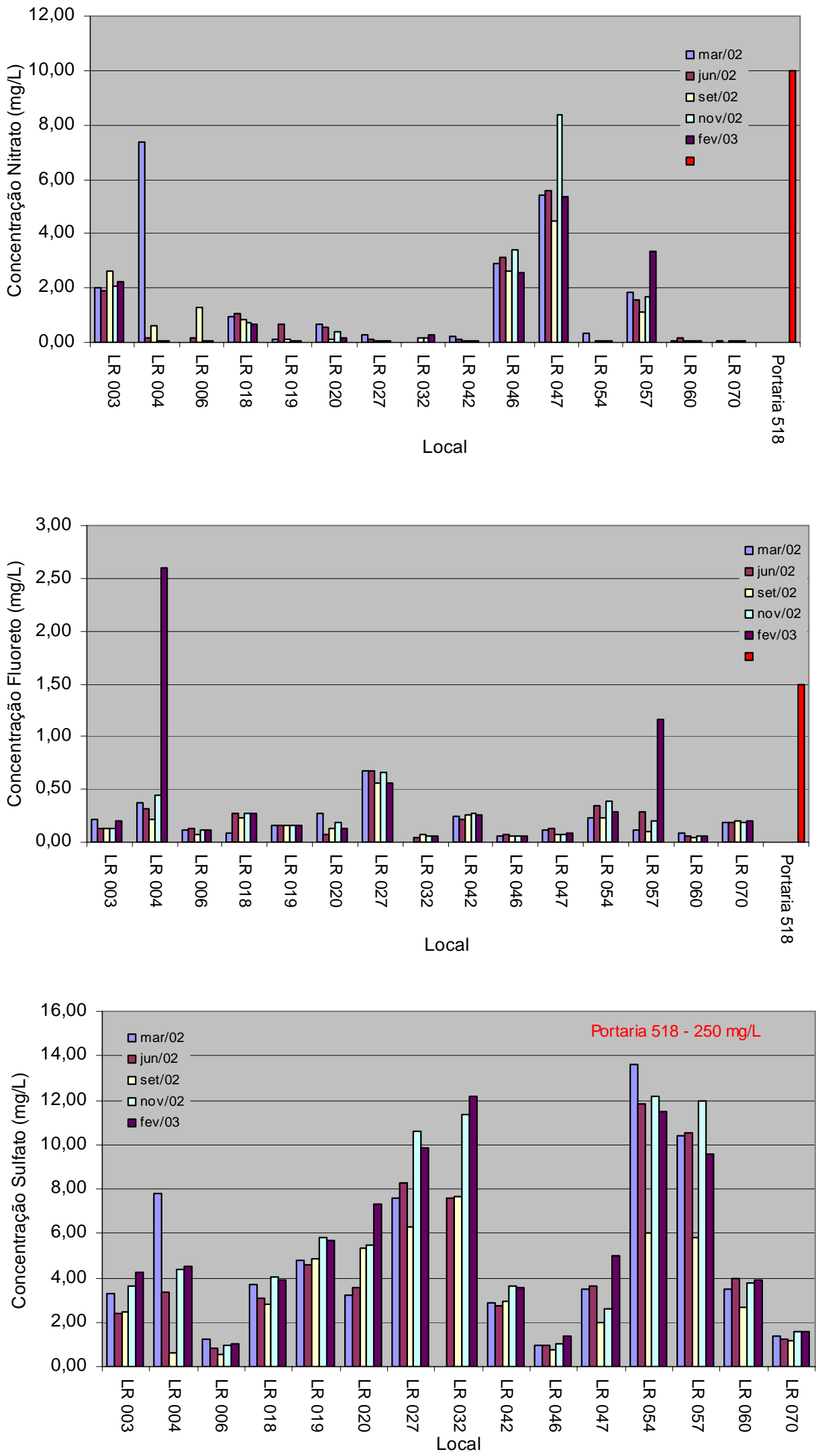

Figura 6.10 - Distribuição dos elementos nitrato, fluoreto e sulfato em amostras de águas subterrâneas. 
A Tabela A2 (Apendice A) apresenta os resultados da variação das concentrações dos parâmetros avaliados nas amostras de água subterrâneas.

Como nos mananciais de serra, não foi observada distribuição para os elementos Cr, Ni, Cu, Mo, Ag, Sn, V, Co, As, Se, Sb, Hg, Cd e do fosfato, durante todo o período do monitoramento.

Concentrações de $\mathrm{Mn}$ em desacordo com a legislação de potabilidade foram encontrados em praticamente todos os poços durante o monitoramento, exceção para o poço Serrote, em Registro, onde todas as avaliações realizadas atenderam ao padrão de potabilidade. Aproximadamente 64\% das amostras analisadas apresentaram valores em desacordo com a Legislação. Nas águas de poços a concentração de manganês variou de $0,007 \mathrm{mg} \cdot \mathrm{L}^{-1}$ a $1,21 \mathrm{mg} \cdot \mathrm{L}^{-1}$, sendo o maior valor encontrado no poço Barra do Batatal em Eldorado.

A concentração de ferro total nas águas subterrâneas da região variou de $0,01 \mathrm{mg} \cdot \mathrm{L}^{-1}$ a $5,42 \mathrm{mg} \cdot \mathrm{L}^{-1}$ (Santa Rita - Miracatu). Em torno de $68 \%$ das amostras avaliadas apresentaram valores acima do estabelecido para potabilidade.

Essas altas concentrações de Fe e Mn nas águas subterrâneas devem estar associadas à matriz mineralógica da região.

Foi observada uma distribuição para o $\mathrm{Pb}$ nas águas de poços, com valores variando de 0,001 a 0,02 mg. $\mathrm{L}^{-1}$. Apenas duas amostras isoladas apresentaram valores acima do estabelecido como padrão de potabilidade. Bairro do Braço, no município de Eldorado e Despézio no município de São Lourenço da Serra, com valores $0,02 \mathrm{mg} \cdot \mathrm{L}^{-1}$ e $0,01 \mathrm{mg} \cdot \mathrm{L}^{-1}$ respectivamente.

A Tabela 6.2, apresenta um resumo dos resultados quanto à razão entre o número de valores que não estão de acordo com a Legislação e o número total de análises realizadas para esses parâmetros. 
Tabela 6.2 - Razão entre o número de valores que não estão de acordo com a Legislação e o número total de análises realizadas para esses parâmetros.

\begin{tabular}{|l|l|l|l|}
\hline Manancial & Mn & Fe & $\mathrm{Pb}$ \\
\hline RR 003 & - & $01 / 05$ & - \\
\hline RR 004 & $05 / 05$ & $05 / 05$ & - \\
\hline RR 006 & $05 / 05$ & $05 / 05$ & - \\
\hline RR 018 & $01 / 05$ & $03 / 05$ & $01 / 05$ \\
\hline RR 019 & $05 / 05$ & $02 / 05$ & - \\
\hline RR 020 & $05 / 05$ & $04 / 05$ & - \\
\hline RR 027 & $05 / 05$ & $05 / 05$ & - \\
\hline RR 032 & $05 / 05$ & $05 / 05$ & - \\
\hline RR 042 & $04 / 05$ & $04 / 05$ & - \\
\hline RR 046 & $01 / 05$ & $02 / 05$ & - \\
\hline RR 047 & $05 / 05$ & $04 / 05$ & $01 / 05$ \\
\hline RR054 & $05 / 05$ & $04 / 05$ & - \\
\hline RR 060 & $01 / 05$ & $01 / 05$ & - \\
\hline RR 070 & $05 / 05$ & $04 / 04$ & - \\
\hline
\end{tabular}

Teores elevados de $\mathrm{Mg}$ e $\mathrm{Ca}$ foram encontrados em todas as amostras de água subterrânea, com valores variando de 2,0 a 14,6 mg. $\mathrm{L}^{-1}$ e 1,83 a 53,2 mg. $\mathrm{L}^{-1}$, respectivamente. Os teores elevados de $\mathrm{Ca}$ e Mg (dureza) podem ocorrer nos aqüíferos subterrâneos sedimentares e cristalinos.

\subsubsection{Manancial Superficial - Água Bruta e Tratada}

Foram avaliados os 18 mananciais superficiais do Vale do Ribeira, bem como amostras de água tratada das estações de tratamento de água (ETA’s).

As figuras: Figura 6.11 a Figura 6.15 apresentam os resultados da distribuição dos parâmetros avaliados nas captações superficiais (água bruta). Também são apresentados nas figuras os limites estabelecidos pela Resolução CONAMA 357/05, e a Portaria 518/04. Nessas Figuras, pode-se observar a distribuição de cada elemento em todas as captações bem como a distribuição da água tratada. 

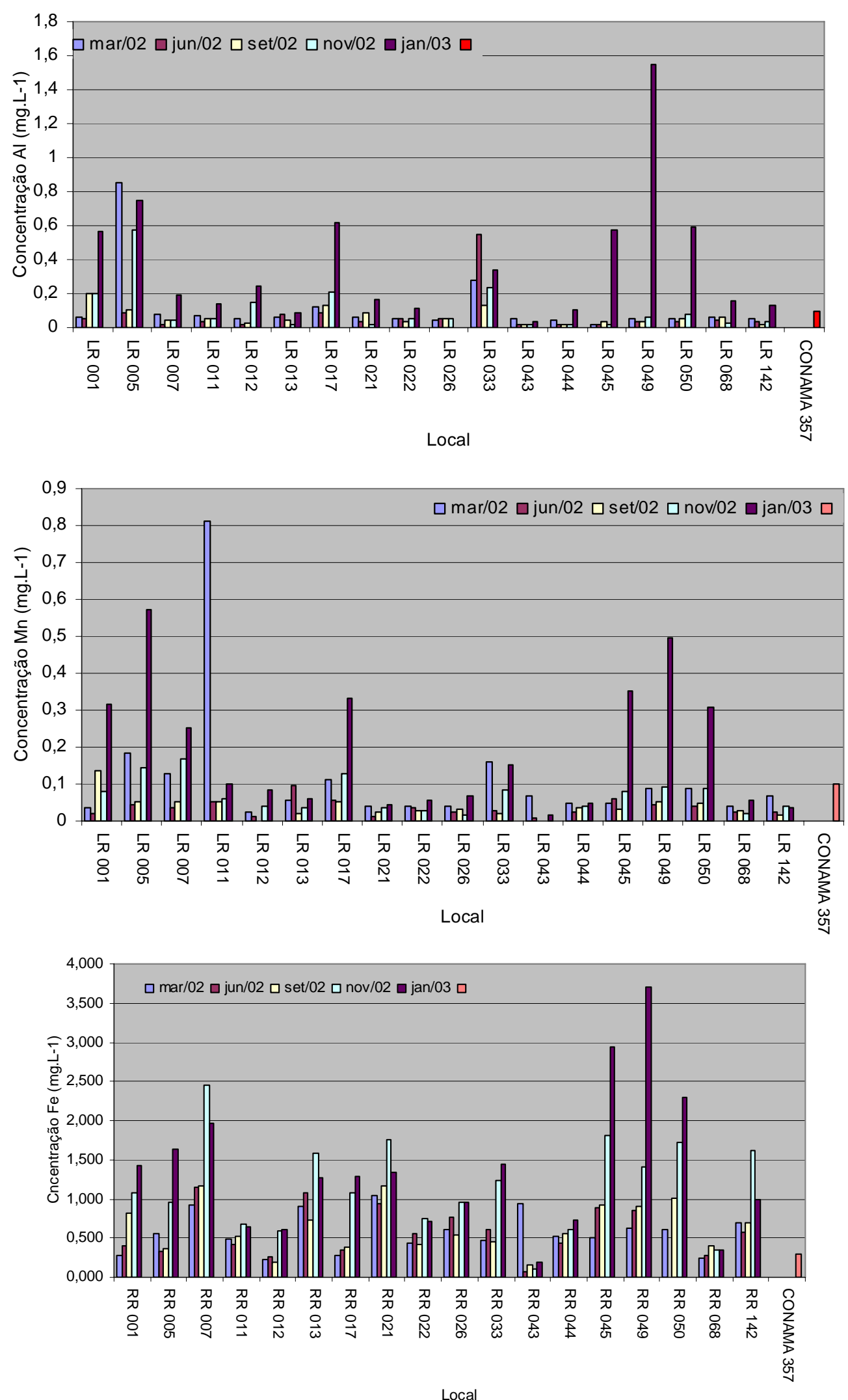

Figura 6.11 - Distribuição dos elementos Al, Mn e Fe em amostras de água bruta. 

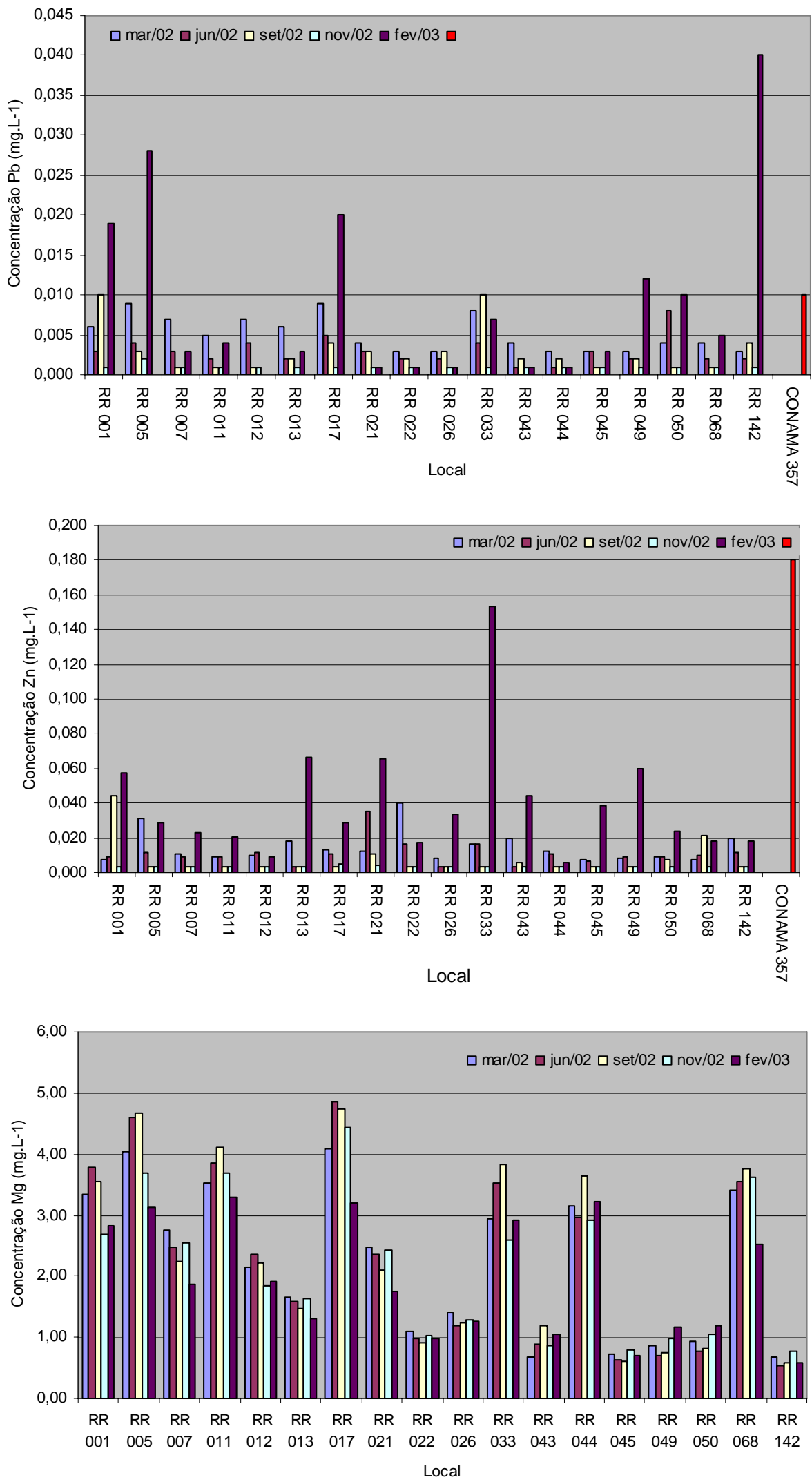

Figura 6.12 - Distribuição dos elementos chumbo, zinco e magnésio em amostras de água bruta. 

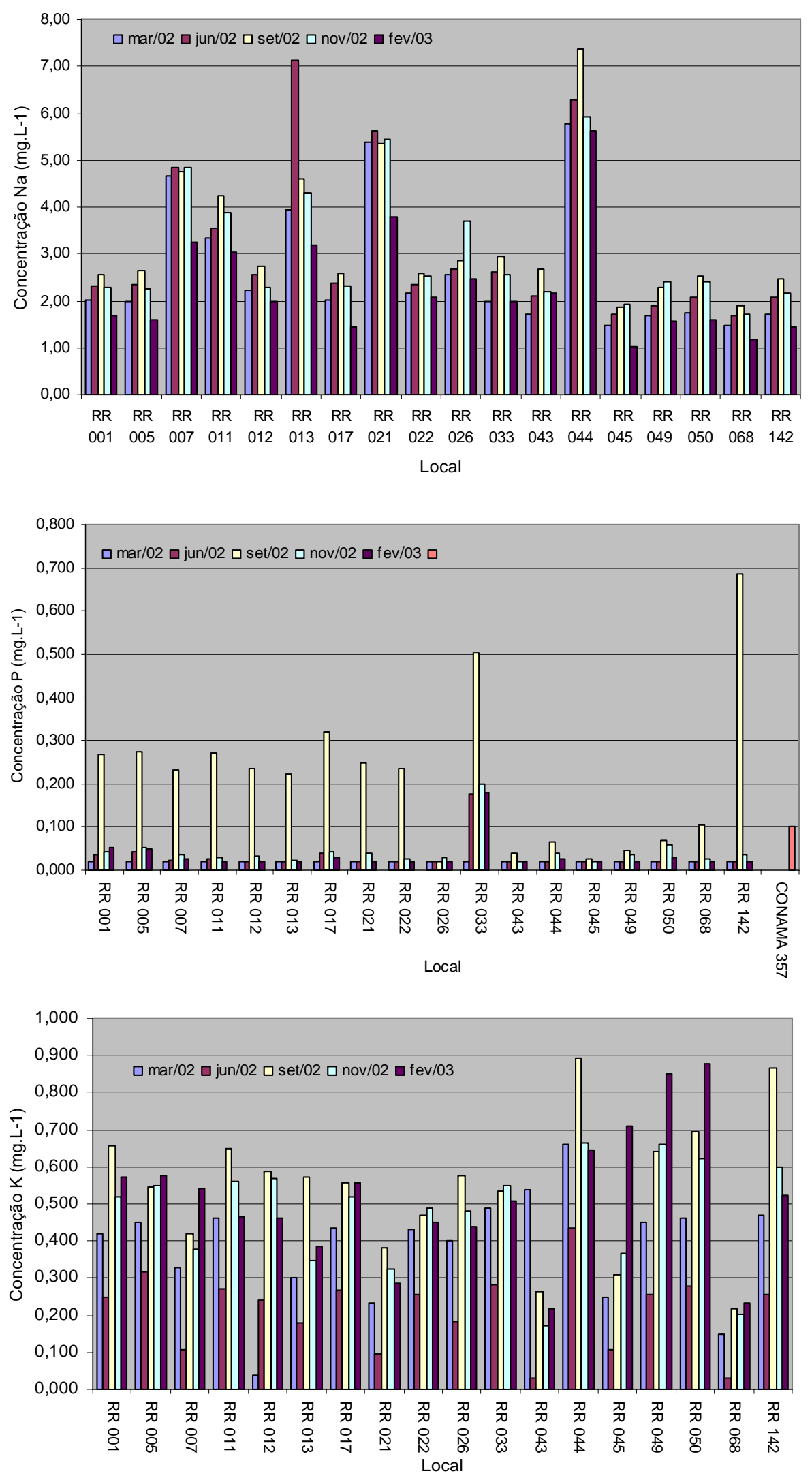

Figura 6.13 - Distribuição dos elementos sódio, fósforo e potássio em amostras de água bruta. 

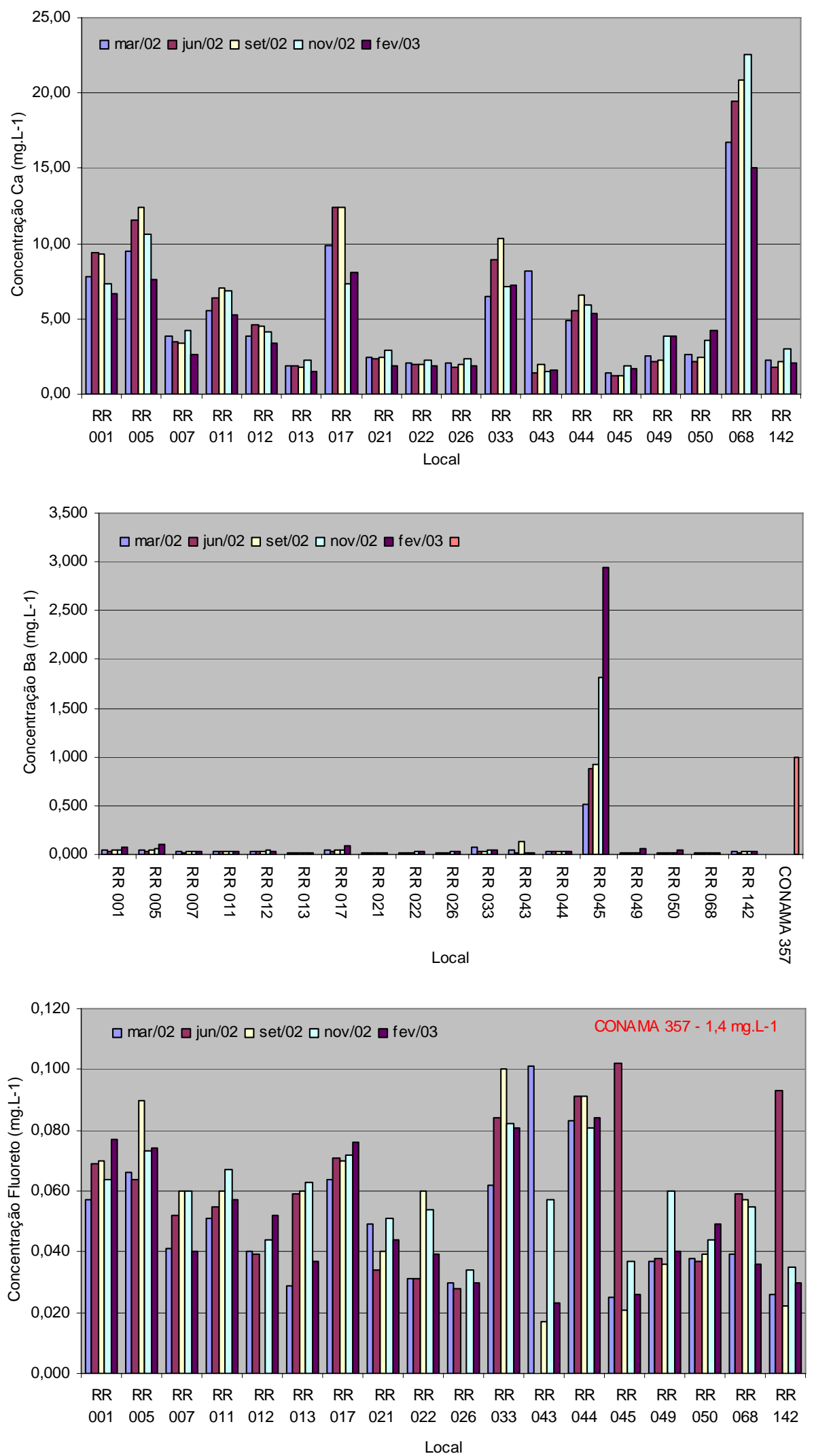

Figura 6.14 - Distribuição dos elementos cálcio, bário e fluoreto em amostras de água bruta. 

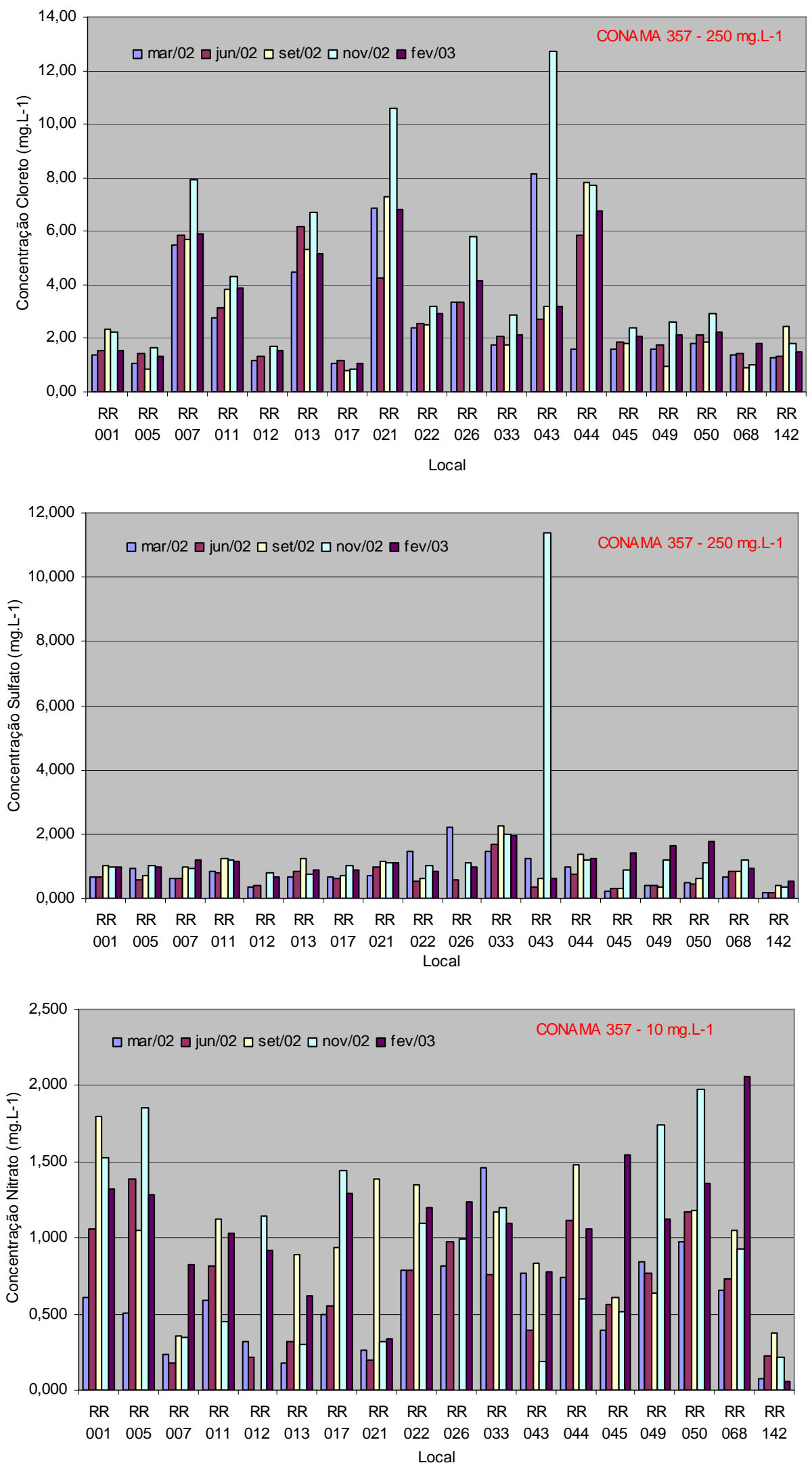

Figura 6.15 - Distribuição dos elementos cloreto, sulfato e nitrato em amostras de água bruta. 
Não foi observada, para as amostras de água bruta, distribuição para os elementos $\mathrm{Cr}, \mathrm{Ni}, \mathrm{Cu}, \mathrm{Mo}, \mathrm{Sn}, \mathrm{V}, \mathrm{Co}, \mathrm{As}, \mathrm{Se}, \mathrm{Sb}, \mathrm{Hg}$ e Cd, durante todo o monitoramento.

Os elementos B e Ag apresentaram medidas em alguns sistemas, nas coletas do período de seca (junho/02), mas com valores um pouco acima do limite de quantificação dos elementos.

As distribuições dos elementos $\mathrm{Al}, \mathrm{Mn}, \mathrm{Fe}, \mathrm{P}$ e $\mathrm{Pb}$ apresentaram valores em desacordo com a classificação do CONAMA 357 para rios Classe II. No caso do Fe 91\% das amostras apresentam valores acima da legislação, já para o $\mathrm{Al}, \mathrm{Mn}$ e $\mathrm{P}$ o não atendimento corresponde a $30 \%, 19 \%$ e $17 \%$ das amostras respectivamente.

As maiores concentrações para o $\mathrm{Al}, \mathrm{Mn}$, Fe foram observados no período de chuva.

$\mathrm{Na}$ avaliação de fósforo nos mananciais superficiais, apresentou um comportamento de não atendimento a Legislação, para todas as coletas realizadas em setembro, período de seca .

O Pb apresentou um distribuição com concentrações variando de 0,001 $\mathrm{mg} \cdot \mathrm{L}^{-1}$ a $0,04 \mathrm{mg} \cdot \mathrm{L}^{-1}$, apresentando 5 resultados acima do estabelecido pela legislação. As maiores concentrações forma observadas também no período de chuva, nas captações localizadas no Rio Ribeira do Iguape, evidênciando o problema de contaminação de $\mathrm{Pb}$ na região.

A Tabela 6.3, apresenta um resumo dos resultados quanto à razão entre o número de valores que não estão de acordo com a CONAMA 357 e o número total de análises realizadas para esses parâmetros em amostras de água bruta. 
Tabela 6.3 - Razão entre o número de valores que não estão de acordo com a Legislação e o número total de análises realizadas para esses parâmetros em mananciais superficiais.

\begin{tabular}{|l|l|l|l|l|}
\hline Manancial & Al & Mn & Fe & Pb \\
\hline RR001 & $3 / 5$ & $2 / 5$ & $4 / 5$ & $1 / 5$ \\
\hline RR005 & $4 / 5$ & $3 / 5$ & $5 / 5$ & $1 / 5$ \\
\hline RR 007 & $1 / 5$ & $3 / 5$ & $5 / 5$ & $1 / 5$ \\
\hline RR 011 & $1 / 5$ & $1 / 5$ & $5 / 5$ & $1 / 5$ \\
\hline RR 012 & $2 / 5$ & - & $3 / 5$ & $1 / 5$ \\
\hline RR 013 & - & - & $5 / 5$ & $1 / 5$ \\
\hline RR 017 & $4 / 5$ & $3 / 5$ & $4 / 5$ & $1 / 5$ \\
\hline RR 021 & $1 / 5$ & - & $5 / 5$ & $1 / 5$ \\
\hline RR 022 & $1 / 5$ & - & $5 / 5$ & $1 / 5$ \\
\hline RR 026 & - & - & $5 / 5$ & $1 / 5$ \\
\hline RR 033 & $5 / 5$ & $2 / 5$ & $5 / 5$ & $4 / 5$ \\
\hline RR043 & - & - & $4 / 5$ & - \\
\hline RR 044 & - & - & $5 / 5$ & $1 / 5$ \\
\hline RR 045 & $1 / 5$ & $1 / 5$ & $5 / 5$ & - \\
\hline RR049 & $1 / 5$ & $1 / 5$ & $5 / 5$ & - \\
\hline RR050 & $1 / 5$ & $1 / 5$ & $5 / 5$ & $1 / 5$ \\
\hline RR068 & $1 / 5$ & - & $4 / 5$ & - \\
\hline RR142 & $1 / 5$ & - & $5 / 5$ & $1 / 5$ \\
\hline & & & & \\
\hline
\end{tabular}

As figuras: Figura 6.16 a Figura 6.20, apresentam a distribuiçao dos elementos contemplados nestes estudo na água tratada. 

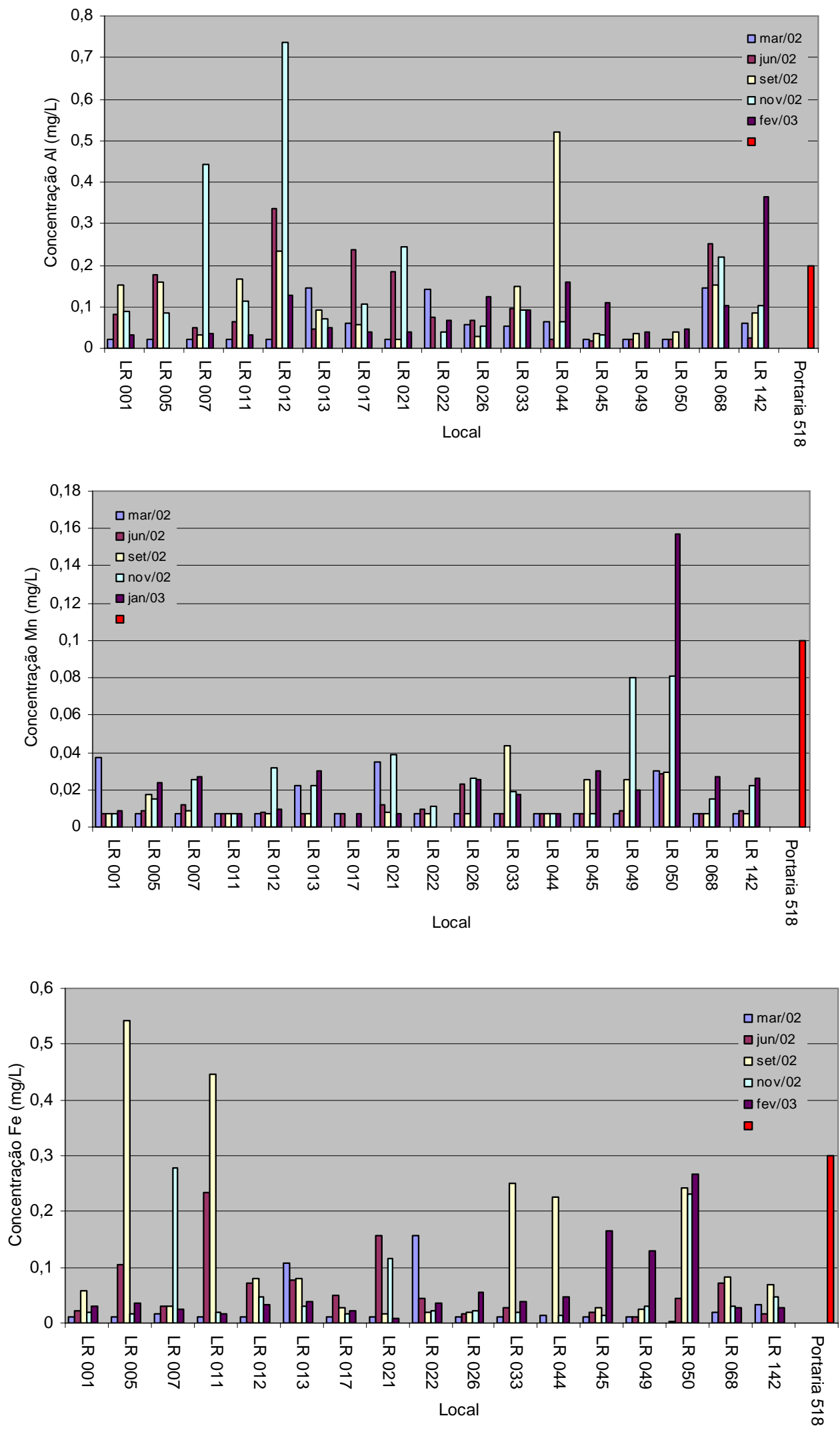

Figura 6.16 - Distribuição dos elementos alumínio, manganês e ferro em amostras de água tratada. 

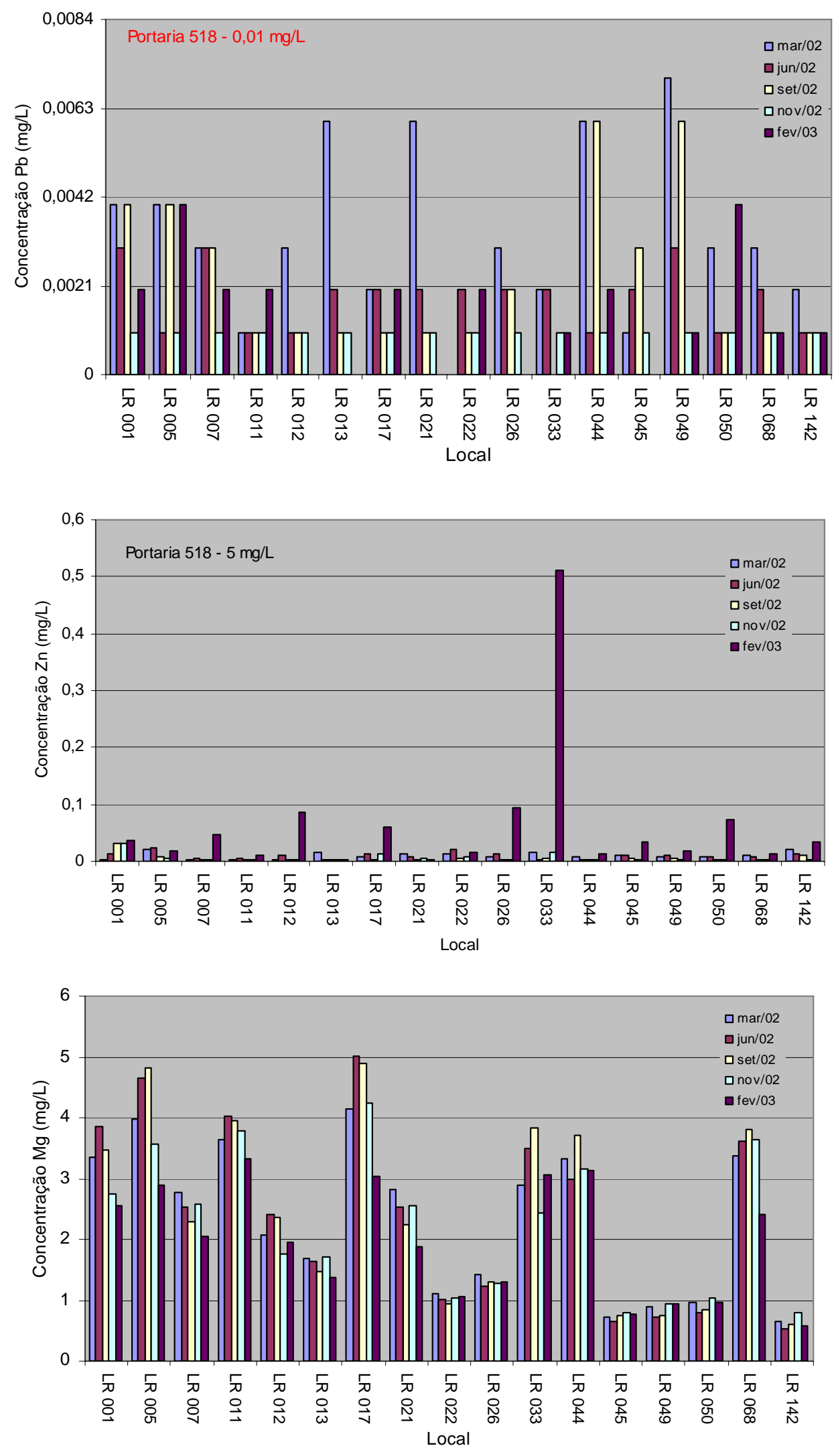

Figura 6.17 - Distribuição dos elementos chumbo, zinco e magnésio em amostras de água tratada. 

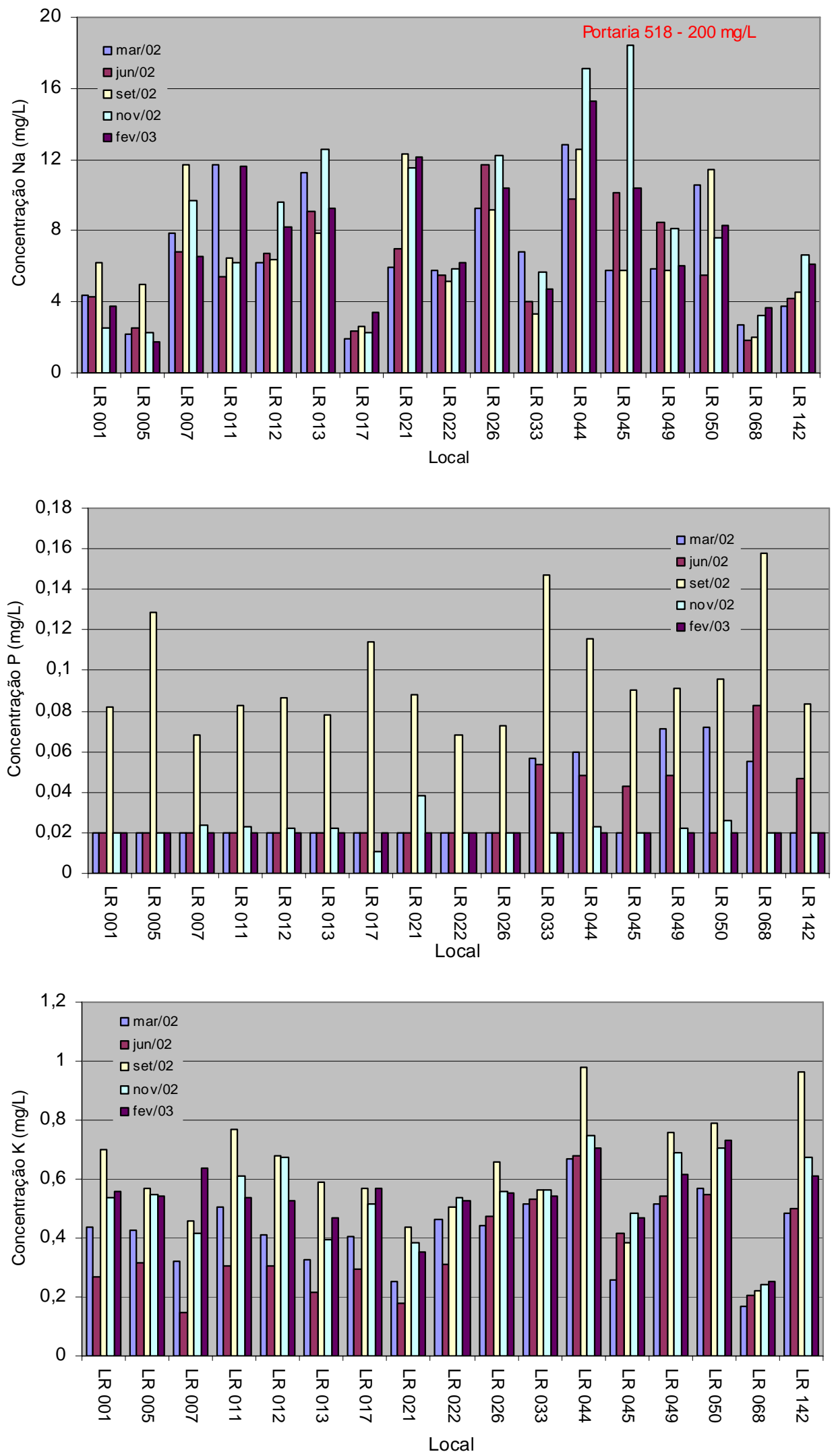

Figura 6.18 - Distribuição dos elementos sódio, fósforo e potássio em amostras de água tratada. 

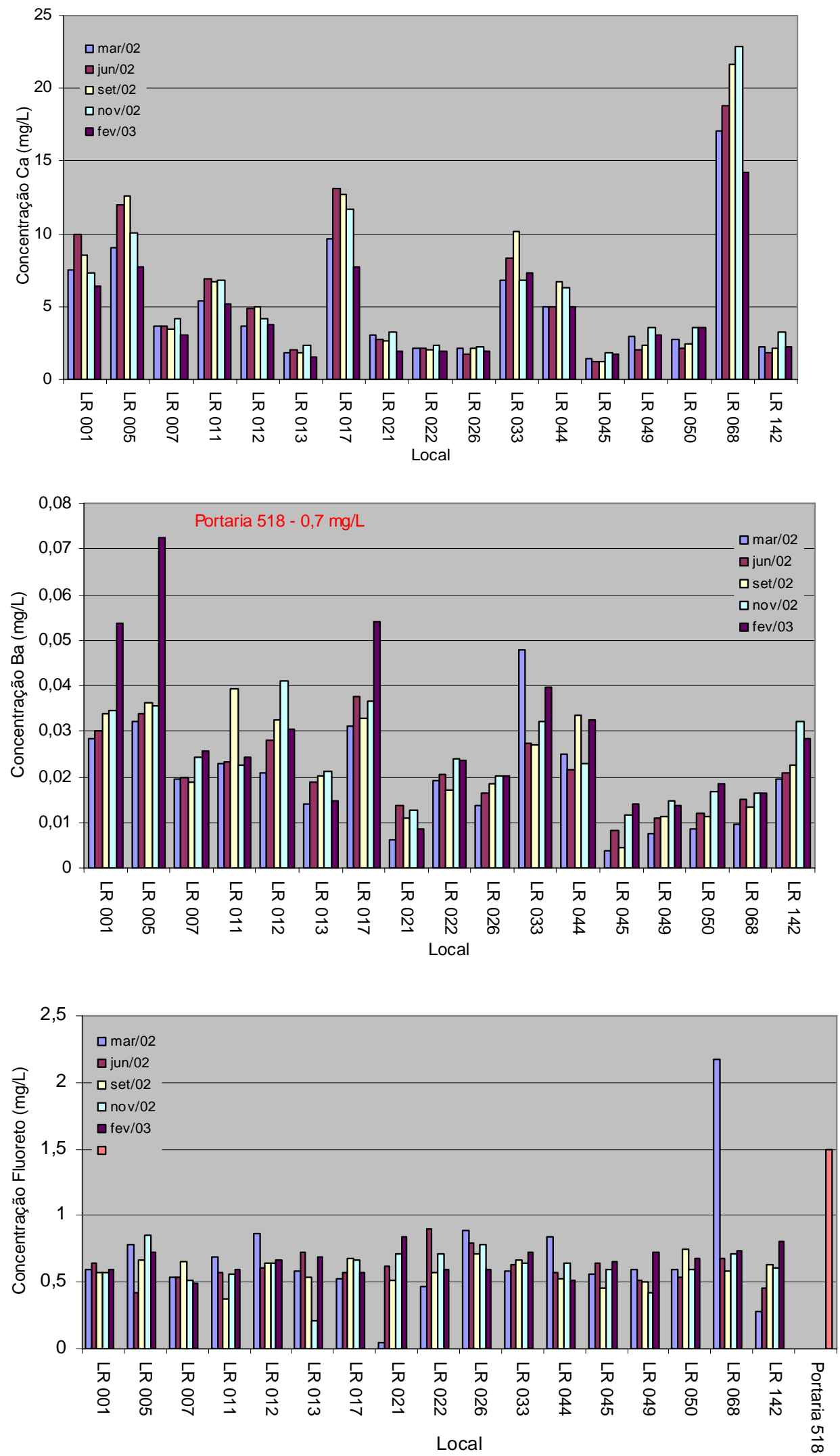

Figura 6.19 - Distribuição dos elementos cálcio, bário e fluoreto em amostras de água tratada. 

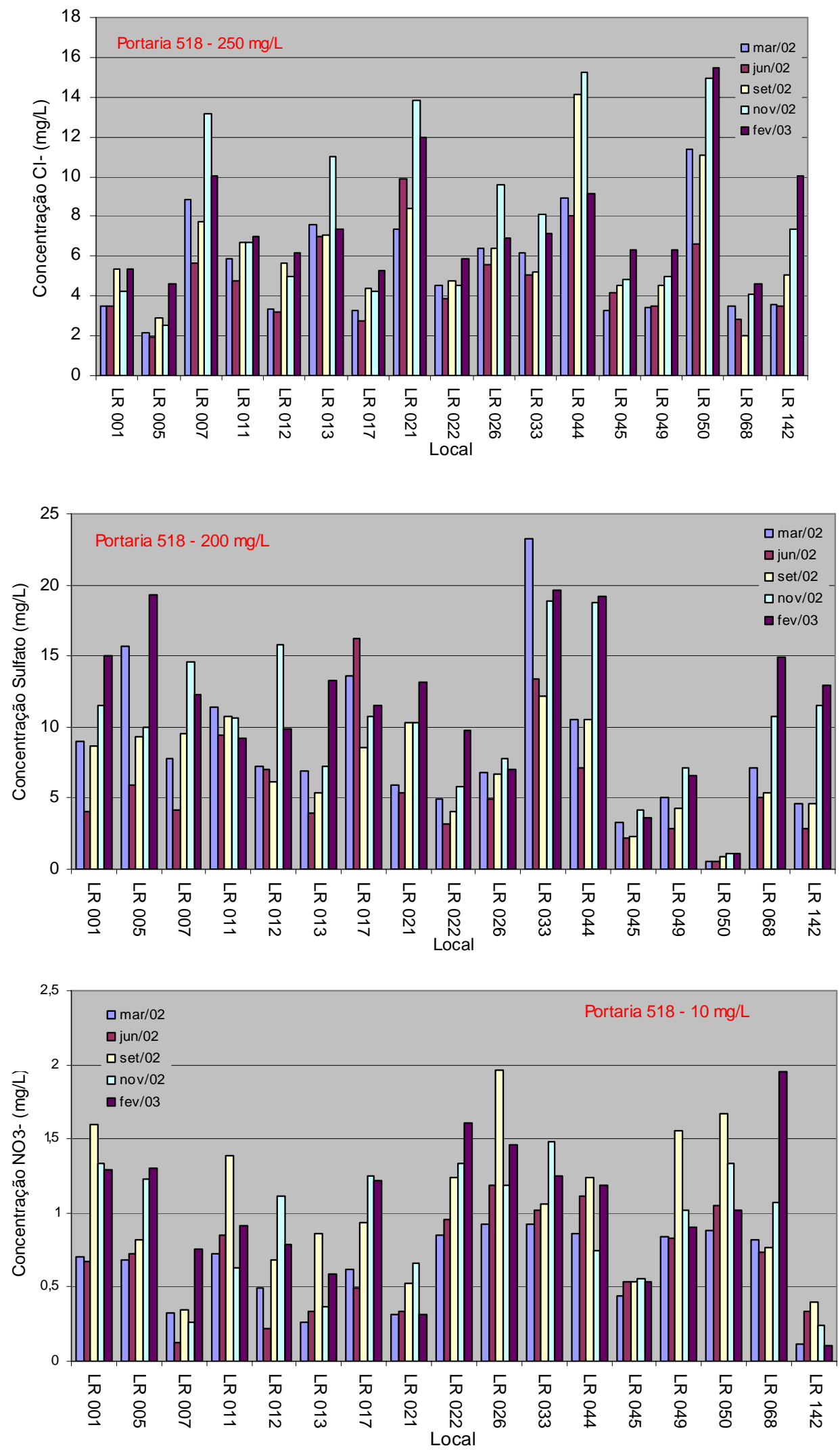

Figura 6.20 - Distribuição dos elementos cloreto, sulfato e nitrato em amostras de água tratada. 
Avaliando-se as medidas verificou-se que, como na água bruta alguns elementos apresentaram valores abaixo do limite de determinação da metodologia aplicada (Cr, Ni, Mo, Sn, V, Co, As, Sb, Hg e Cd).

Os elementos B e Ag apresentaram medidas em alguns sistemas, nas coletas do período de seca (junho/02), mas com valores um pouco acima do limite de quantificação dos elementos.

Comparando-se as concentraçoes dos metais nas águas brutas e tratada em cada município (Apêndice B - Tabelas B.3 e B.4), podemos observar que há uma redução para a maioria dos metais, sendo que para o $\mathrm{Al}, \mathrm{Mn}$ e $\mathrm{Fe}$ essa redução é praticamente total. A alta concentração de ferro verificada na região, bem acima dos padrões estabelecidos pela CONAMA 357, está relacionada provavelmente a matriz mineralógica, no qual o ferro deve estar associado.

Para os elementos $\mathrm{K}, \mathrm{Mg}$ e Ca não foram observadas reduções nas concentrações pelo processo de tratamento de água. Já para o sódio e sulfato, foram observadas concentrações maiores na água tratada. Esse aumento na concentração está associado ao próprio processo de tratamento, visto que estas fazem parte dos insumos utilizados nas ETA's.

Com relação a fluoretação e cloração, podemos observar que são realizados em todos os sistemas.

\subsubsection{Comparação manacial superficial, manancial de serra e poços.}

Nas figuras: Figura 6.21 a Figura 6.28, são apresentados os gráficos tipo Box-plot, comparando as distribuições de alguns elementos nos diferentes mananciais. 


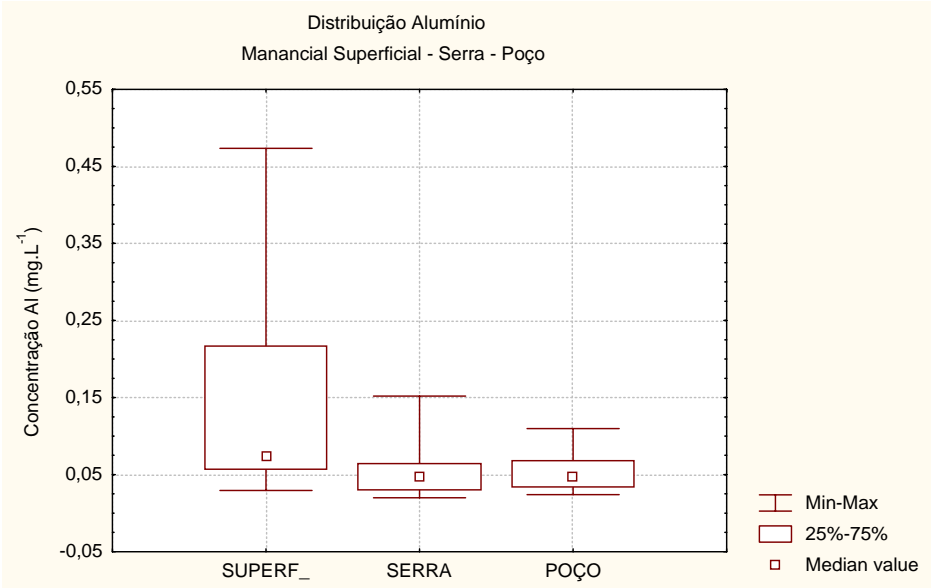

Figura 6.21 - Distribuição de alumínio em amostras de água de manancial superficial, de serra e poço.

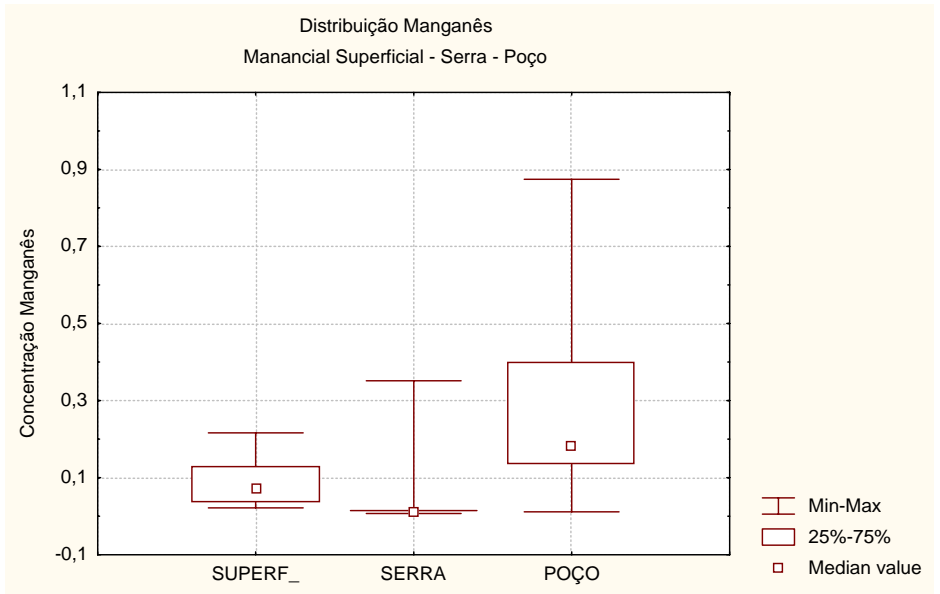

Figura 6.22 - Distribuição de manganês em amostras de água de manancial superficial, de serra e poço.

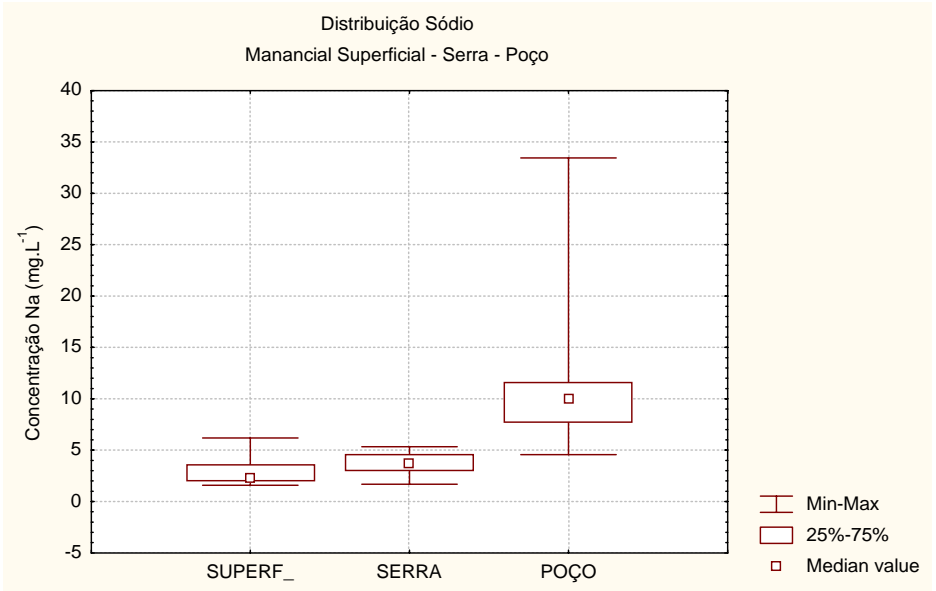

Figura 6.23 - Distribuição de sódio em amostras de água de manancial superficial, de serra e poço. 


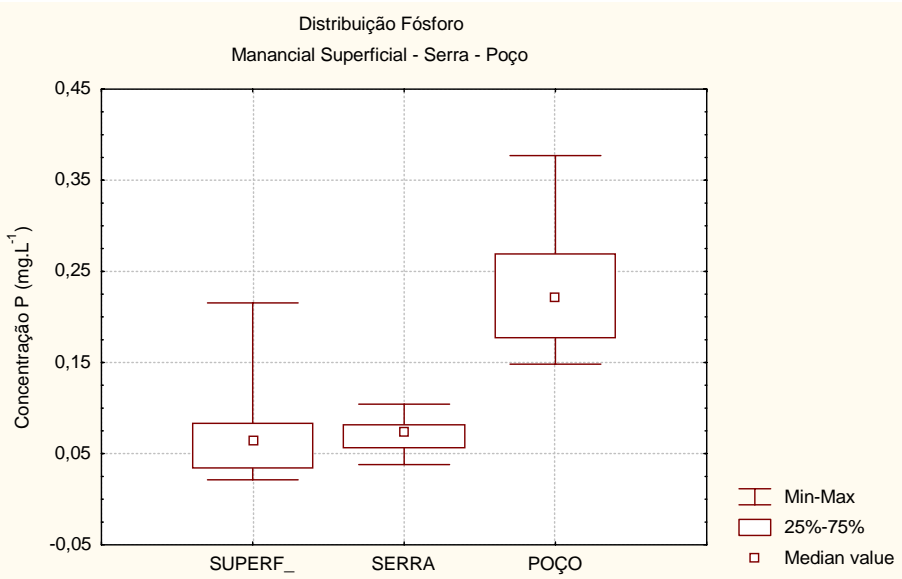

Figura 6.24 - Distribuição de fósforo em amostras de água de manancial superficial, de serra e poço.

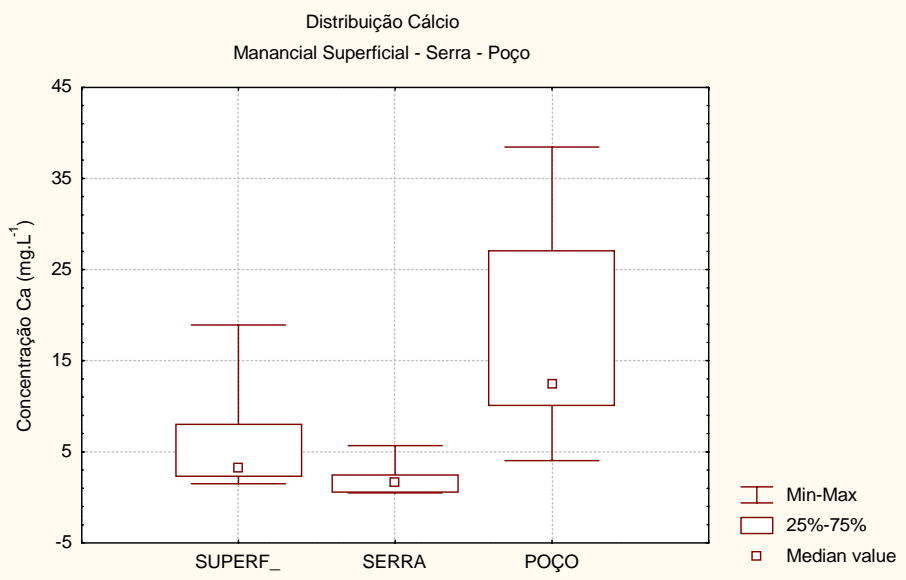

Figura 6.25 - Distribuição de cálcio em amostras de água de manancial superficial, de serra e poço.

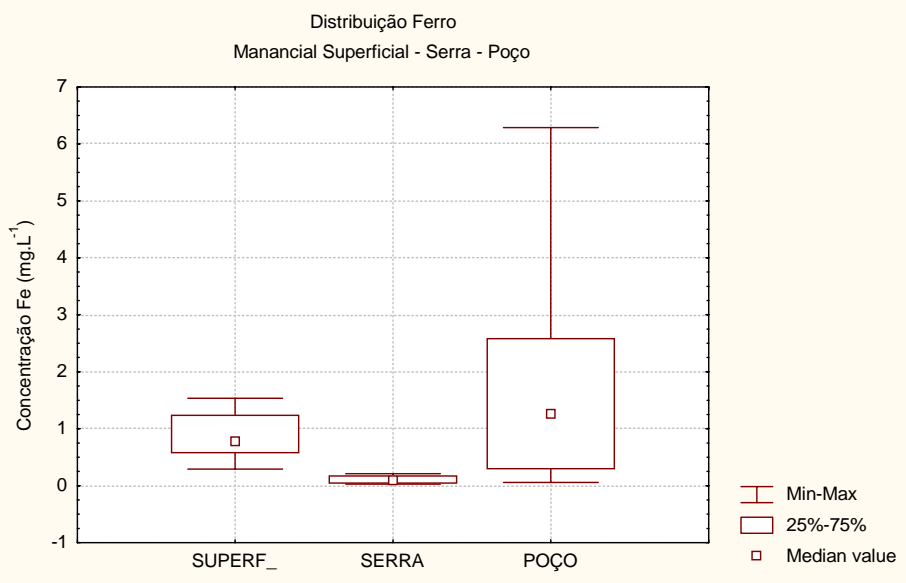

Figura 6.26 - Distribuição de ferro em amostras de água de manancial superficial, de serra e poço. 


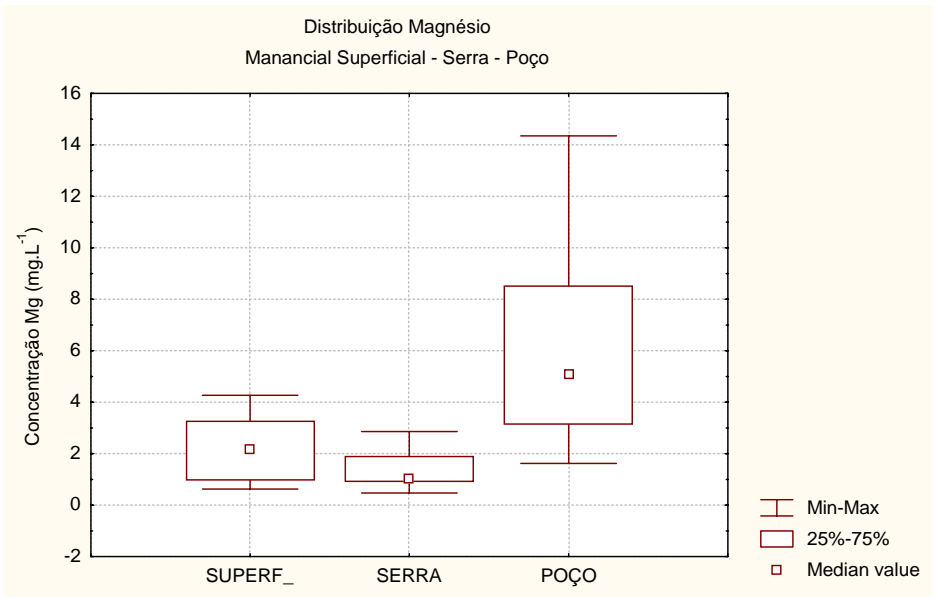

Figura 6.27 - Distribuição de magnésio em amostras de água de manancial superficial, de serra e poço.

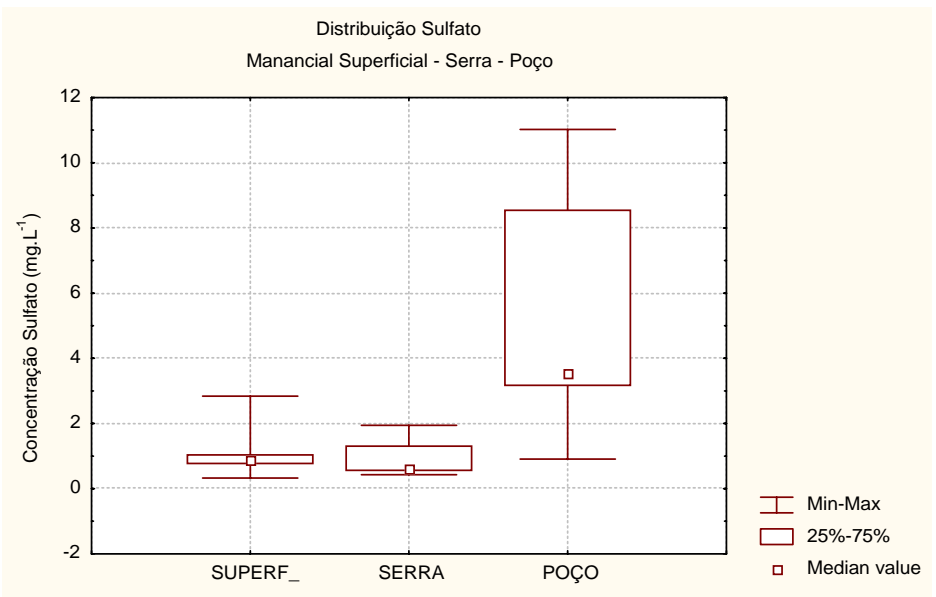

Figura 6.28 - Distribuição de sulfato em amostras de água de manancial superficial, de serra e poço.

Observa-se concentrações maiores dos elementos $\mathrm{SO}_{4}{ }^{2-}, \mathrm{Mg}, \mathrm{Fe}, \mathrm{Ca}$, $\mathrm{Mn}, \mathrm{Na}$ e $\mathrm{Cl}^{-}$em mananciais subterrâneos, quando comparado aos mananciais superficiais e de serra.

Esse fato deve-se as características dos aqüíferos da região. As águas do aqüífero Cristalino na faixa litorânea apresentam alto teor de cloreto, enquanto no aqǘ́fero Sedimentar o ânion predominante é o bicarbonato. As águas dos aqǘferos são classificadas como bicarbonatadas sódicas e cálcicas e cloretadas sódicas e cálcicas. No aqüífero Critalino ocorre salinização da água, em razão de 
fraturas mais profundas e associadas ao possível bombeamento excessivo do poço que estende o cone de rebaixamento de forma suficiente para provocar o avanço da intrusão de água salina no aqüífero.

Apresenta-se a seguir um resumo dos resultados obtidos no período do monitoramento. Nas tabelas: Tabela 6.4 e Tabela 6.5, são apresentados os valores médios, a faixa de distribuição dos elementos nas amostras de água de captações superficiais, mananciais de serra e poços dos sistemas de produtores do Vale do Ribeira, assim como os limites estabelecidos pelo CONAMA 357 para corpos de água Classe II e pela Portaria 518 do Ministério de Saúde para água para consumo humano.

Tabela 6.4 - Média e faixa de concentração $\left(\mathrm{mg}^{\mathrm{L}} \mathrm{L}^{-1}\right)$ de metais e elementos iônicos em águas superficiais, mananciais de serra e poços dos sistemas produtores do Vale do Ribeira, bem como os limites estabelecidos para água potável pela Portaria 518/MS de 2004 - Água Distribuída.

\begin{tabular}{|c|c|c|c|c|c|c|c|}
\hline \multirow[b]{2}{*}{ Elemento } & \multicolumn{2}{|r|}{ Poços } & \multicolumn{2}{|c|}{ Manancial de Serra } & \multicolumn{2}{|c|}{ Captações Superficiais ETA } & \multirow{2}{*}{\begin{tabular}{|r|}
$\begin{array}{r}\text { Portaria } \\
\text { 518/MS }\end{array}$ \\
$\left(\mathrm{mg} \cdot \mathrm{L}^{-1}\right)$
\end{tabular}} \\
\hline & $\begin{array}{l}\text { média } \\
\left(\mathrm{mg} \cdot \mathrm{L}^{-1}\right)\end{array}$ & $\begin{array}{l}\text { faixa } \\
\text { concentração } \\
\left(\mathrm{mg} \cdot \mathrm{L}^{-1}\right)\end{array}$ & $\begin{array}{l}\text { média } \\
\left(\mathrm{mg} \cdot \mathrm{L}^{-1}\right)\end{array}$ & $\begin{array}{l}\text { faixa } \\
\text { concentração } \\
\left(\mathrm{mg} \cdot \mathrm{L}^{-1}\right)\end{array}$ & $\begin{array}{l}\text { média } \\
\left(\mathrm{mg} \cdot \mathrm{L}^{-1}\right)\end{array}$ & $\begin{array}{l}\text { faixa } \\
\text { concentração } \\
\left(\mathrm{mg} \cdot \mathrm{L}^{-1}\right)\end{array}$ & \\
\hline $\mathrm{Ag}$ & 0,012 & $0,005-0,022$ & 0,022 & $0,005-0,026$ & 0,008 & $0,005-0,011$ & \\
\hline $\mathrm{Al}$ & 0,06 & $0,02-0,16$ & 0,08 & $0,02-0,63$ & 0,11 & $0,02-0,74$ & 0,2 \\
\hline As & 0,008 & $0,001-0,02$ & $<0,001$ & - & $<0,001$ & & 0,01 \\
\hline $\mathrm{B}$ & 0,015 & $0,001-0,020$ & 0,025 & $0,003-0,105$ & 0,011 & $0,003-0,016$ & \\
\hline $\mathrm{Ba}$ & 0,09 & $0,010-0,48$ & 0,026 & $0,004-0,2$ & 0,025 & $0,004-0,072$ & 0,7 \\
\hline $\mathrm{Ca}$ & 18,8 & $1,8-53,2$ & 2,25 & $0,40-19,8$ & 7,2 & $1,2-36,8$ & \\
\hline $\mathrm{Cd}$ & 0,0009 & $0,0003-0,002$ & 0,0004 & $0,0003-0,0004$ & 0,02 & $0,0003-0,02$ & 0,005 \\
\hline $\mathrm{Co}$ & $<0,05$ & & & $<0,05$ & $<0,05$ & & \\
\hline $\mathrm{Cr}$ & $<0,03$ & & $<0,03$ & & $<0,03$ & & 0,05 \\
\hline $\mathrm{Cu}$ & 0,056 & $0,02-0,247$ & $<0,02$ & & $<0,02$ & & 2 \\
\hline $\mathrm{Fe}$ & 1,95 & $0,01-7,18$ & 0,12 & $0,01-0,82$ & 0,09 & $0,01-0,54$ & 0,3 \\
\hline $\mathrm{Hg}$ & $<0,0008$ & & $<0,0008$ & $<0,0008$ & & & 0,001 \\
\hline $\mathrm{K}$ & 1,24 & $0,10-3,34$ & & & 0,57 & $0,15-1,88$ & \\
\hline $\mathrm{Mg}$ & 6,11 & $1,10-14,6$ & 1,19 & $0,40-2,05$ & 2,62 & $0,53-7,48$ & \\
\hline $\mathrm{Mn}$ & 0,291 & $0,019-1,31$ & 0,25 & $0,007-5,0$ & 0,024 & $0,007-0,157$ & 0,1 \\
\hline Mo & 0,161 & $0,020-5,0$ & 0,03 & $0,02-0,03$ & $<0,02$ & & \\
\hline $\mathrm{Na}$ & 10,9 & $0,83-38,7$ & 3,80 & $0,88-6,64$ & 7,83 & $1,73-20,0$ & 200 \\
\hline $\mathrm{Ni}$ & 0,035 & $0,02-0,084$ & $<0,02$ & & 0,03 & $0,02-0,03$ & \\
\hline $\mathrm{P}$ & 0,232 & $0,039-0,706$ & 0,10 & $0,02-0,16$ & 0,08 & $0,02-0,46$ & \\
\hline $\mathrm{Pb}$ & 0,003 & $0,001-0,018$ & 0,003 & $0,001-0,005$ & 0,004 & $0,001-0,1$ & 0,01 \\
\hline $\mathrm{Sb}$ & $<0,002$ & & $<0,002$ & & 0,002 & $0,001-0,002$ & 0,005 \\
\hline $\mathrm{Se}$ & 0,002 & $0,001-0,002$ & $<0,001$ & & 0,002 & $0,001-0,002$ & 0,01 \\
\hline Sn & 0,2 & & $<0,2$ & & 0,2 & & \\
\hline $\mathrm{V}$ & $<0,01$ & & $<0,01$ & & $<0,01$ & & \\
\hline $\mathrm{Zn}$ & 0,08 & $0,003-1,72$ & 0,07 & $0,003-1,39$ & 0,02 & $0,003-0,51$ & 5 \\
\hline $\mathrm{F}^{-}$ & 0,24 & $0,043-2,6$ & 0,08 & $0,025-0,31$ & 0,62 & $0,05-2,17$ & 1,5 \\
\hline $\mathrm{Cl}^{-}$ & 6,58 & $0,025-25,8$ & 4,79 & $1,10-12,65$ & 6,89 & $1,95-15,6$ & 250 \\
\hline $\mathrm{NO}_{3}^{-}$ & 1,80 & $0,05-20,0$ & 0,92 & $0,18-3,51$ & 0,82 & $0,05-1,97$ & \\
\hline $\mathrm{PO}_{4}^{3-}$ & 0,16 & $0,05-0,16$ & $<0,05$ & & 0,83 & $0,05-0,94$ & \\
\hline $\mathrm{SO}_{4}^{2-}$ & 4,88 & $0,52-13,6$ & 0,92 & $0,26-4,15$ & 8,62 & $0,55-23,2$ & 250 \\
\hline
\end{tabular}


Tabela 6.5 - Média e faixa de concentração $\left(\mathrm{mg} \cdot \mathrm{L}^{-1}\right)$ de metais e elementos iônicos em água bruta e tratada nos sistemas produtores do Vale do Ribeira que utilizam captação superficial, bem como os limites estabelecidos pelo CONAMA 357 para corpos de água Classe II.

\begin{tabular}{|c|c|c|c|c|c|c|}
\hline \multirow[b]{2}{*}{ Elemento } & \multicolumn{2}{|c|}{$\begin{array}{c}\text { Captações Superficiais } \\
\text { Água Bruta }\end{array}$} & \multirow{2}{*}{$\begin{array}{c}\text { CONAMA } 357 \\
\text { Classe II } \\
\left(\mathrm{mg} \cdot \mathrm{L}^{-1}\right)\end{array}$} & \multicolumn{2}{|c|}{ Água Tratada - ETA } & \multirow{2}{*}{$\begin{array}{l}\text { Portaria 518/MS } \\
\left(\mathrm{mg} \cdot \mathrm{L}^{-1}\right)\end{array}$} \\
\hline & $\begin{array}{l}\text { média } \\
\left(\mathrm{mg} \cdot \mathrm{L}^{-1}\right)\end{array}$ & $\begin{array}{l}\text { faixa } \\
\text { concentração } \\
\left(\mathrm{mg} \cdot \mathrm{L}^{-1}\right)\end{array}$ & & $\begin{array}{l}\text { média } \\
\left(\mathrm{mg}^{-1} \mathrm{~L}^{-1}\right)\end{array}$ & $\begin{array}{l}\text { faixa } \\
\text { concentração } \\
\left(\mathrm{mg} \cdot \mathrm{L}^{-1}\right)\end{array}$ & \\
\hline $\mathrm{Ag}$ & 0,005 & $0,005-0,008$ & 0,01 & 0,008 & $0,005-0,011$ & \\
\hline $\mathrm{Al}$ & 0,14 & $0,04-1,55$ & 0,1 & 0,11 & $0,02-0,74$ & 0,2 \\
\hline As & $<0,001$ & & 0,05 & $<0,001$ & & 0,01 \\
\hline$B$ & 0,01 & $0,003-0,01$ & 0,75 & 0,011 & $0,003-0,016$ & \\
\hline $\mathrm{Ba}$ & 0,03 & $0,005-0,13$ & 1,0 & 0,025 & $0,004-0,072$ & 0,7 \\
\hline $\mathrm{Ca}$ & 6,93 & $1,21-12,4$ & & 7,2 & $1,2-36,8$ & \\
\hline $\mathrm{Cd}$ & 0,0004 & $0,0003-0,0004$ & 0,001 & 0,02 & $0,0003-0,02$ & 0,005 \\
\hline Co & $<0,05$ & & 0,2 & $<0,05$ & & \\
\hline $\mathrm{Cr}$ & $<0,03$ & & & $<0,03$ & & 0,05 \\
\hline $\mathrm{Cu}$ & 0,03 & $0,02-0,04$ & 0,02 & $<0,02$ & & 2 \\
\hline $\mathrm{Fe}$ & 1,07 & $0,18-2,94$ & & 0,09 & $0,01-0,54$ & 0,3 \\
\hline $\mathrm{Hg}$ & $<0,0008$ & & 0,0002 & $<0,0008$ & & 0,001 \\
\hline $\mathrm{K}$ & 0,50 & $0,03-0,89$ & & 0,57 & $0,15-1,88$ & \\
\hline $\mathrm{Mg}$ & 2,49 & $0,53-7,49$ & & 2,62 & $0,53-7,48$ & \\
\hline $\mathrm{Mn}$ & 0,29 & $0,007-5,0$ & 0,10 & 0,024 & $0,007-0,157$ & 0,1 \\
\hline Mo & $<0,02$ & & & $<0,02$ & & \\
\hline $\mathrm{Na}$ & 3,27 & $1,03-10,6$ & & 7,83 & $1,73-20,0$ & 200 \\
\hline $\mathrm{Ni}$ & 0,03 & $0,02-0,03$ & 0,025 & 0,03 & $0,02-0,03$ & \\
\hline $\mathrm{P}$ & 0,11 & $0,05-0,69$ & 0,025 & 0,08 & $0,02-0,46$ & \\
\hline $\mathrm{Pb}$ & 0,005 & $0,001-0,04$ & 0,03 & 0,004 & $0,001-0,1$ & 0,01 \\
\hline $\mathrm{Sb}$ & 0,002 & $0,001-0,002$ & & 0,002 & $0,001-0,002$ & 0,005 \\
\hline Se & 0,002 & $0,001-0,002$ & 0,01 & 0,002 & $0,001-0,002$ & 0,01 \\
\hline Sn & $<0,2$ & & 2,0 & 0,2 & & \\
\hline $\mathrm{V}$ & $<0,001$ & & 0,1 & $<0,01$ & & \\
\hline $\mathrm{Zn}$ & 0,02 & $0,003-0,15$ & 0,18 & 0,02 & $0,003-0,51$ & 5 \\
\hline $\mathrm{F}^{-}$ & 0,05 & $0,025-0,10$ & 1,4 & 0,62 & $0,05-2,17$ & 1,5 \\
\hline $\mathrm{Cl}^{-}$ & 3,49 & $0,025-12,71$ & 250 & 6,89 & $1,95-15,6$ & 250 \\
\hline $\mathrm{NO}_{3}^{-}$ & 0,83 & $0,05-2,06$ & 10 & 0,82 & $0,05-1,97$ & 10 \\
\hline $\mathrm{PO}_{4}^{3-}$ & $<0,05$ & & 0,025 & 0,83 & $0,05-0,94$ & \\
\hline $\mathrm{SO}_{4}{ }^{2-}$ & 1,48 & $0,16-12,2$ & 250 & 8,62 & $0,55-23,2$ & 250 \\
\hline
\end{tabular}

\section{2 - Análise Estatística Multivariada}

Para avaliar melhor a grande base de dados, avaliar correlação entre as variáveis, saber se parte da informação contida por suas séries temporais são comuns à elementos e verificar se existem regiões com o mesmo tipo de comportamento, aplicou-se ferramenta estatística para obtenção de matriz de correlação, análise de fatores pelo método dos componentes principais (ACP) e análise de agrupamento, nos dados referentes a água bruta, tratada, manancial de serra e poço. Foi utilizado o programa estatístico Statistic 7.0 da Statisoft. 
Para todos os sistemas estudados, água bruta, água tratada, manancial de serra e poços, foram consideradas as variáveis $\mathrm{pH}$, turbidez, $\mathrm{Al}, \mathrm{Mn}$,

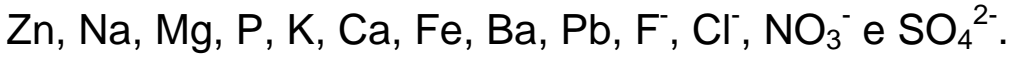

\subsection{1 Água Bruta}

\subsubsection{Análise de correlação}

Para verificar a existência de multivariabilidade entre os dados, ou seja, quais são os parâmetros que possuem uma combinação linear entre si, foi obtida a matriz de correlação para as variáveis estudadas.

A Tabela 6.6 apresenta a matriz de correlação para água bruta, onde são apresentados os coeficientes de correlação entre pH, turbidez e elementos metálicos e iônicos.

Podemos observar várias correlações definidas para a água bruta (12), indicando uma combinação linear entre os parâmetros destacados na tabela. 
Tabela 6.6 - Matriz de correlação entre pH, turbidez, elementos metálicos e iônicos em água bruta.

\begin{tabular}{|c|c|c|c|c|c|c|c|c|c|c|c|c|c|c|c|c|c|}
\hline \multirow[b]{2}{*}{ Variable } & \multicolumn{17}{|c|}{$\begin{array}{l}\text { Correlations (IPEN - Exploração) } \\
\text { Marked correlations are significant at } p<, 05000 \\
\mathrm{~N}=18 \text { (Casewise deletion of missing data) } \\
\end{array}$} \\
\hline & $\mathrm{pH}$ & Turbidez & $\mathrm{Al}$ & $\mathrm{Mn}$ & $\mathrm{Zn}$ & $\mathrm{Na}$ & $\mathrm{Mg}$ & $\mathrm{P}$ & $\mathrm{K}$ & $\mathrm{Ca}$ & $\mathrm{Fe}$ & $\mathrm{Ba}$ & $\mathrm{Pb}$ & F- & $\mathrm{Cl}-$ & NO3- & SO42- \\
\hline $\mathrm{pH}$ & 1,00 & $-0,25$ & 0,27 & 0,35 & $-0,01$ & $-0,30$ & 0,28 & 0,21 & 0,07 & 0,20 & $-0,13$ & $-0,30$ & 0,42 & 0,17 & $-0,31$ & 0,14 & 0,06 \\
\hline Turbidez & $-0,25$ & 1,00 & 0,40 & 0,34 & $-0,03$ & $-0,10$ & 0,13 & $-0,10$ & 0,26 & 0,01 & 0,24 & 0,76 & 0,14 & 0,36 & $-0,27$ & 0,20 & $-0,22$ \\
\hline Al & 0,27 & 0,40 & 1,00 & 0,65 & 0,39 & $-0,38$ & 0,36 & 0,32 & 0,36 & 0,31 & 0,22 & 0,01 & 0,61 & 0,43 & $-0,55$ & 0,54 & $-0,0 s$ \\
\hline $\mathrm{Mn}$ & 0,35 & 0,34 & 0,65 & 1,00 & $-0,03$ & $-0,16$ & 0,43 & 0,09 & 0,39 & 0,18 & 0,30 & 0,12 & 0,37 & 0,31 & $-0,34$ & 0,32 & $-0,21$ \\
\hline $\mathrm{Zn}$ & $-0,01$ & $-0,03$ & 0,39 & $-0,03$ & 1,00 & $-0,04$ & 0,13 & 0,61 & $-0,11$ & 0,07 & 0,13 & $-0,10$ & 0,22 & 0,32 & 0,02 & 0,18 & 0,36 \\
\hline $\mathrm{Na}$ & $-0,30$ & $-0,10$ & $-0,38$ & $-0,16$ & $-0,04$ & 1,00 & 0,18 & $-0,10$ & 0,11 & $-0,25$ & 0,12 & $-0,25$ & $-0,40$ & 0,26 & 0,82 & $-0,32$ & 0,03 \\
\hline $\mathrm{Mg}$ & 0,28 & 0,13 & 0,36 & 0,43 & 0,13 & 0,18 & 1,00 & 0,29 & 0,05 & 0,75 & $-0,38$ & $-0,28$ & 0,30 & 0,76 & $-0,15$ & 0,35 & $-0,02$ \\
\hline $\mathrm{P}$ & 0,21 & $-0,10$ & 0,32 & 0,09 & 0,61 & $-0,10$ & 0,29 & 1,00 & 0,21 & 0,16 & $-0,05$ & $-0,22$ & 0,63 & 0,44 & $-0,27$ & $-0,08$ & $-0,0 C$ \\
\hline K & 0,07 & 0,26 & 0,36 & 0,39 & $-0,11$ & 0,11 & 0,05 & 0,21 & 1,00 & $-0,21$ & 0,20 & $-0,15$ & 0,40 & 0,37 & $-0,24$ & 0,34 & $-0,27$ \\
\hline $\mathrm{Ca}$ & 0,20 & 0,01 & 0,31 & 0,18 & 0,07 & $-0,25$ & 0,75 & 0,16 & $-0,21$ & 1,00 & $-0,46$ & $-0,20$ & 0,27 & 0,48 & $-0,43$ & 0,45 & $-0,01$ \\
\hline $\mathrm{Fe}$ & $-0,13$ & 0,24 & 0,22 & 0,30 & 0,13 & 0,12 & $-0,38$ & $-0,05$ & 0,20 & $-0,46$ & 1,00 & 0,32 & 0,05 & $-0,28$ & 0,14 & $-0,15$ & $-0,34$ \\
\hline $\mathrm{Ba}$ & $-0,30$ & 0,76 & 0,01 & 0,12 & $-0,10$ & $-0,25$ & $-0,28$ & $-0,22$ & $-0,15$ & $-0,20$ & 0,32 & 1,00 & $-0,16$ & $-0,15$ & $-0,17$ & $-0,09$ & $-0,16$ \\
\hline $\mathrm{Pb}$ & 0,42 & 0,14 & 0,61 & 0,37 & 0,22 & $-0,40$ & 0,30 & 0,63 & 0,40 & 0,27 & 0,05 & $-0,16$ & 1,00 & 0,33 & $-0,58$ & 0,12 & $-0,30$ \\
\hline F- & 0,17 & 0,36 & 0,43 & 0,31 & 0,32 & 0,26 & 0,76 & 0,44 & 0,37 & 0,48 & $-0,28$ & $-0,15$ & 0,33 & 1,00 & $-0,06$ & 0,36 & 0,21 \\
\hline $\mathrm{Cl}-$ & $-0,31$ & $-0,27$ & $-0,55$ & $-0,34$ & 0,02 & 0,82 & $-0,15$ & $-0,27$ & $-0,24$ & $-0,43$ & 0,14 & $-0,17$ & $-0,58$ & $-0,06$ & 1,00 & $\mid-0,47$ & 0,41 \\
\hline NO3- & 0,14 & 0,20 & 0,54 & 0,32 & 0,18 & $-0,32$ & 0,35 & $-0,08$ & 0,34 & 0,45 & $-0,15$ & $-0,09$ & 0,12 & 0,36 & $-0,47$ & 1,00 & 0,08 \\
\hline SO42- & 0,06 & $-0,22$ & $-0,09$ & $-0,21$ & 0,36 & 0,03 & $-0,02$ & $-0,00$ & $-0,27$ & $-0,01$ & $-0,34$ & $-0,16$ & $-0,30$ & 0,21 & 0,41 & 0,08 & 1,00 \\
\hline
\end{tabular}


As fortes correlações entre $\mathrm{Mg} / \mathrm{Ca}(0,75), \mathrm{Mg} / \mathrm{F}^{-}(0,76), \mathrm{Ca} / \mathrm{Mg}(0,75)$, sugerem relação com a matriz mineralógica referente ao depósito de fluorita na região e a predominância de rochas carbonáticas.

\subsubsection{Análise de Componentes Principais}

A Tabela 6.7 apresenta um resumo da estatística obtida inicialmente, onde são mostrados os autovalores obtidos para cada componente, depois de submeter à matriz a rotação Varimax (onde o valor do corte é igual a 1), onde temos a fração explicada por cada componente e a porcentagem acumulada.

Tabela 6.7 - Análise de componentes principais - água bruta.

\begin{tabular}{|c|c|c|c|}
\hline Fator & $\begin{array}{c}\text { Autovalor da } \\
\text { componente }\end{array}$ & $\begin{array}{c}\text { Variabilidade } \\
\text { explicada pela } \\
\text { componente (\%) }\end{array}$ & $\begin{array}{c}\text { Variabilidade } \\
\text { total explicada } \\
(\%)\end{array}$ \\
\hline 1 & 4,73 & 27,8 & 27,8 \\
\hline 2 & 2,82 & 16,6 & 44,4 \\
\hline 3 & 2,02 & 11,9 & 56,3 \\
\hline 4 & 1,85 & 10,9 & 67,1 \\
\hline 5 & 1,57 & 9,2 & 76,4 \\
\hline 6 & 1,17 & 6,9 & 83,2 \\
\hline
\end{tabular}

Foram considerados 6 componentes como significativos, sendo que a porcentagem da variabilidade acumulada explicada por elas é de $83,2 \%$ da variabilidade total dos elementos.

A Tabela 6.8 apresenta os componentes retidos e sua matriz de fatores para cada variável. 
Tabela 6.8 - Resultados da análise de componentes principais para a água bruta.

\begin{tabular}{|l|c|c|c|c|c|c|}
\hline Elemento & Fator 1 & Fator 2 & Fator 3 & Fator 4 & Fator 5 & Fator 6 \\
\hline $\mathrm{PH}$ & $-0,56$ & 0,15 & 0,36 & 0,10 & 0,28 & 0,04 \\
\hline Turbidez & 0,87 & 0,13 & 0,07 & 0,00 & 0,37 & 0,10 \\
\hline $\mathrm{Al}$ & 0,14 & 0,16 & 0,41 & 0,35 & 0,70 & $-0,16$ \\
\hline $\mathrm{Mn}$ & 0,08 & 0,13 & 0,17 & 0,02 & 0,78 & 0,11 \\
\hline $\mathrm{Zn}$ & 0,07 & $-0,02$ & 0,01 & 0,72 & 0,03 & $-0,60$ \\
\hline $\mathrm{Na}$ & $-0,04$ & 0,06 & $-0,98$ & $-0,05$ & 0,02 & 0,05 \\
\hline $\mathrm{Mg}$ & $-0,06$ & 0,89 & $-0,11$ & 0,18 & 0,29 & 0,04 \\
\hline $\mathrm{P}$ & $-0,15$ & 0,14 & 0,06 & 0,93 & 0,05 & 0,04 \\
\hline $\mathrm{K}$ & $-0,09$ & $-0,09$ & $-0,13$ & 0,10 & 0,77 & 0,24 \\
\hline $\mathrm{Ca}$ & $-0,05$ & 0,85 & 0,33 & 0,05 & $-0,01$ & $-0,02$ \\
\hline $\mathrm{Fe}$ & 0,29 & $-0,67$ & $-0,13$ & 0,14 & 0,40 & 0,11 \\
\hline $\mathrm{Ba}$ & 0,88 & $-0,21$ & 0,21 & $-0,12$ & $-0,06$ & 0,08 \\
\hline $\mathrm{Pb}^{\mathrm{F}-}$ & $-0,15$ & 0,14 & 0,40 & 0,64 & 0,37 & 0,33 \\
\hline $\mathrm{Cl}^{-}$ & 0,10 & 0,71 & $-0,26$ & 0,37 & 0,42 & $-0,17$ \\
\hline $\mathrm{NO}_{3}{ }^{-}$ & $-0,08$ & $-0,21$ & $-0,85$ & $-0,15$ & $-0,25$ & $-0,27$ \\
\hline $\mathrm{SO}_{4}{ }^{2-}$ & 0,01 & 0,37 & 0,38 & $-0,20$ & 0,55 & $-0,40$ \\
\hline
\end{tabular}

Para auxiliar a interpretação da análise ACP, foi preparada a Tabela 6.9, que salienta os elementos retidos em cada componente, bem como a importância de cada componente na explicação da variabilidade dos elementos na água bruta. 
Tabela 6.9 - Esquematização das informações da ACP para os elementos na água bruta.

\begin{tabular}{|l|l|c|}
\hline & Elementos Retidos & $\begin{array}{c}\text { Variabilidade } \\
\text { explicada (\%) }\end{array}$ \\
\hline Fator 1 & $\mathrm{Ba}$, Turbidez & 27,8 \\
\hline Fator 2 & $\mathrm{Mg}, \mathrm{Ca} \mathrm{e} \mathrm{F}^{-}$ & 16,6 \\
\hline Fator 3 & $\mathrm{Na} \mathrm{e} \mathrm{Cl}$ & 11,9 \\
\hline Fator 4 & $\mathrm{Zn} \mathrm{e} \mathrm{P}$ & 10,9 \\
\hline Fator 5 & $\mathrm{Mn} \mathrm{e} \mathrm{K}^{-}$ & 9,2 \\
\hline Fator 6 & $\mathrm{SO}_{4}{ }^{2-}$ & 6,9 \\
\hline
\end{tabular}

Observando os resultados apresentados na Tabela 6.9, os elementos retidos sugerem que os fatores estão associados a fatores mineralógicos da região, sendo a Bacia do Ribeira composta predominantemente por xistos e filitos, rochas carbonáticas e depósito de fluorita na região do Vale do Ribeira.

O transporte de sólidos em suspensão é um fenômeno marcante, devido aos altos desníveis topográficos, sendo potencial fornecedor de grandes massas de materiais clásticos carreáveis. Estas características hidrológicas tornam-se mais relevantes por favorecerem processos de assoreamento do rio, resultante de processos erosivos, fenômeno típico de épocas de chuva na região (CETESB, 2000).

Na Figura 6.29 apresenta-se uma representação gráfica dos resultados dos 3 primeiros fatores extraídos da análise de fatores. 

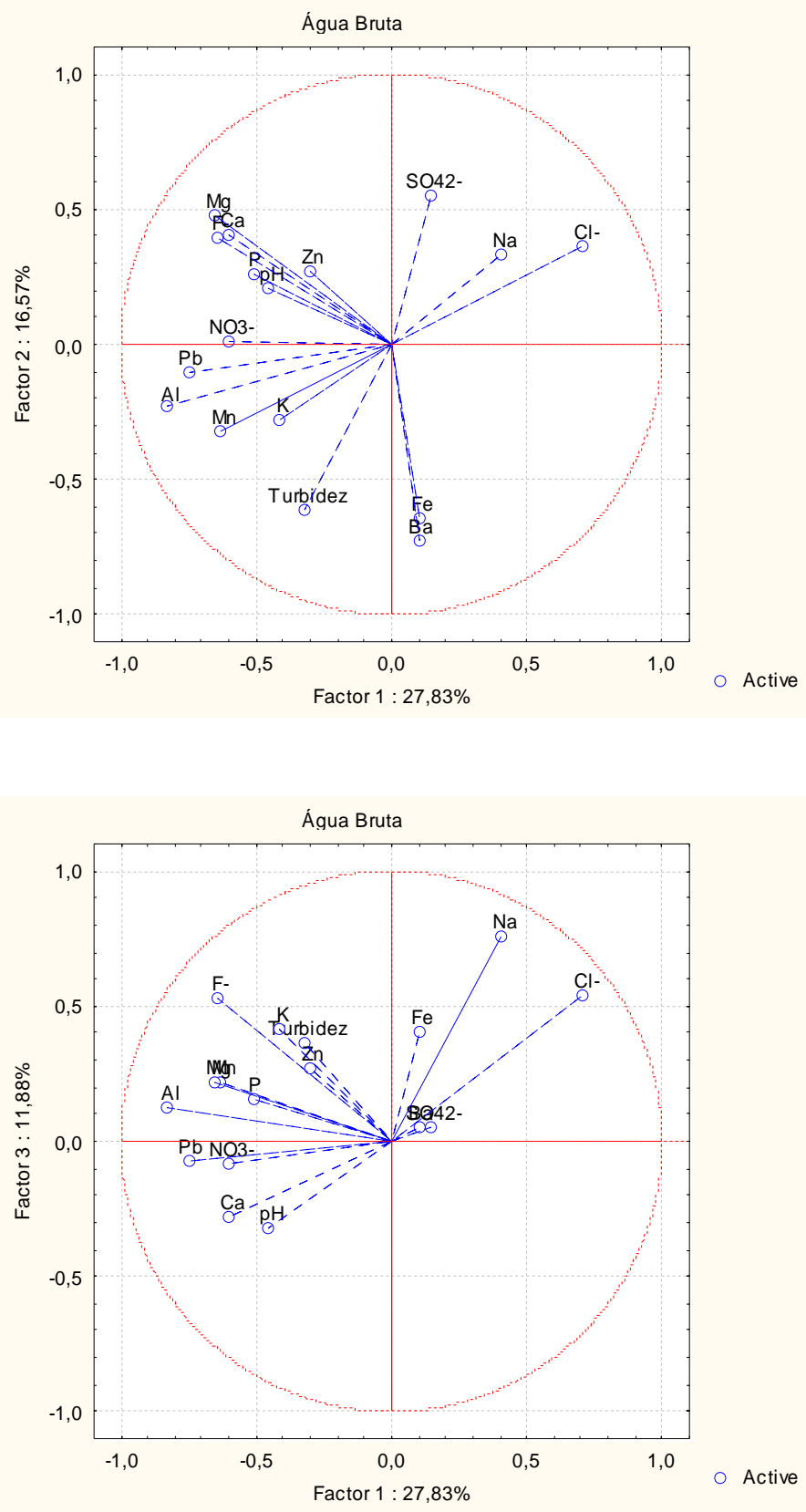

Figura 6.29 - Projeção das variáveis retidas nos fatores 1, 2 e 3.

Na Figura 6.30 apresenta-se o dendograma (projeção dos pontos de coleta) obtido para a água bruta, identificando regiões com o mesmo tipo de comportamento em relação a todas as variáveis avaliadas neste estudo. Uma outra forma de apresentar esses resultados foi a projeção dos pontos de coleta (Figura 6.31). 


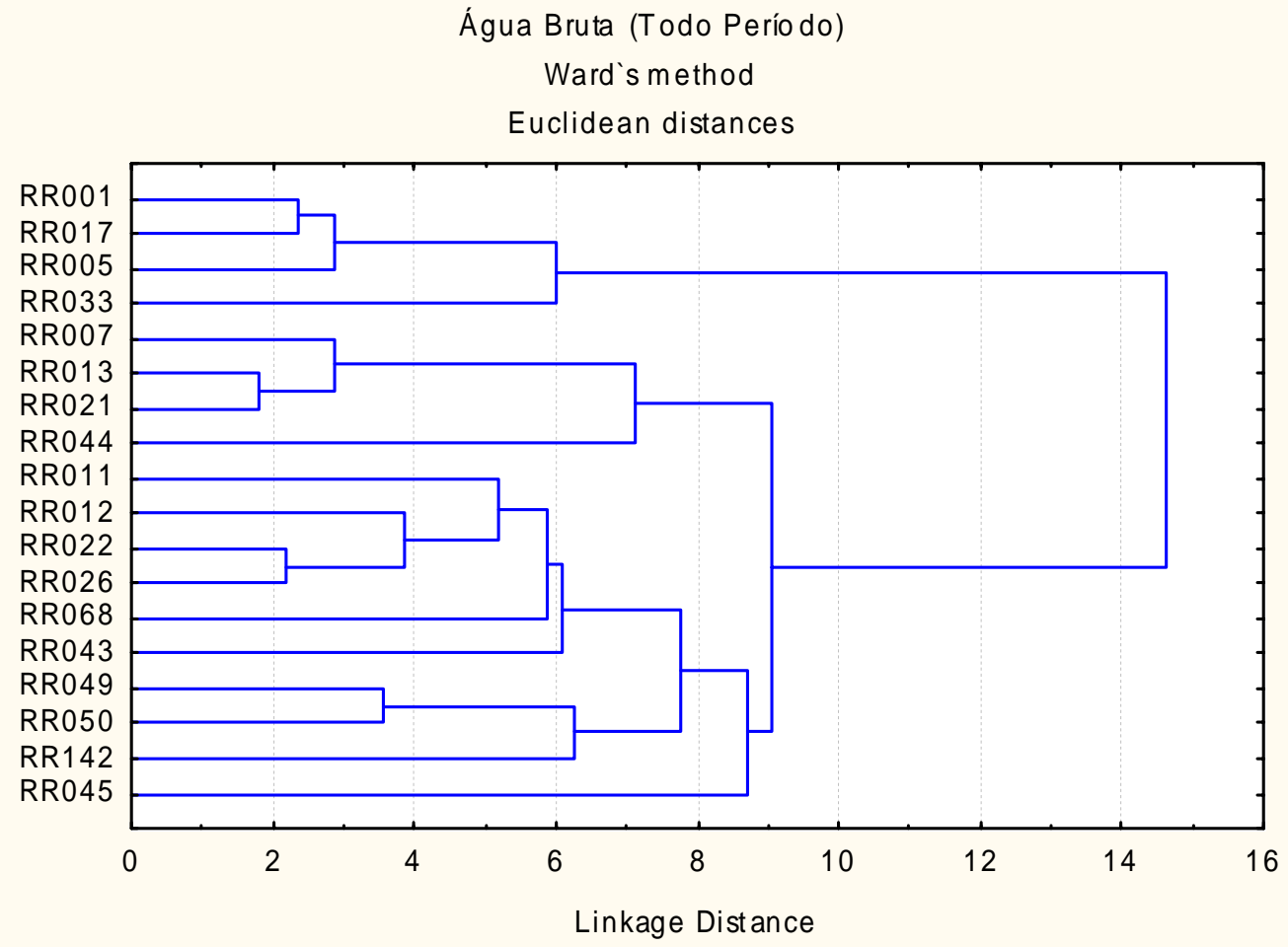

Figura 6.30 - Dendograma da concentração dos elementos avaliados para água bruta.

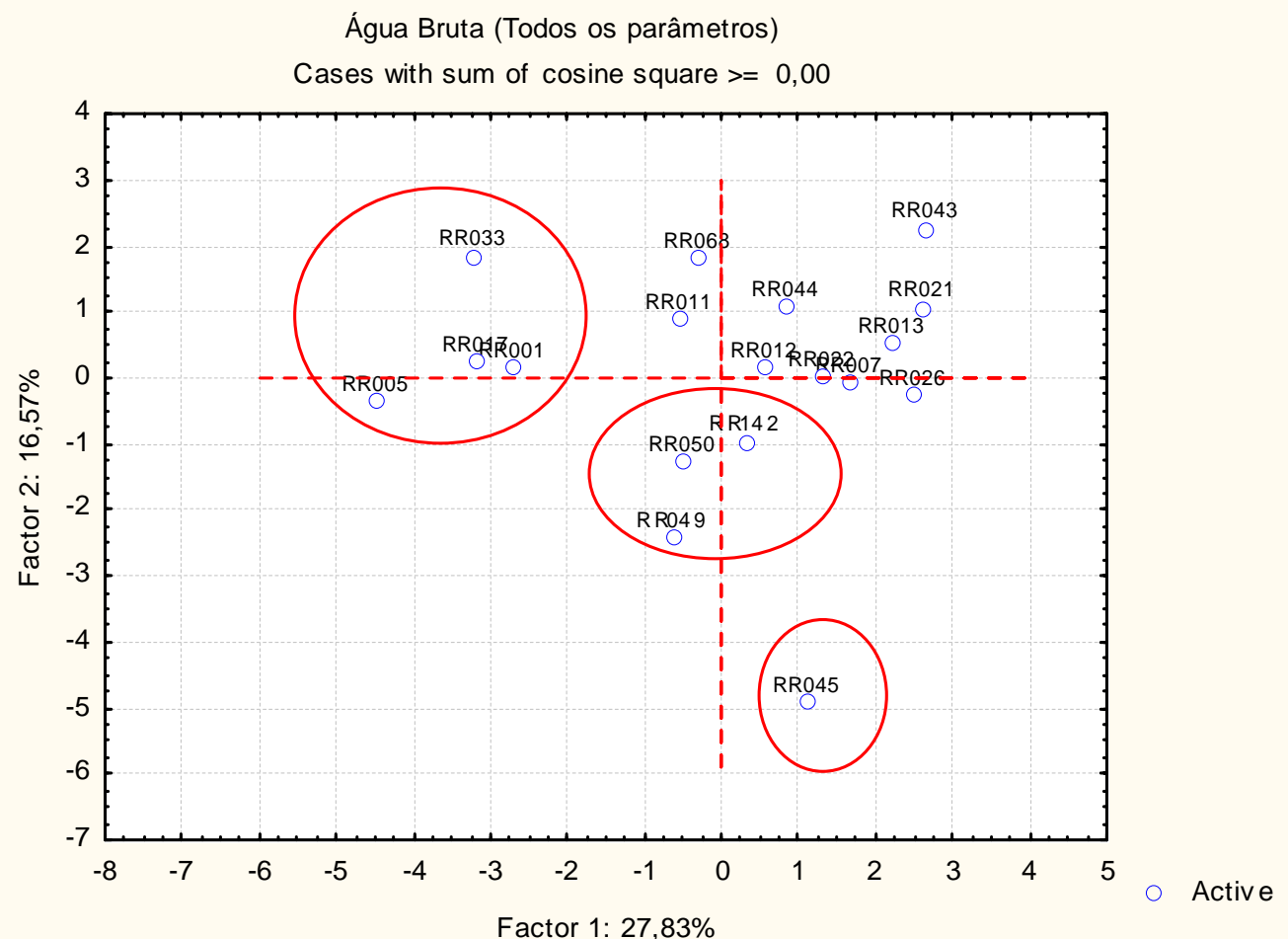

Figura 6.31 - Projeção dos pontos de captação - água bruta. 
Observa-se uma nítida separação entre as captações RR001-Registro, RR005-Sete Barras, RR017-Eldorado e RR033-Iguape. Esses 4 pontos referemse às captações de água existentes no Rio Ribeira de Iguape, indicando uma diferença no comportamento dos parâmetros avaliados nessa região quando comparadas com as restantes e, indicando uma característica do corpo de água utilizado para as captações.

\subsection{2 Água Tratada}

\subsubsection{Análise de correlação}

Para verificar a existência de multivariabilidade entre os dados, ou seja, quais são os parâmetros que possuem uma combinação linear entre si, foi obtida a matriz de correlação para as variáveis estudadas para água tratada.

A Tabela 6.10 apresenta a matriz de correlação para água tratada, onde são apresentados os coeficientes de correlação entre pH, turbidez e elementos metálicos e iônicos.

Podemos observar várias correlações definidas para a água tratada (14), indicando uma combinação linear entre os parâmetros destacados na Tabela. 
Tabela 6.10 - Matriz de correlação entre pH, turbidez, elementos metálicos e iônicos em água tratada.

\begin{tabular}{|c|c|c|c|c|c|c|c|c|c|c|c|c|c|c|c|c|c|}
\hline \multirow[b]{2}{*}{ Variable } & \multicolumn{17}{|c|}{\begin{tabular}{|l|} 
Correlations (Tratada-médias) \\
Marked correlations are significant at $p<, 05000$ \\
$\mathrm{~N}=17$ (Casewise deletion of missing data) \\
\end{tabular}} \\
\hline & $\mathrm{pH}$ & \begin{tabular}{|l|} 
Turbidez \\
\end{tabular} & $\mathrm{Al}$ & $\mathrm{Mn}$ & $\mathrm{Zn}$ & $\mathrm{Na}$ & $\mathrm{Mg}$ & $\mathrm{P}$ & $\mathrm{K}$ & $\mathrm{Ca}$ & $\mathrm{Fe}$ & $\mathrm{Ba}$ & $\mathrm{Pb}$ & Fluoreto & Cloreto & Nitrato & Sulfato \\
\hline $\mathrm{pH}$ & 1,00 & $-0,19$ & $-0,22$ & $-0,16$ & $-0,19$ & 0,18 & 0,07 & 0,04 & 0,03 & 0,12 & 0,11 & $-0,20$ & $-0,05$ & 0,12 & $-0,24$ & 0,35 & $-0,18$ \\
\hline Turbidez & $-0,19$ & 1,00 & 0,16 & 0,27 & $-0,10$ & 0,08 & 0,17 & $-0,31$ & $-0,14$ & $-0,09$ & 0,57 & 0,12 & 0,29 & $-0,21$ & 0,25 & $-0,22$ & $-0,01$ \\
\hline $\mathrm{Al}$ & $-0,22$ & 0,16 & 1,00 & $-0,40$ & 0,04 & $-0,06$ & 0,30 & 0,12 & $-0,10$ & 0,31 & $-0,21$ & 0,30 & 0,51 & 0,28 & $-0,10$ & $-0,24$ & 0,40 \\
\hline $\mathrm{Mn}$ & $-0,16$ & 0,27 & $-0,40$ & 1,00 & 0,20 & 0,15 & $-0,44$ & 0,19 & 0,27 & $-0,26$ & 0,45 & $-0,40$ & 0,12 & $-0,01$ & 0,49 & 0,18 & $-0,56$ \\
\hline $\mathrm{Zn}$ & $-0,19$ & $-0,10$ & 0,04 & 0,20 & 1,00 & $-0,30$ & $-0,09$ & $-0,23$ & 0,24 & $-0,05$ & $-0,23$ & 0,40 & 0,01 & 0,53 & $-0,21$ & 0,32 & $-0,03$ \\
\hline $\mathrm{Na}$ & 0,18 & 0,08 & $-0,06$ & 0,15 & $-0,30$ & 1,00 & $-0,38$ & $-0,20$ & 0,29 & $-0,66$ & 0,06 & $-0,51$ & 0,16 & $-0,17$ & 0,73 & $-0,16$ & $-0,25$ \\
\hline $\mathrm{Mg}$ & 0,07 & 0,17 & 0,30 & $-0,44$ & $-0,09$ & $-0,38$ & 1,00 & 0,22 & $-0,19$ & 0,74 & 0,18 & 0,69 & $-0,08$ & 0,13 & $-0,21$ & 0,19 & 0,78 \\
\hline $\mathrm{P}$ & 0,04 & $-0,31$ & 0,12 & 0,19 & $-0,23$ & $-0,20$ & 0,22 & 1,00 & 0,04 & 0,59 & 0,06 & $-0,08$ & $-0,04$ & 0,19 & $-0,01$ & 0,32 & 0,25 \\
\hline $\mathrm{K}$ & 0,03 & $-0,14$ & $-0,10$ & 0,27 & 0,24 & 0,29 & $-0,19$ & 0,04 & 1,00 & $-0,38$ & 0,19 & 0,23 & $-0,03$ & 0,00 & 0,32 & 0,26 & 0,00 \\
\hline $\mathrm{Ca}$ & 0,12 & $-0,09$ & 0,31 & $-0,26$ & $-0,05$ & $-0,66$ & 0,74 & 0,59 & $-0,38$ & 1,00 & 0,01 & 0,40 & $-0,07$ & 0,33 & $-0,46$ & 0,31 & 0,47 \\
\hline $\mathrm{Fe}$ & 0,11 & 0,57 & $-0,21$ & 0,45 & $-0,23$ & 0,06 & 0,18 & 0,06 & 0,19 & 0,01 & 1,00 & 0,08 & 0,15 & $-0,03$ & 0,30 & 0,09 & $-0,06$ \\
\hline $\mathrm{Ba}$ & $-0,20$ & 0,12 & 0,30 & $-0,40$ & 0,40 & $-0,51$ & 0,69 & $-0,08$ & 0,23 & 0,40 & 0,08 & 1,00 & $-0,09$ & 0,25 & $-0,37$ & 0,18 & 0,72 \\
\hline $\mathrm{Pb}$ & $-0,05$ & 0,29 & 0,51 & 0,12 & 0,01 & 0,16 & $-0,08$ & $-0,04$ & $-0,03$ & $-0,07$ & 0,15 & $-0,09$ & 1,00 & 0,27 & $-0,01$ & $-0,24$ & $-0,16$ \\
\hline Fluoreto & 0,12 & $-0,21$ & 0,28 & $-0,01$ & 0,53 & $-0,17$ & 0,13 & 0,19 & 0,00 & 0,33 & $-0,03$ & 0,25 & 0,27 & 1,00 & $-0,26$ & 0,64 & 0,11 \\
\hline Cloreto & $-0,24$ & 0,25 & $-0,10$ & 0,49 & $-0,21$ & 0,73 & $-0,21$ & $-0,01$ & 0,32 & $-0,46$ & 0,30 & $-0,37$ & $-0,01$ & $-0,26$ & 1,00 & $-0,13$ & $-0,13$ \\
\hline Nitrato & 0,35 & $-0,22$ & $-0,24$ & 0,18 & 0,32 & $-0,16$ & 0,19 & 0,32 & 0,26 & 0,31 & 0,09 & 0,18 & $-0,24$ & 0,64 & $-0,13$ & 1,00 & 0,06 \\
\hline Sulfato & $-0,18$ & $-0,01$ & 0,40 & $-0,56$ & $-0,03$ & $-0,25$ & 0,78 & 0,25 & 0,00 & 0,47 & $-0,06$ & 0,72 & $-0,16$ & 0,11 & $-0,13$ & 0,06 & 1,00 \\
\hline
\end{tabular}


Para a matriz do sulfato, observa-se boa correlação para $\mathrm{Mn}(0,56), \mathrm{Mg}$ $(0,78)$ e $\mathrm{Ba}(0,72)$. Esses elementos provem possivelmente da matriz mineralógica e podem estar associados também a impurezas dos insumos utilizados no processo de tratamento de água. Todas as ETA's do Vale do Ribeiro utilizam $\mathrm{Al}_{2} \mathrm{SO}_{4}$ como agente coagulante. Estudo realizado na avaliação de lodo de ETA's da região (REIS, 2006) demonstrou que o Mn na estação de tratamento está associado ao insumo utilizado na mesma.

\subsubsection{Análise de Componentes Principais}

A Tabela 6.11 apresenta um resumo da estatística obtida inicialmente, onde são mostrados os autovalores obtidos para cada componente, depois de submeter a matriz à rotação Varimax (onde o valor do corte é igual a 1), onde temos a fração explicada por cada componente e a porcentagem acumulada.

Em função do critério de autovalores acima de 1, 7 componentes foram considerados como significativos, sendo que a porcentagem de variabilidade acumulada explicada por eles é de 89,0\%. Observa-se que o primeiro componente é responsável por $25,5 \%$, o segundo por $14 \%$, o terceiro por $12 \%$ e assim sucessivamente.

Tabela 6.11 - Análise de componentes principais - água tratada.

\begin{tabular}{|c|c|c|c|}
\hline Fator & $\begin{array}{c}\text { Autovalor da } \\
\text { componente }\end{array}$ & $\begin{array}{c}\text { Variabilidade } \\
\text { explicada pela } \\
\text { componente (\%) }\end{array}$ & $\begin{array}{c}\text { Variabilidade } \\
\text { total explicada } \\
(\%)\end{array}$ \\
\hline 1 & 4,33 & 25,5 & 25,5 \\
\hline 2 & 2,41 & 14,2 & 39,7 \\
\hline 3 & 2,11 & 12,4 & 52,1 \\
\hline 4 & 1,92 & 11,3 & 63,4 \\
\hline 5 & 1,63 & 9,6 & 73,0 \\
\hline 6 & 1,46 & 8,6 & 81,6 \\
\hline 7 & 1,26 & 7,4 & 89,0 \\
\hline
\end{tabular}


A Tabela 6.12 apresenta os componentes retidos e sua matriz de fatores para cada variável.

Tabela 6.12 - Resultados da análise de componentes principais para a água tratada.

\begin{tabular}{|l|c|c|c|c|c|c|}
\hline Elemento & Fator 1 & Fator 2 & Fator 3 & Fator 4 & Fator 5 & Fator 6 \\
\hline $\mathrm{PH}$ & $-0,56$ & 0,15 & 0,36 & 0,10 & 0,28 & 0,04 \\
\hline Turbidez & 0,87 & 0,13 & 0,07 & 0,00 & 0,37 & 0,10 \\
\hline $\mathrm{Al}$ & 0,14 & 0,16 & 0,41 & 0,35 & 0,70 & $-0,16$ \\
\hline $\mathrm{Mn}$ & 0,08 & 0,13 & 0,17 & 0,02 & 0,78 & 0,11 \\
\hline $\mathrm{Zn}$ & 0,07 & $-0,02$ & 0,01 & 0,72 & 0,03 & $-0,60$ \\
\hline $\mathrm{Na}$ & $-0,04$ & 0,06 & $-0,98$ & $-0,05$ & 0,02 & 0,05 \\
\hline $\mathrm{Mg}$ & $-0,06$ & 0,89 & $-0,11$ & 0,18 & 0,29 & 0,04 \\
\hline $\mathrm{P}$ & $-0,15$ & 0,14 & 0,06 & 0,93 & 0,05 & 0,04 \\
\hline $\mathrm{K}$ & $-0,09$ & $-0,09$ & $-0,13$ & 0,10 & 0,77 & 0,24 \\
\hline $\mathrm{Ca}$ & $-0,05$ & 0,85 & 0,33 & 0,05 & $-0,01$ & $-0,02$ \\
\hline $\mathrm{Fe}$ & 0,29 & $-0,67$ & $-0,13$ & 0,14 & 0,40 & 0,11 \\
\hline $\mathrm{Ba}$ & 0,88 & $-0,21$ & 0,21 & $-0,12$ & $-0,06$ & 0,08 \\
\hline $\mathrm{Pb}$ & $-0,15$ & 0,14 & 0,40 & 0,64 & 0,37 & 0,33 \\
\hline $\mathrm{F}-$ & 0,10 & 0,71 & $-0,26$ & 0,37 & 0,42 & $-0,17$ \\
\hline $\mathrm{Cl}^{-}$ & $-0,08$ & $-0,21$ & $-0,85$ & $-0,15$ & $-0,25$ & $-0,27$ \\
\hline $\mathrm{NO}_{3}^{-}$ & 0,01 & 0,37 & 0,38 & $-0,20$ & 0,55 & $-0,40$ \\
\hline $\mathrm{SO}_{4}{ }^{2-}$ & $-0,16$ & 0,09 & $-0,13$ & $-0,01$ & $-0,19$ & $-0,85$ \\
\hline
\end{tabular}

Para auxiliar a interpretação da análise ACP, foi preparada a Tabela 6.13, que salienta os elementos retidos em cada componente, bem como a importância de cada componente na explicação da variabilidade dos elementos na água bruta. 
Tabela 6.13 - Esquematização das informações da ACP para os elementos em água tratada.

\begin{tabular}{|l|l|c|}
\hline & \multicolumn{1}{|c|}{ Elementos Retidos } & $\begin{array}{c}\text { Variabilidade } \\
\text { explicada (\%) }\end{array}$ \\
\hline Fator 1 & $\mathrm{Mg}, \mathrm{Ba} \mathrm{e} \mathrm{SO}_{4}{ }^{2-}$ & 25,5 \\
\hline Fator 2 & $\mathrm{P}$ & 14,2 \\
\hline Fator 3 & Turbidez e Fe & 12,4 \\
\hline Fator 4 & $\mathrm{Zn}$ & 11,3 \\
\hline Fator 5 & $\mathrm{Al} \mathrm{e} \mathrm{Pb}$ & 9,6 \\
\hline Fator 6 & $\mathrm{Na}, \mathrm{Ke} \mathrm{Cl}^{-}$ & 8,6 \\
\hline Fator 7 & $\mathrm{pH}$ & 7,4 \\
\hline
\end{tabular}

Observando a Tabela 6.13, os elementos retidos sugerem que os fatores estão associados a aos insumos utilizados no processo de tratamento de água. $\mathrm{O} \mathrm{Al}_{2}\left(\mathrm{SO}_{4}\right)_{3}$ é utilizado como agente coagulante em todas as estações do Vale do Ribeira. As concentrações de sulfato encontradas em amostras de água tratada foram maiores do que as concentrações em água bruta, confirmado a contribuição pelo tratamento.

Na Figura 6.32 apresenta-se uma representação gráfica dos resultados dos 3 primeiros fatores extraídos da análise de fatores. 

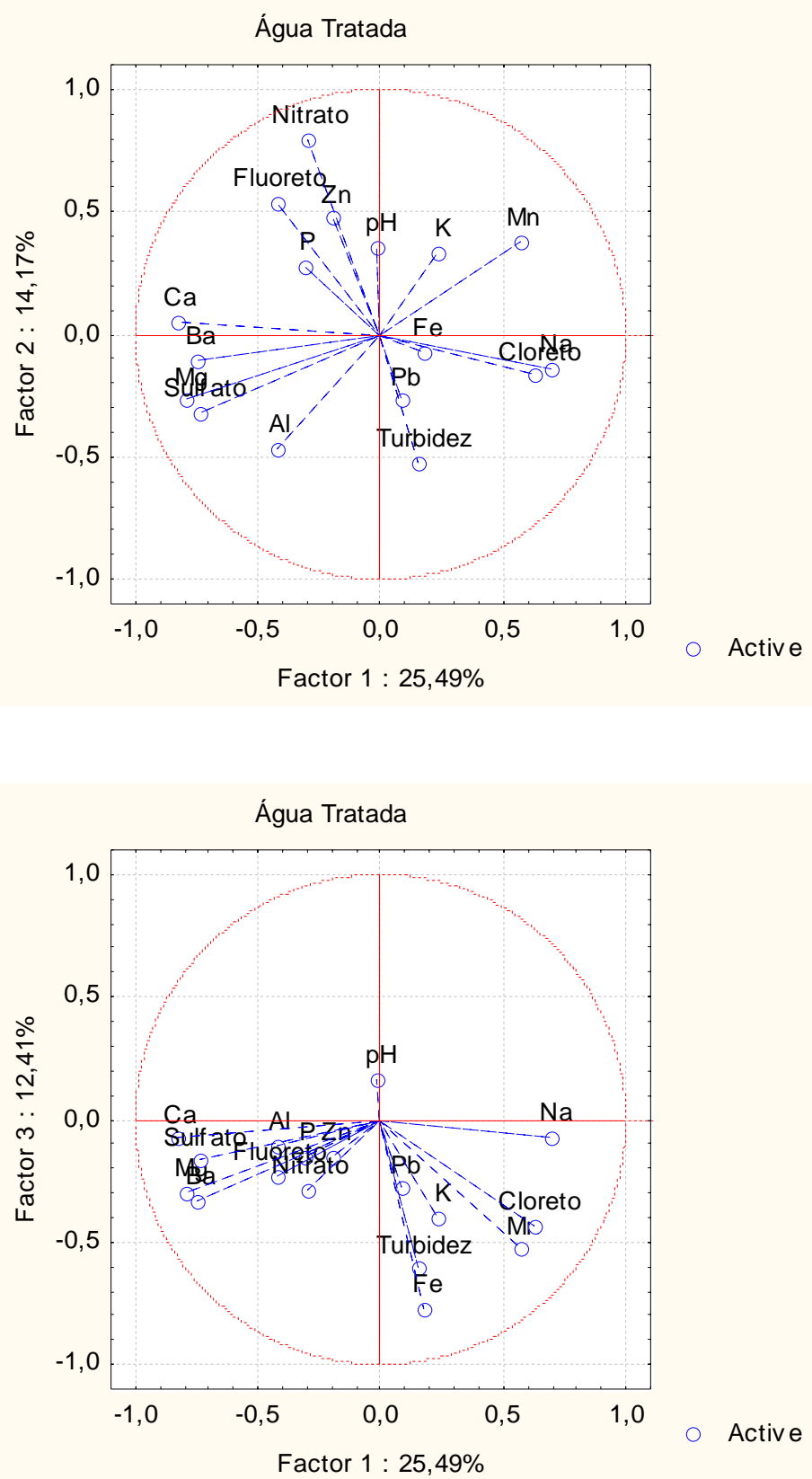

Figura 6.32 - Projeção das variáveis retidas nos fatores 1, 2 e 3.

Na Figura 6.33 apresenta-se o dendograma (projeção dos pontos de coleta) obtido para a água bruta, identificando regiões com o mesmo tipo de comportamento em relação a todas as variáveis avaliadas neste estudo.

Observam-se dois grupos de sistemas separados, este fato provavelmente está associado ao tipo de estação e a população atendida. 


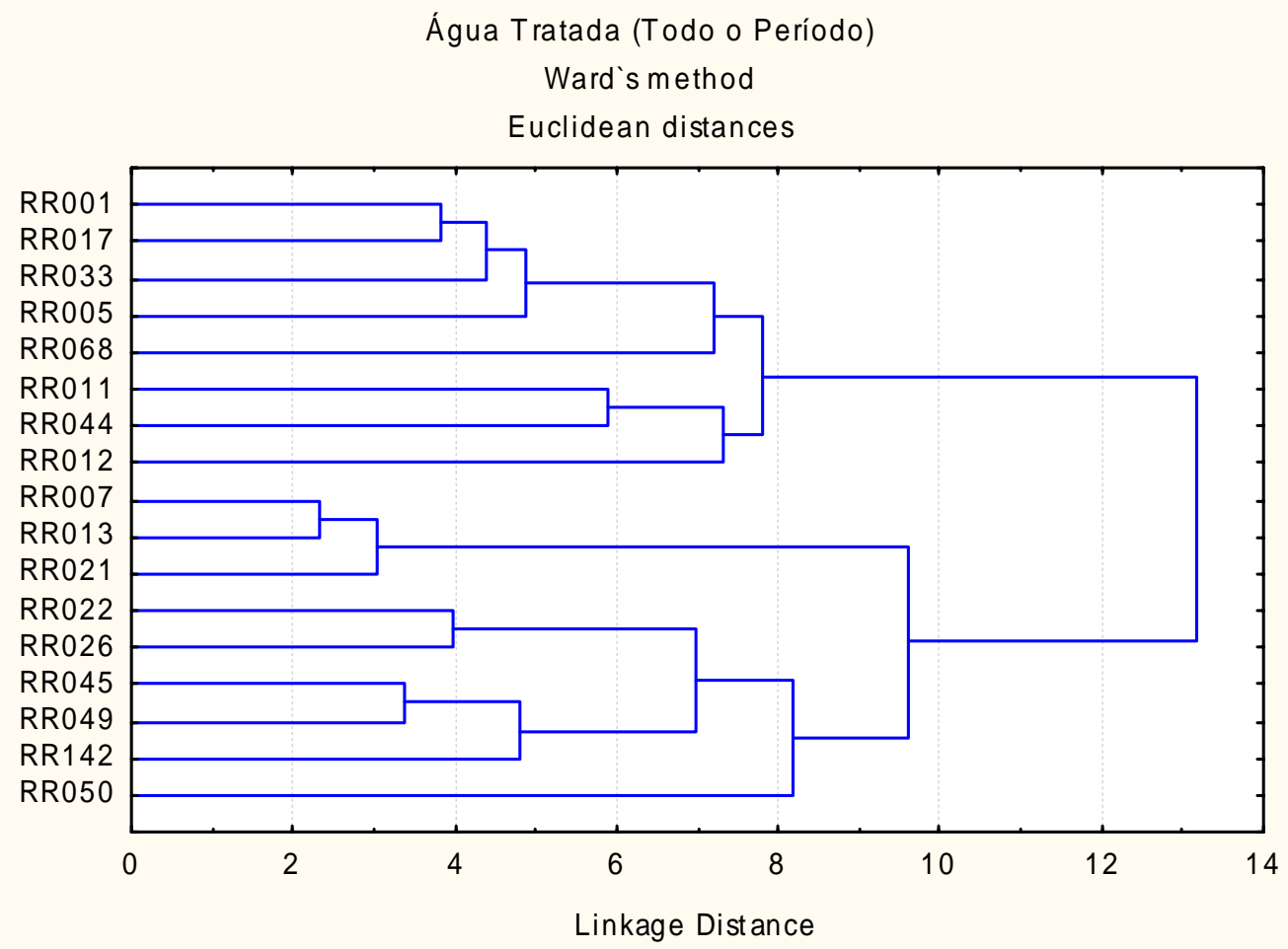

Figura 6.33 - Dendograma da concentração dos elementos avaliados para água tratada.

Projection of the cases on the factor-plane $\left(\begin{array}{ll}1 \times 2 & 2\end{array}\right)$

Cases with sum of cosine square $>=0,00$

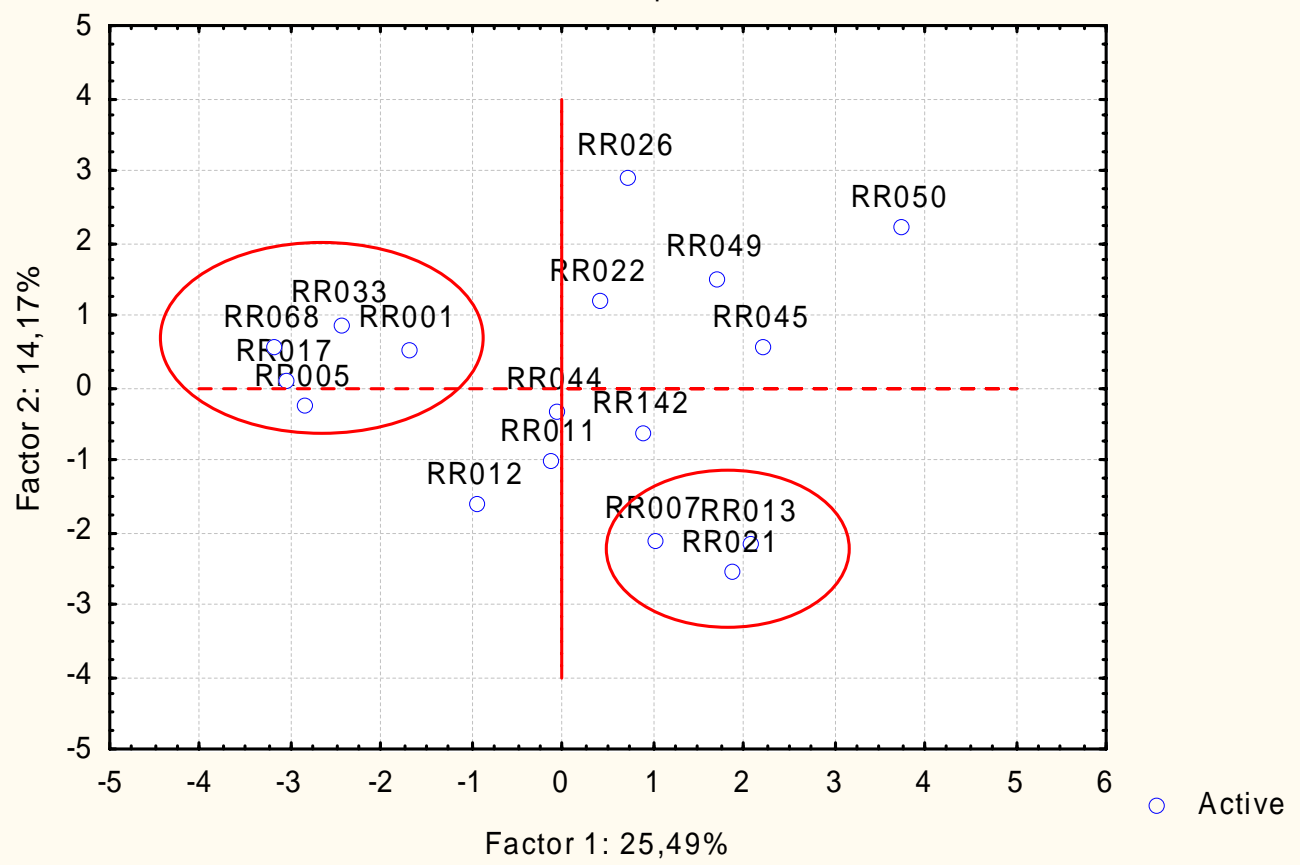

Figura 6.34 - Projeção dos pontos de coleta. 


\subsubsection{Manancial de Serra}

\subsubsection{Análise de correlação}

Para verificar a existência de multivariabilidade entre os dados, ou seja, quais são os parâmetros que possuem uma combinação linear entre si, foi obtida a matriz de correlação para as variáveis estudadas para manancial de serra.

A Tabela 6.14 apresenta a matriz de correlação para manancial de serra, onde são apresentados os coeficientes de correlação entre pH, turbidez e elementos metálicos e iônicos.

Podemos observar várias correlações definidas para manancial serra (14), indicando uma combinação linear entre os parâmetros destacados na tabela.

Para a matriz do turbidez, observa-se boa correlação para $\mathrm{Mn}(0,80)$, Zn $(0,91)$. Esses elementos provem possivelmente da matriz mineralógica, ligado ao material em suspensão que advém do arraste de (solo) terra resultante de processos erosivos, fenômeno típico de épocas de chuva na região. 
Tabela 6.14 - Matriz de correlação entre pH, turbidez, elementos metálicos e iônicos em manancial de serra.

\begin{tabular}{|c|c|c|c|c|c|c|c|c|c|c|c|c|c|c|c|c|c|}
\hline \multirow[b]{2}{*}{ Variable } & \multicolumn{17}{|c|}{$\begin{array}{l}\text { Correlations (serra médias) } \\
\text { Marked correlations are significant at } p<, 05000 \\
\mathrm{~N}=10 \text { (Casewise deletion of missing data) }\end{array}$} \\
\hline & $\mathrm{pH}$ & Turbidez & $\mathrm{Al}$ & $\mathrm{Mn}$ & $\mathrm{Zn}$ & $\mathrm{Na}$ & $\mathrm{Mg}$ & $\mathrm{P}$ & $\mathrm{K}$ & $\mathrm{Ca}$ & $\mathrm{Fe}$ & $\mathrm{Ba}$ & $\mathrm{Pb}$ & $\mathrm{F}$ & $\mathrm{Cl}$ & $\mathrm{NO} 3$ & SO4 \\
\hline $\mathrm{pH}$ & 1,00 & 0,29 & $-0,03$ & 0,44 & 0,22 & $-0,40$ & 0,33 & $-0,08$ & $-0,10$ & 0,43 & $-0,02$ & $-0,54$ & 0,62 & $-0,46$ & $-0,88$ & 0,58 & $-0,63$ \\
\hline Turbidez & 0,29 & 1,00 & 0,06 & 0,80 & 0,91 & 0,15 & 0,34 & 0,00 & 0,21 & $-0,03$ & 0,41 & $-0,19$ & 0,35 & 0,16 & $-0,50$ & 0,27 & $-0,35$ \\
\hline $\mathrm{Al}$ & $-0,03$ & 0,06 & 1,00 & 0,17 & 0,04 & 0,06 & $-0,45$ & 0,04 & 0,39 & $-0,11$ & 0,43 & 0,57 & $-0,00$ & $-0,05$ & 0,06 & 0,47 & 0,63 \\
\hline $\mathrm{Mn}$ & 0,44 & 0,80 & 0,17 & 1,00 & 0,73 & 0,14 & 0,03 & 0,28 & 0,15 & $-0,14$ & 0,39 & $-0,15$ & 0,24 & $-0,07$ & $-0,53$ & 0,24 & $-0,38$ \\
\hline $\mathrm{Zn}$ & 0,22 & 0,91 & 0,04 & 0,73 & 1,00 & 0,30 & 0,50 & $-0,01$ & 0,34 & 0,19 & 0,09 & $-0,05$ & 0,36 & $-0,04$ & $-0,42$ & 0,21 & $-0,23$ \\
\hline $\mathrm{Na}$ & $-0,40$ & 0,15 & 0,06 & 0,14 & 0,30 & 1,00 & $-0,21$ & $-0,11$ & 0,77 & 0,18 & 0,16 & 0,20 & 0,00 & $-0,14$ & 0,36 & $-0,42$ & 0,14 \\
\hline $\mathrm{Mg}$ & 0,33 & 0,34 & $-0,45$ & 0,03 & 0,50 & $-0,21$ & 1,00 & $-0,37$ & $-0,05$ & 0,58 & $-0,46$ & $-0,24$ & 0,60 & $-0,13$ & $-0,39$ & 0,32 & $-0,31$ \\
\hline $\mathrm{P}$ & $-0,08$ & 0,00 & 0,04 & 0,28 & $-0,01$ & $-0,11$ & $-0,37$ & 1,00 & $-0,11$ & $-0,43$ & 0,13 & 0,33 & $-0,61$ & 0,05 & $-0,15$ & $-0,26$ & $-0,14$ \\
\hline $\mathrm{K}$ & $-0,10$ & 0,21 & 0,39 & 0,15 & 0,34 & 0,77 & $-0,05$ & $-0,11$ & 1,00 & 0,50 & 0,34 & 0,43 & 0,34 & $-0,34$ & $-0,01$ & 0,12 & 0,16 \\
\hline $\mathrm{Ca}$ & 0,43 & $-0,03$ & $-0,11$ & $-0,14$ & 0,19 & 0,18 & 0,58 & $-0,43$ & 0,50 & 1,00 & $-0,31$ & $-0,03$ & 0,71 & $-0,73$ & $-0,40$ & 0,42 & $-0,23$ \\
\hline $\mathrm{Fe}$ & $-0,02$ & 0,41 & 0,43 & 0,39 & 0,09 & 0,16 & $-0,46$ & 0,13 & 0,34 & $-0,31$ & 1,00 & 0,18 & 0,09 & 0,21 & $-0,16$ & 0,27 & $-0,07$ \\
\hline $\mathrm{Ba}$ & $-0,54$ & $-0,19$ & 0,57 & $-0,15$ & $-0,05$ & 0,20 & $-0,24$ & 0,33 & 0,43 & $-0,03$ & 0,18 & 1,00 & $-0,27$ & $-0,07$ & 0,34 & 0,15 & 0,67 \\
\hline $\mathrm{Pb}$ & 0,62 & 0,35 & $-0,00$ & 0,24 & 0,36 & 0,00 & 0,60 & $-0,61$ & 0,34 & 0,71 & 0,09 & $-0,27$ & 1,00 & $-0,35$ & $-0,52$ & 0,65 & $-0,30$ \\
\hline$F$ & $-0,46$ & 0,16 & $-0,05$ & $-0,07$ & $-0,04$ & $-0,14$ & $-0,13$ & 0,05 & $-0,34$ & $-0,73$ & 0,21 & $-0,07$ & $-0,35$ & 1,00 & 0,46 & $-0,41$ & 0,29 \\
\hline $\mathrm{Cl}$ & $-0,88$ & $-0,50$ & 0,06 & $-0,53$ & $-0,42$ & 0,36 & $-0,39$ & $-0,15$ & $-0,01$ & $-0,40$ & $-0,16$ & 0,34 & $-0,52$ & 0,46 & 1,00 & $-0,62$ & 0,74 \\
\hline $\mathrm{NO} 3$ & 0,58 & 0,27 & 0,47 & 0,24 & 0,21 & $-0,42$ & 0,32 & $-0,26$ & 0,12 & 0,42 & 0,27 & 0,15 & 0,65 & $-0,41$ & $-0,62$ & 1,00 & $-0,05$ \\
\hline SO4 & $-0,63$ & $-0,35$ & 0,63 & $-0,38$ & $-0,23$ & 0,14 & $-0,31$ & $-0,14$ & 0,16 & $-0,23$ & $-0,07$ & 0,67 & $-0,30$ & 0,29 & 0,74 & $-0,05$ & 1,00 \\
\hline
\end{tabular}




\subsubsection{Análise de Componentes Principais}

A Tabela 6.15 apresenta um resumo da estatística obtida inicialmente, onde são mostrados os autovalores obtidos para cada componente, depois de submeter a matriz à rotação Varimax (onde o valor do corte é igual a 1), onde temos a fração explicada por cada componente e a porcentagem acumulada.

Em função do critério de autovalores acima de 1, foram considerados 6 componentes como significativos, sendo que a porcentagem de variabilidade acumulada explicada por eles é de 93,6\%. Observa-se que os 3 primeiros componentes são responsáveis por $66 \%$ da variabilidade total.

Tabela 6.15 - Análise de componentes principais - manancial de serra.

\begin{tabular}{|c|c|c|c|}
\hline Fator & $\begin{array}{c}\text { Autovalor da } \\
\text { componente }\end{array}$ & $\begin{array}{c}\text { Variabilidade } \\
\text { explicada pela } \\
\text { componente (\%) }\end{array}$ & $\begin{array}{c}\text { Variabilidade } \\
\text { total explicada } \\
(\%)\end{array}$ \\
\hline 1 & 5,26 & 31,0 & 31,0 \\
\hline 2 & 3,17 & 18,6 & 49,6 \\
\hline 3 & 2,75 & 16,2 & 65,8 \\
\hline 4 & 2,05 & 12,1 & 77,9 \\
\hline 5 & 1,52 & 8,95 & 86,8 \\
\hline 6 & 1,16 & 6,82 & 93,6 \\
\hline
\end{tabular}

A Tabela 6.16 apresenta os componentes retidos e sua matriz de fatores para cada variável. 
Tabela 6.16 - Resultados da análise de componentes principais para manancial de serra.

\begin{tabular}{|l|c|c|c|c|c|c|}
\hline Elemento & Fator 1 & Fator 2 & Fator 3 & Fator 4 & Fator 5 & Fator 6 \\
\hline $\mathrm{PH}$ & 0,25 & 0,10 & 0,77 & $-0,33$ & 0,17 & $-0,34$ \\
\hline Turbidez & 0,97 & 0,13 & 0,01 & 0,03 & 0,12 & $-0,09$ \\
\hline $\mathrm{Al}$ & 0,07 & 0,50 & 0,11 & 0,01 & 0,05 & 0,79 \\
\hline $\mathrm{Mn}$ & 0,83 & 0,30 & 0,20 & 0,03 & $-0,19$ & $-0,11$ \\
\hline $\mathrm{Zn}$ & 0,94 & $-0,20$ & 0,08 & 0,21 & 0,07 & 0,03 \\
\hline $\mathrm{Na}$ & 0,11 & 0,07 & $-0,18$ & 0,97 & 0,02 & 0,01 \\
\hline $\mathrm{Mg}$ & 0,39 & $-0,73$ & 0,22 & $-0,16$ & 0,42 & $-0,12$ \\
\hline $\mathrm{P}$ & 0,13 & 0,09 & 0,04 & $-0,09$ & $-0,95$ & 0,07 \\
\hline $\mathrm{K}$ & 0,19 & 0,15 & 0,25 & 0,83 & 0,16 & 0,34 \\
\hline $\mathrm{Ca}$ & $-0,06$ & $-0,42$ & 0,70 & 0,36 & 0,42 & 0,02 \\
\hline $\mathrm{Fe}$ & 0,30 & 0,86 & $-0,01$ & 0,10 & 0,03 & 0,12 \\
\hline $\mathrm{Ba}$ & $-0,08$ & $-0,02$ & $-0,04$ & 0,23 & $-0,29$ & 0,88 \\
\hline $\mathrm{Pb}^{\mathrm{F}-}$ & 0,29 & $-0,04$ & 0,54 & 0,06 & 0,74 & $-0,08$ \\
\hline $\mathrm{Cl}^{-}$ & 0,16 & 0,16 & $-0,86$ & $-0,31$ & 0,06 & $-0,04$ \\
\hline $\mathrm{NO}_{3}{ }^{-}$ & $-0,47$ & $-0,06$ & $-0,78$ & 0,27 & 0,03 & 0,25 \\
\hline $\mathrm{SO}_{4}{ }^{2-}$ & 0,24 & 0,15 & 0,66 & $-0,36$ & 0,39 & 0,41 \\
\hline
\end{tabular}

Para auxiliar a interpretação da análise ACP, foi preparada a Tabela 6.17, que salienta os elementos retidos em cada componente, bem como a importância de cada componente na explicação da variabilidade dos elementos em águas de manancial de serra. 
Tabela 6.17 - Esquematização das informações da ACP para os elementos em manancial de serra.

\begin{tabular}{|l|l|c|}
\hline & \multicolumn{1}{|c|}{ Elementos Retidos } & $\begin{array}{c}\text { Variabilidade } \\
\text { explicada (\%) }\end{array}$ \\
\hline Fator 1 & Turbidez, Al, Mn & 31,0 \\
\hline Fator 2 & $\mathrm{Mg}, \mathrm{Fe}$ & 18,6 \\
\hline Fator 3 & $\mathrm{pH}, \mathrm{Ca}, \mathrm{F}^{-}, \mathrm{Cl}^{-}$ & 16,2 \\
\hline Fator 4 & $\mathrm{Na} \mathrm{e} \mathrm{K}$ & 12,1 \\
\hline Fator 5 & $\mathrm{P} \mathrm{e} \mathrm{Pb}$ & 8,95 \\
\hline Fator 6 & $\mathrm{Ba} \mathrm{e} \mathrm{SO}{ }^{2-}$ & 6,82 \\
\hline
\end{tabular}

Observando a Tabela 6.17, nota-se que o primeiro e segundo fator explicam aproximadamente $50 \%$ da variabilidade total em águas de manancial de serra. Os elementos retidos sugerem estar associados a fatores mineralógicos.

$\mathrm{Na}$ Figura 6.35 apresenta-se uma representação gráfica dos resultados dos 2 primeiros fatores.

Verifica-se uma forte similaridade de comportamento entre as variáveis localizadas no mesmo quadrante e, quanto mais próximas elas estiverem maior a similaridade de comportamento. Temos uma similaridade de comportamento para as variáveis $\mathrm{Pb}, \mathrm{NO}_{3}{ }^{-}, \mathrm{K}, \mathrm{Fe}$, turbidez, $\mathrm{Zn}$ e $\mathrm{Mn}$, ou seja, quando a concentração de uma dessas variáveis aumenta, de maneira geral a concentração das outras também aumenta, sendo esse comportamento mais evidente para turbidez, Zn e $\mathrm{Mn}$.

No quadrante superior temos uma similaridade de comportamento para as variáveis $\mathrm{pH}, \mathrm{Ca}$ e $\mathrm{Mg}$, com comportamento semelhante ao explicado anteriormente e, com uma relação inversa ao quadrante inferior, ou seja, quando a concentração destas variáveis aumenta, existe uma tendência de diminuição da concentração das variáveis anteriores (quadrante inferior). 


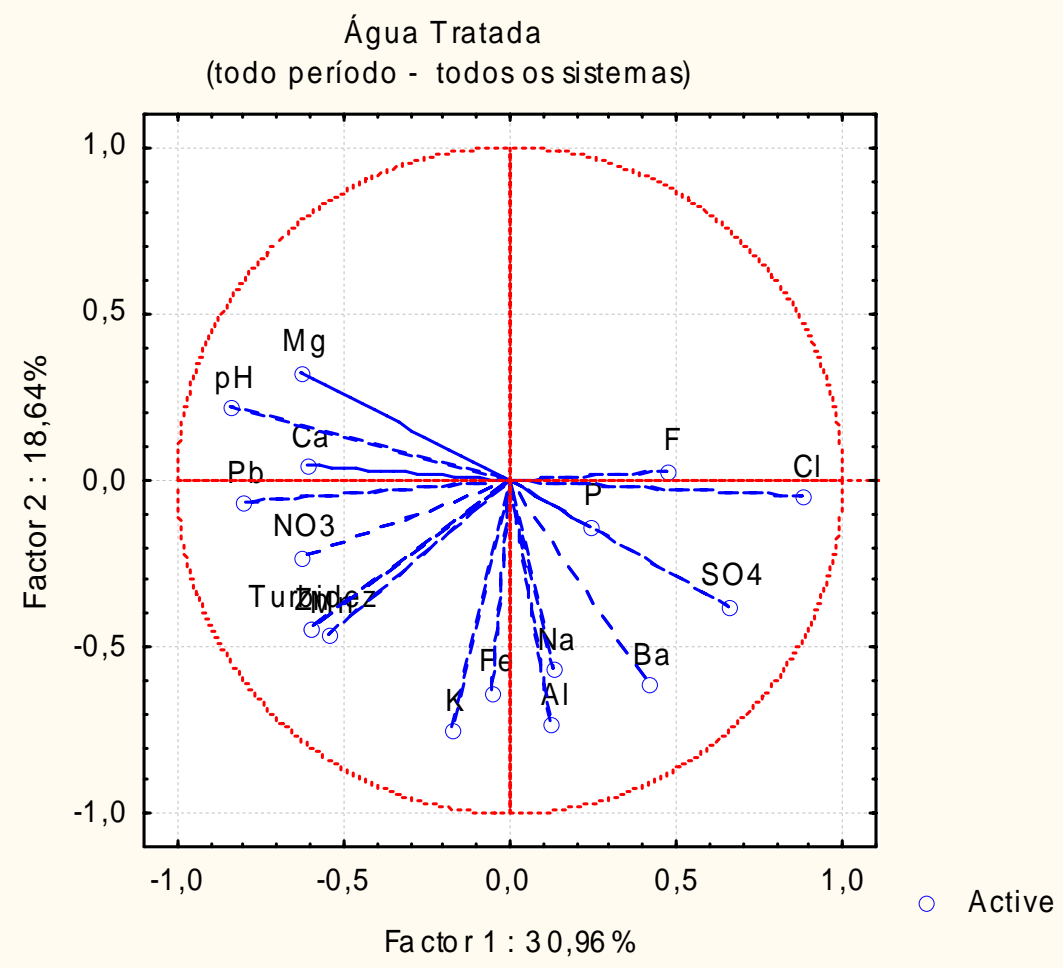

Figura 6.35 - Projeção das variáveis retidas nos fatores 1 e 2 em manancial de serra.

Na Figura 6.36 apresenta-se o dendograma obtido para manancial de serra, identificando regiões com o mesmo tipo de comportamento em relação a todas as variáveis avaliadas neste estudo.

Observa-se pela Figura 6.36, uma similaridade de comportamento em mananciais de serra localizados no mesmo município, como por exemplo as captações RR029-Musácea e RR030-Pedrinhas, ambas localizadas no município de Miracatu; RR052-Ana Dias e RR053-Raposo Tavares localizadas no município de Itariri.

No caso das captações RR014-Ariri localizada em Cananéia e a RR061- Pedrinhas localizada no município de Ilha Comprida, pode ser observada uma similaridade de comportamento, dada principalmente pela concentração de $\mathrm{Cl}^{-}$e na maiores do que as apresentadas nas demais captações, demonstrando uma clara influência da água do mar. 
Não se evidência nenhuma captação em manancial de serra com comportamento que se distancie das demais.

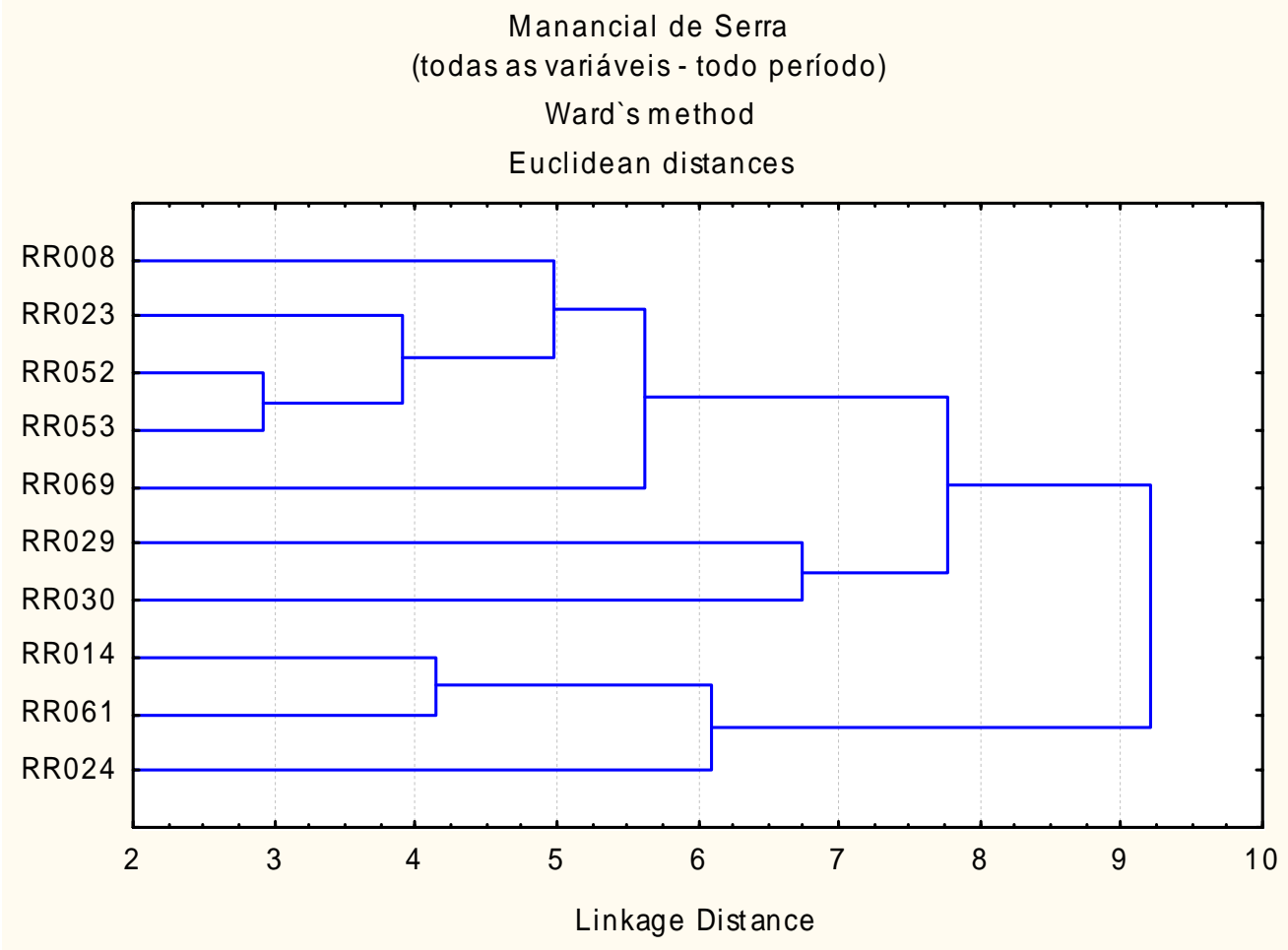

Figura 6.36 - Dendograma da concentração dos elementos avaliados para água de manancial de serra.

\subsubsection{Manancial Subterrâneo (Poços)}

\subsubsection{Análise de correlação}

Para verificar a existência de multivariabilidade entre os dados, ou seja, quais são os parâmetros que possuem uma combinação linear entre si, foi obtida a matriz de correlação para as variáveis estudadas para águas de poços. 
A Tabela 6.18 apresenta a matriz de correlação para água de poço, onde são apresentados os coeficientes de correlação entre $\mathrm{pH}$, turbidez e elementos metálicos e iônicos.

Podemos observar várias correlações definidas para a água de poço (14), indicando uma combinação linear entre os parâmetros destacados na tabela. 
Tabela 6.18 - Matriz de correlação entre pH, turbidez, elementos metálicos e iônicos em água de poços.

\begin{tabular}{|c|c|c|c|c|c|c|c|c|c|c|c|c|c|c|c|c|c|}
\hline \multirow[b]{2}{*}{ Variable } & \multicolumn{17}{|c|}{$\begin{array}{l}\text { Correlations (Poço-média (s Ag e B)) } \\
\text { Marked correlations are significant at } p<, 05000 \\
\mathrm{~N}=15 \text { (Casewise deletion of missing data) } \\
\end{array}$} \\
\hline & $\mathrm{pH}$ & Turbidez & $\mathrm{Al}$ & $\mathrm{Mn}$ & $\mathrm{Zn}$ & $\mathrm{Na}$ & $\mathrm{Mg}$ & $\mathrm{P}$ & $\mathrm{K}$ & $\mathrm{Ca}$ & $\mathrm{Fe}$ & $\mathrm{Ba}$ & $\mathrm{Pb}$ & Fluoreto & Cloreto & Nitrato & Sulfato \\
\hline $\mathrm{pH}$ & 1,00 & $-0,05$ & $\begin{array}{l}-0,08 \\
\end{array}$ & $-0,08$ & $-0,29$ & 0,04 & 0,78 & 0,06 & 0,65 & $\begin{array}{l}-0,07 \\
\end{array}$ & 0,03 & 0,91 & 0,06 & $-0,14$ & $-0,14$ & $-0,35$ & $-0,07$ \\
\hline Turbidez & $-0,05$ & 1,00 & 0,44 & 0,75 & 0,34 & $-0,06$ & 0,40 & $-0,38$ & $-0,08$ & 0,70 & 0,63 & $-0,17$ & $-0,35$ & $-0,28$ & 0,60 & $-0,38$ & 0,39 \\
\hline Al & $-0,08$ & 0,44 & 1,00 & 0,88 & $-0,21$ & $-0,10$ & 0,30 & $-0,17$ & $-0,55$ & 0,70 & $-0,03$ & $-0,25$ & 0,18 & $-0,07$ & 0,49 & $-0,14$ & $-0,01$ \\
\hline $\mathrm{Mn}$ & $-0,08$ & 0,75 & 0,88 & 1,00 & $-0,01$ & $-0,01$ & 0,35 & $-0,35$ & $-0,41$ & 0,77 & 0,21 & $-0,26$ & $-0,08$ & $-0,14$ & 0,60 & $-0,18$ & 0,14 \\
\hline $\mathrm{Zn}$ & $-0,29$ & 0,34 & $-0,21$ & $-0,01$ & 1,00 & 0,26 & $-0,22$ & 0,08 & 0,04 & $-0,05$ & 0,77 & $-0,16$ & $-0,33$ & 0,22 & 0,22 & $-0,43$ & 0,28 \\
\hline $\mathrm{Na}$ & 0,04 & $-0,06$ & $-0,10$ & $-0,01$ & 0,26 & 1,00 & 0,01 & $-0,16$ & 0,16 & 0,01 & 0,03 & $-0,05$ & 0,03 & 0,48 & 0,23 & $-0,23$ & 0,35 \\
\hline $\mathrm{Mg}$ & 0,78 & 0,40 & 0,30 & 0,35 & $-0,22$ & 0,01 & 1,00 & $-0,27$ & 0,39 & 0,32 & 0,24 & 0,60 & $-0,07$ & $-0,18$ & 0,33 & $-0,50$ & 0,12 \\
\hline $\mathrm{P}$ & 0,06 & $-0,38$ & $-0,17$ & $-0,35$ & 0,08 & $-0,16$ & $-0,27$ & 1,00 & $-0,33$ & $-0,25$ & $-0,00$ & 0,00 & $-0,09$ & 0,03 & $-0,51$ & $-0,14$ & $-0,61$ \\
\hline $\mathrm{K}$ & 0,65 & $-0,08$ & $-0,55$ & $-0,41$ & 0,04 & 0,16 & 0,39 & $-0,33$ & 1,00 & $-0,34$ & 0,11 & 0,78 & $-0,07$ & $-0,07$ & $-0,15$ & $-0,16$ & 0,39 \\
\hline $\mathrm{Ca}$ & $-0,07$ & 0,70 & 0,70 & 0,77 & $-0,05$ & 0,01 & 0,32 & $-0,25$ & $-0,34$ & 1,00 & 0,25 & $-0,24$ & 0,01 & $-0,10$ & 0,37 & $-0,08$ & 0,21 \\
\hline $\mathrm{Fe}$ & 0,03 & 0,63 & $-0,03$ & 0,21 & 0,77 & 0,03 & 0,24 & $-0,00$ & 0,11 & 0,25 & 1,00 & 0,05 & $-0,36$ & $-0,13$ & 0,27 & $-0,52$ & 0,24 \\
\hline $\mathrm{Ba}$ & 0,91 & $-0,17$ & $-0,25$ & $-0,26$ & $-0,16$ & $-0,05$ & 0,60 & 0,00 & 0,78 & $-0,24$ & 0,05 & 1,00 & 0,06 & $-0,19$ & $-0,33$ & $-0,20$ & $-0,08$ \\
\hline $\mathrm{Pb}$ & 0,06 & $-0,35$ & 0,18 & $-0,08$ & $-0,33$ & 0,03 & $-0,07$ & $-0,09$ & $-0,07$ & 0,01 & $-0,36$ & 0,06 & 1,00 & $-0,16$ & 0,03 & 0,35 & $-0,16$ \\
\hline Fluore & $-0,14$ & $-0,28$ & $-0,07$ & $-0,14$ & 0,22 & 0,48 & $-0,18$ & 0,03 & $-0,07$ & $-0,10$ & $-0,13$ & $-0,19$ & $-0,16$ & 1,00 & 0,05 & $-0,19$ & 0,31 \\
\hline Cloreto & $-0,14$ & & 0,49 & 0,60 & 0,22 & 0,23 & 0,33 & $-0,51$ & $-0,15$ & 0,37 & 0,27 & $-0,33$ & 0,03 & 0,05 & 1,00 & $-0,32$ & 0,41 \\
\hline Nitrato & $-0,35$ & $-0,38$ & $-0,14$ & $-0,18$ & $-0,43$ & $-0,23$ & $-0,50$ & $-0,14$ & $-0,16$ & $-0,08$ & $-0,52$ & $-0,20$ & 0,35 & $-0,19$ & $-0,32$ & 1,00 & $-0,40$ \\
\hline Sulfato & $-0,07$ & 0,39 & $-0,01$ & 0,14 & 0,28 & 0,35 & 0,12 & $-0,61$ & 0,39 & 0,21 & 0,24 & $-0,08$ & $-0,16$ & 0,31 & 0,41 & $-0,40$ & 1,00 \\
\hline
\end{tabular}




\subsubsection{Análise de Componentes Principais}

A Tabela 6.19 apresenta um resumo da estatística obtida inicialmente, onde são mostrados os autovalores obtidos para cada componente, depois de submeter a matriz à rotação Varimax (onde o valor do corte é igual a 1), onde temos a fração explicada por cada componente e a porcentagem acumulada.

Em função do critério de autovalores acima de 1, foram considerados 5 componentes como significativos, sendo que a porcentagem de variabilidade acumulada explicada por eles é de 83\%. Observa-se que os 3 primeiros componentes são responsáveis por $63 \%$ da variabilidade total.

Tabela 6.19 - Análise de componentes principais - água poços.

\begin{tabular}{|c|c|c|c|}
\hline Fator & $\begin{array}{c}\text { Autovalor da } \\
\text { componente }\end{array}$ & $\begin{array}{c}\text { Variabilidade } \\
\text { explicada pela } \\
\text { componente (\%) }\end{array}$ & $\begin{array}{c}\text { Variabilidade } \\
\text { total explicada } \\
(\%)\end{array}$ \\
\hline 1 & 4,56 & 26,8 & 26,8 \\
\hline 2 & 3,47 & 20,4 & 47,2 \\
\hline 3 & 2,73 & 16,1 & 63,3 \\
\hline 4 & 1,92 & 11,3 & 74,5 \\
\hline 5 & 1,38 & 8,14 & 82,7 \\
\hline
\end{tabular}

A Tabela 6.20 apresenta os componentes retidos e sua matriz de fatores para cada variável. 
Tabela 6.20 - Resultados da análise de componentes principais para água de poço.

\begin{tabular}{|l|r|r|r|r|r|}
\hline Elemento & Fator 1 & Fator 2 & Fator 3 & Fator 4 & \multicolumn{1}{|c|}{ Fator 5 } \\
\hline $\mathrm{pH}$ & 0,05 & $-0,98$ & $-0,07$ & $-0,09$ & 0,00 \\
\hline Turbidez & $-0,68$ & $-0,04$ & 0,55 & 0,36 & $-0,24$ \\
\hline $\mathrm{Al}$ & $-0,93$ & 0,03 & $-0,19$ & $-0,10$ & 0,02 \\
\hline $\mathrm{Mn}$ & $-0,94$ & 0,03 & 0,07 & 0,12 & $-0,07$ \\
\hline $\mathrm{Zn}$ & 0,11 & 0,24 & 0,84 & 0,10 & 0,20 \\
\hline $\mathrm{Na}$ & 0,02 & $-0,04$ & 0,05 & 0,24 & 0,77 \\
\hline $\mathrm{Mg}$ & $-0,42$ & $-0,85$ & 0,07 & 0,12 & $-0,03$ \\
\hline $\mathrm{P}$ & 0,23 & 0,04 & 0,16 & $-0,92$ & 0,03 \\
\hline $\mathrm{K}$ & 0,51 & $-0,67$ & 0,10 & 0,50 & $-0,01$ \\
\hline $\mathrm{Ca}$ & $-0,83$ & 0,03 & 0,06 & 0,13 & $-0,09$ \\
\hline $\mathrm{Fe}$ & $-0,16$ & $-0,10$ & 0,89 & 0,11 & $-0,13$ \\
\hline $\mathrm{Ba}$ & 0,30 & $-0,91$ & $-0,04$ & 0,00 & $-0,13$ \\
\hline $\mathrm{Pb}^{-0,0,04}$ & $-0,01$ & $-0,65$ & 0,06 & $-0,02$ \\
\hline $\mathrm{F}-$ & $-0,10$ & 0,16 & 0,02 & $-0,03$ & 0,86 \\
\hline $\mathrm{Cl}^{-}$ & $-0,63$ & 0,07 & 0,17 & 0,45 & 0,21 \\
\hline $\mathrm{NO}_{3}^{-}$ & 0,25 & 0,44 & $-0,63$ & 0,09 & $-0,40$ \\
\hline $\mathrm{SO}_{4}{ }^{2-}$ & $-0,09$ & $-0,03$ & 0,27 & 0,76 & 0,38 \\
\hline
\end{tabular}

Para auxiliar a interpretação da análise ACP, foi preparada a Tabela 6.21, que salienta os elementos retidos em cada componente, bem como a importância de cada componente na explicação da variabilidade dos elementos em águas de manancial de serra. 
Tabela 6.21 - Esquematização das informações da ACP para os elementos em água de poço.

\begin{tabular}{|l|l|c|}
\hline & \multicolumn{1}{|c|}{ Elementos Retidos } & $\begin{array}{c}\text { Variabilidade } \\
\text { explicada (\%) }\end{array}$ \\
\hline Fator 1 & $\mathrm{Al}, \mathrm{Mn} \mathrm{e} \mathrm{Ca}$ & 26,8 \\
\hline Fator 2 & $\mathrm{pH}, \mathrm{Mg} \mathrm{e} \mathrm{Ba}$ & 20,4 \\
\hline Fator 3 & $\mathrm{Zn} \mathrm{e} \mathrm{Fe}$ & 16,1 \\
\hline Fator 4 & $\mathrm{Pe} \mathrm{SO}_{4}^{2-}$ & 11,3 \\
\hline Fator 5 & $\mathrm{Na} \mathrm{e} \mathrm{F}$ & 8,14 \\
\hline
\end{tabular}

Observando a Tabela 6.21, nota-se que o primeiro e segundo fator explicam aproximadamente $50 \%$ da variabilidade total em águas de poços.

Os elementos retidos na primeira e no segundo fator sugerem que estes fatores estão associados às formações rochosas associadas ao sistema aquífero, compostos por rochas ígneas e metamórficas, bem como rochas sedimentares cenozóicas.

As águas subterrâneas contidas nas sub-bacias hidrográficas componentes da Bacia Hidrográfia do Ribeira de Iguape e Litoral Sul distribuemse por dois sistemas aquíferos distintos caracterizados por tipos de formações rochosas bastante diferenciadas do ponto de vista litológico que compõem o Aquífero Cristalino e Sedimentar. As águas dos aquíferos foram classificadas como bicarbonatadas sódicas e cálcicas e cloretadas sódicas e bicarbonatadas cálcicas. (CETEC, 2000).

Na Figura 6.37 apresenta-se uma representação gráfica dos resultados dos 2 primeiros fatores.

Verifica-se uma forte similaridade de comportamento entre as variáveis $\mathrm{SO}_{4}{ }^{2-}$ e $\mathrm{Fe}$; $\mathrm{Na}$ e $\mathrm{Mg}$; com comportamento inversamente proporcional Ca e Mn. 


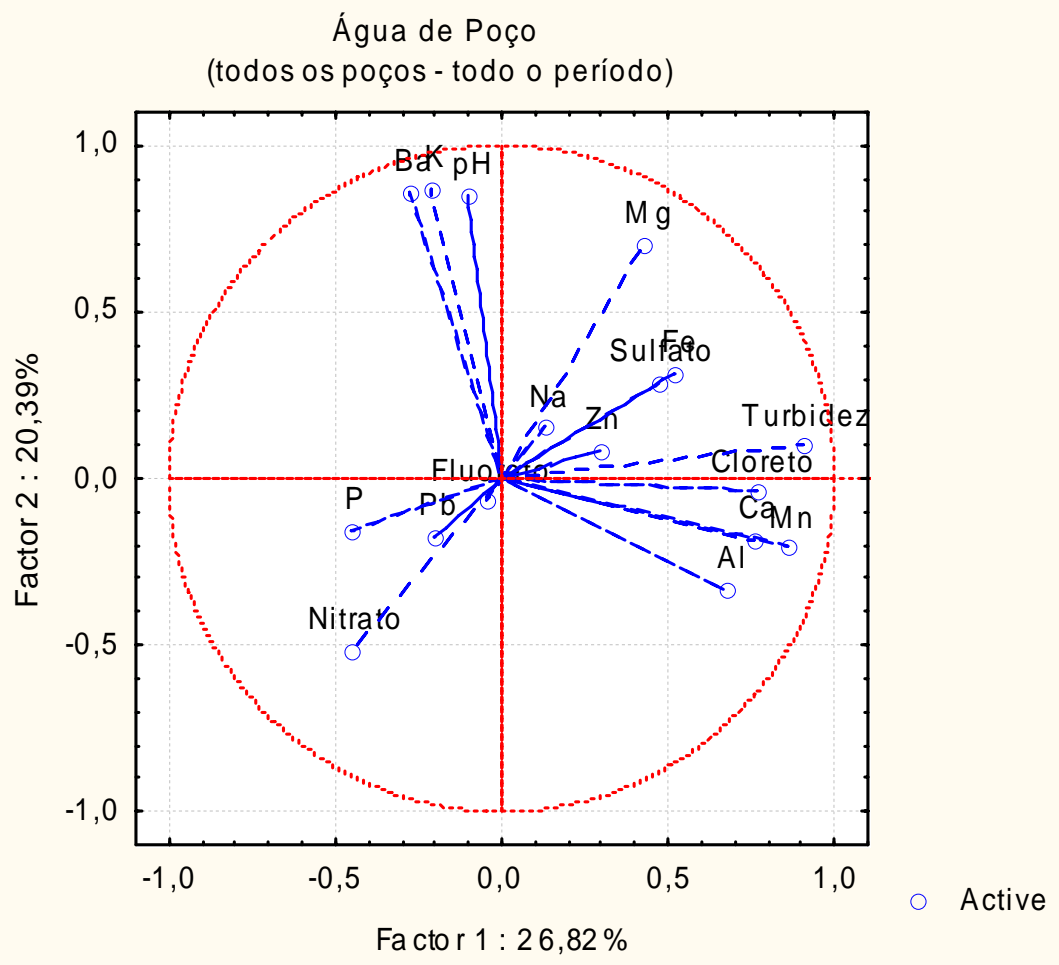

Figura 6.37 - Projeção das variáveis retidas nos fatores 1 e 2.

Na Figura 6.38 apresenta-se o dendograma obtido para a água bruta, identificando regiões com o mesmo tipo de comportamento em relação a todas as variáveis avaliadas neste estudo.

Não se evidência nenhuma captação em manancial subterrâneo com comportamento que se distancie das demais, com exceção da RR-060 - Vila Deco, poço localizado em Cajati. 
Água de Poço

(todas as variáveis - todo o período)

Ward`s method

Euclidean distances

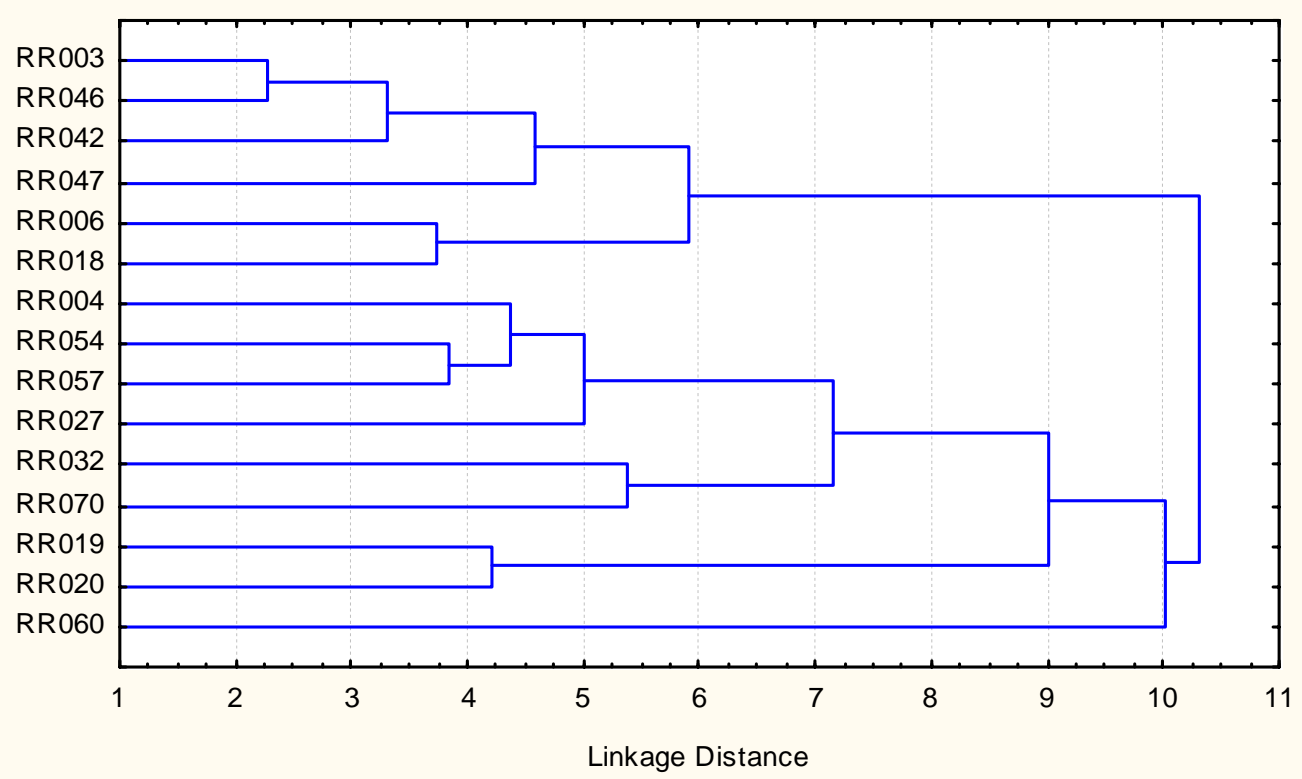

Figura 6.38 - Dendograma da concentração dos elementos avaliados para água de poço.

\subsection{Análise Discriminante e Melhores Predictores}

Com o objetivo de determinar quais elementos químicos mais contribuem na classificação da qualidade da água em uma região, foi utilizada a técnica de análise descriminante e de melhores predictores.

O caminho para estabelecer esses relacionamentos são diversos. $O$ ponto crítico em todos eles é o tamanho da amostra. A base de dados utilizada traz 5 observações para cada região (18 regiões no caso de manacial superficial), no entanto, esse número garante pouca significância para estabelecer algum critério que resulte na conclusão. Os dados, no entanto, podem revelar quais elementos são mais importantes para discriminar uma região. Por exemplo, podemos análisar que os elementos $\mathrm{Mg}$, $\mathrm{Ca}$ e $\mathrm{Na}$ contribuem significativamente para discriminar as 18 regiões, estabelecendo um modelo adequado para evidenciar que a presença desses elementos classifica as regiões. Para garantir a 
qualidade da água, é preciso observar outras informações que não estão totalmente contempladas nessa base de dados.

Portanto, a metodologia de estudo avalia quais elementos são importantes para classificar a região onde os dados foram coletados.

Utilizou-se o Software STATISTICA 7 da StatiSoft, no ambiente Data Mining com seus recursos e técnicas para mineração da informação. O primeiro passo foi o reconhecimento dos dados e seu relacionamento interno (entre variáveis). Atenção especial foi dada à Análise Discriminante (GDA Analysis) e à Análise de Melhores Preditores (Feature Selection). A Figura 6.39, mostra o ambiente de "Mining" onde as análises foram representadas.

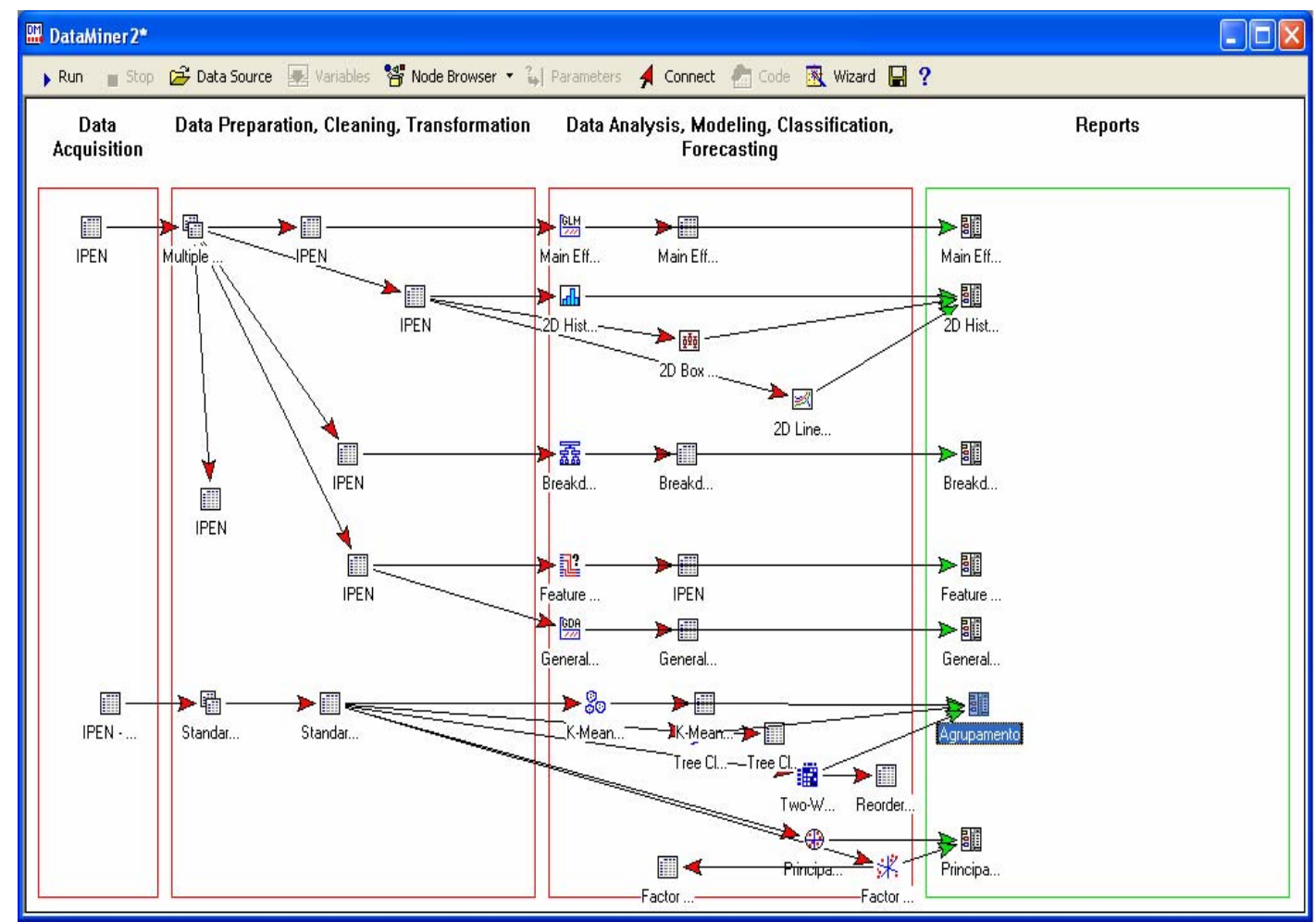

Figura 6.39 - Tela do ambiente "Minning", onde as análises são representadas. 


\subsubsection{Análise de Melhores Preditores:}

O objetivo idéia dessa técnica é evidenciar quais elementos são mais importantes (em termos de contribuição) para discriminar grupos, ou seja regiões de onde as amostras foram coletadas. Na Figura 6.40, temos a representação esquemática dos resultados obtidos.

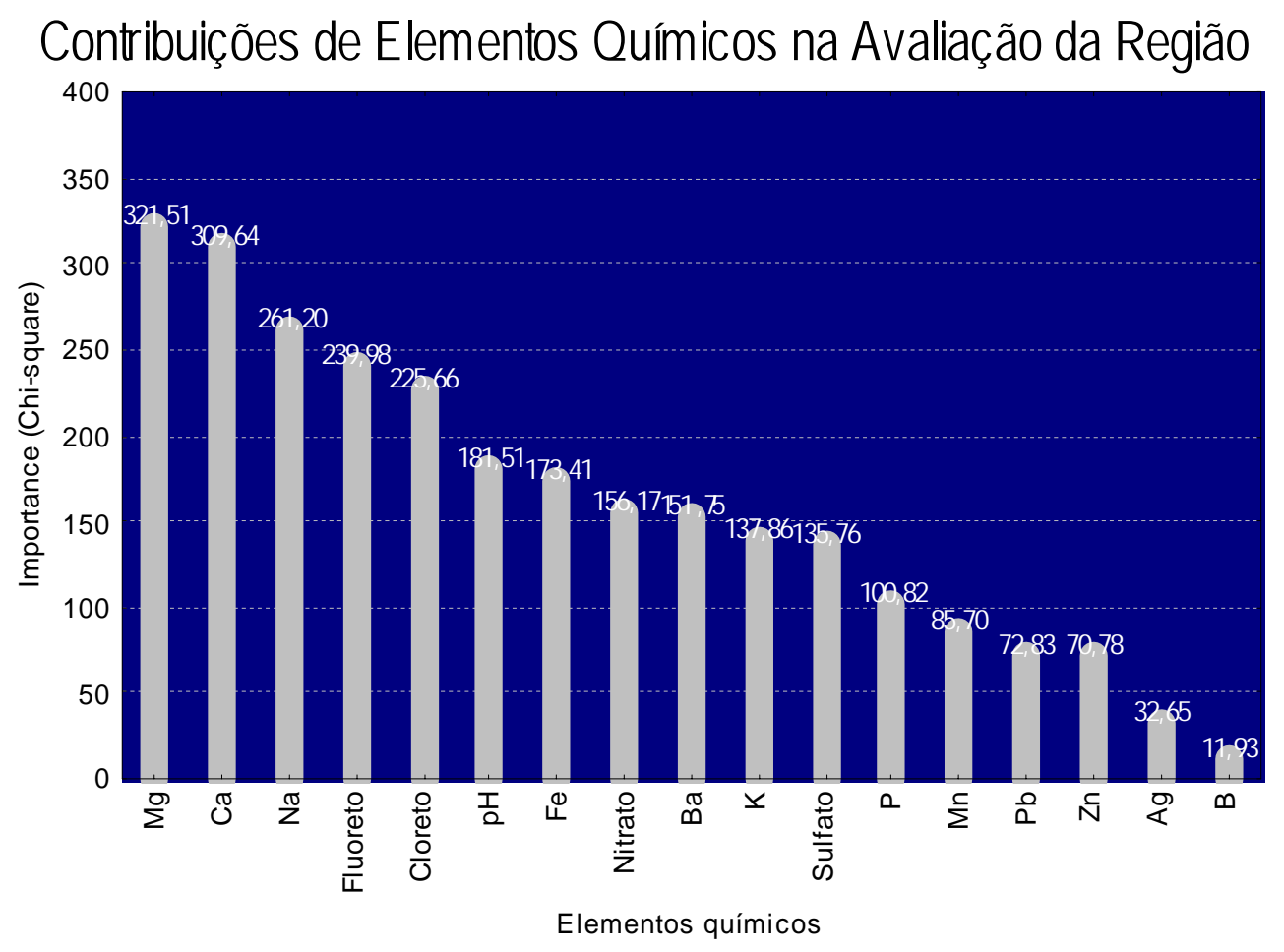

Figura 6.40 - Representação esquemática da análise de melhores preditores Água bruta.

A estatística Qui-Quadrado mede a significância de cada elemento nesta tarefa de discriminar regiões. Observando os resultados apresentados na Figura 6.40, temos indicação de que os elementos $\mathrm{Mg}$, Ca e $\mathrm{Na}$ são os 3 mais importantes para separar regiões.

O mesmo procedimento foi realizado para avaliação das regiões comutilizando os dados de mananciais de serra e captações subterrâneas. Nas figuras: Figura 6.41 e Figura 6.42, são apresentadas as representações 
esquemáticas para as regiões avaliando mananciais de serra e captações subterrâneas.

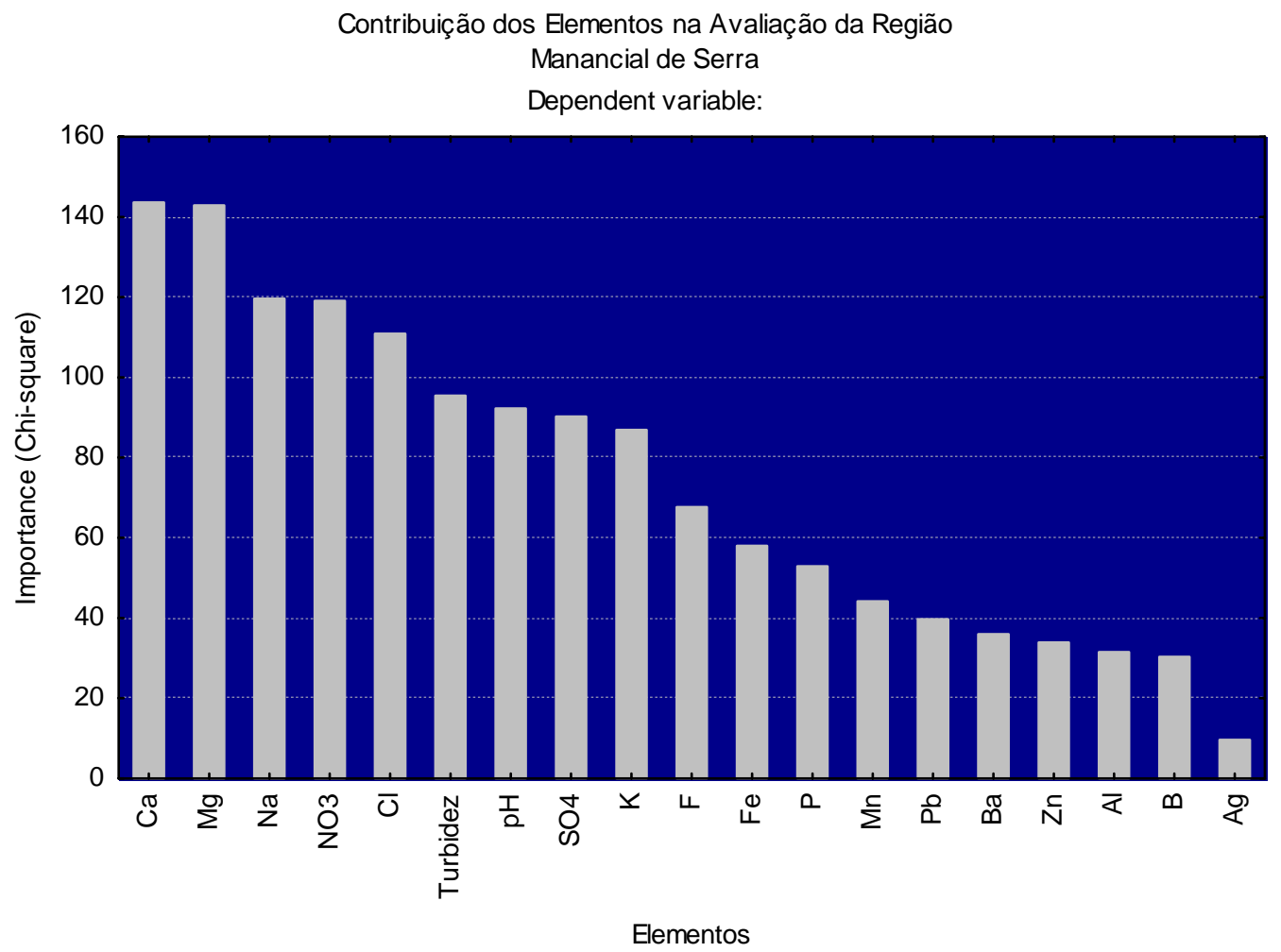

Figura 6.41 - Representação esquemática da análise de melhores preditores Manancial de Serra.

Observando os resultados apresentados na Figura 6.41 e na Figura 6.42, temos indicação de que os elementos $\mathrm{Mg}$, Ca e $\mathrm{Na}$ são também os 3 elementos mais importantes para separar regiões. Tem-se portanto, uma forte indicação de que esses 3 elementos podem caracterizar a região do Vale do Ribeira. 


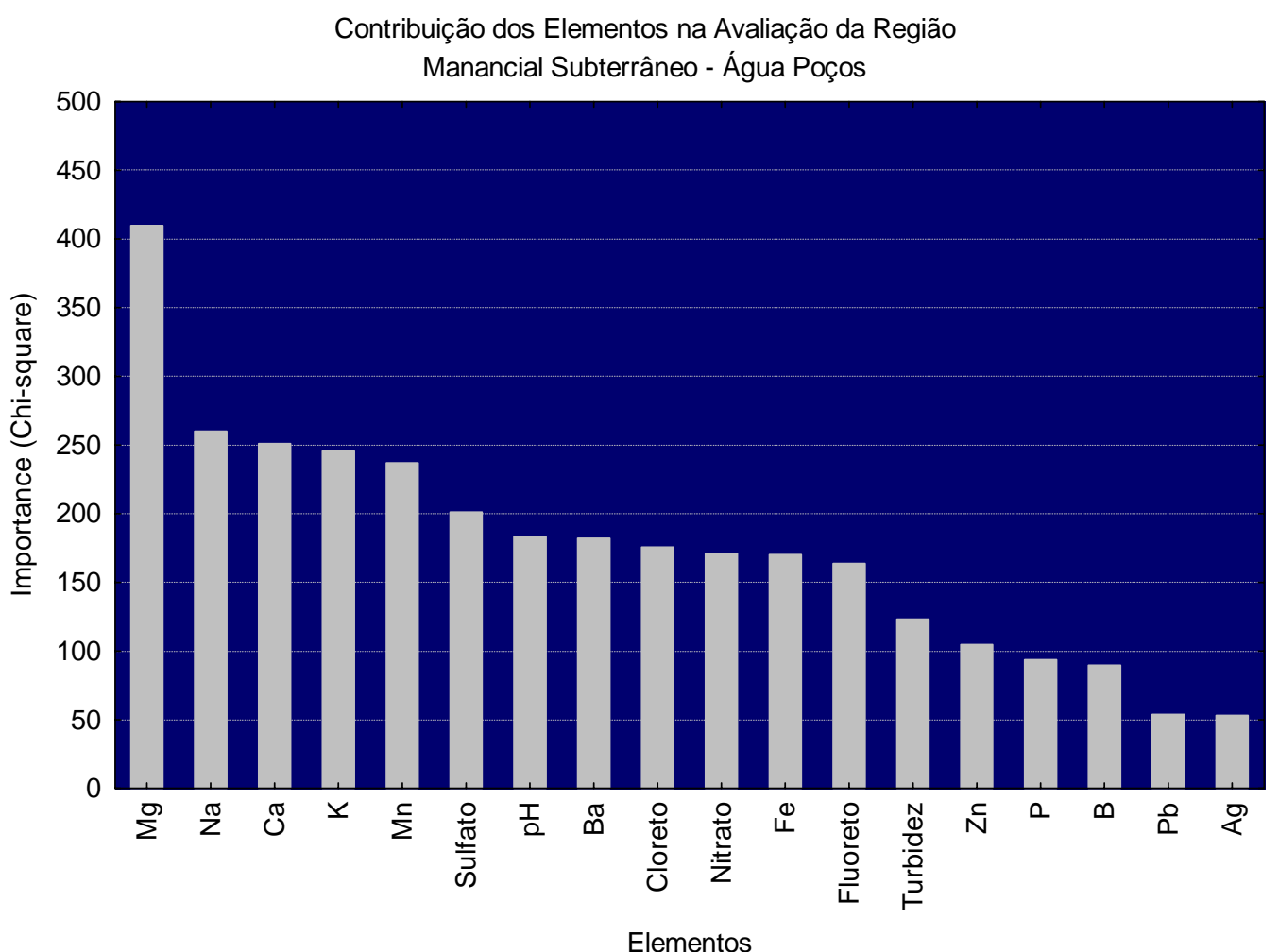

Figura 6.42 - Representação esquemática da análise de melhores preditores Manancial Subterrâneo - Água de poços.

\subsubsection{Análise Discriminante:}

Uma das pressuposições da análise discriminante é que uma porcentagem considerável de correlações seja significante e não menor que 0,30. A Tabela 6.22 apresenta a matriz de correlação obtida. 
Tabela 6.22 - Matriz de correlação para água bruta.

\begin{tabular}{|c|c|c|c|c|c|c|c|c|c|c|c|c|}
\hline \multirow[b]{2}{*}{ Variable } & \multicolumn{12}{|c|}{$\begin{array}{l}\text { Correlations (SUperficia (todos os meses)) } \\
\text { Marked correlations are significant at } p<, 05000 \\
\mathrm{~N}=77 \text { (Casewise deletion of missing data) }\end{array}$} \\
\hline & \begin{tabular}{|l|}
$\mathrm{Al}$ \\
\end{tabular} & $\mathrm{Ag}$ & B & $\mathrm{Mn}$ & $\mathrm{Zn}$ & $\mathrm{Na}$ & $\mathrm{Mg}$ & $P$ & K & $\mathrm{Ca}$ & $\mathrm{Fe}$ & $\mathrm{Ba}$ \\
\hline $\mathrm{Al}$ & 1,00 & & & & & & & & & & & \\
\hline $\mathrm{Ag}$ & $-0,10$ & 1,00 & & & & & & & & & & \\
\hline B & $-0,15$ & 0,60 & 1,00 & & & & & & & & & \\
\hline $\mathrm{Mn}$ & 0,64 & $-0,11$ & $-0,15$ & 1,00 & & & & & & & & \\
\hline $\mathrm{Zn}$ & 0,43 & $-0,05$ & $-0,05$ & 0,29 & 1,00 & & & & & & & \\
\hline $\mathrm{Na}$ & $-0,30$ & $-0,10$ & 0,09 & $-0,17$ & $-0,17$ & 1,00 & & & & & & \\
\hline $\mathrm{Mg}$ & 0,06 & $-0,10$ & $-0,11$ & 0,10 & $-0,01$ & 0,18 & 1,00 & & & & & \\
\hline $\mathrm{P}$ & $-0,03$ & $-0,10$ & $-0,14$ & $-0,13$ & $-0,03$ & 0,07 & 0,17 & 1.00 & & & & \\
\hline K & 0,41 & $-0,28$ & $-0,29$ & 0,36 & 0,09 & 0,04 & $-0,01$ & 0,35 & 1,00 & & & \\
\hline $\mathrm{Ca}$ & 0,07 & 0,07 & $-0,02$ & $-0,00$ & $-0,01$ & $-0,22$ & 0,73 & 0,11 & $-0,11$ & 1,00 & & \\
\hline $\mathrm{Fe}$ & 0,61 & $-0,17$ & $-0,17$ & 0,50 & 0,33 & $-0,01$ & $-0,31$ & $-0,11$ & 0,44 & $-0,31$ & 1,00 & \\
\hline $\mathrm{Ba}$ & 0,14 & $-0,05$ & $-0,07$ & 0,18 & 0,06 & $-0,22$ & $-0,24$ & $-0,10$ & 0,07 & $-0,17$ & 0,38 & 1,00 \\
\hline $\mathrm{Pb}$ & 0,45 & $-0,08$ & $-0,08$ & 0,42 & 0,28 & $-0,29$ & 0,04 & 0,01 & 0,19 & 0,05 & 0,18 & $-0,05$ \\
\hline Fluoreto & 0,10 & 0,13 & 0,06 & 0,05 & 0,02 & 0,19 & 0,51 & 0,18 & 0,18 & 0,37 & $-0,11$ & $-0,16$ \\
\hline Cloreto & $-0,23$ & $-0,11$ & $-0,03$ & $-0,14$ & $-0,06$ & 0,69 & $-0,15$ & $-0,08$ & $-0,01$ & $-0,34$ & 0,15 & $-0,11$ \\
\hline Nitrato & 0,35 & $-0,18$ & $-0,09$ & 0,20 & 0,09 & $-0,22$ & 0,18 & 0,12 & 0,45 & 0,27 & 0,13 & 0,06 \\
\hline Sulfato & 0,08 & $-0,10$ & $-0,11$ & 0,01 & 0,05 & 0,00 & $-0,03$ & 0,03 & 0,01 & $-0,03$ & $-0,01$ & $-0,01$ \\
\hline $\mathrm{pH}$ & $-0,07$ & $-0,01$ & $-0,12$ & $-0,03$ & $-0,03$ & $-0,22$ & 0,19 & $-0,02$ & $-0,14$ & 0,08 & $-0,27$ & $-0,28$ \\
\hline
\end{tabular}

Foi utilizada a Análise Discriminante dado que, muitas correlações (37) se evidenciaram significantes e adequadas para a análise em questão.

O resultado da análise foi uma classificação com acerto de 97,40\%. Ou seja, a função discriminante nos assegura uma classificação com índice de acerto geral neste percentual.

As funções discriminantes são apresentadas na Tabela 6.23. São 16 funções que abordam a estrutura de classificação das regiões. Por exemplo, na $1^{\mathrm{a}}$ Coluna em Root 1, a função discriminante obtida é:

$$
\begin{aligned}
Z_{1}= & 6,81-0,63 \cdot A l+129,11 \cdot A g-72,91 \cdot B-2,68 \cdot \mathrm{Mn}+ \\
& +8,20 \cdot \mathrm{Zn}+0,98 \cdot \mathrm{Na}-1,64 \cdot \mathrm{Mg}+2,73 \cdot \mathrm{P}-0,27 \cdot \mathrm{K}+ \\
& -0,45 \cdot \mathrm{Ca}+\text { 0,84.Fe }+1,40 \cdot \mathrm{Ba}-11,49 \cdot \mathrm{Pb}+7,18 \cdot \text { Flueratano }+ \\
& + \text { 0,25.Cloreto - 1,51.Nitrato - 0,33.Sulfato - 0,56.pH. }
\end{aligned}
$$

Dessa forma, é feito com cada "Root" na tabela. Todas as 16 equações são combinadas para nos fornecer o resultado discriminante. 
Tabela 6.23 - Funções discriminantes.

\begin{tabular}{|c|c|c|c|c|c|c|c|c|c|}
\hline \multirow[b]{2}{*}{ Variable } & \multicolumn{9}{|c|}{$\begin{array}{l}\text { Raw Coefficients (SUperficia (todos os meses) in Análise IPEN) } \\
\text { for Canonical Variables }\end{array}$} \\
\hline & Root 1 & Root 2 & Root 3 & Root 4 & Root 5 & Root 6 & Root 7 & Root 8 & Roo \\
\hline $\mathrm{Al}$ & $-0,6249$ & $-1,592$ & $-1,359$ & $-1,4449$ & $-3,438$ & $-1,43129$ & $-2,32$ & 2,40 & -0 \\
\hline $\mathrm{Ag}$ & 129,1055 & 1084,739 & $-976,290$ & 352,0711 & 951,033 & 14,16682 & $-1084,36$ & $-1479,90$ & -118 \\
\hline$B$ & $-72,9088$ & $-241,766$ & 74,733 & 220,4851 & $-215,200$ & 92,91130 & 129,57 & $-12,23$ & 130 \\
\hline $\mathrm{Mn}$ & $-2,6794$ & $-2,162$ & $-1,740$ & $-0,9063$ & $-0,457$ & $-2,66374$ & 2,39 & $-1,62$ & -1 \\
\hline $\mathrm{Zn}$ & 2035 & $-10,349$ & $-19,048$ & $-7,0308$ & 2,341 & & $-16,90$ & 16,76 & 14 \\
\hline $\mathrm{Na}$ & 0,9842 & $-0,266$ & $-0,932$ & & $-0,237$ & 1,07 & 0,31 & 0,27 & \\
\hline $\mathrm{Mg}$ & 398 &, 666 & 179 & & 0,885 & $-0,67707$ & $-0,06$ & $-0,43$ & -0 \\
\hline $\mathrm{P}$ & 2,7308 & 4,059 & 602 & $-2,3027$ & 8,273 & 486 & $-3,34$ & 2,00 & 2 , \\
\hline $\mathrm{K}$ & 718 & $-4,687$ & & & $-5,757$ & & $-1,15$ & $-4,26$ & 0 \\
\hline $\mathrm{Ca}$ & & 0,737 & $-0,6$ & & $-0,1$ & & 0,10 & $-0,06$ & 0 \\
\hline $\mathrm{Fe}$ & & 354 & & 74 & & & 1,72 & 0,27 & 0 \\
\hline $\mathrm{Ba}$ & 029 & 0,314 & 1,324 & $-4,65$ & $-1,829$ & & 0,25 & $-1,15$ & 1 \\
\hline $\mathrm{Pb}$ & $-11,4935$ & 3,263 & 11,069 & 39,2182 & 47,461 & 40,95344 & $-18,93$ & $-72,41$ & 58 \\
\hline Fluore & 7,1848 & $-25,894$ & 54,814 & $-21,8080$ & $-9,700$ & 19,47913 & $-13,32$ & 25,37 & 20 \\
\hline Clore & & & & $-0,2358$ & $-0,134$ & $-0,67370$ & $-0,11$ & $-0,25$ & 0 \\
\hline Nitrat & 133 & $-0,053$ & $-0,817$ & $-0,0654$ & $-0,583$ & $-0,70330$ & 0,95 & 1,41 & 0 \\
\hline Sulfato & $-0,3337$ & 0,608 & 0,380 & 0,3504 & 0,049 & 0,31524 & 0,00 & 0,23 & 0 \\
\hline $\mathrm{pH}$ & $-0,5615$ & $-0,224$ & 1,763 & 2,1994 & $-0,300$ & $-1,25919$ & 1,59 & $-0,52$ & 3 \\
\hline Cons & 6,8105 & 5,921 & $\begin{array}{c}-6,686 \\
\end{array}$ & $-18,7399$ & $-1,654$ & 5,22574 & $-7,94$ & 11,21 & $\underline{-26}$ \\
\hline Eigen & 32,6191 & 25,216 & 10,421 & \begin{tabular}{c|}
5,8241 \\
\end{tabular} & $2,2,598$ & 1,80846 & 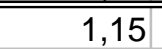 & |1,05 & $\overline{0}$ \\
\hline Cum.Prop & 0,3972 & 0,704 & 0,831 & 0,9020 & 0,934 & 0,95571 & 0,97 & 0,98 & 0 \\
\hline
\end{tabular}

As variáveis que mais discriminaram o resultado podem ser vistas na tabela de ajuste usando o método stepwise. Na Tabela 6.24 são apresentados os resultados obtidos. Essa tabela mostra o "passo a passo" de um método stepwise de inserção de variáveis no modelo a partir de seu poder de discriminação. Observe a coluna 'F to enter', o maior valor obtido é 48,47 (Mg). O segundo maior obtido é 40,23 (Ca) e, assim por diante. 
Tabela 6.24 - Resumo do método "stepwise".

\begin{tabular}{|c|c|c|c|c|c|c|c|}
\hline \multirow[b]{2}{*}{ Effect } & \multicolumn{7}{|c|}{$\begin{array}{l}\text { Summary of stepwise regression; variable: Grupo (SUperficia (todos os meses)) } \\
\text { Forward stepwise } \\
\text { P to enter: ,05, P to remove: ,05 }\end{array}$} \\
\hline & Steps & \begin{tabular}{|c|} 
Degr. of \\
Freedom \\
\end{tabular} & $\begin{array}{c}\mathrm{F} \text { to } \\
\text { remove }\end{array}$ & $\begin{array}{c}\mathrm{P} \text { to } \\
\text { remove }\end{array}$ & \begin{tabular}{c|}
$\mathrm{F}$ to \\
enter
\end{tabular} & \begin{tabular}{c|c}
$\mathrm{P}$ to \\
enter
\end{tabular} & $\begin{array}{l}\text { Effect } \\
\text { status }\end{array}$ \\
\hline $\mathrm{Al}$ & Step Number 1 & 17 & & & 1,16834 & 0,317681 & Out \\
\hline $\mathrm{Ag}$ & & 17 & & & 0,84473 & 0,637316 & Out \\
\hline B & & 17 & & & 0,68125 & 0,808163 & Out \\
\hline $\mathrm{Mn}$ & & 17 & & & 1,00076 & 0,470513 & Out \\
\hline $\mathrm{Zn}$ & & 17 & & & 0,71346 & 0,776782 & Out \\
\hline $\mathrm{Na}$ & & 17 & & & 21,69642 & 0,000000 & Out \\
\hline $\mathrm{Mg}$ & & 17 & & & 48,46914 & 0,000000 & Entered \\
\hline $\mathrm{P}$ & & 17 & & & 1,25384 & 0,254507 & Out \\
\hline K & & 17 & & & 2,46241 & 0,005540 & Out \\
\hline $\mathrm{Ca}$ & & 17 & & & 40,22692 & 0,000000 & Out \\
\hline $\mathrm{Fe}$ & & 17 & & & 2,86836 & 0,001415 & Out \\
\hline $\mathrm{Ba}$ & & 17 & & & 12,04397 & 0,000000 & Out \\
\hline $\mathrm{Pb}$ & & 17 & & & 1,03342 & 0,437984 & Out \\
\hline Fluoreto & & 17 & & & 3,75170 & 0,000078 & Out \\
\hline Cloreto & & 17 & & & 10,44045 & 0,000000 & Out \\
\hline Nitrato & & 17 & & & 3,28275 & 0,000357 & Out \\
\hline Sulfato & & 17 & & & 0,88327 & 0,595096 & Out \\
\hline $\mathrm{pH}$ & & 17 & & & 4,86147 & 0,000003 & Out \\
\hline
\end{tabular}

No estudo aplicado, foi observado quais variáveis foram significativas para entrar no modelo discriminante. Foram consideradas variáveis com um nível de significância de 0,05 (probabilidade).

A Figura 6.43 representa a função discriminante obtida para os mananciais superficiais do Vale do Ribeira, a partir do conhecimento dos elementos de cada região, fornecendo uma idéia da conclusão desta análise. 


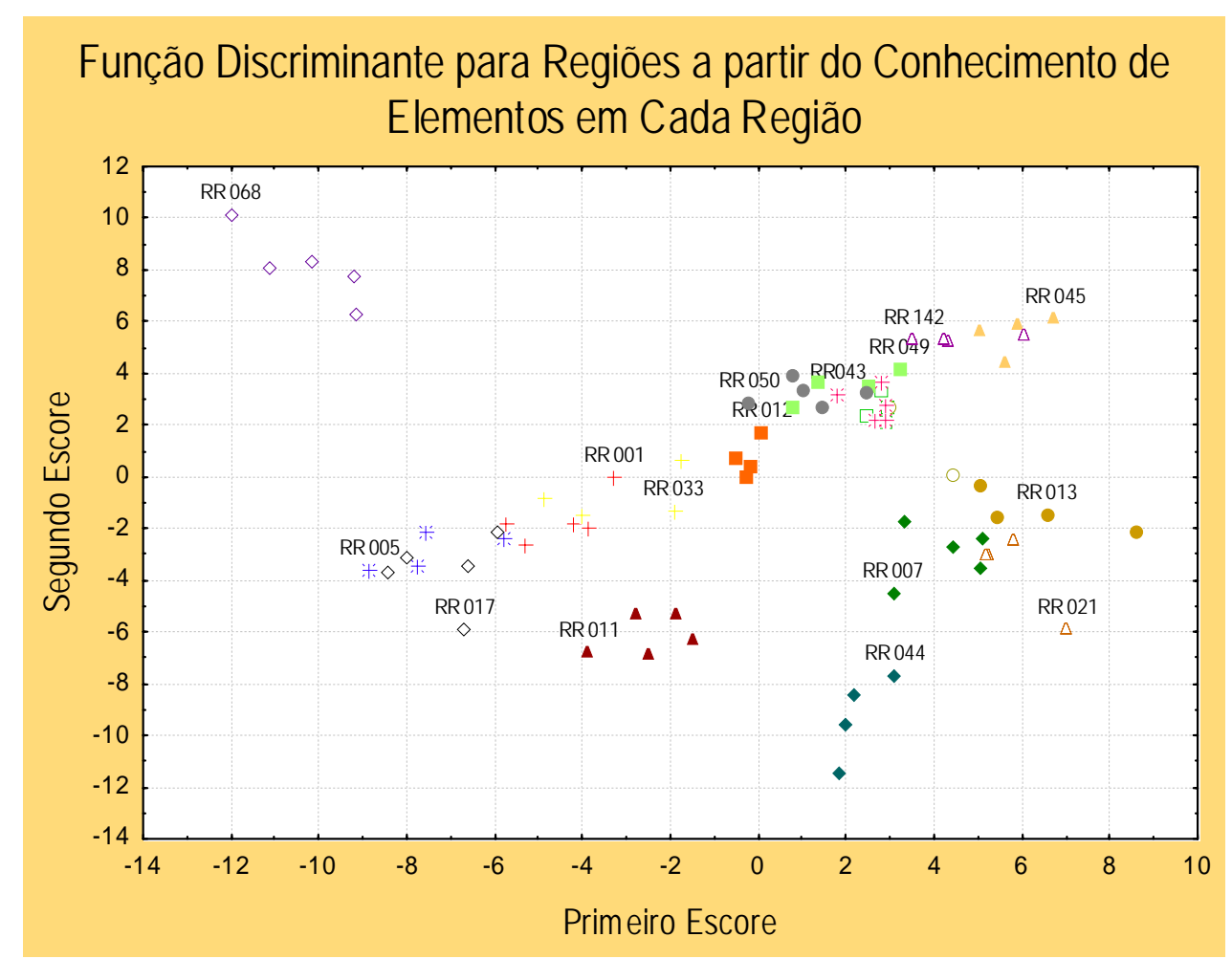

Figura 6.43 - Representação da função discriminante para captações superficiais.

Podemos observar que alguns grupos estão bem definidos, tais como RR044, RR017, RR068. Outros parecem misturados, no entanto se pudéssemos enxergar num espaço com 16 dimensões, perceberíamos que os grupos estão bem formados e bem interpretados como visto no percentual de classificação de aproximadamente $97,40 \%$ de acerto.

\subsection{Análise de Sedimentos}

\subsubsection{Distribuição Granulométrica}

As distribuições granulométricas para os sedimentos de fundo coletados nos mananciais superficiais de serra, no mesmo ponto da coleta da amostra de água apresentou a fração areia predominante nos pontos avaliados, sendo que a distribuição variou de areia muito grossa a areia muito fina. 


\subsubsection{Determinação de metais e elementos-traço em sedimentos}

Foi determinado o teor de macro e micro constituintes em 28 amostras de sedimentos provenientes de áreas de captação de água destinadas ao abastecimento público, tanto captação superficial como manancial de serra, utilizando-se a técnica de ICP-OES para a fração disponível. Foram avaliadas duas amostras, uma representando o período de seca e a outra o período de chuva.

No Brasil, ainda não há níveis estabelecidos por lei para os teores toleráveis de elementos considerados tóxicos em sedimentos. Os resultados obtidos foram comparados aos valores de referência TEL e PEL, estabelecidos pelo CCME (1991).

Segundo a legislação canadense, há dois limites que devem ser considerados: o TEL (Threshold Effect Level), que indica o nível abaixo do qual não ocorre efeito adverso à comunidade biológica; e o PEL (Probable Effect Level), que é o nível provável de efeito adverso à comunidade biológica. Para o chumbo em sedimentos de água doce, o TEL é 35,0 $\mu \mathrm{g} \mathrm{g}^{-1}$ e o PEL é 91,3 $\mu \mathrm{g} \mathrm{g}^{-1}$ (CETESB, 2001). Esses indicadores têm sido utilizados atualmente também pela Cetesb, em seus relatórios (CETESB, 2003).

A Tabela 6.25 apresenta um resumo dos valores médios obtidos para os elementos disponíveis presentes no sedimento, com indicação do local onde foram encontradas as maiores concentrações. Analisando-se o teor dos metais encontrados nas amostras de sedimentos do Vale do Ribeira, verifica-se que, segundo a legislação canadense, com exceção do $\mathrm{Pb}$, nas regiões de Sete Barras e Eldorado, os demais elementos analisados encontram-se com concentrações bem abaixo do valor estipulado para o PEL (Probable Effect Level - nível provável de efeito adverso à comunidade biológica.) 
Tabela 6.25 - Média e faixa de concentração $\left(\mu \mathrm{g} \mathrm{g}^{-1}\right)$ de elementos disponíveis em sedimentos pertencentes as áreas de captação da Bacia do Vale do Ribeira.

\begin{tabular}{|c|c|c|c|}
\hline Elemento & Média $\left(\mu \mathrm{g} \mathrm{g}{ }^{-1}\right)$ & Faixa de Concentação $\left(\mu \mathrm{g} \mathrm{g}^{-1}\right)$ & $P E L\left(\mu g^{-1}\right)$ \\
\hline $\mathrm{Al}$ & $\begin{array}{l}964,4 \text { (Jun/02) } \\
714,3 \text { (Fev 02) }\end{array}$ & $\begin{array}{l}190 \text { - } 3308 \text { (Pedrinhas) } \\
72-3098 \text { (SL da Serra) }\end{array}$ & \\
\hline $\mathrm{Cd}$ & $\begin{array}{l}0,24(\mathrm{Jun} / 02) \\
0,20(\mathrm{Fev} / 03)\end{array}$ & $\begin{array}{l}0,02-0,49 \text { (Eldorado) } \\
0,02-0,58 \text { (S.L. da Serra) }\end{array}$ & 3,5 \\
\hline $\mathrm{Cr}$ & $\begin{array}{l}1,57 \text { (jun/02) } \\
0,86(\text { Fev/03) }\end{array}$ & $\begin{array}{l}0,43-6,02 \text { (Iguape) } \\
0,16-3,42 \text { (S.L. da Serra) }\end{array}$ & 90 \\
\hline $\mathrm{Cu}$ & $\begin{array}{l}7,45(\mathrm{Jun} / 02) \\
6,01(\mathrm{Fev} / 03)\end{array}$ & $\begin{array}{l}2,14-20,9 \text { (Paiol do.Meio) } \\
1,12-23,4 \text { (S.L. da Serra) }\end{array}$ & 197 \\
\hline $\mathrm{Ni}$ & $\begin{array}{ll}2,11 & (\mathrm{Jun} / 02) \\
1,38 & (\mathrm{Fev} / 03)\end{array}$ & $\begin{array}{l}0,37-9,4 \text { (B. do Azeite) } \\
0,26-2,9 \text { (S.L da Serra) }\end{array}$ & \\
\hline $\mathrm{Fe}$ & $\begin{array}{l}3111 \text { (Jun/02) } \\
1404(\mathrm{Fev} / 03)\end{array}$ & $\begin{array}{l}\text { 95,7 - } 1147 \text { (S.L.Serra) } \\
57-5823 \text { (B. do Turvo) }\end{array}$ & \\
\hline $\mathrm{Mn}$ & $\begin{array}{l}393,6(\mathrm{Jun} / 02) \\
300,3(\mathrm{Fev} / 03)\end{array}$ & $\begin{array}{l}\text { 95,7 - } 1147 \text { (S.L.Serra) } \\
49,5-798 \text { (B. do Turvo) } \\
\end{array}$ & \\
\hline $\mathrm{Pb}$ & $\begin{array}{l}27,0(\mathrm{Jun} / 02) \\
13,7(\mathrm{Fev} / 03)\end{array}$ & $\begin{array}{l}5,98-342,8 \text { (Eldorado) } \\
2,47-72,2 \text { (S.L. da Serra) }\end{array}$ & 91,3 \\
\hline $\mathrm{Zn}$ & $\begin{array}{l}21,7(\text { Jun/02) } \\
20,0(\text { Fev/03) }\end{array}$ & $\begin{array}{l}7,0-64,2 \text { (Eldorado) } \\
1,21-101,2 \text { (S.L.Serra) }\end{array}$ & 315 \\
\hline
\end{tabular}

Além disso, foi avaliada a concentração total de metais e elementos traço utilizando a técnica de fluorescência de raios- $X$. Atenção especial foi dada ao elemento chumbo, uma vez que este elemento tem se apresentado como um dos principais contaminantes na área.

As tabelas: Tabela 6.26 e Tabela 6.27, apresentam os resultados obtidos para a fração lixiviada e total dos elementos avaliados em sedimentos de manancial superficial e de serra. 
Tabela 6.26 - Distribuição de elementos (macro constituintes) na fração total e lixiviada das amostras de sedimentos (fração < $0,63 \mu \mathrm{m})$.

\begin{tabular}{|c|c|c|c|c|c|c|c|c|c|c|c|c|c|c|c|}
\hline \multirow{3}{*}{\multicolumn{2}{|c|}{ Local }} & \multicolumn{14}{|c|}{ Concentração } \\
\hline & & \multicolumn{2}{|c|}{$\mathbf{A l}$} & \multicolumn{2}{|c|}{ é } & \multicolumn{2}{|c|}{$\mathrm{Mg}$} & \multicolumn{2}{|c|}{$\mathrm{K}$} & \multicolumn{2}{|c|}{ Ca \%) } & \multicolumn{2}{|c|}{$\mathrm{Na}(\%)$} & \multicolumn{2}{|c|}{ Mn } \\
\hline & & $\mathrm{T}(\%)$ & $\begin{array}{l}\mathrm{L} \\
\left(\mu \mathrm{g} \cdot \mathrm{g}^{-1}\right)\end{array}$ & $\mathrm{T}(\%)$ & $\begin{array}{l}\mathrm{L} \\
\left(\mu \mathrm{g} \cdot \mathrm{g}^{-1}\right)\end{array}$ & $\mathrm{T}(\%)$ & $\left(\mu g \cdot g^{-1}\right)$ & $\mathrm{T}(\%)$ & $\begin{array}{l}\mathrm{L} \\
\left(\mu \mathrm{g} \cdot \mathrm{g}^{-1}\right)\end{array}$ & $\mathrm{T}(\%)$ & $\begin{array}{l}\mathrm{L} \\
\left(\mu \mathrm{g} \cdot \mathrm{g}^{-1}\right)\end{array}$ & $\mathrm{T}(\%)$ & $\left(\mu \mathrm{g} \cdot \mathrm{g}^{-1}\right)$ & $\mathrm{T}(\%)$ & $\begin{array}{l}\mathrm{L} \\
\left(\mu \mathrm{g} \cdot \mathrm{g}^{-1}\right)\end{array}$ \\
\hline RR001 & Registro & $9,2 \pm 0,3$ & $544 \pm 3$ & $\begin{array}{l}4,84 \pm \\
0,07\end{array}$ & $\begin{array}{l}2673 \pm \\
542\end{array}$ & $\begin{array}{l}1,54 \pm \\
0,03\end{array}$ & $\begin{array}{l}380 \pm \\
10\end{array}$ & $\begin{array}{l}1,83 \pm \\
0,01\end{array}$ & $\begin{array}{l}55,0 \pm \\
2,7\end{array}$ & $\begin{array}{l}0,719 \pm \\
0,007\end{array}$ & $\begin{array}{l}1279 \pm \\
53\end{array}$ & $\begin{array}{l}0,58 \pm \\
0,04\end{array}$ & $\begin{array}{l}14,8 \pm \\
0,3\end{array}$ & $\begin{array}{l}0,129 \pm 0 \\
, 001\end{array}$ & $\begin{array}{l}435 \pm \\
28\end{array}$ \\
\hline RR005 & Sete Barras & $\begin{array}{l}9,50 \pm \\
0,02\end{array}$ & $450 \pm 2$ & $\begin{array}{l}5,00 \pm \\
0,03\end{array}$ & $\begin{array}{l}1270 \pm 1 \\
30\end{array}$ & $\begin{array}{l}1,65 \pm \\
0,01\end{array}$ & $\begin{array}{l}526 \pm \\
13\end{array}$ & $\begin{array}{l}1,879 \pm 0 \\
, 003\end{array}$ & $\begin{array}{l}47,9 \pm \\
1,7\end{array}$ & $\begin{array}{l}0,883 \pm \\
0,003\end{array}$ & $\begin{array}{l}2008 \pm \\
57\end{array}$ & $\begin{array}{l}0,69 \pm \\
0,02\end{array}$ & $\begin{array}{l}11,4 \pm \\
1,4\end{array}$ & $\begin{array}{l}0,142 \pm 0 \\
, 001\end{array}$ & $\begin{array}{l}530 \pm \\
57\end{array}$ \\
\hline RR007 & Jacupiranga & $\begin{array}{l}4,27 \pm \\
0,02\end{array}$ & $263 \pm 2$ & $\begin{array}{l}1,91 \pm \\
0,02\end{array}$ & $\begin{array}{l}3601 \pm \\
439\end{array}$ & $\begin{array}{l}0,314 \pm 0 \\
, 003\end{array}$ & $\begin{array}{l}81,2 \pm \\
4,2\end{array}$ & $\begin{array}{l}0,817 \pm 0 \\
, 002\end{array}$ & $\begin{array}{l}21,3 \pm \\
1,0\end{array}$ & $\begin{array}{l}0,277 \pm \\
0,001\end{array}$ & $286 \pm 23$ & $\begin{array}{l}0,207 \pm 0 \\
, 004\end{array}$ & $\begin{array}{l}11,3 \pm \\
0,7\end{array}$ & $\begin{array}{l}0,083 \pm 0 \\
, 001\end{array}$ & $\begin{array}{l}277 \pm \\
24\end{array}$ \\
\hline RR011 & Cajati & $8,2 \pm 0,2$ & $448 \pm 36$ & $\begin{array}{l}4,14 \pm \\
0,04\end{array}$ & $\begin{array}{l}1316 \pm \\
108\end{array}$ & $\begin{array}{l}1,24 \pm \\
0,04\end{array}$ & $\begin{array}{l}307 \pm \\
7,8\end{array}$ & $\begin{array}{l}1,95 \pm \\
0,01\end{array}$ & $\begin{array}{l}35,5 \pm \\
8,2\end{array}$ & $\begin{array}{l}0,916 \pm \\
0,005\end{array}$ & $\begin{array}{l}944 \pm \\
25\end{array}$ & $\begin{array}{l}1,08 \pm \\
0,04\end{array}$ & $\begin{array}{l}11,5 \pm \\
0,1\end{array}$ & $\begin{array}{l}0,093 \pm 0 \\
, 001\end{array}$ & $\begin{array}{l}355 \pm \\
15\end{array}$ \\
\hline RR012 & B.Turvo & $\begin{array}{l}9,29 \pm \\
0,08\end{array}$ & $976 \pm 17$ & $\begin{array}{l}2,09 \pm \\
0,01\end{array}$ & $\begin{array}{l}4235 \pm \\
226\end{array}$ & $\begin{array}{l}0,93 \pm \\
0,02\end{array}$ & $\begin{array}{l}241 \pm \\
25,9\end{array}$ & $\begin{array}{l}1,81 \pm \\
0,01\end{array}$ & $\begin{array}{l}69,4 \pm \\
3,1\end{array}$ & $\begin{array}{l}0,315 \pm \\
0,001\end{array}$ & $\begin{array}{l}893 \pm \\
35\end{array}$ & $\begin{array}{l}0,24 \pm \\
0,01\end{array}$ & $\begin{array}{l}114,9 \pm \\
13,9\end{array}$ & $\begin{array}{l}0,148 \pm 0 \\
, 001\end{array}$ & $\begin{array}{l}542 \pm \\
36\end{array}$ \\
\hline RR013 & Cananéia & $7,3 \pm 0,2$ & $271 \pm 18$ & $\begin{array}{l}3,32 \pm \\
0,04\end{array}$ & $\begin{array}{l}1181 \pm \\
156\end{array}$ & $\begin{array}{l}1,20 \pm \\
0,03\end{array}$ & $\begin{array}{l}46,2 \pm \\
4,4\end{array}$ & $\begin{array}{l}1,62 \pm \\
0,01\end{array}$ & $\begin{array}{l}17,4 \pm \\
1,4\end{array}$ & $\begin{array}{l}0,350 \pm \\
0,002\end{array}$ & $\begin{array}{l}178 \pm \\
10\end{array}$ & $\begin{array}{l}0,54 \pm \\
0,02\end{array}$ & $\begin{array}{l}14,4 \pm \\
4,0\end{array}$ & $\begin{array}{l}0,048 \pm 0 \\
, 001\end{array}$ & $\begin{array}{l}118 \pm \\
13\end{array}$ \\
\hline RR017 & Eldorado & $8,8 \pm 0,2$ & $341 \pm 21$ & $\begin{array}{l}4,96 \pm \\
0,02\end{array}$ & $\begin{array}{l}1604 \pm \\
194\end{array}$ & $\begin{array}{l}1,48 \pm \\
0,02\end{array}$ & $\begin{array}{l}602 \pm \\
20\end{array}$ & $\begin{array}{l}1,84 \pm \\
0,02\end{array}$ & $\begin{array}{l}33,4 \pm \\
0,7\end{array}$ & $\begin{array}{l}1,12 \pm \\
0,01\end{array}$ & $\begin{array}{l}2130 \pm \\
37\end{array}$ & $\begin{array}{l}0,88 \pm \\
0,04\end{array}$ & $\begin{array}{l}10,3 \pm \\
2,7\end{array}$ & $\begin{array}{l}0,115 \pm 0 \\
, 001\end{array}$ & $\begin{array}{l}342 \pm \\
21\end{array}$ \\
\hline RR021 & P.-Açú & $\begin{array}{l}10,4 \pm 0, \\
2\end{array}$ & $464 \pm 40$ & $\begin{array}{l}3,96 \pm \\
0,03\end{array}$ & $\begin{array}{l}1701 \pm \\
222\end{array}$ & $\begin{array}{l}1,73 \pm \\
0,02\end{array}$ & $\begin{array}{l}206 \pm \\
13\end{array}$ & $\begin{array}{l}2,94 \pm \\
0,03\end{array}$ & $\begin{array}{l}47,8 \pm \\
2,9\end{array}$ & $\begin{array}{l}0,837 \pm \\
0,002 \\
\end{array}$ & $\begin{array}{l}1408 \pm \\
110\end{array}$ & $\begin{array}{l}0,91 \pm \\
0,03\end{array}$ & $\begin{array}{l}16,5 \pm \\
4,3\end{array}$ & $\begin{array}{l}0,085 \pm 0 \\
, 001\end{array}$ & $\begin{array}{l}151 \pm \\
28\end{array}$ \\
\hline RR022 & Juquiá & $\begin{array}{l}8,35 \pm \\
0,15\end{array}$ & $577 \pm 23$ & $\begin{array}{l}4,67 \pm \\
0,03\end{array}$ & $\begin{array}{l}2924 \pm \\
179\end{array}$ & $\begin{array}{l}1,61 \pm \\
0,07\end{array}$ & $\begin{array}{l}254 \pm \\
14\end{array}$ & $\begin{array}{l}1,72 \pm \\
0,01\end{array}$ & $\begin{array}{l}139 \pm \\
12\end{array}$ & $\begin{array}{l}0,510 \pm \\
0,005\end{array}$ & $\begin{array}{l}1015 \pm \\
15\end{array}$ & $\begin{array}{l}0,354 \pm 0 \\
, 020\end{array}$ & $\begin{array}{l}19,6 \pm \\
3,7\end{array}$ & $\begin{array}{l}0,074 \pm 0 \\
, 001\end{array}$ & $\begin{array}{l}233 \pm \\
11\end{array}$ \\
\hline RR026 & Miracatu & $8,5 \pm 0,2$ & $516 \pm 49$ & $\begin{array}{l}4,52 \pm \\
0,03\end{array}$ & $\begin{array}{l}2839 \pm \\
136\end{array}$ & $\begin{array}{l}1,53 \pm \\
0,03\end{array}$ & $\begin{array}{l}201 \pm \\
9,2\end{array}$ & $\begin{array}{l}1,74 \pm \\
0,01\end{array}$ & $\begin{array}{l}66,8 \pm \\
2,5 \\
\end{array}$ & $\begin{array}{l}0,514 \pm \\
0,003\end{array}$ & $\begin{array}{l}652 \pm \\
19 \\
\end{array}$ & $\begin{array}{l}0,38 \pm \\
0,03\end{array}$ & $\begin{array}{l}15,2 \pm \\
2,8\end{array}$ & $\begin{array}{l}0,082 \pm 0 \\
, 001\end{array}$ & $192 \pm 8$ \\
\hline RR030 & O.Barros & $9,0 \pm 0,2$ & $\begin{array}{l}1039 \pm \\
20\end{array}$ & $\begin{array}{l}5,49 \pm \\
0,02\end{array}$ & $\begin{array}{l}976 \pm \\
30\end{array}$ & $\begin{array}{l}2,35 \pm \\
0,02\end{array}$ & $\begin{array}{l}807 \pm \\
33\end{array}$ & $\begin{array}{l}2,60 \pm \\
0,02\end{array}$ & $\begin{array}{l}106 \pm \\
2,6\end{array}$ & $\begin{array}{l}1,28 \pm \\
0,01\end{array}$ & $\begin{array}{l}2686 \pm \\
68\end{array}$ & $\begin{array}{l}0,96 \pm \\
0,04\end{array}$ & $\begin{array}{l}41,3 \pm \\
2,4\end{array}$ & $\begin{array}{l}0,093 \pm 0 \\
, 001\end{array}$ & $261 \pm 4$ \\
\hline RR033 & Iguape & $9,2 \pm 0,2$ & $406 \pm 26$ & $\begin{array}{l}4,74 \pm \\
0,04\end{array}$ & $\begin{array}{l}2613 \pm \\
232\end{array}$ & $\begin{array}{l}1,46 \pm \\
0,02\end{array}$ & $\begin{array}{l}246 \pm \\
13\end{array}$ & $\begin{array}{l}1,79 \pm \\
0,01\end{array}$ & $\begin{array}{l}34,9 \pm \\
2,8\end{array}$ & $\begin{array}{l}0,701 \pm \\
0,003\end{array}$ & $\begin{array}{l}977 \pm \\
57\end{array}$ & $\begin{array}{l}0,64 \pm \\
0,03\end{array}$ & $\begin{array}{l}230 \pm \\
30\end{array}$ & $\begin{array}{l}0,123 \pm 0 \\
, 001\end{array}$ & $\begin{array}{l}369 \pm \\
20\end{array}$ \\
\hline RR043 & Itariri & $\begin{array}{l}10,7 \pm 0, \\
4\end{array}$ & $\begin{array}{l}1368 \pm \\
30\end{array}$ & $11,5 \pm 0,2$ & $\begin{array}{l}1410 \pm \\
237\end{array}$ & $\begin{array}{l}3,83 \pm \\
0,03\end{array}$ & $\begin{array}{l}685 \pm \\
36\end{array}$ & $\begin{array}{l}3,04 \pm \\
0,06\end{array}$ & $\begin{array}{l}75,9 \pm \\
0,5\end{array}$ & $\begin{array}{l}1,51 \pm \\
0,01\end{array}$ & $\begin{array}{l}2360 \pm \\
122\end{array}$ & $\begin{array}{l}1,4 \pm \\
0,1\end{array}$ & $\begin{array}{l}27,8 \pm \\
3,2\end{array}$ & $\begin{array}{l}0,016 \pm 0 \\
, 002\end{array}$ & $299 \pm 2$ \\
\hline RR044 & P.Toledo & $\begin{array}{l}11,5 \pm 0, \\
1\end{array}$ & $\begin{array}{l}1025 \pm \\
13\end{array}$ & $\begin{array}{l}5,84 \pm \\
0,02\end{array}$ & $\begin{array}{l}2565 \pm \\
197\end{array}$ & $\begin{array}{l}2,08 \pm \\
0,01\end{array}$ & $861 \pm 27$ & $\begin{array}{l}2,41 \pm \\
0,02\end{array}$ & $\begin{array}{l}102 \pm \\
10\end{array}$ & $\begin{array}{l}1,39 \pm \\
0,01\end{array}$ & $\begin{array}{l}2601 \pm \\
134\end{array}$ & $\begin{array}{l}1,52 \pm \\
0,04\end{array}$ & $\begin{array}{l}236 \pm \\
26\end{array}$ & $\begin{array}{l}0,147 \pm 0 \\
, 001\end{array}$ & $\begin{array}{l}866 \pm \\
32\end{array}$ \\
\hline RR045 & Juquitiba & $\begin{array}{l}6,74 \pm \\
0,03 \\
\end{array}$ & $\begin{array}{l}1082 \pm \\
60 \\
\end{array}$ & $\begin{array}{l}2,79 \pm \\
0,01\end{array}$ & $\begin{array}{l}1930 \pm \\
135 \\
\end{array}$ & $\begin{array}{l}0,99 \pm \\
0,01\end{array}$ & $\begin{array}{l}97,2 \pm \\
7,6 \\
\end{array}$ & $\begin{array}{l}1,23 \pm \\
0,01\end{array}$ & $\begin{array}{l}63,3 \pm \\
2,7 \\
\end{array}$ & $\begin{array}{l}0,215 \pm \\
0,001 \\
\end{array}$ & $\begin{array}{l}502 \pm \\
41 \\
\end{array}$ & $\begin{array}{l}0,165 \pm 0 \\
, 006\end{array}$ & $\begin{array}{l}15,5 \pm \\
1,8\end{array}$ & $\begin{array}{l}0,066 \pm 0 \\
, 001 \\
\end{array}$ & $\begin{array}{l}267 \pm \\
12 \\
\end{array}$ \\
\hline RR049 & SLSerra & $8,0 \pm 0,2$ & $\begin{array}{l}2113 \pm \\
14\end{array}$ & $\begin{array}{l}4,71 \pm \\
0,04\end{array}$ & $\begin{array}{l}6336 \pm \\
293\end{array}$ & $\begin{array}{l}1,54 \pm \\
0,02\end{array}$ & $\begin{array}{l}134 \pm \\
12\end{array}$ & $\begin{array}{l}1,693 \pm 0 \\
, 003\end{array}$ & $\begin{array}{l}123 \pm \\
6,5\end{array}$ & $\begin{array}{l}0,817 \pm \\
0,004\end{array}$ & $\begin{array}{l}2908 \pm \\
167\end{array}$ & $\begin{array}{l}0,32 \pm \\
0,02\end{array}$ & $\begin{array}{l}21,0 \pm \\
1,2\end{array}$ & $\begin{array}{l}0,086 \pm 0 \\
, 001\end{array}$ & $\begin{array}{l}790 \pm \\
50\end{array}$ \\
\hline RR050 & P.do Meio & $8,2 \pm 0,1$ & $879 \pm 13$ & $\begin{array}{l}3,81 \pm \\
0,03\end{array}$ & $\begin{array}{l}4421 \pm \\
112\end{array}$ & $\begin{array}{l}1,27 \pm \\
0,02\end{array}$ & $\begin{array}{l}109 \pm \\
2,2 \\
\end{array}$ & $\begin{array}{l}1,42 \pm \\
0,01 \\
\end{array}$ & $\begin{array}{l}65,6 \pm \\
1,0\end{array}$ & $\begin{array}{l}0,304 \pm \\
0,001 \\
\end{array}$ & $\begin{array}{l}633 \pm \\
56\end{array}$ & $\begin{array}{l}0,24 \pm \\
0,01\end{array}$ & $890 \pm 12$ & $\begin{array}{l}0,084 \pm 0 \\
, 001\end{array}$ & $409 \pm 3$ \\
\hline RR068 & Iporanga & $\begin{array}{l}6,34 \pm \\
0,01\end{array}$ & $449 \pm 14$ & $\begin{array}{l}4,95 \pm \\
0,05\end{array}$ & $\begin{array}{l}2692 \pm \\
182\end{array}$ & $\begin{array}{l}1,41 \pm \\
0,01\end{array}$ & $\begin{array}{l}130 \pm \pm \\
8,9\end{array}$ & $\begin{array}{l}1,74 \pm \\
0,06\end{array}$ & $\begin{array}{l}22,2 \pm \\
2,4\end{array}$ & $\begin{array}{l}0,327 \pm \\
0,001\end{array}$ & $\begin{array}{l}1098 \pm \\
46\end{array}$ & $\begin{array}{l}0,41 \pm \\
0,02\end{array}$ & $\begin{array}{l}9,17 \pm \\
0,7\end{array}$ & $\begin{array}{l}0,057 \pm 0 \\
, 001\end{array}$ & $\begin{array}{l}360 \pm \\
15\end{array}$ \\
\hline RR142 & B.Turvo & $7,7 \pm 0,2$ & $729 \pm 21$ & $\begin{array}{l}4,23 \pm \\
0,02\end{array}$ & $\begin{array}{l}3291 \pm \\
288\end{array}$ & $\begin{array}{l}1,22 \pm \\
0,03\end{array}$ & $\begin{array}{l}169 \pm \\
14,7\end{array}$ & $\begin{array}{l}1,91 \pm \\
0,02\end{array}$ & $\begin{array}{l}58,1 \pm \\
0,1\end{array}$ & $\begin{array}{l}0,808 \pm \\
0,006\end{array}$ & $\begin{array}{l}761 \pm \\
48\end{array}$ & $\begin{array}{l}0,94 \pm \\
0,04\end{array}$ & $\begin{array}{l}79,7 \pm \\
8,9\end{array}$ & $\begin{array}{l}0,073 \pm 0 \\
, 002\end{array}$ & $\begin{array}{l}343 \pm \\
17\end{array}$ \\
\hline
\end{tabular}




\section{Cont.}

\begin{tabular}{|c|c|c|c|c|c|c|c|c|c|c|c|c|c|c|c|}
\hline \multirow{4}{*}{\multicolumn{2}{|c|}{ Local }} & \multirow{2}{*}{\multicolumn{14}{|c|}{ Concentração }} \\
\hline & & & & & & & & & & & & & & & \\
\hline & & \multicolumn{2}{|c|}{ Al } & \multicolumn{2}{|c|}{ é } & \multicolumn{2}{|c|}{$\mathrm{Mg}$} & \multicolumn{2}{|c|}{$\mathrm{K}$} & \multicolumn{2}{|c|}{ Ca \%) } & \multicolumn{2}{|c|}{$\mathrm{Na}(\%)$} & \multicolumn{2}{|c|}{ Mn } \\
\hline & & $\mathrm{T}(\%)$ & $\begin{array}{l}\mathrm{L} \\
\left(\mu \mathrm{g} \cdot \mathrm{g}^{-1}\right)\end{array}$ & $\mathrm{T}(\%)$ & $\begin{array}{l}\mathrm{L} \\
\left(\mu \mathrm{g} \cdot \mathrm{g}^{-1}\right)\end{array}$ & $\mathrm{T}(\%)$ & $\left(\mu \mathrm{g} . \mathrm{g}^{-1}\right)$ & $\mathrm{T}(\%)$ & $\begin{array}{l}\mathrm{L} \\
\left(\mu \mathrm{g} \cdot \mathrm{g}^{-1}\right)\end{array}$ & $\mathrm{T}(\%)$ & $\begin{array}{l}\mathrm{L} \\
\left(\mu \mathrm{g} \cdot \mathrm{g}^{-1}\right)\end{array}$ & $\mathrm{T}(\%)$ & $\left(\mu \mathrm{g} \cdot \mathrm{g}^{-1}\right)$ & $\mathrm{T}(\%)$ & $\begin{array}{l}\mathrm{L} \\
\left(\mu \mathrm{g} \cdot \mathrm{g}^{-1}\right)\end{array}$ \\
\hline RR008 & B.Azeite & $8,0 \pm 0,2$ & $\begin{array}{l}1467 \pm \\
17\end{array}$ & $\begin{array}{l}3,69 \pm \\
0,02\end{array}$ & $\begin{array}{l}1017 \pm \\
123\end{array}$ & $\begin{array}{l}1,25 \pm \\
0,04 \\
\end{array}$ & $\begin{array}{l}484 \pm \\
24 \\
\end{array}$ & $\begin{array}{l}2,08 \pm \\
0,01\end{array}$ & $\begin{array}{l}110 \pm \\
16,2\end{array}$ & $\begin{array}{l}0,277 \pm \\
0,001\end{array}$ & $\begin{array}{l}1177 \pm \\
69\end{array}$ & $\begin{array}{l}0,53 \pm \\
0,03 \\
\end{array}$ & $\begin{array}{l}37,2 \pm \\
3,1\end{array}$ & $\begin{array}{l}0,077 \pm \\
0,001\end{array}$ & $\begin{array}{l}497 \pm \\
46\end{array}$ \\
\hline RR014 & Ariri & $\begin{array}{l}13,5 \pm 0, \\
4\end{array}$ & $786 \pm 22$ & $10,0 \pm 0,1$ & $\begin{array}{l}1208 \pm \\
74\end{array}$ & $\begin{array}{l}1,64 \pm \\
0,02\end{array}$ & $\begin{array}{l}241 \pm \\
36\end{array}$ & $\begin{array}{l}0,828 \pm 0 \\
, 002\end{array}$ & $\begin{array}{l}35,5 \pm \\
9,6\end{array}$ & $\begin{array}{l}0,246 \pm \\
0,001\end{array}$ & $\begin{array}{l}450 \pm \\
53\end{array}$ & $\begin{array}{l}0,154 \pm \\
0,006\end{array}$ & $\begin{array}{l}36,0 \pm \\
1,9\end{array}$ & $\begin{array}{l}0,013 \pm \\
0,002\end{array}$ & $141 \pm 3$ \\
\hline RR023 & Colonização & $\begin{array}{l}10,9 \pm 0, \\
3\end{array}$ & $614 \pm 12$ & $\begin{array}{l}4,65 \pm \\
0,05\end{array}$ & $\begin{array}{l}3776 \pm \\
299\end{array}$ & $\begin{array}{l}1,87 \pm \\
0,02\end{array}$ & $\begin{array}{l}263 \pm \\
26\end{array}$ & $\begin{array}{l}2,74 \pm \\
0,02\end{array}$ & $\begin{array}{l}124 \pm \\
21\end{array}$ & $\begin{array}{l}0,662 \pm \\
0,005\end{array}$ & $\begin{array}{l}1834 \\
\pm 187 \\
\end{array}$ & $\begin{array}{l}0,86 \pm \\
0,04\end{array}$ & $\begin{array}{l}44,3 \pm \\
0,9\end{array}$ & $\begin{array}{l}0,103 \pm \\
0,001\end{array}$ & $\begin{array}{l}467 \pm \\
16\end{array}$ \\
\hline RR024 & B.lporanga & $\begin{array}{l}6,14 \pm \\
0,04 \\
\end{array}$ & $629 \pm 36$ & $\begin{array}{l}3,49 \pm \\
0,01 \\
\end{array}$ & $\begin{array}{l}909 \pm \\
67 \\
\end{array}$ & $\begin{array}{l}0,78 \pm \\
0,02 \\
\end{array}$ & $\begin{array}{l}325 \pm \\
37 \\
\end{array}$ & $\begin{array}{l}0,997 \pm \\
0,004 \\
\end{array}$ & $\begin{array}{l}67,0 \pm \\
5,3 \\
\end{array}$ & $\begin{array}{l}0,250 \pm \\
0,001 \\
\end{array}$ & $\begin{array}{l}1664 \pm \\
153 \\
\end{array}$ & $\begin{array}{l}0,16 \pm \\
0,01 \\
\end{array}$ & $23,8 \pm$ & $\begin{array}{l}0,143 \pm \\
0,001 \\
\end{array}$ & $\begin{array}{l}324 \pm \\
21 \\
\end{array}$ \\
\hline RR029 & Musácea & $8,1 \pm 0,2$ & $635 \pm 22$ & $\begin{array}{l}4,90 \pm \\
0,03\end{array}$ & $\begin{array}{l}664 \pm \\
51\end{array}$ & $\begin{array}{l}1,74 \pm \\
0,03\end{array}$ & $\begin{array}{l}683 \pm \\
28\end{array}$ & $\begin{array}{l}1,59 \pm \\
0,01\end{array}$ & $\begin{array}{l}110 \pm \\
18\end{array}$ & $\begin{array}{l}0,855 \pm \\
0,005\end{array}$ & $\begin{array}{l}2390 \pm \\
322\end{array}$ & $\begin{array}{l}0,45 \pm \\
0,01\end{array}$ & $\begin{array}{l}270 \pm \\
33\end{array}$ & $\begin{array}{l}0,097 \pm \\
0,001\end{array}$ & $\begin{array}{l}405 \pm \\
62\end{array}$ \\
\hline RR052 & Ana Dias & $\begin{array}{l}10,6 \pm 0, \\
4\end{array}$ & $\begin{array}{l}1263 \pm \\
67\end{array}$ & $9,6 \pm 0,1$ & $\begin{array}{l}739 \pm \\
70 \\
\end{array}$ & $\begin{array}{l}3,10 \pm \\
0,02 \\
\end{array}$ & $\begin{array}{l}761 \pm \\
36 \\
\end{array}$ & $\begin{array}{l}2,04 \pm \\
0,03 \\
\end{array}$ & $\begin{array}{l}76,6 \pm \\
1,4 \\
\end{array}$ & $\begin{array}{l}1,10 \pm \\
0,01 \\
\end{array}$ & $\begin{array}{r}2445 \\
\pm 184 \\
\end{array}$ & $\begin{array}{l}0,78 \pm \\
0,04 \\
\end{array}$ & $\begin{array}{l}38,4 \pm \\
5,5 \\
\end{array}$ & $\begin{array}{l}0,038 \pm \\
0,001 \\
\end{array}$ & $\begin{array}{l}315 \pm \\
45\end{array}$ \\
\hline RR053 & R.Tavares & $8,6 \pm 0,2$ & $\begin{array}{l}1053 \pm \\
27\end{array}$ & $\begin{array}{l}7,45 \pm \\
0,04\end{array}$ & $\begin{array}{l}2090 \pm \\
127\end{array}$ & $\begin{array}{l}2,43 \pm \\
0,01\end{array}$ & $\begin{array}{l}394 \pm \\
17\end{array}$ & $\begin{array}{l}1,54 \pm \\
0,01\end{array}$ & $\begin{array}{l}92,6 \pm \\
2,2\end{array}$ & $\begin{array}{l}0,633 \pm \\
0,004\end{array}$ & $\begin{array}{l}2050 \pm \\
32\end{array}$ & $\begin{array}{l}0,27 \pm \\
0,02\end{array}$ & $\begin{array}{l}30,3 \pm \\
0,3\end{array}$ & $\begin{array}{l}0,035 \pm \\
0,001\end{array}$ & $\begin{array}{l}197 \pm \\
15\end{array}$ \\
\hline RR061 & Pedrinhas & & $\begin{array}{l}2984 \pm \\
46\end{array}$ & & $\begin{array}{l}2955 \pm \\
224\end{array}$ & & $\begin{array}{l}1297 \pm \\
136\end{array}$ & & $\begin{array}{l}84,3 \pm \\
1,2\end{array}$ & & $\begin{array}{l}3591 \pm \\
134\end{array}$ & & $\begin{array}{l}46,3 \pm \\
1,3\end{array}$ & & $130 \pm 5$ \\
\hline RR069 & B.da Serra & $\begin{array}{l}7,25 \pm \\
0,05 \\
\end{array}$ & $131 \pm 8$ & $\begin{array}{l}, 91 \pm \\
0,01 \\
\end{array}$ & $\begin{array}{l}280 \pm \\
31\end{array}$ & $\begin{array}{l}1,38 \pm \\
0,02 \\
\end{array}$ & $\begin{array}{l}93,8 \pm \\
2,6\end{array}$ & $\begin{array}{l}2,24 \pm \\
0,01 \\
\end{array}$ & $\begin{array}{l}10,3 \pm \\
1,1\end{array}$ & $\begin{array}{l}0,198 \pm \\
0,001 \\
\end{array}$ & $\begin{array}{l}149 \pm \\
16\end{array}$ & $\begin{array}{l}0,619 \pm \\
0,005 \\
\end{array}$ & $\begin{array}{l}5,5 \pm \\
0,3\end{array}$ & $\begin{array}{l}0,014 \pm \\
0,001 \\
\end{array}$ & $99,4 \pm 7$ \\
\hline
\end{tabular}

T - Concentração Total

L- Concentração Disponível (lixiviação HCl 0,1N) 
Tabela 6.27 - Concentração total e lixiviada de metais tóxicos nas amostras de sedimentos de fundo (fração < 0,63 $\mu \mathrm{m})$ dos mananciais superficiais e de serra do Vale do Ribeira.

\begin{tabular}{|c|c|c|c|c|c|c|c|c|c|c|c|c|c|c|c|}
\hline & & \multicolumn{14}{|c|}{ Concentração $\left(\mu . g . \mathrm{g}^{-1}\right)$} \\
\hline & & \multicolumn{2}{|c|}{$\mathbf{P b}$} & \multicolumn{2}{|c|}{$\mathrm{Zn}$} & \multicolumn{2}{|c|}{$\mathrm{Cr}$} & \multicolumn{2}{|c|}{$\mathrm{Cu}$} & \multicolumn{2}{|c|}{$\mathrm{Ni}$} & \multicolumn{2}{|c|}{$\mathbf{V}$} & \multicolumn{2}{|c|}{$\mathbf{B a}$} \\
\hline Local & & $T$ & $\mathrm{~L}$ & $T$ & $\mathrm{~L}$ & $T$ & $\mathrm{~L}$ & $T$ & $\mathrm{~L}$ & $\mathrm{~T}$ & $\mathrm{~L}$ & $T$ & $\mathrm{~L}$ & $T$ & $\mathrm{~L}$ \\
\hline RR001 & Registro & $71 \pm 3$ & $\begin{array}{l}37,8 \pm \\
4,1\end{array}$ & $73 \pm 2$ & $\begin{array}{l}25,6 \pm \\
2,3\end{array}$ & $98 \pm 5$ & $\begin{array}{l}10,2 \pm \\
0,1\end{array}$ & $50 \pm 2$ & $\begin{array}{l}10,2 \pm \\
0,7\end{array}$ & $75 \pm 2$ & $\begin{array}{l}2,0 \pm \\
0,1\end{array}$ & $188 \pm 2$ & $\begin{array}{l}17,5 \pm \\
1,4\end{array}$ & $\begin{array}{l}991 \pm \\
24\end{array}$ & $\begin{array}{l}267 \pm \\
11\end{array}$ \\
\hline RR005 & Sete Barras & $78,3 \pm 1,0$ & $\begin{array}{l}42,1 \pm \\
2,4\end{array}$ & $67 \pm 2$ & $\begin{array}{l}26,5 \pm \\
0,7\end{array}$ & $97 \pm 4$ & $\begin{array}{l}8,1 \pm \\
0,3\end{array}$ & $47 \pm 1$ & $\begin{array}{l}8,1 \pm \\
0,1\end{array}$ & $80 \pm 2$ & $\begin{array}{l}1,7 \pm \\
0,3\end{array}$ & $187 \pm 2$ & $\begin{array}{l}17,8 \pm \\
0,9\end{array}$ & $\begin{array}{l}1033 \pm \\
17\end{array}$ & $\begin{array}{l}279 \pm \\
24\end{array}$ \\
\hline RR007 & Jacupiranga & $13,7 \pm 1,2$ & $\begin{array}{l}5,7 \pm \\
1,7\end{array}$ & $40,0 \pm 2,5$ & $\begin{array}{l}12,0 \pm \\
0,8\end{array}$ & $94 \pm 6$ & $\begin{array}{l}3,0 \pm \\
0,8\end{array}$ & $6,6 \pm 06$ & $\begin{array}{l}3,0 \pm \\
0,9\end{array}$ & $\begin{array}{l}24,5 \pm 0 \\
, 9\end{array}$ & $\begin{array}{l}1,9 \pm \\
0,2\end{array}$ & $93 \pm 2$ & $\begin{array}{l}10,7 \pm \\
1,3\end{array}$ & $\begin{array}{l}342 \pm \\
18\end{array}$ & $93 \pm 8$ \\
\hline RR011 & Cajati & $16,8 \pm 1,3$ & $\begin{array}{l}6,7 \pm \\
0,3\end{array}$ & $48 \pm 1$ & $\begin{array}{l}7,3 \pm \\
0,9\end{array}$ & $155 \pm 4$ & $\begin{array}{l}4,4 \pm \\
0,3\end{array}$ & $\begin{array}{l}9,5 \pm \\
2,1\end{array}$ & $\begin{array}{l}4,4 \pm \\
0,6\end{array}$ & $80 \pm 1$ & $\begin{array}{l}1,7 \pm \\
0,1\end{array}$ & $145 \pm 3$ & $\begin{array}{l}18,4 \pm \\
3,6\end{array}$ & $\begin{array}{l}921 \pm \\
10\end{array}$ & $\begin{array}{l}210 \pm \\
14\end{array}$ \\
\hline RR012 & B.Turvo & $65,7 \pm 0,8$ & $\begin{array}{l}11,0 \pm \\
2,2\end{array}$ & $70 \pm 3$ & $\begin{array}{l}16,2 \pm \\
2,9\end{array}$ & $31 \pm 4$ & $\begin{array}{l}4,4 \pm \\
0,1\end{array}$ & $\begin{array}{l}6,5 \pm \\
0,7\end{array}$ & $\begin{array}{l}4,4 \pm \\
0,3\end{array}$ & $50 \pm 2$ & $\begin{array}{l}1,5 \pm \\
0,2\end{array}$ & $159 \pm 5$ & $\begin{array}{l}17,0 \pm \\
1.8\end{array}$ & $\begin{array}{l}697 \pm \\
26\end{array}$ & $\begin{array}{l}254 \pm \\
12\end{array}$ \\
\hline RR013 & Cananéia & $27 \pm 3$ & $\begin{array}{l}5,5 \pm \\
1,9\end{array}$ & $61 \pm 1$ & $\begin{array}{l}6,2 \pm \\
0,7\end{array}$ & $107 \pm 7$ & $\begin{array}{l}2,4 \pm \\
0,8\end{array}$ & $\begin{array}{l}22,6 \pm \\
0,9\end{array}$ & $\begin{array}{l}2,4 \pm \\
0,7\end{array}$ & $57 \pm 2$ & $\begin{array}{l}0,80 \pm \\
0,2\end{array}$ & $141 \pm 5$ & $\begin{array}{l}8,6 \pm \\
1,1\end{array}$ & $\begin{array}{l}713 \pm \\
35\end{array}$ & $\begin{array}{l}75,7 \pm \\
4,2\end{array}$ \\
\hline RR017 & Eldorado & $142 \pm 2$ & $\begin{array}{l}44,8 \pm \\
3,2\end{array}$ & $78 \pm 1$ & $\begin{array}{l}48,4 \pm \\
2,2\end{array}$ & $112 \pm 5$ & $\begin{array}{l}11,2 \pm \\
0,6\end{array}$ & $\begin{array}{l}26,5 \pm \\
1,9\end{array}$ & $\begin{array}{l}11,2 \pm \\
0,7\end{array}$ & $103 \pm 5$ & $\begin{array}{l}1,6 \pm \\
0,4\end{array}$ & $195 \pm 6$ & $\begin{array}{l}22,3 \pm \\
2,2\end{array}$ & $\begin{array}{l}1388 \pm \\
65\end{array}$ & $\begin{array}{l}362 \pm \\
13\end{array}$ \\
\hline RR021 & P.-Açú & $32,9 \pm 1,3$ & $\begin{array}{l}4,6 \pm \\
0,4\end{array}$ & $79 \pm 3$ & $\begin{array}{l}9,7 \pm \\
0,4\end{array}$ & $62 \pm 5$ & $\begin{array}{l}4,6 \pm \\
0,3\end{array}$ & $\begin{array}{l}6,5 \pm \\
0,5\end{array}$ & $\begin{array}{l}4,6 \pm \\
0,5\end{array}$ & $110 \pm 4$ & $\begin{array}{l}1,4 \pm \\
0,1\end{array}$ & $203 \pm 8$ & $\begin{array}{l}12,9 \pm \\
0,9\end{array}$ & $\begin{array}{l}1465 \pm \\
48\end{array}$ & $\begin{array}{l}238 \pm \\
26\end{array}$ \\
\hline RR022 & Juquiá & $26,0 \pm 1,7$ & $\begin{array}{l}10,0 \pm \\
0,4\end{array}$ & $66 \pm 2$ & $\begin{array}{l}14,0 \pm \\
1,3\end{array}$ & $95 \pm 6$ & $\begin{array}{l}5,8 \pm \\
0,2\end{array}$ & $25 \pm 2$ & $\begin{array}{l}5,8 \pm \\
0,3\end{array}$ & $60 \pm 3$ & $\begin{array}{l}1,0 \pm \\
0,1\end{array}$ & $183 \pm 5$ & $\begin{array}{l}15,2 \pm \\
1,0\end{array}$ & $\begin{array}{l}815 \pm \\
17\end{array}$ & $\begin{array}{l}159 \pm \\
1,4\end{array}$ \\
\hline RR026 & Miracatu & $25,6 \pm 1.7$ & $\begin{array}{l}7,8 \pm \\
0,1\end{array}$ & $67 \pm 1$ & $\begin{array}{l}12,6 \pm \\
1,2\end{array}$ & $98 \pm 3$ & $\begin{array}{l}6,0 \pm \\
0,4\end{array}$ & $24 \pm 1$ & $\begin{array}{l}6,0 \pm \\
0,1\end{array}$ & $60 \pm 3$ & $\begin{array}{l}1,2 \pm \\
0,1\end{array}$ & $192 \pm 2$ & $\begin{array}{l}27,4 \pm \\
2,3\end{array}$ & $\begin{array}{l}803 \pm \\
33\end{array}$ & $\begin{array}{l}248 \pm \\
20\end{array}$ \\
\hline RR030 & O.Barros & $18,8 \pm 2,2$ & $\begin{array}{l}8,6 \pm \\
0,6\end{array}$ & $40,0 \pm 0,5$ & $\begin{array}{l}, 0 \pm \\
0,1\end{array}$ & $113 \pm 9$ & $\begin{array}{l}4,4 \pm \\
0,1\end{array}$ & $\begin{array}{l}26,5 \pm \\
1,2\end{array}$ & $\begin{array}{l}4,4 \pm \\
0,2\end{array}$ & $79 \pm 1$ & $\begin{array}{l}1,1 \pm \\
0,1\end{array}$ & $141 \pm 4$ & $\begin{array}{l}14,5 \pm \\
1,1\end{array}$ & $\begin{array}{l}936 \pm \\
30\end{array}$ & $\begin{array}{l}257 \pm \\
32\end{array}$ \\
\hline RR033 & Iguape & $62 \pm 4$ & $\begin{array}{l}11,4 \pm \\
1,0\end{array}$ & $71 \pm 1$ & $\begin{array}{l}20,8 \pm \\
1,3\end{array}$ & $98 \pm 3$ & $\begin{array}{l}6,7 \pm \\
0,4\end{array}$ & $\begin{array}{l}35,9 \pm \\
1,3\end{array}$ & $\begin{array}{l}6,7 \pm \\
0,5\end{array}$ & $76 \pm 3$ & $\begin{array}{l}1,4 \pm \\
0,5\end{array}$ & $186 \pm 7$ & $\begin{array}{l}23,9 \pm \\
2,9\end{array}$ & $\begin{array}{l}989 \pm \\
37\end{array}$ & $\begin{array}{l}63,9 \pm \\
7,6\end{array}$ \\
\hline RR043 & Itariri & $14,2 \pm 1,9$ & $\begin{array}{l}7,1 \pm \\
0,9\end{array}$ & $<1$ & $\begin{array}{l}23,4 \pm \\
1,1\end{array}$ & $\begin{array}{l}314 \pm 1 \\
0\end{array}$ & $\begin{array}{l}5,7 \pm \\
0,7\end{array}$ & $39,4 \pm 3$ & $\begin{array}{l}5,7 \pm \\
0,2\end{array}$ & $161 \pm 7$ & $\begin{array}{l}1,6 \pm \\
0,3\end{array}$ & $\begin{array}{l}195 \pm \\
10\end{array}$ & $\begin{array}{l}32,7 \pm \\
3,6\end{array}$ & $\begin{array}{l}2123 \pm \\
66\end{array}$ & $\begin{array}{l}416 \pm \\
1,1\end{array}$ \\
\hline RR044 & P.Toledo & $16,7 \pm 2,4$ & $\begin{array}{l}5,4 \pm \\
0,8\end{array}$ & $29 \pm 1$ & $\begin{array}{l}14,3 \pm \\
0,6\end{array}$ & $167 \pm 6$ & $\begin{array}{l}7,8 \pm \\
0,2\end{array}$ & $\begin{array}{l}31,9 \pm \\
1,9\end{array}$ & $\begin{array}{l}7,8 \pm \\
0,2\end{array}$ & $115 \pm 2$ & $\begin{array}{l}2,8 \pm \\
0,9\end{array}$ & $230 \pm 8$ & $\begin{array}{l}13,1 \pm \\
1,2\end{array}$ & $\begin{array}{l}1320 \pm \\
33\end{array}$ & $\begin{array}{l}440 \pm \\
22\end{array}$ \\
\hline RR045 & Juquitiba & $38,0 \pm 2$ & $\begin{array}{l}10,3 \pm \\
1,8\end{array}$ & $167 \pm 5$ & $\begin{array}{l}28,3 \pm \\
2,3\end{array}$ & $40 \pm 5$ & $\begin{array}{l}12,0 \pm \\
0,5\end{array}$ & $\begin{array}{l}42,5 \pm \\
0,5\end{array}$ & $\begin{array}{l}12,0 \pm \\
1,1\end{array}$ & $\begin{array}{l}24,5 \pm 1 \\
, 6\end{array}$ & $\begin{array}{l}1,1 \pm \\
0,1\end{array}$ & $107 \pm 5$ & $\begin{array}{l}31,9 \pm \\
2,1\end{array}$ & $\begin{array}{l}308 \pm \\
30\end{array}$ & $\begin{array}{l}93,0 \pm \\
4,6\end{array}$ \\
\hline RR049 & SLSerra & $111 \pm 3$ & $\begin{array}{l}46,6 \pm \\
3,7\end{array}$ & $122 \pm 5$ & $\begin{array}{l}65,6 \pm \\
5,0\end{array}$ & $74 \pm 2$ & $\begin{array}{l}16,1 \pm \\
0,8\end{array}$ & $\begin{array}{l}41,5 \pm \\
2,6\end{array}$ & $\begin{array}{l}16,1 \pm \\
1.0\end{array}$ & $50 \pm 2$ & $\begin{array}{l}2,0 \pm \\
0,3\end{array}$ & $142 \pm 5$ & $\begin{array}{l}34,3 \pm \\
3,9\end{array}$ & $\begin{array}{l}653 \pm \\
20\end{array}$ & $\begin{array}{l}233 \pm \\
36\end{array}$ \\
\hline RR050 & P.do Meio & $44 \pm 2$ & $\begin{array}{l}15,8 \pm \\
3,7\end{array}$ & $76 \pm 3$ & $\begin{array}{l}32,7 \pm \\
2,4\end{array}$ & $85 \pm 2$ & $\begin{array}{l}17,7 \pm \\
0,5\end{array}$ & $\begin{array}{l}27,3 \pm \\
1,9\end{array}$ & $\begin{array}{l}17,7 \pm \\
4,6\end{array}$ & $43 \pm 2$ & $\begin{array}{l}1,6 \pm \\
0,5\end{array}$ & $173 \pm 4$ & $\begin{array}{l}28,4 \pm \\
3,1\end{array}$ & $\begin{array}{l}572 \pm \\
31\end{array}$ & $\begin{array}{l}123 \pm \\
18\end{array}$ \\
\hline
\end{tabular}




\section{Cont.}

\begin{tabular}{|c|c|c|c|c|c|c|c|c|c|c|c|c|c|c|c|}
\hline \multirow{4}{*}{ Local } & & \multicolumn{14}{|c|}{ Concentração $\left(\mu . g . g^{-1}\right)$} \\
\hline & & \multicolumn{2}{|c|}{$\mathbf{P b}$} & \multicolumn{2}{|c|}{$\mathrm{Zn}$} & \multicolumn{2}{|c|}{$\mathrm{Cr}$} & \multicolumn{2}{|c|}{$\mathrm{Cu}$} & \multicolumn{2}{|c|}{$\mathrm{Ni}$} & \multicolumn{2}{|c|}{$\mathbf{V}$} & \multicolumn{2}{|c|}{$\mathbf{B a}$} \\
\hline & & $\mathrm{T}$ & $\mathrm{L}$ & $\mathrm{T}$ & $\mathrm{L}$ & $T$ & $\mathrm{~L}$ & $T$ & $\mathrm{~L}$ & $T$ & $\mathrm{~L}$ & $T$ & $\mathrm{~L}$ & $T$ & $\mathrm{~L}$ \\
\hline & & & & & & & & & & & & & & & \\
\hline RR068 & Iporanga & $38,9 \pm 1,6$ & $\begin{array}{l}15,0 \pm \\
2,5\end{array}$ & $51 \pm 1$ & $\begin{array}{l}16,3 \pm \\
1,2\end{array}$ & $87 \pm 3$ & $\begin{array}{l}9,7 \pm \\
0,5\end{array}$ & $32 \pm 1$ & $\begin{array}{l}9,7 \pm \\
1,0\end{array}$ & $52 \pm 2$ & $\begin{array}{l}2,4 \pm \\
0,3\end{array}$ & $118 \pm 4$ & $\begin{array}{l}15,4 \pm \\
1,9\end{array}$ & $\begin{array}{l}687 \pm \\
20\end{array}$ & $\begin{array}{l}136 \pm \\
7,3\end{array}$ \\
\hline RR142 & B.Turvo & $17,9 \pm 0,5$ & $\begin{array}{l}9,4 \pm \\
0,6\end{array}$ & $47 \pm 2$ & $\begin{array}{l}12,6 \pm \\
0,8\end{array}$ & $104 \pm 4$ & $\begin{array}{l}3,1 \pm \\
0,2 \\
\end{array}$ & $\begin{array}{l}10,1 \pm \\
1,5\end{array}$ & $\begin{array}{l}3,1 \pm \\
0,1 \\
\end{array}$ & $82 \pm 4$ & $\begin{array}{l}0,61 \pm \\
0,2\end{array}$ & $151 \pm 8$ & $\begin{array}{l}9,5 \pm \\
0,9 \\
\end{array}$ & $\begin{array}{l}1002 \pm \\
50\end{array}$ & $\begin{array}{l}206 \pm \\
27\end{array}$ \\
\hline RR008 & B.Azeite & $36,6 \pm 2,6$ & $\begin{array}{l}22,4 \pm \\
1,9\end{array}$ & $172 \pm 3$ & $\begin{array}{l}46,3 \pm \\
2,1\end{array}$ & $72 \pm 3$ & $\begin{array}{l}2,3 \pm \\
0,6\end{array}$ & $\begin{array}{l}18,3 \pm \\
1,3\end{array}$ & $\begin{array}{l}2,3 \pm \\
0,2\end{array}$ & $45 \pm 3$ & $\begin{array}{l}5,1 \pm \\
0,6\end{array}$ & $138 \pm 3$ & $\begin{array}{l}8,0 \pm \\
1,2\end{array}$ & $\begin{array}{l}529 \pm \\
57\end{array}$ & $\begin{array}{l}182 \pm \\
8,0\end{array}$ \\
\hline RR014 & Ariri & $18,8 \pm 1,7$ & $\begin{array}{l}10,6 \pm \\
1,0\end{array}$ & $<1$ & $\begin{array}{l}23,0 \pm \\
2,3\end{array}$ & $215 \pm 8$ & $\begin{array}{l}8,0 \pm \\
0,3\end{array}$ & $\begin{array}{l}12,5 \pm \\
0,9\end{array}$ & $\begin{array}{l}8,0 \pm \\
0,2\end{array}$ & $\begin{array}{l}62,2 \pm 5 \\
, 2\end{array}$ & $\begin{array}{l}1,6 \pm \\
0,2\end{array}$ & $\begin{array}{l}686 \pm \\
24\end{array}$ & $\begin{array}{l}31,4 \pm \\
3,8\end{array}$ & $\begin{array}{l}900 \pm \\
87\end{array}$ & $\begin{array}{l}249 \pm \\
25\end{array}$ \\
\hline RR023 & Colonização & $\begin{array}{l}2,74 \pm 0,0 \\
2\end{array}$ & $\begin{array}{l}9,4 \pm \\
0,3 \\
\end{array}$ & $54 \pm 3$ & $\begin{array}{l}14,0 \pm \\
1,6\end{array}$ & $68 \pm 2$ & $\begin{array}{l}3,0 \pm \\
0,3\end{array}$ & $<1$ & $\begin{array}{l}3,0 \pm \\
0,1\end{array}$ & $128 \pm 5$ & $\begin{array}{l}1,0 \pm \\
0,2\end{array}$ & $204 \pm 7$ & $\begin{array}{l}23,7 \pm \\
1,8\end{array}$ & $\begin{array}{l}1789 \pm \\
50\end{array}$ & $\begin{array}{l}500 \pm \\
28\end{array}$ \\
\hline RR024 & B.Iporanga & $16,4 \pm 2,4$ & $\begin{array}{l}7,9 \pm \\
0,6\end{array}$ & $39,8 \pm 1,3$ & $\begin{array}{l}13,1 \pm \\
0,3\end{array}$ & $69 \pm 6$ & $\begin{array}{l}3,3 \pm \\
0,3\end{array}$ & $\begin{array}{l}14,1 \pm \\
1,2\end{array}$ & $\begin{array}{l}3,3 \pm \\
0,1\end{array}$ & $\begin{array}{l}30,5 \pm 3 \\
, 5\end{array}$ & $\begin{array}{l}1,8 \pm \\
0,7\end{array}$ & $122 \pm 4$ & $\begin{array}{l}17,3 \pm \\
2,1\end{array}$ & $\begin{array}{l}437 \pm \\
56\end{array}$ & $\begin{array}{l}600 \pm \\
79\end{array}$ \\
\hline RR029 & Musácea & $20,1 \pm 0,9$ & $\begin{array}{l}6,0 \pm \\
0,4\end{array}$ & $55 \pm 2$ & $\begin{array}{l}9,8 \pm \\
0,2\end{array}$ & $135 \pm 6$ & $\begin{array}{l}4,7 \pm \\
0,5\end{array}$ & $\begin{array}{l}21,6 \pm \\
0,4\end{array}$ & $\begin{array}{l}4,7 \pm \\
0,2\end{array}$ & $59 \pm 1$ & $\begin{array}{l}2,4 \pm \\
0,3\end{array}$ & $\begin{array}{l}167 \pm \\
10\end{array}$ & $\begin{array}{l}15,9 \pm \\
1,8 \\
\end{array}$ & $\begin{array}{l}759 \pm \\
16\end{array}$ & $\begin{array}{l}338 \pm \\
12\end{array}$ \\
\hline RR052 & Ana Dias & $18,7 \pm 2,2$ & $\begin{array}{l}9,4 \pm \\
0,2\end{array}$ & $<1$ & $\begin{array}{l}20,0 \pm \\
1,5\end{array}$ & $230 \pm 6$ & $\begin{array}{l}6,5 \pm \\
1,1\end{array}$ & $51 \pm 2$ & $\begin{array}{l}6,5 \pm \\
0,3\end{array}$ & $124 \pm 5$ & $\begin{array}{l}2,2 \pm \\
0,6\end{array}$ & $258 \pm 5$ & $\begin{array}{l}24,3 \pm \\
1,7\end{array}$ & $1697 \pm$ & $\begin{array}{l}679 \pm \\
62\end{array}$ \\
\hline RR053 & R.Tavares & $22,5 \pm 1,5$ & $\begin{array}{l}8,0 \pm \\
0,3\end{array}$ & $<1$ & $\begin{array}{l}20,4 \pm \\
2,5\end{array}$ & $156 \pm 8$ & $\begin{array}{l}7,4 \pm \\
0,2\end{array}$ & $\begin{array}{l}35,1 \pm \\
1,5\end{array}$ & $\begin{array}{l}7,4 \pm \\
0,8\end{array}$ & $76 \pm 2$ & $\begin{array}{l}2,1 \pm \\
0,1\end{array}$ & $227 \pm 7$ & $\begin{array}{l}41,4 \pm \\
2,5\end{array}$ & $\begin{array}{l}1088 \pm \\
3\end{array}$ & $\begin{array}{l}712 \pm \\
10\end{array}$ \\
\hline RR061 & Pedrinhas & & $\begin{array}{l}25,1 \pm \\
2,1\end{array}$ & & $\begin{array}{l}26,5 \pm \\
4,3\end{array}$ & & $\begin{array}{l}5,0 \pm \\
0,5\end{array}$ & & $\begin{array}{l}5,0 \pm \\
0,2\end{array}$ & & $\begin{array}{l}1,5 \pm \\
0,3\end{array}$ & & $\begin{array}{l}14,5 \pm \\
1,3\end{array}$ & & $\begin{array}{l}263 \pm \\
48\end{array}$ \\
\hline RR069 & B.da Serra & $18,8 \pm 2,1$ & $\begin{array}{l}4,2 \pm \\
0,2\end{array}$ & $20 \pm 1$ & $\begin{array}{l}11,1 \pm \\
0,5\end{array}$ & $132 \pm 5$ & $\begin{array}{l}5,0 \pm \\
0,1\end{array}$ & $\begin{array}{l}18,6 \pm \\
0,6\end{array}$ & $\begin{array}{l}5,0 \pm \\
0,5\end{array}$ & $60 \pm 2$ & $\begin{array}{l}1,8 \pm \\
0,2\end{array}$ & $135 \pm 2$ & $\begin{array}{l}4,6 \pm \\
0,2\end{array}$ & $740 \pm 3$ & $\begin{array}{l}24,0 \pm \\
8\end{array}$ \\
\hline
\end{tabular}

$\mathrm{T}$ - Concentração Total

L - Concentração Disponível (lixiviação $\mathrm{HCl}$ 0,1N) 
Pelos resultados, verificou-se que os elementos presentes em maiores concentrações nas amostras de sedimentos foram o $\mathrm{Al}, \mathrm{Fe}, \mathrm{Mn}, \mathrm{Ca}, \mathrm{K}$ e $\mathrm{Na}$. Os elementos $\mathrm{Pb}$ e $\mathrm{Zn}$ também presentes na fração total com concentrações variando de 2 a $142 \mathrm{mg} \cdot \mathrm{g}^{-1}$ e 1 a $172 \mathrm{mg} \cdot \mathrm{g}^{-1}$, respectivamente.

Avaliando-se a porcentagem de metal lixiviado em relação à concentração total, apresentada na Tabela 6.28, observa-se uma maior disponibilidade para os elementos $\mathrm{Pb}, \mathrm{Mn}$, Cu e Zn, quando comparados aos outros.

Tabela 6.28 - Porcentagem das concentrações dos elementos disponível em relação à concentração total.

\begin{tabular}{|l|c|}
\hline Elemento & $\begin{array}{c}\text { Disponível/Total } \\
(\%)\end{array}$ \\
\hline $\mathrm{Mn}$ & 51,5 \\
\hline $\mathrm{Pb}$ & 49,2 \\
\hline $\mathrm{Cu}$ & 31,5 \\
\hline $\mathrm{Zn}$ & 30,0 \\
\hline $\mathrm{Ca}$ & 22,2 \\
\hline $\mathrm{Cr}$ & 7,6 \\
\hline $\mathrm{Fe}$ & 5,6 \\
\hline $\mathrm{Ni}$ & 3,0 \\
\hline $\mathrm{Ca}$ & 2,4 \\
\hline $\mathrm{Mg}$ & 2,1 \\
\hline $\mathrm{Al}$ & 0,9 \\
\hline
\end{tabular}

Avaliando-se a os resultados encontrados neste estudo com dados da literatura, apresentados na Tabela 6.29, observa-se uma nítida diferença entre os teores de chumbo e zinco encontrados nos sedimentos do Vale do Ribeira, com os maiores valores na região (194 $\mu \mathrm{g} \cdot \mathrm{g}^{-1}$ e $66 \mu \mathrm{g} \cdot \mathrm{g}^{-1}$ respectivamente).

Outros estudos já demonstraram que os sedimentos do rio Ribeira apresentam concentrações de chumbo de até $175 \mu \mathrm{g} \cdot \mathrm{g}^{-1}$ (Cunha, 2003), provenientes provavelmente 
de antigos descartes de minas e depósitos de rejeitos minerais, com altas concentrações de chumbo expostos nas proximidades da Plumbum (Adrianópolis-PR). 
Tabela 6.29 - Comparação entre as concentrações de metais na fase lixiviada em $\mu \mathrm{g} \mathrm{g}^{-1}$, de sedimento seco (fração < 0,63 $\mu$ m), em vários trabalhos da literatura, com os resultados encontrados neste trabalho.

\begin{tabular}{|c|c|c|c|c|c|c|c|c|c|c|c|c|c|c|c|}
\hline & \multicolumn{15}{|c|}{ Concentração $\left(\mu \mathrm{g} \mathrm{g}^{-1}\right)$} \\
\hline & Mg & $\mathrm{Al}$ & $\mathbf{P}$ & $\mathrm{Ca}$ & $\mathrm{Cr}$ & Mn & Fe & Co & $\mathrm{Ni}$ & $\mathrm{Cu}$ & Zn & $\mathrm{Ag}$ & Cd & $\mathbf{B a}$ & $\mathbf{P b}$ \\
\hline \multicolumn{16}{|l|}{$\begin{array}{l}\text { Rio Ribeira } \\
\text { Iguape }\end{array}$} \\
\hline Iguape & 246 & 406 & 89,2 & 977 & 3,2 & 369 & 2613 & 6,6 & 1,4 & 6,7 & 20,8 & - & 0,16 & 63,9 & 11,4 \\
\hline Eldorado & 602 & 341 & 87,0 & 2130 & 0,7 & 342 & 1604 & 5,5 & 1,6 & 11,1 & 48,4 & - & 0,34 & 362 & 194 \\
\hline Registro & 380 & 544 & 51,7 & 1279 & 0,9 & 435 & 2673 & 8,3 & 1,9 & 10,2 & 25,6 & - & 0,29 & 267 & 37,8 \\
\hline Sete Barras & 526 & 450 & 62,5 & 2008 & 0,7 & 530 & 1270 & 5,9 & 1,7 & 8,1 & 26,5 & - & 0,12 & 279 & 42,1 \\
\hline \multicolumn{16}{|l|}{$\begin{array}{l}\text { Rio São } \\
\text { Lourenço }\end{array}$} \\
\hline S.L.da Serra & 1025 & 2113 & 233 & 2908 & 2,9 & 790 & 6336 & 16,2 & 2,0 & 16,1 & 65,6 & - & 0,53 & 232 & 46,6 \\
\hline Paiol Meio & 109 & 879 & 33,4 & 633 & 2,3 & 409 & 4421 & 10,6 & 1,6 & 17,7 & 32,7 & - & 0,29 & 123 & 15,8 \\
\hline Miracatu & 201 & 516 & 28,8 & 652 & 1,2 & 192 & 2839 & 7,6 & 1,2 & 6,0 & 12,6 & & 0,23 & 248 & 7,8 \\
\hline $\begin{array}{l}\text { Rio Jaguari } \\
\text { Mirim (a) }\end{array}$ & 136 & 436 & 18,9 & 826 & 1,1 & 763 & 3134 & 3,5 & 1,0 & 7,7 & 10,4 & 2,6 & 0,3 & 1358 & 4,7 \\
\hline $\begin{array}{l}\text { Rio Canoas } \\
\text { (a) }\end{array}$ & 205 & 349 & 8,0 & 987 & 1,7 & 499 & 3144 & 4,3 & 1,7 & 6,5 & 5,5 & 0,14 & 1,5 & 973 & 2,3 \\
\hline $\begin{array}{l}\text { Ribeirão da } \\
\text { Capelinha (a) }\end{array}$ & 120 & 625 & 8,1 & 743 & 1,2 & 493 & 10721 & 3,7 & 1,7 & 2,8 & 7,1 & ND & 0,4 & 898 & 5,7 \\
\hline $\begin{array}{l}\text { Ribeirão da } \\
\text { Prata (a) }\end{array}$ & 91 & 1058 & 6,9 & 1006 & 2,0 & 4310 & 18386 & 15,5 & 4,0 & 11,1 & 14,8 & 0,14 & 1,3 & 2983 & 5,9 \\
\hline $\begin{array}{l}\text { Córrego da } \\
\text { Fartura (a) }\end{array}$ & 99 & 1289 & 11,3 & 818 & 1,1 & 1005 & 3971 & 4,6 & 1,8 & 4,7 & 19,3 & ND & 0,5 & 1090 & 3,0 \\
\hline $\begin{array}{l}\text { Córrego dos } \\
\text { Cascais (a) }\end{array}$ & 55 & 1003 & 3 & 503 & 0,6 & 520 & 769 & 1,7 & 0,6 & 0,6 & 10,8 & 0,04 & 0,2 & 782 & 3,5 \\
\hline $\begin{array}{l}\text { Mina da } \\
\text { Encosta (a) }\end{array}$ & 107 & 740 & 3,7 & 767 & 1,0 & 686 & 3672 & 2,5 & 1,2 & 1,9 & 6,6 & ND & 0,4 & 876 & 6,3 \\
\hline $\begin{array}{l}\text { Córrego Sto. } \\
\text { Ambrosio (a) }\end{array}$ & 102 & 881 & 4,3 & 927 & 0,9 & 565 & 1983 & 2,6 & 1,3 & 3,4 & 5,5 & ND & 5,8 & 819 & 3,0 \\
\hline $\begin{array}{l}\text { Rio do Peixe } \\
\text { (a) }\end{array}$ & 291 & 2231 & 7,3 & 4151 & 2,0 & 1232 & 6389 & 3,3 & 2,1 & 2,9 & 6,0 & 0,03 & 0,7 & 3669 & 4,6 \\
\hline $\begin{array}{l}\text { Ribeirão } \\
\text { Doce (a) }\end{array}$ & 168 & 863 & 14 & 1280 & 1,7 & 1809 & 1183 & 9,1 & 3,0 & 5,8 & 7,1 & 0,05 & 1,0 & 3635 & 5,9 \\
\hline
\end{tabular}


Cont.

\begin{tabular}{|c|c|c|c|c|c|c|c|c|c|c|c|c|c|c|c|}
\hline & & & & & & & ncentr: & ão ( & & & & & & & \\
\hline & Mg & Al & $\mathbf{P}$ & $\mathrm{Ca}$ & $\mathrm{Cr}$ & Mn & $\mathrm{Fe}$ & Co & $\mathrm{Ni}$ & $\mathrm{Cu}$ & $Z n$ & $\mathrm{Ag}$ & Cd & $\mathrm{Ba}$ & $\mathrm{Pb}$ \\
\hline $\begin{array}{l}\text { Córrego da } \\
\text { Anhuma (a) }\end{array}$ & 120 & 637 & 4,0 & 637 & 1,5 & 312 & 5907 & 5,4 & 2,3 & 3,7 & 6,8 & 0,15 & 1,8 & 2085 & 4,5 \\
\hline Rio Verde (a) & 399 & 1248 & 52 & 809 & 1,2 & 628 & 5372 & 5,4 & 2,3 & 3,7 & 6,8 & 0,15 & 1,8 & 2085 & 4,5 \\
\hline $\begin{array}{l}\text { Lagoa do } \\
\text { Infernão (b) }\end{array}$ & - & 2942 & 345 & 200 & 7,33 & 104 & 13251 & - & 6,9 & 17,9 & 31,5 & - & 0,44 & - & 5,24 \\
\hline $\begin{array}{l}\text { Lagoa do } \\
\text { Frutal (b) }\end{array}$ & - & 2297 & 64,6 & 230 & 7,96 & 255 & 12991 & - & 3,76 & 17,3 & 21,4 & - & 0,35 & - & 4,41 \\
\hline $\begin{array}{l}\text { Lagoa } \\
\text { Infernão (c) }\end{array}$ & - & - & - & - & 1,4 & 120 & 4300 & - & 1,90 & 8,50 & 3,90 & - & 0,09 & - & 2,60 \\
\hline $\begin{array}{l}\text { Lagoa do } \\
\text { Óleo(c) }\end{array}$ & - & - & - & - & 0,94 & 120 & 5300 & - & 0,90 & 6,70 & 14,8 & - & 0,03 & - & 0,85 \\
\hline $\begin{array}{l}\text { Lagoa do } \\
\text { Quilombo (c) }\end{array}$ & - & - & - & - & 1,50 & 300 & 4300 & - & 0,76 & 7,5 & 13,1 & - & 0,03 & - & 2,00 \\
\hline $\begin{array}{l}\text { Lagoa do } \\
\text { Diogo(c) }\end{array}$ & - & - & - & - & 1,50 & 168 & 3200 & - & 0,90 & 7,00 & 6,0 & - & 0,01 & - & 2,00 \\
\hline $\begin{array}{l}\text { C. do } \\
\text { Cafundó(c) }\end{array}$ & - & - & - & - & - & 36,2 & 1364 & - & 0,14 & 4,66 & 6,15 & - & 0,08 & - & 1,22 \\
\hline $\begin{array}{l}\text { Córrego Boa } \\
\text { Sorte (c) }\end{array}$ & - & - & - & - & 0,44 & 81,0 & 2722 & - & - & 2,20 & 3,00 & - & - & - & 0,15 \\
\hline $\begin{array}{l}\text { Córrego Jataí } \\
\text { (c) }\end{array}$ & - & - & - & - & 1,06 & 127 & 2464 & - & 1,03 & 6,65 & 7,15 & - & 0,05 & - & 1,31 \\
\hline
\end{tabular}

Fonte:

(a) LEMES, M.J.L., 2001 - Mogi-Guaçú e Pardo - extração com HCl 0,1 mol..-1

(b) GATTI, L.V., 1997 - Lagoas do Rio Mogi-Guaçú - extração com HCl 0,1 mol..-1

(c) LIMA, 1990 - apud GATTI, 1997 - Lagoas e Córrego na Estação Ecológica de Jataí - extração com $\mathrm{HCl}$ 0,1 mol.L-1 


\section{CONCLUSÕES}

Os processos de industrialização e de urbanização, nas últimas décadas, têm tornado cada vez mais crítica a questão da contaminação do meio ambiente. Entre os diversos contaminantes, os metais têm contribuído de forma significativa para a poluição do ar, da água e do solo, transformando-se em mais uma perigosa classe de contaminantes, uma vez que a intervenção humana na sua geração e utilização como subproduto de atividades industriais, tem criado graves problemas, em escala local e global, levando a um estresse da natureza, associado aos seus efeitos crônicos à saúde humana (BRAYNER, 1998).

A avaliação das condições ambientais utilizando variáveis físicas e químicas, principalmente os metais, na coluna de água e no sedimento é uma importante ferramenta não só para o conhecimento da sua distribuição no ecossistema, e seu perfil em função do tempo, como também para o balizamento de medidas a serem tomadas para melhorar e preservar a qualidade ambiental e proteger a saúde da população.

Foram avaliados os 43 sistemas produtores do Vale do Ribeira, caracterizando, desta forma, os mananciais da região com vistas ao abastecimento público.

As áreas de captação estudadas não estão comprometidas quanto à contribuição de metais tóxicos. Concentrações elevadas de $\mathrm{Mn}$, Fe e Al foram observadas nas águas da região. Foi observada sazonalidade nas características da coluna de água no aporte de alguns elementos. Maiores concentrações foram observadas na época de chuva.

O processo de tratamento de água foi avaliado, mostrando uma redução praticamente total para alguns elelemtos ( $\mathrm{Mn}, \mathrm{Fe}, \mathrm{Al})$. A alteração da concentração de determinados elementos, após a etapa de tratamento nas 
ETA's, mostra claramente a necessidade de controlar a quallidade dos insumos utilizados. Foi observado um aumento significativo nas concentrações de $\mathrm{Ca}, \mathrm{Mg}$, $\mathrm{Na}$ e $\mathrm{SO}_{4}{ }^{2-}$, além de um aumento na concentração de alguns metais tóxico como, por exemplo, a Ag.

Nas amostras de água para abastecimento público (manancial de serra, água de poço e água tratada) analisadas, a concentração média de todos os elementos encontram-se abaixo dos limites estabelecidos pela Portaria 518/MS.

Os mananciais de serra, superficial e subterrâneo apresentam características diferentes em relação à concentração de elementos, como Ca, Fe, $\mathrm{Mn}, \mathrm{Na}$ entre outros.

Não foram obtidos perfis para os elementos $\mathrm{B}, \mathrm{Ag}, \mathrm{Cd}, \mathrm{Cu}, \mathrm{Ni}, \mathrm{Hg}, \mathrm{As}$, $\mathrm{Se}, \mathrm{Sb}, \mathrm{V}, \mathrm{Sn}, \mathrm{Mo}$, Co e fosfato nas amostras de água em mananciais superficiais, de serra e subterrâneo, bem como nas amostras de água tratada. $O$ fator limitante para avaliação do perfil desses elementos foi o limite de quantificação das técnicas utilizadas.

Com relação a presença de $\mathrm{Pb}$, este foi observado um perfil em todos os sitemas, porém com valores extremamente baixos, não ultrapassando em nenhuma amostra o limite estabelecido pela Portaria 518, para abastecimento público.

O fato de ter sido constatada a presença de chumbo nas amostras de água, possibilita considerar que ainda está ocorrendo contribuição do metal ao sistema aquático. Esta contribuição pode ser atribuída parte às fontes remanescentes dos processos de mineração e de beneficiamento de chumbo, que permanencem, após o fim destas atividades, na forma de pilhas de rejeitos; parte pela contribuição do sedimento e do particulado suspenso que são compartimentos com forte tendência a associarem metais contaminantes em sua constituição e parte por fenômenos de remobilização, atribuídas a possíveis processos de dessorção deste metal do sedimento para a coluna d'água. 


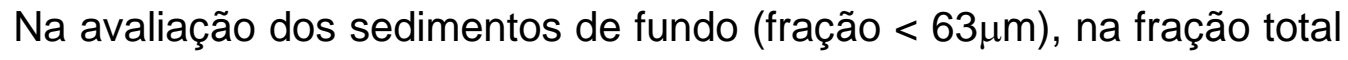
as maiores concentrações foram encontradas para os elementos $\mathrm{Al}$, Fe e Mg. Foram observadas concentrações altas para os elementos $\mathrm{Pb}$ e $\mathrm{Zn}$.

$\mathrm{Na}$ fração disponível do sedimento de fundo foram observadas altas concentrações de $\mathrm{Pb}$, com níveis acima do $\mathrm{PEL}$, principalmente nos sedimentos das captações no Rio Ribeira de Iguape (Eldorado e Sete Barras), mostrando que esses sedimentos estão impactados. Mudanças no pH poderão disponibilizar esse elemento para a coluna de água.

As ferramentas analíticas aplicadas neste estudo, combinadas com uma base múltipla de dados de monitoramento, objetivaram, avaliar e a qualidade da água das captações utilizadas para abastecimento público.

Nesse sentido, destaca-se a importância dos resultados qualitativos uma vez que as respostas quantitativas requerem ainda um incremento no número de observações para definirem menores intervalos de predição e melhores coeficientes de determinação. Isso permitiria a definição de modelos mais ajustados e com maior força de prognosticar valores futuros de dados qualitativos em sub-bacias que não apresentem avaliação da qualidade de suas águas.

Dessa forma, ressalta-se a importância de se manter o banco de dados atualizado de modo a permitir, inicialmente, a construção de uma base de dados sólida e consistente e, posteriormente, a agregação de informações de uso e ocupação urbana e rural para a implementação de modelos que avaliem tanto a carga pontual como a difusa. Esse banco de dados e seus produtos devem ser de fácil acesso aos usuários, garantindo o fluxo da informação nos diversos segmentos da sociedade.

É importante salientar que a qualidade da água não se traduz apenas pelas suas características físicas e químicas, mas pela qualidade de todo o recurso hídrico que envolve a saúde e o funcionamento equilibrado do ecossistema, incluindo aí as plantas, a comunidade aquática e seus habitantes. 
A caracterização dos mananciais forneceu um "background" da região, funcionando como uma fotografia atual da região a ser utilizada na avaliação de eventuais impactos antropogênicos. É importante considerar estes dados como referência para o monitoramento da região e evitar modificações no conteúdo de metais que possam levá-la a uma situação negativa.

O trabalho é uma contribuição ao estudo da Portaria 518/2004/MS, que remete a avaliação do manancial. 
APÊNDICE A: Estatística Descritiva 
Tabela A.1 - Estatística descritiva para as concentrações $\left(\mathrm{mg} \cdot \mathrm{L}^{-1}\right)$ de metais e íons em manancial de serra.

\begin{tabular}{|c|c|c|c|c|c|c|c|c|c|c|}
\hline \multicolumn{2}{|c|}{ Parâmetro } & \multirow{2}{*}{$\begin{array}{l}\text { LR008 } \\
5\end{array}$} & \multirow{2}{*}{$\begin{array}{l}\text { LR } 014 \\
5\end{array}$} & \multirow{2}{*}{$\begin{array}{l}\text { LR } 023 \\
5\end{array}$} & \multirow{2}{*}{$\begin{array}{l}\text { LR } 024 \\
5\end{array}$} & \multirow{2}{*}{$\begin{array}{l}\text { LR } 029 \\
4\end{array}$} & \multirow{2}{*}{$\begin{array}{l}\text { LR } 052 \\
5\end{array}$} & \multirow{2}{*}{$\begin{array}{l}\text { LR } 053 \\
5\end{array}$} & \multirow{2}{*}{$\begin{array}{l}\text { LR } 061 \\
5\end{array}$} & \multirow{2}{*}{$\begin{array}{l}\text { LR } 069 \\
5\end{array}$} \\
\hline$B$ & $\mathrm{~N}$ & & & & & & & & & \\
\hline & média & 0,007 & 0,012 & 0,055 & 0,105 & 0,010 & 0,006 & 0,007 & 0,014 & 0,009 \\
\hline & Mediana & 0,007 & 0,012 & 0,055 & 0,105 & 0,010 & 0,006 & 0,007 & 0,014 & 0,009 \\
\hline & Minimo & $<0,003$ & $<0,003$ & $<0,003$ & $<0,003$ & $<0,003$ & $<0,003$ & $<0,003$ & $<0,003$ & $<0,003$ \\
\hline & Maximo & 0,008 & 0,013 & 0,055 & 0,105 & 0,010 & 0,007 & 0,008 & 0,014 & 0,009 \\
\hline \multirow[t]{5}{*}{$\mathrm{Al}$} & $\mathrm{N}$ & 5 & 5 & 5 & 5 & 4 & 5 & 5 & 5 & 5 \\
\hline & média & 0,083 & 0,044 & 0,083 & 0,185 & 0,080 & 0,038 & 0,042 & 0,106 & 0,045 \\
\hline & Mediana & 0,095 & 0,041 & 0,098 & 0,046 & 0,059 & 0,044 & 0,042 & 0,106 & 0,045 \\
\hline & Minimo & 0,023 & $<0,02$ & $<0,02$ & $<0,02$ & $<0,02$ & $<0,02$ & $<0,02$ & $<0,02$ & $<0,02$ \\
\hline & Maximo & 0,131 & 0,075 & 0,129 & 0,626 & 0,127 & 0,044 & 0,055 & 0,156 & 0,057 \\
\hline \multirow[t]{5}{*}{$\mathrm{Cr}$} & $\mathrm{N}$ & 5 & 5 & 5 & 5 & 4 & 5 & 5 & 5 & 5 \\
\hline & média & & & & & & & & & \\
\hline & Mediana & & & & & & & & & \\
\hline & Minimo & $<0,03$ & $<0,03$ & $<0,03$ & $<0,03$ & $<0,03$ & $<0,03$ & $<0,03$ & $<0,03$ & $<0,03$ \\
\hline & Maximo & & & & & & & & & \\
\hline \multirow[t]{5}{*}{$\mathrm{Mn}$} & $\mathrm{N}$ & 5 & 5 & 5 & 5 & 4 & 5 & 5 & 5 & 5 \\
\hline & média & 0,014 & 0,018 & 0,013 & 0,015 & 0,022 & 0,017 & 0,032 & 0,010 & 2,130 \\
\hline & Mediana & 0,014 & 0,018 & 0,009 & 0,015 & 0,022 & 0,017 & 0,032 & 0,010 & 1,370 \\
\hline & Minimo & $<0,007$ & $<0,007$ & $<0,007$ & $<0,007$ & $<0,007$ & $<0,007$ & $<0,007$ & $<0,007$ & $<0,007$ \\
\hline & Maximo & 0,016 & 0,018 & 0,022 & 0,023 & 0,024 & 0,017 & 0,032 & 0,011 & 5,00 \\
\hline \multirow[t]{5}{*}{$\mathrm{Ni}$} & $\mathrm{N}$ & 5 & 5 & 5 & 5 & 4 & 5 & 5 & 5 & 5 \\
\hline & média & & & & & & & & & \\
\hline & Mediana & & & & & & & & & \\
\hline & Minimo & $<0,02$ & $<0,02$ & $<0,02$ & $<0,02$ & $<0,02$ & $<0,02$ & $<0,02$ & $<0,02$ & $<0,02$ \\
\hline & Maximo & & & & & & & & & \\
\hline \multirow[t]{5}{*}{$\mathrm{Cu}$} & $\mathrm{N}$ & 5 & 5 & 5 & 5 & 4 & 5 & 5 & 5 & 5 \\
\hline & média & & & & & & & & & \\
\hline & Mediana & & & & & & & & & \\
\hline & Minimo & $<0,02$ & $<0,02$ & $<0,02$ & $<0,02$ & $<0,02$ & $<0,02$ & $<0,02$ & $<0,02$ & $<0,02$ \\
\hline & Maximo & & & & & & & & & \\
\hline \multirow[t]{5}{*}{$\mathrm{Zn}$} & $\mathrm{N}$ & 5 & 5 & 5 & 5 & 4 & 5 & 5 & 5 & 5 \\
\hline & média & 0,010 & 0,024 & 0,016 & 0,024 & 0,064 & 0,013 & 0,012 & 0,014 & 0,498 \\
\hline & Mediana & 0,011 & 0,009 & 0,014 & 0,008 & 0,064 & 0,012 & 0,007 & & 0,049 \\
\hline & Minimo & $<0,003$ & $<0,003$ & 0,007 & $<0,003$ & $<0,003$ & $<0,003$ & $<0,003$ & $<0,003$ & 0,005 \\
\hline & Maximo & 0,017 & 0,059 & 0,032 & 0,058 & 0,118 & 0,024 & 0,029 & 0,022 & 1,390 \\
\hline \multirow[t]{5}{*}{ Mo } & $\mathrm{N}$ & 5 & 5 & 5 & 5 & 4 & 5 & 5 & 5 & 5 \\
\hline & média & 0,036 & & & & & & 0,033 & & \\
\hline & Mediana & 0,036 & & & & & & 0,033 & & \\
\hline & Minimo & $<0,02$ & $<0,02$ & $<0,02$ & $<0,02$ & $<0,02$ & $<0,02$ & $<0,02$ & $<0,02$ & $<0,02$ \\
\hline & Maximo & 0,036 & & & & & & 0,033 & & \\
\hline \multirow[t]{5}{*}{$\mathrm{Ag}$} & $\mathrm{N}$ & 5 & 5 & 5 & 5 & 4 & 5 & 5 & 5 & 5 \\
\hline & média & 0,006 & & & & 0,026 & & 0,019 & & \\
\hline & Mediana & 0,006 & & & & 0,026 & & 0,019 & & \\
\hline & Minimo & $<0,005$ & $<0,005$ & $<0,005$ & $<0,005$ & $<0,005$ & $<0,005$ & $<0,005$ & $<0,005$ & $<0,005$ \\
\hline & Maximo & 0,006 & & & & 0,026 & & 0,019 & & \\
\hline
\end{tabular}


Cont.

\begin{tabular}{|c|c|c|c|c|c|c|c|c|c|c|}
\hline \multicolumn{2}{|c|}{ Parâmetro } & \multirow{2}{*}{$\begin{array}{l}\text { LR008 } \\
5\end{array}$} & \multirow{2}{*}{$\begin{array}{l}\text { LR } 014 \\
5\end{array}$} & \multirow{2}{*}{$\begin{array}{l}\text { LR } 023 \\
5\end{array}$} & \multirow{2}{*}{$\begin{array}{l}\text { LR } 024 \\
5\end{array}$} & \multirow{2}{*}{$\begin{array}{l}\text { LR } 029 \\
4\end{array}$} & \multirow{2}{*}{$\begin{array}{l}\text { LR } 052 \\
5\end{array}$} & \multirow{2}{*}{$\begin{array}{l}\text { LR } 053 \\
5\end{array}$} & \multirow{2}{*}{$\begin{array}{l}\text { LR } 061 \\
5\end{array}$} & \multirow{2}{*}{$\begin{array}{l}\text { LR } 069 \\
5\end{array}$} \\
\hline $\mathrm{Sn}$ & $\mathrm{N}$ & & & & & & & & & \\
\hline & média & & & & & & & & & \\
\hline & Mediana & & & & & & & & & \\
\hline & Minimo & $<0,20$ & $<0,20$ & $<0,20$ & $<0,20$ & $<0,20$ & $<0,20$ & $<0,20$ & $<0,20$ & $<0,20$ \\
\hline & Maximo & & & & & & & & & \\
\hline \multirow[t]{5}{*}{$\mathrm{V}$} & $\mathrm{N}$ & 5 & 5 & 5 & 5 & 4 & 5 & 5 & 5 & 5 \\
\hline & média & & & & & & & & & \\
\hline & Mediana & & & & & & & & & \\
\hline & Minimo & $<0,01$ & $<0,01$ & $<0,01$ & $<0,01$ & $<0,01$ & $<0,01$ & $<0,01$ & $<0,01$ & $<0,01$ \\
\hline & Maximo & & & & & & & & & \\
\hline \multirow[t]{5}{*}{$\mathrm{Na}$} & $\mathrm{N}$ & 5 & 5 & 5 & 5 & 4 & 5 & 5 & 5 & 5 \\
\hline & média & 2,90 & 5,33 & 4,52 & 3,54 & 5,30 & 3,01 & 3,70 & 4,18 & 1,69 \\
\hline & Mediana & 2,91 & 5,23 & 4,92 & 3,13 & 5,67 & 2,81 & 3,57 & 4,73 & 1,04 \\
\hline & Minimo & 2,37 & 4,23 & 2,37 & 2,67 & 4,11 & 2,67 & 3,21 & 1,02 & 0,88 \\
\hline & Maximo & 3,33 & 6,64 & 5,30 & 4,52 & 5,74 & 3,99 & 4,56 & 5,56 & 2,83 \\
\hline \multirow[t]{5}{*}{$\mathrm{Mg}$} & $\mathrm{N}$ & 5 & 5 & 5 & 5 & 4 & 5 & 5 & 5 & 5 \\
\hline & média & 0,469 & 1,06 & 0,893 & 0,957 & 1,89 & 0,941 & 1,048 & 0,925 & 2,53 \\
\hline & Mediana & 0,463 & 1,05 & 0,966 & 0,655 & 1,94 & 0,848 & 1,080 & 0,887 & 1,31 \\
\hline & Minimo & 0,404 & 0,960 & 0,569 & 0,568 & 1,63 & 0,788 & 0,860 & 0,719 & 0,935 \\
\hline & Maximo & 0,547 & 1,16 & 1,03 & 1,99 & 2,05 & 1,36 & 1,12 & 1,31 & 5,30 \\
\hline \multirow[t]{5}{*}{$\mathrm{P}$} & $\mathrm{N}$ & 5 & 5 & 5 & 5 & 4 & 5 & 5 & 5 & 5 \\
\hline & média & 0,071 & 0,082 & 0,104 & 0,083 & 0,093 & 0,118 & 0,096 & 0,118 & 0,127 \\
\hline & Mediana & 0,051 & 0,057 & 0,125 & 0,089 & 0,093 & 0,112 & 0,100 & 0,102 & 0,130 \\
\hline & Minimo & $<0,02$ & $<0,02$ & 0,040 & $<0,02$ & $<0,02$ & 0,022 & $<0,02$ & $<0,02$ & $<0,02$ \\
\hline & Maximo & 0,130 & 0,131 & 0,144 & 0,120 & 0,099 & 0,150 & 0,164 & 0,155 & 0,148 \\
\hline \multirow[t]{5}{*}{$\mathrm{Ca}$} & $\mathrm{N}$ & 5 & 5 & 5 & 5 & 4 & 5 & 5 & 5 & 5 \\
\hline & média & 0,554 & 0,497 & 2,52 & 2,21 & 2,98 & 1,47 & 1,72 & 0,693 & 7,60 \\
\hline & Mediana & 0,576 & 0,509 & 2,70 & 1,99 & 2,96 & 1,20 & 1,82 & 0,696 & 0,618 \\
\hline & Minimo & 0,407 & 0,396 & 1,51 & 1,74 & 2,35 & 1,13 & 0,935 & 0,591 & 0,468 \\
\hline & Maximo & 0,654 & 0,582 & 2,92 & 2,94 & 3,64 & 2,47 & 2,26 & 0,847 & 19,80 \\
\hline \multirow[t]{5}{*}{$\mathrm{Fe}$} & $\mathrm{N}$ & 5 & 5 & 5 & 5 & 4 & 5 & 5 & 5 & 5 \\
\hline & média & 0,210 & 0,042 & 0,134 & 0,098 & 0,171 & 0,033 & 0,096 & 0,217 & 0,073 \\
\hline & Mediana & 0,060 & 0,026 & 0,138 & 0,033 & 0,170 & 0,030 & 0,087 & 0,147 & 0,074 \\
\hline & Minimo & 0,042 & 0,018 & 0,086 & 0,016 & 0,074 & 0,017 & 0,032 & $<0,004$ & 0,028 \\
\hline & Maximo & 0,818 & 0,106 & 0,172 & 0,246 & 0,269 & 0,060 & 0,224 & 0,550 & 0,124 \\
\hline \multirow[t]{5}{*}{$\mathrm{Ba}$} & $\mathrm{N}$ & 5 & 5 & 5 & 5 & 4 & 5 & 5 & 5 & 5 \\
\hline & média & 0,004 & 0,017 & 0,031 & 0,059 & 0,019 & 0,014 & 0,019 & 0,057 & 0,015 \\
\hline & Mediana & 0,004 & 0,017 & 0,032 & 0,020 & 0,020 & 0,012 & 0,020 & 0,031 & 0,007 \\
\hline & Minimo & 0,003 & 0,016 & 0,022 & 0,019 & 0,015 & 0,009 & 0,017 & 0,005 & 0,004 \\
\hline & Maximo & 0,005 & 0,020 & 0,034 & 0,200 & 0,021 & 0,021 & 0,021 & 0,193 & 0,036 \\
\hline \multirow[t]{5}{*}{ Co } & $\mathrm{N}$ & 5 & 5 & 5 & 5 & 4 & 5 & 5 & 5 & 5 \\
\hline & média & & & & & & & & & \\
\hline & Mediana & & & & & & & & & \\
\hline & Minimo & $<0,05$ & $<0,05$ & $<0,05$ & $<0,05$ & $<0,05$ & $<0,05$ & $<0,05$ & $<0,05$ & $<0,05$ \\
\hline & Maximo & & & & & & & & & \\
\hline
\end{tabular}


Cont.

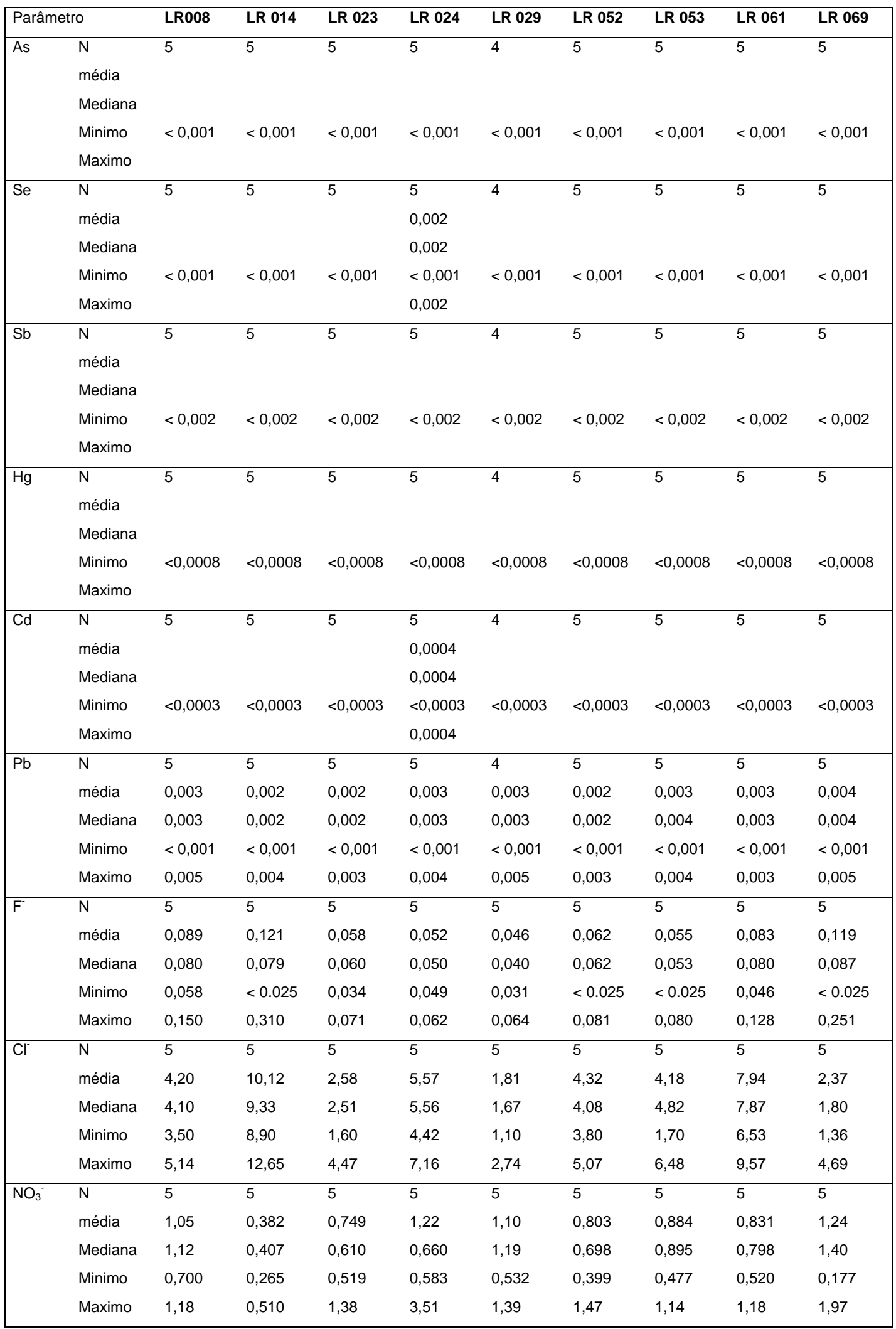


Cont.

\begin{tabular}{|lllllllllll|}
\hline Parâmetro & LR008 & LR 014 & LR 023 & LR 024 & LR 029 & LR 052 & LR 053 & LR 061 & LR 069 \\
\hline $\mathrm{PO}_{4}{ }^{3-}$ & $\mathrm{N}$ & 5 & 5 & 5 & 5 & 5 & 5 & 5 & 5 & 5 \\
& & & & & & & & & & \\
& média & & 0,255 & & & & & & & \\
& Mediana & & 0,255 & & & & & & & \\
& Minimo & $<0.05$ & $<0.05$ & $<0.05$ & $<0.05$ & $<0.05$ & $<0.05$ & $<0.05$ & $<0.05$ & $<0.05$ \\
& Maximo & & 0,255 & & & & & & & \\
\hline $\mathrm{SO}_{4}{ }^{2-}$ & $\mathrm{N}$ & 5 & 5 & 5 & 5 & 5 & 5 & 5 & 5 & 5 \\
& média & 0,816 & 1,47 & 0,502 & 1,94 & 0,430 & 0,599 & 0,582 & 1,30 & 0,629 \\
& Mediana & 0,795 & 1,49 & 0,441 & 1,38 & 0,377 & 0,577 & 0,650 & 1,41 & 0,590 \\
& Minimo & 0,626 & 1,23 & 0,420 & 1,14 & 0,293 & 0,512 & 0,256 & 0,850 & 0,433 \\
Maximo & 0,990 & 1,68 & 0,758 & 4,15 & 0,613 & 0,695 & 0,759 & 1,70 & 0,826 \\
\hline
\end{tabular}


Tabela A.2 - Estatística descritiva para as concentrações $\left(\mathrm{mg} \cdot \mathrm{L}^{-1}\right)$ de metais e íons em poços.

\begin{tabular}{|c|c|c|c|c|c|c|c|c|c|c|c|c|c|c|c|c|}
\hline \multicolumn{2}{|c|}{ Parâmetro } & \multirow{2}{*}{$\begin{array}{l}\text { LR } 003 \\
4\end{array}$} & \multirow{2}{*}{$\begin{array}{l}\text { LR } 004 \\
5\end{array}$} & \multirow{2}{*}{$\begin{array}{l}\text { LR } 006 \\
5\end{array}$} & \multirow{2}{*}{$\begin{array}{l}\text { LR } 018 \\
5\end{array}$} & \multirow{2}{*}{$\begin{array}{l}\text { LR } 019 \\
5\end{array}$} & \multirow{2}{*}{$\begin{array}{l}\text { LR } 020 \\
5\end{array}$} & \multirow{2}{*}{$\begin{array}{l}\text { LR } 027 \\
5\end{array}$} & \multirow{2}{*}{$\begin{array}{l}\text { LR } 032 \\
4\end{array}$} & \multirow{2}{*}{\begin{tabular}{|l} 
LR 042 \\
5
\end{tabular}} & \multirow{2}{*}{\begin{tabular}{|l} 
LR 046 \\
5
\end{tabular}} & \multirow{2}{*}{$\begin{array}{l}\text { LR } 047 \\
5\end{array}$} & \multirow{2}{*}{$\begin{array}{l}\text { LR } 054 \\
5\end{array}$} & \multirow{2}{*}{$\begin{array}{l}\text { LR } 057 \\
5\end{array}$} & \multirow{2}{*}{$\begin{array}{l}\text { LR } 060 \\
5\end{array}$} & \multirow{2}{*}{$\begin{array}{l}\text { LR } 070 \\
5\end{array}$} \\
\hline $\mathrm{Ag}$ & $\mathrm{N}$ & & & & & & & & & & & & & & & \\
\hline & Média & & & 0,004 & 0,005 & 0,012 & 0,008 & 0,015 & & 0,014 & 0,014 & 0,021 & 0,019 & 0,013 & 0,004 & 0,012 \\
\hline & Mediana & & & 0,004 & 0,005 & 0,012 & 0,008 & 0,015 & & 0,014 & 0,014 & 0,021 & 0,019 & 0,013 & 0,004 & 0,012 \\
\hline & Mínimo & $<0,005$ & $<0,005$ & $<0,005$ & $<0,005$ & $<0,005$ & $<0,005$ & $<0,005$ & $<0,005$ & $<0,005$ & $<0,005$ & $<0,005$ & $<0,005$ & $<0,005$ & $<0,005$ & $<0,005$ \\
\hline & Máximo & & & 0,004 & 0,005 & 0,019 & 0,008 & 0,022 & & 0,020 & 0,020 & 0,021 & 0,019 & 0,021 & 0,004 & 0,020 \\
\hline \multirow[t]{5}{*}{$\mathrm{Al}$} & $\mathrm{N}$ & 4 & 5 & 5 & 5 & 5 & 5 & 5 & 4 & 5 & 5 & 5 & 5 & 5 & 5 & 5 \\
\hline & Média & 0,045 & 0,047 & 0,074 & 0,069 & 0,110 & 0,100 & 0,031 & 0,046 & 0,055 & 0,033 & 0,043 & 0,062 & 0,063 & 0,027 & 0,058 \\
\hline & Mediana & 0,035 & 0,044 & 0,078 & 0,055 & 0,113 & 0,096 & 0,028 & 0,035 & 0,048 & 0,038 & 0,046 & 0,063 & 0,063 & 0,028 & 0,054 \\
\hline & Mínimo & $<0,02$ & 0,021 & 0,053 & 0,036 & 0,085 & 0,052 & 0,004 & $<0,020$ & $<0,020$ & $<0,020$ & $<0,020$ & $<0,020$ & $<0,020$ & $<0,020$ & 0,041 \\
\hline & Máximo & 0,074 & 0,085 & 0,087 & 0,122 & 0,135 & 0,155 & 0,062 & 0,076 & 0,099 & 0,039 & 0,049 & 0,082 & 0,086 & 0,041 & 0,079 \\
\hline \multirow[t]{5}{*}{ As } & $\mathrm{N}$ & 4 & 4 & 4 & 4 & 4 & 5 & 5 & 4 & 5 & 5 & 5 & 5 & 5 & 5 & 5 \\
\hline & Média & & & & 0,001 & 0,007 & 0,020 & 0,005 & & & & & & & & \\
\hline & Mediana & & & & 0,001 & 0,007 & 0,020 & 0,005 & & & & & & & & \\
\hline & Mínimo & $<0,001$ & $<0,001$ & $<0,001$ & $<0,001$ & $<0,001$ & $<0,001$ & $<0,001$ & $<0,001$ & $<0,001$ & $<0,001$ & $<0,001$ & $<0,001$ & $<0,001$ & $<0,001$ & $<0,001$ \\
\hline & Máximo & & & & 0,001 & 0,007 & 0,020 & 0,006 & & & & & & & & \\
\hline \multirow[t]{5}{*}{ B } & $\mathrm{N}$ & 4 & 5 & 5 & 5 & 5 & 5 & 5 & 4 & 5 & 5 & 5 & 5 & 5 & 5 & 5 \\
\hline & Média & 0,008 & 0,012 & 0,012 & 0,010 & 0,011 & 0,010 & 0,058 & & 0,018 & 0,007 & 0,006 & 0,014 & 0,009 & 0,009 & 0,021 \\
\hline & Mediana & 0,008 & 0,012 & 0,012 & 0,010 & 0,011 & 0,010 & 0,054 & & 0,018 & 0,007 & 0,006 & 0,014 & 0,009 & 0,009 & 0,021 \\
\hline & Mínimo & $<0,003$ & $<0,003$ & $<0,003$ & $<0,003$ & $<0,003$ & $<0,003$ & $<0,003$ & $<0,003$ & $<0,003$ & $<0,003$ & $<0,003$ & $<0,003$ & $<0,003$ & $<0,003$ & $<0,003$ \\
\hline & Máximo & 0,010 & 0,014 & 0,014 & 0,012 & 0,013 & 0,011 & 0,092 & & 0,021 & 0,010 & 0,008 & 0,014 & 0,009 & 0,009 & 0,021 \\
\hline \multirow[t]{5}{*}{$\mathrm{Ba}$} & $\mathrm{N}$ & 5 & 5 & 5 & 5 & 5 & 5 & 5 & 4 & 5 & 5 & 5 & 5 & 5 & 5 & 4 \\
\hline & Média & 0,090 & 0,089 & 0,118 & 0,044 & 0,079 & 0,037 & 0,043 & 0,079 & 0,047 & 0,027 & 0,040 & 0,089 & 0,098 & 0,347 & 0,118 \\
\hline & Mediana & 0,094 & 0,074 & 0,141 & 0,023 & 0,108 & 0,040 & 0,041 & 0,079 & 0,052 & 0,027 & 0,024 & 0,107 & 0,011 & 0,398 & 0,117 \\
\hline & Mínimo & 0,073 & 0,069 & 0,020 & 0,019 & 0,014 & 0,021 & 0,039 & 0,073 & 0,024 & 0,026 & 0,022 & 0,011 & 0,010 & 0,122 & 0,112 \\
\hline & Máximo & 0,100 & 0,144 & 0,149 & 0,121 & 0,118 & 0,047 & 0,053 & 0,084 & 0,054 & 0,029 & 0,100 & 0,116 & 0,443 & 0,467 & 0,124 \\
\hline \multirow[t]{5}{*}{$\mathrm{Cd}$} & $\mathrm{N}$ & 5 & 5 & 5 & 5 & 5 & 5 & 5 & 4 & 5 & 5 & 5 & 5 & 5 & 5 & 4 \\
\hline & Média & 0,0003 & & 0,0003 & & & & & & & 0,002 & & & & & \\
\hline & Mediana & 0,0003 & & 0,0003 & & & & & & & 0,002 & & & & & \\
\hline & Mínimo & $<0,0001$ & $<0,0001$ & $<0,0001$ & $<0,0001$ & $<0,0001$ & $<0,0001$ & $<0,0001$ & $<0,0001$ & $<0,0001$ & $<0,0001$ & $<0,0001$ & $<0,0001$ & $<0,0001$ & $<0,0001$ & $<0,0001$ \\
\hline & Máximo & 0,0003 & & 0,0003 & & & & & & & 0,002 & & & & & \\
\hline
\end{tabular}




\section{Cont.}

\begin{tabular}{|c|c|c|c|c|c|c|c|c|c|c|c|c|c|c|c|c|}
\hline \multicolumn{2}{|c|}{ Parâmetro } & \multirow{2}{*}{$\begin{array}{l}\text { LR } 003 \\
5\end{array}$} & \multirow{2}{*}{$\begin{array}{l}\text { LR } 004 \\
5\end{array}$} & \multirow{2}{*}{$\begin{array}{l}\text { LR } 006 \\
5\end{array}$} & \multirow{2}{*}{$\begin{array}{l}\text { LR } 018 \\
5\end{array}$} & \multirow{2}{*}{$\begin{array}{l}\text { LR } 019 \\
5\end{array}$} & \multirow{2}{*}{$\begin{array}{l}\text { LR } 020 \\
5\end{array}$} & \multirow{2}{*}{$\begin{array}{l}\text { LR } 027 \\
5\end{array}$} & \multirow{2}{*}{$\begin{array}{l}\text { LR } 032 \\
4\end{array}$} & \multirow{2}{*}{$\begin{array}{l}\text { LR } 042 \\
5\end{array}$} & \multirow{2}{*}{$\begin{array}{l}\text { LR } 046 \\
5\end{array}$} & \multirow{2}{*}{$\begin{array}{l}\text { LR } 047 \\
5\end{array}$} & \multirow{2}{*}{$\begin{array}{l}\text { LR } 054 \\
5\end{array}$} & \multirow{2}{*}{$\begin{array}{l}\text { LR } 057 \\
5\end{array}$} & \multirow{2}{*}{$\begin{array}{l}\text { LR } 060 \\
5\end{array}$} & \multirow{2}{*}{$\begin{array}{l}\text { LR } 070 \\
4\end{array}$} \\
\hline Co & $\mathrm{N}$ & & & & & & & & & & & & & & & \\
\hline & Média & & & & & & & & & & & & & & & \\
\hline & Mediana & & & & & & & & & & & & & & & \\
\hline & Mínimo & $<0,05$ & $<0,05$ & $<0,05$ & $<0,05$ & $<0,05$ & $<0,05$ & $<0,05$ & $<0,05$ & $<0,05$ & $<0,05$ & $<0,05$ & $<0,05$ & $<0,05$ & $<0,05$ & $<0,05$ \\
\hline & Máximo & & & & & & & & & & & & & & & \\
\hline \multirow[t]{5}{*}{$\mathrm{Cr}$} & $\mathrm{N}$ & 4 & 5 & 5 & 5 & 5 & 5 & 5 & 4 & 5 & 5 & 5 & 5 & 5 & 5 & 5 \\
\hline & Média & & & & & & & & & & & & & & & \\
\hline & Mediana & & & & & & & & & & & & & & & \\
\hline & Mínimo & $<0,03$ & $<0,03$ & $<0,03$ & $<0,03$ & $<0,03$ & $<0,03$ & $<0,03$ & $<0,03$ & $<0,03$ & $<0,03$ & $<0,03$ & $<0,03$ & $<0,03$ & $<0,03$ & $<0,03$ \\
\hline & Máximo & & & & & & & & & & & & & & & \\
\hline \multirow[t]{5}{*}{$\mathrm{Ca}$} & $\mathrm{N}$ & 5 & 5 & 5 & 5 & 5 & 5 & 5 & 4 & 5 & 5 & 5 & 5 & 5 & 5 & 4 \\
\hline & Média & 12,53 & 19,75 & 34,63 & 26,96 & 38,46 & 27,13 & 12,02 & 36,96 & 10,02 & 5,15 & 12,01 & 21,63 & 11,27 & 4,04 & 9,57 \\
\hline & Mediana & 11,82 & 14,32 & 36,50 & 20,90 & 44,40 & 26,43 & 11,70 & 36,87 & 11,01 & 4,26 & 7,46 & 23,20 & 13,30 & 2,54 & 9,11 \\
\hline & Mínimo & 11,20 & 13,70 & 20,70 & 18,10 & 4,88 & 12,90 & 11,50 & 33,60 & 4,80 & 3,72 & 6,98 & 14,30 & 2,20 & 1,83 & 8,78 \\
\hline & Máximo & 15,60 & 41,70 & 43,40 & 53,20 & 52,90 & 39,70 & 12,70 & 40,50 & 12,60 & 8,05 & 30,80 & 24,33 & 14,40 & 10,40 & 11,30 \\
\hline \multirow[t]{5}{*}{$\mathrm{Cu}$} & $\mathrm{N}$ & 4 & 5 & 5 & 5 & 5 & 5 & 5 & 4 & 5 & 5 & 5 & 5 & 5 & 5 & 5 \\
\hline & Média & & & & & & & & 0,044 & & 0,030 & & & 0,134 & & \\
\hline & Mediana & & & & & & & & 0,044 & & 0,024 & & & 0,134 & & \\
\hline & Mínimo & $<0,02$ & $<0,02$ & $<0,02$ & $<0,02$ & $<0,02$ & $<0,02$ & $<0,02$ & $<0,02$ & $<0,02$ & $<0,02$ & $<0,02$ & $<0,02$ & $<0,02$ & $<0,02$ & $<0,02$ \\
\hline & Máximo & & & & & & & & 0,044 & & 0,051 & & & 0,247 & & \\
\hline \multirow[t]{5}{*}{$\mathrm{Fe}$} & $\mathrm{N}$ & 5 & 5 & 5 & 5 & 5 & 5 & 5 & 4 & 5 & 5 & 5 & 5 & 5 & 5 & 4 \\
\hline & Média & 0,337 & 1,10 & 0,535 & 1,68 & 2,86 & 2,57 & 1,84 & 5,70 & 0,890 & 0,218 & 0,902 & 2,79 & 0,290 & 1,48 & 6,06 \\
\hline & Mediana & 0,042 & 1,24 & 0,476 & 1,91 & 2,92 & 2,75 & 2,06 & 5,72 & 0,946 & 0,108 & 0,589 & 3,50 & 0,303 & 0,038 & 6,36 \\
\hline & Mínimo & 0,025 & 0,415 & 0,275 & 0,090 & $<0,01$ & 0,14 & 1,08 & 4,61 & 0,122 & 0,055 & 0,257 & 0,428 & 0,050 & 0,014 & 4,69 \\
\hline & Máximo & 1,24 & 1,36 & 0,959 & 3,18 & 5,35 & 4,72 & 2,09 & 6,76 & 1,40 & 0,488 & 2,51 & 4,03 & 0,493 & 7,18 & 6,85 \\
\hline \multirow[t]{5}{*}{$\mathrm{Hg}$} & $\mathrm{N}$ & 5 & 5 & 5 & 5 & 5 & 5 & 5 & 4 & 5 & 5 & 5 & 5 & 5 & 5 & 5 \\
\hline & Média & & & & & & & & & & & & & & & \\
\hline & Mediana & & & & & & & & & & & & & & & \\
\hline & Mínimo & $<0,0008$ & $<0,0008$ & $<0,0008$ & $<0,0008$ & $<0,0008$ & $<0,0008$ & $<0,0008$ & $<0,0008$ & $<0,0008$ & $<0,0008$ & $<0,0008$ & $<0,0008$ & $<0,0008$ & $<0,0008$ & $<0,0008$ \\
\hline & Máximo & & & & & & & & & & & & & & & \\
\hline
\end{tabular}




\section{Cont.}

\begin{tabular}{|c|c|c|c|c|c|c|c|c|c|c|c|c|c|c|c|c|}
\hline \multicolumn{2}{|c|}{ Parâmetro } & \multirow{2}{*}{$\begin{array}{l}\text { LR } 003 \\
5\end{array}$} & \multirow{2}{*}{$\begin{array}{l}\text { LR } 004 \\
5\end{array}$} & \multirow{2}{*}{$\begin{array}{l}\text { LR } 006 \\
5\end{array}$} & \multirow{2}{*}{$\begin{array}{l}\text { LR } 018 \\
5\end{array}$} & \multirow{2}{*}{$\begin{array}{l}\text { LR } 019 \\
5\end{array}$} & \multirow{2}{*}{$\begin{array}{l}\text { LR } 020 \\
5\end{array}$} & \multirow{2}{*}{$\begin{array}{l}\text { LR } 027 \\
5\end{array}$} & \multirow{2}{*}{$\begin{array}{l}\text { LR } 032 \\
4\end{array}$} & \multirow{2}{*}{$\begin{array}{l}\text { LR } 042 \\
5\end{array}$} & \multirow{2}{*}{$\begin{array}{l}\text { LR } 046 \\
5\end{array}$} & \multirow{2}{*}{$\begin{array}{l}\text { LR } 047 \\
5\end{array}$} & \multirow{2}{*}{$\begin{array}{l}\text { LR } 054 \\
5\end{array}$} & \multirow{2}{*}{$\begin{array}{l}\text { LR } 057 \\
5\end{array}$} & \multirow{2}{*}{$\begin{array}{l}\text { LR } 060 \\
5\end{array}$} & \multirow{2}{*}{$\begin{array}{l}\text { LR } 070 \\
4\end{array}$} \\
\hline $\mathrm{K}$ & $\mathrm{N}$ & & & & & & & & & & & & & & & \\
\hline & Média & 1,34 & 1,07 & 1,06 & 0,670 & 0,650 & 0,861 & 1,40 & 1,66 & 0,848 & 0,802 & 1,23 & 1,66 & 1,61 & 2,63 & 1,10 \\
\hline & Mediana & 1,40 & 1,04 & 1,16 & 0,657 & 0,779 & 0,698 & 1,51 & 1,72 & 0,875 & 0,768 & 1,10 & 1,77 & 1,22 & 2,87 & 1,12 \\
\hline & Mínimo & 1,07 & 1,030 & 0,651 & 0,587 & 0,103 & 0,584 & 0,909 & 1,49 & 0,730 & 0,641 & 1,05 & 1,24 & 1,20 & 1,17 & 1,03 \\
\hline & Máximo & 1,44 & 1,19 & 1,20 & 0,79 & 0,80 & 1,53 & 1,59 & 1,74 & 0,884 & 1,15 & 1,78 & 1,81 & 3,20 & 3,34 & 1,14 \\
\hline \multirow[t]{5}{*}{$\mathrm{Mg}$} & $\mathrm{N}$ & 4 & 5 & 5 & 5 & 5 & 5 & 5 & 4 & 5 & 5 & 5 & 5 & 5 & 5 & 5 \\
\hline & Média & 5,08 & 6,34 & 5,07 & 7,61 & 9,24 & 10,53 & 4,03 & 7,44 & 3,14 & 2,13 & 2,37 & 8,54 & 1,62 & 14,35 & 4,19 \\
\hline & Mediana & 5,06 & 6,38 & 5,10 & 6,81 & 11,20 & 11,30 & 4,01 & 7,44 & 3,10 & 2,06 & 2,40 & 8,82 & 1,63 & 14,30 & 4,16 \\
\hline & Mínimo & 4,95 & 6,19 & 4,95 & 6,77 & 1,10 & 7,10 & 3,87 & 7,40 & 3,07 & 2,00 & 2,15 & 7,92 & 1,54 & 14,00 & 4,12 \\
\hline & Máximo & 5,26 & 6,45 & 5,13 & 10,83 & 11,70 & 12,20 & 4,19 & 7,49 & 3,22 & 2,46 & 2,50 & 9,01 & 1,69 & 14,60 & 4,30 \\
\hline \multirow[t]{5}{*}{$\mathrm{Mn}$} & $\mathrm{N}$ & 4 & 5 & 5 & 5 & 5 & 5 & 5 & 4 & 5 & 5 & 5 & 5 & 5 & 5 & 5 \\
\hline & Média & 0,026 & 0,184 & 0,458 & 0,251 & 0,803 & 1,091 & 0,169 & 0,383 & 0,163 & 0,067 & 0,138 & 0,244 & 0,210 & 0,017 & 0,169 \\
\hline & Mediana & 0,008 & 0,177 & 0,451 & 0,012 & 0,776 & 1,140 & 0,156 & 0,385 & 0,202 & 0,055 & 0,141 & 0,244 & 0,214 & 0,017 & 0,170 \\
\hline & Mínimo & $<0,019$ & 0,165 & 0,424 & 0,010 & 0,764 & $<0,019$ & 0,146 & 0,359 & 0,021 & 0,047 & 0,108 & 0,215 & 0,161 & $<0,019$ & 0,128 \\
\hline & Máximo & 0,062 & 0,205 & 0,514 & 0,969 & 0,919 & 1,310 & 0,222 & 0,406 & 0,210 & 0,109 & 0,156 & 0,264 & 0,254 & 0,019 & 0,193 \\
\hline \multirow[t]{5}{*}{ Mo } & $\mathrm{N}$ & 4 & 5 & 5 & 5 & 5 & 5 & 5 & 4 & 5 & 5 & 5 & 5 & 5 & 5 & 5 \\
\hline & Média & & & & & & 0,022 & & & & & & & 1,17 & & 0,030 \\
\hline & Mediana & & & & & & 0,022 & & & & & & & 0,214 & & 0,030 \\
\hline & Mínimo & $<0,02$ & & $<0,02$ & & $<0,02$ & $<0,02$ & $<0,02$ & $<0,02$ & $<0,02$ & $<0,02$ & $<0,02$ & $<0,02$ & $<0,02$ & $<0,02$ & $<0,02$ \\
\hline & Máximo & & & & & & 0,030 & & & & & & & 5,00 & & 0,030 \\
\hline \multirow[t]{5}{*}{$\mathrm{Na}$} & $\mathrm{N}$ & 4 & 5 & 5 & 5 & 5 & 5 & 5 & 4 & 5 & 5 & 5 & 5 & 5 & 5 & 5 \\
\hline & Média & 8,54 & 8,80 & 13,58 & 12,45 & 7,66 & 11,51 & 33,45 & 10,02 & 7,65 & 4,56 & 7,12 & 10,21 & 10,18 & 10,94 & 8,14 \\
\hline & Mediana & 8,61 & 8,81 & 13,70 & 13,30 & 9,56 & 11,90 & 34,80 & 10,16 & 7,80 & 4,71 & 7,21 & 10,27 & 10,40 & 11,50 & 8,27 \\
\hline & Mínimo & 8,22 & 8,49 & 12,90 & 9,15 & 0,833 & 8,97 & 25,80 & 9,15 & 7,13 & 3,47 & 6,69 & 8,45 & 9,14 & 9,14 & 7,52 \\
\hline & Máximo & 8,71 & 9,03 & 13,99 & 13,70 & 9,71 & 13,50 & 38,73 & 10,60 & 7,86 & 5,24 & 7,38 & 11,80 & 10,64 & 12,70 & 8,35 \\
\hline \multirow[t]{5}{*}{$\mathrm{Ni}$} & $\mathrm{N}$ & 4 & 5 & 5 & 5 & 5 & 5 & 5 & 4 & 5 & 5 & 5 & 5 & 5 & 5 & 5 \\
\hline & Média & & 0,026 & 0,027 & 0,025 & 0,039 & 0,042 & 0,036 & & 0,037 & 0,033 & 0,034 & 0,034 & 0,052 & 0,043 & 0,034 \\
\hline & Mediana & & 0,026 & 0,027 & 0,025 & 0,039 & 0,042 & 0,036 & & 0,037 & 0,033 & 0,034 & 0,034 & 0,047 & 0,043 & 0,034 \\
\hline & Mínimo & $<0,02$ & $<0,02$ & $<0,02$ & 0,021 & $<0,02$ & $<0,02$ & $<0,02$ & $<0,02$ & $<0,02$ & $<0,02$ & $<0,02$ & $<0,02$ & $<0,02$ & $<0,02$ & $<0,02$ \\
\hline & Máximo & & 0,026 & 0,027 & 0,030 & 0,039 & 0,042 & 0,036 & & 0,037 & 0,033 & 0,034 & 0,034 & 0,084 & 0,043 & 0,040 \\
\hline
\end{tabular}




\section{Cont.}

\begin{tabular}{|c|c|c|c|c|c|c|c|c|c|c|c|c|c|c|c|c|}
\hline \multicolumn{2}{|c|}{ Parâmetro } & \multirow{2}{*}{$\begin{array}{l}\text { LR } 003 \\
5\end{array}$} & \multirow{2}{*}{$\begin{array}{l}\text { LR } 004 \\
5\end{array}$} & \multirow{2}{*}{$\begin{array}{l}\text { LR } 006 \\
5\end{array}$} & \multirow{2}{*}{$\begin{array}{l}\text { LR } 018 \\
5\end{array}$} & \multirow{2}{*}{$\begin{array}{l}\text { LR } 019 \\
5\end{array}$} & \multirow{2}{*}{$\begin{array}{l}\text { LR } 020 \\
5\end{array}$} & \multirow{2}{*}{$\begin{array}{l}\text { LR } 027 \\
5\end{array}$} & \multirow{2}{*}{$\begin{array}{l}\text { LR } 032 \\
4\end{array}$} & \multirow{2}{*}{$\begin{array}{l}\text { LR } 042 \\
5\end{array}$} & \multirow{2}{*}{$\begin{array}{l}\text { LR } 046 \\
5\end{array}$} & \multirow{2}{*}{$\begin{array}{l}\text { LR } 047 \\
5\end{array}$} & \multirow{2}{*}{$\begin{array}{l}\text { LR } 054 \\
5\end{array}$} & \multirow{2}{*}{$\begin{array}{l}\text { LR } 057 \\
5\end{array}$} & \multirow{2}{*}{$\begin{array}{l}\text { LR } 060 \\
5\end{array}$} & \multirow{2}{*}{$\begin{array}{l}\text { LR } 070 \\
4\end{array}$} \\
\hline $\mathrm{P}$ & $\mathrm{N}$ & & & & & & & & & & & & & & & \\
\hline & Média & 0,250 & 0,257 & 0,270 & 0,261 & 0,215 & 0,148 & 0,214 & 0,173 & 0,377 & 0,269 & 0,163 & 0,177 & 0,163 & 0,222 & 0,324 \\
\hline & Mediana & 0,254 & 0,260 & 0,296 & 0,187 & 0,265 & 0,139 & 0,110 & 0,168 & 0,340 & 0,190 & 0,145 & 0,125 & 0,127 & 0,092 & 0,311 \\
\hline & Mínimo & 0,150 & 0,145 & 0,161 & 0,078 & 0,057 & 0,067 & 0,085 & 0,086 & 0,254 & 0,065 & 0,050 & 0,086 & 0,063 & 0,039 & 0,274 \\
\hline & Máximo & 0,346 & 0,424 & 0,412 & 0,637 & 0,355 & 0,260 & 0,612 & 0,269 & 0,541 & 0,706 & 0,298 & 0,303 & 0,267 & 0,687 & 0,400 \\
\hline \multirow[t]{5}{*}{$\mathrm{Pb}$} & $\mathrm{N}$ & 5 & 5 & 5 & 5 & 5 & 5 & 5 & 4 & 5 & 5 & 5 & 5 & 5 & 5 & 4 \\
\hline & Média & 0,002 & 0,002 & 0,004 & 0,005 & 0,003 & 0,002 & 0,002 & 0,001 & 0,003 & 0,002 & 0,005 & 0,002 & 0,004 & 0,003 & 0,003 \\
\hline & Mediana & 0,002 & 0,002 & 0,004 & 0,002 & 0,003 & 0,002 & 0,002 & 0,001 & 0,002 & 0,002 & 0,004 & 0,002 & 0,002 & 0,002 & 0,002 \\
\hline & Mínimo & $<0,001$ & $<0,001$ & $<0,001$ & 0,001 & $<0,001$ & 0,001 & $<0,001$ & $<0,001$ & $<0,001$ & $<0,001$ & $<0,001$ & $<0,001$ & 0,001 & 0,001 & $<0,001$ \\
\hline & Máximo & 0,003 & 0,002 & 0,007 & 0,018 & 0,003 & 0,004 & 0,003 & 0,001 & 0,004 & 0,002 & 0,011 & 0,002 & 0,010 & 0,007 & 0,004 \\
\hline \multirow[t]{5}{*}{$\mathrm{Sb}$} & $\mathrm{N}$ & 5 & 5 & 5 & 5 & 5 & 5 & 5 & 4 & 5 & 5 & 5 & 5 & 5 & 5 & 5 \\
\hline & Média & & & & & & & & & & & & & & & \\
\hline & Mediana & & & & & & & & & & & & & & & \\
\hline & Mínimo & $<0,001$ & $<0,001$ & $<0,001$ & $<0,001$ & $<0,001$ & $<0,001$ & $<0,001$ & $<0,001$ & $<0,001$ & $<0,001$ & $<0,001$ & $<0,001$ & $<0,001$ & $<0,001$ & $<0,001$ \\
\hline & Máximo & & & & & & & & & & & & & & & \\
\hline \multirow[t]{5}{*}{ Se } & $\mathrm{N}$ & 5 & 5 & 5 & 5 & 5 & 5 & 5 & 4 & 5 & 5 & 5 & 5 & 5 & 5 & 4 \\
\hline & Média & & 0,001 & 0,002 & & & & & & & & & & & & \\
\hline & Mediana & & 0,001 & 0,002 & & & & & & & & & & & & \\
\hline & Mínimo & $<0,001$ & $<0,001$ & $<0,001$ & $<0,001$ & $<0,001$ & $<0,001$ & $<0,001$ & $<0,001$ & $<0,001$ & $<0,001$ & $<0,001$ & $<0,001$ & $<0,001$ & $<0,001$ & $<0,001$ \\
\hline & Máximo & & 0,001 & 0,002 & & & & & & & & & & & & \\
\hline \multirow[t]{5}{*}{ Sn } & $\mathrm{N}$ & 4 & 5 & 5 & 5 & 5 & 5 & 5 & 4 & 5 & 5 & 5 & 5 & 5 & 5 & 5 \\
\hline & Média & & & & & 0,200 & & & & & & & & & & \\
\hline & Mediana & & & & & 0,200 & & & & & & & & & & \\
\hline & Mínimo & $<0,20$ & $<0,20$ & $<0,20$ & $<0,20$ & $<0,20$ & $<0,20$ & $<0,20$ & $<0,2$ & $<0,20$ & $<0,20$ & $<0,20$ & $<0,20$ & $<0,20$ & $<0,20$ & $<0,20$ \\
\hline & Máximo & & & & & 0,200 & & & & & & & & & & \\
\hline \multirow[t]{5}{*}{$\mathrm{V}$} & $\mathrm{N}$ & 4 & 5 & 5 & 5 & 5 & 5 & 5 & 4 & 5 & 5 & 5 & 5 & 5 & 5 & 5 \\
\hline & Média & & & & & & & & & & & & & & & \\
\hline & Mediana & & & & & & & & & & & & & & & \\
\hline & Mínimo & $<0,01$ & $<0,01$ & $<0,01$ & $<0,01$ & $<0,01$ & $<0,01$ & $<0,01$ & $<0,01$ & $<0,01$ & $<0,01$ & $<0,01$ & $<0,01$ & $<0,01$ & $<0,01$ & $<0,01$ \\
\hline & Máximo & & & & & & & & & & & & & & & \\
\hline
\end{tabular}




\section{Cont.}

\begin{tabular}{|c|c|c|c|c|c|c|c|c|c|c|c|c|c|c|c|c|}
\hline \multicolumn{2}{|c|}{ Parâmetro } & \multirow{2}{*}{$\begin{array}{l}\text { LR } 003 \\
4\end{array}$} & \multirow{2}{*}{$\begin{array}{l}\text { LR } 004 \\
5\end{array}$} & \multirow{2}{*}{$\begin{array}{l}\text { LR } 006 \\
5\end{array}$} & \multirow{2}{*}{$\begin{array}{l}\text { LR } 018 \\
5\end{array}$} & \multirow{2}{*}{$\begin{array}{l}\text { LR } 019 \\
5\end{array}$} & \multirow{2}{*}{$\begin{array}{l}\text { LR } 020 \\
5\end{array}$} & \multirow{2}{*}{$\begin{array}{l}\text { LR } 027 \\
5\end{array}$} & \multirow{2}{*}{$\begin{array}{l}\text { LR } 032 \\
4\end{array}$} & \multirow{2}{*}{$\begin{array}{l}\text { LR } 042 \\
5\end{array}$} & \multirow{2}{*}{$\begin{array}{l}\text { LR } 046 \\
5\end{array}$} & \multirow{2}{*}{$\begin{array}{l}\text { LR } 047 \\
5\end{array}$} & \multirow{2}{*}{$\begin{array}{l}\text { LR } 054 \\
5\end{array}$} & \multirow{2}{*}{$\begin{array}{l}\text { LR } 057 \\
5\end{array}$} & \multirow{2}{*}{$\begin{array}{l}\text { LR } 060 \\
5\end{array}$} & \multirow{2}{*}{$\begin{array}{l}\text { LR } 070 \\
5\end{array}$} \\
\hline $\mathrm{Zn}$ & $\mathrm{N}$ & & & & & & & & & & & & & & & \\
\hline & Média & 0,033 & 0,050 & 0,018 & 0,040 & 0,012 & 0,064 & 0,098 & 0,085 & 0,037 & 0,033 & 0,442 & 0,041 & 0,077 & 0,011 & 0,160 \\
\hline & Mediana & 0,030 & 0,043 & 0,018 & 0,026 & 0,006 & 0,068 & 0,014 & 0,091 & 0,031 & 0,035 & 0,021 & 0,039 & 0,071 & 0,008 & 0,135 \\
\hline & Mínimo & 0,015 & 0,031 & $<0,003$ & 0,012 & 0,003 & 0,027 & 0,011 & 0,038 & 0,027 & 0,019 & $<0,003$ & 0,030 & 0,033 & $\begin{array}{l}<, 0003 \\
0,\end{array}$ & 0,085 \\
\hline & Máximo & 0,059 & 0,088 & 0,030 & 0,109 & 0,036 & 0,088 & 0,433 & 0,120 & 0,061 & 0,047 & 1,720 & 0,054 & 0,138 & 0,023 & 0,332 \\
\hline \multirow[t]{5}{*}{$\mathrm{F}$} & $\mathrm{N}$ & 5 & 5 & 5 & 5 & 5 & 5 & 5 & 4 & 5 & 5 & 5 & 5 & 5 & 5 & 5 \\
\hline & Média & 0,161 & 0,790 & 0,111 & 0,231 & 0,159 & 0,158 & 0,627 & 0,058 & 0,245 & 0,060 & 0,098 & 0,295 & 0,371 & 0,061 & 0,191 \\
\hline & Mediana & 0,135 & 0,380 & 0,120 & 0,274 & 0,160 & 0,136 & 0,662 & 0,060 & 0,252 & 0,057 & 0,086 & 0,289 & 0,197 & 0,060 & 0,191 \\
\hline & Mínimo & 0,126 & 0,211 & 0,071 & 0,090 & 0,151 & 0,067 & 0,553 & 0,043 & 0,213 & 0,052 & 0,073 & 0,228 & 0,105 & 0,050 & 0,180 \\
\hline & Máximo & 0,210 & 2,600 & 0,124 & 0,278 & 0,164 & 0,270 & 0,680 & 0,067 & 0,266 & 0,075 & 0,131 & 0,385 & 1,158 & 0,080 & 0,202 \\
\hline \multirow[t]{5}{*}{$\mathrm{Cl}^{-}$} & $\mathrm{N}$ & 5 & 5 & 5 & 5 & 5 & 5 & 5 & 4 & 5 & 5 & 5 & 5 & 5 & 5 & 5 \\
\hline & Média & 4,84 & 5,04 & 4,00 & 9,20 & 5,08 & 17,40 & 7,68 & 8,19 & 5,06 & 2,99 & 5,31 & 8,86 & 6,78 & 3,63 & 4,64 \\
\hline & Mediana & 5,33 & 5,81 & 3,95 & 7,72 & 5,03 & 16,19 & 8,15 & 8,43 & 4,87 & 3,00 & 5,66 & 9,03 & 7,28 & 3,77 & 4,47 \\
\hline & Mínimo & 2,81 & 0,64 & 2,84 & 5,65 & 4,10 & 8,14 & 5,82 & 0,00 & 4,54 & 1,99 & 3,16 & 1,55 & 4,09 & 2,08 & 3,83 \\
\hline & Máximo & 6,68 & 7,28 & 4,86 & 16,26 & 6,55 & 25,81 & 8,66 & 12,71 & 6,31 & 3,95 & 6,32 & 14,07 & 8,48 & 4,81 & 5,81 \\
\hline \multirow[t]{5}{*}{$\mathrm{NO}_{3}{ }^{-}$} & $\mathrm{N}$ & 5 & 5 & 5 & 5 & 5 & 5 & 5 & 4 & 5 & 5 & 5 & 5 & 5 & 5 & 5 \\
\hline & Média & 2,16 & 2,73 & 7,16 & 0,856 & 0,293 & 0,385 & 0,145 & 0,198 & 0,143 & 2,91 & 5,86 & 0,320 & 1,918 & 0,174 & \\
\hline & Mediana & 2,07 & 0,64 & 1,31 & 0,856 & 0,110 & 0,412 & 0,102 & 0,191 & 0,143 & 2,88 & 5,44 & 0,320 & 1,689 & 0,174 & \\
\hline & Mínimo & 1,91 & $<0,05$ & $<0,05$ & 0,677 & $<0,05$ & 0,109 & $<0,05$ & $<0,05$ & $<0,05$ & 2,57 & 4,49 & $<0,05$ & 1,125 & $<0,05$ & $<0,05$ \\
\hline & Máximo & 2,60 & 7,39 & 20,01 & 1,09 & 0,683 & 0,680 & 0,270 & 0,255 & 0,200 & 3,38 & 8,39 & 0,320 & 3,362 & 0,174 & \\
\hline \multirow[t]{5}{*}{$\mathrm{PO}_{4}{ }^{3-}$} & $\mathrm{N}$ & 5 & 5 & 5 & 5 & 5 & 5 & 5 & 4 & 5 & 5 & 5 & 5 & 5 & 5 & 5 \\
\hline & Média & & & & & & & & & 0,164 & & & & & & \\
\hline & Mediana & & & & & & & & & & & & & & & \\
\hline & Mínimo & $<0.05$ & $<0.05$ & $<0.05$ & $<0.05$ & $<0.05$ & $<0.05$ & $<0.05$ & $<0.05$ & $<0.05$ & $<0.05$ & $<0.05$ & $<0.05$ & $<0.05$ & $<0.05$ & $<0.05$ \\
\hline & Máximo & & & & & & & & & 0,164 & & & & & & \\
\hline \multirow[t]{5}{*}{$\mathrm{SO}_{4}{ }^{2-}$} & $\mathrm{N}$ & 5 & 5 & 5 & 5 & 5 & 5 & 5 & 4 & 5 & 5 & 5 & 5 & 5 & 5 & 5 \\
\hline & Média & 3,19 & 4,12 & 0,907 & 3,51 & 5,14 & 4,97 & 8,53 & 9,70 & 3,14 & 1,01 & 3,33 & 11,02 & 9,67 & 3,56 & 1,39 \\
\hline & Mediana & 3,27 & 4,39 & 0,984 & 3,72 & 4,84 & 5,33 & 8,25 & 9,52 & 2,92 & 0,950 & 3,47 & 11,80 & 10,42 & 3,75 & 1,34 \\
\hline & Mínimo & 2,38 & 0,602 & 0,519 & 2,80 & 4,59 & 3,20 & 6,31 & 7,58 & 2,71 & 0,761 & 2,00 & 6,00 & 5,85 & 2,67 & 1,20 \\
\hline & Máximo & 4,24 & 7,78 & 1,21 & 4,04 & 5,79 & 7,30 & 10,60 & 12,20 & 3,65 & 1,36 & 5,00 & 13,62 & 11,98 & 3,98 & 1,59 \\
\hline
\end{tabular}


Tabela A.3 - Estatística descritiva para as concentrações (mg. $\left.\mathrm{L}^{-1}\right)$ de metais e íons em água bruta.

\begin{tabular}{|c|c|c|c|c|c|c|c|c|c|c|c|c|c|c|c|c|c|c|c|c|}
\hline \multicolumn{2}{|c|}{ Parâmetro } & \multirow{2}{*}{$\begin{array}{r}\text { LR } 001 \\
5\end{array}$} & \multirow{2}{*}{$\begin{array}{r}\text { LR } 005 \\
5\end{array}$} & \multirow{2}{*}{$\begin{array}{r}\text { LR } 007 \\
5\end{array}$} & \multirow{2}{*}{$\begin{array}{r}\text { LR } 011 \\
5\end{array}$} & \multirow{2}{*}{$\begin{array}{r}\text { LR } 012 \\
5\end{array}$} & \multirow{2}{*}{$\begin{array}{r}\text { LR } 013 \\
5\end{array}$} & \multirow{2}{*}{$\begin{array}{r}\text { LR } 017 \\
5\end{array}$} & \multirow{2}{*}{$\begin{array}{r}\text { LR } 021 \\
5\end{array}$} & \multirow{2}{*}{$\begin{array}{r}\text { LR } 022 \\
5\end{array}$} & \multirow{2}{*}{$\begin{array}{r}\text { LR } 026 \\
5\end{array}$} & \multirow{2}{*}{$\begin{array}{r}\text { LR } 030 \\
3\end{array}$} & \multirow{2}{*}{$\begin{array}{r}\text { LR } 033 \\
5\end{array}$} & \multirow{2}{*}{$\begin{array}{r}\text { LR } 043 \\
5\end{array}$} & \multirow{2}{*}{$\begin{array}{r}\text { LR } 044 \\
5\end{array}$} & \multirow{2}{*}{$\begin{array}{r}\text { LR } 045 \\
5\end{array}$} & \multirow{2}{*}{$\begin{array}{r}\text { LR } 049 \\
5\end{array}$} & \multirow{2}{*}{$\begin{array}{r}\text { LR } 050 \\
5\end{array}$} & \multirow{2}{*}{$\begin{array}{r}\text { LR } 068 \\
5\end{array}$} & \multirow{2}{*}{$\begin{array}{r}\text { LR } 142 \\
5\end{array}$} \\
\hline $\mathrm{Ag}$ & $\mathrm{N}$ & & & & & & & & & & & & & & & & & & & \\
\hline & Média & & & & & & & & & & & & & 0,006 & 0,005 & & 0,005 & 0,006 & 0,007 & 0,008 \\
\hline & Mediana & & & & & & & & & & & & & 0,006 & 0,005 & & 0,005 & 0,006 & 0,007 & 0,008 \\
\hline & Mínimo & $<0,005$ & $<0,005$ & $<0,005$ & $<0,005$ & $<0,005$ & $<0,005$ & $<0,005$ & $<0,005$ & $<0,005$ & $<0,005$ & $<0,005$ & $<0,005$ & $<0,005$ & $<0,005$ & $<0,005$ & $<0,005$ & $<0,005$ & $<0,005$ & $<0,005$ \\
\hline & Máximo & & & & & & & & & & & & & 0,006 & 0,005 & & 0,005 & 0,006 & 0,007 & 0,008 \\
\hline \multirow[t]{5}{*}{ Al } & $N$ & 5 & 5 & 5 & 5 & 5 & 5 & 5 & 5 & 5 & 5 & 3 & 5 & 5 & 5 & 5 & 5 & 5 & 5 & 5 \\
\hline & Média & 0,217 & 0,473 & 0,076 & 0,071 & 0,098 & 0,065 & 0,233 & 0,084 & 0,061 & 0,061 & 0,020 & 0,307 & 0,044 & 0,055 & 0,305 & 0,347 & 0,161 & 0,068 & 0,054 \\
\hline & Mediana & 0,199 & 0,578 & 0,045 & 0,054 & 0,053 & 0,068 & 0,127 & 0,071 & 0,054 & 0,051 & 0,020 & 0,280 & 0,044 & 0,040 & 0,305 & 0,050 & 0,050 & 0,060 & 0,033 \\
\hline & Mínimo & 0,053 & 0,086 & 0,014 & 0,039 & 0,017 & $<0,020$ & 0,086 & $<0,020$ & 0,033 & 0,040 & $<0,020$ & 0,128 & $<0,02$ & $<0,020$ & $<0,04$ & 0,038 & 0,034 & 0,024 & 0,021 \\
\hline & Máximo & 0,568 & 0,850 & 0,195 & 0,142 & 0,243 & 0,084 & 0,618 & 0,163 & 0,111 & 0,111 & 0,020 & 0,545 & 0,050 & 0,103 & 0,572 & 1,550 & 0,592 & 0,154 & 0,132 \\
\hline \multirow[t]{5}{*}{ As } & $N$ & 5 & 5 & 5 & 5 & 5 & 5 & 5 & 5 & 5 & 5 & 3 & 5 & 5 & 5 & 5 & 5 & 5 & 5 & 5 \\
\hline & Média & & & & & & & & & & & & & & & & & & & \\
\hline & Mediana & & & & & & & & & & & & & & & & & & & \\
\hline & Mínimo & $<0,001$ & $<0,001$ & $<0,001$ & $<0,001$ & $<0,001$ & $<0,001$ & $<0,001$ & $<0,001$ & $<0,001$ & $<0,001$ & $<0,001$ & $<0,001$ & $<0,001$ & $<0,001$ & $<0,001$ & $<0,001$ & $<0,001$ & $<0,001$ & $<0,001$ \\
\hline & Máximo & & & & & & & & & & & & & & & & & & & \\
\hline \multirow[t]{5}{*}{ B } & $N$ & 5 & 5 & 5 & 5 & 5 & 5 & 5 & 5 & 5 & 5 & 3 & 5 & 5 & 5 & 5 & 5 & 5 & 5 & 5 \\
\hline & Média & & & & & & & & 0,007 & & & & & 0,010 & & & 0,011 & 0,011 & 0,011 & 0,010 \\
\hline & Mediana & & & & & & & & 0,007 & & & & & 0,010 & & & 0,011 & 0,011 & 0,011 & 0,010 \\
\hline & Mínimo & $<0,003$ & $<0,003$ & $<0,003$ & $<0,003$ & $<0,003$ & $<0,003$ & $<0,003$ & $<0,003$ & $<0,003$ & $<0,003$ & $<0,003$ & $<0,003$ & $<0,003$ & $<0,003$ & $<0,003$ & $<0,003$ & $<0,003$ & $<0,003$ & $<0,003$ \\
\hline & Máximo & & & & & & & & 0,007 & & & & & 0,010 & & & 0,011 & 0,011 & 0,011 & 0,010 \\
\hline $\mathrm{Ba}$ & $N$ & 5 & 5 & 5 & 5 & 5 & 5 & 5 & 5 & 5 & 5 & 3 & 5 & 5 & 5 & 5 & 5 & 5 & 5 & 5 \\
\hline & Média & 0,047 & 0,055 & 0,028 & 0,028 & 0,032 & 0,020 & 0,049 & 0,011 & 0,023 & 0,021 & 0,016 & 0,046 & 0,042 & 0,030 & 0,011 & 0,021 & 0,018 & 0,015 & 0,026 \\
\hline & Mediana & 0,043 & 0,048 & 0,031 & 0,028 & 0,030 & 0,020 & 0,040 & 0,012 & 0,021 & 0,021 & 0,016 & 0,047 & 0,014 & 0,032 & 0,009 & 0,012 & 0,013 & 0,015 & 0,024 \\
\hline & Mínimo & 0,030 & 0,034 & 0,020 & 0,025 & 0,026 & 0,017 & 0,036 & 0,008 & 0,020 & 0,018 & 0,015 & 0,028 & 0,012 & 0,025 & 0,005 & 0,009 & 0,010 & 0,010 & 0,022 \\
\hline & Máximo & 0,078 & 0,102 & 0,033 & 0,031 & 0,039 & 0,022 & 0,089 & 0,014 & 0,027 & 0,024 & 0,017 & 0,074 & 0,128 & 0,033 & 0,020 & 0,053 & 0,037 & 0,019 & 0,035 \\
\hline $\mathrm{Cd}$ & $\mathrm{N}$ & 5 & 5 & 5 & 5 & 5 & 5 & 5 & 5 & 5 & 5 & 3 & 5 & 5 & 5 & 5 & 5 & 5 & 5 & 5 \\
\hline & Média & & 0,0004 & & & & & & & & & & & 0,0003 & & & & & 0,0007 & 0,0003 \\
\hline & Mediana & & 0,0004 & & & & & & & & & & & 0,0003 & & & & & 0,0007 & 0,0003 \\
\hline & Mínimo & $<0,0001$ & $<0,0001$ & $<0,0001$ & $<0,0001$ & $<0,0001$ & $<0,0001$ & $<0,0001$ & $<0,0001$ & $<0,0001$ & $<0,0001$ & $<0,0001$ & $<0,0001$ & $<0,0001$ & $<0,0001$ & $<0,0001$ & $<0,0001$ & $<0,0001$ & $<0,0001$ & $<0,0001$ \\
\hline & Máximo & & 0,0004 & & & & & & & & & & & 0,0003 & & & & & 0,001 & 0,0003 \\
\hline
\end{tabular}


Cont.

\begin{tabular}{|c|c|c|c|c|c|c|c|c|c|c|c|c|c|c|c|c|c|c|c|c|}
\hline \multicolumn{2}{|c|}{ Parâmetro } & \multirow{2}{*}{$\frac{\text { LR } 001}{5}$} & \multirow{2}{*}{$\begin{array}{r}\text { LR } 005 \\
5\end{array}$} & \multirow{2}{*}{$\begin{array}{r}\text { LR } 007 \\
5\end{array}$} & \multirow{2}{*}{ LR 011} & \multirow{2}{*}{$\frac{\text { LR } 012}{5}$} & \multirow{2}{*}{ LR 013} & \multirow{2}{*}{$\frac{\text { LR } 017}{5}$} & \multirow{2}{*}{$\begin{array}{r}\text { LR } 021 \\
5\end{array}$} & \multirow{2}{*}{$\begin{array}{r}\text { LR } 022 \\
5\end{array}$} & \multirow{2}{*}{$\begin{array}{r}\text { LR } 026 \\
5\end{array}$} & \multirow{2}{*}{$\frac{\text { LR } 030}{3}$} & \multirow{2}{*}{$\begin{array}{r}\text { LR } 033 \\
5\end{array}$} & \multirow{2}{*}{$\begin{array}{r}\text { LR } 043 \\
5\end{array}$} & \multirow{2}{*}{$\begin{array}{r}\text { LR } 044 \\
5\end{array}$} & \multirow{2}{*}{ LR 045} & \multirow{2}{*}{$\begin{array}{r}\text { LR } 049 \\
5\end{array}$} & \multirow{2}{*}{$\begin{array}{r}\text { LR } 050 \\
5\end{array}$} & \multirow{2}{*}{$\frac{\text { LR } 068}{5}$} & \multirow{2}{*}{$\begin{array}{l}\text { LR } 142 \\
5\end{array}$} \\
\hline Co & $\mathrm{N}$ & & & & & & & & & & & & & & & & & & & \\
\hline & Média & & & & & & & & & & & & & & & & & & & \\
\hline & Mediana & & & & & & & & & & & & & & & & & & & \\
\hline & Mínimo & $<0,05$ & $<0,05$ & $<0,05$ & $<0,05$ & $<0,05$ & $<0,05$ & $<0,05$ & $<0,05$ & $<0,05$ & $<0,05$ & $<0,05$ & $<0,05$ & $<0,05$ & $<0,05$ & $<0,05$ & $<0,05$ & $<0,05$ & $<0,05$ & $<0,05$ \\
\hline & Máximo & & & & & & & & & & & & & & & & & & & \\
\hline \multirow[t]{5}{*}{$\mathrm{Cr}$} & $\mathrm{N}$ & 5 & 5 & 5 & 5 & 5 & 5 & 5 & 5 & 5 & 5 & 3 & 5 & 5 & 5 & 5 & 5 & 5 & 5 & 5 \\
\hline & Média & & & & & & & & & & & & & & & & & & & \\
\hline & Mediana & & & & & & & & & & & & & & & & & & & \\
\hline & Mínimo & $<0,03$ & $<0,03$ & $<0,03$ & $<0,03$ & $<0,03$ & $<0,03$ & $<0,03$ & $<0,03$ & $<0,03$ & $<0,03$ & $<0,03$ & $<0,03$ & $<0,03$ & $<0,03$ & $<0,03$ & $<0,03$ & $<0,03$ & $<0,03$ & $<0,03$ \\
\hline & Máximo & & & & & & & & & & & & & & & & & & & \\
\hline \multirow[t]{5}{*}{$\mathrm{Ca}$} & $\mathrm{N}$ & 5 & 5 & 5 & 5 & 5 & 5 & 5 & 5 & 5 & 5 & 3 & 5 & 5 & 5 & 5 & 5 & 5 & 5 & 5 \\
\hline & Média & 8,10 & 10,33 & 3,53 & 6,23 & 4,09 & 1,88 & 10,02 & 2,42 & 2,03 & 2,01 & 5,69 & 8,02 & 2,94 & 5,65 & 1,50 & 2,95 & 3,02 & 18,94 & 2,25 \\
\hline & Mediana & 7,78 & 10,60 & 3,48 & 6,43 & 4,15 & 1,87 & 9,90 & 2,45 & 1,98 & 1,94 & 5,71 & 7,25 & 1,64 & 5,52 & 1,45 & 2,58 & 2,62 & 19,48 & 2,18 \\
\hline & Mínimo & 6,71 & 7,63 & 2,67 & 5,23 & 3,35 & 1,54 & 7,32 & 1,85 & 1,86 & 1,79 & 4,63 & 6,50 & 1,37 & 4,93 & 1,21 & 2,16 & 2,21 & 15,00 & 1,79 \\
\hline & Máximo & 9,38 & 12,40 & 4,23 & 7,06 & 4,62 & 2,26 & 12,40 & 2,93 & 2,27 & 2,35 & 6,72 & 10,30 & 8,22 & 6,61 & 1,87 & 3,88 & 4,23 & 22,60 & 3,00 \\
\hline \multirow[t]{5}{*}{$\mathrm{Cu}$} & $\mathrm{N}$ & 5 & 5 & 5 & 5 & 5 & 5 & 5 & 5 & 5 & 5 & 3 & 5 & 5 & 5 & 5 & 5 & 5 & 5 & 5 \\
\hline & Média & & & & & & & & & & & & & & & & & & & \\
\hline & Mediana & & & & & & & & & & & & & & & & & & & \\
\hline & Mínimo & $<0,02$ & $<0,02$ & $<0,02$ & $<0,02$ & $<0,02$ & $<0,02$ & $<0,02$ & $<0,02$ & $<0,02$ & $<0,02$ & $<0,02$ & $<0,02$ & $<0,02$ & $<0,02$ & $<0,02$ & $<0,02$ & $<0,02$ & $<0,02$ & $<0,02$ \\
\hline & Máximo & & & & & & & & & & & & & & & & & & & \\
\hline Fé & $\mathrm{N}$ & 5 & 5 & 5 & 5 & 5 & 5 & 5 & 5 & 5 & 5 & 3 & 5 & 5 & 5 & 5 & 5 & 5 & 5 & 5 \\
\hline & Média & 0,801 & 0,767 & 1,54 & 0,546 & 0,374 & 1,11 & 0,672 & 1,25 & 0,577 & 0,768 & 0,020 & 0,843 & 0,293 & 0,567 & 1,41 & 1,50 & 1,41 & 0,326 & 0,914 \\
\hline & Mediana & 0,819 & 0,550 & 1,17 & 0,517 & 0,260 & 1,07 & 0,374 & 1,16 & 0,559 & 0,759 & 0,018 & 0,610 & 0,148 & 0,550 & 0,923 & 0,898 & 1,37 & 0,344 & 0,700 \\
\hline & Mínimo & 0,280 & 0,337 & 0,930 & 0,415 & 0,183 & 0,729 & 0,285 & 0,939 & 0,422 & 0,547 & 0,015 & 0,446 & 0,078 & 0,436 & 0,510 & 0,630 & 0,610 & 0,250 & 0,567 \\
\hline & Máximo & 1,43 & 1,63 & 2,45 & 0,674 & 0,605 & 1,58 & 1,28 & 1,76 & 0,752 & 0,963 & 0,027 & 1,450 & 0,940 & 0,727 & 2,94 & 3,70 & 2,30 & 0,407 & 1,62 \\
\hline $\mathrm{Hg}$ & $\mathrm{N}$ & 5 & 5 & 5 & 5 & 5 & 5 & 5 & 5 & 5 & 5 & 3 & 5 & 5 & 5 & 5 & 5 & 5 & 5 & 5 \\
\hline & Média & & & & & & & & & & & & & & & & & & & \\
\hline & Mediana & & & & & & & & & & & & & & & & & & & \\
\hline & Mínimo & $<0,0008$ & $<0,0008$ & $<0,0008$ & $<0,0008$ & $<0,0008$ & $<0,0008$ & $<0,0008$ & $<0,0008$ & $<0,0008$ & $<0,0008$ & $<0,0008$ & $<0,0008$ & $<0,0008$ & $<0,0008$ & $<0,0008$ & $<0,0008$ & $<0,0008$ & $<0,0008$ & $<0,0008$ \\
\hline & Máximo & & & & & & & & & & & & & & & & & & & \\
\hline
\end{tabular}


Cont.

\begin{tabular}{|c|c|c|c|c|c|c|c|c|c|c|c|c|c|c|c|c|c|c|c|c|}
\hline Parâ & & LR 001 & LR 005 & LR 007 & LR 011 & LR 012 & LR 013 & LR 017 & LR 021 & LR 022 & LR 026 & LR 030 & LR 033 & LR 043 & LR 044 & LR 045 & LR 049 & LR 050 & LR 068 & LR 142 \\
\hline \multirow[t]{5}{*}{ K } & $N$ & 5 & 5 & 5 & 5 & 5 & 5 & 5 & 5 & 5 & 5 & 3 & 5 & 5 & 5 & 5 & 5 & 5 & 5 & 5 \\
\hline & Média & 0,484 & 0,489 & 0,355 & 0,481 & 0,379 & 0,357 & 0,468 & 0,265 & 0,419 & 0,415 & 0,444 & 0,473 & 0,298 & 0,660 & 0,349 & 0,572 & 0,586 & 0,201 & 0,543 \\
\hline & Mediana & 0,519 & 0,547 & 0,376 & 0,465 & 0,462 & 0,347 & 0,519 & 0,288 & 0,452 & 0,439 & 0,428 & 0,507 & 0,240 & 0,660 & 0,311 & 0,642 & 0,622 & 0,211 & 0,522 \\
\hline & Mínimo & 0,249 & 0,318 & 0,108 & 0,270 & 0,040 & 0,178 & 0,269 & 0,097 & 0,255 & 0,182 & 0,401 & 0,281 & $<0,03$ & 0,434 & 0,108 & 0,256 & 0,278 & $<0,03$ & 0,256 \\
\hline & Máximo & 0,658 & 0,577 & 0,542 & 0,648 & 0,586 & 0,571 & 0,559 & 0,383 & 0,487 & 0,575 & 0,503 & 0,550 & 0,540 & 0,894 & 0,711 & 0,851 & 0,878 & 0,234 & 0,867 \\
\hline \multirow[t]{5}{*}{$\mathrm{Mg}$} & $N$ & 5 & 5 & 5 & 5 & 5 & 5 & 5 & 5 & 5 & 5 & 3 & 5 & 5 & 5 & 5 & 5 & 5 & 5 & 5 \\
\hline & Média & 3,24 & 4,03 & 2,38 & 3,70 & 2,10 & 1,53 & 4,27 & 2,22 & 0,997 & 1,27 & 2,86 & 3,16 & 0,935 & 3,178 & 0,688 & 0,895 & 0,955 & 3,37 & 0,624 \\
\hline & Mediana & 3,33 & 4,05 & 2,48 & 3,70 & 2,14 & 1,59 & 4,44 & 2,35 & 0,978 & 1,25 & 2,64 & 2,94 & 0,893 & 3,150 & 0,694 & 0,860 & 0,940 & 3,55 & 0,581 \\
\hline & Mínimo & 2,69 & 3,12 & 1,86 & 3,30 & 1,84 & 1,31 & 3,21 & 1,74 & 0,912 & 1,20 & 2,57 & 2,58 & 0,670 & 2,910 & 0,606 & 0,710 & 0,780 & 2,51 & 0,529 \\
\hline & Máximo & 3,79 & 4,67 & 2,76 & 4,11 & 2,36 & 1,65 & 4,86 & 2,47 & 1,10 & 1,39 & 3,37 & 3,83 & 1,19 & 3,640 & 0,798 & 1,16 & 1,19 & 3,77 & 0,77 \\
\hline \multirow[t]{5}{*}{$\mathrm{Mn}$} & $\mathrm{N}$ & 5 & 5 & 5 & 5 & 5 & 5 & 5 & 5 & 5 & 5 & 3 & 5 & 5 & 5 & 5 & 5 & 5 & 5 & 5 \\
\hline & Média & 0,118 & 0,199 & 0,127 & 0,216 & 0,040 & 0,054 & 0,136 & 0,031 & 0,037 & 0,037 & & 0,090 & 0,031 & 0,040 & 0,114 & 0,156 & 0,115 & 3,640 & 0,038 \\
\hline & Mediana & 0,080 & 0,144 & 0,128 & 0,060 & 0,033 & 0,055 & 0,113 & 0,037 & 0,036 & 0,031 & & 0,085 & 0,017 & 0,042 & 0,059 & 0,090 & 0,088 & 3,548 & 0,037 \\
\hline & Mínimo & 0,021 & 0,043 & 0,035 & 0,052 & $<0,0070$ & 0,019 & 0,051 & 0,014 & 0,027 & 0,017 & & 0,022 & $<0,0070$ & 0,023 & 0,030 & 0,046 & 0,041 & 2,510 & 0,016 \\
\hline & Máximo & 0,316 & 0,574 & 0,251 & 0,812 & 0,085 & 0,096 & 0,331 & 0,043 & 0,056 & 0,070 & & 0,160 & 0,070 & 0,050 & 0,351 & 0,498 & 0,307 & 5,000 & 0,070 \\
\hline \multirow[t]{5}{*}{ Mo } & $\mathrm{N}$ & 5 & 5 & 5 & 5 & 5 & 5 & 5 & 5 & 5 & 5 & 3 & 5 & 5 & 5 & 5 & 5 & 5 & 5 & 5 \\
\hline & Média & & & & & & & & & & & & & & & & & & & \\
\hline & Mediana & & & & & & & & & & & & & & & & & & & \\
\hline & Mínimo & $<0,02$ & $<0,02$ & $<0,02$ & $<0,02$ & $<0,02$ & $<0,02$ & $<0,02$ & $<0,02$ & $<0,02$ & $<0,02$ & $<0,02$ & $<0,02$ & $<0,02$ & $<0,02$ & $<0,02$ & $<0,02$ & $<0,02$ & $<0,02$ & $<0,02$ \\
\hline & Máximo & & & & & & & & & & & & & & & & & & & \\
\hline \multirow[t]{5}{*}{ Mo } & $\mathrm{N}$ & 5 & 5 & 5 & 5 & 5 & 5 & 5 & 5 & 5 & 5 & 3 & 5 & 5 & 5 & 5 & 5 & 5 & 5 & 5 \\
\hline & Média & & & & & & & & & & & & & & & & & & & \\
\hline & Mediana & & & & & & & & & & & & & & & & & & & \\
\hline & Mínimo & $<0,02$ & $<0,02$ & $<0,02$ & $<0,02$ & $<0,02$ & $<0,02$ & $<0,02$ & $<0,02$ & $<0,02$ & $<0,02$ & $<0,02$ & $<0,02$ & $<0,02$ & $<0,02$ & $<0,02$ & $<0,02$ & $<0,02$ & $<0,02$ & $<0,02$ \\
\hline & Máximo & & & & & & & & & & & & & & & & & & & \\
\hline \multirow[t]{5}{*}{$\mathrm{Na}$} & $\mathrm{N}$ & 5 & 5 & 5 & 5 & 5 & 5 & 5 & 5 & 5 & 5 & 3 & 5 & 5 & 5 & 5 & 5 & 5 & 5 & 5 \\
\hline & Média & 2,18 & 2,16 & 4,47 & 3,61 & 2,35 & 4,63 & 2,15 & 5,12 & 2,34 & 2,86 & 3,57 & 2,42 & 2,17 & 6,20 & 1,59 & 1,96 & 2,07 & 1,58 & 1,97 \\
\hline & Mediana & 2,30 & 2,27 & 4,76 & 3,56 & 2,30 & 4,29 & 2,33 & 5,39 & 2,35 & 2,68 & 3,63 & 2,56 & 2,16 & 5,92 & 1,70 & 1,90 & 2,08 & 1,67 & 2,07 \\
\hline & Mínimo & 1,67 & 1,58 & 3,24 & 3,04 & 1,97 & 3,19 & 1,45 & 3,80 & 2,07 & 2,46 & 3,10 & 1,97 & 1,71 & 5,61 & 1,03 & 1,55 & 1,58 & 1,17 & 1,44 \\
\hline & Máximo & 2,55 & 2,64 & 4,85 & 4,24 & 2,73 & 7,13 & 2,58 & 5,61 & 2,58 & 3,70 & 3,98 & 2,94 & 2,67 & 7,38 & 1,91 & 2,42 & 2,53 & 1,89 & 2,47 \\
\hline
\end{tabular}


Cont.

\begin{tabular}{|c|c|c|c|c|c|c|c|c|c|c|c|c|c|c|c|c|c|c|c|c|}
\hline Parâ & & LR 001 & LR 005 & LR 007 & LR 011 & LR 012 & LR 013 & LR 017 & LR 021 & LR 022 & LR 026 & LR 030 & LR 033 & LR 043 & LR 044 & LR 045 & LR 049 & LR 050 & LR 068 & LR 142 \\
\hline \multirow[t]{5}{*}{$\mathrm{Ni}$} & $\mathrm{N}$ & 5 & 5 & 5 & 5 & 5 & 5 & 5 & 5 & 5 & 5 & 3 & 5 & 5 & 5 & 5 & 5 & 5 & 5 & 5 \\
\hline & Média & & & & & & & & & & 0,028 & & & & & & & & & \\
\hline & Mediana & & & & & & & & & & 0,028 & & & & & & & & & \\
\hline & Mínimo & $<0,02$ & $<0,02$ & $<0,02$ & $<0,02$ & $<0,02$ & $<0,02$ & $<0,02$ & $<0,02$ & $<0,02$ & $<0,02$ & $<0,02$ & $<0,02$ & $<0,02$ & $<0,02$ & $<0,02$ & $<0,02$ & $<0,02$ & $<0,02$ & $<0,02$ \\
\hline & Máximo & & & & & & & & & & 0,028 & & & & & & & & & \\
\hline \multirow[t]{5}{*}{ P } & $N$ & 5 & 5 & 5 & 5 & 5 & 5 & 5 & 5 & 5 & 5 & 3 & 5 & 5 & 5 & 5 & 5 & 5 & 5 & 5 \\
\hline & Média & 0,100 & 0,105 & 0,079 & 0,109 & 0,133 & 0,123 & 0,108 & 0,143 & 0,130 & 0,030 & 0,038 & 0,264 & 0,039 & 0,044 & 0,027 & 0,041 & 0,053 & 0,065 & 0,362 \\
\hline & Mediana & 0,047 & 0,052 & 0,031 & 0,030 & 0,133 & 0,123 & 0,042 & 0,143 & 0,130 & 0,030 & 0,038 & 0,189 & 0,039 & 0,041 & 0,027 & 0,041 & 0,060 & 0,065 & 0,362 \\
\hline & Mínimo & $<0,05$ & $<0,05$ & $<0,05$ & $<0,05$ & $<0,05$ & $<0,05$ & $<0,05$ & $<0,05$ & $<0,05$ & $<0,05$ & $<0,05$ & $<0,05$ & $<0,05$ & $<0,05$ & $<0,05$ & $<0,05$ & $<0,05$ & $<0,05$ & $<0,05$ \\
\hline & Máximo & 0,269 & 0,274 & 0,231 & 0,272 & 0,234 & 0,222 & 0,320 & 0,248 & 0,235 & 0,030 & 0,044 & 0,502 & 0,039 & 0,065 & 0,027 & 0,045 & 0,070 & 0,103 & 0,686 \\
\hline \multirow[t]{5}{*}{$\mathrm{Pb}$} & $\mathrm{N}$ & 5 & 5 & 5 & 5 & 5 & 5 & 5 & 5 & 5 & 5 & 3 & 5 & 5 & 5 & 5 & 5 & 5 & 5 & 5 \\
\hline & Média & 0,008 & 0,009 & 0,004 & 0,003 & 0,006 & 0,003 & 0,008 & 0,003 & 0,002 & 0,003 & 0,004 & 0,007 & 0,003 & 0,002 & 0,003 & 0,004 & 0,005 & 0,004 & 0,012 \\
\hline & Mediana & 0,006 & 0,004 & 0,003 & 0,003 & 0,006 & 0,003 & 0,005 & 0,003 & 0,002 & 0,003 & 0,004 & 0,008 & 0,003 & 0,001 & 0,003 & 0,002 & 0,004 & 0,004 & 0,004 \\
\hline & Mínimo & 0,001 & 0,002 & $<0,001$ & $<0,001$ & $<0,001$ & $<0,001$ & 0,001 & $<0,001$ & $<0,001$ & $<0,001$ & $<0,001$ & $<0,001$ & $<0,001$ & 0,001 & $<0,001$ & 0,001 & 0,001 & $<0,001$ & $<0,001$ \\
\hline & Máximo & 0,019 & 0,028 & 0,007 & 0,005 & 0,007 & 0,006 & 0,020 & 0,004 & 0,003 & 0,003 & 0,005 & 0,010 & 0,004 & 0,003 & 0,003 & 0,012 & 0,010 & 0,005 & 0,040 \\
\hline \multirow[t]{5}{*}{$\mathrm{Sb}$} & $\mathrm{N}$ & 5 & 5 & 5 & 5 & 5 & 5 & 5 & 5 & 5 & 5 & 3 & 5 & 5 & 5 & 5 & 5 & 5 & 5 & 5 \\
\hline & Média & & & & & 0,002 & & & & & & & & & & & & & & \\
\hline & Mediana & & & & & 0,002 & & & & & & & & & & & & & & \\
\hline & Mínimo & $<0,001$ & $<0,001$ & $<0,001$ & $<0,001$ & $<0,001$ & $<0,001$ & $<0,001$ & $<0,001$ & $<0,001$ & $<0,001$ & $<0,001$ & $<0,001$ & $<0,001$ & $<0,001$ & $<0,001$ & $<0,001$ & $<0,001$ & $<0,001$ & $<0,001$ \\
\hline & Máximo & & & & & 0,002 & & & & & & & & & & & & & & \\
\hline \multirow[t]{5}{*}{ Se } & $N$ & 5 & 5 & 5 & 5 & 5 & 5 & 5 & 5 & 5 & 5 & 3 & 5 & 5 & 5 & 5 & 5 & 5 & 5 & 5 \\
\hline & Média & & & & & 0,002 & & 0,002 & 0,001 & 0,002 & & & & & & 0,002 & & & & \\
\hline & Mediana & & & & & 0,002 & & 0,002 & 0,001 & 0,002 & & & & & & 0,002 & & & & \\
\hline & Mínimo & $<0,001$ & $<0,001$ & $<0,001$ & $<0,001$ & $<0,001$ & $<0,001$ & $<0,001$ & $<0,001$ & $<0,001$ & $<0,001$ & $<0,001$ & $<0,001$ & $<0,001$ & $<0,001$ & $<0,001$ & $<0,001$ & $<0,001$ & $<0,001$ & $<0,001$ \\
\hline & Máximo & & & & & 0,002 & & 0,002 & 0,001 & 0,002 & & & & & & 0,002 & & & & \\
\hline \multirow[t]{5}{*}{ Sn } & $\mathrm{N}$ & 5 & 5 & 5 & 5 & 5 & 5 & 5 & 5 & 5 & 5 & 3 & 5 & 5 & 5 & 5 & 5 & 5 & 5 & 5 \\
\hline & Média & & & & & & & & & & & & & & & & & & & \\
\hline & Mediana & & & & & & & & & & & & & & & & & & & \\
\hline & Mínimo & $<0,2$ & $<0,2$ & $<0,2$ & $<0,2$ & $<0,2$ & $<0,2$ & $<0,2$ & $<0,2$ & $<0,2$ & $<0,2$ & $<0,2$ & $<0,2$ & $<0,2$ & $<0,2$ & $<0,2$ & $<0,2$ & $<0,2$ & $<0,2$ & $<0,2$ \\
\hline & Máximo & & & & & & & & & & & & & & & & & & & \\
\hline
\end{tabular}


Cont.

\begin{tabular}{|c|c|c|c|c|c|c|c|c|c|c|c|c|c|c|c|c|c|c|c|c|}
\hline \multicolumn{2}{|c|}{ Parâmetro } & \multirow{2}{*}{$\frac{\text { LR } 001}{5}$} & LR 005 & LR 007 & LR 011 & LR 012 & LR 013 & \multirow{2}{*}{$\frac{\text { LR } 017}{5}$} & \multirow{2}{*}{ LR 021} & \multirow{2}{*}{$\frac{\text { LR } 022}{5}$} & \multirow{2}{*}{$\begin{array}{r}\text { LR } 026 \\
5\end{array}$} & \multirow{2}{*}{$\frac{\text { LR } 030}{3}$} & \multirow{2}{*}{$\begin{array}{r}\text { LR } 033 \\
5\end{array}$} & \multirow{2}{*}{$\begin{array}{r}\text { LR } 043 \\
5\end{array}$} & \multirow{2}{*}{$\frac{\text { LR } 044}{5}$} & \multirow{2}{*}{ LR 045} & \multirow{2}{*}{$\begin{array}{r}\text { LR } 049 \\
5\end{array}$} & \multirow{2}{*}{$\begin{array}{r}\text { LR } 050 \\
5\end{array}$} & \multirow{2}{*}{ LR 068} & \multirow{2}{*}{$\begin{array}{l}\text { LR } 142 \\
5\end{array}$} \\
\hline V & $\mathrm{N}$ & & 5 & 5 & 5 & 5 & 5 & & & & & & & & & & & & & \\
\hline & Média & & & & & & & & & & & & & & & & & & & \\
\hline & Mediana & & & & & & & & & & & & & & & & & & & \\
\hline & Mínimo & $<0,01$ & $<0,01$ & $<0,01$ & $<0,01$ & $<0,01$ & $<0,01$ & $<0,01$ & $<0,01$ & $<0,01$ & $<0,01$ & $<0,01$ & $<0,01$ & $<0,01$ & $<0,01$ & $<0,01$ & $<0,01$ & $<0,01$ & $<0,01$ & $<0,01$ \\
\hline & Máximo & & & & & & & & & & & & & & & & & & & \\
\hline \multirow[t]{5}{*}{$\mathrm{Zn}$} & $\mathrm{N}$ & 5 & 5 & 5 & 5 & 5 & 5 & 5 & 5 & 5 & 5 & 3 & 5 & 5 & 5 & 5 & 5 & 5 & 5 & 5 \\
\hline & Média & 0,024 & & 0,011 & 0,013 & 0,010 & 0,042 & 0,014 & 0,025 & 0,019 & 0,021 & 0,017 & 0,062 & 0,024 & 0,009 & 0,017 & 0,026 & 0,012 & 0,014 & 0,013 \\
\hline & Mediana & 0,009 & & 0,010 & 0,009 & 0,010 & 0,042 & 0,012 & 0,012 & 0,017 & 0,021 & 0,017 & 0,016 & 0,020 & 0,011 & 0,007 & 0,009 & 0,009 & 0,014 & 0,015 \\
\hline & Mínimo & 0,003 & $<0,003$ & $<0,003$ & $<0,003$ & $<0,003$ & $<0,003$ & $<0,003$ & 0,004 & $<0,003$ & $<0,003$ & $<0,003$ & $<0,003$ & $<0,003$ & $<0,003$ & $<0,003$ & $<0,003$ & $<0,003$ & $<0,003$ & $<0,003$ \\
\hline & Máximo & 0,057 & & 0,023 & 0,021 & 0,011 & 0,066 & 0,029 & 0,065 & 0,040 & 0,033 & 0,031 & 0,153 & 0,045 & 0,012 & 0,039 & 0,060 & 0,024 & 0,021 & 0,020 \\
\hline \multirow[t]{5}{*}{$F^{-}$} & $N$ & 5 & 5 & 5 & 5 & 4 & 5 & 5 & 5 & 5 & 4 & 3 & 5 & 5 & 5 & 5 & 5 & 5 & 5 & 5 \\
\hline & Média & 0,067 & 0,073 & 0,051 & 0,058 & 0,044 & 0,050 & 0,071 & 0,044 & 0,043 & 0,031 & 0,040 & 0,082 & 0,041 & 0,050 & 0,086 & 0,047 & 0,042 & 0,041 & 0,049 \\
\hline & Mediana & 0,069 & 0,073 & 0,052 & 0,057 & 0,042 & 0,059 & 0,071 & 0,044 & 0,039 & 0,030 & 0,040 & 0,082 & 0,030 & 0,040 & 0,084 & 0,032 & 0,038 & 0,039 & 0,055 \\
\hline & Mínimo & 0,057 & 0,064 & 0,040 & 0,051 & 0,039 & 0,029 & 0,064 & 0,034 & 0,031 & 0,028 & 0,037 & 0,062 & 0,022 & 0,036 & 0,081 & 0,081 & 0,036 & 0,037 & 0,036 \\
\hline & Máximo & 0,077 & 0,090 & 0,060 & 0,067 & 0,052 & 0,063 & 0,076 & 0,051 & 0,060 & 0,034 & 0,043 & 0,100 & 0,093 & 0,101 & 0,091 & 0,102 & 0,060 & 0,049 & 0,059 \\
\hline \multirow[t]{5}{*}{$\mathrm{Cl}^{-}$} & $N$ & 5 & 5 & 5 & 5 & 4 & 5 & 5 & 5 & 5 & 4 & 3 & 5 & 5 & 5 & 5 & 5 & 5 & 5 & 5 \\
\hline & Média & 1,81 & 1,26 & 6,17 & 3,59 & 1,44 & 5,55 & 0,99 & 7,17 & 2,70 & 4,16 & 3,77 & 2,13 & 1,68 & 6,00 & 5,96 & 1,95 & 1,81 & 2,18 & 1,31 \\
\hline & Mediana & 1,55 & 1,31 & 5,83 & 3,83 & 1,44 & 5,30 & 1,08 & 6,88 & 2,53 & 3,75 & 4,06 & 2,10 & 1,51 & 3,20 & 6,77 & 1,88 & 1,76 & 2,11 & 1,41 \\
\hline & Mínimo & 1,40 & 0,830 & 5,48 & 2,77 & 1,16 & 4,46 & 0,780 & 4,25 & 2,38 & 3,33 & 2,55 & 1,76 & 1,28 & 2,73 & 1,62 & 1,58 & 0,976 & 1,79 & 0,9 \\
\hline & Máximo & 2,36 & 1,64 & 7,95 & 4,33 & 1,73 & 6,69 & 1,18 & 10,61 & 3,19 & 5,83 & 4,70 & 2,90 & 2,47 & 12,71 & 7,83 & 2,38 & 2,60 & 2,91 & 1,81 \\
\hline $\mathrm{NO}_{3}{ }^{-}$ & $\mathrm{N}$ & 5 & 5 & 5 & 5 & 4 & 5 & 5 & 5 & 5 & 4 & 3 & 5 & 5 & 5 & 5 & 5 & 5 & 5 & 5 \\
\hline & Média & 1,26 & 1,22 & 0,388 & 0,801 & 0,649 & 0,459 & 0,945 & 0,499 & 1,05 & 1,01 & 1,09 & 1,14 & 0,190 & 0,593 & 1,00 & 0,72 & 1,02 & 1,33 & 1,08 \\
\hline & Mediana & 1,32 & 1,28 & 0,345 & 0,813 & 0,618 & 0,314 & 0,940 & 0,314 & 1,10 & 0,985 & 1,00 & 1,17 & 0,220 & 0,771 & 1,06 & 0,561 & 0,839 & 1,18 & 0,923 \\
\hline & Mínimo & 0,606 & 0,508 & 0,177 & 0,451 & 0,220 & 0,177 & 0,495 & 0,195 & 0,785 & 0,819 & 0,949 & 0,763 & 0,053 & 0,191 & 0,602 & 0,393 & 0,633 & 0,974 & 0,656 \\
\hline & Máximo & 1,80 & 1,86 & 0,828 & 1,12 & 1,14 & 0,89 & 1,44 & 1,39 & 1,35 & 1,24 & 1,33 & 1,46 & 0,373 & 0,834 & 1,48 & 1,55 & 1,75 & 1,98 & 2,06 \\
\hline $\mathrm{PO}_{4}{ }^{3-}$ & $N$ & 5 & 5 & 5 & 5 & 4 & 5 & 5 & 5 & 5 & 4 & 3 & 5 & 5 & 5 & 5 & 5 & 5 & 5 & 5 \\
\hline & Média & & & & & & & & & & & & & & & & & & & \\
\hline & Mediana & & & & & & & & & & & & & & & & & & & \\
\hline & Mínimo & $<0.05$ & $<0.05$ & $<0.05$ & $<0.05$ & $<0.05$ & $<0.05$ & $<0.05$ & $<0.05$ & $<0.05$ & $<0.05$ & $<0.05$ & $<0.05$ & $<0.05$ & $<0.05$ & $<0.05$ & $<0.05$ & $<0.05$ & $<0.05$ & $<0.05$ \\
\hline & Máximo & & & & & & & & & & & & & & & & & & & \\
\hline
\end{tabular}


Cont.

\begin{tabular}{|lrrrrrrrrrrrrrrrrrrrrr}
\hline Parâmetro & LR 001 & LR 005 & LR 007 & LR 011 & LR 012 & LR 013 & LR 017 & LR 021 & LR 022 & LR 026 & LR 030 & LR 033 & LR 043 & LR 044 & LR 045 & LR 049 & LR 050 & LR 068 & LR 142 \\
\hline $\mathrm{SO}_{4}{ }^{2-}$ & $\mathrm{N}$ & 5 & 5 & 5 & 5 & 4 & 5 & 5 & 5 & 5 & 4 & 3 & 5 & 5 & 5 & 5 & 5 & 5 & 5 & 5 & \\
& Média & 0,859 & 0,848 & 0,866 & 1,05 & 0,543 & 0,867 & 0,784 & 1,00 & 0,901 & 1,21 & 0,735 & 1,88 & 1,11 & 2,84 & 1,12 & 0,633 & 0,793 & 0,894 & 0,891 & \\
& Mediana & 0,957 & 0,940 & 0,911 & 1,14 & 0,516 & 0,829 & 0,690 & 1,09 & 0,858 & 1,03 & 0,693 & 1,97 & 0,359 & 0,633 & 1,21 & 0,330 & 0,416 & 0,621 & 0,831 \\
& Mínimo & 0,668 & 0,576 & 0,620 & 0,818 & 0,343 & 0,654 & 0,629 & 0,727 & 0,553 & 0,556 & 0,661 & 1,47 & 0,163 & 0,364 & 0,767 & 0,239 & 0,345 & 0,458 & 0,674 \\
& Máximo & 1,02 & 1,02 & 1,22 & 1,23 & 0,796 & 1,23 & 1,03 & 1,13 & 1,44 & 2,22 & 0,852 & 2,28 & 0,523 & 11,36 & 1,39 & 1,42 & 1,62 & 1,78 & 1,18 \\
\hline
\end{tabular}


Tabela A.4- Estatística descritiva para as concentrações (mg. $\left.\mathrm{L}^{-1}\right)$ de metais e íons em água tratada.

\begin{tabular}{|c|c|c|c|c|c|c|c|c|c|c|c|c|c|c|c|c|c|c|c|c|c|}
\hline Parâmetro & & LR 001 & LR005 & LR 007 & LR011 & LR012 & LR013 & LR017 & LR 021 & LR022 & LR026 & LR030 & LR032 & LR033 & LR043 & LR044 & LR045 & LR049 & LR050 & LR068 & LR142 \\
\hline \multirow[t]{5}{*}{$\mathrm{Ag}$} & $\mathrm{N}$ & 5 & 5 & 5 & 5 & 5 & 5 & 5 & 5 & 5 & 5 & 1 & 2 & 5 & 1 & 5 & 5 & 5 & 5 & 5 & 5 \\
\hline & Média & 0,006 & 0,007 & 0,008 & 0,007 & 0,007 & 0,008 & 0,010 & 0,011 & 0,010 & 0,011 & $<0,005$ & & & & & & & & & \\
\hline & Mediana & 0,006 & 0,007 & 0,008 & 0,007 & 0,007 & 0,008 & 0,010 & 0,011 & 0,010 & 0,011 & & & & & & & & & & \\
\hline & Mínimo & $<0,005$ & $<0,005$ & $<0,005$ & $<0,005$ & $<0,005$ & $<0,005$ & $<0,005$ & $<0,005$ & $<0,005$ & $<0,005$ & $<0,005$ & $<0,005$ & $<0,005$ & $<0,005$ & $<0,005$ & $<0,005$ & $<0,005$ & $<0,005$ & $<0,005$ & $<0,005$ \\
\hline & Máximo & 0,006 & 0,007 & 0,008 & 0,007 & 0,007 & 0,008 & 0,010 & 0,011 & 0,010 & 0,011 & & & & & & & & & & \\
\hline \multirow[t]{5}{*}{$\mathrm{Al}$} & $N$ & 5 & 5 & 5 & 5 & 5 & 5 & 5 & 5 & 5 & 5 & 1 & 2 & 5 & 1 & 5 & 5 & 5 & 5 & 5 & 5 \\
\hline & Média & 0,089 & 0,141 & 0,140 & 0,095 & 0,359 & 0,081 & 0,100 & 0,122 & 0,080 & 0,065 & 0,035 & 0,059 & 0,096 & & 0,166 & 0,048 & 0,033 & 0,041 & 0,174 & 0,127 \\
\hline & Mediana & 0,086 & 0,161 & 0,043 & 0,090 & 0,285 & 0,071 & 0,060 & 0,112 & 0,070 & 0,056 & & 0,059 & 0,092 & & 0,063 & 0,033 & 0,036 & 0,041 & 0,153 & 0,084 \\
\hline & Mínimo & $<0,02$ & $<0,02$ & $<0,02$ & $<0,02$ & $<0,02$ & 0,046 & 0,040 & $<0,02$ & $<0,02$ & 0,028 & & 0,057 & 0,052 & 0,028 & 0,023 & $<0,02$ & $<0,02$ & $<0,02$ & 0,103 & 0,024 \\
\hline & Máximo & 0,153 & 0,176 & 0,442 & 0,167 & 0,737 & 0,144 & 0,236 & 0,245 & 0,143 & 0,123 & & 0,062 & 0,150 & & 0,522 & 0,108 & 0,040 & 0,045 & 0,250 & 0,366 \\
\hline \multirow[t]{5}{*}{ As } & $\mathrm{N}$ & 5 & 5 & 5 & 5 & 5 & 5 & 5 & 5 & 4 & 5 & 1 & 2 & 5 & 1 & 4 & 4 & 5 & 5 & 4 & 5 \\
\hline & Média & & & & & & & & & & & & & & & & & & & & \\
\hline & Mediana & & & & & & & & & & & & & & & & & & & & \\
\hline & Mínimo & $<0,001$ & $<0,001$ & $<0,001$ & $<0,001$ & $<0,001$ & $<0,001$ & $<0,001$ & $<0,001$ & $<0,001$ & $<0,001$ & $<0,001$ & $<0,001$ & $<0,001$ & $<0,001$ & $<0,001$ & $<0,001$ & $<0,001$ & $<0,001$ & $<0,001$ & $<0,001$ \\
\hline & Máximo & & & & & & & & & & & & & & & & & & & & \\
\hline \multirow[t]{5}{*}{ B } & $\mathrm{N}$ & 5 & 5 & 5 & 5 & 5 & 5 & 5 & 5 & 5 & 5 & 1 & 2 & 5 & 1 & 5 & 5 & 5 & 5 & 5 & 5 \\
\hline & Média & 0,011 & 0,012 & 0,014 & 0,013 & 0,010 & 0,010 & 0,007 & 0,013 & 0,010 & 0,012 & $<0,003$ & 0,009 & & $<0,003$ & & & & & & \\
\hline & Mediana & 0,011 & 0,012 & 0,014 & 0,013 & 0,010 & 0,010 & 0,007 & 0,013 & 0,010 & 0,012 & & 0,009 & & & & & & & & \\
\hline & Mínimo & $<0,003$ & $<0,003$ & $<0,003$ & $<0,003$ & $<0,003$ & $<0,003$ & $<0,003$ & $<0,003$ & $<0,003$ & $<0,003$ & & $<0,003$ & $<0,003$ & & $<0,003$ & $<0,003$ & $<0,003$ & $<0,003$ & $<0,003$ & $<0,003$ \\
\hline & Máximo & 0,011 & 0,012 & 0,014 & 0,013 & 0,010 & 0,013 & 0,010 & 0,016 & 0,012 & 0,012 & & 0,009 & & & & & & & & \\
\hline \multirow[t]{5}{*}{$\mathrm{Ba}$} & $\mathrm{N}$ & 5 & 5 & 5 & 5 & 5 & 5 & 5 & 5 & 5 & 5 & 1 & 2 & 5 & 1 & 5 & 5 & 5 & 5 & 5 & 5 \\
\hline & Média & 0,036 & 0,042 & 0,022 & 0,027 & 0,031 & 0,018 & 0,038 & 0,010 & 0,021 & 0,018 & 0,013 & 0,063 & 0,035 & & 0,027 & 0,008 & 0,012 & 0,013 & 0,014 & 0,025 \\
\hline & Mediana & 0,034 & 0,036 & 0,020 & 0,023 & 0,030 & 0,019 & 0,037 & 0,011 & 0,021 & 0,018 & & 0,063 & 0,032 & & 0,025 & 0,008 & 0,011 & 0,012 & 0,015 & 0,023 \\
\hline & Mínimo & 0,028 & 0,032 & 0,019 & 0,023 & 0,021 & 0,014 & 0,031 & 0,006 & 0,017 & 0,014 & & 0,062 & 0,027 & 0,021 & 0,022 & 0,004 & 0,007 & 0,009 & 0,010 & 0,019 \\
\hline & Máximo & 0,054 & 0,072 & 0,026 & 0,039 & 0,041 & 0,021 & 0,054 & 0,014 & 0,024 & 0,020 & & 0,065 & 0,048 & & 0,034 & 0,014 & 0,015 & 0,018 & 0,016 & 0,032 \\
\hline \multirow[t]{5}{*}{$\mathrm{Cd}$} & N & 5 & 5 & 5 & 5 & 5 & 5 & 5 & 5 & 5 & 5 & 1 & 2 & 5 & 1 & 5 & 5 & 5 & 5 & 5 & 5 \\
\hline & Média & & & & & & & & & & 0,002 & & & & & & & & & & 0,0003 \\
\hline & Mediana & & & & & & & & & & 0,002 & & & & & & & & & & 0,0003 \\
\hline & Mínimo & $<0,0001$ & $<0,0001$ & $<0,0001$ & $<0,0001$ & $<0,0001$ & $<0,0001$ & $<0,0001$ & $<0,0001$ & $<0,0001$ & $<0,0001$ & $<0,0001$ & $<0,0001$ & $<0,0001$ & $<0,0001$ & $<0,0001$ & $<0,0001$ & $<0,0001$ & & $<0,0001$ & $<0,0001$ \\
\hline & Máximo & & & & & & & & & & 0,002 & & & & & & & & & & 0,0003 \\
\hline
\end{tabular}


Cont.

\begin{tabular}{|c|c|c|c|c|c|c|c|c|c|c|c|c|c|c|c|c|c|c|c|c|c|}
\hline Parâmetro & & LR 001 & LR005 & LR 007 & LR011 & LR012 & LR013 & LR017 & LR 021 & LR022 & LR026 & LR030 & LR032 & LR033 & LR043 & LR044 & LR045 & LR049 & LR050 & LR068 & LR142 \\
\hline \multirow[t]{5}{*}{ Co } & N & 5 & 5 & 5 & 5 & 5 & 5 & 5 & 5 & 5 & 5 & 1 & 2 & 5 & 1 & 5 & 5 & 5 & 5 & 5 & 5 \\
\hline & Média & & & & & & & & & & & & & & & & & & & & \\
\hline & Mediana & & & & & & & & & & & & & & & & & & & & \\
\hline & Mínimo & $<0,05$ & $<0,05$ & $<0,05$ & $<0,05$ & $<0,05$ & $<0,05$ & $<0,05$ & $<0,05$ & $<0,05$ & $<0,05$ & $<0,05$ & $<0,05$ & $<0,05$ & $<0,05$ & $<0,05$ & $<0,05$ & $<0,05$ & $<0,05$ & $<0,05$ & $<0,05$ \\
\hline & Máximo & & & & & & & & & & & & & & & & & & & & \\
\hline \multirow[t]{5}{*}{$\mathrm{Cr}$} & $N$ & 5 & 5 & 5 & 5 & 5 & 5 & 5 & 5 & 5 & 5 & 1 & 2 & 5 & 1 & 5 & 5 & 5 & 5 & 5 & 5 \\
\hline & Média & & & & & & & & & & & & & & & & & & & & \\
\hline & Mediana & & & & & & & & & & & & & & & & & & & & \\
\hline & Mínimo & $<0,03$ & $<0,03$ & $<0,03$ & $<0,03$ & $<0,03$ & $<0,03$ & $<0,03$ & $<0,03$ & $<0,03$ & $<0,03$ & $<0,03$ & $<0,03$ & $<0,03$ & $<0,03$ & $<0,03$ & $<0,03$ & $<0,03$ & $<0,03$ & $<0,03$ & $<0,03$ \\
\hline & Máximo & & & & & & & & & & & & & & & & & & & & \\
\hline \multirow[t]{5}{*}{$\mathrm{Ca}$} & $\mathrm{N}$ & 5 & 5 & 5 & 5 & 5 & 5 & 5 & 5 & 5 & 5 & 1 & 2 & 5 & 1 & 5 & 5 & 5 & 5 & 5 & 5 \\
\hline & Média & 7,94 & 10,29 & 3,57 & 6,20 & 4,30 & 1,92 & 10,96 & 2,73 & 2,12 & 2,02 & 7,08 & 35,79 & 7,88 & & 5,58 & 1,49 & 2,81 & 2,87 & 18,92 & 2,34 \\
\hline & Mediana & 7,49 & 10,10 & 3,64 & 6,73 & 4,16 & 1,85 & 11,70 & 2,77 & 2,12 & 2,09 & & 35,79 & 7,35 & & 5,00 & 1,42 & 2,98 & 2,74 & 18,81 & 2,22 \\
\hline & Mínimo & 6,38 & 7,74 & 3,00 & 5,17 & 3,67 & 1,52 & 7,68 & 1,97 & 1,98 & 1,72 & & 34,78 & 6,76 & 2,60 & 4,97 & 1,21 & 2,05 & 2,09 & 14,20 & 1,82 \\
\hline & Máximo & 9,92 & 12,60 & 4,15 & 6,91 & 4,96 & 2,36 & 13,09 & 3,21 & 2,32 & 2,22 & & 36,80 & 10,20 & & 6,67 & 1,83 & 3,55 & 3,54 & 22,90 & 3,21 \\
\hline \multirow[t]{5}{*}{$\mathrm{Cu}$} & $\mathrm{N}$ & 5 & 5 & 5 & 5 & 5 & 5 & 5 & 5 & 5 & 5 & 1 & 2 & 5 & 1 & 5 & 5 & 5 & 5 & 5 & 5 \\
\hline & Média & & & & & & & & & & & & & & & & & & & & \\
\hline & Mediana & & & & & & & & & & & & & & & & & & & & \\
\hline & Mínimo & $<0,02$ & $<0,02$ & $<0,02$ & $<0,02$ & $<0,02$ & $<0,02$ & $<0,02$ & $<0,02$ & $<0,02$ & $<0,02$ & $<0,02$ & $<0,02$ & $<0,02$ & $<0,02$ & $<0,02$ & $<0,02$ & $<0,02$ & $<0,02$ & $<0,02$ & $<0,02$ \\
\hline & Máximo & & & & & & & & & & & & & & & & & & & & \\
\hline \multirow[t]{5}{*}{$\mathrm{Fe}$} & $\mathrm{N}$ & 5 & 5 & 5 & 5 & 5 & 5 & 5 & 5 & 5 & 5 & 1 & 2 & 5 & 1 & 5 & 5 & 5 & 5 & 5 & 5 \\
\hline & Média & 0,032 & 0,174 & 0,075 & 0,179 & 0,057 & 0,066 & 0,025 & 0,074 & 0,055 & 0,024 & 0,030 & 0,325 & 0,084 & & 0,075 & 0,056 & 0,041 & 0,157 & 0,046 & 0,039 \\
\hline & Mediana & 0,026 & 0,070 & 0,029 & 0,127 & 0,059 & 0,077 & 0,021 & 0,066 & 0,036 & 0,019 & & 0,325 & 0,033 & & 0,031 & 0,023 & 0,024 & 0,232 & 0,030 & 0,034 \\
\hline & Mínimo & $<0,010$ & 0,016 & 0,016 & $<0,010$ & $<0,010$ & 0,029 & 0,010 & $<0,010$ & 0,018 & 0,010 & & 0,281 & 0,020 & 0,040 & $<0,01$ & $<0,01$ & 0,010 & $<0,01$ & 0,019 & 0,016 \\
\hline & Máximo & 0,059 & 0,541 & 0,277 & 0,446 & 0,079 & 0,108 & 0,050 & 0,156 & 0,156 & 0,055 & & 0,369 & 0,250 & & 0,226 & 0,164 & 0,129 & 0,267 & 0,082 & 0,069 \\
\hline \multirow[t]{5}{*}{$\mathrm{Hg}$} & $\mathrm{N}$ & 5 & 5 & 5 & 5 & 5 & 5 & 5 & 5 & 5 & 5 & 1 & 2 & 5 & 1 & 4 & 4 & 5 & 5 & 4 & 5 \\
\hline & Média & & & & & & & & & & & & & & & & & & & & \\
\hline & Mediana & & & & & & & & & & & & & & & & & & & & \\
\hline & Mínimo & $<0,0008$ & $<0,0008$ & $<0,0008$ & $<0,0008$ & $<0,0008$ & $<0,0008$ & $<0,0008$ & $<0,0008$ & $<0,0008$ & $<0,0008$ & $<0,0008$ & $<0,0008$ & $<0,0008$ & $<0,0008$ & $<0,0008$ & $<0,0008$ & $<0,0008$ & $<0,0008$ & $<0,0008$ & $<0,0008$ \\
\hline & Máximo & & & & & & & & & & & & & & & & & & & & \\
\hline
\end{tabular}


Cont.

\begin{tabular}{|c|c|c|c|c|c|c|c|c|c|c|c|c|c|c|c|c|c|c|c|c|c|}
\hline Parâmetro & & LR 001 & LR005 & LR 007 & LR011 & LR012 & LR013 & LR017 & LR 021 & LR022 & LR026 & LR030 & LR032 & LR033 & LR043 & LR044 & LR045 & LR049 & LR050 & LR068 & LR142 \\
\hline \multirow[t]{5}{*}{ K } & $\mathrm{N}$ & 5 & 5 & 5 & 5 & 5 & 5 & 5 & 5 & 5 & 5 & 1 & 2 & 5 & 1 & 5 & 5 & 5 & 5 & 5 & 5 \\
\hline & Média & 0,500 & 0,480 & 0,395 & 0,547 & 0,519 & 0,399 & 0,470 & 0,321 & 0,467 & 0,538 & 0,534 & 1,848 & 0,543 & & 0,756 & 0,402 & 0,626 & 0,668 & 0,218 & 0,647 \\
\hline & Mediana & 0,539 & 0,541 & 0,416 & 0,539 & 0,524 & 0,394 & 0,515 & 0,351 & 0,503 & 0,554 & & 1,848 & 0,544 & & 0,705 & 0,417 & 0,617 & 0,704 & 0,219 & 0,609 \\
\hline & Mínimo & 0,267 & 0,316 & 0,146 & 0,308 & 0,304 & 0,218 & 0,295 & 0,180 & 0,308 & 0,442 & & 1,820 & 0,515 & 0,383 & 0,666 & 0,259 & 0,517 & 0,549 & 0,171 & 0,485 \\
\hline & Máximo & 0,701 & 0,569 & 0,635 & 0,771 & 0,678 & 0,592 & 0,568 & 0,439 & 0,539 & 0,660 & & 1,876 & 0,563 & & 0,977 & 0,483 & 0,760 & 0,788 & 0,253 & 0,965 \\
\hline \multirow[t]{5}{*}{ Mg } & $\mathrm{N}$ & 5 & 5 & 5 & 5 & 5 & 5 & 5 & 5 & 5 & 5 & 1 & 2 & 5 & 1 & 5 & 5 & 5 & 5 & 5 & 5 \\
\hline & Média & 3,19 & 3,98 & 2,44 & 3,74 & 2,11 & 1,58 & 4,27 & 2,40 & 1,03 & 1,30 & 3,40 & 7,36 & 3,15 & & 3,26 & 0,742 & 0,848 & 0,924 & 3,37 & 0,629 \\
\hline & Mediana & 3,34 & 3,98 & 2,53 & 3,78 & 2,08 & 1,63 & 4,25 & 2,52 & 1,03 & 1,29 & & 7,36 & 3,07 & & 3,15 & 0,750 & 0,881 & 0,965 & 3,62 & 0,592 \\
\hline & Mínimo & 2,55 & 2,89 & 2,06 & 3,32 & 1,77 & 1,38 & 3,04 & 1,87 & 0,95 & 1,22 & & 7,23 & 2,43 & 1,34 & 2,98 & 0,660 & 0,730 & 0,800 & 2,40 & 0,530 \\
\hline & Máximo & 3,86 & 4,82 & 2,76 & 4,03 & 2,40 & 1,72 & 5,02 & 2,83 & 1,12 & 1,42 & & 7,48 & 3,84 & & 3,71 & 0,798 & 0,950 & 1,04 & 3,81 & 0,787 \\
\hline \multirow[t]{5}{*}{ Mn } & $\mathrm{N}$ & 5 & 5 & 5 & 5 & 5 & 5 & 5 & 5 & 5 & 5 & 1 & 2 & 5 & 1 & 5 & 5 & 5 & 5 & 5 & 5 \\
\hline & Média & 0,023 & 0,016 & 0,018 & & 0,017 & 0,025 & & 0,020 & 0,010 & 0,020 & & 0,038 & 0,027 & & 0,013 & 0,020 & 0,034 & 0,065 & 0,016 & 0,019 \\
\hline & Mediana & 0,023 & 0,016 & 0,018 & & 0,010 & 0,022 & & 0,012 & 0,010 & 0,024 & & 0,038 & 0,019 & & 0,013 & 0,020 & 0,023 & 0,030 & 0,015 & 0,022 \\
\hline & Mínimo & 0,008 & 0,009 & $<0,007$ & $<0,007$ & $<0,007$ & $<0,007$ & $<0,007$ & 0,007 & $<0,007$ & $<0,007$ & $<0,007$ & 0,022 & $<0,007$ & $<0,007$ & $<0,007$ & $<0,007$ & $<0,007$ & 0,029 & $<0,007$ & $<0,007$ \\
\hline & Máximo & 0,037 & 0,024 & 0,027 & & 0,032 & 0,030 & & 0,039 & 0,011 & 0,026 & & 0,055 & 0,044 & & 0,013 & 0,025 & 0,080 & 0,157 & 0,027 & 0,027 \\
\hline \multirow[t]{5}{*}{ Mo } & $\mathrm{N}$ & 5 & 5 & 5 & 5 & 5 & 5 & 5 & 5 & 5 & 5 & 1 & 2 & 5 & 1 & 5 & 5 & 5 & 5 & 5 & 5 \\
\hline & Média & & & & & & & & & & & & & & & & & & & & \\
\hline & Mediana & & & & & & & & & & & & & & & & & & & & \\
\hline & Mínimo & $<0,02$ & $<0,02$ & $<0,02$ & $<0,02$ & $<0,02$ & $<0,02$ & $<0,02$ & $<0,02$ & $<0,02$ & $<0,02$ & $<0,02$ & $<0,02$ & $<0,02$ & $<0,02$ & $<0,02$ & $<0,02$ & $<0,02$ & $<0,02$ & $<0,02$ & $<0,02$ \\
\hline & Máximo & & & & & & & & & & & & & & & & & & & & \\
\hline \multirow[t]{5}{*}{$\mathrm{Na}$} & $\mathrm{N}$ & 5 & 5 & 5 & 5 & 5 & 5 & 5 & 5 & 5 & 5 & 1 & 2 & 5 & 1 & 5 & 5 & 5 & 5 & 5 & 5 \\
\hline & Média & 4,24 & 2,71 & 8,51 & 8,28 & 7,43 & 10,02 & 2,54 & 9,77 & 5,72 & 10,53 & 8,45 & 18,90 & 4,90 & & 13,52 & 10,10 & 6,84 & 8,67 & 2,69 & 5,03 \\
\hline & Mediana & 4,28 & 2,23 & 7,83 & 6,44 & 6,75 & 9,26 & 2,40 & 11,50 & 5,80 & 10,40 & & 18,90 & 4,69 & & 12,80 & 10,17 & 6,04 & 8,27 & 2,72 & 4,52 \\
\hline & Mínimo & 2,54 & 1,73 & 6,57 & 5,45 & 6,22 & 7,84 & 1,92 & 5,95 & 5,14 & 9,13 & & 17,78 & 3,28 & 4,32 & 9,78 & 5,76 & 5,78 & 5,50 & 1,81 & 3,76 \\
\hline & Máximo & 6,20 & 4,95 & 11,70 & 11,70 & 9,62 & 12,60 & 3,40 & 12,30 & 6,22 & 12,20 & & 20,02 & 6,77 & & 17,10 & 18,40 & 8,44 & 11,40 & 3,69 & 6,65 \\
\hline \multirow[t]{5}{*}{$\mathrm{Ni}$} & $N$ & 5 & 5 & 5 & 5 & 5 & 5 & 5 & 5 & 5 & 5 & 1 & 2 & 5 & 1 & 5 & 5 & 5 & 5 & 5 & 5 \\
\hline & Média & & & & & & & & & 0,030 & & & & & & & 0,030 & 0,027 & & 0,031 & 0,034 \\
\hline & Mediana & & & & & & & & & 0,030 & & & & & & & 0,030 & 0,027 & & 0,031 & 0,034 \\
\hline & Mínimo & $<0,02$ & $<0,02$ & $<0,02$ & $<0,02$ & $<0,02$ & $<0,02$ & $<0,02$ & $<0,02$ & $<0,02$ & $<0,02$ & $<0,02$ & $<0,02$ & $<0,02$ & $<0,02$ & $<0,02$ & $<0,02$ & $<0,02$ & $<0,02$ & $<0,02$ & $<0,02$ \\
\hline & Máximo & & & & & & & & & 0,030 & & & & & & & 0,030 & 0,028 & & 0,031 & 0,034 \\
\hline
\end{tabular}


Cont.

\begin{tabular}{|c|c|c|c|c|c|c|c|c|c|c|c|c|c|c|c|c|c|c|c|c|c|}
\hline Parâmetro & & LR 001 & LR005 & LR 007 & LR011 & LR012 & LR013 & LR017 & LR 021 & LR022 & LR026 & LR030 & LR032 & LR033 & LR043 & LR044 & LR045 & LR049 & LR050 & LR068 & LR142 \\
\hline \multirow[t]{5}{*}{ P } & $\mathrm{N}$ & 5 & 5 & 5 & 5 & 5 & 5 & 5 & 5 & 5 & 5 & 1 & 2 & 5 & 1 & 5 & 5 & 5 & 5 & 5 & 5 \\
\hline & Média & 0,082 & 0,129 & 0,046 & 0,053 & 0,054 & 0,078 & 0,062 & 0,063 & 0,068 & 0,073 & 0,071 & 0,290 & 0,086 & & 0,062 & 0,067 & 0,058 & 0,065 & 0,098 & 0,065 \\
\hline & Mediana & 0,082 & 0,129 & 0,046 & 0,053 & 0,054 & 0,078 & 0,062 & 0,063 & 0,068 & 0,073 & & 0,290 & 0,057 & & 0,054 & 0,067 & 0,060 & 0,072 & 0,082 & 0,065 \\
\hline & Mínimo & $<0,02$ & 0,129 & $<0,02$ & $<0,02$ & $<0,02$ & $<0,02$ & $<0,02$ & $<0,02$ & $<0,02$ & $<0,02$ & & 0,118 & $<0,02$ & 0,101 & $<0,02$ & $<0,02$ & $<0,02$ & $<0,02$ & 0,055 & $<0,02$ \\
\hline & Máximo & 0,082 & 0,129 & 0,068 & 0,083 & 0,087 & 0,078 & 0,114 & 0,088 & 0,068 & 0,073 & & 0,462 & 0,147 & & 0,116 & 0,090 & 0,091 & 0,096 & 0,158 & 0,083 \\
\hline \multirow[t]{5}{*}{$\mathrm{Pb}$} & $N$ & 5 & 5 & 5 & 5 & 5 & 5 & 5 & 5 & 5 & 5 & 1 & 2 & 5 & 1 & 5 & 5 & 5 & 5 & 5 & 5 \\
\hline & Média & 0,003 & 0,004 & 0,003 & 0,001 & 0,003 & 0,003 & 0,002 & 0,003 & 0,026 & 0,002 & & 0,002 & 0,002 & & 0,004 & 0,002 & 0,004 & 0,003 & 0,002 & 0,001 \\
\hline & Mediana & 0,003 & 0,004 & 0,003 & 0,001 & 0,003 & 0,002 & 0,002 & 0,002 & 0,002 & 0,002 & & 0,002 & 0,002 & & 0,004 & 0,002 & 0,005 & 0,003 & 0,002 & 0,001 \\
\hline & Mínimo & 0,001 & $<0,001$ & $<0,001$ & $<0,001$ & $<0,001$ & $<0,001$ & $<0,001$ & $<0,001$ & $<0,001$ & $<0,001$ & $<0,001$ & 0,001 & $<0,001$ & 0,003 & $<0,001$ & $<0,001$ & $<0,001$ & $<0,001$ & $<0,001$ & $<0,001$ \\
\hline & Máximo & 0,004 & 0,004 & 0,003 & 0,002 & 0,003 & 0,006 & 0,002 & 0,006 & 0,100 & 0,003 & & 0,002 & 0,002 & & 0,006 & 0,003 & 0,007 & 0,004 & 0,003 & 0,002 \\
\hline \multirow[t]{5}{*}{$\mathrm{Sb}$} & $\mathrm{N}$ & 5 & 5 & 5 & 5 & 5 & 5 & 5 & 5 & 5 & 5 & 1 & 2 & 5 & 1 & 4 & 4 & 5 & 5 & 4 & 5 \\
\hline & Média & & & & & 0,002 & & & & & & & & & & & & & & & \\
\hline & Mediana & & & & & 0,002 & & & & & & & & & & & & & & & \\
\hline & Mínimo & $<0,001$ & $<0,001$ & $<0,001$ & $<0,001$ & $<0,001$ & $<0,001$ & $<0,001$ & $<0,001$ & $<0,001$ & $<0,001$ & $<0,001$ & $<0,001$ & $<0,001$ & $<0,001$ & $<0,001$ & $<0,001$ & $<0,001$ & $<0,001$ & $<0,001$ & $<0,001$ \\
\hline & Máximo & & & & & 0,002 & & & & & & & & & & & & & & & \\
\hline \multirow[t]{5}{*}{$\mathrm{Se}$} & $N$ & 5 & 5 & 5 & 5 & 5 & 5 & 5 & 5 & 5 & 5 & 1 & 2 & 5 & 1 & 5 & 5 & 5 & 5 & 5 & 5 \\
\hline & Média & & & & & & & 0,003 & 0,002 & 0,002 & & & & & & & 0,001 & 0,002 & 0,001 & & \\
\hline & Mediana & & & & & & & 0,003 & 0,002 & 0,002 & & & & & & & 0,001 & 0,002 & 0,001 & & \\
\hline & Mínimo & $<0,001$ & $<0,001$ & $<0,001$ & $<0,001$ & $<0,001$ & $<0,001$ & $<0,001$ & $<0,001$ & $<0,001$ & $<0,001$ & $<0,001$ & $<0,001$ & $<0,001$ & $<0,001$ & $<0,001$ & $<0,001$ & $<0,001$ & $<0,001$ & $<0,001$ & $<0,001$ \\
\hline & Máximo & & & & & & & 0,003 & 0,002 & 0,002 & & & & & & & 0,001 & 0,002 & 0,001 & & \\
\hline \multirow[t]{5}{*}{ Sn } & $N$ & 5 & 5 & 5 & 5 & 5 & 5 & 5 & 5 & 5 & 5 & 1 & 2 & 5 & 1 & 5 & 5 & 5 & 5 & 5 & 5 \\
\hline & Média & & & & & & & & & & & & & 0,200 & & & & & & & \\
\hline & Mediana & & & & & & & & & & & & & 0,200 & & & & & & & \\
\hline & Mínimo & $<0,20$ & $<0,20$ & $<0,20$ & $<0,20$ & $<0,20$ & $<0,20$ & $<0,20$ & $<0,20$ & $<0,20$ & $<0,20$ & $<0,20$ & $<0,20$ & $<0,20$ & $<0,20$ & $<0,20$ & $<0,20$ & $<0,20$ & $<0,20$ & $<0,20$ & $<0,20$ \\
\hline & Máximo & & & & & & & & & & & & & 0,200 & & & & & & & \\
\hline \multirow[t]{5}{*}{ V } & $N$ & 5 & 5 & 5 & 5 & 5 & 5 & 5 & 5 & 5 & 5 & 1 & 2 & 5 & 1 & 5 & 5 & 5 & 5 & 5 & 5 \\
\hline & Média & & & & & & & & & & & & & & & & & & & & \\
\hline & Mediana & & & & & & & & & & & & & & & & & & & & \\
\hline & Mínimo & $<0,01$ & $<0,01$ & $<0,01$ & $<0,01$ & $<0,01$ & $<0,01$ & $<0,01$ & $<0,01$ & $<0,01$ & $<0,01$ & $<0,01$ & $<0,01$ & $<0,01$ & $<0,01$ & $<0,01$ & $<0,01$ & $<0,01$ & $<0,01$ & $<0,01$ & $<0,01$ \\
\hline & Máximo & & & & & & & & & & & & & & & & & & & & \\
\hline
\end{tabular}


Cont.

\begin{tabular}{|c|c|c|c|c|c|c|c|c|c|c|c|c|c|c|c|c|c|c|c|c|c|}
\hline Parâmetro & & LR 001 & LR005 & LR 007 & LR011 & LR012 & LR013 & LR017 & LR 021 & LR022 & LR026 & LR030 & LR032 & LR033 & LR043 & LR044 & LR045 & LR049 & LR050 & LR068 & LR142 \\
\hline \multirow[t]{5}{*}{$\mathrm{Zn}$} & $\mathrm{N}$ & 5 & 5 & 5 & 5 & 5 & 5 & 5 & 5 & 5 & 5 & 1 & 2 & 5 & 1 & 5 & 5 & 5 & 5 & 5 & 5 \\
\hline & Média & 0,022 & 0,015 & 0,018 & 0,005 & 0,034 & 0,009 & 0,024 & 0,009 & 0,013 & 0,029 & 0,011 & 0,028 & 0,136 & & 0,011 & 0,015 & 0,011 & 0,023 & 0,010 & 0,020 \\
\hline & Mediana & 0,030 & 0,017 & 0,006 & 0,004 & 0,012 & 0,009 & 0,013 & 0,009 & 0,014 & 0,010 & & 0,028 & 0,015 & & 0,011 & 0,010 & 0,009 & 0,008 & 0,011 & 0,017 \\
\hline & Mínimo & 0,003 & 0,005 & $<0,003$ & 0,003 & $<0,003$ & $<0,003$ & $<0,003$ & $<0,003$ & 0,004 & $<0,003$ & & 0,026 & $<0,003$ & 0,009 & $<0,003$ & $<0,003$ & $<0,003$ & $<0,003$ & $<0,003$ & $<0,003$ \\
\hline & Máximo & 0,037 & 0,023 & 0,047 & 0,010 & 0,086 & 0,015 & 0,061 & 0,012 & 0,020 & 0,095 & & 0,030 & 0,510 & & 0,014 & 0,033 & 0,018 & 0,074 & 0,013 & 0,034 \\
\hline \multirow[t]{5}{*}{ F- } & $\mathrm{N}$ & 5 & 5 & 5 & 5 & 5 & 5 & 5 & 5 & 5 & 5 & & 2 & 5 & & 5 & 5 & 5 & 5 & 5 & 5 \\
\hline & Média & 0,594 & 0,687 & 0,544 & 0,559 & 0,686 & 0,550 & 0,604 & 0,549 & 0,647 & 0,754 & & 0,345 & 0,649 & & 0,619 & 0,583 & 0,550 & 0,631 & 0,979 & 0,555 \\
\hline & Mediana & 0,595 & 0,719 & 0,536 & 0,578 & 0,646 & 0,588 & 0,577 & 0,618 & 0,595 & 0,785 & & 0,345 & 0,638 & & 0,573 & 0,599 & 0,513 & 0,601 & 0,718 & 0,604 \\
\hline & Mínimo & 0,568 & 0,421 & 0,485 & 0,373 & 0,608 & 0,206 & 0,523 & 0,052 & 0,464 & 0,593 & & 0,201 & 0,588 & & 0,517 & 0,457 & 0,425 & 0,532 & 0,587 & 0,279 \\
\hline & Máximo & 0,639 & 0,850 & 0,651 & 0,688 & 0,869 & 0,729 & 0,679 & 0,842 & 0,894 & 0,884 & & 0,489 & 0,721 & & 0,842 & 0,655 & 0,720 & 0,752 & 2,171 & 0,804 \\
\hline \multirow[t]{5}{*}{$\mathrm{Cl}$} & $\mathrm{N}$ & 5 & 5 & 5 & 5 & 5 & 5 & 5 & 5 & 5 & 5 & & 2 & 5 & & 5 & 5 & 5 & 5 & 5 & 5 \\
\hline & Média & 4,39 & 2,82 & 9,10 & 6,21 & 4,68 & 8,01 & 3,99 & 10,30 & 4,70 & 6,97 & & 15,00 & 6,33 & & 11,10 & 4,63 & 4,56 & 11,91 & 3,41 & 5,90 \\
\hline & Mediana & 4,26 & 2,53 & 8,89 & 6,68 & 4,97 & 7,37 & 4,26 & 9,91 & 4,52 & 6,37 & & 15,00 & 6,14 & & 9,16 & 4,55 & 4,52 & 11,38 & 3,47 & 5,09 \\
\hline & Mínimo & 3,46 & 1,95 & 5,66 & 4,78 & 3,21 & 7,01 & 2,75 & 7,35 & 3,85 & 5,60 & & 14,40 & 5,04 & & 8,04 & 3,25 & 3,44 & 6,64 & 1,97 & 3,47 \\
\hline & Máximo & 5,37 & 4,59 & 13,15 & 7,02 & 6,18 & 11,04 & 5,32 & 13,86 & 5,86 & 9,60 & & 15,60 & 8,11 & & 15,26 & 6,36 & 6,31 & 15,45 & 4,65 & 10,04 \\
\hline \multirow[t]{5}{*}{ NO3- } & $\mathrm{N}$ & 5 & 5 & 5 & 5 & 5 & 5 & 5 & 5 & 5 & 5 & & 2 & 5 & & 5 & 5 & 5 & 5 & 5 & 5 \\
\hline & Média & 1,12 & 0,95 & 0,36 & 0,90 & 0,66 & 0,48 & 0,90 & 0,43 & 1,20 & 1,35 & & 0,129 & 1,15 & & 1,03 & 0,522 & 1,03 & 1,19 & 1,07 & 0,239 \\
\hline & Mediana & 1,29 & 0,82 & 0,33 & 0,85 & 0,68 & 0,37 & 0,93 & 0,34 & 1,24 & 1,19 & & 0,129 & 1,06 & & 1,12 & 0,538 & 0,907 & 1,05 & 0,816 & 0,241 \\
\hline & Mínimo & 0,677 & 0,685 & 0,121 & 0,626 & 0,220 & 0,264 & 0,491 & 0,310 & 0,847 & 0,929 & & 0,000 & 0,924 & & 0,743 & 0,444 & 0,830 & 0,878 & 0,731 & 0,101 \\
\hline & Máximo & 1,59 & 1,30 & 0,76 & 1,39 & 1,11 & 0,86 & 1,25 & 0,66 & 1,61 & 1,97 & & 0,129 & 1,48 & & 1,24 & 0,552 & 1,56 & 1,67 & 1,95 & 0,400 \\
\hline \multirow[t]{5}{*}{ PO43- } & $\mathrm{N}$ & 5 & 5 & 5 & 5 & 5 & 5 & 5 & 5 & 5 & 5 & & 2 & 5 & & 5 & 5 & 5 & 5 & 5 & 5 \\
\hline & Média & & & & & & & & & & & & & & & & & & 0,728 & & 0,937 \\
\hline & Mediana & & & & & & & & & & & & & & & & & & 0,728 & & 0,937 \\
\hline & Mínimo & $<0.05$ & $<0.05$ & $<0.05$ & $<0.05$ & $<0.05$ & $<0.05$ & $<0.05$ & $<0.05$ & $<0.05$ & $<0.05$ & & & $<0.05$ & & $<0.05$ & $<0.05$ & $<0.05$ & $<0.05$ & $<0.05$ & $<0.05$ \\
\hline & Máximo & & & & & & & & & & & & & & & & & & 0,817 & & 0,937 \\
\hline \multirow[t]{5}{*}{ SO4 2- } & $\mathrm{N}$ & 5 & 5 & 5 & 5 & 5 & 5 & 5 & 5 & 5 & 5 & & 2 & 5 & & 5 & 5 & 5 & 5 & 5 & 5 \\
\hline & Média & 9,64 & 12,04 & 9,66 & 10,29 & 9,23 & 7,33 & 12,12 & 9,05 & 5,55 & 6,65 & & 7,93 & 17,42 & & 13,20 & 3,10 & 5,15 & 0,824 & 8,62 & 7,31 \\
\hline & Mediana & 8,99 & 9,96 & 9,55 & 10,62 & 7,26 & 6,90 & 11,54 & 10,33 & 4,95 & 6,84 & & 7,93 & 18,84 & & 10,49 & 3,24 & 4,99 & 0,876 & 7,13 & 4,63 \\
\hline & Mínimo & 4,02 & 5,87 & 4,18 & 9,21 & 6,16 & 3,91 & 8,50 & 5,43 & 3,15 & 4,93 & & 7,74 & 12,12 & & 7,13 & 2,23 & 2,84 & 0,554 & 5,02 & 2,84 \\
\hline & Máximo & 15,02 & 19,32 & 14,55 & 11,42 & 15,79 & 13,23 & 16,17 & 13,17 & 9,75 & 7,80 & & 8,13 & 23,20 & & 19,17 & 4,18 & 7,15 & 1,06 & 14,86 & 12,98 \\
\hline
\end{tabular}


APÊNDICE B: Box Plots 

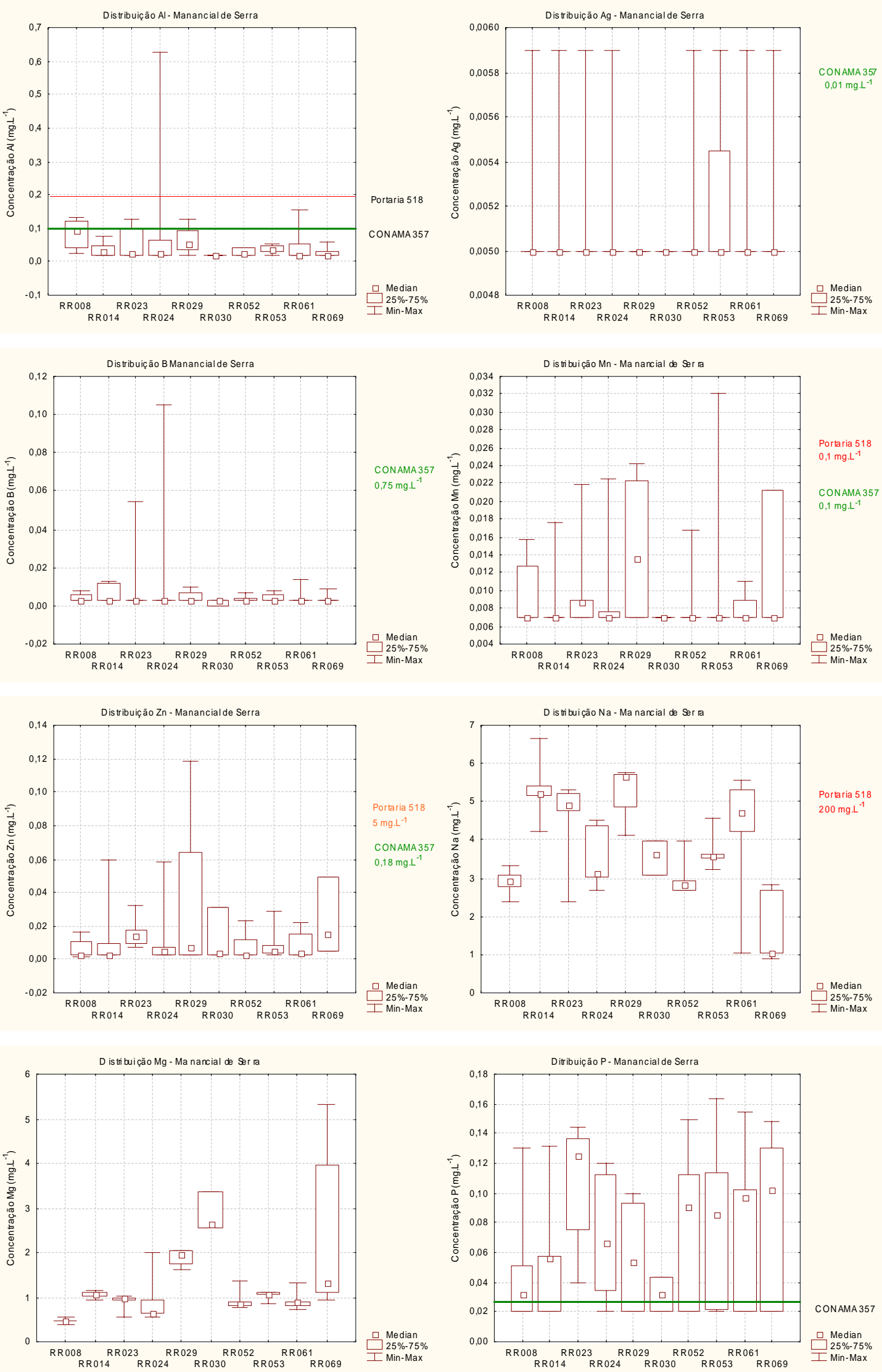

Figura B.1 - Distribuição de metais e ânions em amostras de água de manancial de serra. 

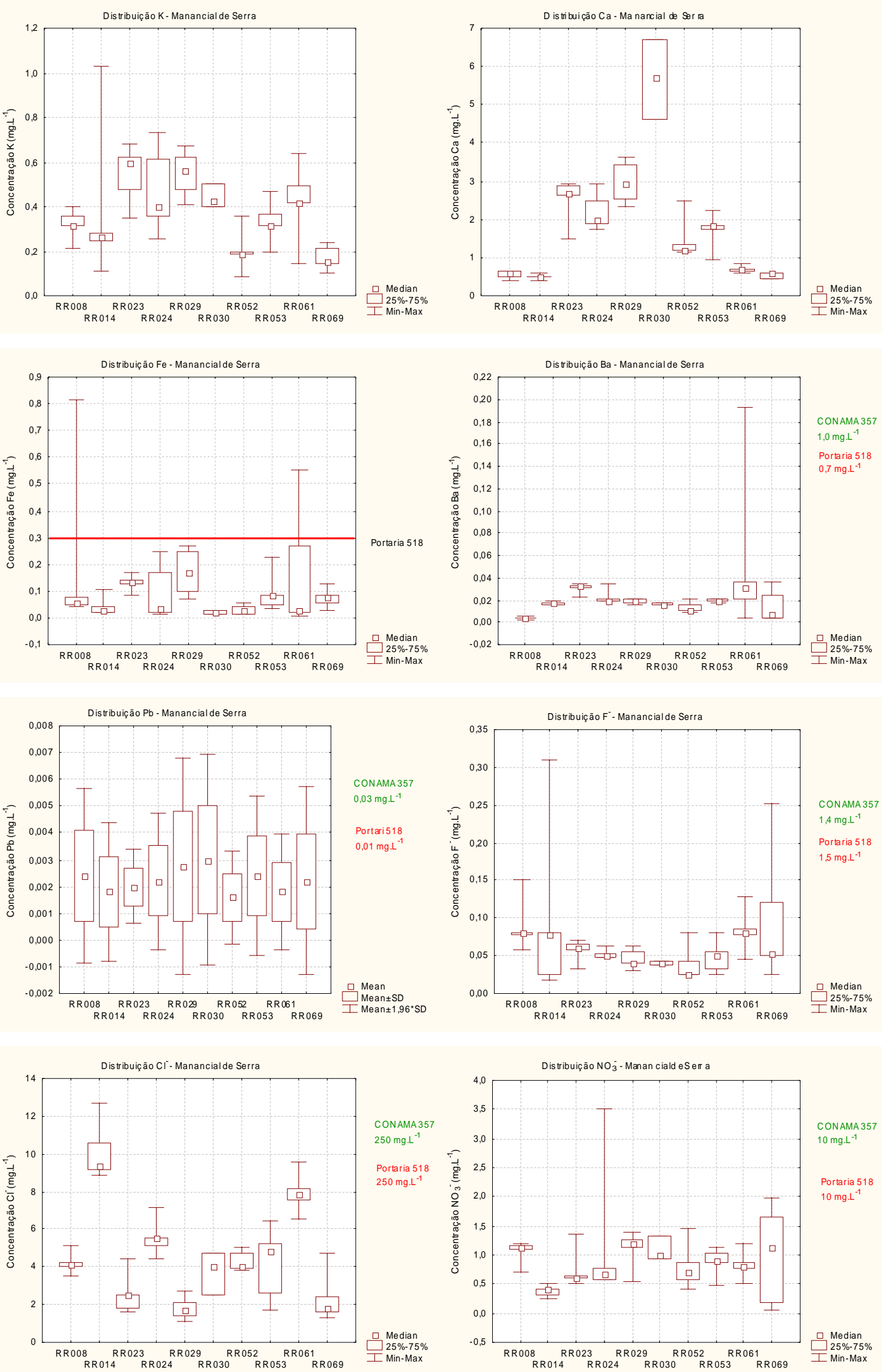

Figura B.1 - Distribuição de metais e ânions em amostras de água de manancial de serra. (cont.) 

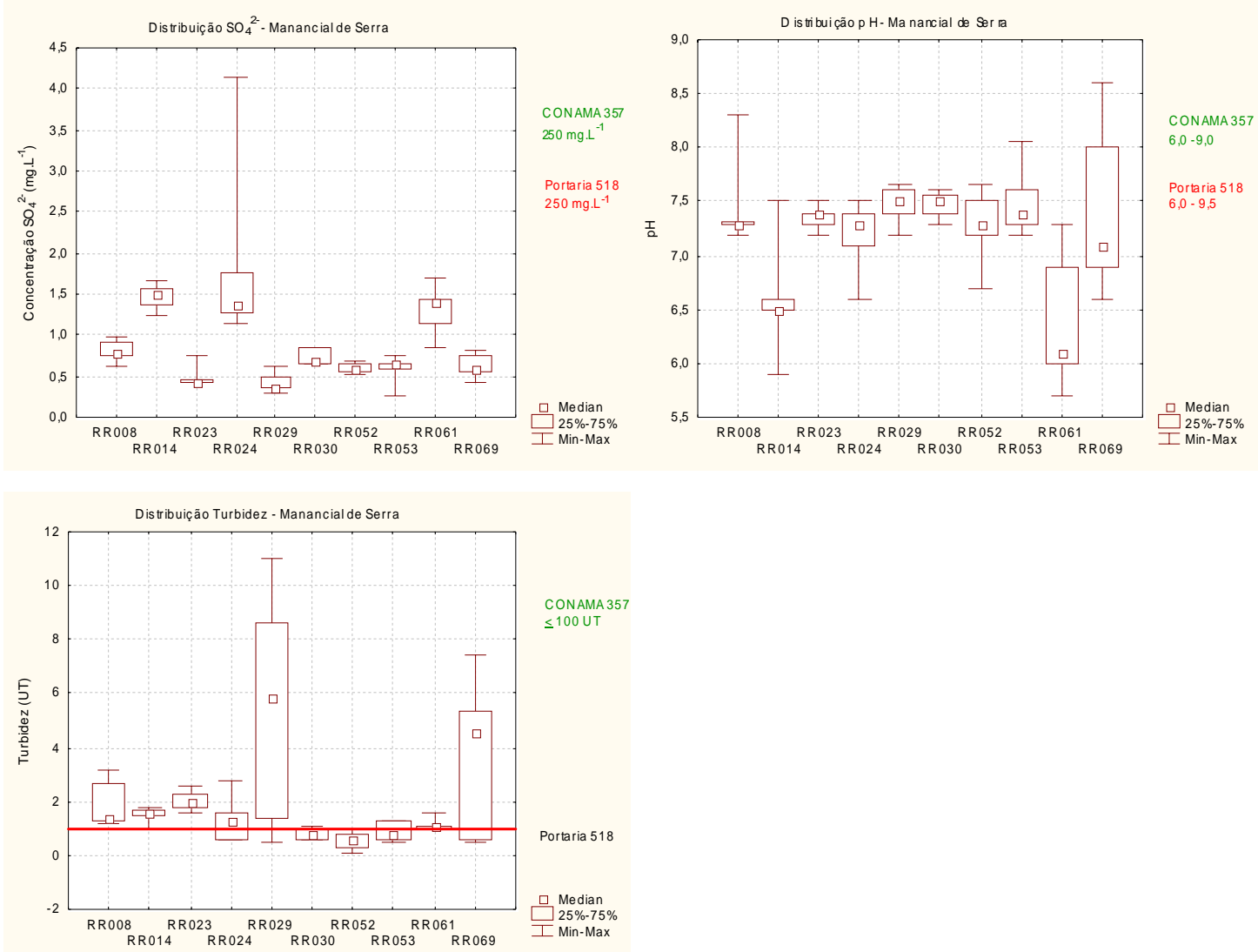

Figura B.1 - Distribuição de metais e ânions em amostras de água de manancial de serra. (cont) 

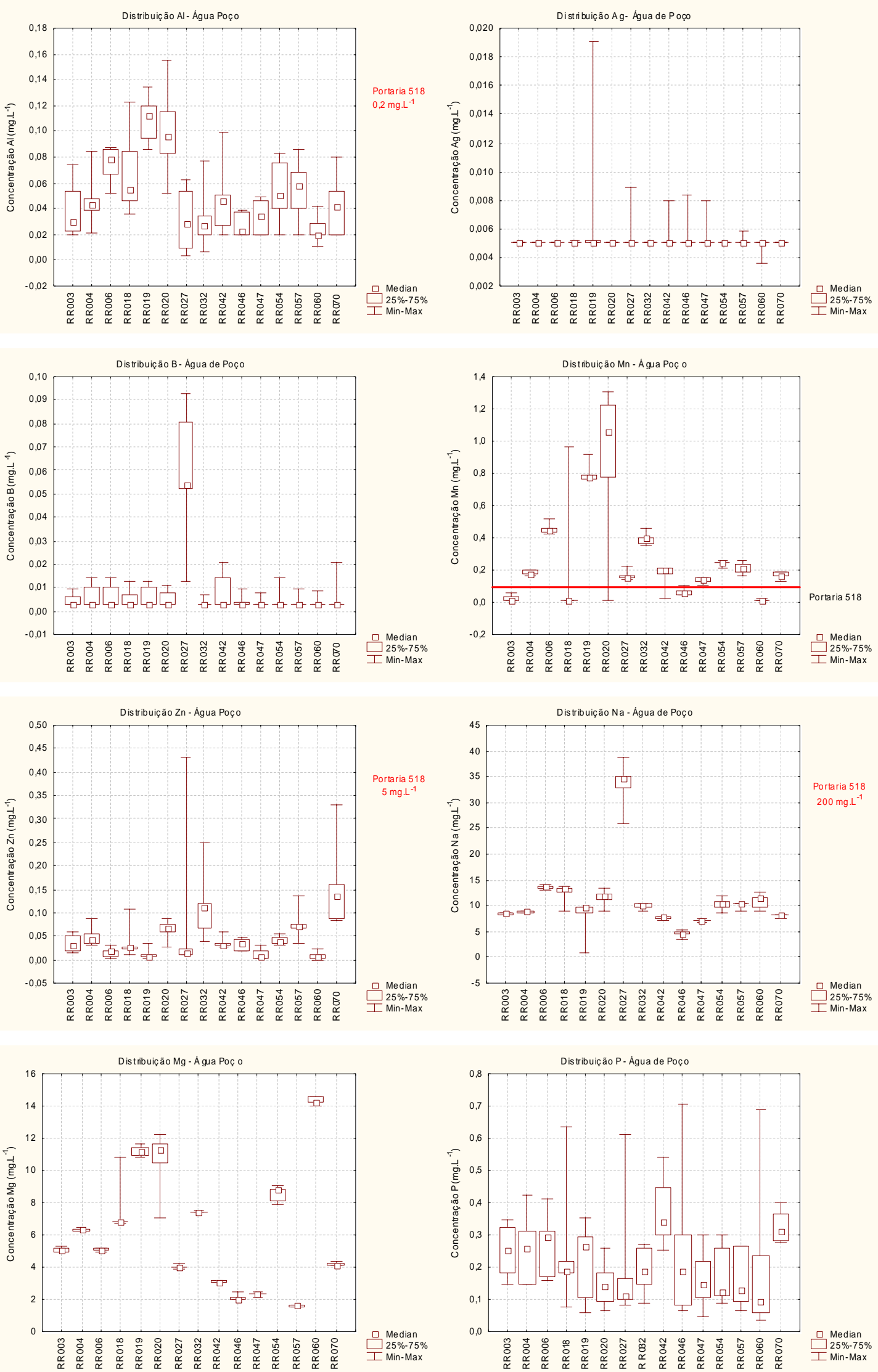

Figura B.2 - Distribuição de metais e ânions em amostras de água de manancial subterrâneo (poços). 

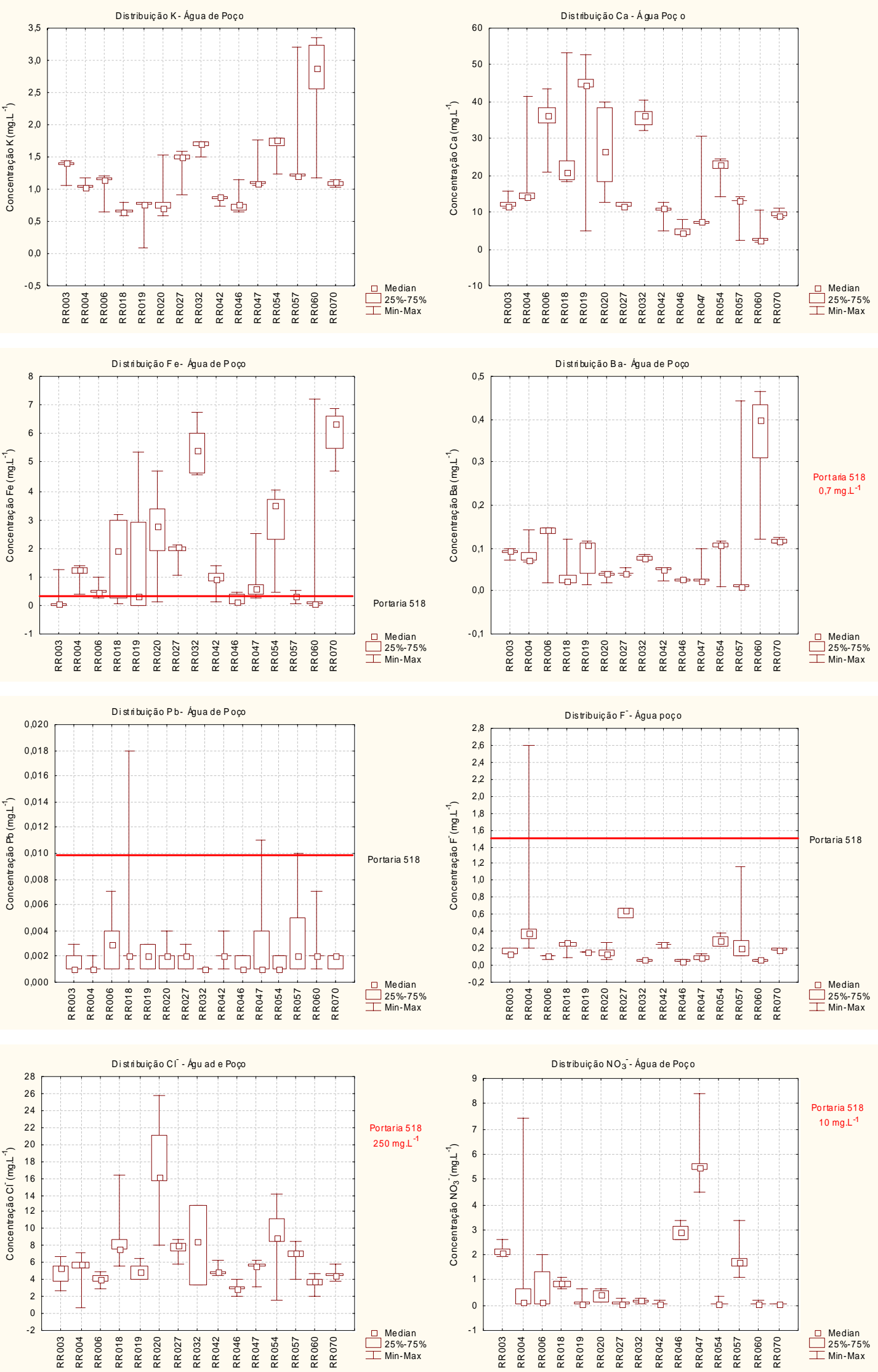

Figura B.2 - Distribuição de metais e ânions em amostras de água de manancial subterrâneo (poços). (cont.) 

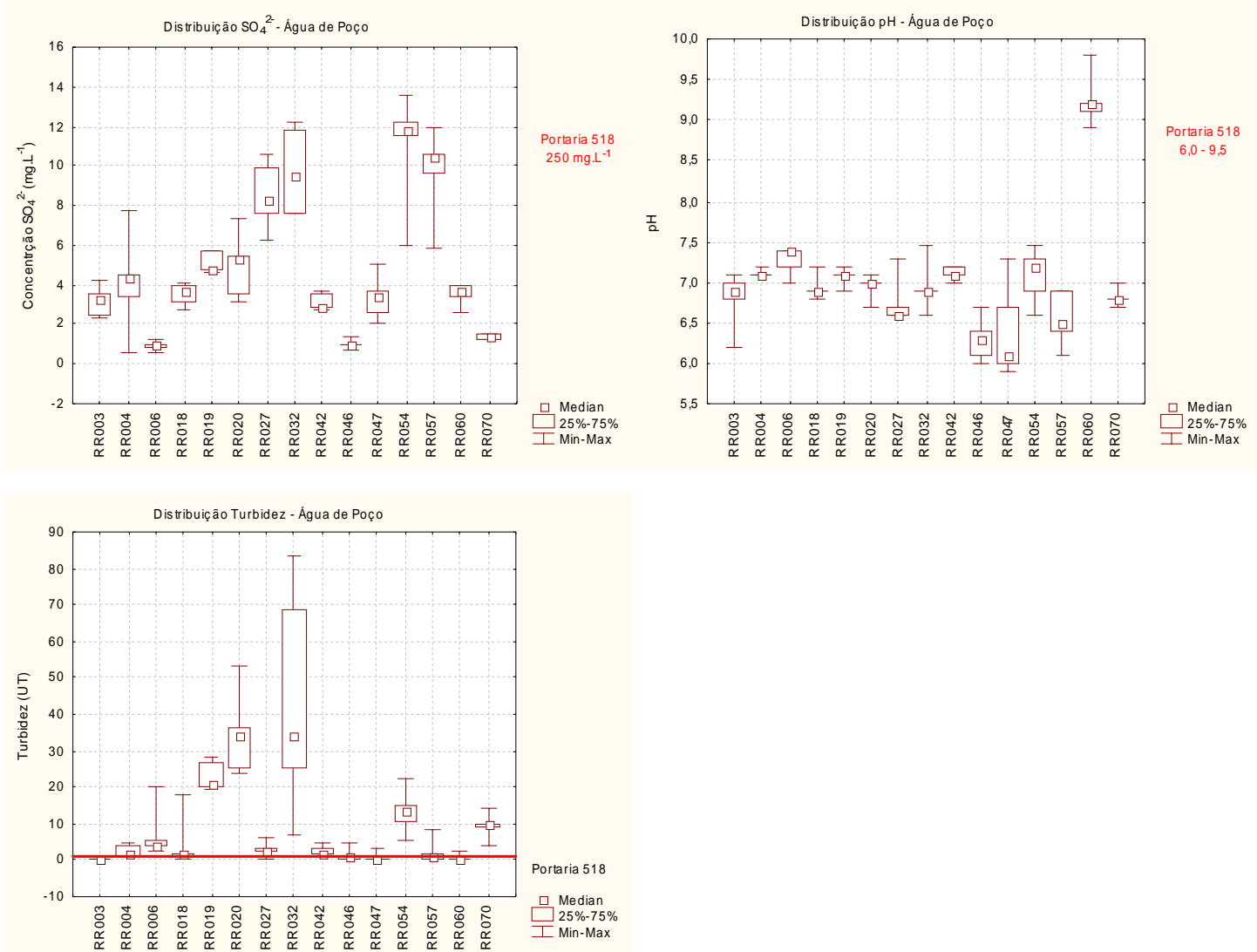

Figura B.2 - Distribuição de metais e ânions em amostras de água de manancial subterrâneo (poços). (cont.) 

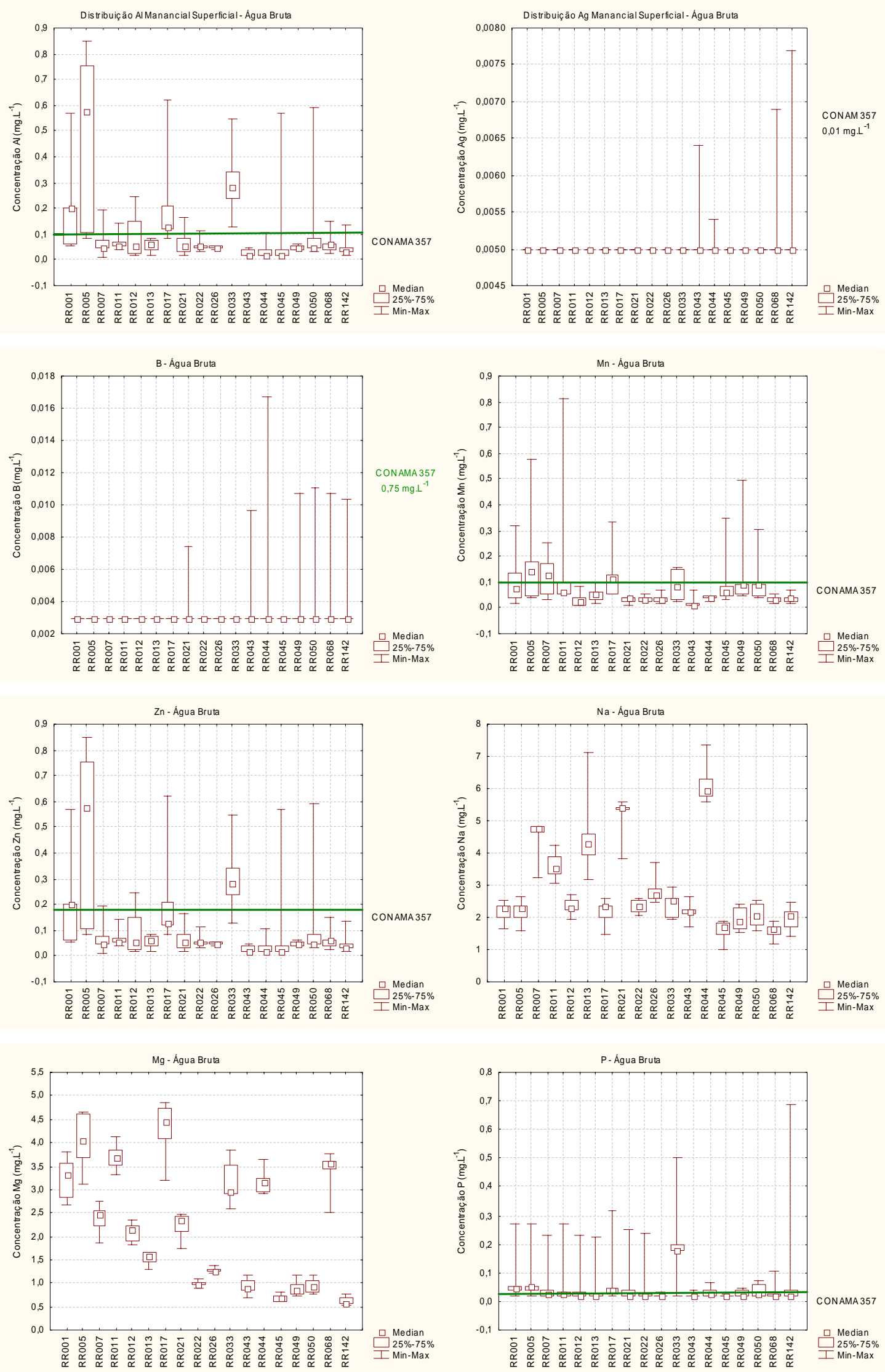

Figura B.3 - Distribuição de metais e ânions em amostras de água de manancial superficial (água bruta). 

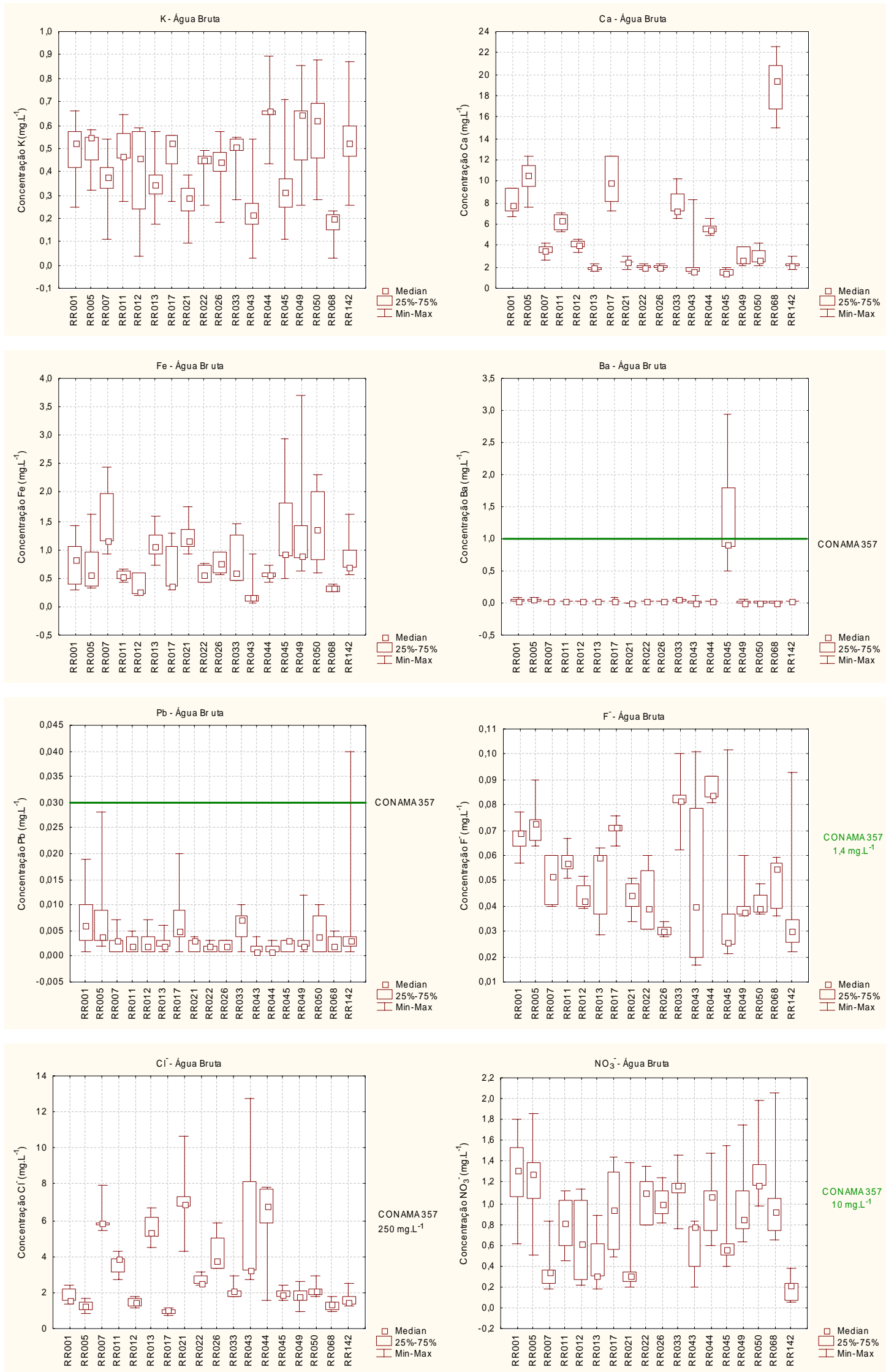

Figura B.3 - Distribuição de metais e ânions em amostras de água de manancial superficial (água bruta). (cont.) 

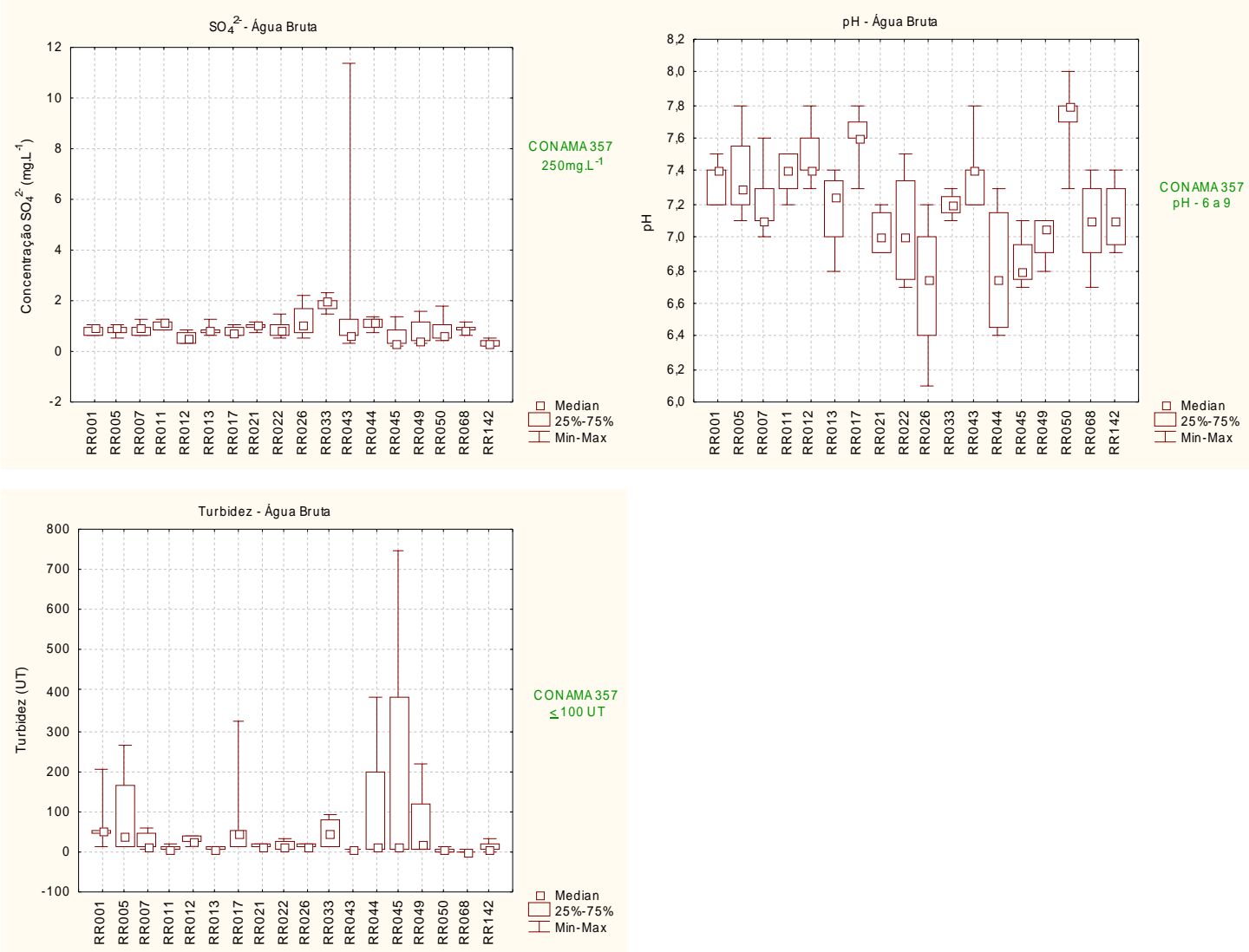

Figura B.3 - Distribuição de metais e ânions em amostras de água de manancial superficial (água bruta). 

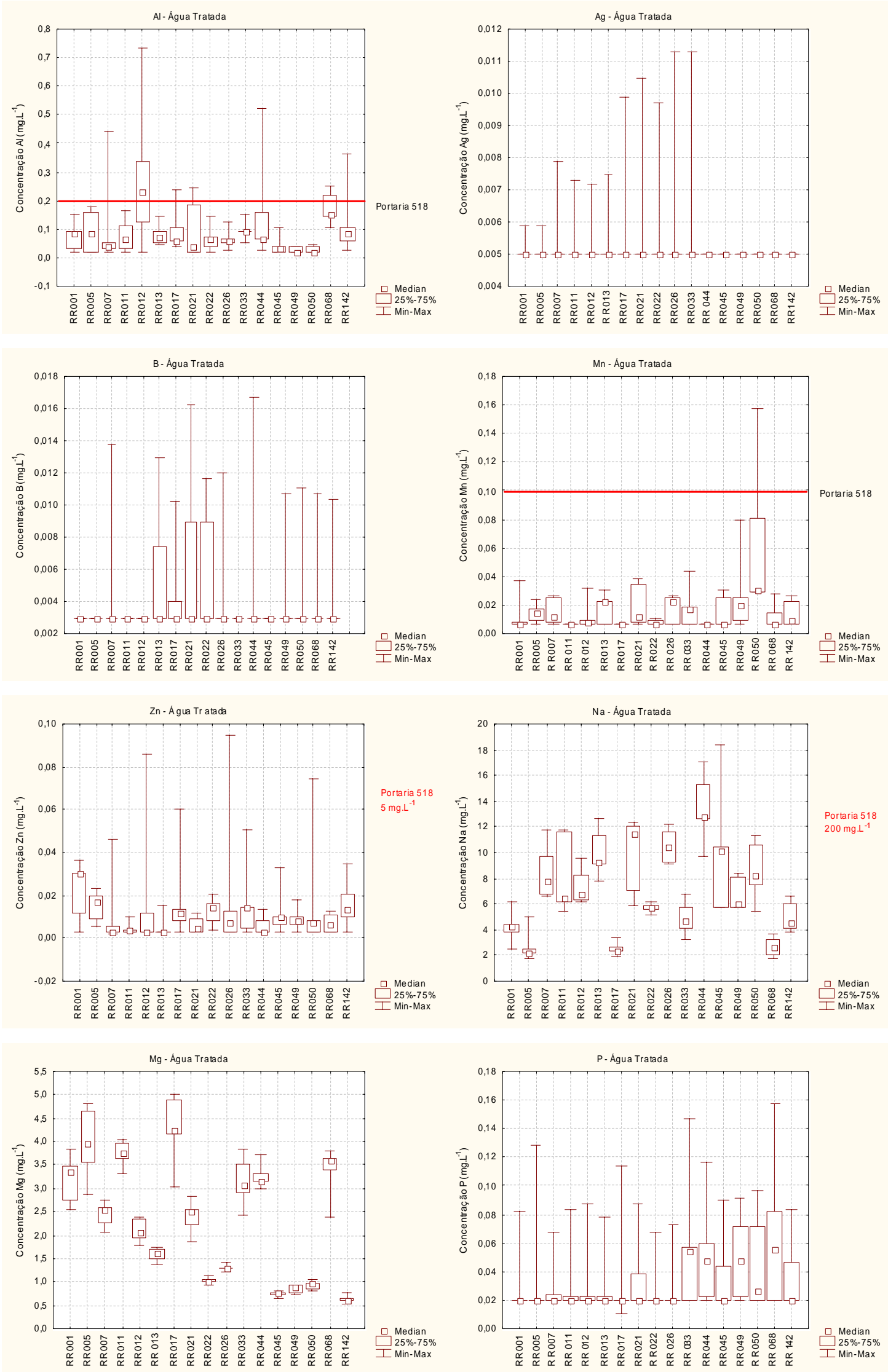

Figura B.4 - Distribuição de metais e ânions em amostras de água tratada. 

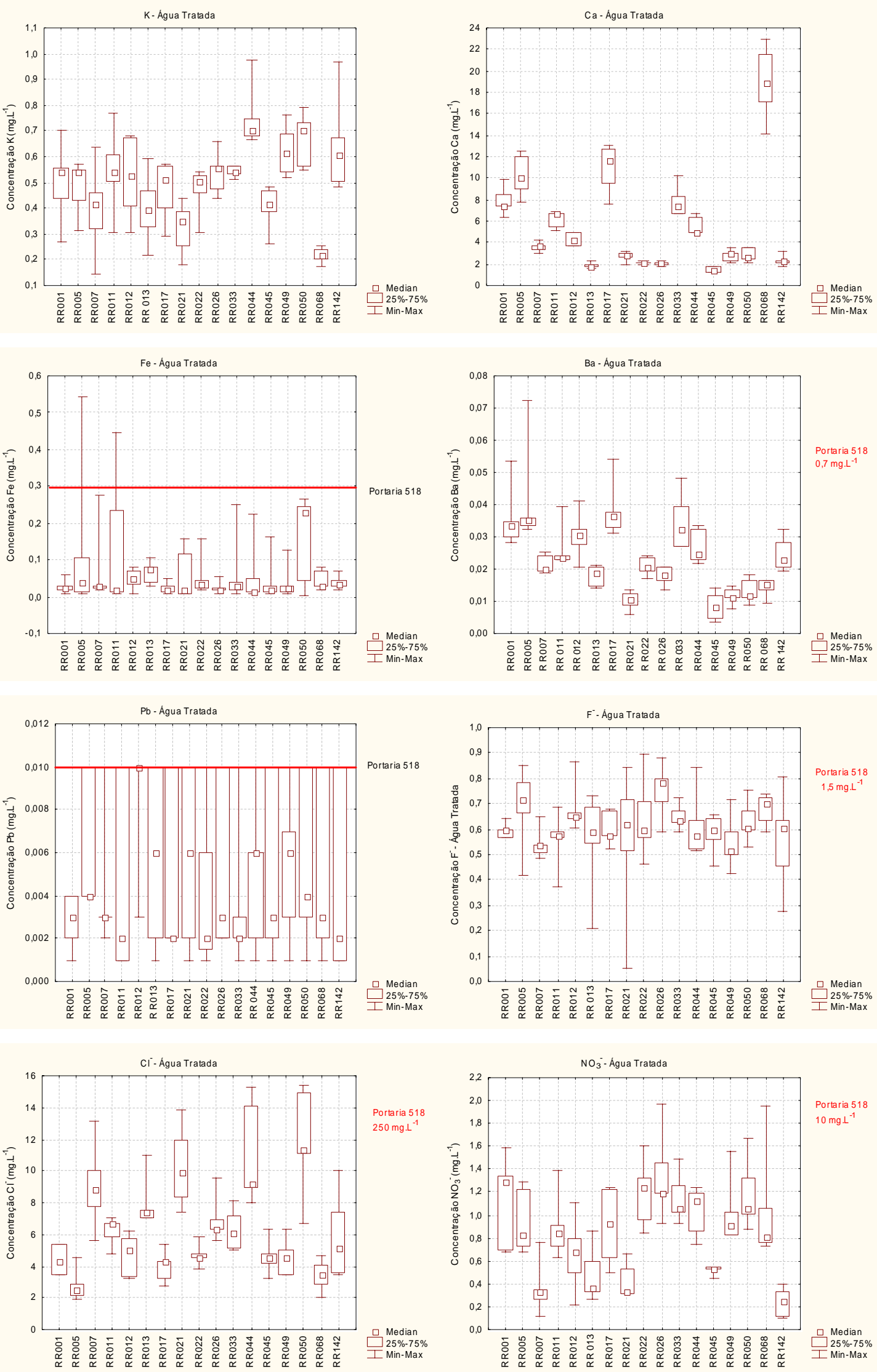

Figura B.4 - Distribuição de metais e ânions em amostras de água tratada. (cont.) 

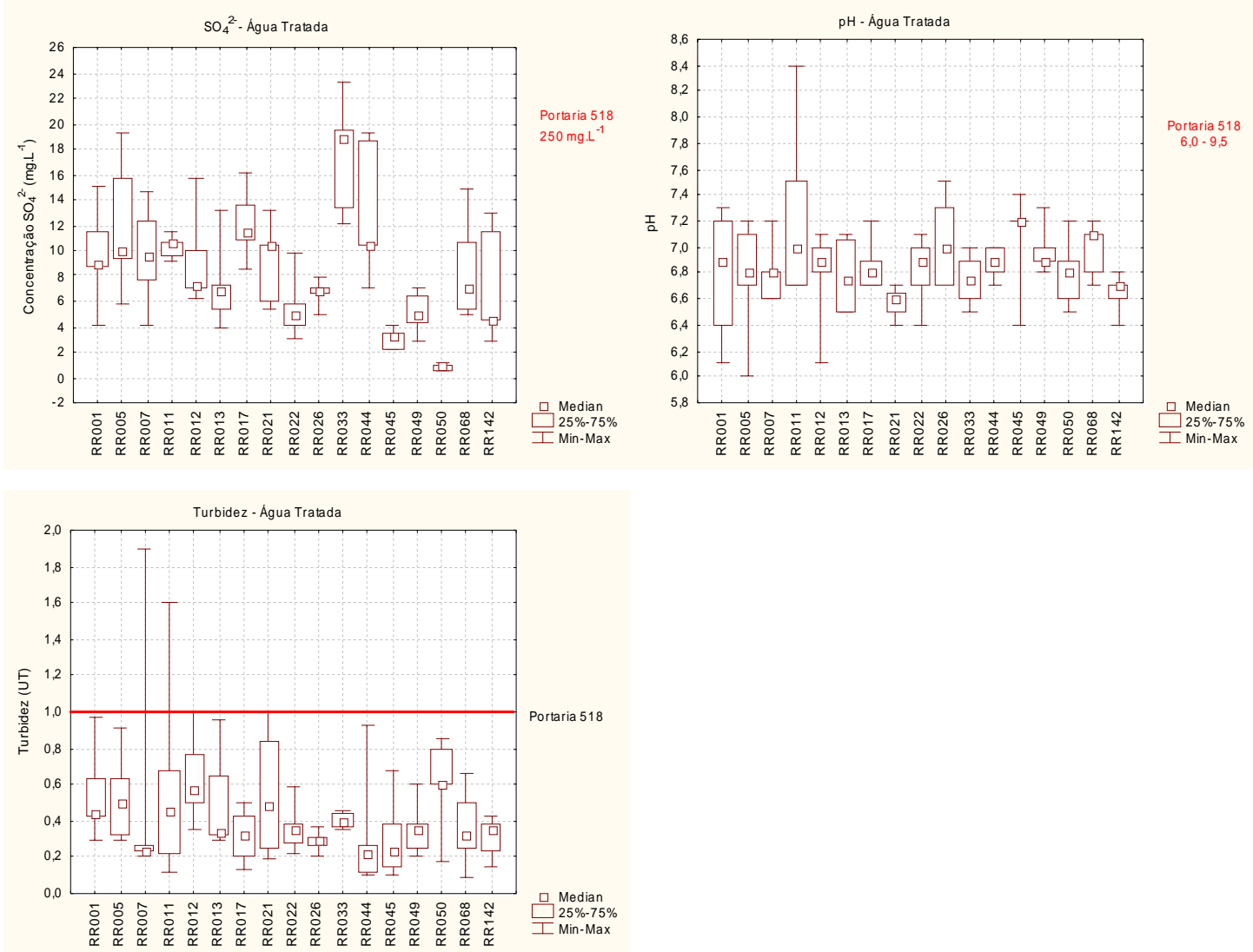

Figura B.4 - Distribuição de metais e ânions em amostras de água tratada. (cont.) 
APÊNDICE C: Freqüência de Distribuição 

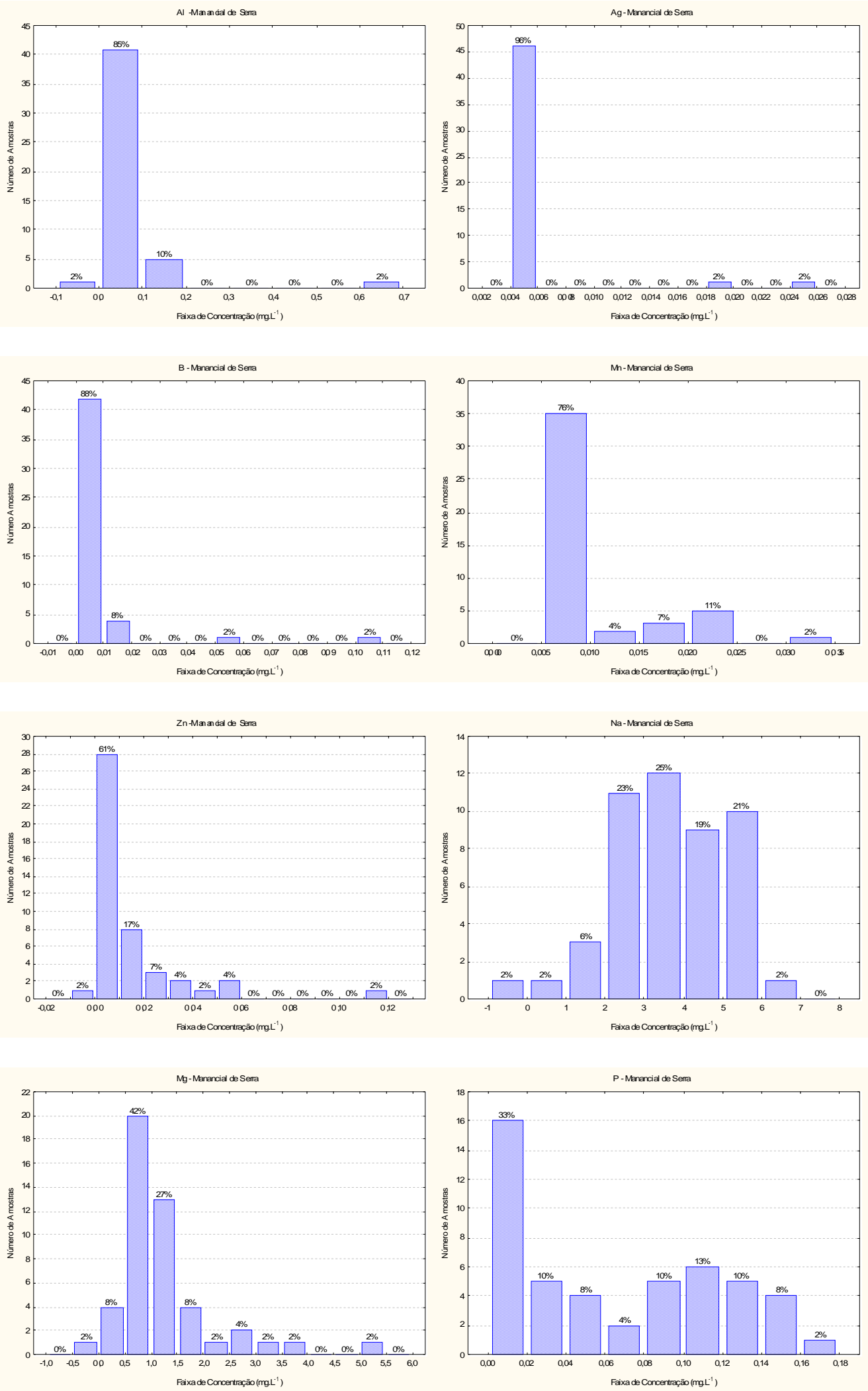

Figura C.1 - Frequência de distribuição de metais e ânions em amostras de água de manancial de serra. 

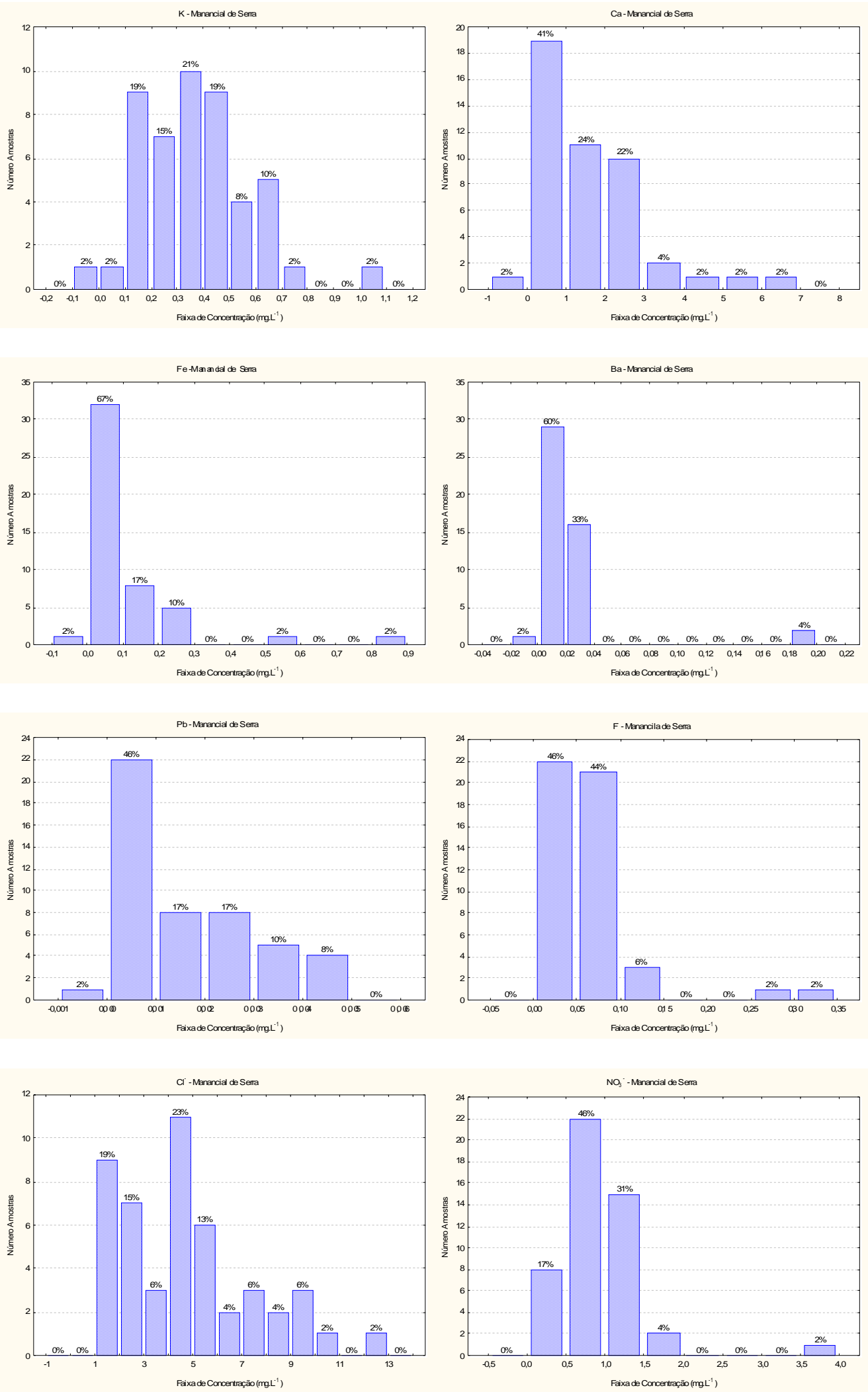

Figura C.1 - Frequência de distribuição de metais e ânions em amostras de água de manancial de serra (cont.). 

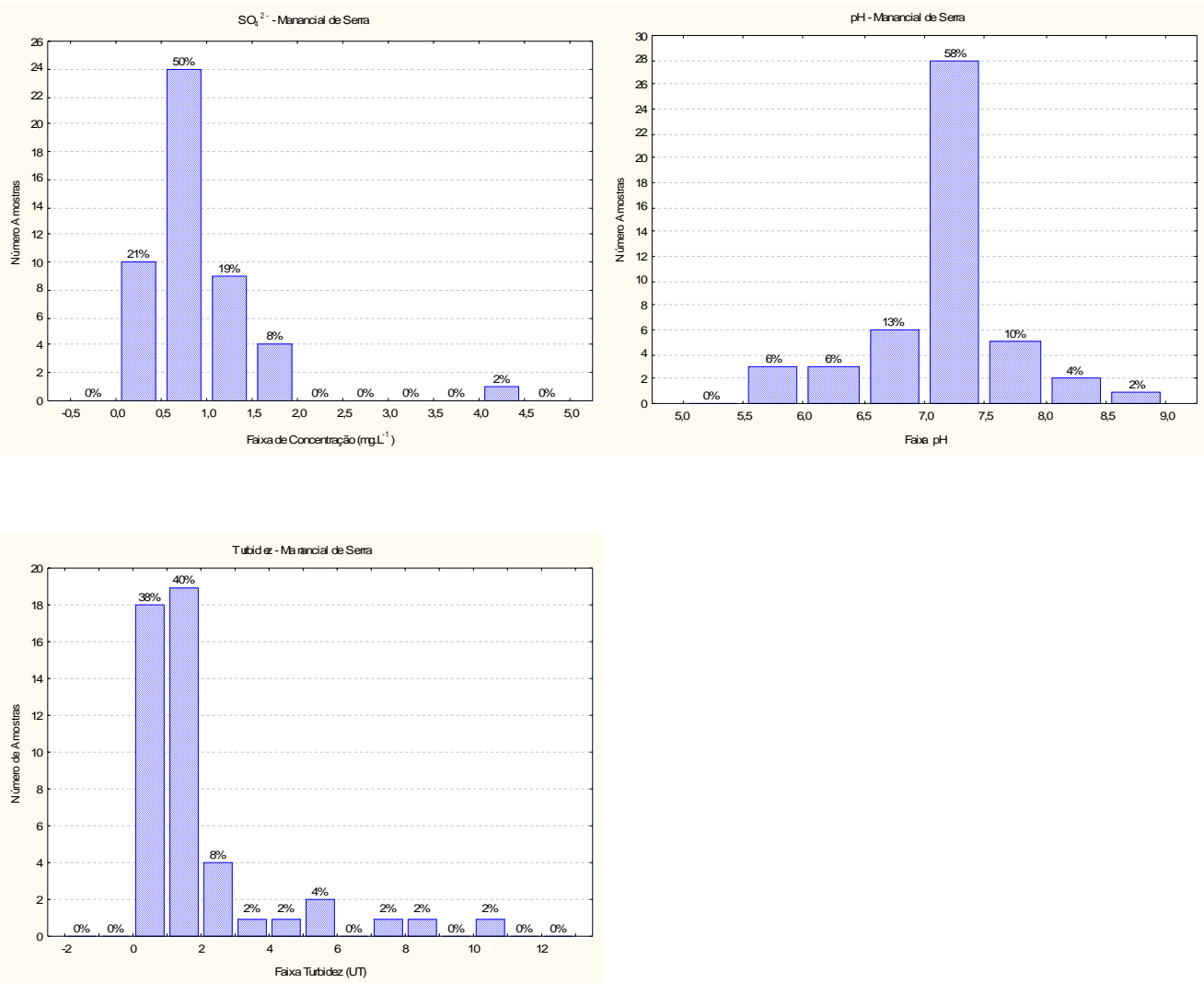

Figura C.1 - Freqüência de distribuição de metais e ânions em amostras de água de manancial de serra (cont.). 

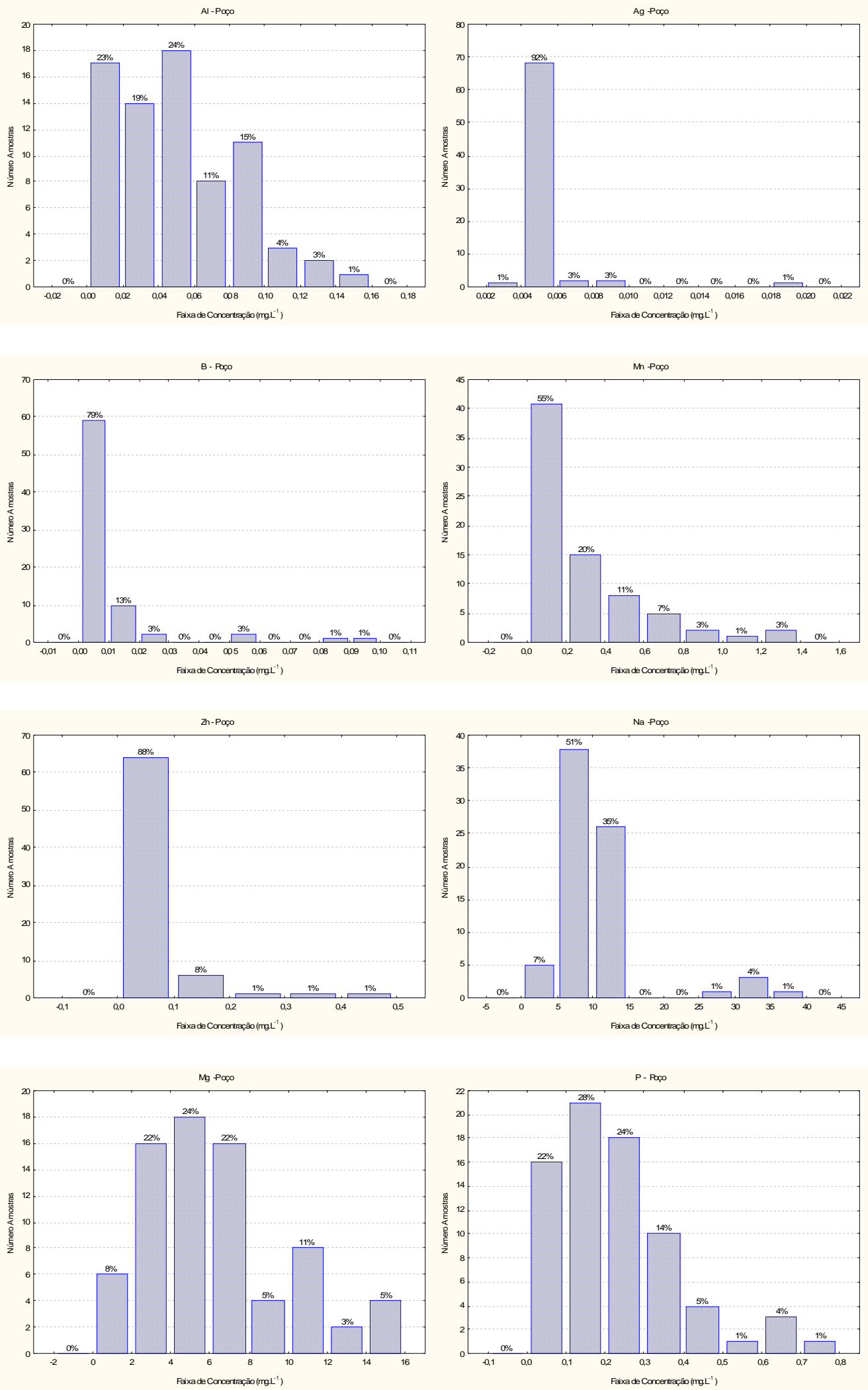

Figura C.2- Freqüência de distribuição de metais e ânions em amostras de água de manancial subterrâneo (poços). 

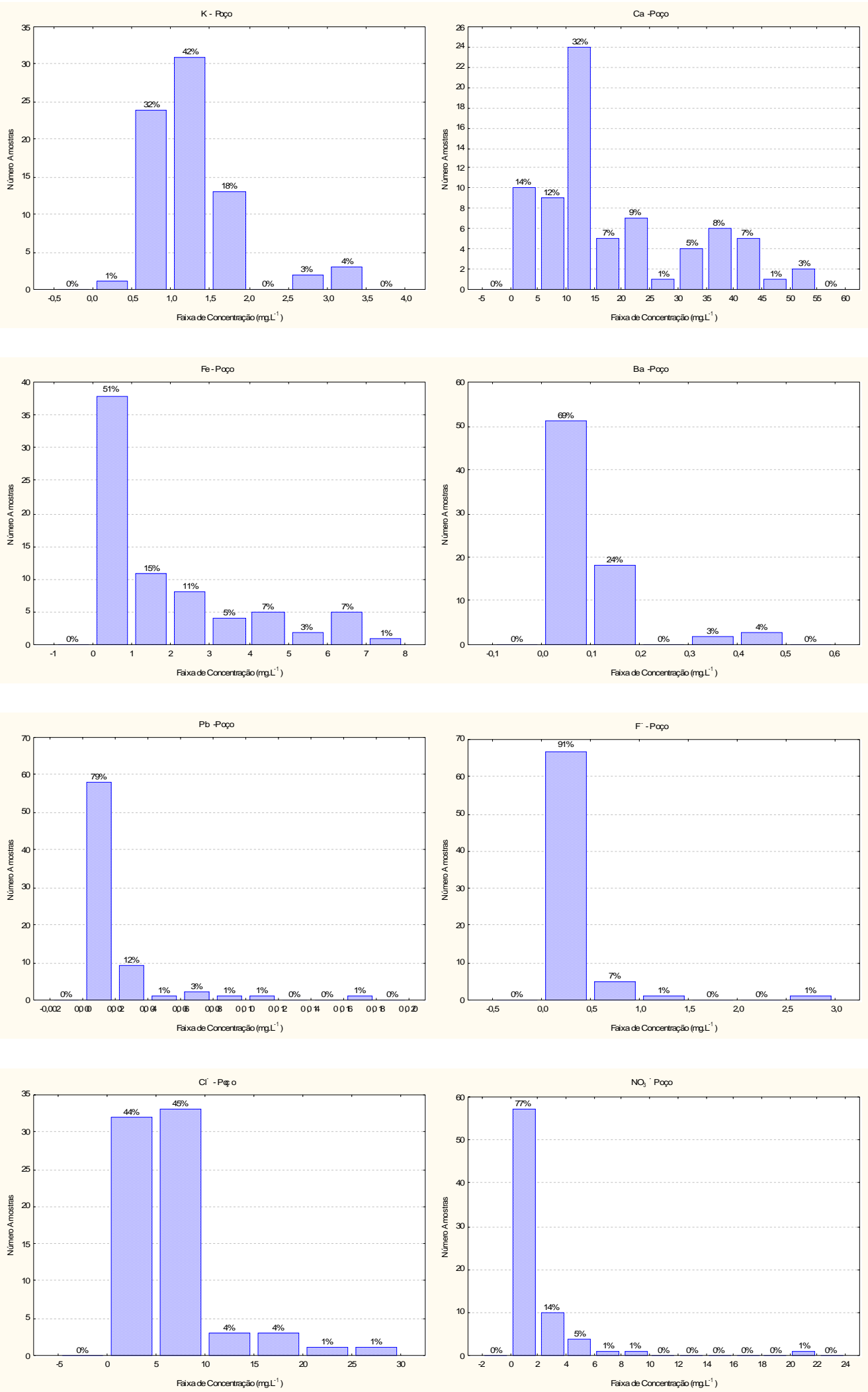

Figura C.2- Freqüência de distribuição de metais e ânions em amostras de água de manancial subterrâneo (poços). (cont.) 

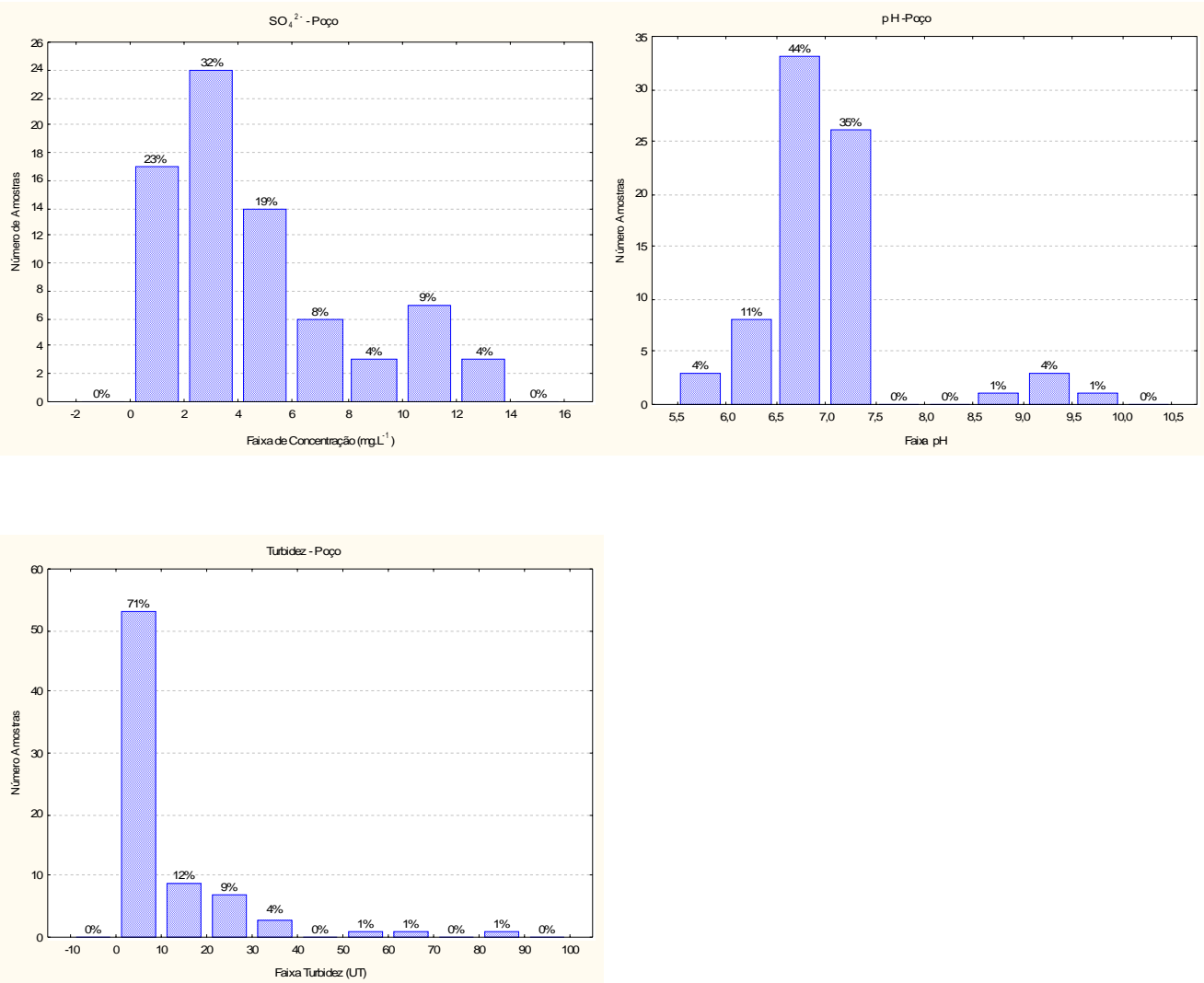

Figura C.2- Freqüência de distribuição de metais e ânions em amostras de água de manancial subterrâneo (poços). (cont.) 

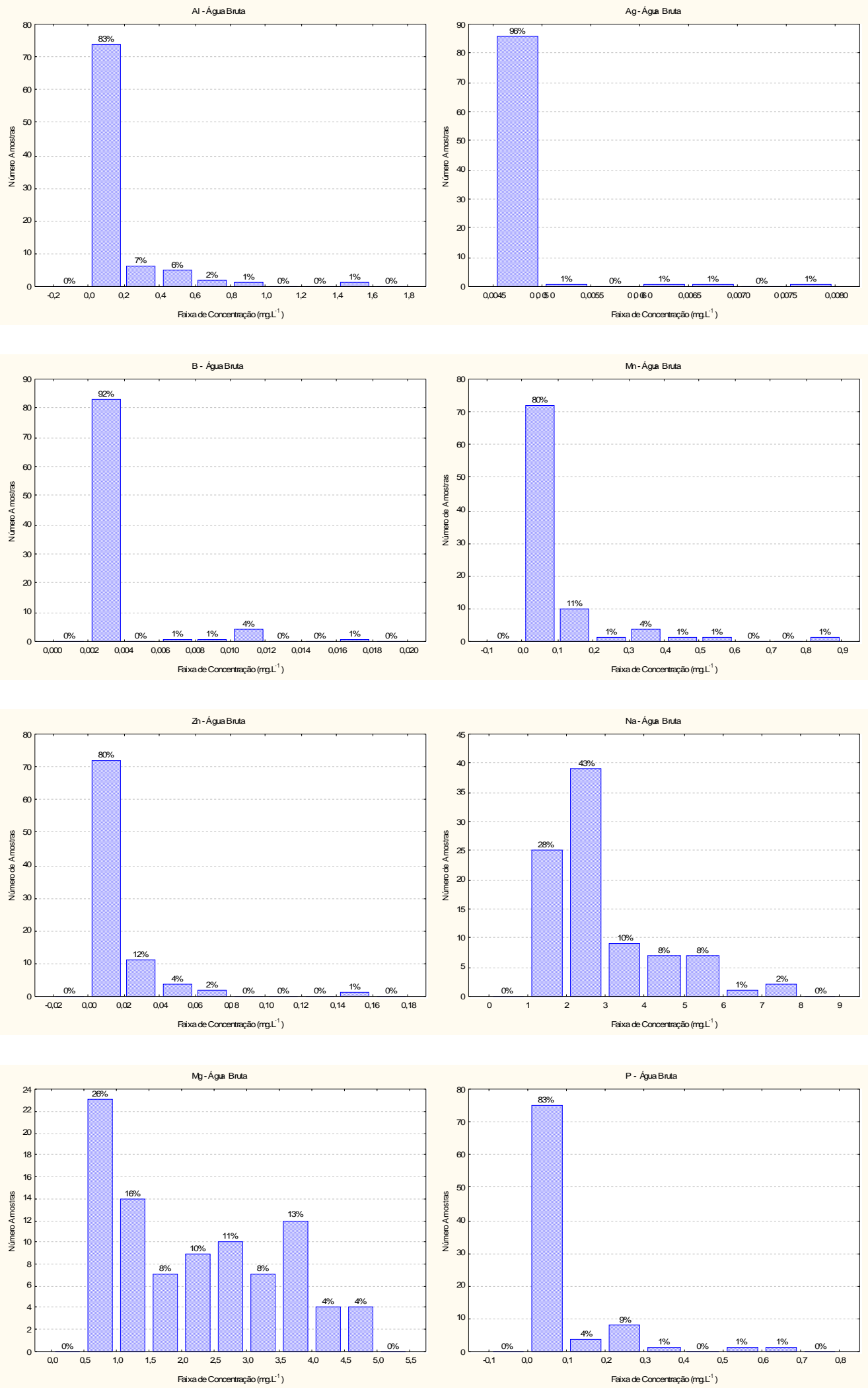

Figura C.3 - Freqüência de distribuição de metais e ânions em amostras de água de manancial superficial (água bruta). 

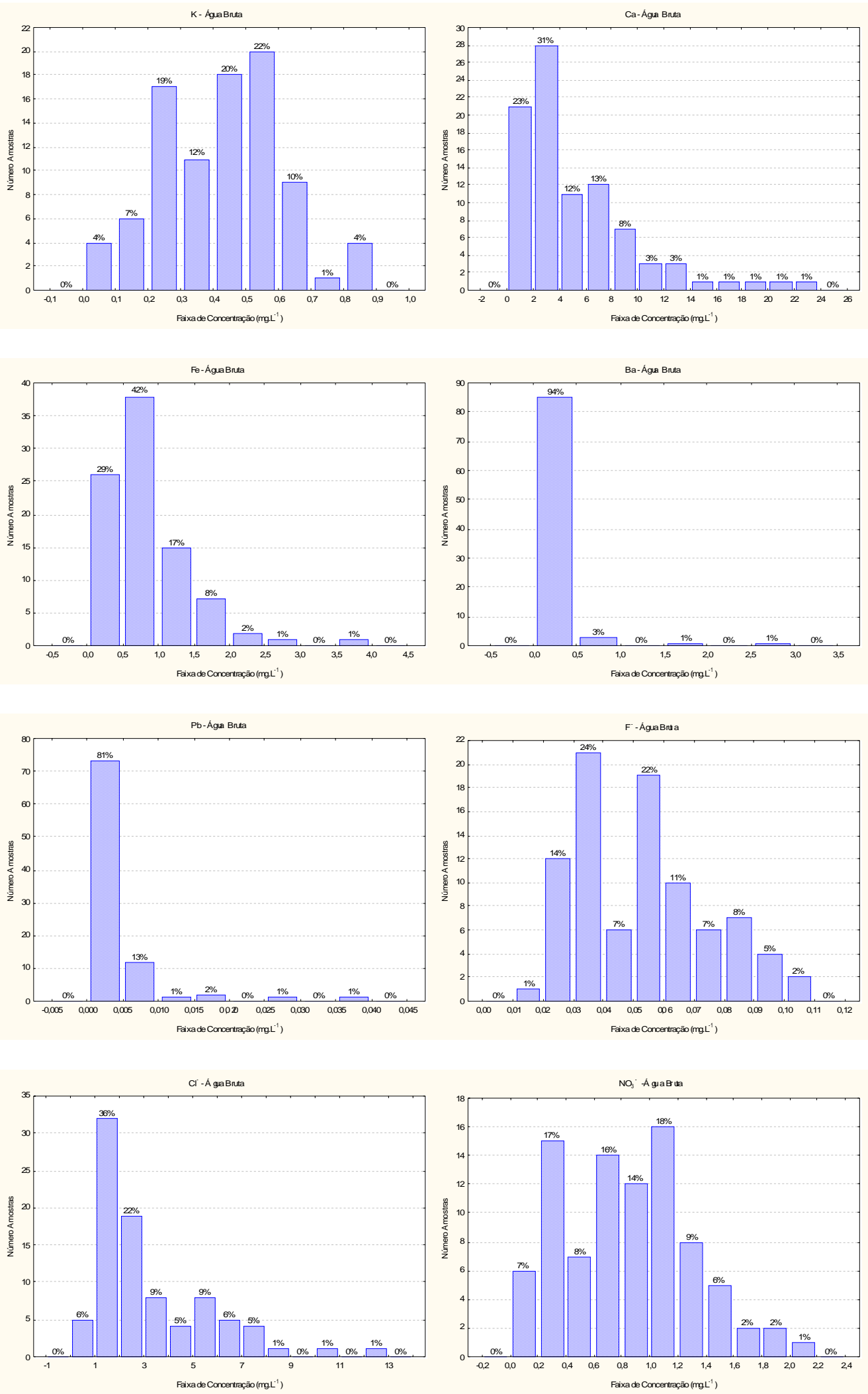

Figura C.3 - Freqüência de distribuição de metais e ânions em amostras de água de manancial superficial (água bruta). (cont.) 

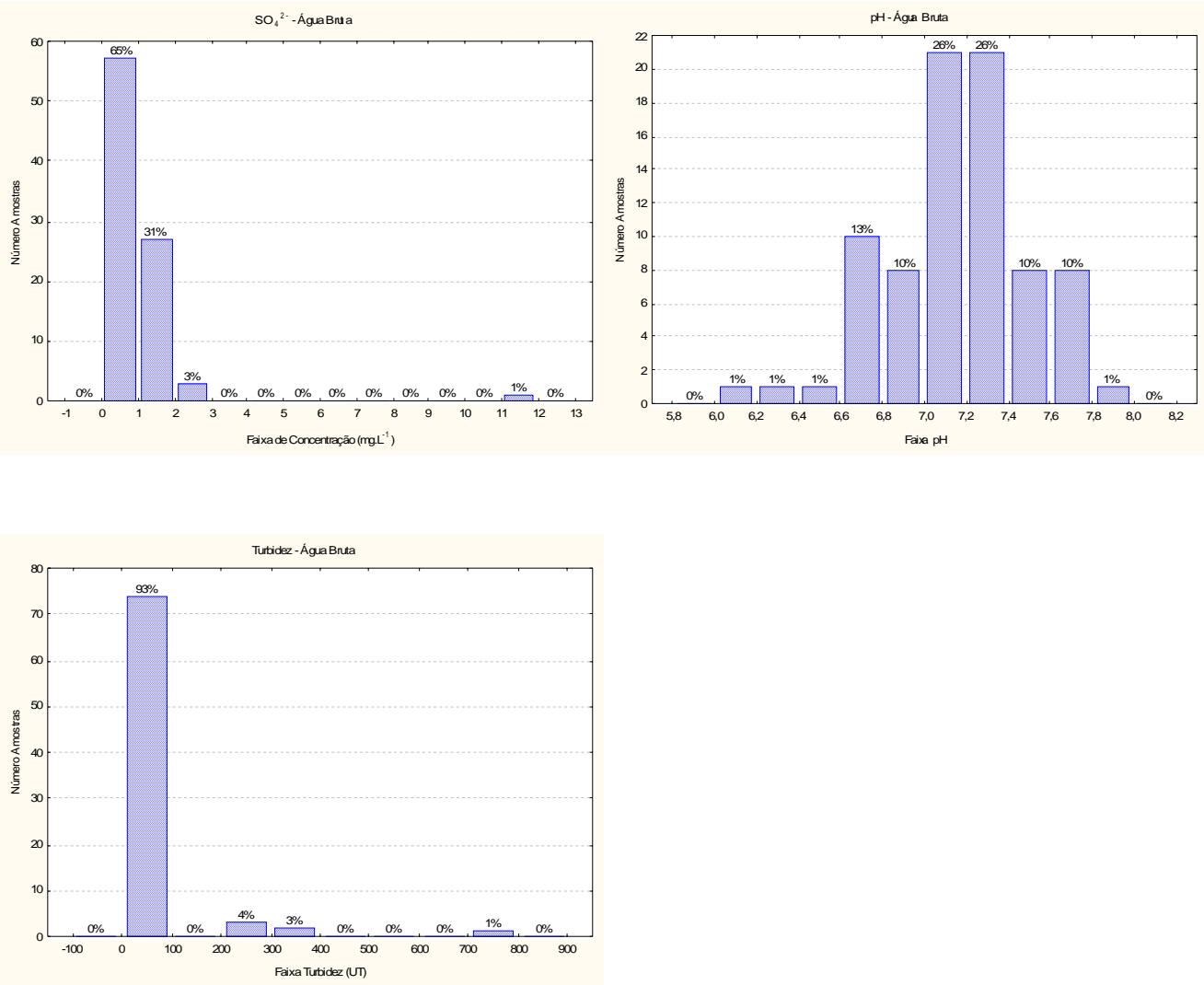

Figura C.3 - Freqüência de distribuição de metais e ânions em amostras de água de manancial superficial (água bruta). (cont.) 

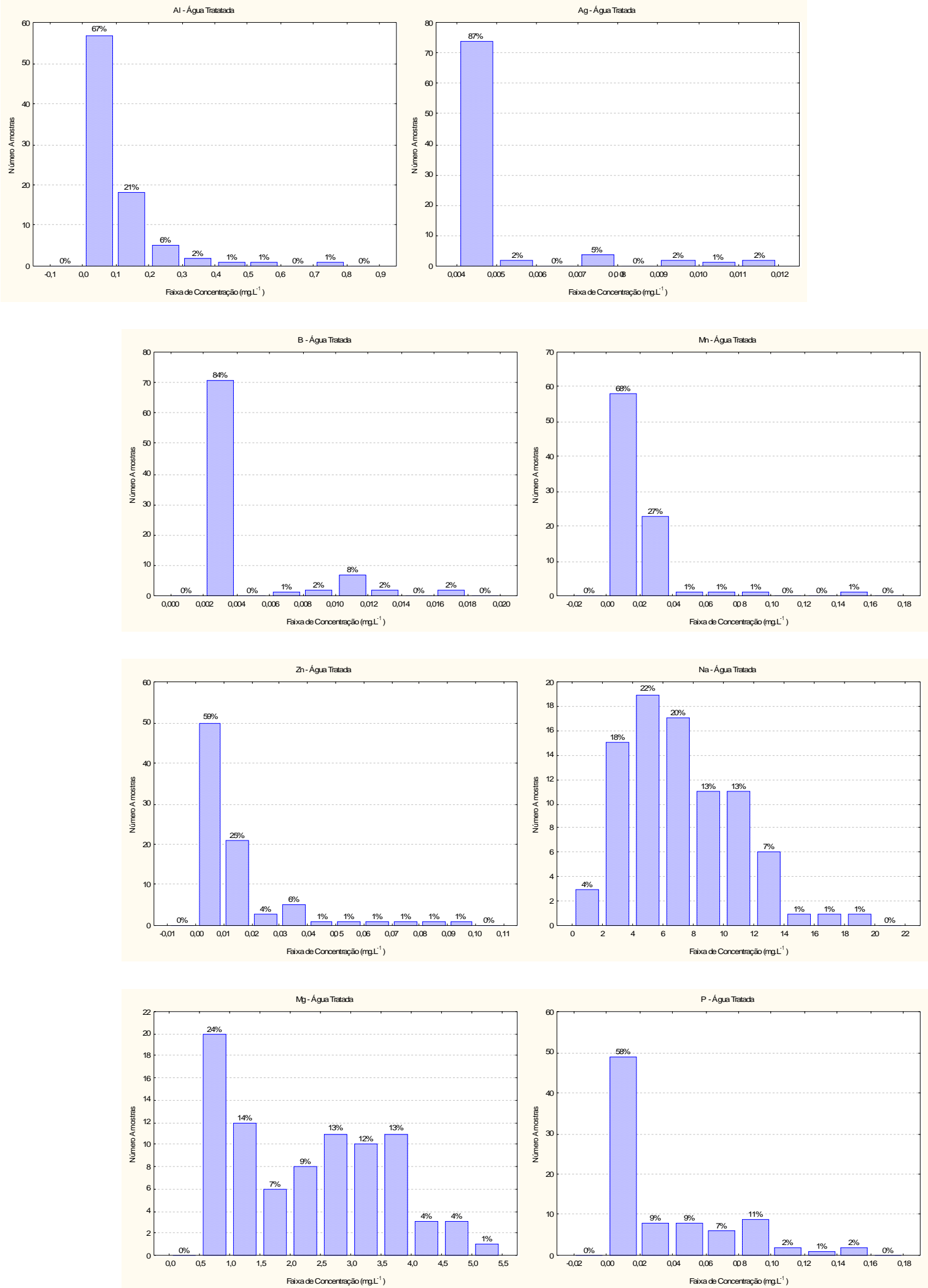

Figura C.4 - Freqüência de distribuição de metais e ânions em amostras de água tratada. 

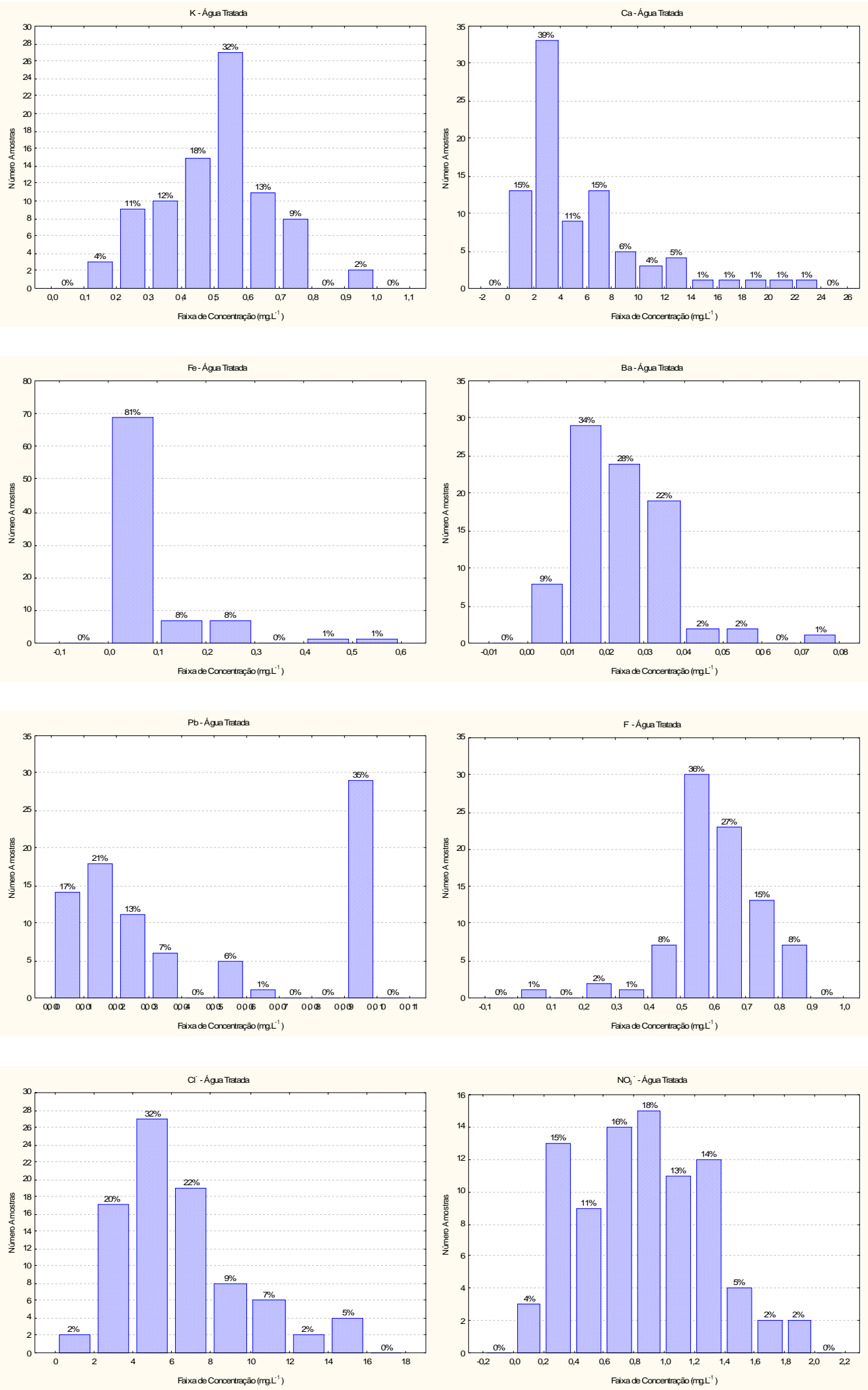

Figura C.4 - Freqüência de distribuição de metais e ânions em amostras de água tratada. (cont.) 

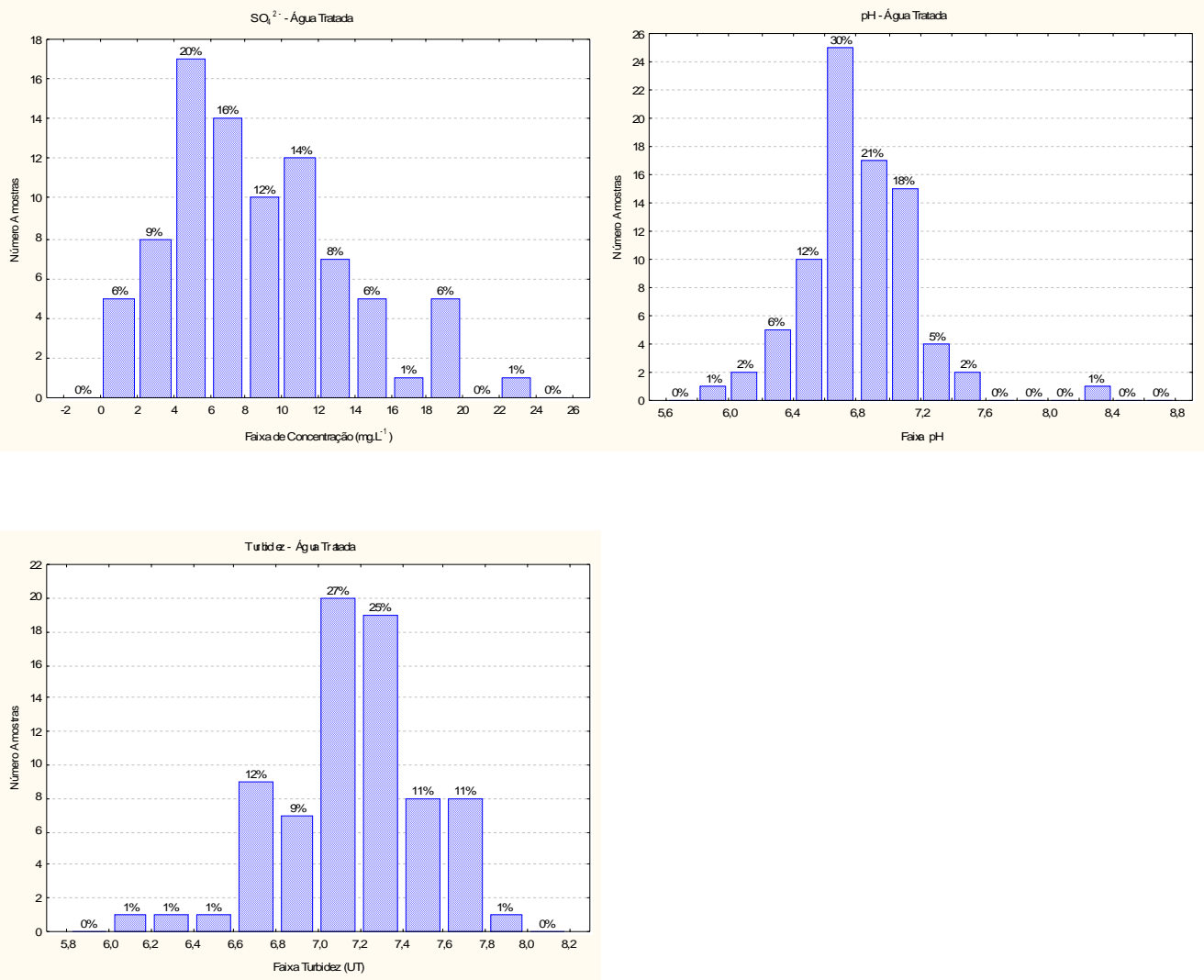

Figura C.4 - Freqüência de distribuição de metais e ânions em amostras de água tratada. (cont.) 
APÊNDICE D: Alisamentos 

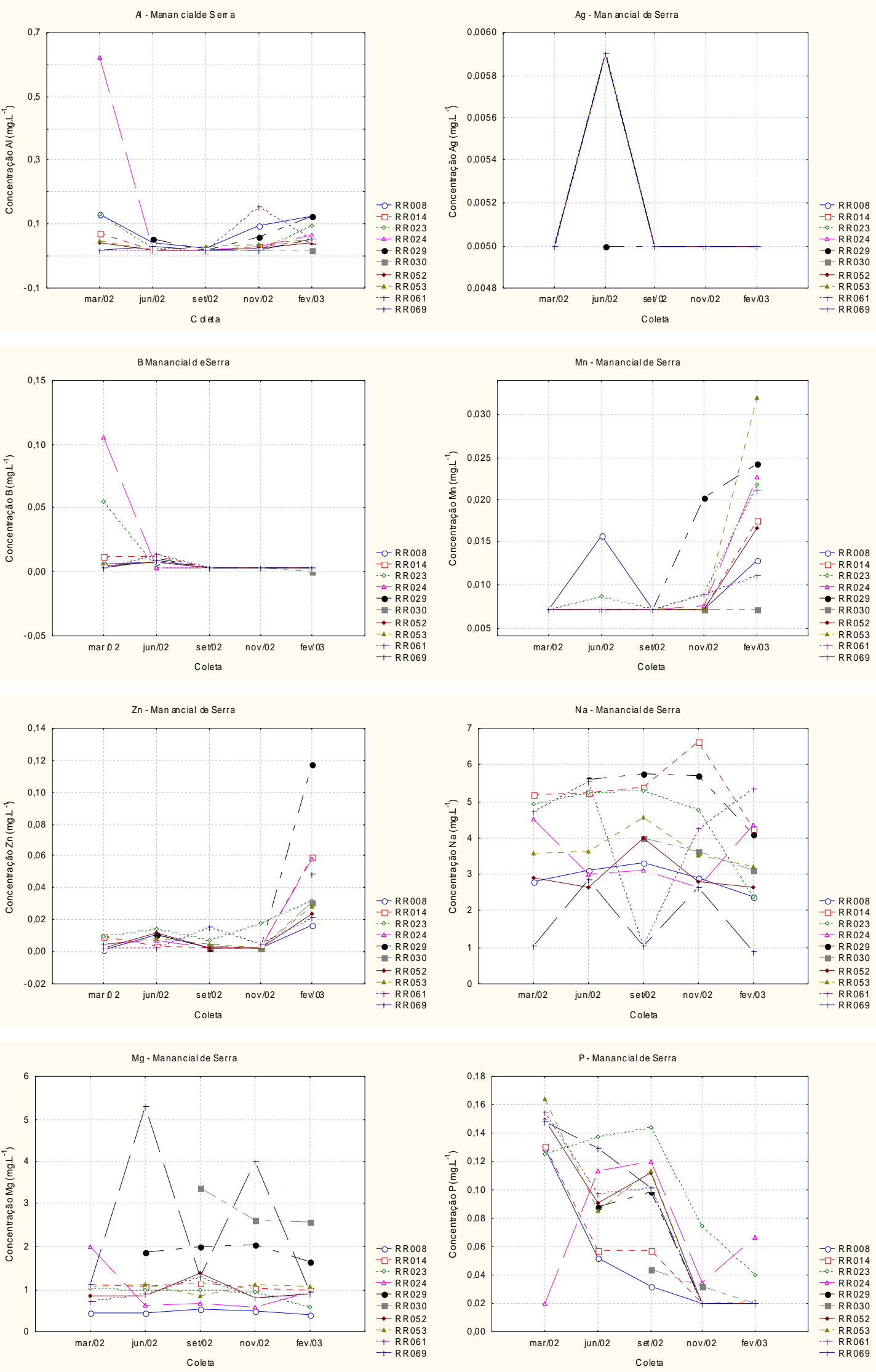

Figura D.1 - Alisamentos das concentrações de metais e ânions em amostras de água de manancial de serra em função do tempo de coleta. 

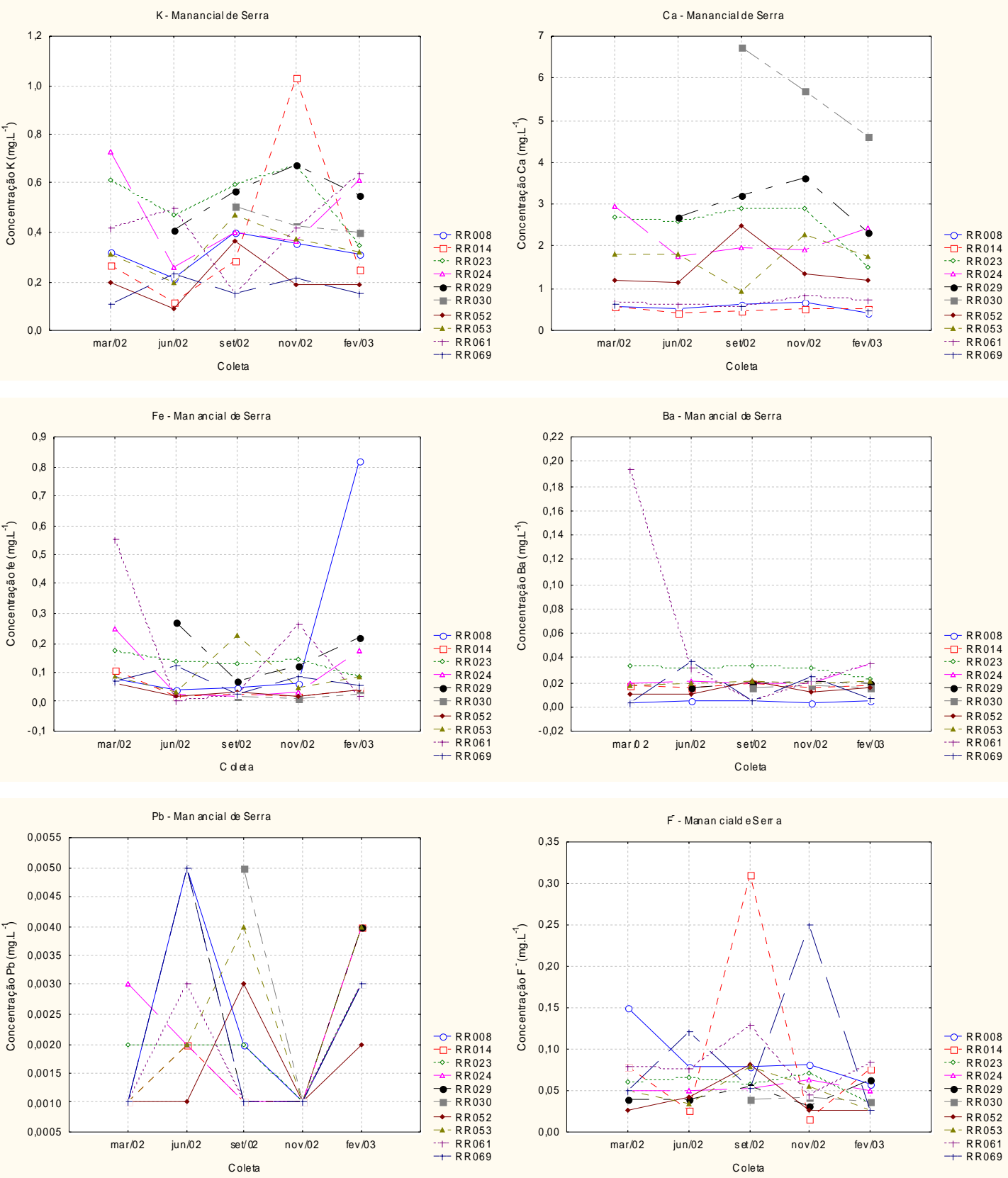

$\mathrm{Cl}^{-}$- Manan cial deSerr a
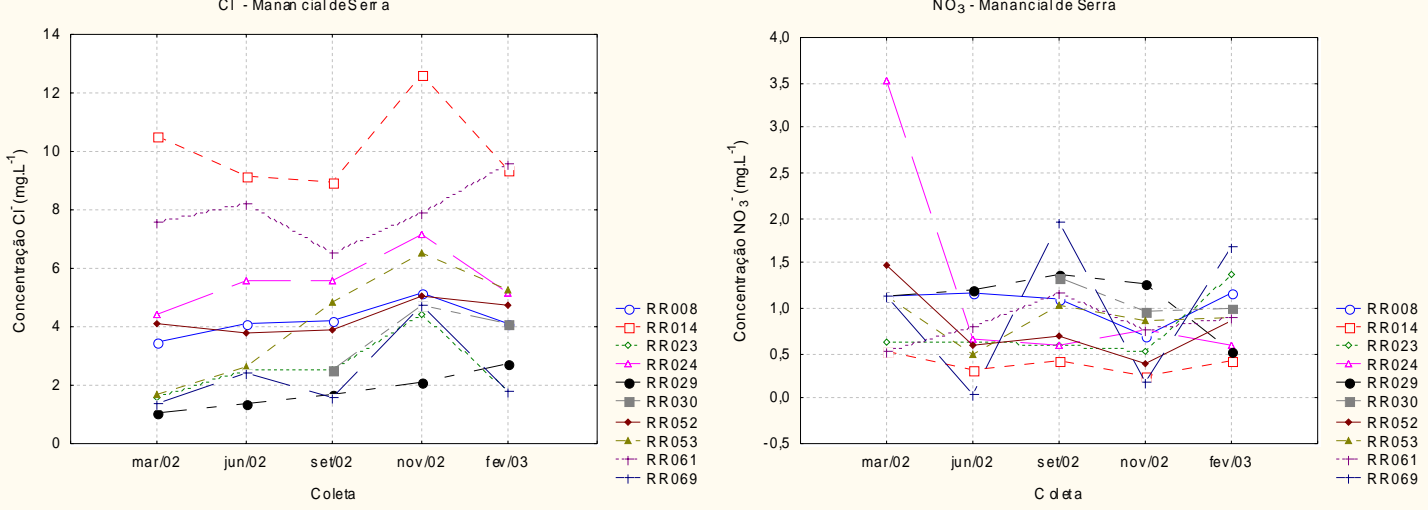

Figura D.1 - Alisamentos das concentrações de metais e ânions em amostras de água de manancial de serra em função do tempo de coleta. (cont) 

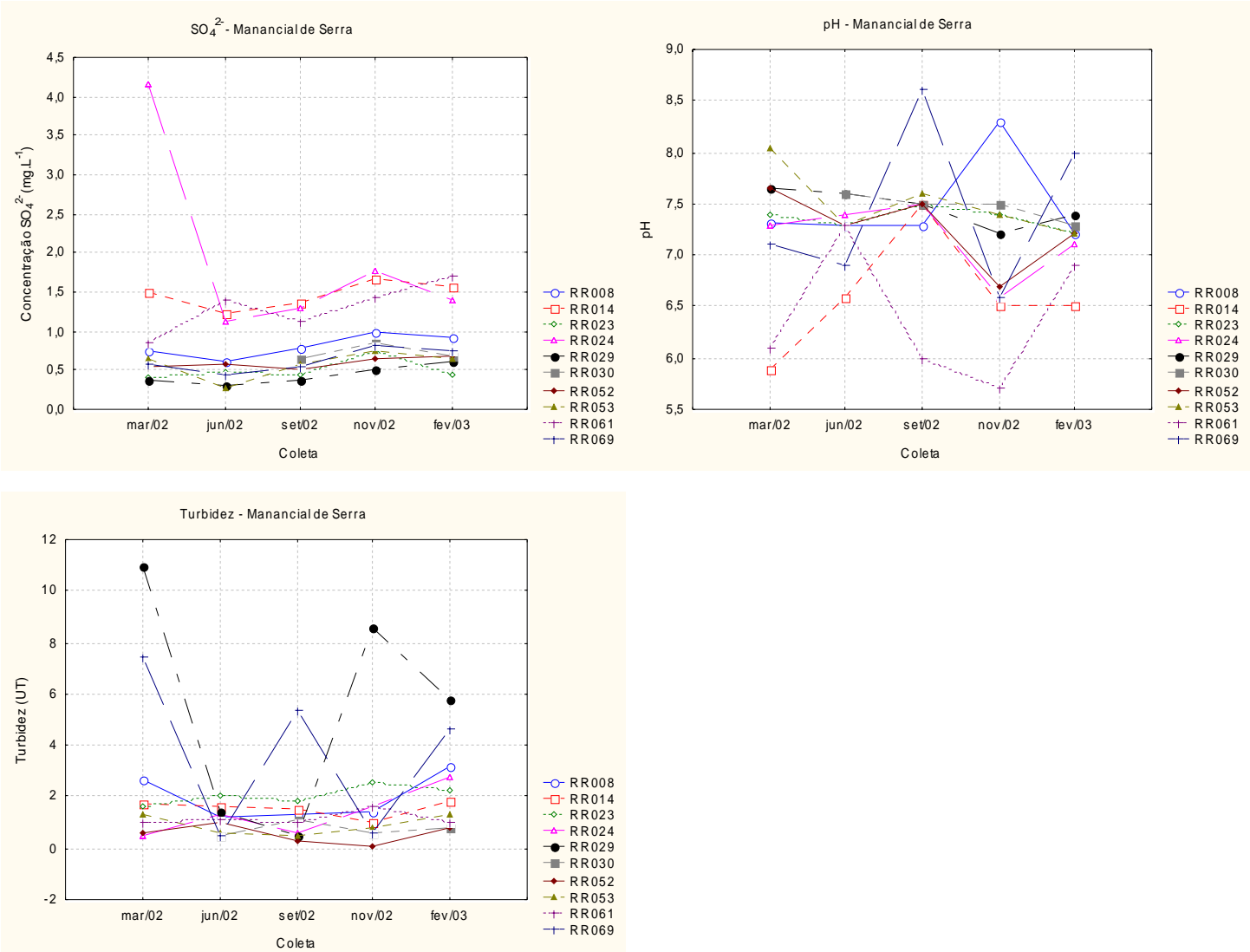

Figura D.1 - Alisamentos das concentrações de metais e ânions em amostras de água de manancial de serra em função do tempo de coleta. (cont) 

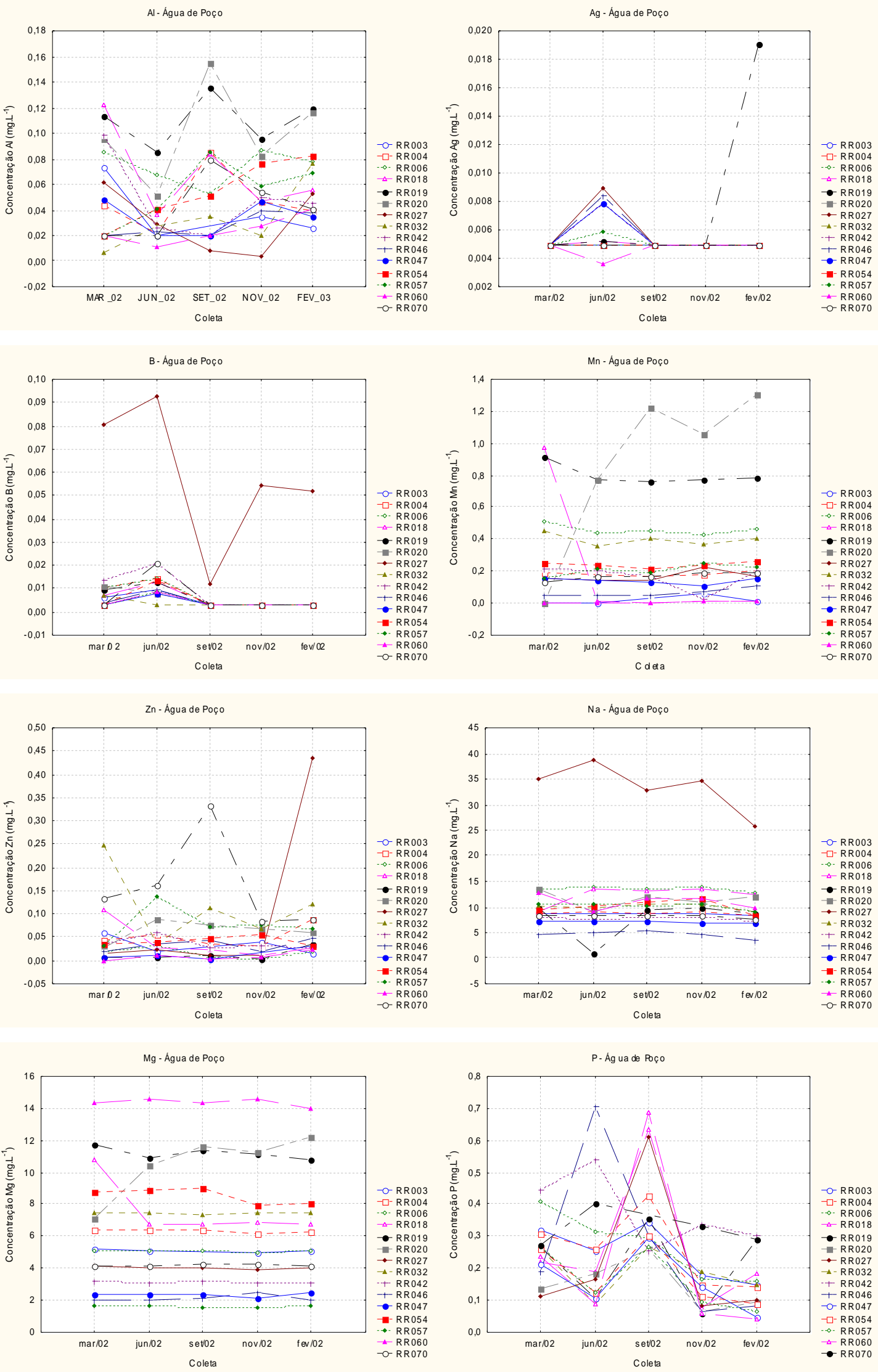

Figura D.2 - Alisamentos das concentrações de metais e ânions em amostras de água de manancial subterrâneo (poços) em função do tempo de coleta. 

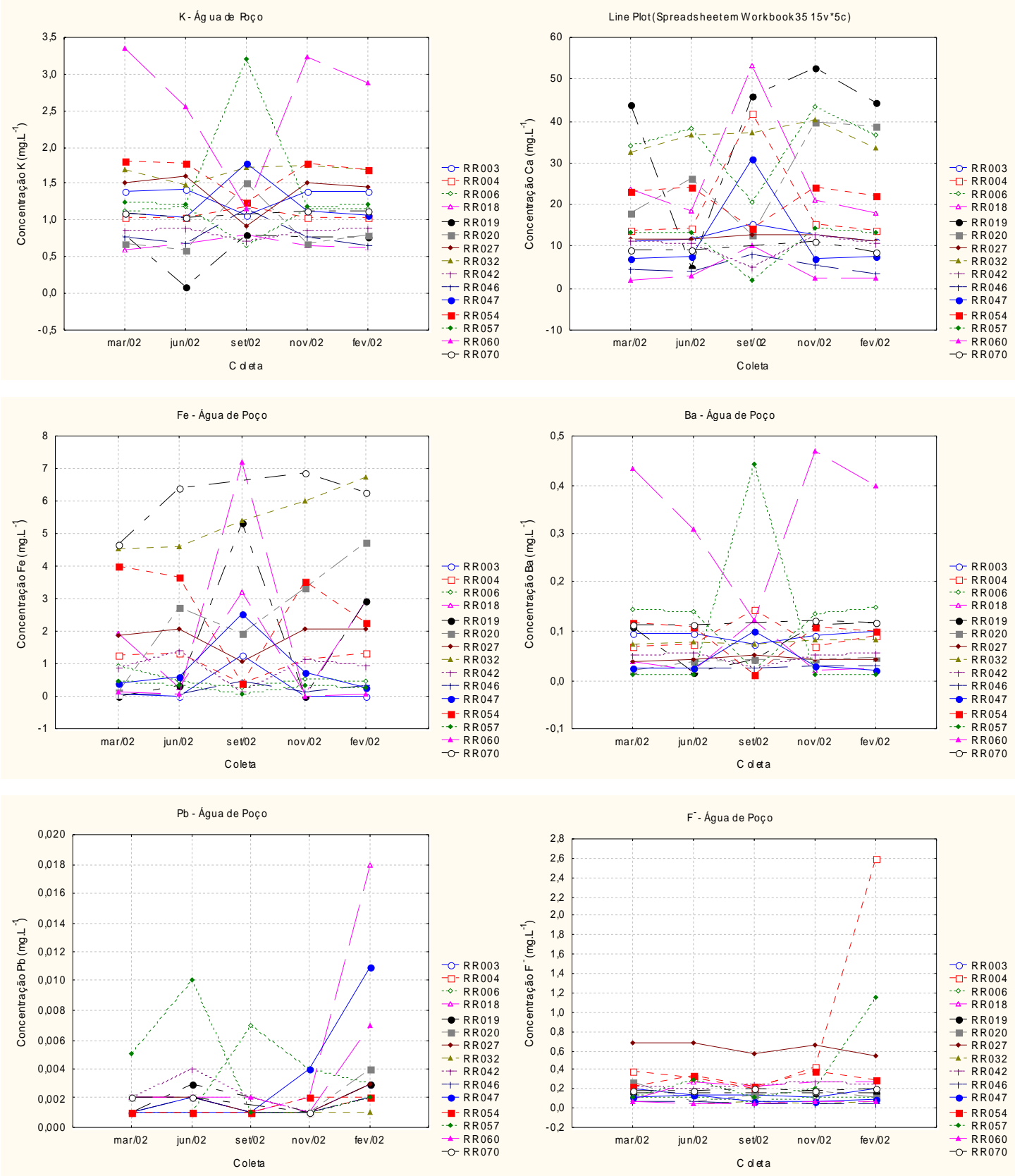

$\mathrm{Cl}^{\circ}$ - Água de Poço
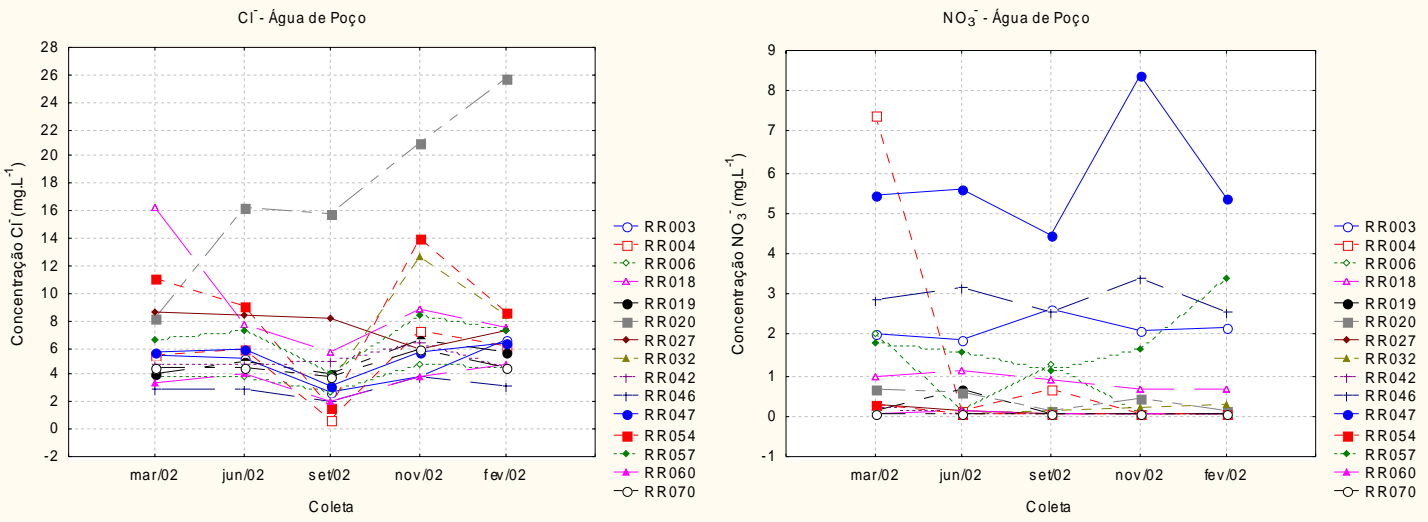

Figura D.2 - Alisamentos das concentrações de metais e ânions em amostras de água de manancial subterrâneo (poços) em função do tempo de coleta. (cont.) 
$\mathrm{SO}_{4}^{2-}$ - Agua de $\mathrm{Poc} \mathrm{O}$

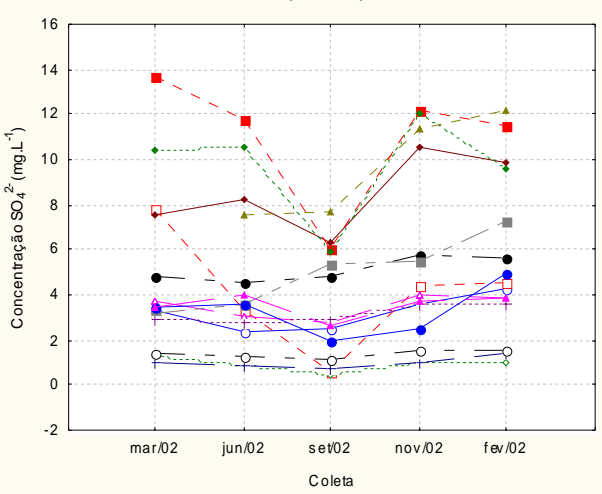

Turbidez - Água Poço

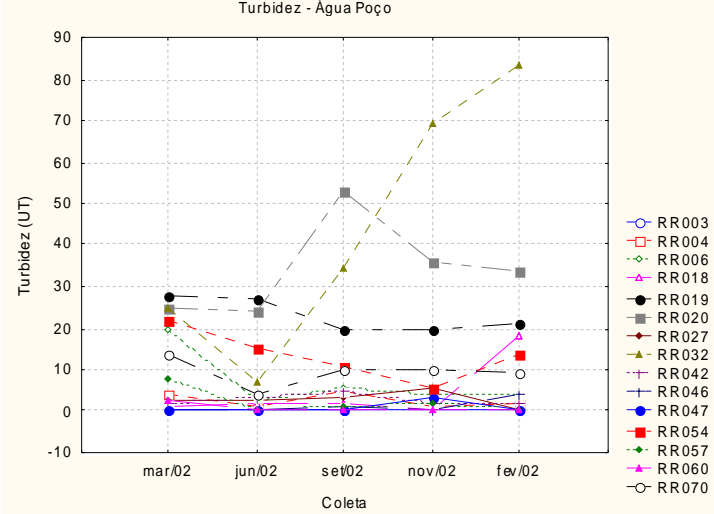

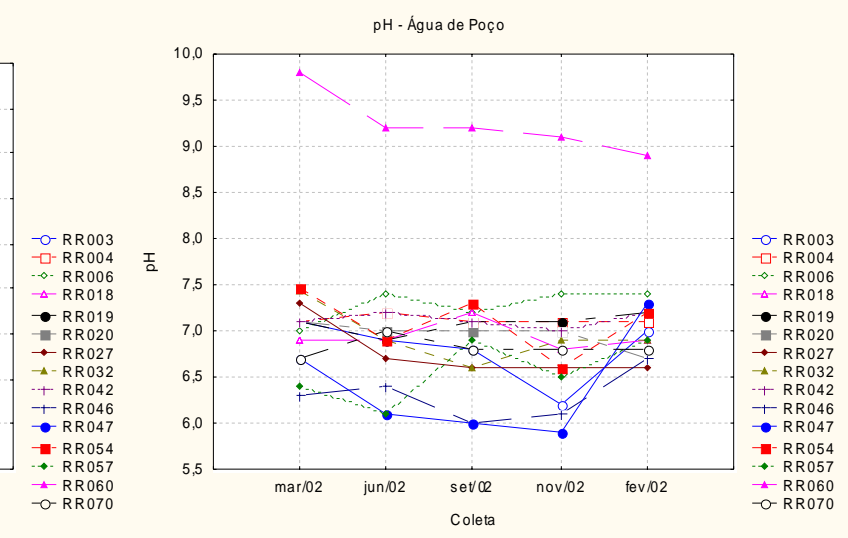

Cole

Figura D.2 - Alisamentos das concentrações de metais e ânions em amostras de água de manancial subterrâneo (poços) em função do tempo de coleta. (cont.) 

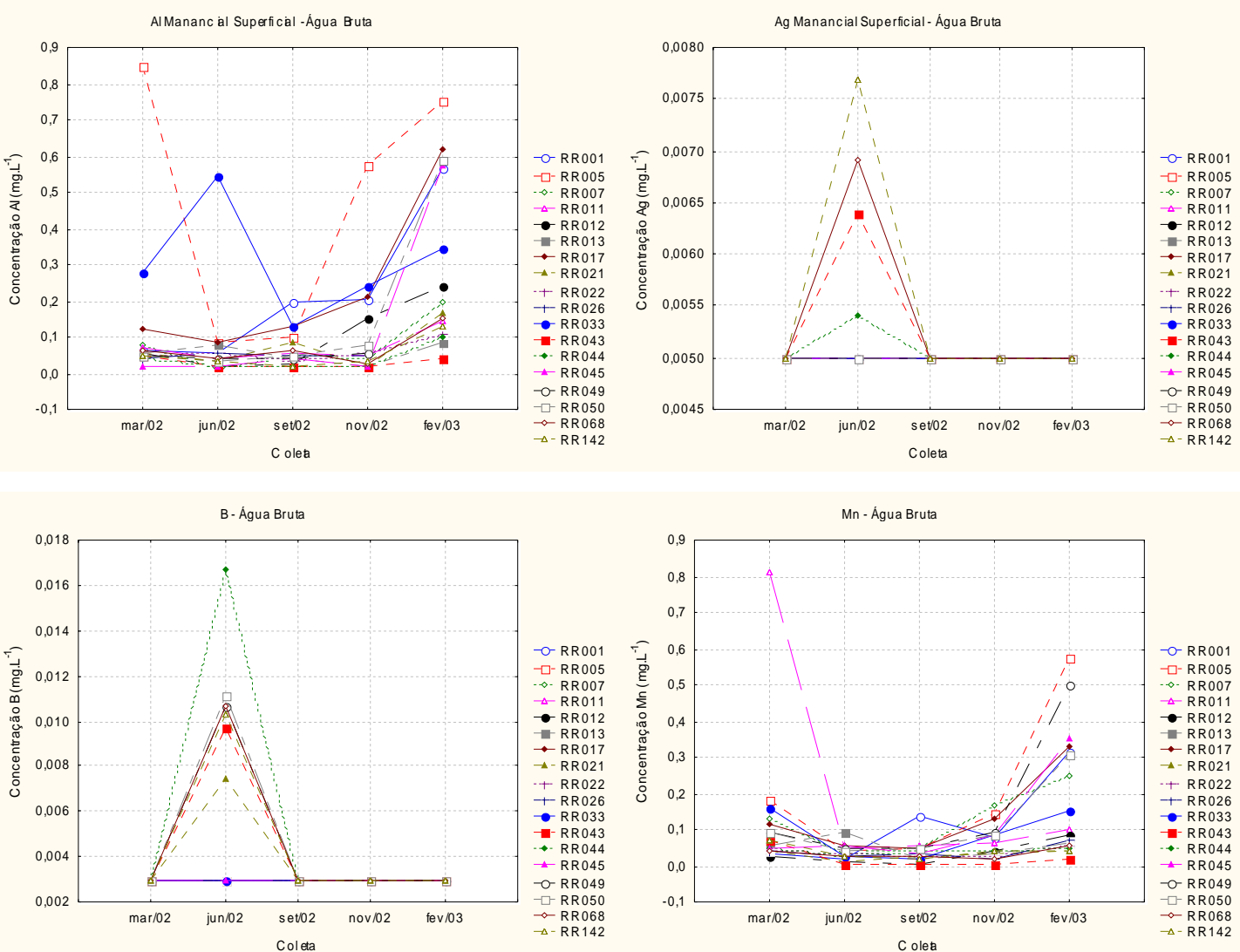

Zn - Água Bruta
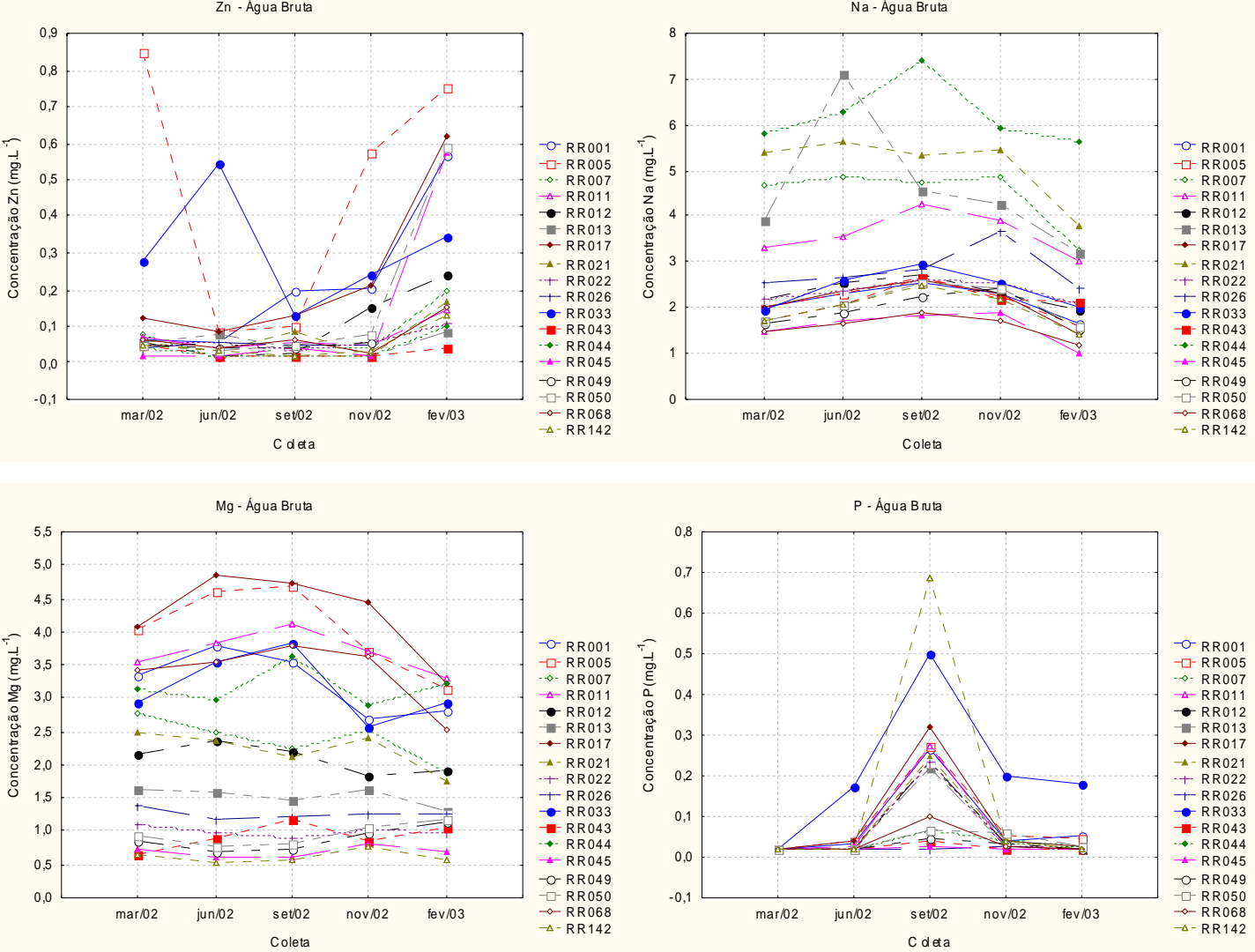

Figura D.3 - Alisamentos das concentrações de metais e ânions em amostras de água de manancial superficial (água bruta) em função do tempo de coleta. 

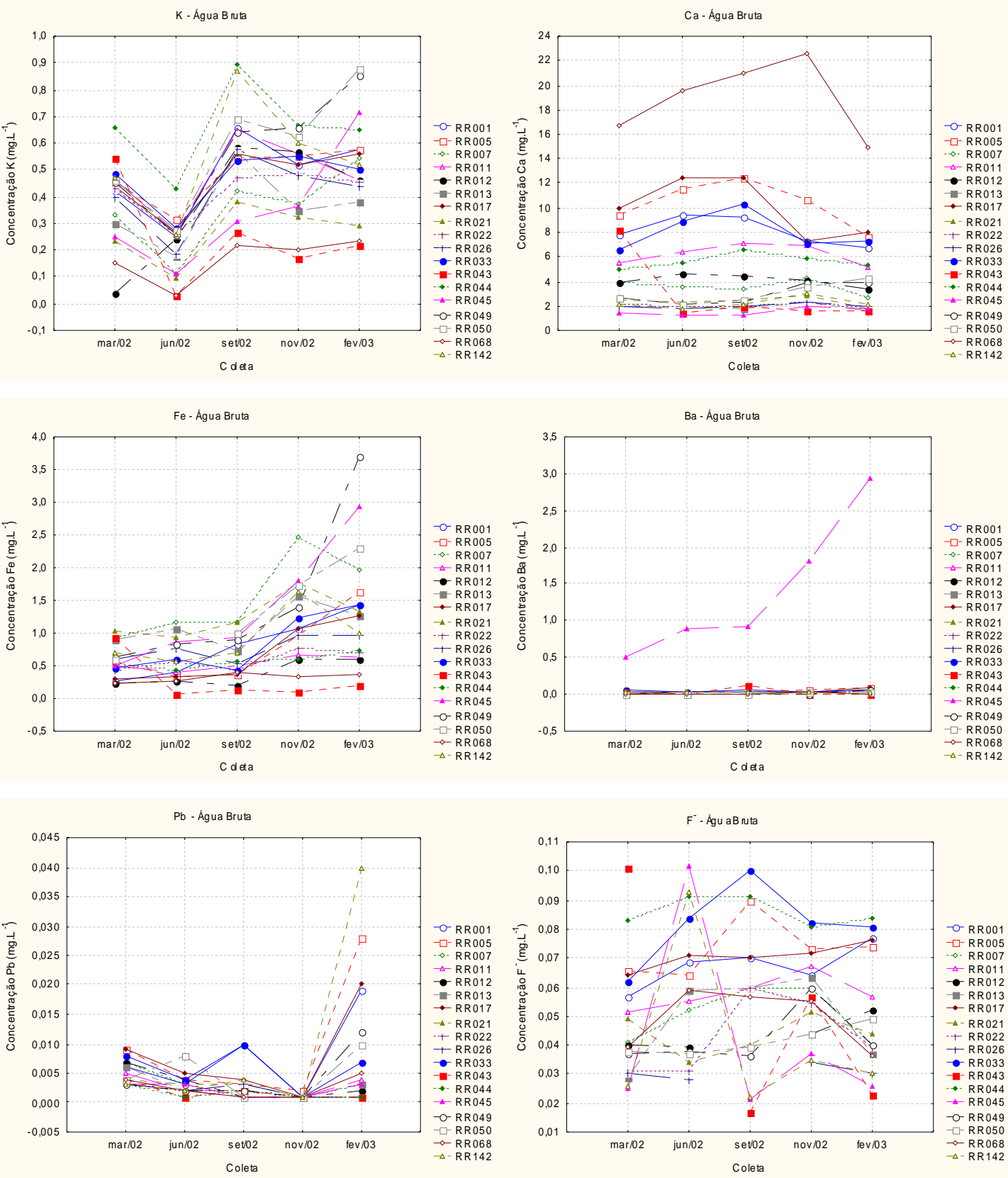

$\mathrm{Cl}^{-}$- Água Bruta

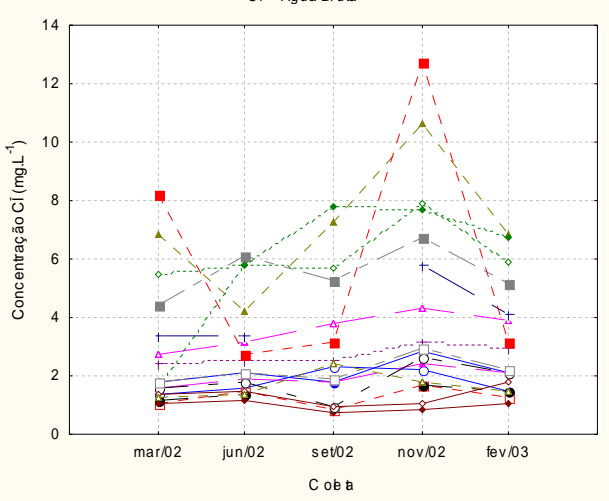

$\mathrm{NO}_{3}$ - Áqua Bruta

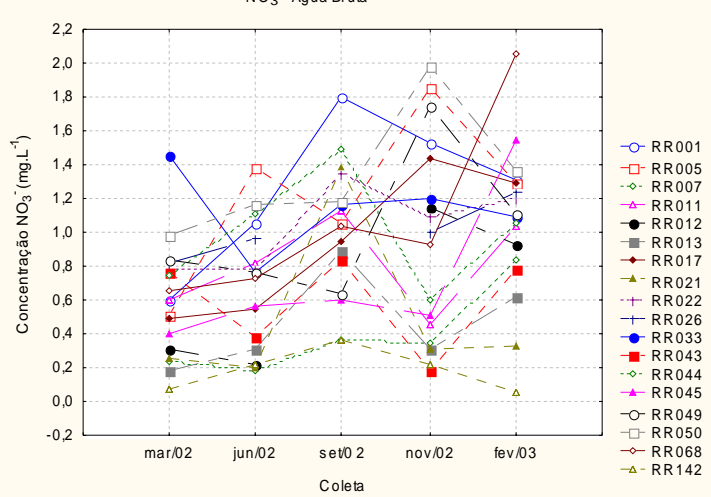

Figura D.3 - Alisamentos das concentrações de metais e ânions em amostras de água de manancial superficial (água bruta) em função do tempo de coleta. (cont.) 

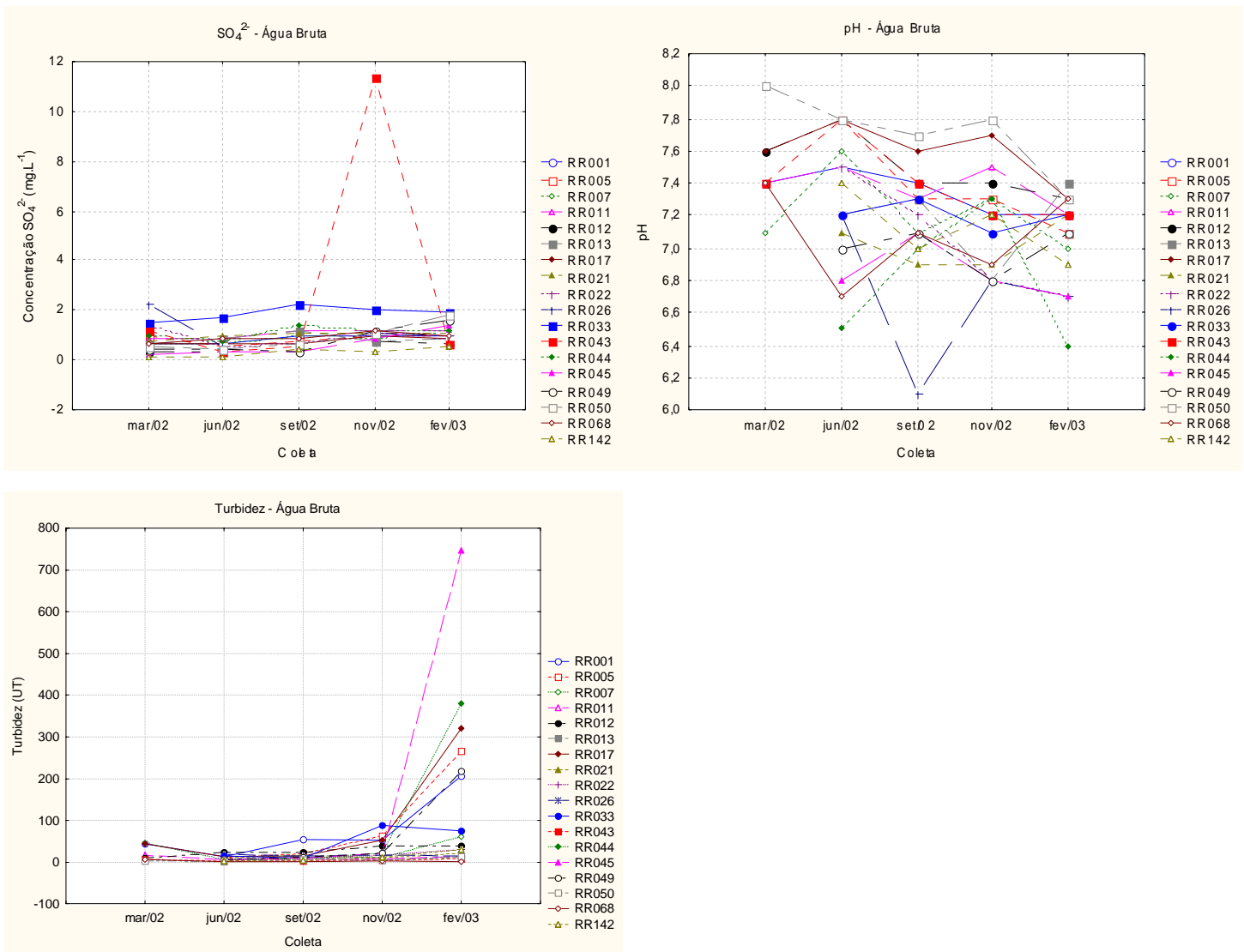

Figura D.3 - Alisamentos das concentrações de metais e ânions em amostras de água de manancial superficial (água bruta) em função do tempo de coleta. 

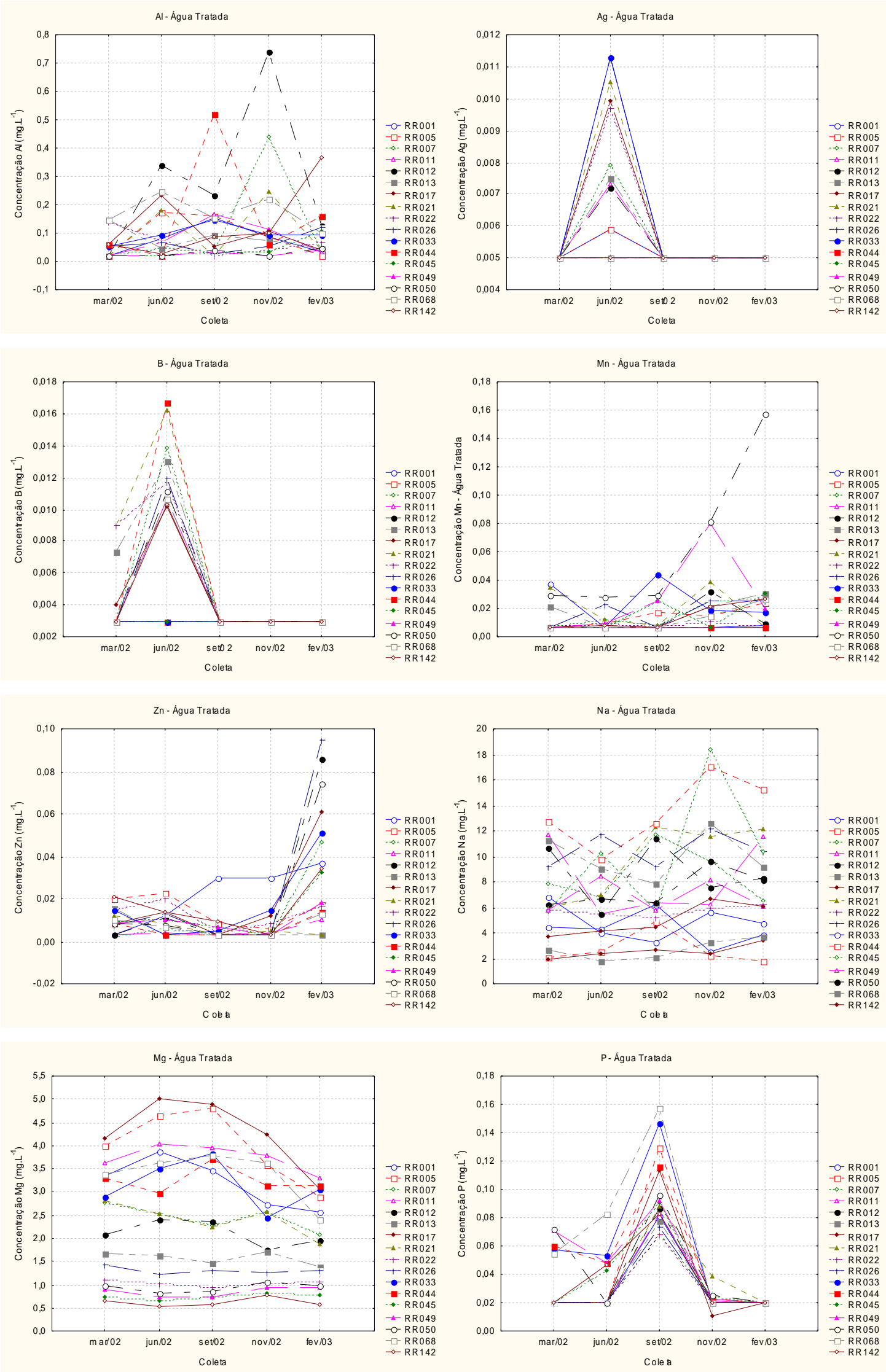

Figura D.4 - Alisamentos das concentrações de metais e ânions em amostras de água tratada em função do tempo de coleta. 

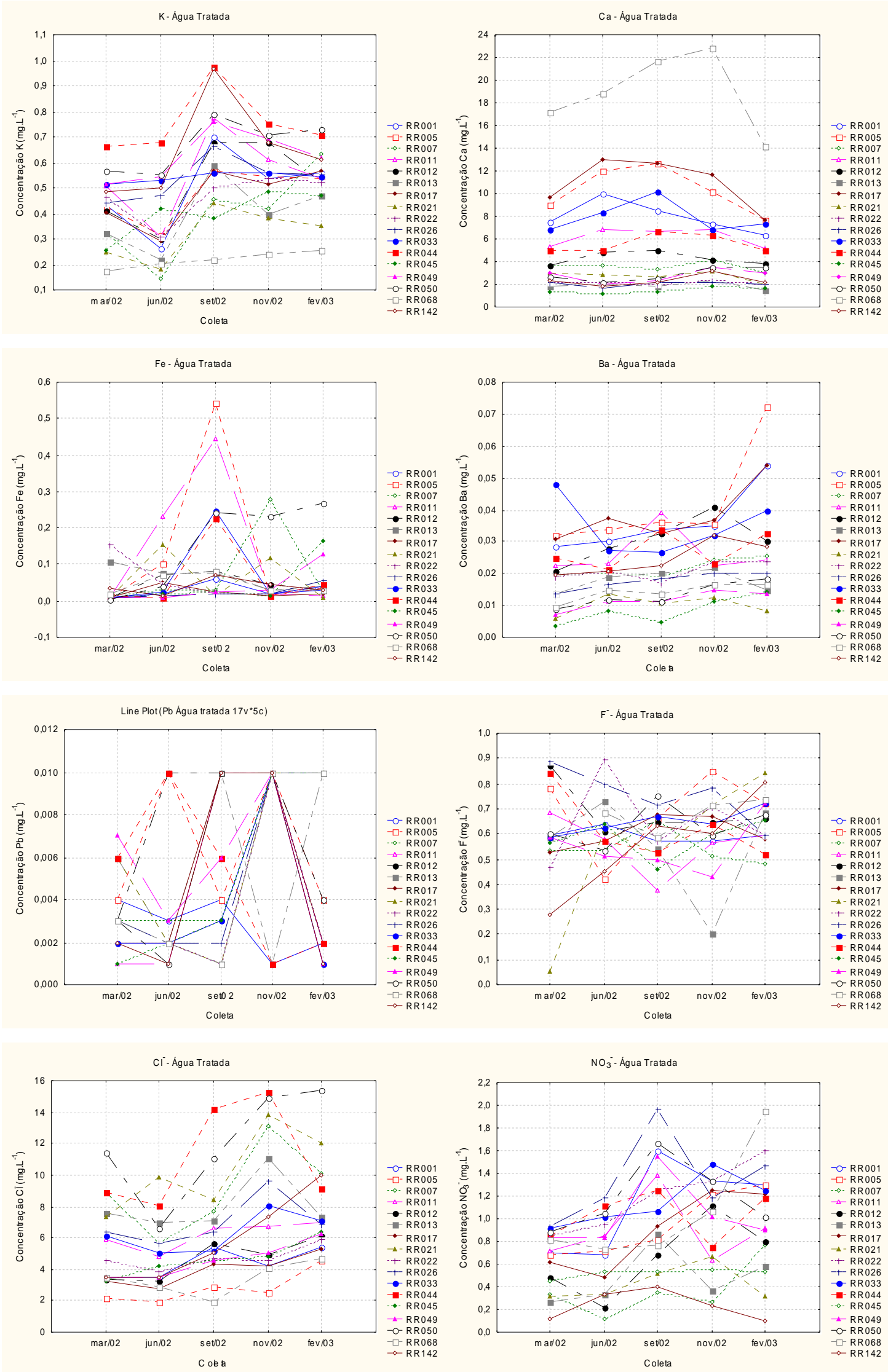

Figura D.4 - Alisamentos das concentrações de metais e ânions em amostras de água tratada em função do tempo de coleta. (cont.) 

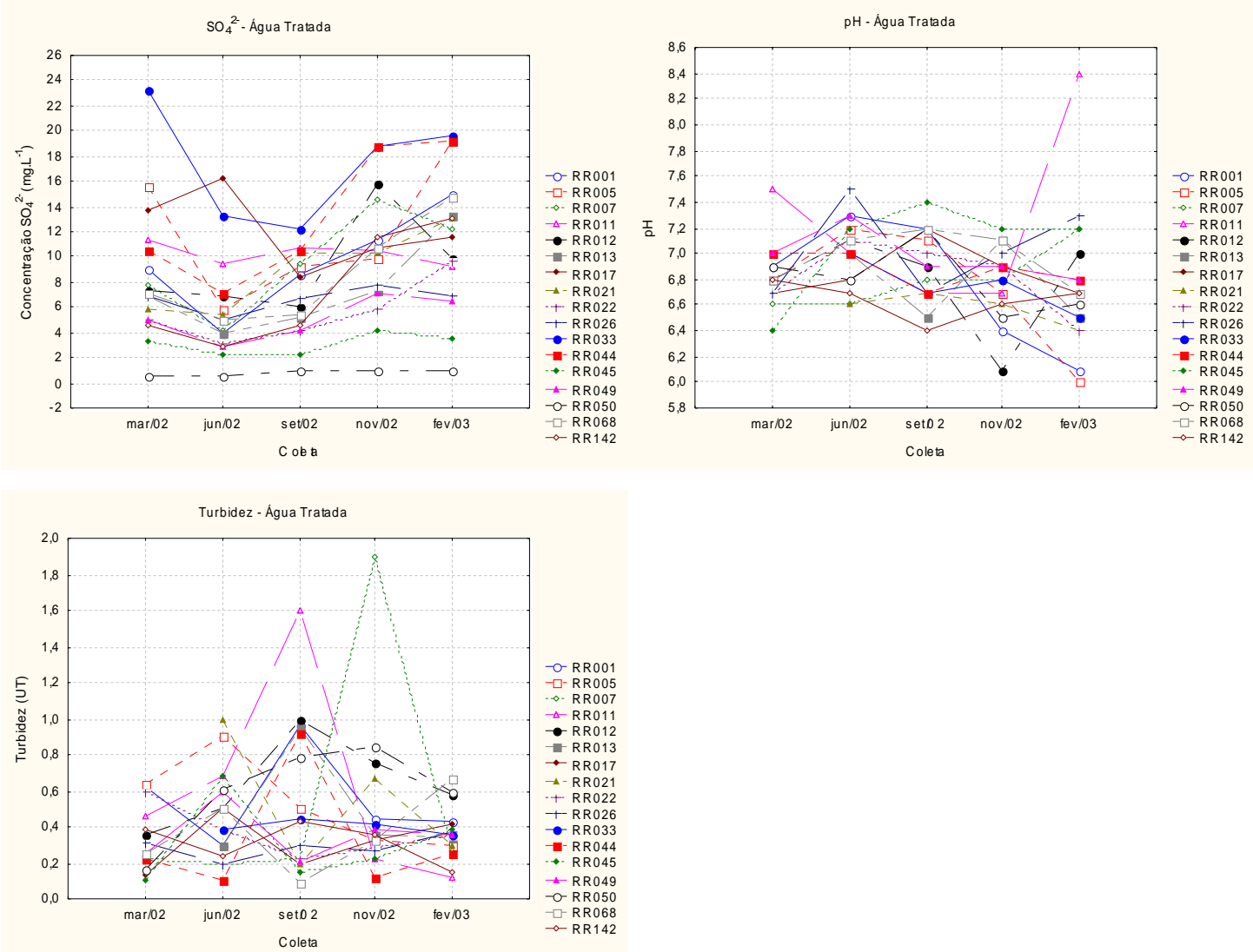

Figura D.4 - Alisamentos das concentrações de metais e ânions em amostras de água tratada em função do tempo de coleta. (cont.) 
APÊNDICE E: Dendogramas 

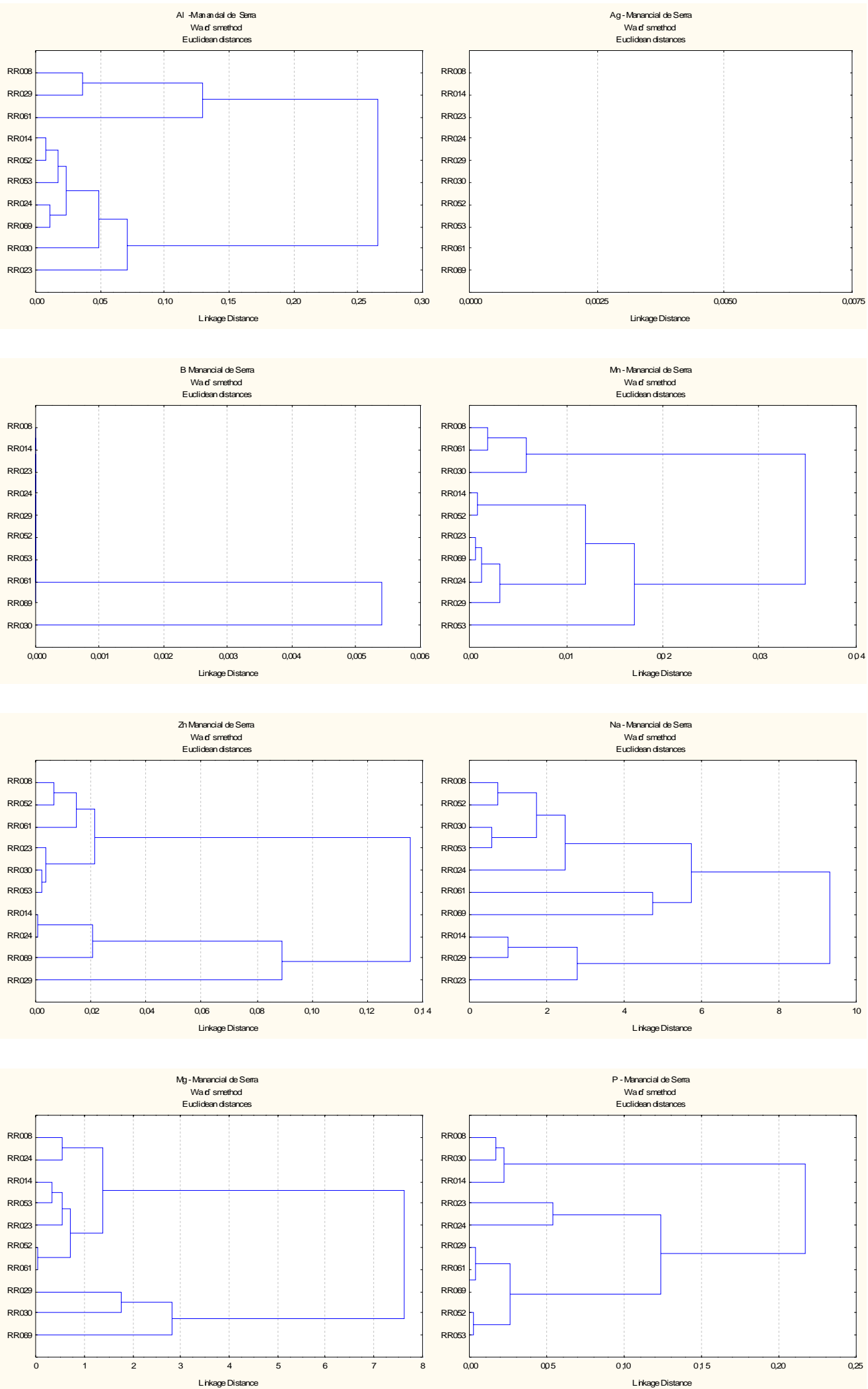

Figura E.1 - Dendrogramas das concentrações de metais e ânions em amostras de água de manancial de serra. 

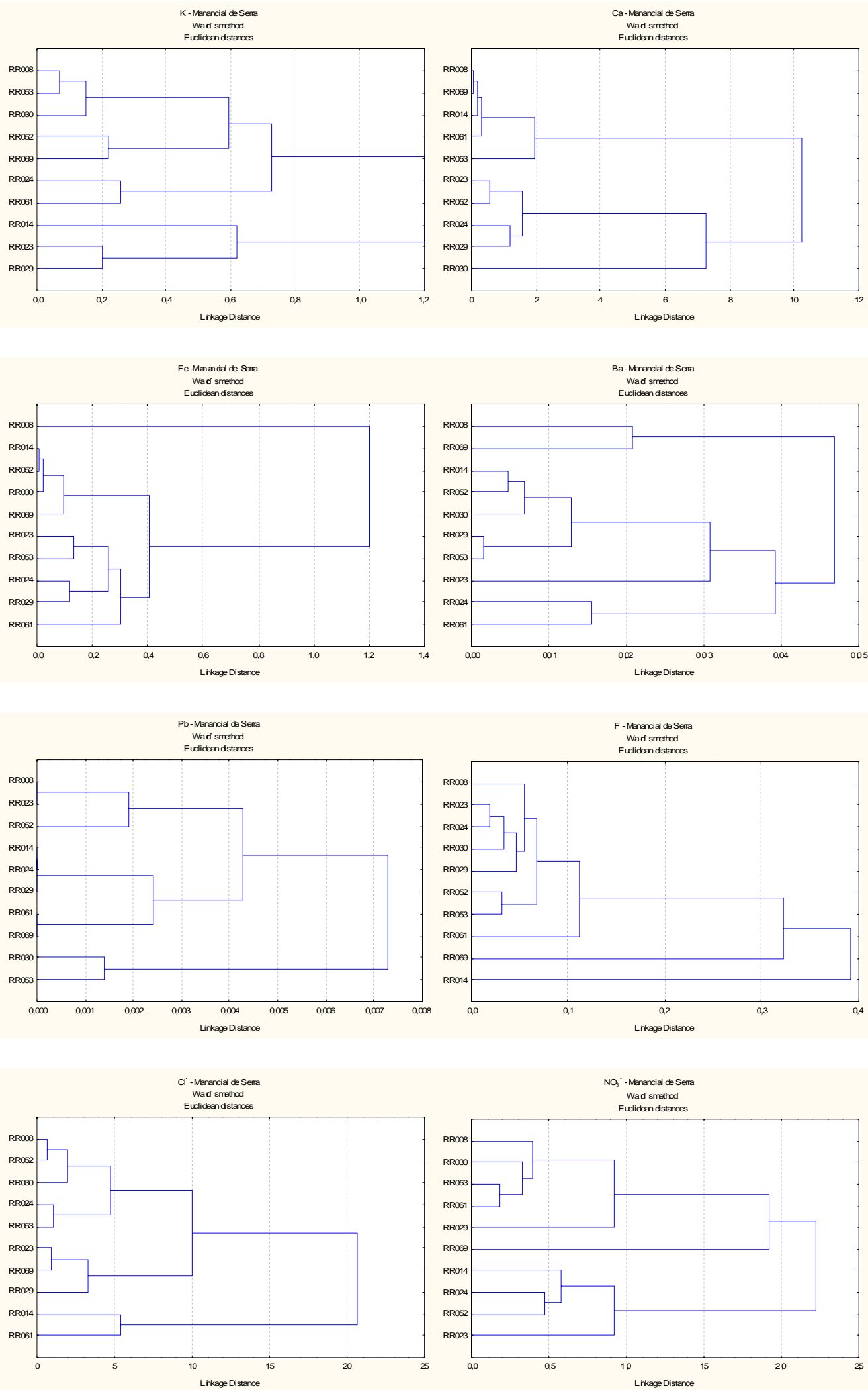

Figura E.1 - Dendrogramas das concentrações de metais e ânions em amostras de água de manancial de serra. (cont.) 
$\mathrm{SO}_{4}{ }^{2}$ - Marancial de Serf

Wad' smethod
Euclideandstances

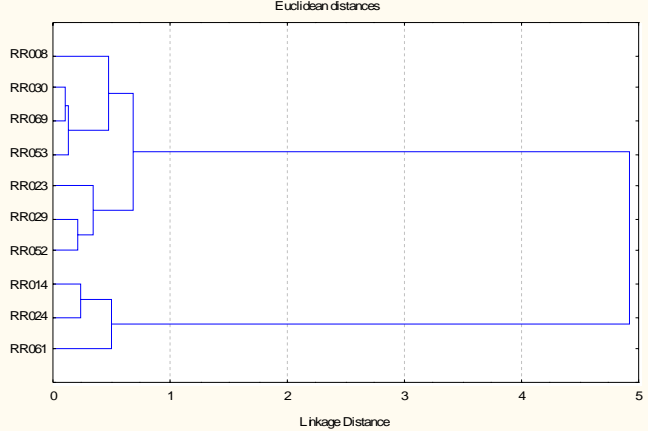

2 Linkage Distance

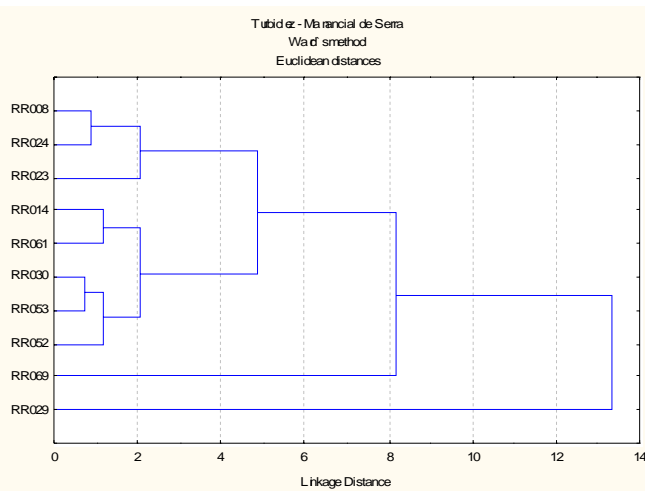

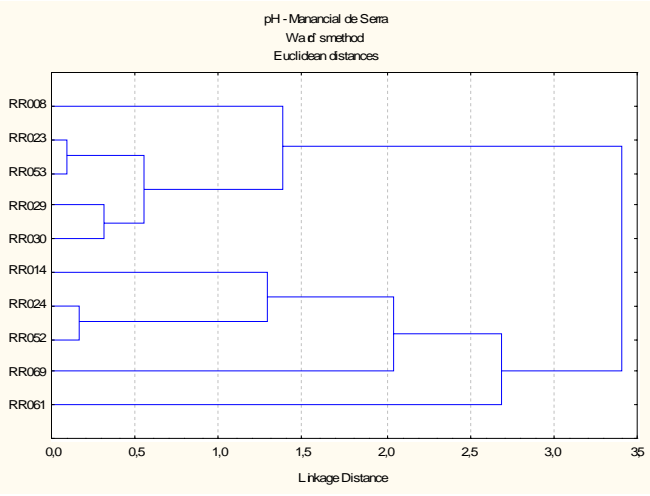

Euclidean distanoes 

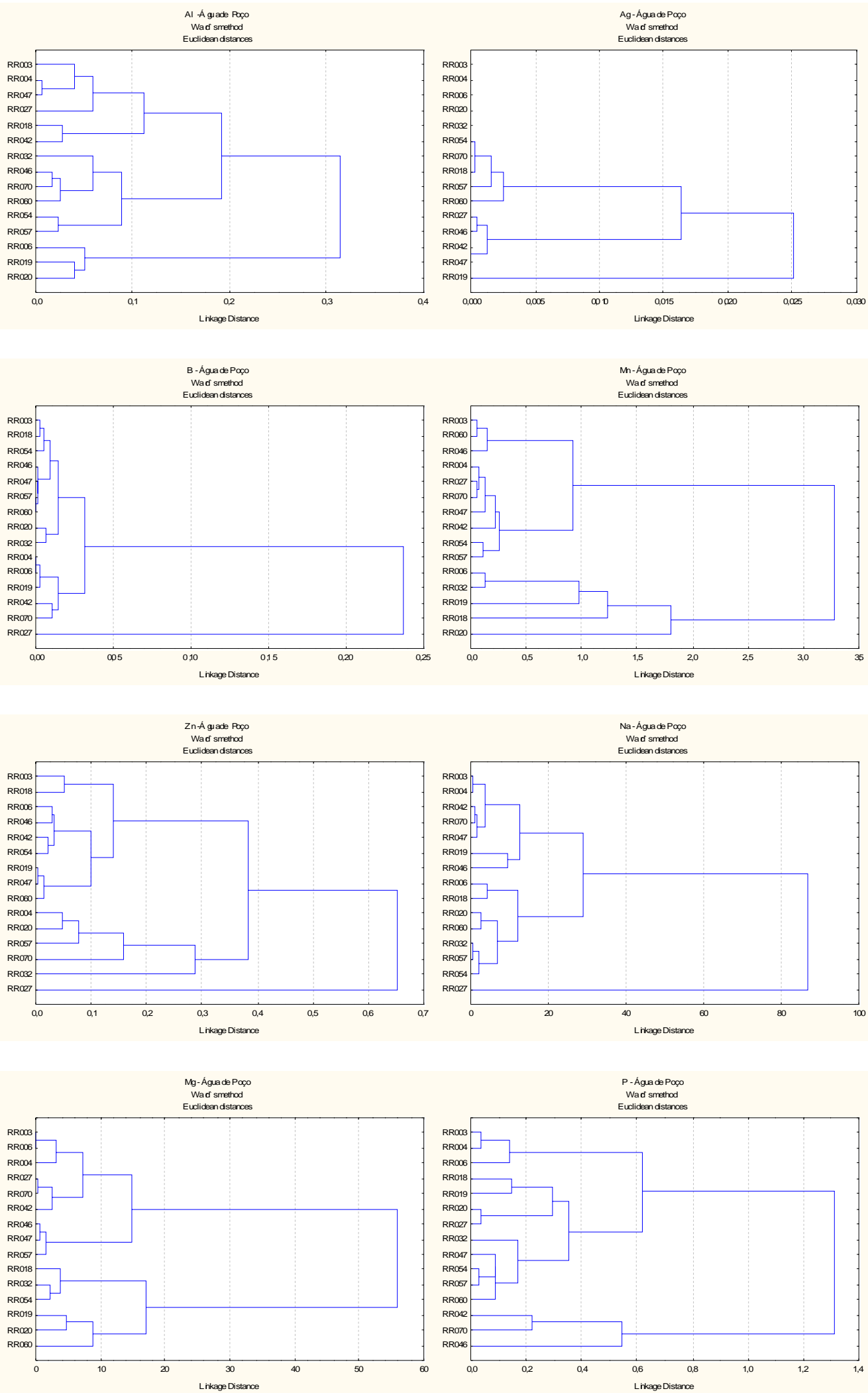

Figura E.2 - Dendrogramas das concentrações de metais e ânions em amostras de água de manancial subterrâneo (poços). 

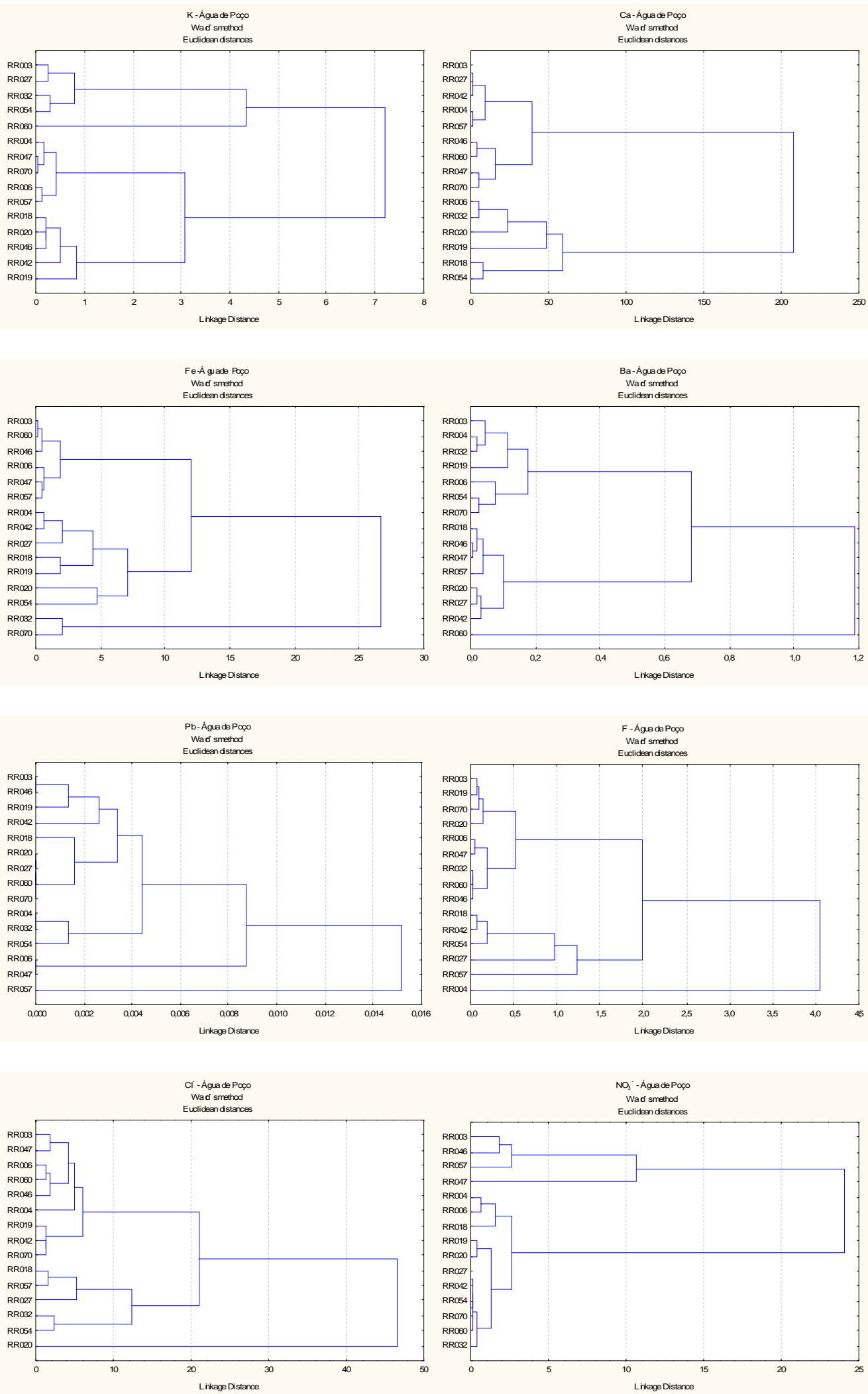

Figura E.2 - Dendrogramas das concentrações de metais e ânions em amostras de água de manancial subterrâneo (poços). (cont.) 

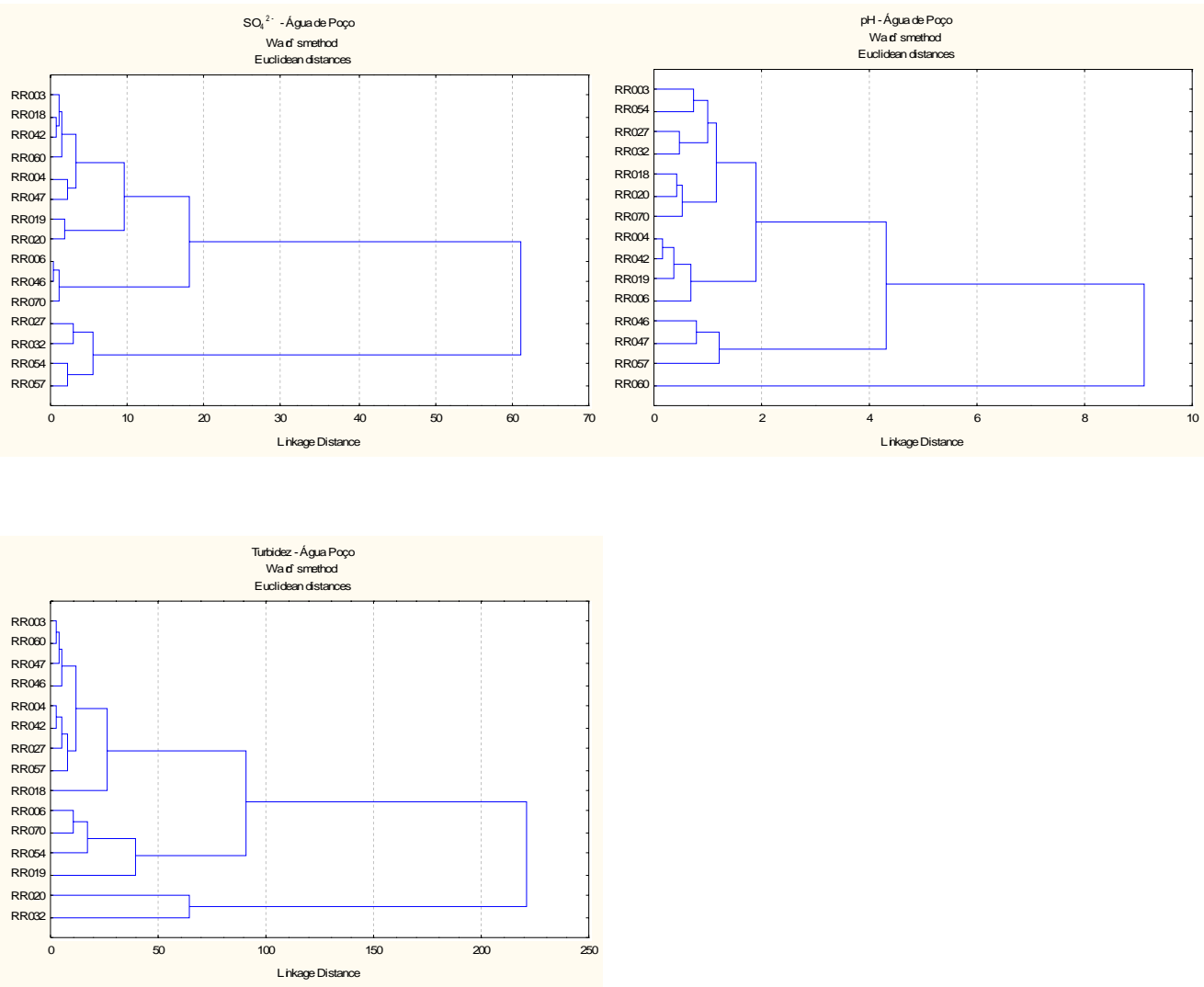

Figura E.2 - Dendrogramas das concentrações de metais e ânions em amostras de água de manancial subterrâneo (poços). (cont.) 

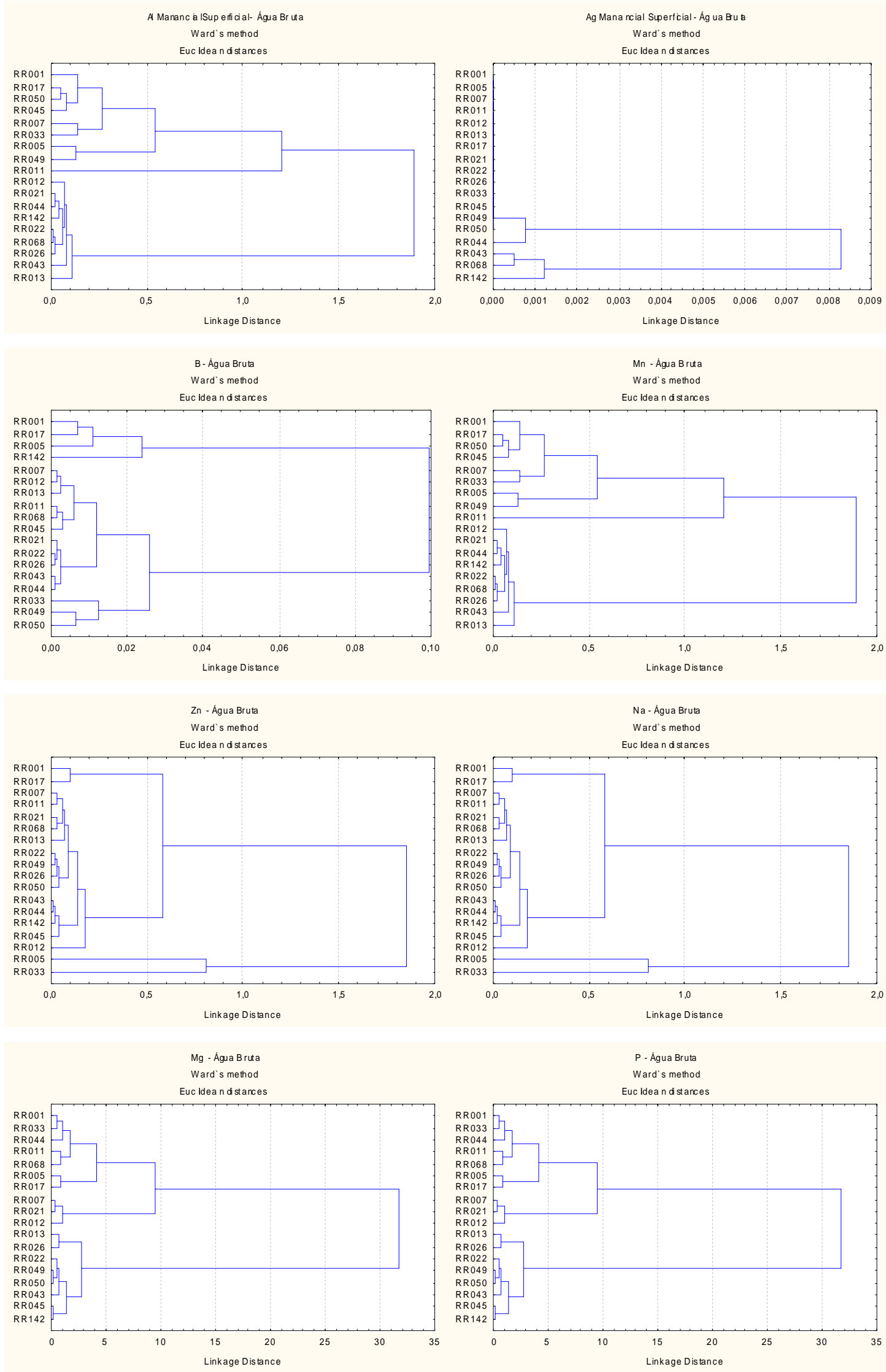

Figura E.3 - Dendrogramas das concentrações de metais e ânions em amostras de água de manancial superficial (água bruta). 

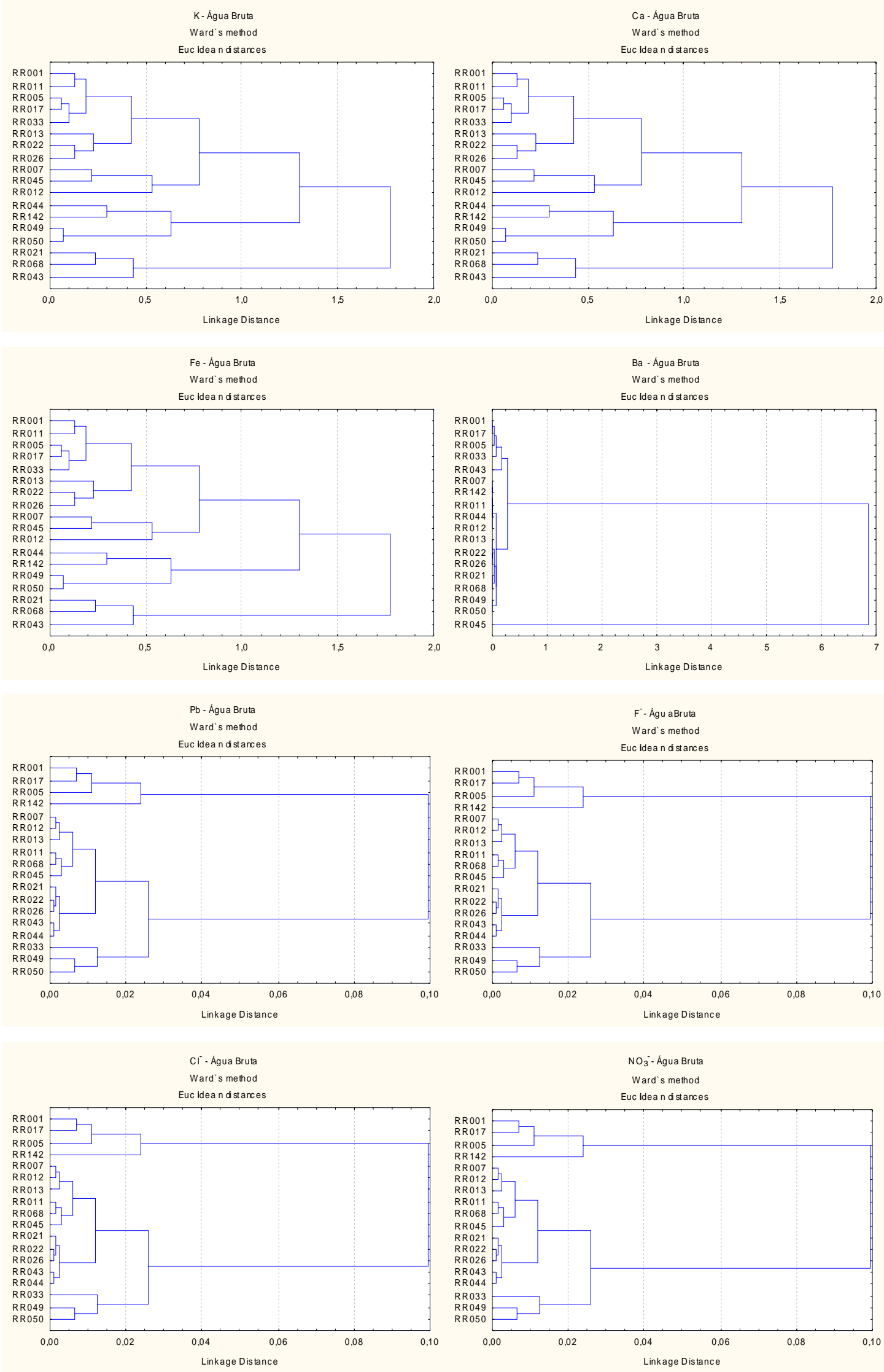

Figura E.3 - Dendrogramas das concentrações de metais e ânions em amostras de água de manancial superficial (água bruta). (cont.) 

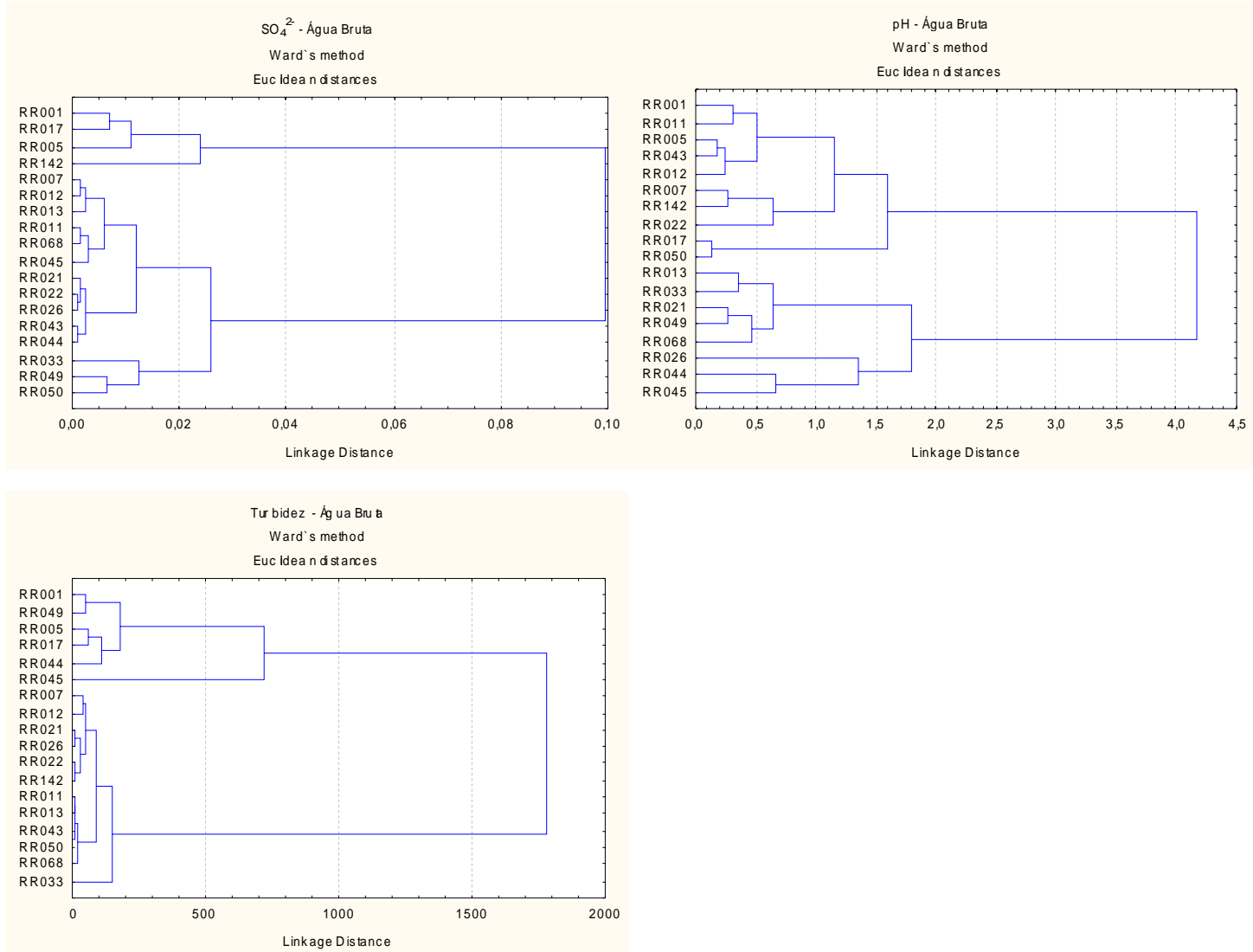

Figura E.3 - Dendrogramas das concentrações de metais e ânions em amostras de água de manancial superficial (água bruta). (cont.) 

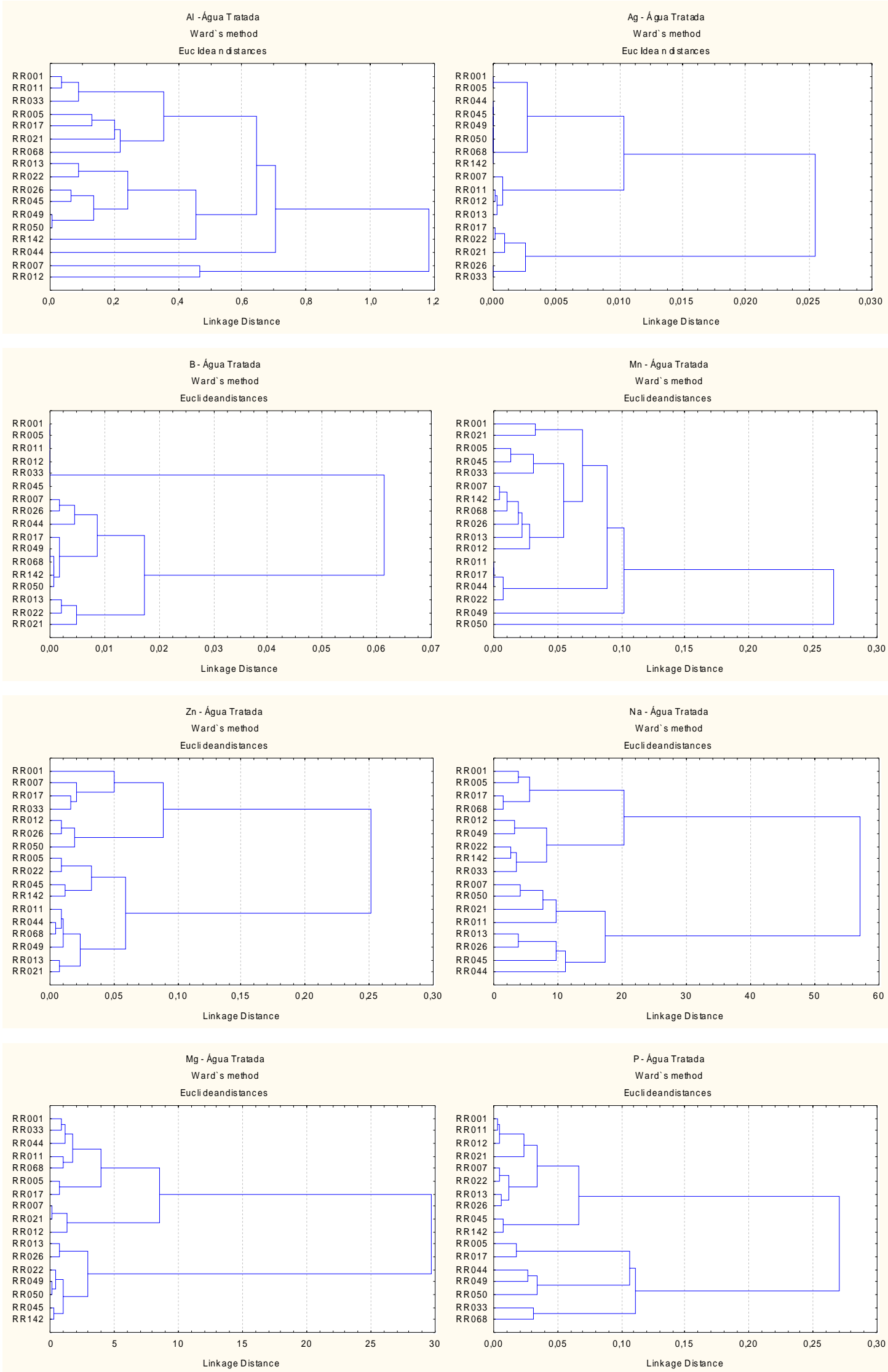

Figura E.4 - Dendrogramas das concentrações de metais e ânions em amostras de água tratada. 

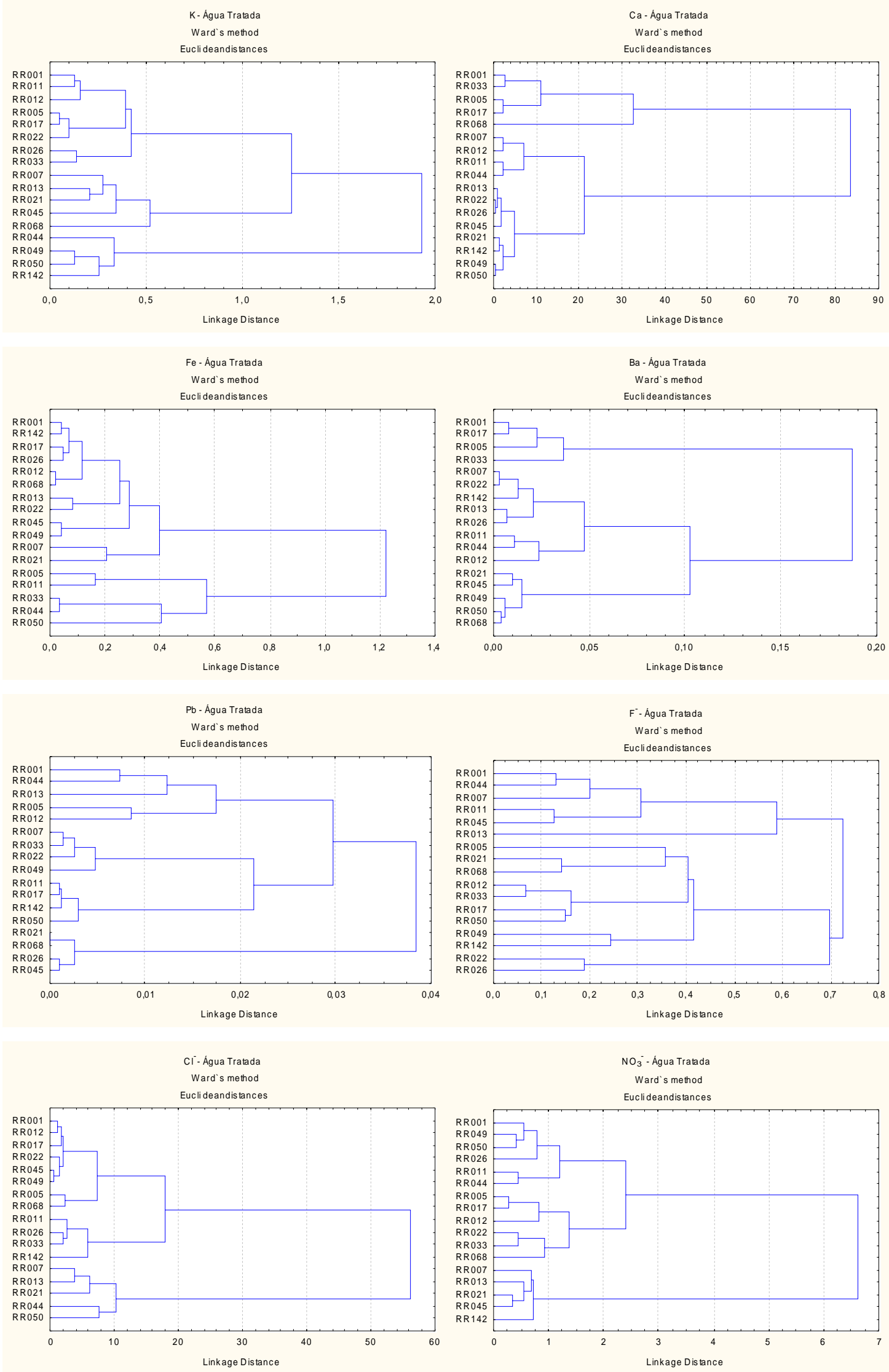

Figura E.4 - Dendrogramas das concentrações de metais e ânions em amostras de água tratada. (cont.) 

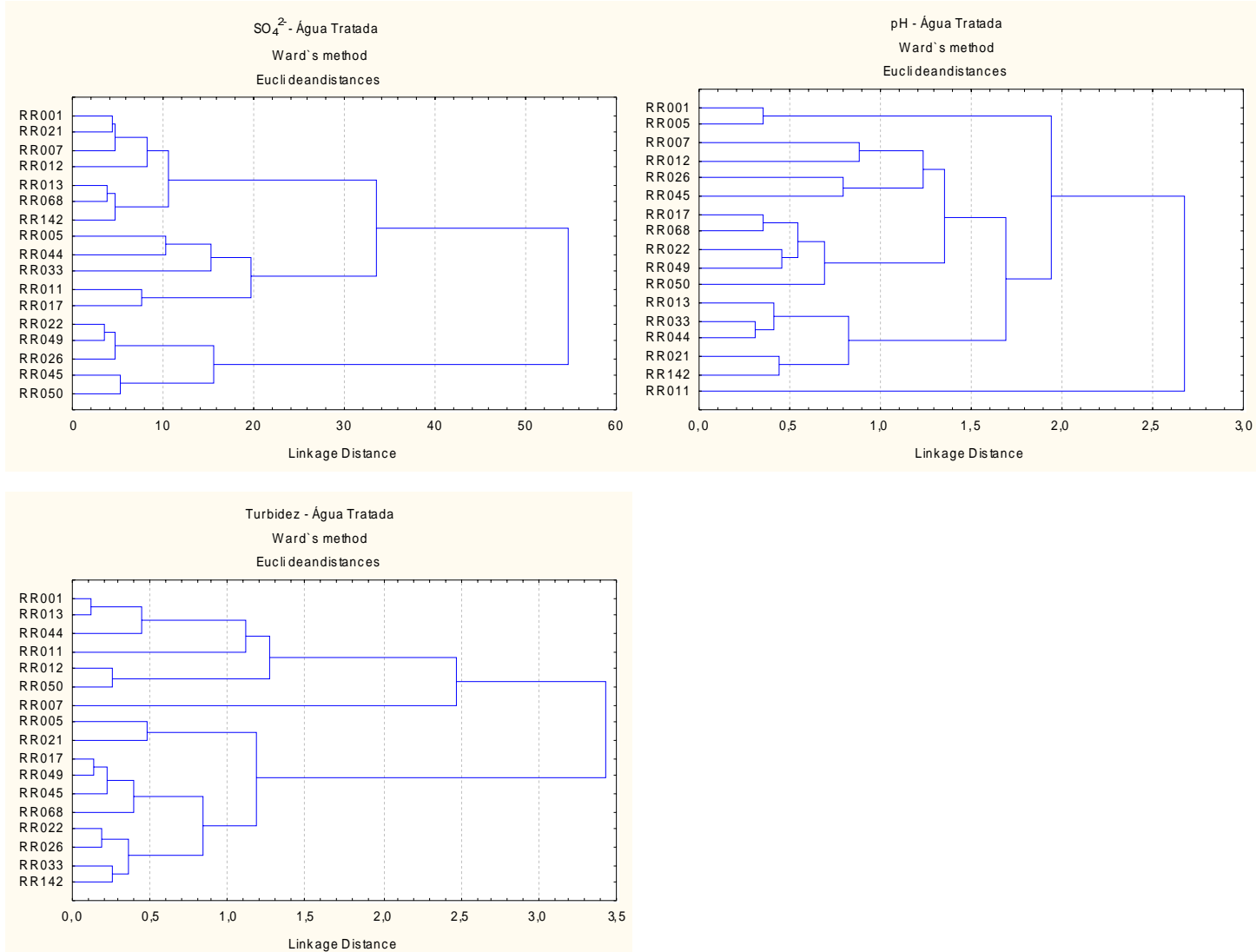

Figura E.4 - Dendrogramas das concentrações de metais e ânions em amostras de água tratada. (cont.) 


\title{
REFERÊNCIAS BIBLIOGRÁFICAS
}

\author{
ANA - AGÊNCIA NACIONAL DE ÁGUAS A Evolução da Gestão dos \\ Recursos Hídricos no Brasil. Março 2002.
}

ANA - AGÊNCIA NACIONAL DE ÁGUAS Plano Nacional de Recursos Hídricos - Documento base de referência, cap. 3, 4, 7 e 8. Disponível em: $<$ http://www.ana.gov.br/pnrh/index.htm>. Acesso em 08/2003.

ARRIBÉRE, P.A.; RIBEIRO GUEVARA, S.; SANCHÉZ, R.S.; GIL, M.I.; ROMÁN ROSS, G.; DAURADE, L.E.; FAJON, V.; HORVAT, M., ALCALDE, R.; KESTELMAN, A.J. Heavy metals in the vicinity of a chlor-alkali factory in the upper Negro River ecosystem, Northern Patagonia, Argentina. The Science of the Total Environmental, vol. 301, p. 187-203, 2003.

ASUBIOJO, O.I.; NKONO, N.A.; OLUWOLE, A.F.; WARD, N.I.; AKANLE, O.A.; SPYROU, N.M. Trace elements in drinking water and groundwater samples in Southern Nigeria. The Science of the Total Environmental, vol. 208, p. 1-8, 1997.

BERNDT, M.P.; HATZELL, H.H.; CRANDALL, C.A.; TURTORA,M.; PITTMAN, J.R.; OAKSFORD, E.T. Water quality in the Georgia - Florida Coastal Plain - Georgia and Florida, 1992 - 96. US Department of the Interior, US Geological Survey, Circular 1151. 1998.

BRABO, E.S; SANTOS, E.O.; JESUS, I.M.; MASCARENHAS, A.F.S.; FAIL, K.F. Mercury contamination of fish and exposures of an indigenous community in Para State, Brazil. Environmental Research Section A, v.84, p. 197-203, 2000.

BRAYNER, F.M.N. Determinação de taxas de retenção de metais-traço por sedimentos orgânicos em um viveiro de piscicultura em área estuarina e urbana. Tese (Doutorado). Escola de Engenharia de São Carlos. Universidade de São Paulo. 1998.

BUSSAB, W.O. \& MORETTINI, P.A. Estatística Básica. 4aa ed. São Paulo. 321p., 1987.

BUSSAB, W.O.; MIAZAKI, E.S.; ANDRADE, D.F. Introdução a Análise de Agrupamentos. 9 Simpósio Nacional de Probabilidade e Estatística. São Paulo. 105p, 1990. 
CATI - COORDENADORIA DE ASSISTÊNCIA TÉCNICA INTEGRAL Projeto L.U.P.A. Levantamento das Unidades de Produção Agropecuária. Disponível em <htp:// www.cati.sp.gov.br>. Acesso em 20/07/2001.

CCME (Canadian Council of Ministers of the Environment). Protocol for the derivation of Canadian sediment quality guidelines for the protection of aquatic life. CCME-EPC-98 /e. Prepared by Environment Canada, Guidelines Division, Technical Secretariat of the CCME Task Group on /water Quality Guidelines, Ottawa, Canada. 1999.

CETESB - COMPANHIA DE TECNOLOGIA DE SANEAMENTO AMBIENTAL Relatório de água interiores do Estado de São Paulo de 2001. São Paulo: CETESB 2001.

CETESB - COMPANHIA DE TECNOLOGIA DE SANEAMENTO AMBIENTAL Microbiologia Ambiental, vol. 1, n 10, São Paulo: CETESB, 1991.

CETESB - COMPANHIA DE TECNOLOGIA DE SANEAMENTO AMBIENTAL Relatório de águas interiores do Estado de São Paulo de 2003. Disponível em: <http://www.cetesb.sp.gov.br/Agua> . Acesso em 04/2004.

CETESB - COMPANHIA DE TECNOLOGIA DE SANEAMENTO AMBIENTAL Relatório de águas interiores do Estado de São Paulo de 1999. São Paulo: CETESB 1999.

CETESB - COMPANHIA DE TECNOLOGIA DE SANEAMENTO AMBIENTAL Relatório de Qualidade das Águas Interiores do Estado de São Paulo. Série Relatórios, São Paulo: CETESB, 1991.

CETESB - COMPANHIA DE TECNOLOGIA DE SANEAMENTO AMBIENTAL Sedimentos - Determinação da distribuição granulométrica, L6 160, São Paulo: CETESB 1995.

CONAMA - MINISTÉRIO DO DESENVOLVIMENTO URBANO E MEIO AMBIENTE. CONSELHO NACIONAL DO MEIO AMBIENTE. "Resolução $n^{0}$ 20", Brasília, Brasil.

CONAMA - MINISTÉRIO DO DESENVOLVIMENTO URBANO E MEIO AMBIENTE. CONSELHO NACIONAL DOMEIO AMBIENTE. "Resolução $\mathrm{n}^{0}$ 357", de 18/06/86, D.O.U., de 30/07/86, Brasília, Brasil.

CONSTITUIÇÃO DA REPÚBLICA FEDERATIVA DO BRASIL, Brasília, Senado Federal, Centro Gráfico, 1988.

Lei federal 6.938/81- Política Nacional Meio Ambiente.

Lei federal 8.080/90 - Condições de Promoção da Saúde. 
Lei Federal 9.433/97 - Política Nacional de Gestão dos Recursos Hídricos

CONSTITUIÇÃO DO ESTADO DE SÃO PAULO. Assembléia Legislativa do Estado de São Paulo, 1989.

Lei estadual 7.663/91 - Política Estadual de Recursos Hídricos.

Lei estadual 7.750/92 - Política Estadual de Saneamento.

Lei Estadual 9.866/97 - Política Estadual de Proteção aos Mananciais

CRAUN, G.F. Review of epidemiological studies of aluminum and neurological disorders. Environ. Geochem. Health, vol. 12, p. 125-135, 1990.

CUNHA, F.C. Estudos de geoquímica ambiental no Vale do Ribeira, nos estados de São Paulo e Paraná, e o impacto na saúde pública. Tese (Doutorado), Instituto de Geociências, Universidade Estadual de Campinas. 2003.

DAEE - DEPARTAMENTO DE ÁGUAS E ENERGIA ELÉTRICA Disponibilidade de água na bacia do Ribeira de Iguape, Relatório, DAEE 2000.

DANTAS, ESK; COTRIM, MEB; FURUSAWA, HA; PIRES, MAF. Antimony Determination in River and Drinking Water by AAS and ICP-OES. In: Seventh Rio Symposium on Atomic Spectrometry. 7 a 12 de abril, 2002, Florianópolis, SC.

EPSTEIN, S.G. Human exposure to aluminum. Environ Geochem. Health, vol. 12, p. 65-70, 1990.

EYSINK, G.G.J.; PÁDUA, H.B.; BERTOLETTI, S.A.E.P.; COIMBRA MARTINS, M.; NAVAS PEREIRA, D. Metais pesados no Vale do Ribeira de Iguape e Iguape-Cananéia. AMBIENTE 2, v.1, p. 6-13, 1988.

FERGUSON, B.K. The concept of landscape health. Journal of Environmental Management, v. 40, p.129-137, 1994..

FIGUEIREDO, B.R. Minérios e Meio Ambiente, PADCT/GTM-CNPq, Editora da Unicamp, Campinas, 2000, 401p.

FIGUEIREDO, B.R.; CUNHA, F.G.; PAOLIELO, M.M.B.; CAPITANI, E.M.; SAKUMA, A.; ENZWEILER, J. Environment and human exposure to lead, cadmium and arsenic in the Ribeira Valley, southeastern Brazil. In:

International Symposium on Environmental Geochemistry, 2003, Edinburgh, Scotland. Book of Abstract, p. 49.

FLATEN, T.P. Geographical associations between aluminum in drinking water and death rates with dementia (including Alzheimer's disease), 
Parkinson's disease and amyotrophic lateral sclerosis in Norway. Environ Geochem Health, vol. 12, p. 152-167, 1990.

FÖRSTNER, U.; VITTMANN, G.T.H. Metal pollution in the aquatic environment. Springer-Verlag. 486p, 1983.

FOSTER, R.B.; BATES, J.M. Heavy metals in the hydrological cycle: trends and explanation. Hydrological Processes, v.10, p. 227-261, 1996.

FURUSAWA, HA; DANTAS, ESK; COTRIM, MEB; PIRES, MAF. Arsenic and Selenium Evaluation in Human Consumption destination Waters. In: Seventh Rio Symposium on Atomic Spectrometry. 7 a 12 de abril, 2002, Florianópolis, SC.

GATTI, L.V. Distribuição de metais em testemunhos de sedimentos de duas lagoas marginais do Rio Moji-Guaçu (E.E. de Jataí, Luiz Antônio, SP). 1997. Tese (Doutorado) - Universidade de São Paulo, São Carlos, SP.

GARBARINO, J.R; HAYES, H.C; ROTH, D.A.; ANTWEILER, R.C.; BRINTON, T.I.; TAYLOR, H.E. Heavy metals in the Mississipi River. Reston: US Geological Survey, 1995. (Circular, 1133).

GERAB, F. Técnicas analíticas nucleares aplicadas à medida em larga escala de aerossóis atmosféricos na região Amazônica. Tese (Doutoramento). Instituto de Física. Universidade de São Paulo, 1996.

GOLDWATER, L.J. Mercury in the environment. Scientific American, vol.224, n.5, p. 15-21, 1971.

GUIMARÃES, J.R.D.; MEILI, M.; HYLANDER, L.D.; SILVA, E.D.E.; ROULET, M.; MAURO, J.B.N.; LEMOS, R.A. Mercury net methylation in five tropical flood plain regions of Brazil: high in the root zone of floating macrophyte mats but low in surface sediments and flooded soils. The Science of the Total Environment, v. 261, n. 1-3, p. 99-107, 2000.

HOGAN, D.J.; CARMO, R.L.; ALVES, H.P.F., RODRIGUES, I.A. Desenvolvimento sustentável no Vale do Ribeira (SP): conservação ambiental e melhoria das condições de vida da população. Disponível em <http://www.unicamp.br/nepo/staff/roberto/valeribeira.thm>. Acesso em: $12 / 2001$.

HUGGETT, D.B.; STEEVENS, J.A.; ALLGOOD, J.C.; LUTKEN, C.B.; GRACE, C.A.; BENSON, W.H. Mercury in sediments and fish from north Mississipi lakes. Chemosphere, vol.42, p. 923-929, 2001.

HURLEY, P.J.; BENOIT, J.M.; BABIARZ, C.L.; SHAFER, M.M.; ANDREN, A.W.; SULLIVAN, J.R.; HAMMOND, R.; WEBB, D.A. Influences of water shed characteristic on mercury levels in Wisconsin rivers. Environmental Science and Technology, vol. 29, p. 1867-1875, 1995. 
IBGE. Pesquisa Nacional de Saneamento Básico: 2000. Rio de Janeiro; IBGE, 2002.

IG/CETESB/DAEE. Mapeamento da vulnerabilidade e risco de poluição das águas subterrâneas no estado de São Paulo. Vol. I. Governo do Estado de São Paulo, Secretaria de Estado do Meio Ambiente, Secretaria de Recursos Hídricos, Saneamento e Obras, São Paulo.

IPT - INSTITUTO DE PESQUISAS TECNOLÓGICAS Mapa Geológico do Estado. São Paulo : IPT, 1981.

JENKINS, R. X-ray fluorescence spectrometry. John Wiley.New York, 1998.

KARR, J.R. Biological integrity: a long-neglected aspect of water resourse managment. Ecological Applications, vol.1, p. 66-84, 1991.

KATSUÓKA, L. Avaliação do Impacto da Atividade Agropecuária na Qualidade da Água em Áreas de Captação Superficial nas Bacias Hidrográficas dos Rios Mogi-Guaçu e Pardo. 2001. Tese (Doutorado) Instituto de Pesquisas Energéticas e Nucleares, São Paulo.

LACHANCE, G.; CLAISSE, F. Quantitative x-ray fluorescence analysis Theory and Application. John Wiley\& Sons, London, 1995.

LAXEN, D.P.H.; HARRISON, R.M. Cleaning methods for polyethene containers prior to the determination of trace metals in freshwater samples.

Anal. Chem, vol. 53, p. 345. 1981;

LEITE, M.A. Análise o aporte, da taxa de sedimentação e da concentração de metais na água, plâncton e sedimento do Reservatório de Salto Grande, Americana - SP. 2002.Tese (Doutorado). Escola de Engenharia de São Carlos, Universidade de São Paulo.

LEMES, M.J.L. Avaliação de metais e elementos-traço em águas e sedimentos das bacias hidrográficas dos rios Mogi-Guacú e Pardo, São Paulo. SP. 2001. Dissertação (Mestrado), - Instituto de Pesquisas Energéticas e Nucleares, São Paulo.

LIMA, A.P.S; MÜLLER, R.C.S.; SARKIS, J.E.S.; ALVES, C.N.; BENTES, M.H.S.; BRABO, E.; SANTOS, E.O. Mercury contamination in fish from Santarém, Pará, Brazil. Environmental Research Section A, vol. 83, p.117-122, 2000.

MARQUES, M.N.; COTRIM, M.E.B.; PIRES, M.A.F. Pesticide Monitoring in Ribeira Valley, Southeastern Brazilian. In: IX Congresso Mundial de Água, outubro, 2003, Madri, Espanha. 
MATRINI, J.A.; BONZONGO, J.C.J.; LYONS, W.B. Mercury concentrations in surface waters from fluvials systems draining historical precious metals minning areas in southeastern U.S.A. Applied Geochemistry, vol. 14, p.147, 158, 1999.

MINISTÉRIO DA SAÚDE. Portaria nº 518 de 25/04/04, Brasil.

MOLISANI, M.M.; SALOMÃO, M.S.M.B.; OVALLE, A.R.C.; REZENDE, C.E.; LACERDA, L.D.; CARVALHO, C.E.V. Heavy metals in sediments of the lower Paraíba do Sul river and estuary, R.J., Brazil. Bulletin of Environmental Contamination and Toxicology, vol. 63, p. 682-690, 1999.

MORAES, R.P. Transporte de chumbo e metais associados no rio Ribeira de Iguape. Dissertação (Mestrado) - Instituto de Geociências Universidade de Campinas - SP. 1997.

NEAL, C.; HOUSE, W.A.; WHITTON, B.A.; LEEKS, G.J.L. Foreword to special issue: Water quality and biology of UK rivers entering the North Sea: The Land Ocean Interation Study (LOIS) and associated work. The science of the Total Environment, vol. 210-211, p.1-4, 1998.

NEAL, C.; JARVIE, H.P.; WHITTON, B.A.; GEMMELL, J. The water quality of the river Wear, north-east England. The science of the Total Environment, vol. 251-252, p. 153-172, 2000b.

NEAL, C.; WILLIANS, R.J.; NEAL, M.; BHARDWAJ, L.C.; WICKAM, H.; HARROW, M.; HILL, L.K. The water quality of the River Thames at a rural site downstream of oxford. The science of the Total Environment, vol. 251-252, p.441-457, 2000a.

NRIAGU, J.O. A history of global metal pollution. Science, vol. 2772, p.223224, 1996.

PESTANA, M.H.D; FORMOSO, M.L.L.; TEIXEIRA, E.C. Heavy metals in stream sediments from copper and gold mining areas in southern Brazil. Journal of Cheochemical Exploration, vol. 58, n.2/3, p.133-143, 1997.

PESTANA, M.H.D.; LECHLER, P.; FORMOSOS, M.L.L., MILLER, J. Mercury in sediments from gold and copper exploitation areas in the Camaquã River Basin, southern Brazil. Journal of South American Earth Science, vol. 13, p. 537-547, 2000.

PIRES, M.A F. Programas de Avaliação de Risco.São Paulo: IPEN/CNEN-SP, 1999 (Relatório Técnico de Viagem).

PIRES, M.A F.; COTRIM, M.E B. Modelagem Diagnóstica e Prognóstica da qualidade da água em áreas de captação. PADCT/FINEP, 2000. (Relatório técnico-científico). 
PIRES, M.A.F.; COTRIM; M.E.B.; MARQUES; M. N.; MOREL; M.B.C B.; JARDIM, E.A.J.; CINTRA FILHO, O.A; FLORES; A; FACINCANI;V; OLIVEIRA; M.A.O.; IGNÁCIO; M.; MIZIARA; S.N. ; FRANÇA, J.T.L.; PIVELLI ,R.; MANCUSO, P. Qualidade da água para consumo Humano: uma oportunidade de avaliação da concepção e aplicabilidade da nova legislação - Portaria 1469/MS/00. Revista Brasileira de Pesquisa e Desenvolvimento, vol 3, n 2, p 127-138, 2001.

POLLS, I. How people in the regulated community view biological integrity. Journal of the North American Benthological Society, vol. 13, n 4, p. 598-604, 1994.

PORTO, R.L.L.; BRANCO, S.M.; CLEARY, R.W.; COIMBRA, R.M.; EIGER, S.; LUCA, S.J.; NOGUEIRA, V.P.Q.; PORTO, M.F.A. Hidrologia Ambiental, 3ª ed. Edusp, São Paulo, 414p., 1991.

REBOUÇAS, A.C.; BRAGA, B.; TUNDISI, J.G. Águas Doces no Brasil: capital ecológico, uso e conservação. Escrituras. Editora Escrituras, São Paulo, 1999. $1^{\mathrm{a}}$ ed., p.117-150.

REIS, E.L.T. Abordagem sistêmica do sistema de tratamento de água de Registro, São Paulo, com ênfase na avaliação do impacto do descarte dos resíduos na Bacia Hidrográfica do Rio Ribeira de Iguape. 2006. Tese (Doutorado), - Instituto de Pesquisas Energéticas e Nucleares, São Paulo.

REGISTRO (Prefeitura Municipal). Geografia e Estatística. 2002. Disponível em: <http://www.registro.sp.gov.br/geografia.asp> Acesso em: 25/3/2002.

RELATÓRIO DE SITUAÇÃO DOS RECURSOS HÍDRICOS DO ESTADO DE SÃO PAULO, 2000. Disponível em:<http:// www.sigrh.sp.gov.br>. Acesso em 24/04/2002.

RIETZLER, A.C.; FONSECA, A.L.; LOPES, G.P. Heavy metals in tributaries of Pampulha Reservoir, Minas Gerais. Brazilian Journal of Biology, vol.61, n.3, p. 363-370, 2001.

ROSS, J.L.S.; MOROZ, I.C. Mapa Geomorfológico do Estado de São Paulo. IPT/FAPESP, São Paulo, 1997.

SABESP - COMPANHIA DE SANEAMENTO BÁSICO DO ESTADO DE SÃO PAULO. Disponível em: <http://www.sabesp.com.br>. Acesso em 04/2002.

SCRIMGEOUR, G.J. \& WICKLUM, D. Aquatic ecosystem health an integrity: problems and potential solutions. Journal of the North American

Benthological Society, vol.15, n 2, p. 254-261, 1996. 
SEDAE - FUNDAÇÃO SISTEMA ESTADUAL E ANALISE DE DADOS. Disponível em: <http:// WWW.sedae.gov.br>. Acesso em 09/2002.

SETTI, A.A.; LIMA, J.E.F.W.; CHAVES, A.G.M.; PEREIRA, I.C Introdução ao gerenciamento de recursos hídricos . Agência Nacional de Energia Elétrica, Superintendência de Estudos e Informações Hidrológicas, Brasília, 2001. Edição multimídia, 207.

SORENSEN, E.M.B. Metal poisoning in fish. Boca Raton: CRC Press, 1991. 374p.

STANDARD METHODS FOR THE EXAMINATION OF WATER AND

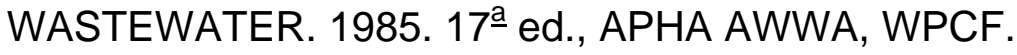

STEEDMAN, R.J.. Ecosystem health as a management goal. Journal of the North American Benthological Society, vol. 13, n 4, p. 606-10, 1996.

TAKAMORI, A.Y.; FIGUEIREDO, B.R. Monitoramento da Qualidade da água do rio Ribeira de Iguape para arsênio e metais pesados. In: 41th Congresso Brasileiro de Geologia, 2002, João Pessoa, PB.

TERTIAN, R.; CLAISSE, F. Principles of quantitative $x$-ray fluorescence analysis. Heyden, 1991.

TESSLER, G.M.; SUGUIO, K.; ROBILLOTA, P.R. Teores de alguns elementos traço metálicos em sedimentos pelíticos da superfície de fundo da região lagunar Cananéia-Iguape. In: Simpósio sobre Ecossistemas da Costa Sul e Sudeste Brasileira, 1987, Cananéia, SP.

TOKALIOGLU, S.; KARTAL, S.; ELCI, L. Determination of heavy metals and their speciation in lake sediments by flame atomic absorption spectrometry after a four-stage sequential extraction procedure. Analytica Chemica Acta, vol. 413, p.33-40, 2000.

TOMAZELLI, A.C.; MARTINELLI, L.A.; AVELAR, W.E.P.; CAMARGO, P.B.; FOSTIER, A.H.; FERRAZ, E.S.B.; KRUG, F.J.; SANTOS, D.J.R.

Biomonitoring of $\mathrm{Pb}$ and $\mathrm{Cd}$ in two impacted watersheds in southeast Brazil using the freshwater mussel Anadontites trapesialis (Lamark, 1819) (Bivalvia: Mycetopodidade) as a biological monitor. Brazilian Archives of Biology and Technology, v.46, n.4, 2003.

URENIUK, G. Os recursos hídricos da Bacia do Rio Ribeira de Iguape e do Litoral Sul. In: SECRETARIA DE ESTADO DO MEIO AMBIENTE I Secretaria da Educação. Programa de Educação Ambiental do Vale do Ribeira: cap. 4, p.121-151, 1989.

URYU, Y.; MALM, O.; THORNTON, I.; PAYNE, I.; CLEARY, D. Mercury contamination of fish and its implications for wildlife of the Tapajós Basin, Brazilian Amazon. Conservation Biology, v.15, n.2, p.438-446, 2001. 
U.S. EPA "Drinking Water Standards and Health Advisories". D.C.EPA 822-B-00-001, 2000.

VEADO, M.A.R.V.; PINTE, G.; OLIVEIRA, A.H.; REVEL, G. Application of instrumental neutron activation and inductively coupled plasma-mass spectrometry to studying the river pollution in the State of Minas Gerais. Journal of Radioanalytical and Nuclear Chemistry, vol. 217, n.1, p. 101106, 1007.

YABE, M.J.S. Determinação de metais pesados em águas superficiais por ICP-OES objetivando caracterização e recuperação de bacias hidrográficas. Tese (Doutorado) - Universidade de São Paulo. 1995.

YAMASHITA, D.M. Mobilidade de arsênio e metais pesados em solos do Vale do Ribeira, Iporanga, SP. Dissertação (Mestrado). Instituto de Geociências. Universidade Estadual de Campinas. 2004. 